$$
\text { NBSIR 76- } 1111
$$

\title{
JOINT U.S.-U.S.S.R. TEST OF U.S. MHD ELECTRODE SYSTEMS IN U.S.S.R. U-02 MHD FACILITY (PHASE I)
}

\section{FINAL REPORT}

ENERGY RESEARCH AND DEVELOPMENT ADMINISTRATION 
Hosler, W. R., Editor, Joint U.S.-U.S.S.R. test of U.S. MHD electrode systems in U.S.S.R. U-02 MHD facility (phase I), Final Report Energy Research and Development Administration, ERDA-76/154, 262 pages (Available from the National Technical Information Services, Springfield, VA 1976).

313

$$
\text { NBSIR>6-\|II }
$$

National Technical Information Service (NTIS)

U.S. Department of Commerce

5285 Port Royal Road

Springfield, Virginia 22161

Price: Printed Copy: $\$ 9.00$

Microfiche: $\$ 3.00$ 


\title{
Joint U.S.-U.S.S.R. \\ Test of U.S. MHD Electrode Systems in U.S.S.R. \\ U-02 MHD Facility (Phase I)
}

\section{FINAL REPORT}

\author{
Edited by \\ William R. Hosler \\ National Bureau of Standards \\ Washington, D.C. 20234
}

Prepared for

Energy Research and Development Administration

by

Battelle Pacific Northwest Laboratory

National Bureau of Standards

Westinghouse Research and Development Laboratory

U.S.S.R. Institute of High Temperatures 



\section{PREFACE}

This report was jointly prepared for the Energy Research and Development Administration by the Battelle Pacific Northwest Laboratory, the National Bureau of Standards, the Westinghouse Research and Development Laboratory and the U.S.S.R. Institute of High Temperatures. The report presents the results of the first joint U.S.-U.S.S.R. test of U.S. MHD electrode materials in the U.S.S.R. U-02 MHD Facility. The electrode walls were designed and built by the Westinghouse Research and Development Laboratory.

The joint test was conducted in implementation of the understanding regarding open-cycle MHD cooperation reached between representatives of the U.S. and U.S.S.R. Joint Working Group for Energy held in Moscow, October 6, 1972 , and endorsed as a cooperative program by the U.S.-U.S.S.R. Joint Committee for Scientific and Technical Cooperation. at its meeting in Washington, D.C., March 21, 1973. Work on the Program was affirmed by the U.S.-U.S.S.R. Joint Committee on Energy at its October 3-4, 1974 meeting in Washington, D.C. 



\section{U.S.}

G. Rudins - Energy Research and Development Administration

S. Schneider - National Bureau of Standards

L. Bates - Battelle Pacific Northwest Laboratories

K. Bowen - Massachusetts Institute of Technology

L. Crawford - University of Tennessee Space Institute

H. Frederikse - National Bureau of Standards

B. Rossing - Westinghouse Research and Development Laboratory

D. D. Marchant - Argonne National Laboratory

$$
\text { U.S.S.R. }
$$

G. P. Telegin - Institute of High Temperatures

D. K. Burenkov - Institute of High Temperatures

A. I. Romanov - Institute of High Temperatures

V. V. Kirillov - Institute of High Temperatures

Organizations that have actively participated in work described in this report are:

1. Battelle Pacific Northwest Laboratory, Richland, Washington.

2. National Bureau of Standards, Washington, D.C.

3. Westinghouse Research and Development Laboratory, Pittsburgh, Pa.

4. Institute of High Temperatures of the Academy of Sciences, Moscow, U.S.S.R.

Personnel that have contributed to the contents of this report or actively participated in the joint test are:

U.S.

G. Rudins

R. J. Wright

B. R. Rossing

W. E. Young

W. R. Hosler

J. L. Bates

T. Negas

C. L. McDaniel

E. N. Farabaugh

A. J. Armstrong

A. Perloff

S. J. Schneider

H. P. R. Frederikse

J. L. Daniel
U.S.S.R.

D. K. Burenkov

G. P. Telegin

V. V. Kirillov

V. I. Zalkind

O. B. Zamyslov

Yu. L. Dolinski

A. I. Romanov

Yu. L. Krasul in

T. I. Borodina

A. S. Golobkova

V. L. Vinogradov

D. A. Vysotskii

F. A. Akopov

A. B. Ivanov

V. D. Liubimov

V. G. Eordon 

ABSTRACT.

INTRODUCTION.

CHAPTER I

DESCRIPTION OF THE TEST FACILITY AND OPERATING CONDITIONS DURING THE TEST.

A. Description of the Test Facility. . . . . . . . . . . . . . . . 4

B. Operating Modes for the Electrode Wall. . . . . . . . . . . . . . . . 11

B.1 Characteristic Thermal Operating Mode for the Electrode Wall . . . 11

B.2 Characteristic Electrical Parameters for the Life Test . . . . . 22

B.3 Electrical Characteristics of the Channel Before and After the Life Test . . . . . . . . . . . . . . . 25

CHAPTER II

MODULE DESCRIPTION, ANALYTICAL PROCEDURES AND RESUlTS OF ANALYSiS • • • • • 42

A. Module Design and Preparation of Materials. . . . . . . . . . . . . . 42

A.1 Overview of Design Considerations. . . . . . . . . . . . . . 42

A. 2 Preparation of Materials . . . . . . . . . . . . . . . 43

A. 3 Electrode Wall Design. . . . . . . . . . . . . . . . . . 45

A.4 Instrumentation. . . . . . . . . . . . . . . . . 49

B. Pre-Test Materials Characterization and Analysis. . . . . . . . . . . 65

B.1 Thermal Diffusivity. . . . . . . . . . . . . . . 65

B.1.1 MgO Insulator . . . . . . . . . . . . . . 66

B.1.2 Electrodes. . . . . . . . . . . . . . 67

B.2 Thermal Expansion. . . . . . . . . . . . . . . . 67

B.3 Chemical Composition . . . . . . . . . . . . . . . 73

B.4 Microstructure . . . . . . . . . . . . . . . 73

B.4.1 MgO Insulator . . . . . . . . . . . . . . . 73

B.4.2 Electrodes. . . . . . . . . . . . . . . . . 83

B.5 Electrical Conductivity. . . . . . . . . . . . . . . . 92 
B.6 Phase Composition.

B.7 Porosity and Pore Size Distribution. . . . . . . . . . . . . . . 92

C. Post-Test Materials Characterization and Analysis . . . . . . . . . . . 103

C.1 Module Dissassembly and Materials Distribution . . . . . . . . . 103

C.2 Phase Composition and Chemical Reactions . . . . . . . . . . . 109

C.2.1 Cathode Materials . . . . . . . . . . . . . . 113

C.2.1.1 Introduction and Methods . . . . . . . . . 113

C.2.1.2 Results, Phase Analysis and Discussion . . . . . 113

C.2.1.2.1 $\mathrm{CeO}_{2}$ Containing Materials . . . . . 113

C.2.1.2.2 $\mathrm{Y}_{2} \mathrm{O}_{3}$ Stabilized $\mathrm{ZrO}_{2}$ (cathode) and
$\mathrm{MgO}_{\text {Insulator . . . . . . . . . } 118}$

C.2.1.2.3 Special Considerations. . . . . . . 119

C.2. 2 Anode Materials . . . . . . . . . . . . . . . . 119

C.3 Electrical Conductivity. . . . . . . . . . . . . . . . . 145

C.4 Metallography and Electron Microprobe Analysis . . . . . . . . . . 145

C.4.1 Specific Observations Concerning Various Materials of

the Tested Channel. . . . . . . . . . . . . 164

C. 5 Radiograph and Current Lead-out Analysis . . . . . . . . . . . 169

D. USSR Results on Pre- and Post-Test Materials Characterization and

Analysis. . . . . . . . . . . . . . . . . . . . . 185

D.1 Magnesium Ceramics in the Channel Insulating Walls . . . . . . . 185

D.2 Phase Composition and Structure of Materials Tested in the U-02 • 195

D.2.1 Objects and Methods of the Studies . . . . . . . . . 195

D.2.2 Results of X-Ray Phase Analysis . . . . . . . . . . . . 196

D.2.3. Discussion of Results . . . . . . . . . . . . 199

D.3 Electrochemical Investigations of Electrodes with Compositions

I $\left(88 \mathrm{ZrO}_{2}-12 \mathrm{Y}_{2} \mathrm{O}_{3}\right)$ and II $\left(82 \mathrm{ZrO}_{2}-18 \mathrm{CeO}_{2}\right) \cdot$. . . . . . . 214

D.3.1 Hot Ceramic Electrodes with Compositions Consisting of

$88 \mathrm{ZrO}_{2}-12 \mathrm{Y}_{2} \mathrm{O}_{3} \cdot$. . . . . . . . . . . . . . 214 
D.3.2 American Specimens with a Composition of $82 \mathrm{ZrO}_{2}-18 \mathrm{CeO}_{2} \cdot .221$

D.4 Qualitative Analysis of the Stability of Electrode Materials,

using the High-Temperature Treatment Method. . . . . . . . . . . . .240

D.4.1 Investigations of the $\mathrm{ZrO}_{2}+\mathrm{Y}_{2} \mathrm{O}_{3}(8.7 \mathrm{~mol} \%)$ carried out in the U.S.S.R. . . . . . . . . . . . . . . 247

CHAPTER IV

CONCLUSIONS (U.S. and U.S.S.R.). • • . • . • . . . . . . . . 256

A. Conclusions from Phase Composition, Chemical Reactions, Metallography and Microprobe Analysis (U.S.) . . . . . . . . . . . . 256

A.1 Conclusions from Phase Composition and Chemical Reactions . . . . 256

A.2 Conclusions from Metallography and Microprobe Analysis. . . . . . 257 



\section{ABSTRACT}

The first (Phase I) joint U.S.-U.S.S.R. test of U.S. electrode materials was carried out in Moscow between September 25 and October 8, 1975 in the Soviet U-02 MHD facility. The test procedure followed closely a predetermined work plan designed to test five different zirconia based materials and the cathode and anode electrode wall modules under MHD operating conditions. The materials which were selected by the Ad Hoc Materials Working Group were $88 \mathrm{ZrO}_{2}-12 \mathrm{Y}_{2} \mathrm{O}_{3}, 82 \mathrm{ZrO}_{2}-18 \mathrm{CeO}_{2}, 50 \mathrm{ZrO}_{2}-50 \mathrm{CeO}_{2}, 25 \mathrm{ZrO}_{2}-75 \mathrm{CeO}_{2}$ and $2 \mathrm{ZrO}_{2}-78 \mathrm{CeO}_{2}-$ $2 \mathrm{Ta}_{2} \mathrm{O}_{5}$. The electrode modules were constructed by Westinghouse Research and Development Laboratory. Each of the five electrode materials had four different current densities established between the anode and cathode during the experiment which lasted a total of 127 hours; 100 hours under MHD power operational conditions.

There were four main phases in the test schedule:

1st phase - Start-up of the channel over a specific heating period. No seed $\left(\mathrm{K}_{2} \mathrm{CO}_{3}\right)$ introduction - 18 hours.

2nd phase - Electrical tests at operating temperature to investigate electrophysical characteristics of the channel and electrodes -6 hours.

3rd phase - Operating life test - 94 hours.

4 th phase - Shut-down of the channel over a specific cool down period 9 hours.

There were also extensive tests made on the modules before their shipment to the U.S.S.R. and after their installation into the U-02 channel but before the start of the lst phase. U.S. and U.S.S.R. personnel were in attendance at all times during the continuous test which was extended from the originally planned total time of 100 hours to 127 hours.

All except six electrode pairs performed satisfactorily during the entire test. These were the pairs which were designated to carry maximum or near maximum current density. Five pairs failed early in the life test and the sixth pair failed in the last several hours. Failure was not due to the electrode materials, however, but due to lead-out melting caused by joule heating in the platinum wires.

The U-02 facility has been fully described and the operational parameters are given for each phase of the test. The electrode and insulating walls have been described and the appropriate parameters that are used to predict the performance of the module are given. 
Extensive pre- and post-test materials characterizations were made to determine the effect of the MHD environment on the electrodes and insulators. Pre-test measurements were made to determine: thermal diffusivity, thermal expansion, chemical composition, microstructure, electrical conductivity, phase comrosition, closed and open porosity and pore size distribution. After the test, the electrode walls were carefully packed and shipped back to the National Bureau of Standards where they were disassembled in such a manner as to allow extensive post-test materials characterization. The analysis work was done by NBS, Battelle NW Laboratories, Westinghouse Research Laboratories and U.S.S.R. Institute for High Temperature Research. These analyses include phase composition and chemical reactions, electrical conductivity, metallography, and electron microprobe analysis. In addition, radiograph and current lead-out analyses were made on the electrode wall sub-modules. There was extensive attack by the seed on the cathode wall resulting in chemical reactions and phase changes of the electrode materials. There was also seed penetration through cracks and pores in both insulator and electrode.

A comparative analysis has been made between the results of this test and the results of previous tests made on materials in the U.S.S.R. U-02 facility.

Significant conclusions were made from the test results which will be of great benefit to future tests in the joint US-USSR cooperative testing program and to the overall program of MHD development for electrical power generation.

A final and important result of this first cooperative test between the U.S. and U.S.S.R. is to show that a project of this size can be arranged, carried out and assessed in the spirit of cooperation and mutual respect that has continued throughout the entire cooperative program. 


\section{INTRODUCTION}

This report is the final document concerning the entire Phase I U-02 test carried out in Moscow between September 25 and October 8, 1975 according to the work program agreed to by the U.S. and the U.S.S.R. sides. The work is in accordance with the existing intergovernmental agreement signed on May 24, 1972, which describes the Program of Scientific and Technical Cooperation between the U,S. and the U.S.S.R. in the field of developing and building an open cycle MHD power station of commercial scale. One of the important directions in the U.S.-U.S.S.R. cooperation in this area is the study of materials. The report includes pre- and post-test information on the materials and on the electrode modules (anode and cathode) as well as data relating to the experimental conditions during the test period.

The National Bureau of Standards, Westinghouse Research and Development Laboratory, Battelle Northwest Laboratories and U.S.S.R. Institute for High Temperatures participated in preparing various sections of this report. Individual credits are given in text.

The report is divided generally into four chapters as designated in Appendix 5, Record of the Fourth Meeting (4-1M) of the U.S.-U.S.S.R. Ad Hoc Working Group c MHD Materials Development.

Chapter I - Description of the Test Facility and Operating Conditions During the Test (U.S.S.R.).

Chapter II - A. Module Design and Materials Preparation (U.S.).

B. Pre-test Materials Characterization and Analysis (U.S. results):

1. Thermal Diffusivity

2. Thermal Expansion

3. Chemical Composition

4. Microstructure

5. Electrical Conductivity

6. Phase Composition

7. Porosity and Pore Size Distribution

C. Post-test Materials Characterization and Analysis (U.S. results).

1. Module Disassembly and Materials Distribution

2. Phase Composition and Chemical Reactions

3. Electrical Conductivity

4. Metallography and Electron Microprobe Anaysis

5. Radiograph and Current Lead-out Analysis

D. U.S.S.R. Results on Pre- and Post-test Materials Characterization and Analysis

Chapter III - Comparative Analysis (U.S.S.R.)

Chapter IV - Conclusions (U.S. and U.S.S.R.) 


\section{CHAPTER I}

Description of the Test Facility and Operating Conditions During the Test

A. Description of the Test Facility (D. K. Burenkov, B. P. Telegin, V. V. Kirillov, V. I. Zalkind, O. B. Zamyslov, Yu. L. Dolinskii)

The experimental channel of the MHD generator consisted of the nozzle section, working section and the diffuser section. At the entrance, before the operating section and at the exit were located water-cooled sections with a gas wall troweled with a coating of zirconia. The working section of the MHD generator channel with a cross section of $64 \times 260 \mathrm{~mm}^{2}$ and $490 \mathrm{~mm}$ long consisted of electrode and insulating walls.

The electrode walls consisted of 20 electrodes with platinum current leads mounted in magnesia blocks (see Fig. A.1). The electrode wall was made of five units with four electrodes of the same material mounted in each one. Each unit had its own copper water-cooled base. During the test, the following groups of the electrode material were included, listed here in the order in which they are located along the channel.

$$
\begin{aligned}
& \text { Group I - 88\% } \mathrm{ZrO}_{2}+12 \% \mathrm{Y}_{2} \mathrm{O}_{3} \\
& \text { Group II }-82 \% \mathrm{ZrO}_{2}+18 \% \mathrm{CeO}_{2} \\
& \text { Group III - 50\% } \mathrm{ZrO}_{2}+50 \% \mathrm{CeO}_{2} \\
& \text { Group IV }-25 \% \mathrm{ZrO}_{2}+75 \% \mathrm{CeO}_{2} \\
& \text { Group V }-20 \% \mathrm{ZrO}_{2}+78 \% \mathrm{CeO}_{2}+2 \% \mathrm{Ta}_{2} \mathrm{O}_{5} .
\end{aligned}
$$

The insulating walls were made of hexagonal ceramic modules made with a MgO base. Each module was soldered or brazed to its copper base which served to remove the heat from the ceramic and transmit it to the cooling water, and the base, in turn, was attached to the metal wall structure (Fig. A.2).

The channel design provided for the possibility of measuring during the experiment thermal fluxes into the components of the electrode and insulating walls by means of calormetric measurements of the cooling water. During the experiment, the temperature of the surface of the fourth anode was measured by means of an optical pyrometer. The temperature of the various electrode components (Fig. A.4.1, Chapter II) and of the upper insulating walls was measured by means of thermocouples imbedded in them. The plasma potential was measured by means of platinum probes which protruded into the plasma stream and which were located on the 
upper insulating wall (see Fig. A.3). The potential of separate components of the channel was also measured. The temperature of the combustion products at the entrance into the channel was measured during the experiment by means of sodium spectral line reversal.

The program of joint experiment consisted of the following components:

- Preheating of the loop and the selection of the thermal operating mode (lst phase).

- Study of electrophysical characteristics of the channel (2nd phase).

- Duration of life test (3rd phase).

- Cooling off of the loop (4th phase).

The preheat of the structure was made according to the requirements of the temperature increase rate (on the average no greater than $2.5{ }^{\circ} \mathrm{C}$ per minute) and the schedule for preheating the structure during the 1st phase was developed accordingly (see Fig. A.4). Prior to the start-up of the combustion chamber, the structure was preheated with air which was electrically heated to $250{ }^{\circ} \mathrm{C}$. The combustion chamber was then started up to operate with the maximum oxidizer excess $(\alpha)$, which would allow stable operation of the combustion chamber. Then, after a $30-$ minute wait, the gradual preheat of the structure was continued by bringing the combustion chamber to the level where $\alpha=1$ and with a subsequent increase of the degree of oxygen enrichment.

The operating mode of the loop for the duration tests of the electrode walls was selected in order to achieve the temperature on the surface of the fourth anode (measured by an optical pyrometer) in the range of 1700 to $1775^{\circ} \mathrm{C}$; the plasma temperature at the entrance of the channel should at this point have been $2600 \mathrm{~K}$.

The operating mode for the loop was established accordingly and during the 2 nd and 3 rd phases of the experiment was maintained with precision $\pm 5 \%$. The following basic parameters were maintained:

Combustion Product Temperature

Total Mass Flow Rate

Static Pressure

Potassium Content in the Plasma

Temperature of the Electrode Surface
$2573 \mathrm{~K}$

$0.75 \mathrm{~kg} / \mathrm{sec}$

$0.83 \mathrm{~atm}$

$1 \%$ (weight)

$1710{ }^{\circ} \mathrm{C}$ optical pyrometer

The cooling down of the structure during the 4 th phase of the experiment corresponded to the reverse schedule for the preheat. 


\section{INSULATION}

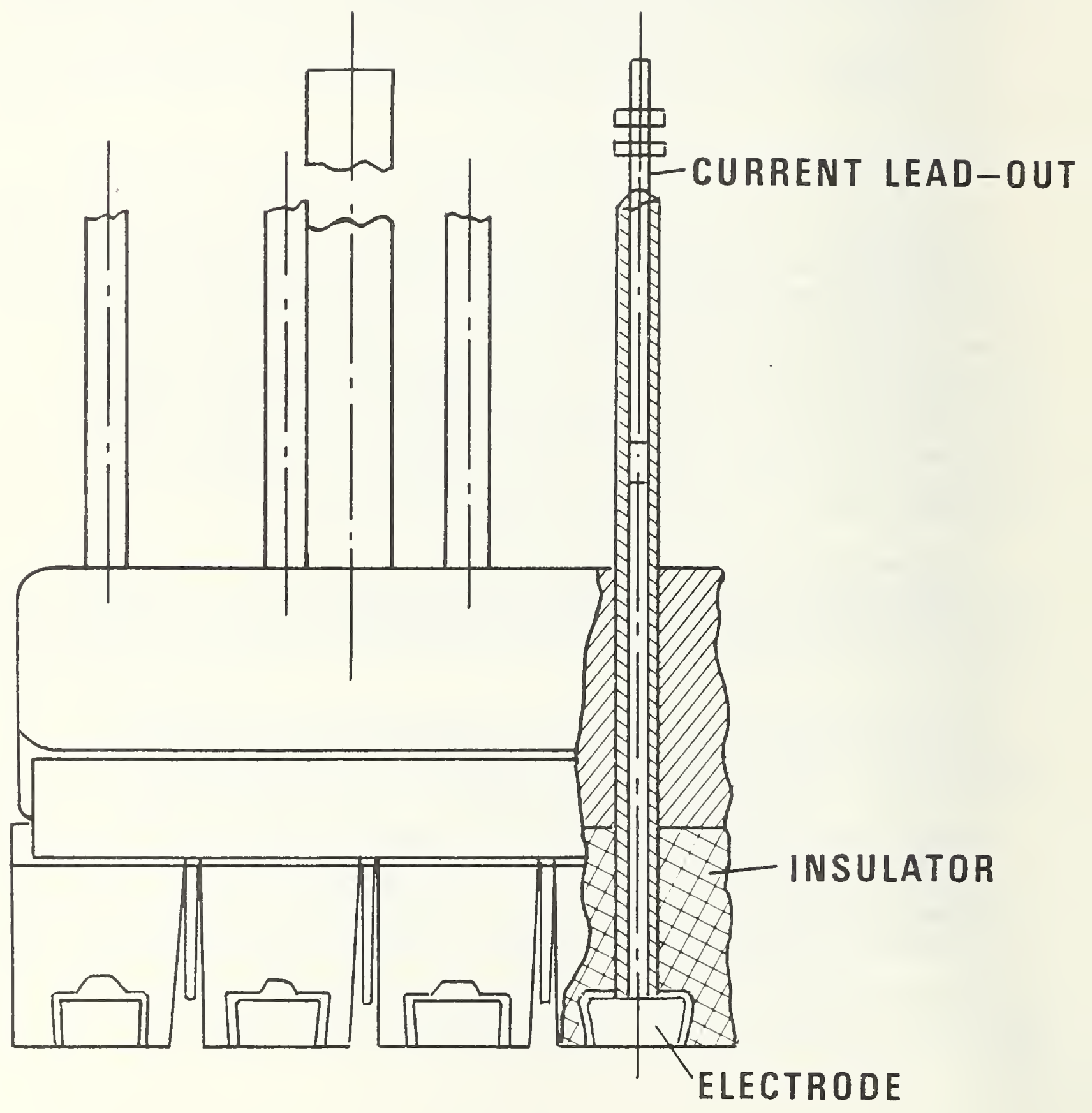

Figure A.1. Schematic Diagram of a Submodule Unit. 


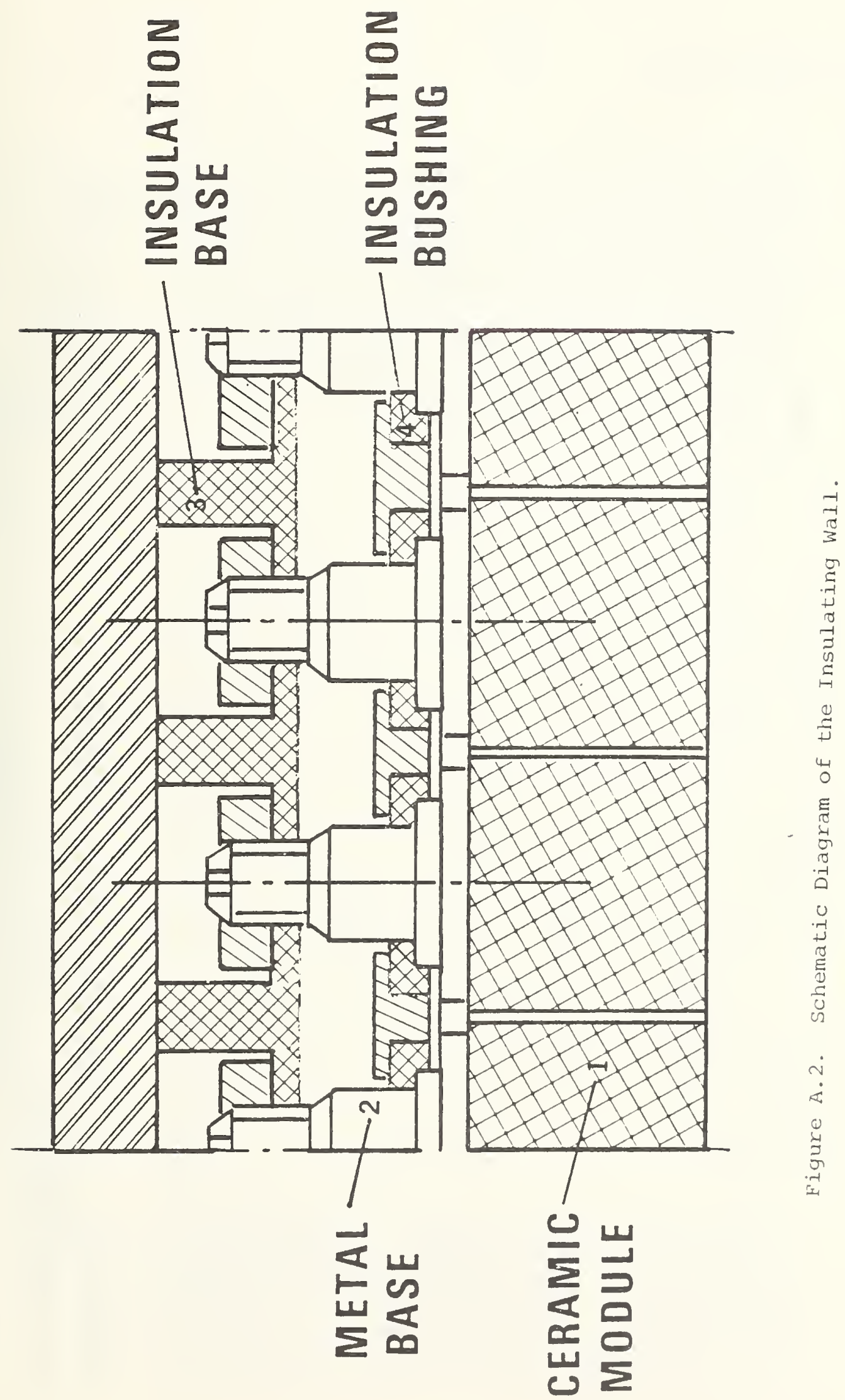




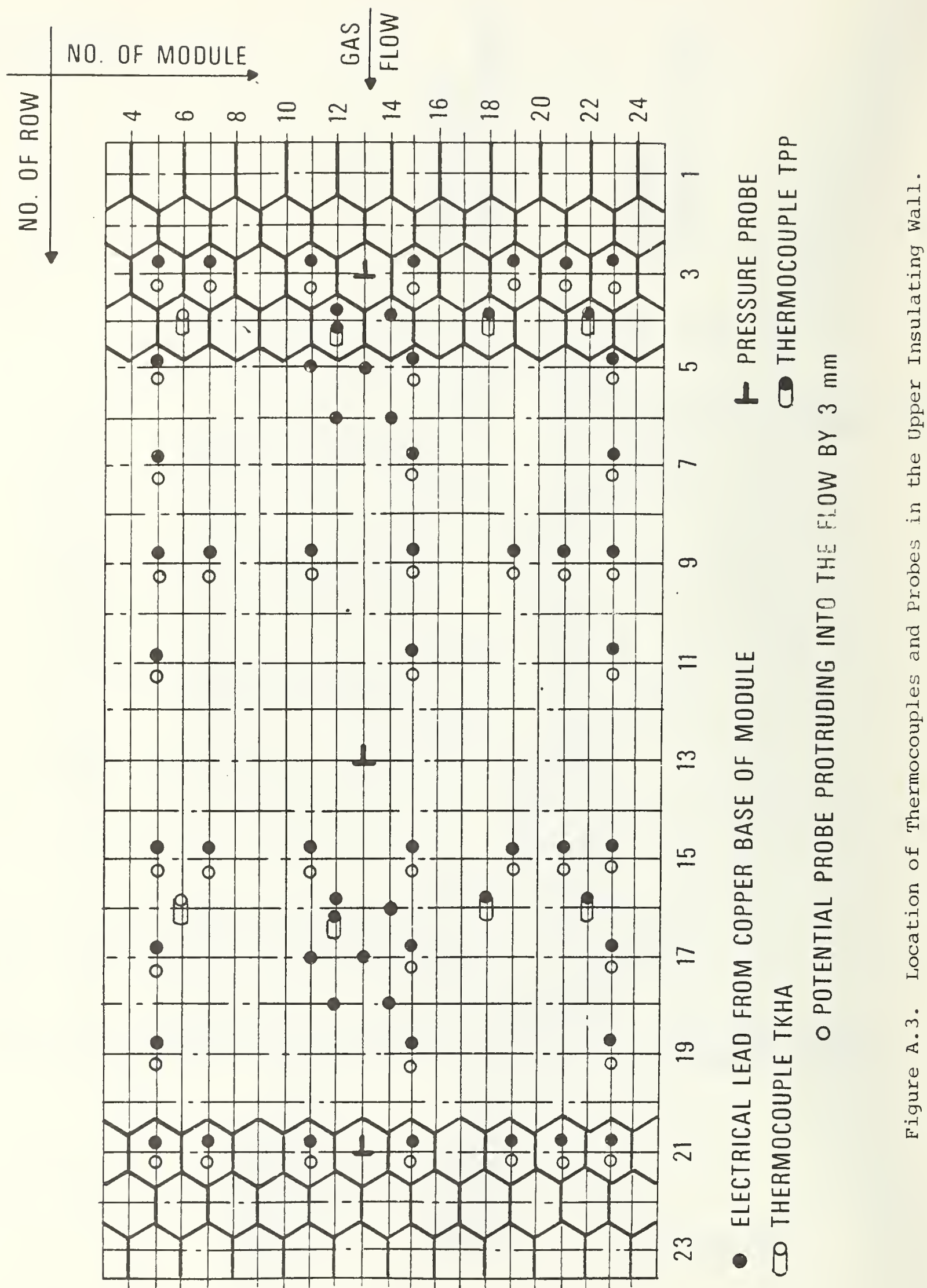




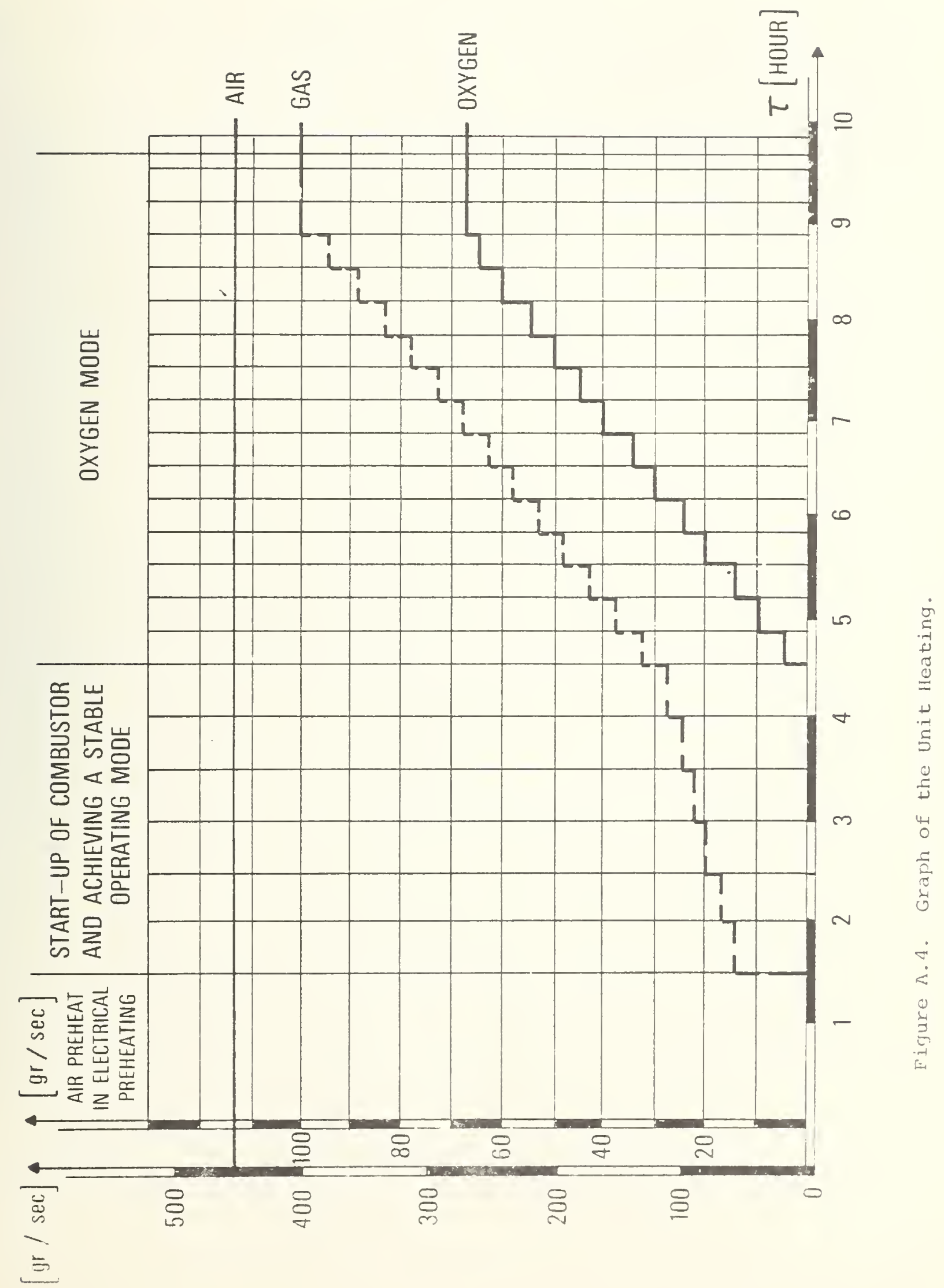


Figure A.1. Schematic diagram of a submodule unit.

Figure A.2. Schematic diagram of the insulating wall.

Figure A.3. Location of thermocouples and proves in the uppt insulating wall.

Figure A.4. Graph of the unit heating. 
B. Operating Modes for the Electrode Walls

\section{B.I Characteristic Thermal Operating Mode for the Electrode Walls}

As was noted earlier, the permissible rate of preheat of the electrode wall structure components was set on the average of $2.5^{\circ} \mathrm{C} / \mathrm{min}$ while the maximal preheat rate for a short period during the start-up of the combustion chamber would be between 50 and $80{ }^{\circ} \mathrm{C} / \mathrm{min}$. With this preheat rate, it was supposed that the thermal stresses in the elements of the structure would not produce destruction or cracking. The analysis of the preheat rate was conducted precisely with this in mind.

The surface temperature of the electrode walls, after the operating mode for duration tests was established, should have been between 1700 and $1775^{\circ} \mathrm{C}$ which, along with the gradual preheat of the structure, was the second purpose of establishing this operating mode. Figures B.I.I to $B .1 .6$ show thermocouple readings taken during ali four phases of the test (the thermocouples were located in various electrodes). On all these figures the duration of the experiment was counted from the moment when the air preheater was turned on. Figure B.1.7 shows the changes in temperature of the electrode surface 2104, as measured by the optical pyrometer. After the air preheat temperature has been raised by means of an electrical heater, the combustion chamber was started up with the maximum permissible rate of oxidizer excess. The average rate of temperature increase according to the readings from the thermocouples located in the electrode modules was about $50^{\circ} \mathrm{C} / \mathrm{min}$. While the facility was approaching a stable operating mode, $\alpha=1$, the rate of temperature increase on the electrode modules was as follows: on the anode 2104 where the thermocouple 非 1 showed the highest temperature, the rate of increase was on the average $1{ }^{\circ} \mathrm{C} / \mathrm{min}$; while on the anode 2517 , where the thermocouple 非54 showed the lowest temperature, the rate of increase was on the average $0.5{ }^{\circ} \mathrm{C} / \mathrm{min}$. Further increase of temperature occurred during the gradual enrichment of air with oxygen, when the temperature increase rate, measured with the thermocouples described above was about $3^{\circ} \mathrm{C} / \mathrm{min}$. During the eleventh hour of the experiment, a fairly rapid change in the parameters of the loop was noted, due to the interruption in the operation of the oxygen tanks while they were being switched. The maximum rates of temperature change registered by the thermocouples were $110{ }^{\circ} \mathrm{C} / \mathrm{min}$; i.e., they were roughly twice as great as those noted during the start-up of the combustion chamber. However, these changes occurred while the temperature of the ceramics was higher; this appears to lessen the hazard of thermal shock. Subsequently, during the actual duration or life test, two more relatively abrupt temperature changes occurred in the channel elements $\left(20{ }^{\circ} \mathrm{C} / \mathrm{min}\right.$ ) due to temporary complications in the operation of the facility loop (Figs. B.1.3 and B.1.5).

When the planned thermal parameters for the duration tests were reached and the electrodes were loaded with the appropriate currents, as per Figs. B.1.2, B.1.3, and B.1.4, the electrode temperatures as read 
from thermocouples 3 millimeters from the electrode surface were recorded by means of the Kaye 8000 data logging system.

The temperature on the anode 2101 (thermocouple 50-51) was 1180 to $1250{ }^{\circ} \mathrm{C}$, on anode 2104 (thermocouples 52 and 53) it was 1100 to $1200{ }^{\circ} \mathrm{C}$, on anode 2517 (thermocouples 54 and 55) it was 950 to $1200{ }^{\circ} \mathrm{C}$. Thus, a certain small decrease in temperature of the electrodes was observed along the channel ( 100 to $130^{\circ} \mathrm{C}$ ). The temperature readings from the thermocouples located in the hot area of the $\mathrm{MgO}$ insulators on the cathode wall was between 980 and $880{ }^{\circ} \mathrm{C}$.

As can be seen in Figures B.1.8 and B.1.9, the thermal fluxes on the electrode wall increased gradually in the course of preheating and then, with a few exceptions, were sufficiently stable or, at any rate, changed within a fairly narrow range during the life tests. It would be appropriate, however, to note the gradual reduction of thermal fluxes by 20 to $25 \%$ during the period between the 39 th hour and the 111 th hour of the experiment. The average thermal fluxes during the period indicated above on all the anode and cathode units are shown in Table B.I.1.

Figure B.1.7 shows changes in time of the surface temperature on the anode 2104 , measured by means of an optical micropyrometer OMP -43 .

As can be seen in Fig. B.1.7, the temperature was $1710^{\circ} \mathrm{C}$, after the steady operating mode was reached. During the 34 th hour of the experiments, the measurements ceased since the optical porthole was, by this time, clogged with ionizing seed. Evidently, the last measurements of the temperature also should not be taken into account, since they were already distorted by the relatively cold accretions of $\mathrm{K}_{2} \mathrm{CO}_{3}$ within the optical porthole. However, the accuracy of measurements taken prior to the formation of $\mathrm{K}_{2} \mathrm{CO}_{3}$ crust is not in doubt.

As can be seen in Table B.1.1, the thermal fluxes are not uniform along the electrode walls; the smaller thermal fluxes occur where the thermocouples and the probes are located. Evidently, part of the heat is lost along the thermocouples and the probes. Also, it is possible that the thermal fluxes are reduced due to the loss of air seal and the leakage of cold air into the system.

Table B.1.1

Thermal Fluxes to the Electrode Units $\left(10^{2} \mathrm{~kW} / \mathrm{m}^{2}\right)$

$21 \quad 22 \quad 23 \quad 24 \quad 25$

Average Thermal

$\begin{array}{cccccl}21 & 22 & 23 & 24 & 25 & \text { Flux to Anode Wal1 } \\ 1.7-1.8 & 2.1-2.3 & 1.45-1.55 & 2.15-2.25 & 1.34-1.4 & 1.75-1.86 \\ 11 & 12 & 13 & 14 & 15 & \begin{array}{l}\text { Average Thermal Flux } \\ \text { to the Cathode Wal1 }\end{array} \\ 2.3-2.5 & 1.9-1.95 & -2.2-2.4 & 1.8-1.95 & 1.8-2.0 & 2.16-2.0\end{array}$




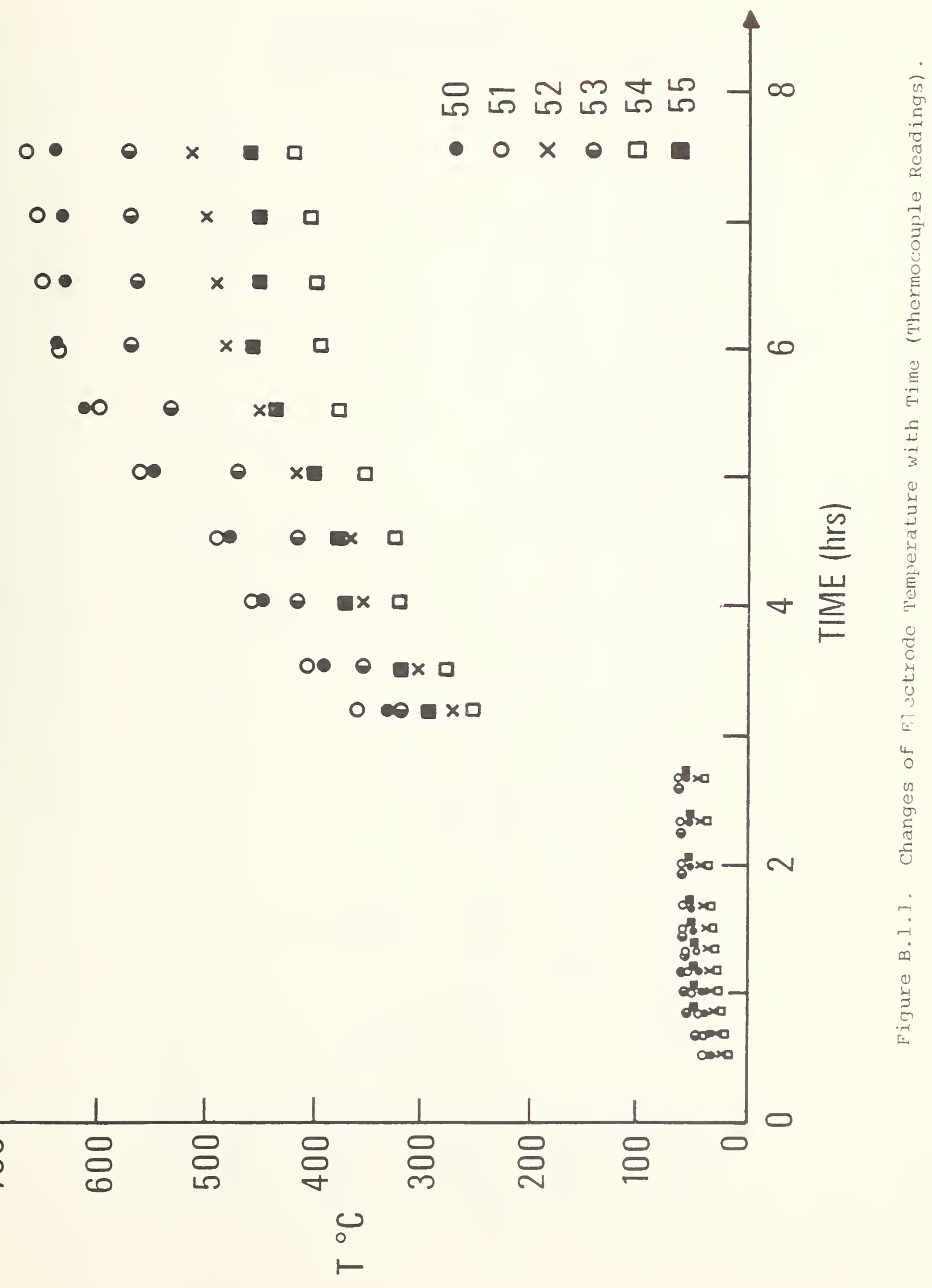




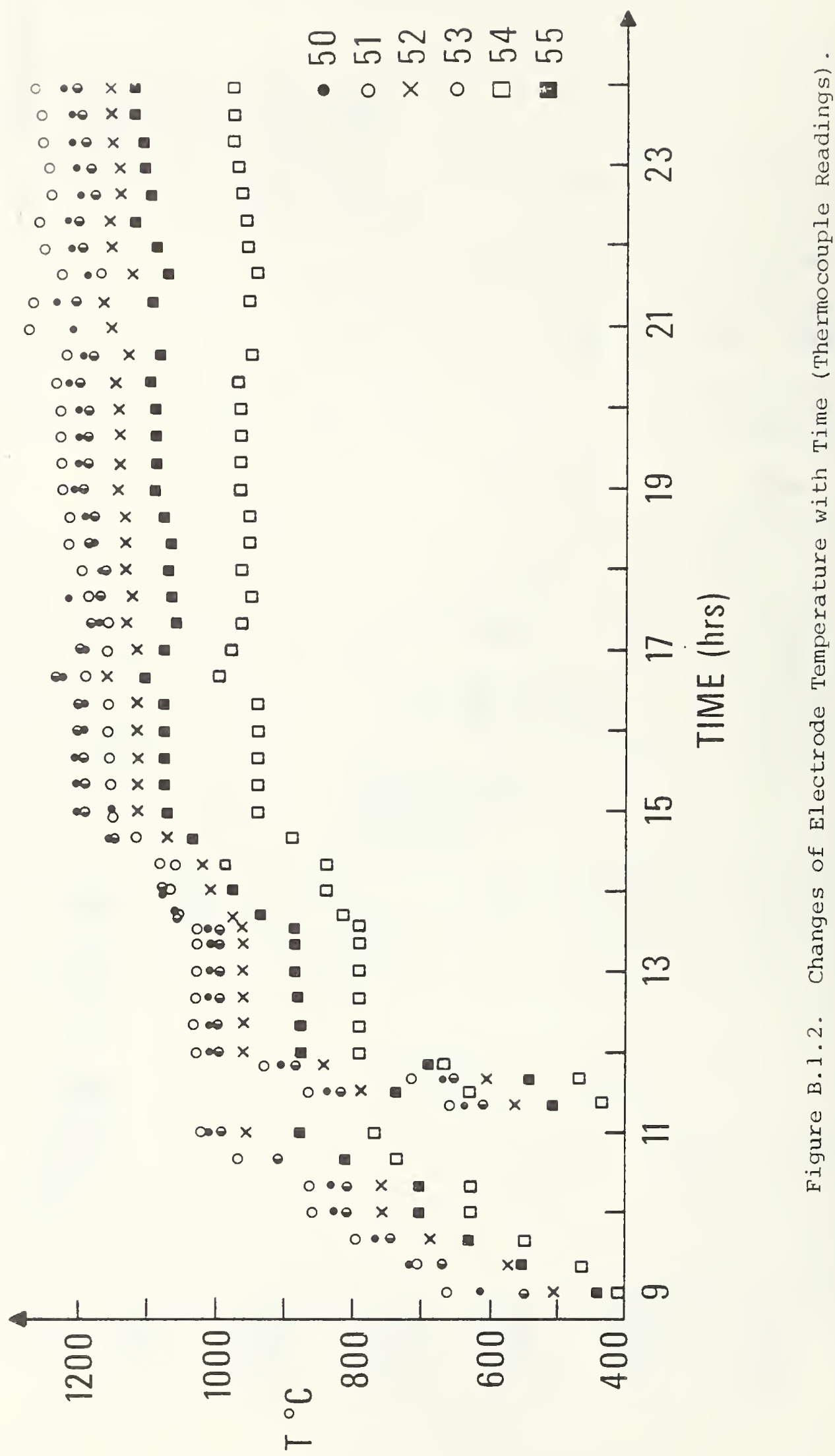




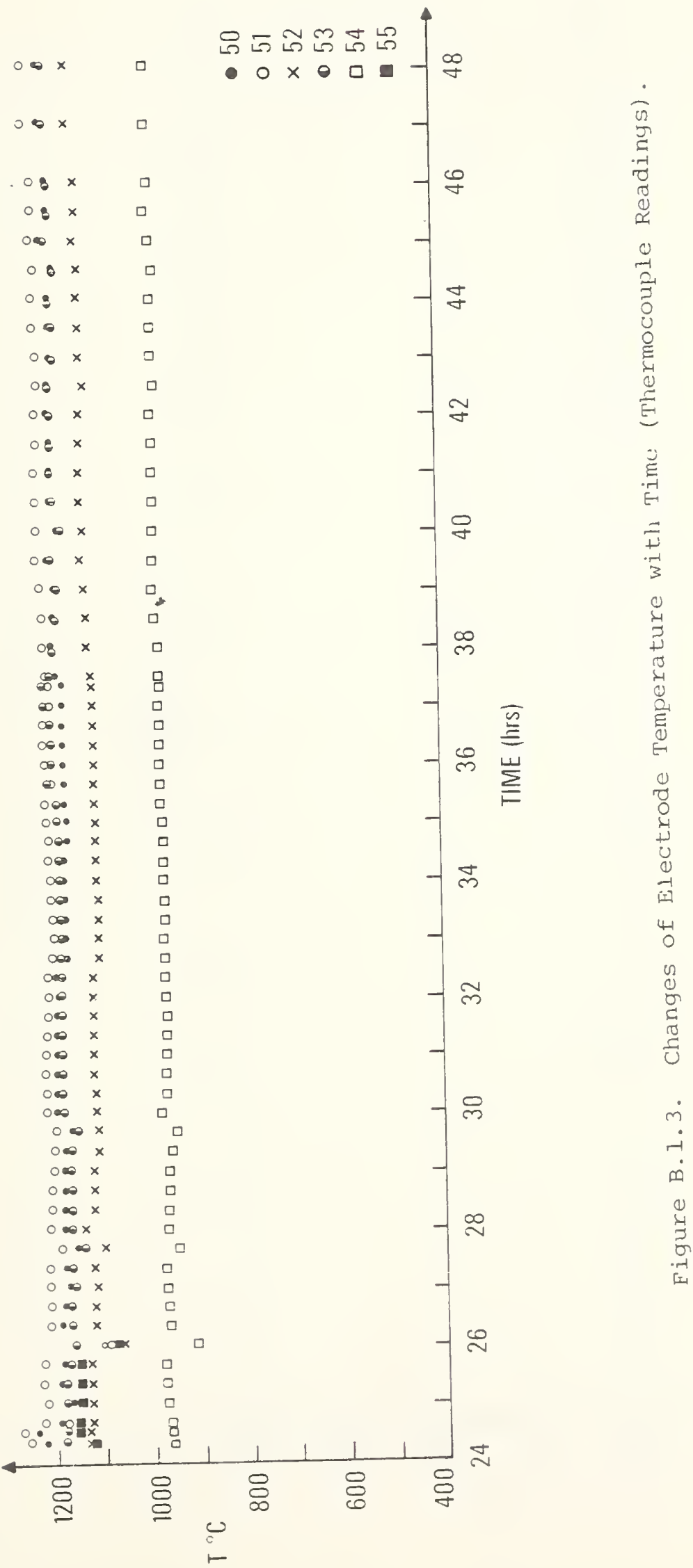




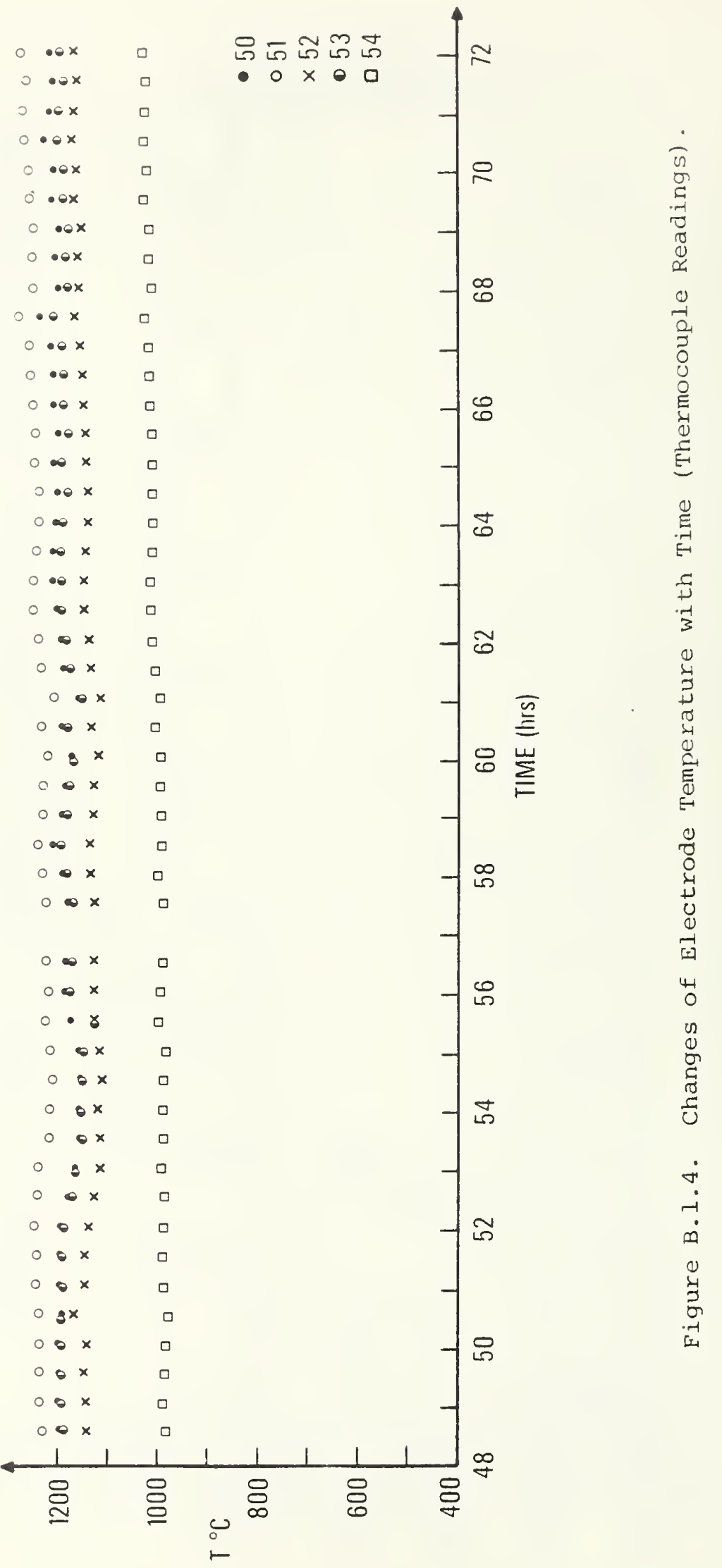




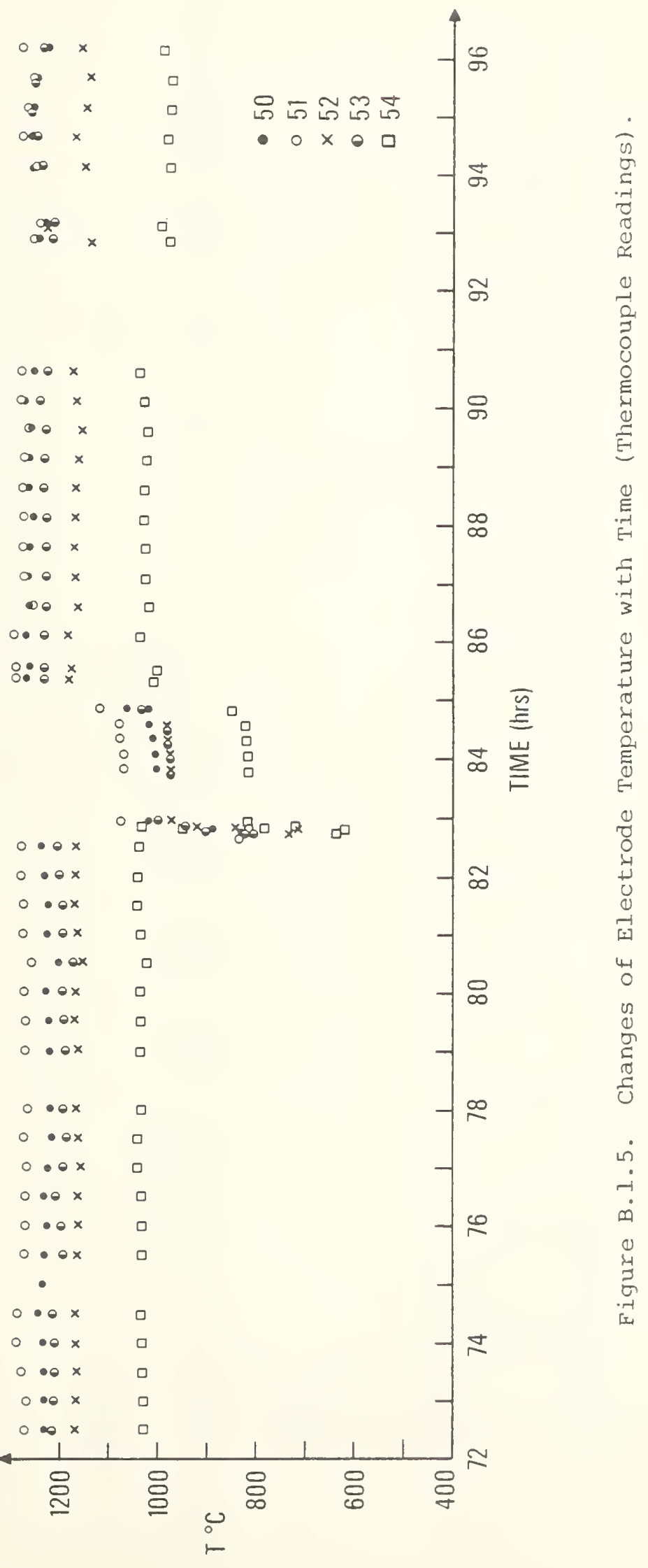




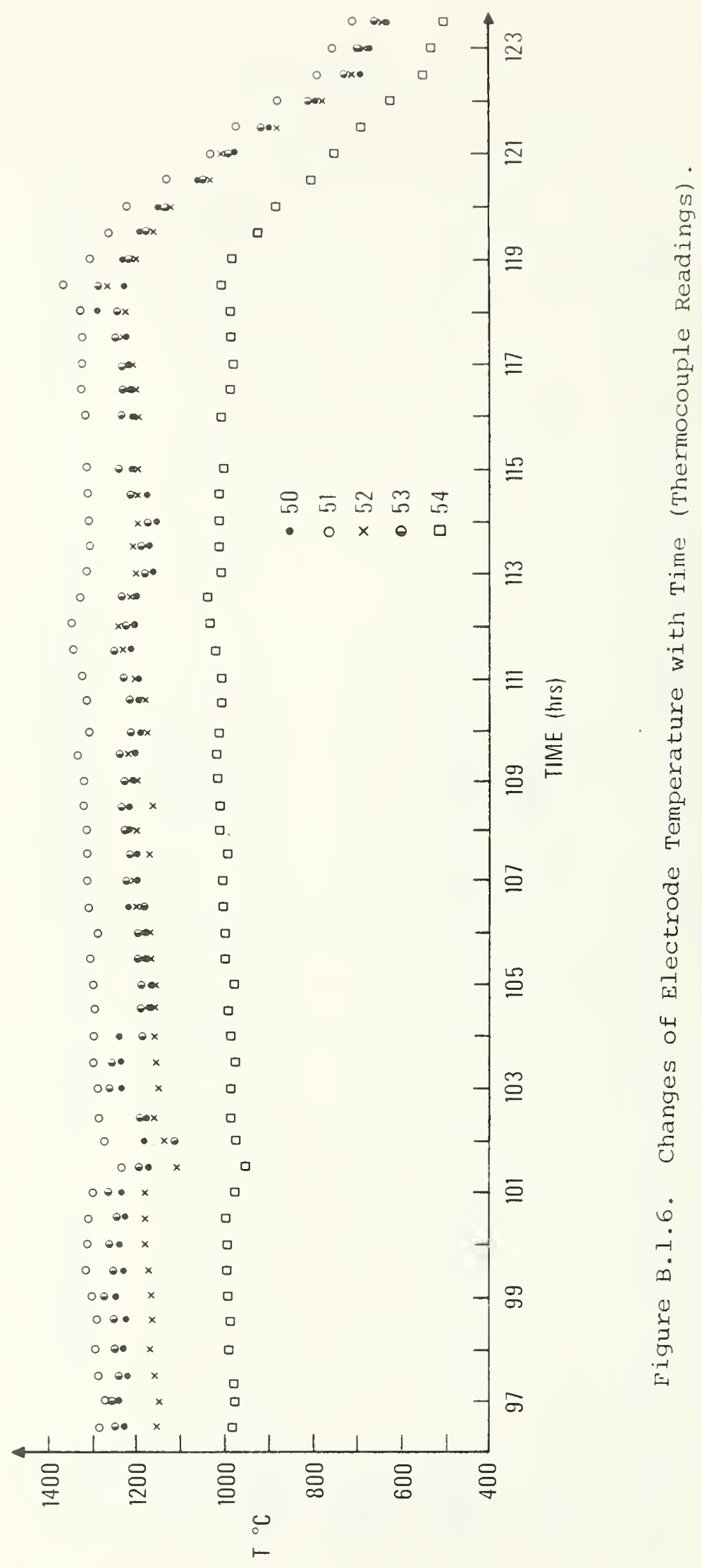




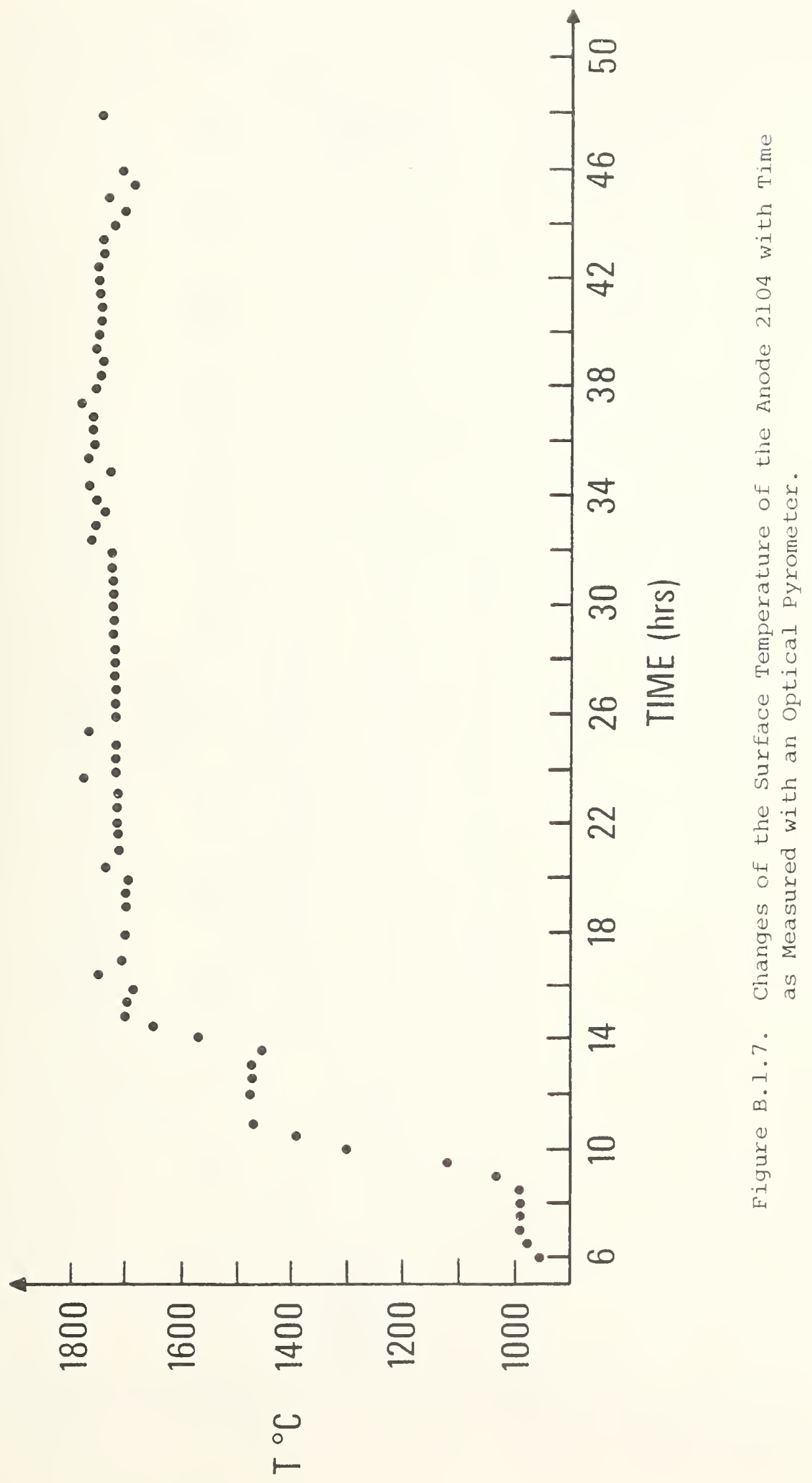




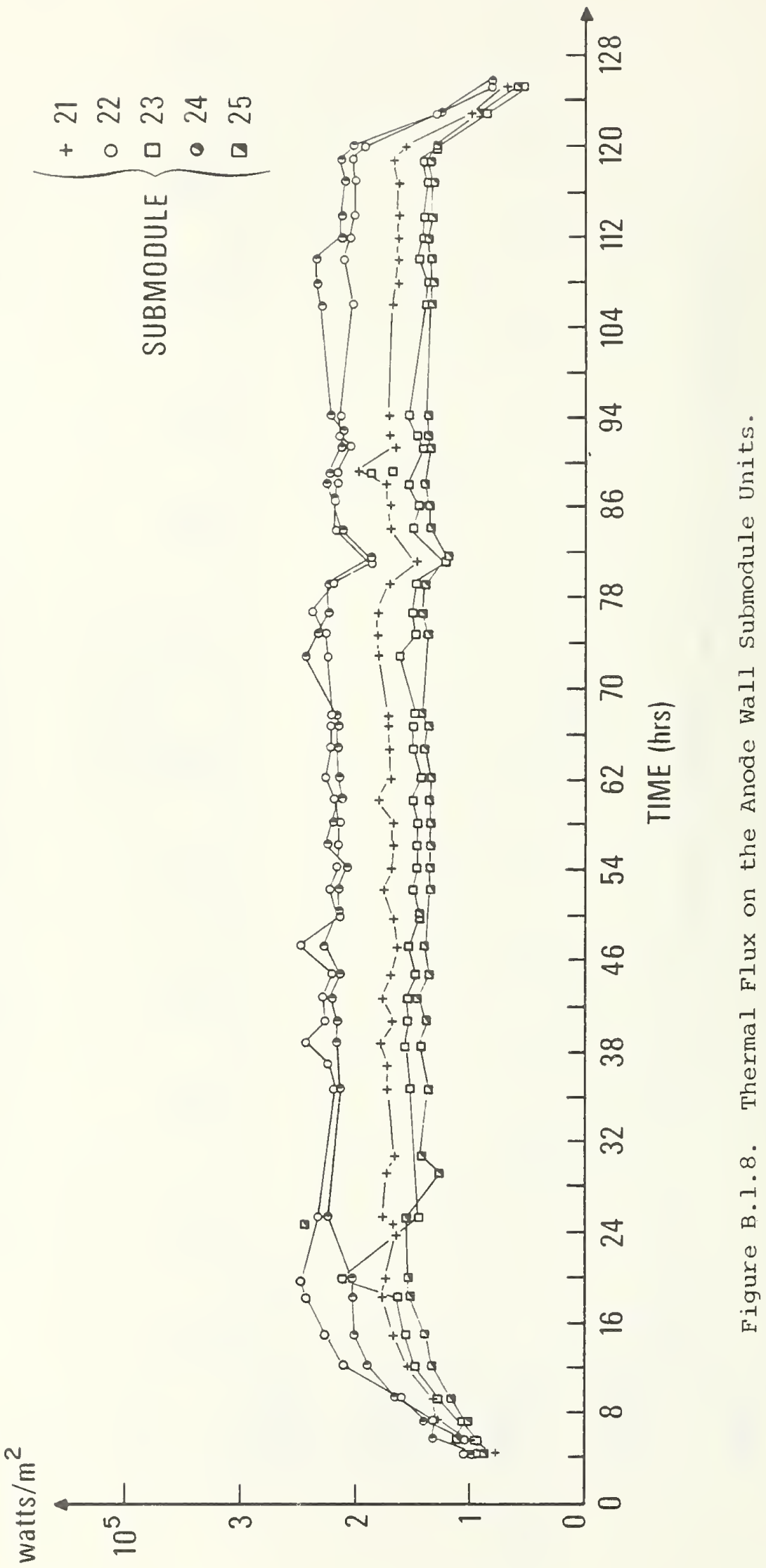




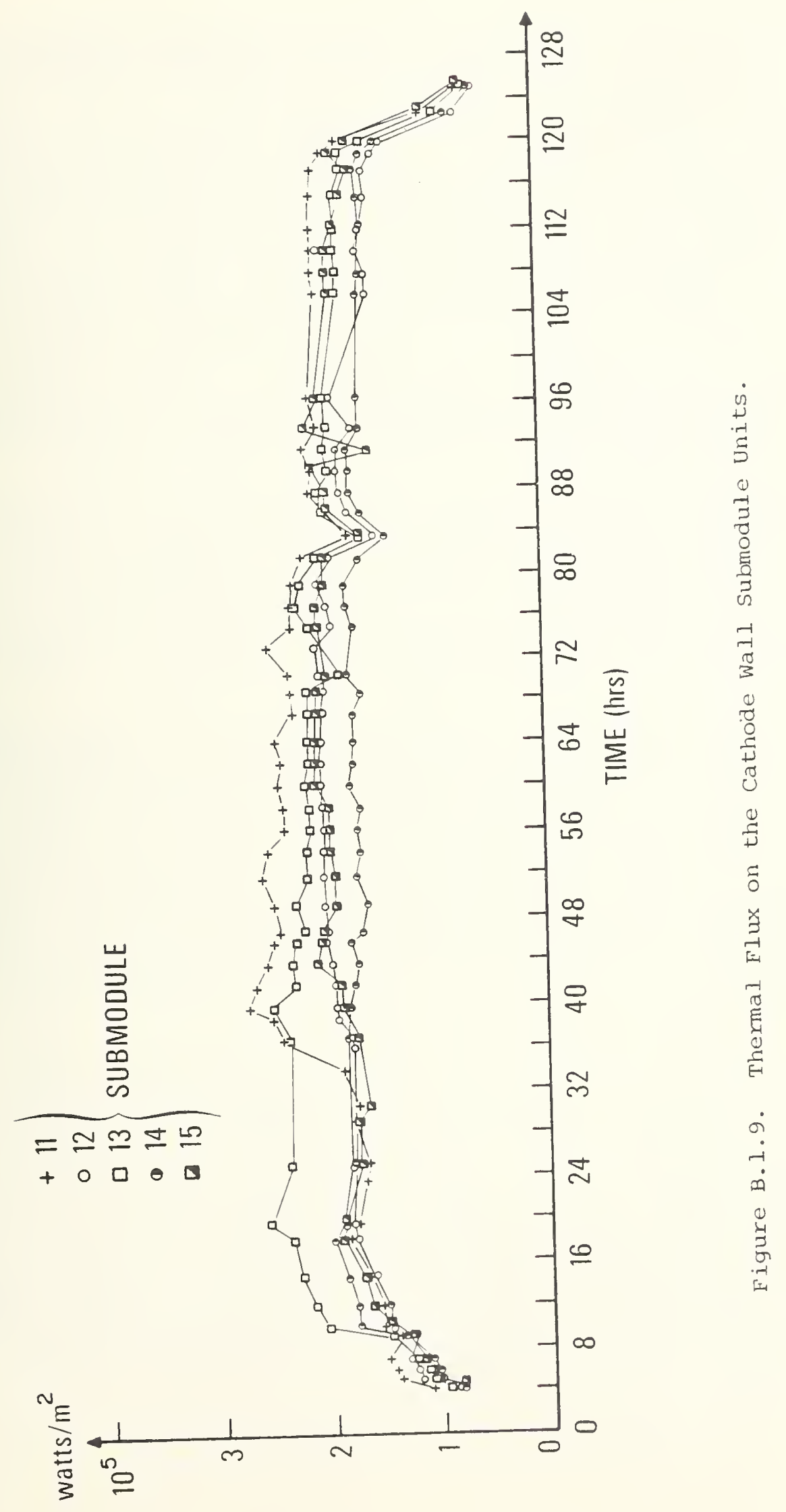


The analysis of experimental and calculated thermal fluxes, as well as the readings from the thermocouples placed inside the electrodes and in the MgO units, made it possible to determine surface temperatures on the rest of the electrode units. During this analysis, an evaluation was made of the difference between the experimental and the calculated thermal fluxes, due to heat losses on insulating walls and along the thermocouples, probes and current lead-outs. These estimates made it possible to establish that the temperature of electrode units of the first cathode module exceeded the temperature of the first anode module by 50 to $100{ }^{\circ} \mathrm{C}$; thus, it was in the range between 1750 and $1800{ }^{\circ} \mathrm{C}$. Taking into consideration the reduction of thermal fluxes along the channel, which agrees sufficiently well with the calculated data provided by the Westinghouse Corporation, the temperature on the electrode units was evenly reduced and on the fifth cathode unit was between 1650 and $1700{ }^{\circ} \mathrm{C}$. Also of interest is the change of temperature on the surface of the electrode when the current passes through the electrode.

As can be seen from Fig. B.1.2 during the 17th hour of the experiment, when the electrodes were for the first time under a load, the temperature of electrode 2101 (at the depth of 3 millimeters) increased by $40{ }^{\circ} \mathrm{C}$ with a current of 5.4 amperes, and at the beginning of the duration run the temperature increased by $80^{\circ} \mathrm{C}$ at 7.8 amperes; the Joule heating of the composition V (anode 2517, thermocouple 非4) was not very great: it was between 20 and $30^{\circ} \mathrm{C}$ at $\mathrm{I}=7.8 \mathrm{amp}$.

During the first 34 hours of the duration test, the temperatures on the electrodes remained constant and the range of readings from the same thermocouples did not vary greatly in time, (as a rule no more than $\pm 20{ }^{\circ} \mathrm{C}$, if one does not count two or three deviations up to $50{ }^{\circ} \mathrm{C}$ ). However, beginning with the $34 \mathrm{th}$ hour of the duration test (57th hour of the experiment), a temperature increase of 20 to $40{ }^{\circ} \mathrm{C}$ in the course of one hour was shown on all thermocouple readings and, subsequently, a slow increase in temperature of the anode wall elements by some 20 to $40{ }^{\circ} \mathrm{C}$ during the next 12 hours, upon which the electrode temperatures had once again stabilized.

\section{B.2 Characteristic Electrical Parameters During the Life Test}

The duration tests of the electrodes were conducted in accordance with the working program of tests which provided for the operation of electrodes of each material group at three levels of current density on the electrodes: $0.24-0.33 \mathrm{~A} / \mathrm{cm}^{2}, 0.5-0.7 \mathrm{~A} / \mathrm{cm}^{2}$, and $1.2 \mathrm{~A} / \mathrm{cm}^{2}$. The operation of electrodes under current was attained by loading them with active resistance with an electrical load coefficient $\mathrm{K}=0.2$ to 0.5 ; $\mathrm{K}=0$ (short circuit operating mode) and $\mathrm{K}=-0.2$ to -0.3 (stagnation operating mode with additional current to electrode pairs from separate external voltage sources). In addition, each material group had one pair operating at $\mathrm{K}=1$ (open circuit). 
Table B.2.1 shows the values of average current and deviations from average currents for different pairs of electrodes during the life test.

As can be seen from Table B.2.1, the electrode couples numbered 9 and $17\left(50 \% \quad \mathrm{ZrO}_{2}\right.$ and $50 \% \quad \mathrm{CeO}_{2}$ and $18 \% \quad \mathrm{ZrO}_{2}$ plus $80 \% \quad \mathrm{CeO}_{2}$ plus $2 \% \quad \mathrm{Ta}_{2} \mathrm{O}_{5}$, i.e., compositions 3 and 5$)$ had currents at $8.5 \mathrm{~A}$ and $8.3 \mathrm{~A}(1.20$ and 1.18 $\left.\mathrm{A} / \mathrm{cm}^{2}\right)$, respectively; the electrode pairs numbers $2,10,14$ and 18 (compositions $1,3,4$, and 5 ) had currents from $3 \mathrm{~A}$ to $4.8 \mathrm{~A}$ ( 0.43 to 0.68 $\left.\mathrm{A} / \mathrm{cm}^{2}\right)$; electrode couples numbers $3,6,11$, and $19(1,2,3$, and 4 compositions) had currents of $1.6 \mathrm{~A}$ to $2.8 \mathrm{~A}\left(0.23 \mathrm{~A} / \mathrm{cm}^{2}\right.$ to $\left.0.31 \mathrm{~A} / \mathrm{cm}^{2}\right)$. The deviations from the average values did not exceed 15 to $18 \%$.

The fourth electrode in each electrode group was tested in the absence of current, i.e., while operating in an idling mode. Figures B.2.1, B.2.2, and B.2.3 show the time dependence of anode-cathode potential difference in electrode pairs tested with various loading regimes. A significant change of the anode-cathode voltage for electrode pairs operating in a stagnation mode was due to the necessity of maintaining current values dictated by the test program schedule. Figure B.2.2 shows the change of the total acting voltage (V source $+\mu \mathrm{x} \overrightarrow{\mathrm{B}} \cdot \overrightarrow{\mathrm{Y}}$; i.e., the sum of voltage from the sources and induced voltage). As can be seen from Fig. B.2.2, the size of the operating voltage fluctuated within $\pm 15 \%$. The applied voltages ranged from 50 to 10 volts; i.e., they were no more than $20 \%$ of the effective voltage. The indicated current fluctuations and effective voltages in the range $\pm 15 \%$ could quite easily be explained by random changes in the thermal parameters of the loop, which, as was provided by the operating schedule, were maintained within $\pm 5 \%$ range. However, in addition to the random fluctuations mentioned above, a gradual, if not very large, reduction of the applied voltage necessary for maintaining the currents at the assigned level (from 30 to 60 volts down to 10 to 20 volts) was observed during the entire test. "Such a change could have little connection with the subsequently described anode-cathode resistance drop (current leaks could have accounted for about $0.5 \mathrm{~A}$ by the end of the duration test); to a great extent this could have been caused by the drop of the effective internal resistance of the channel, due to the increase during the second half of the test of the surface temperature on the anode wall (and judging by the decrease of thermal fluxes, a possible increase in the cathode wall temperature as well), which led to a reduction of electrical resistivity of the near electrode boundary layers of the plasma.

Figure B.2.3 shows the changes in time of the voltage values for 4 , $5,12,13$, and 20 pair of electrodes, operating in an open circuit mode. As was to be expected, these values were smaller than those theoretically calculated. Such difference is due to the fact that next to the indicated pairs there were pairs operating in other modes (for instance, stagnation mode). The abrupt decrease in the open circuit voltage of the fourth and fifth pairs of electrodes after 10 hours of duration tests can, evidently, be explained by the fact that the insulating characteristics of the nozzle section have decreased. This section was troweled with cement and was located upstream from the working section. 


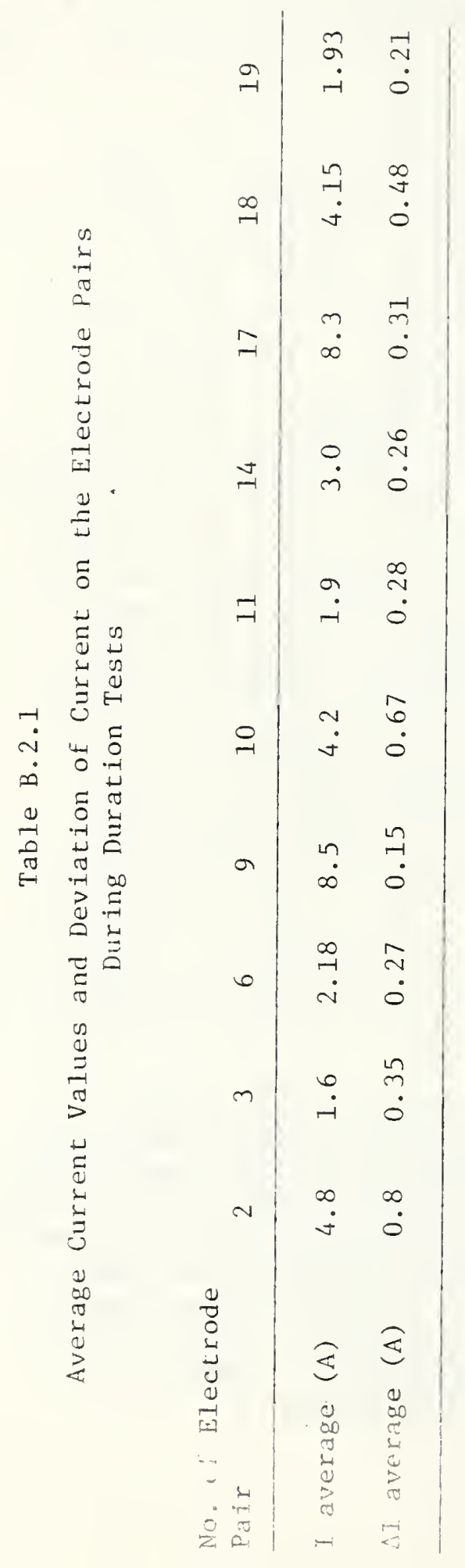


Figures B.2.4 and B.2.5 show the changes in the currents on the electrode pairs of various material groups in the course of duration tests. The duration test analysis shows that the electrical parameters were basically stable and were within the set limits, while the small deviations observed had a definite qualitative explanation. Thus, the electrical and thermal characteristics of the tested electrodes showed them capable of adequate performance on all the electrode pairs, with the exception of those which suffered destruction of the platinum current lead-outs.

\section{B.3 Electrical Characteristics (before and after the Life Test)}

The study of the electrical characteristics of the MHD generator channel was conducted both before the life tests and after them. The main purpose of the test was a comparison of the electrical characteristics of the electrodes made of different materials, as well as the study of the characteristics of the channel as a whole, which made it possible to judge the state of the channel insulation.

Tables B.3.1 and B.3.2 show the short circuit current values and the voltage of the open circuit operating mode before and after the test.

As can be seen from the Tables B.3.1 and B.3.2, the voltage during the open circuit operation before the life test was 155 to 160 volts, the short circuit current from a pair of electrodes from 3 to 4A, while Hall voltage along the operating section was on the order of 90 to 100 volts $(B=1.7 \mathrm{~T})$.

The main purpose of studying the channel wall characteristics was to determine the ratio of the possible current leaks along the insulation of the electrode and insulating walls. The study included measurements of the currents through electrode pairs in different operating modes during simultaneous measurements of the potentials of various elements of the design, various subassemblies of the structure (the potentials of the nozzle section, diffuser, electrodes and potential probes located in various parts of the upper insulation wall) in order to determine the plasma potential. The measured potential distributions made it possible to determine the values of the voltages in the electric field of the plasma core and along the electrode walls. The comparison of the results in order to evaluate the insulation characteristics of the working section are best done utilizing the indicated values of the voltage where

$$
E_{x}=\frac{E_{x} \text { experimental }}{E_{x} \text { theoretical }}
$$




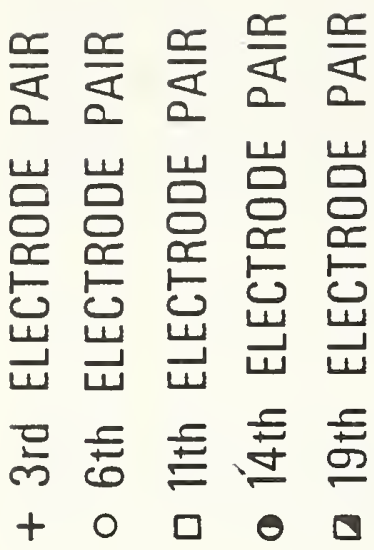

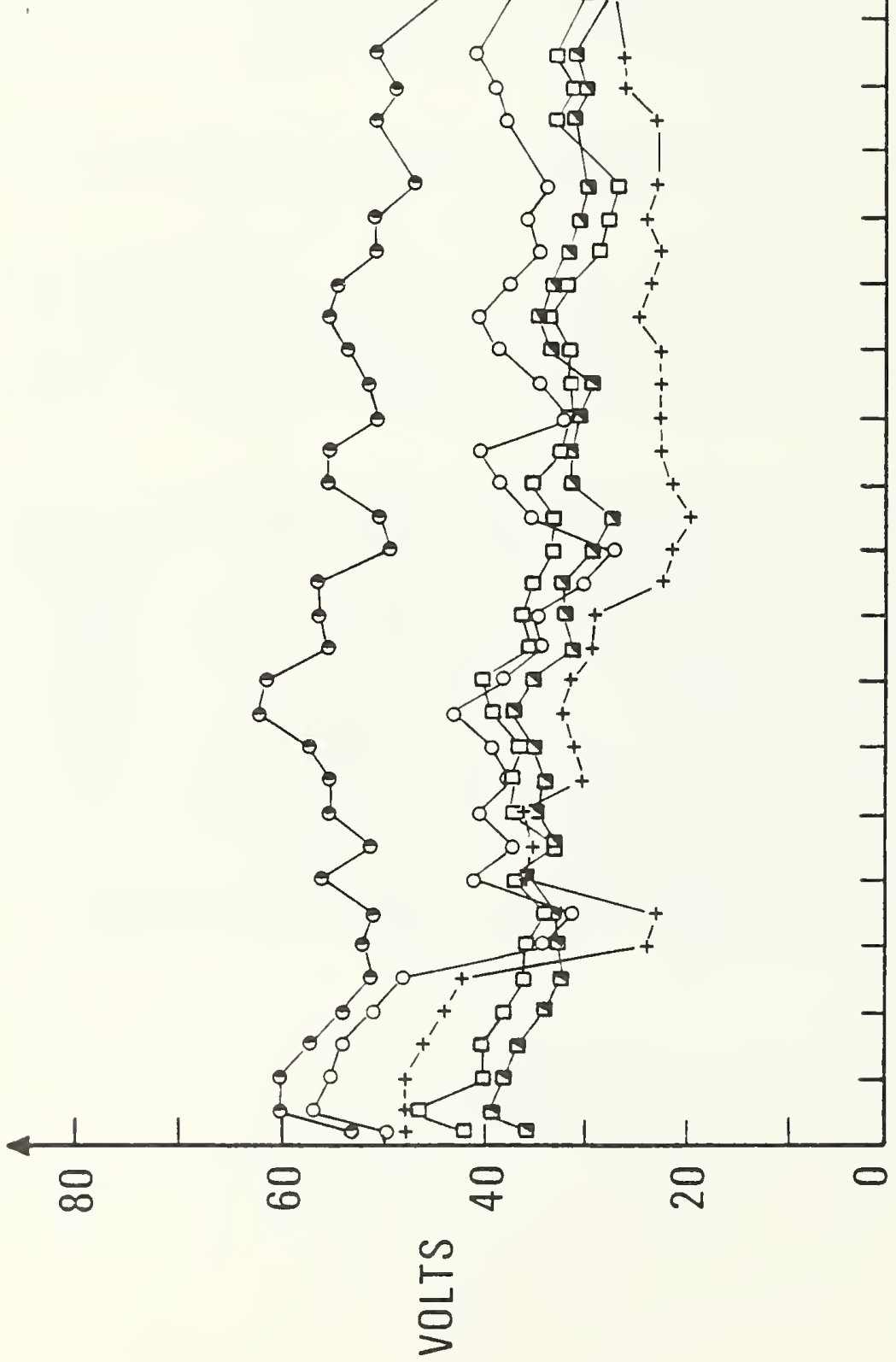

드

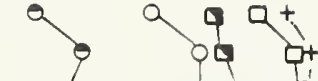

o

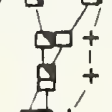

क

品

cit

of

को

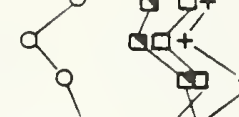

$\sigma$

$\infty$

है

E-

ㄷํㅇ

3

(1)

음

प्रे

48

$-1$

$\Rightarrow 0$

- -1 도

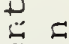

ฮ

$+\overrightarrow{0}=$

2.

o 3

प

F

$\sum$

m

0

ช

至

$\sum 0$.

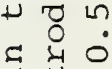

مَا

-1
0

(2) 0

品江

苟若

7

ल

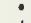

$\stackrel{-1}{\circ}$

$\dot{\sim}$

万 


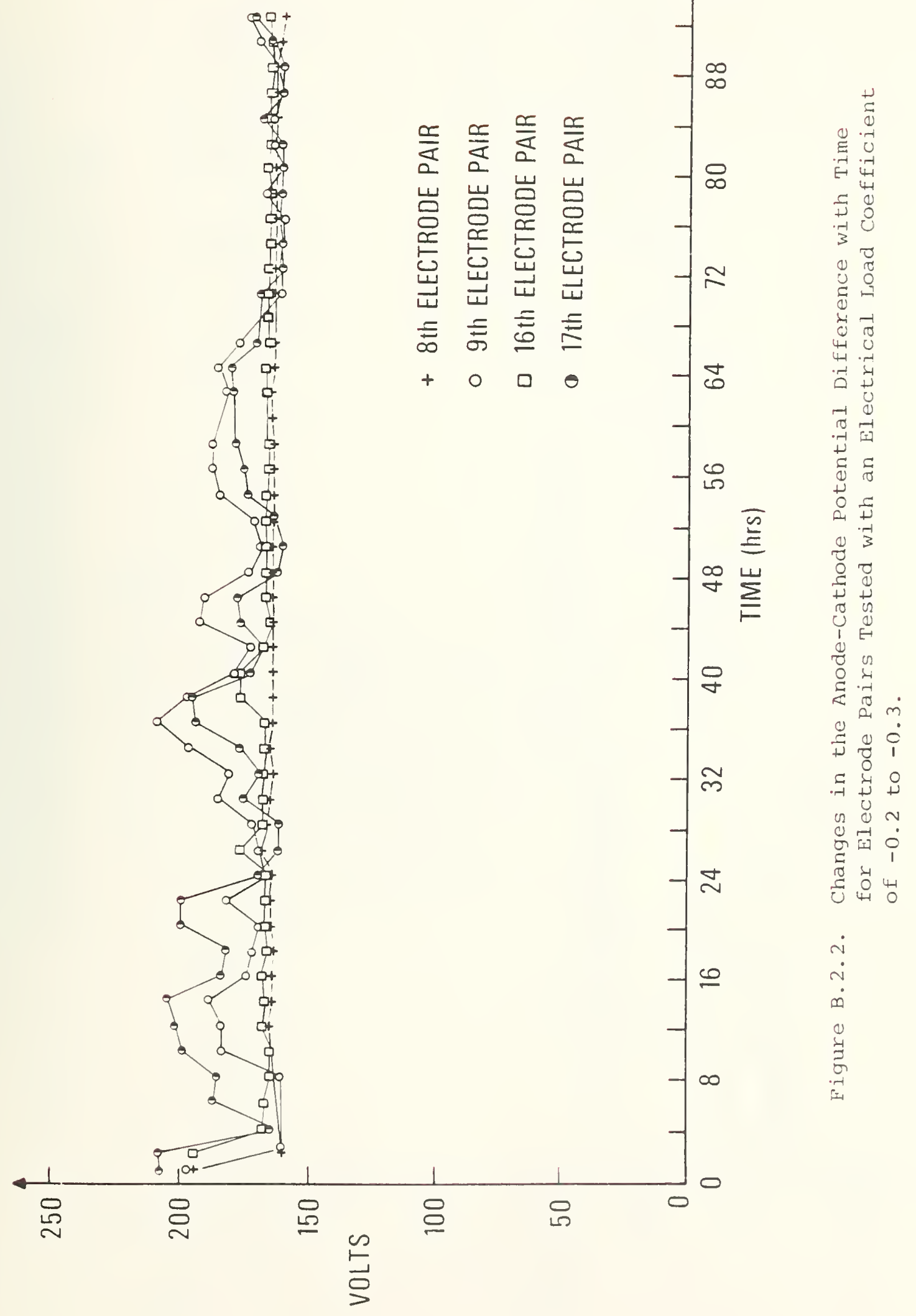




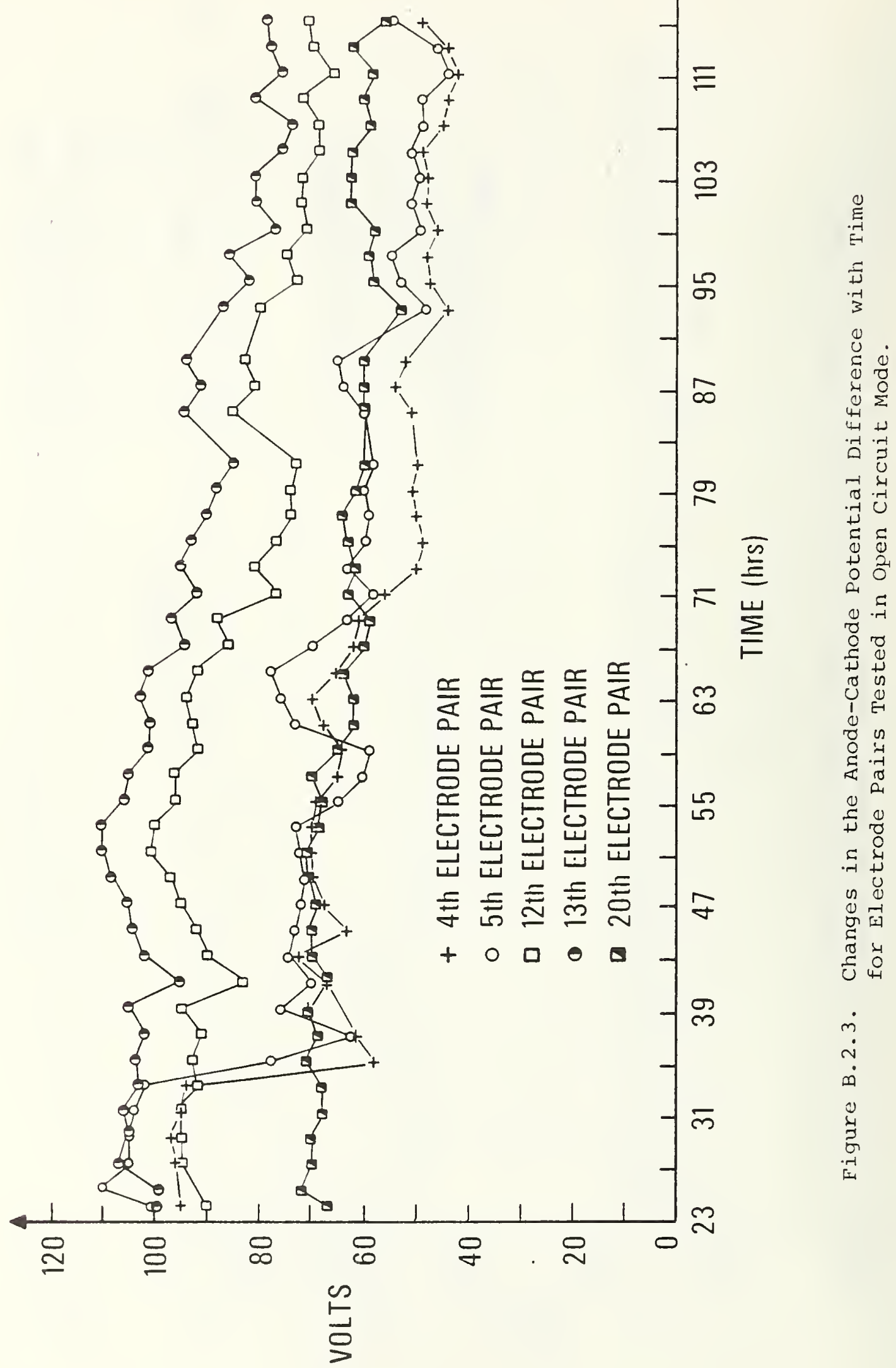



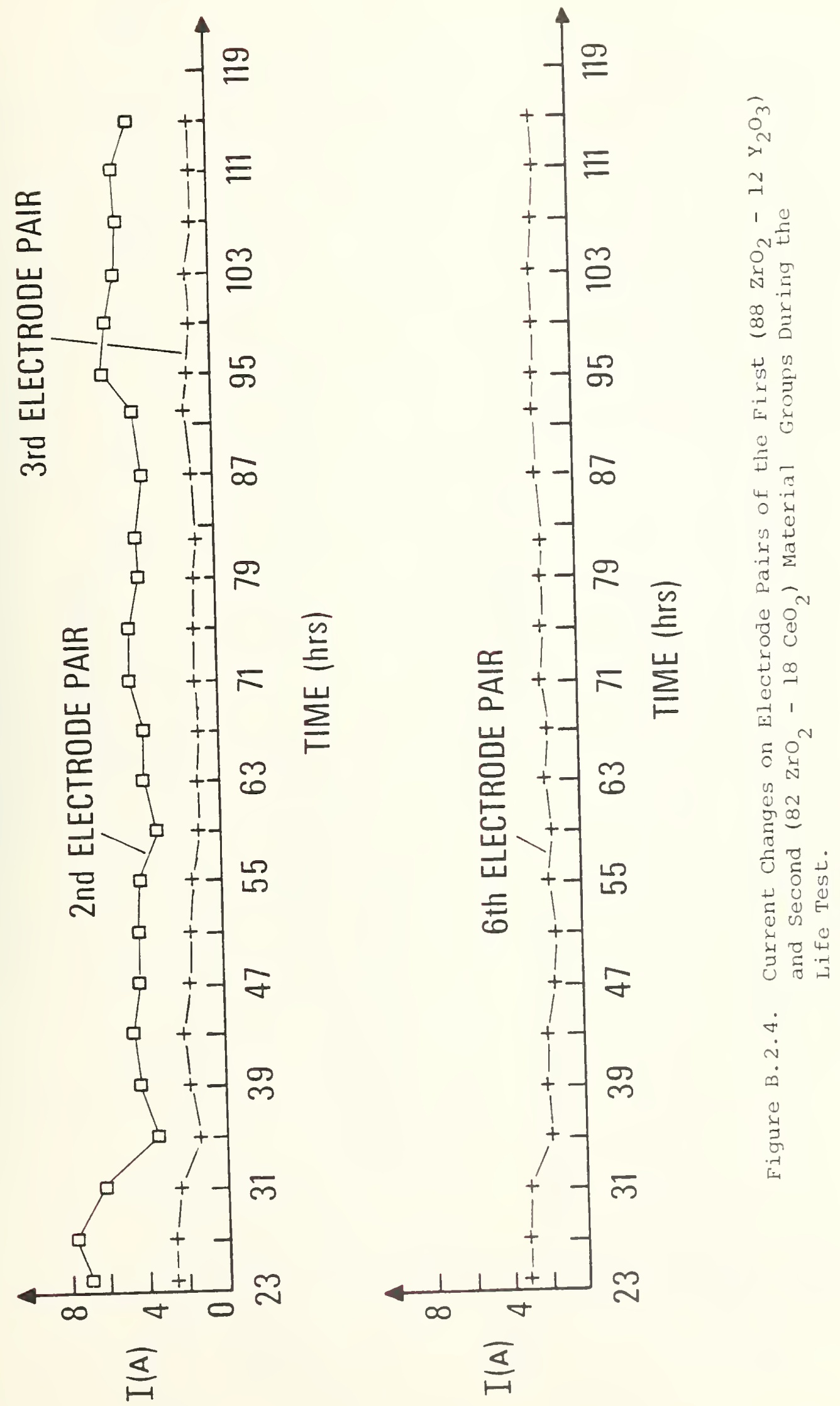

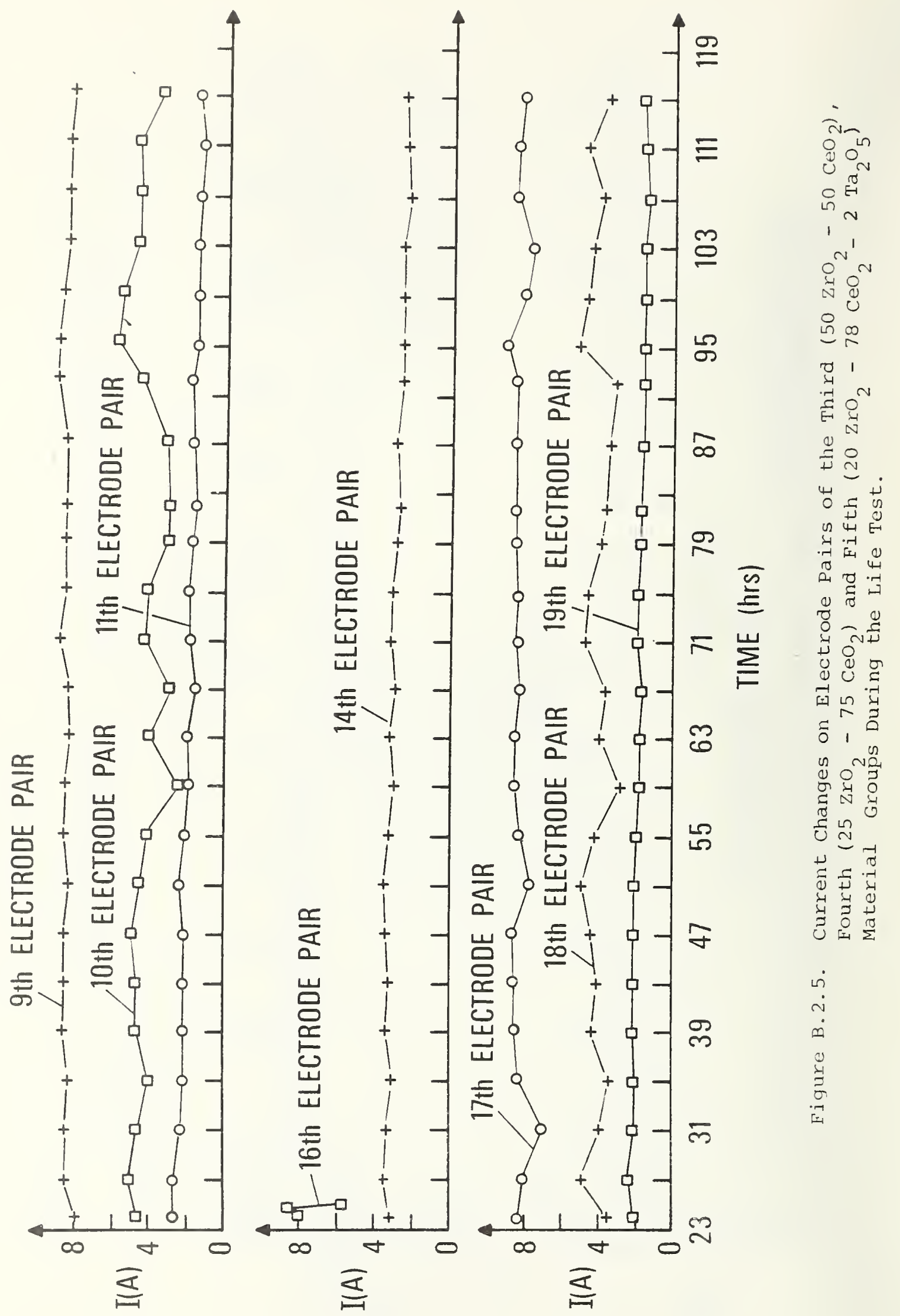


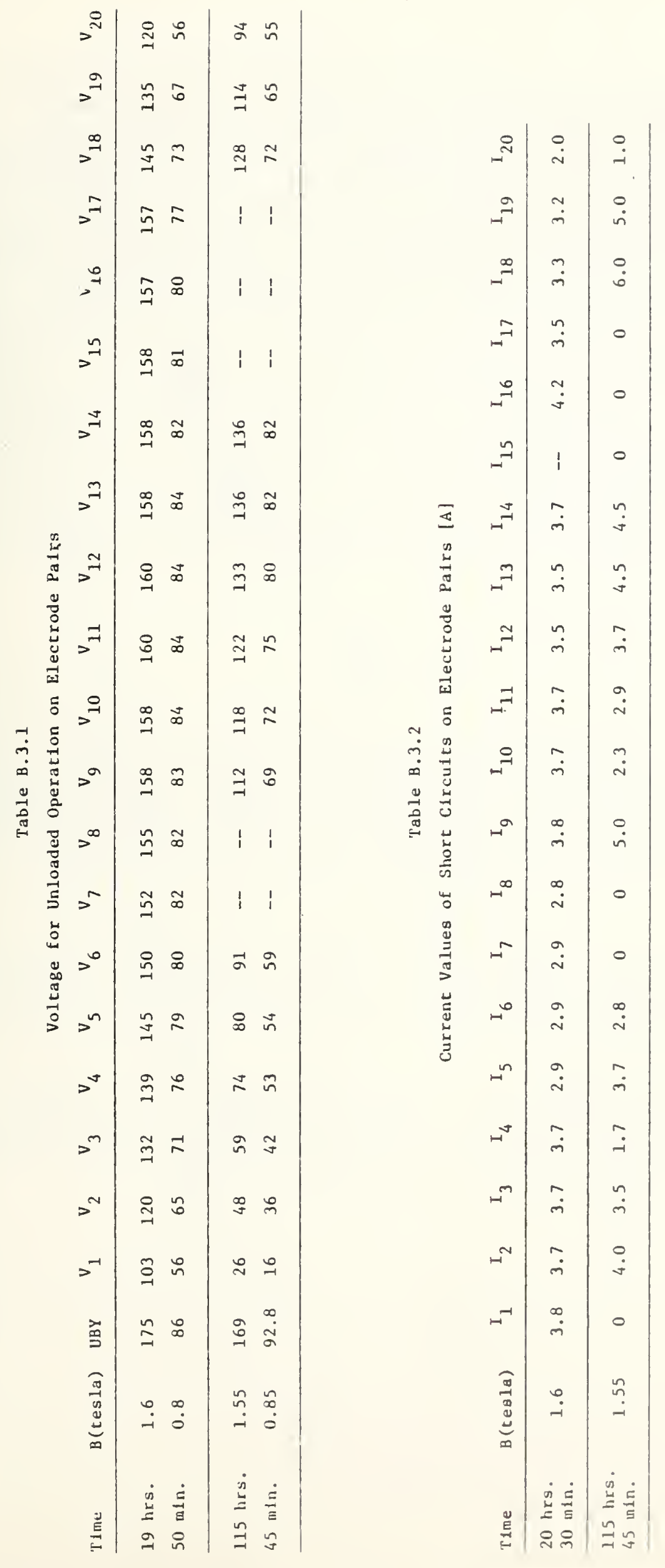


where $E_{X}$ experimental is the definite experiment value of the Hall field voltage and where $E_{X}$ theoretical is the value of the Hall field which would exist at the given average density of the transverse current in a case where the Hall current equals 0 ; i.e., in the absence of Hall current leaks along the insulation. The results shown in Table B.3.3 indicate that the average value of the indicated Hall field before and after duration tests differs insignificantly (roughly by 10-15\%) which shows that the insulation preserves its resistance on the electrode walls (in the axial direction) in fairly good condition for the entire duration of the life tests. In the experiments with a special grounded combustion chamber after the life tests, we have noted a relatively largt decrease of the Hall current in the operating portion of the channel. Evidently, this is connected with certain deterioration of the insulatior level between the working section of the channel and the nozzle and diffuser sections. The measurements of the insulation resistance betweer the given elements testify to this fact. Figures B.3.1 and B.3.2 show the distribution of the potential along the channel in an open circuit mode for several magnetic fields at the beginning and at the end of a run. The average current densities of transverse current in the channel are:

$$
\mathrm{J}_{\mathrm{av}}=\frac{\sum, \mathrm{J}_{\mathrm{i}}}{\mathrm{S}}
$$

where $\mathrm{J}_{i}$ is the current through electrode pair where $S=\mathrm{h} \times \mathrm{L}$ (h is the height of the channel and $\mathrm{L}$ is the length) and these average currents are accordingly equal to $0.22 \mathrm{~A} / \mathrm{cm}^{2}$ and $0.17 \mathrm{~A} / \mathrm{cm}^{2}$. The uniformity of the Hall field along the channel indicates the absence of local short circuits between the electrodes and the ground and between the electrodes.

The program to study the resistance of insulation included:

1. The determination of the effective resistance of insulation between the cathode and the anode of different electrode pairs (on the basis of experience with short circuit and open circuit operation).

2. The measurements of electrode resistance to the adjacent elements, insulation of interelectrode spaces, insulation between electrodes and the water-cooled units and insulation of the electrodes in relationship to ground. 


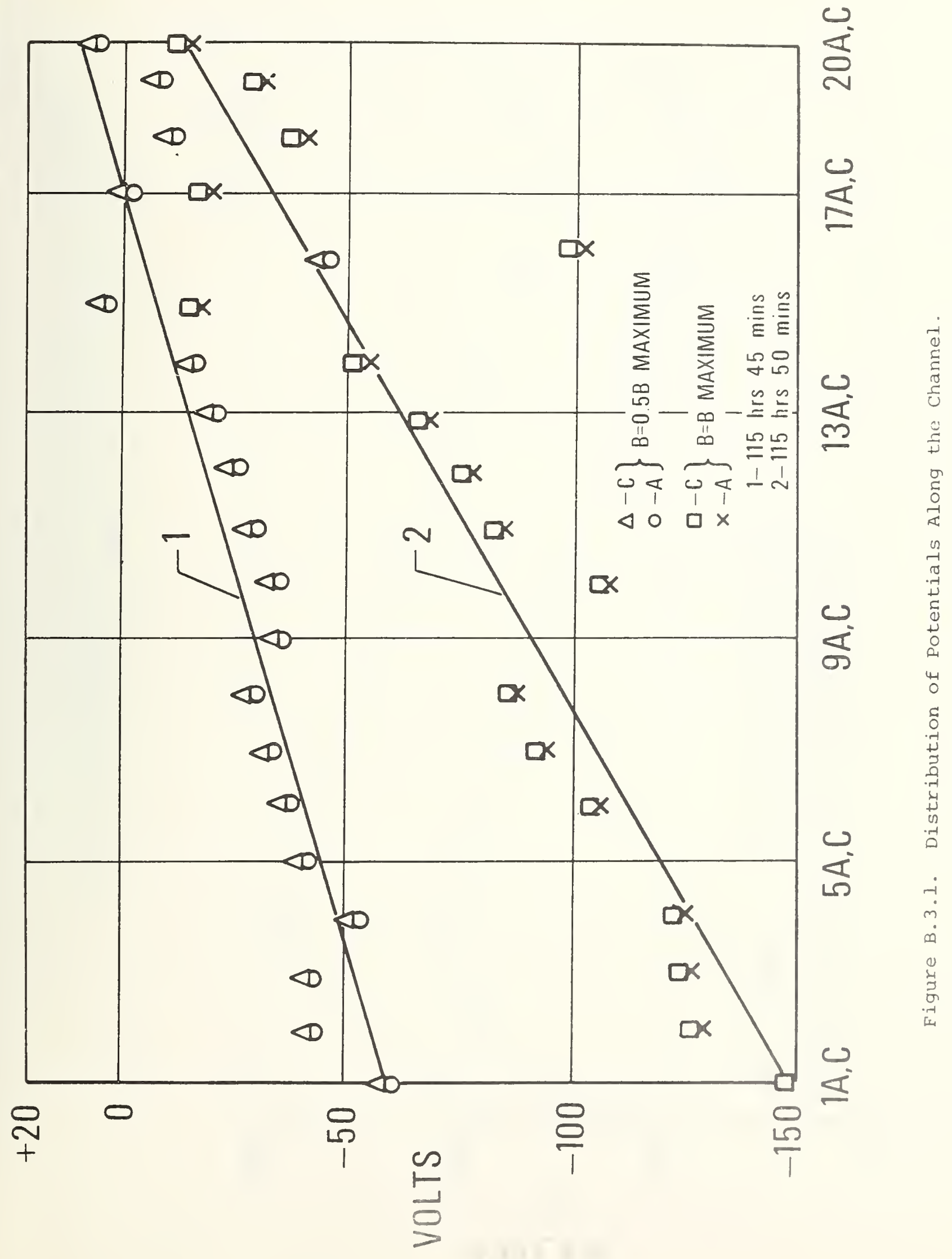




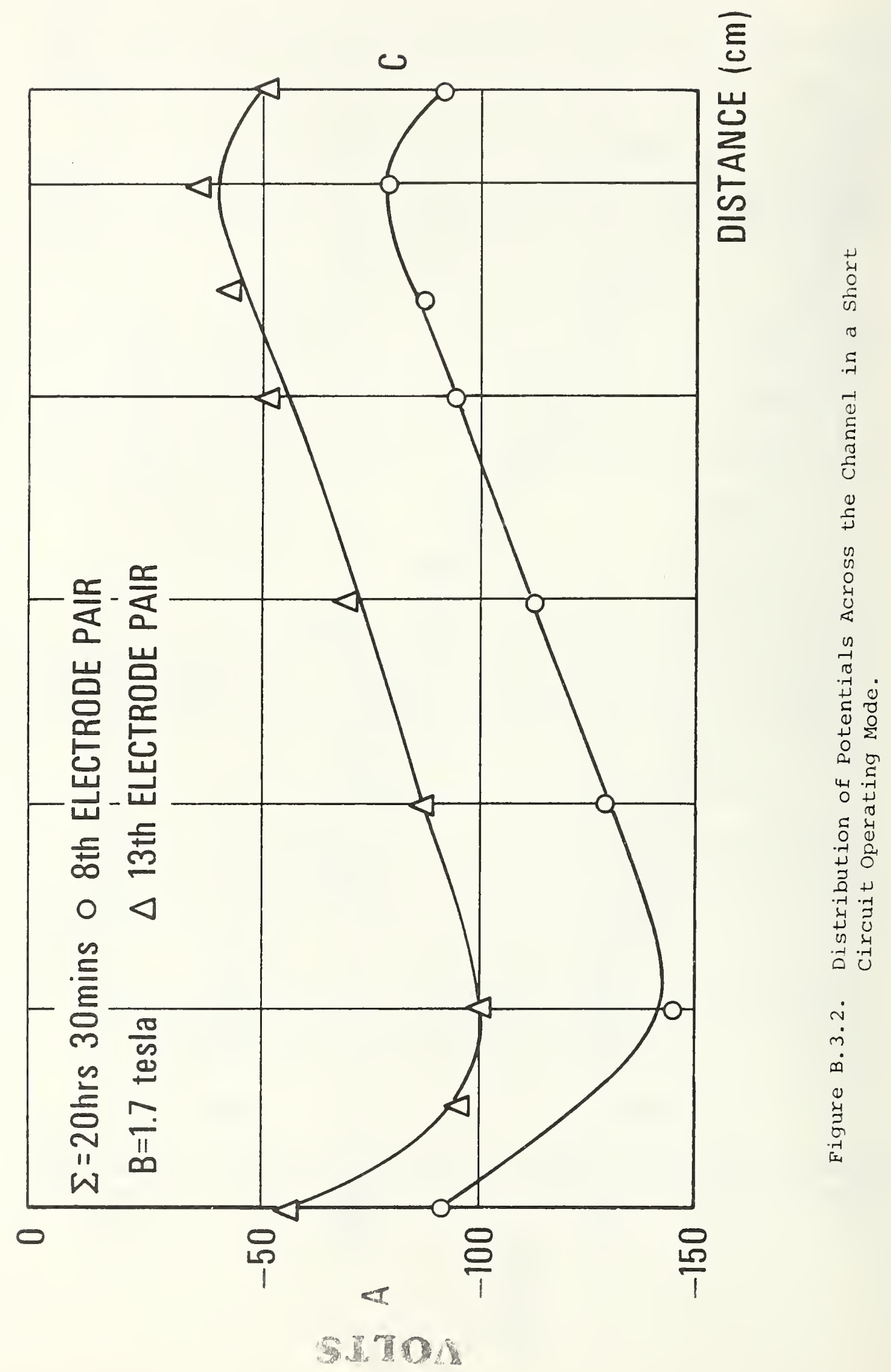


Table B.3.3

Relative Values of Hall Voltages at the Channel in

Different Operating Modes

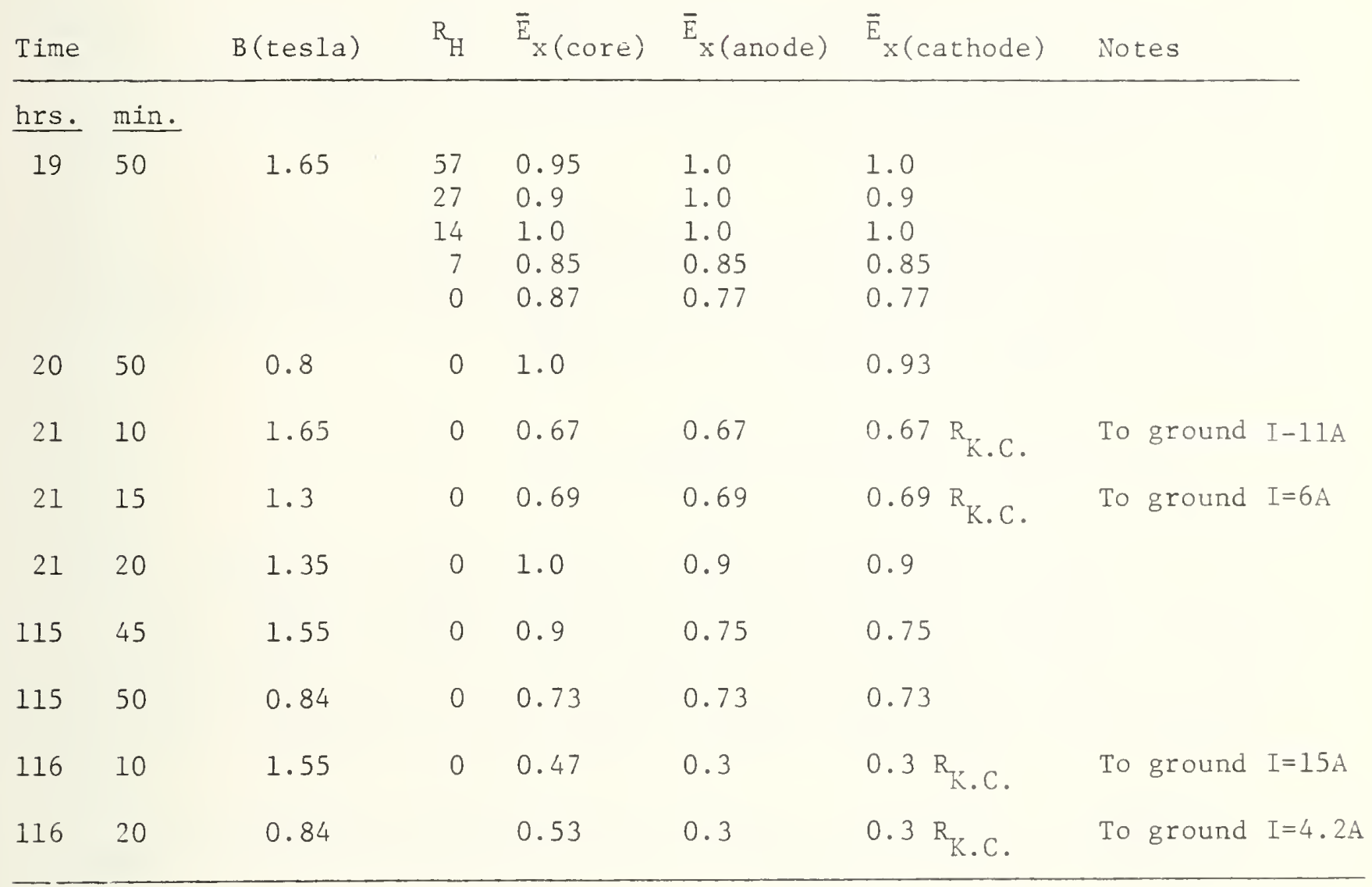


On the basis of the measured voltages of the open circuit mode and the currents of the short circuit, the anode-cathode resistances of all electrode pairs have been determined (Table B.3.4). On the first day of the run, operating with ionizing seed (2nd phase) prior to the beginning of the life tests, the resistance of insulation between anode and cathode fluctuated within the range of 100 to 500 ohms. On the first three and last two electrode pairs, it varied between 60 and 180 ohms, on pairs 4 and 5 it was between 175 and 280 ohms, and on the 6 through 18 pairs, it was between 300 and 500 ohms.

After the duration tests had been conducted, the second set of experiments was conducted with the same operating mode in order to determine the cathode-anode resistance of insulation. These experiments have shown that the overall level of insulation of all the electrode pairs has decreased. The electrode pairs from:

1 to 5 pair - down 16 to 80 ohms;

9 to 14 pair - down 100 to 150 ohms; and

18 to 20 pair - down 60 to 100 ohms.

Thus, the reduction of insulation resistance was in the range of 30 to $40 \%$. The electrical characteristics can also help to judge the effective resistance of the channel in the transverse direction. The study of electrode operation in the open circuit and the short circuit mode prior to the duration tests has shown that the open circuit mode voltage differs from the theoretical value by $10 \%$ at the 6 th to 17 th electrode pairs and by $30 \%$ at the electrode pairs 1 to 5 and 18 to 20 .

During the run, the open circuit mode voltage had changed on the 9 th to 14th electrode pairs by $30 \%$, on the first six pairs it diminished two-fold (at the 2 to 6 pairs).

The reduction of the open circuit mode voltage on the electrode pairs at the end of the channel is, evidently, due to the reduction in the insulation of the nozzle and diffuser sections, troweled with concrete and adjacent to the operating section.

Direct measurements of the insulation level between the elements along the channel have shown that the resistance of the interelectrode space on the first day of the run, when operating without ionizing seed with $\mathrm{G}_{2}=200 \mathrm{~g} / \mathrm{s}$, along the cathode side 400-600 ohms and along the anode side 600-1000 ohms. 


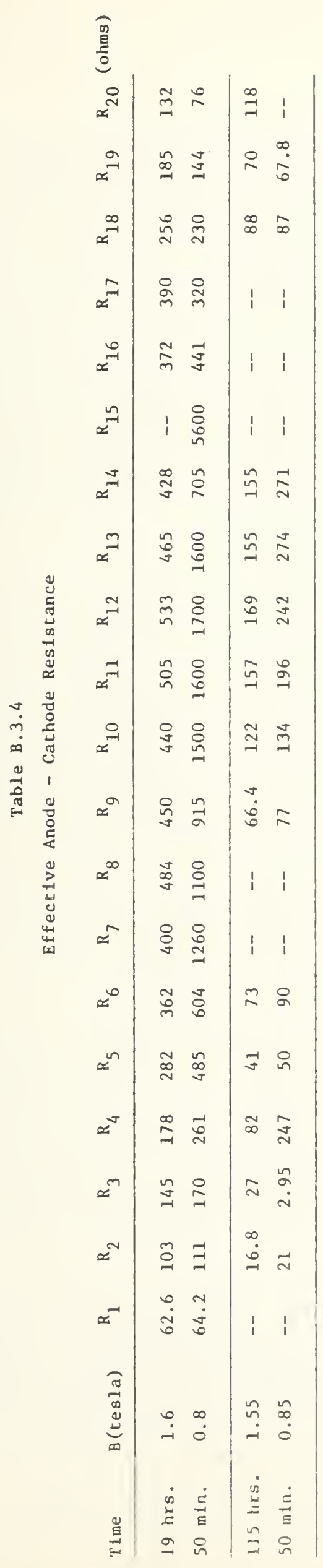


The measurements of insulation in the middle of the run gave the following results: along the cathode side the resistance was 20 to 60 ohms while along the anode side it was 80 to 150 ohms. After the duration tests had been conducted, the resistance of insulation of the interelectrode space on the cathode wall was between 100 and 300 ohms (with the exception of the spaces between the electrodes 1207-1208, 1208-1309, 1312-1413, and 1413-1414, where the resistance was 10 to 30 ohms); which along the anode side the resistance of the insulation of the interelectrode spaces was 50 to 100 ohms. Direct measurements of resistivity of the insulation between the electrodes and the water-cooled units showed that the insulation level on the anode wall was fairly high during the entire run and was on the order of several kilo-ohms and up, and on the cathode wall at the beginning of the run, it was about 5 to 10 kilo-ohms, but by the end of the run it was reduced to several tens of ohms (see Table B.3.5). This was possibly due to the penetration of potassium compounds into the walls during tests under current.

The estimate of possible current leaks to the insulation shows that when the voltage level from external sources is 250 volts and the anodecathode resistance is on the order of 100 ohms, the current losses in the transverse direction by the end of the run could reach $0.5 \mathrm{~A}$. With a current level at most pairs from 3 to $8 \mathrm{~A}$; thus, the losses through insulation leaks were from 5 to $15 \%$. The currents of the leaks in the axial (Hall) direction before and after the test did not exceed 0.1 to $0.2 \mathrm{~A}$. Relatively large current leaks of about $1 \mathrm{~A}$ could develop along the cathode wall through the copper base within each block, however, with the Hall current at 10 to $13 \mathrm{~A}$ they were relatively small.

Thus, the entire set of tests of the electrical characteristics of the channel and of the direct insulation measurement has shown that during the experiments, the resistivity of insulation of both the insulating and electrode walls was sufficiently high and there were no conspicuous current leaks between the segments of the whole structure.

The measured values of the near-electrode voltage drops, when the current in the electrode pair is $3 \mathrm{~A}$ was 40 to 50 volts with anode and 10 to 20 volts on the cathode. The near electrode drops were determined on the basis of the difference between the potential at the current leadouts and the potential voltage probe, located $2.5 \mathrm{~cm}$ from the gas surface of the electrode. This difference of the potential included the voltage drop in the electrode body itself, the voltage drop in the area of the space charge above the electrode and the voltage drop in the gasodynamic boundary layer.

The drop of voltage at the electrodes measured as a difference of the potential between probes located in the electrode and the platinum lead-out was not very great ( 0.7 to $1 \mathrm{~V})$ with a current of 4 to $8 \mathrm{~A}$ and represented a small share of the total voltage drop. This testifies to the relatively small possible Joule heat of the electrodes. The voltage 


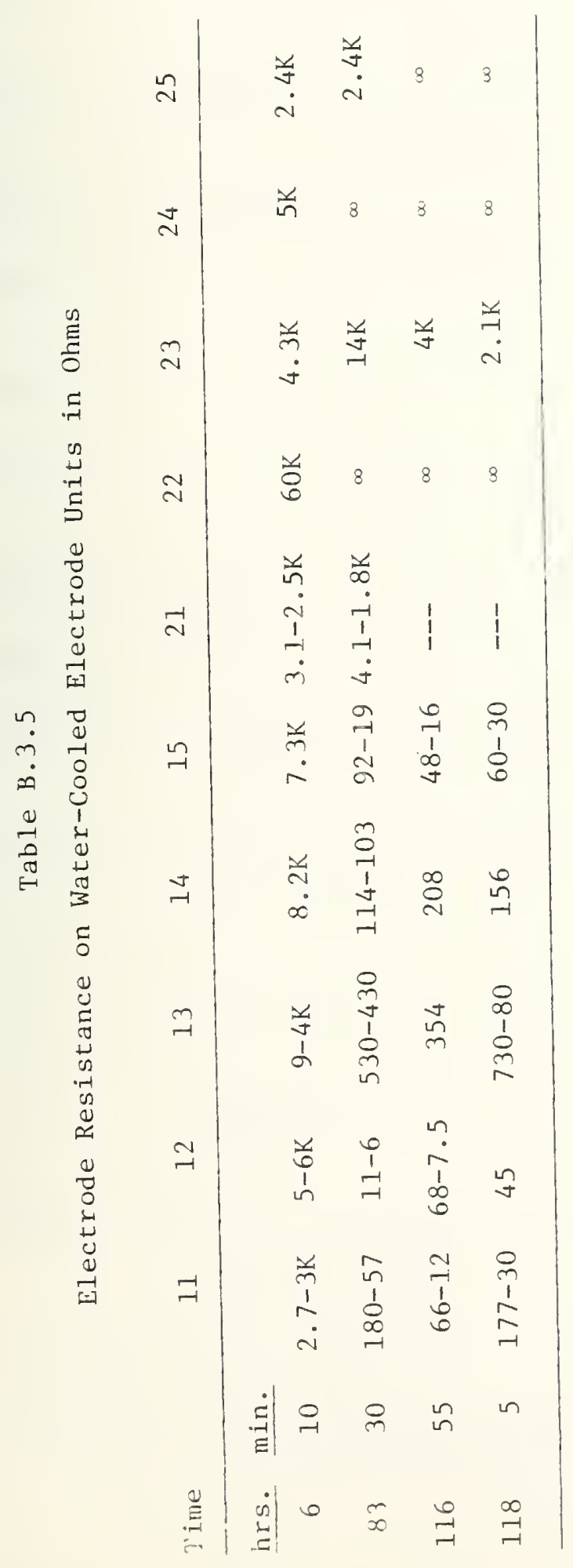


drop within the electrode was stable and, as a rule, up to the very electrical resistance of the electrode body. 
Figure B.1.1. Changes of electrode temperature with time (thermocouple readings).

Figure B.1.2. Changes of electrode temperature with time (thermocouple readings).

Figure B.1.3. Changes of electrode temperature with time (thermocouple readings).

Figure B.1.4. Changes of electrode temperature with time (thermocouple readings).

Figure B.1.5. Changes of electrode temperature with time (thermocouple readings).

Figure B.1.6. Changes of electrode temperature with time (thermocouple readings).

Figure B.1.7. Changes of the surface temperature of the anode 2104 with time as measured with an optical pyrometer.

Figure B.1.8. Thermal flux on the anode wall submodule units.

Figure B.1.9. Thermal flux on the cathode wall submodule units.

Figure B.2.1. Changes in the anode-cathode potential difference with time for electrode pairs tested with the electrical load coefficient of $0.2-0.5$.

Figure B.2.2. Changes in the anode-cathode potential difference with time for electrode pairs tested with an electrical load coefficient of -0.2 to -0.3 .

Figure B.2.3. Changes in the anode-cathode potential difference with time for electrode pairs tested in open circuit mode.

Figure B.2.4. Current changes on electrode pairs of the first $\left(88 \mathrm{ZrO}_{2}-\mathrm{I}_{2} \mathrm{Y}_{2} \mathrm{O}_{3}\right)$ and second $\left(82 \mathrm{ZrO}_{2}-18 \mathrm{CeO}_{2}\right)$ material groups during the life test.

Figure B.2.5. Current changes on electrode pairs of the third $\left(50 \mathrm{ZrO}_{2}-50 \mathrm{CeO}_{2}\right)$, fourth $\left(25 \mathrm{ZrO}_{2}-75 \mathrm{CeO}_{2}\right)$ and Fifth $\left(20 \mathrm{ZrO}_{2}-78 \mathrm{CeO}_{2}-2 \mathrm{Ta}_{2} \mathrm{O}_{5}\right)$ material groups during the life test.

Figure B.3.1. Distribution of potentials along the channel.

Figure B.3.2. Distribution of potentials across the channel in a short circuit operating mode. 


\section{CHAPTER II}

Module Description, Analytical Procedures, and Results of Analysis

A. Module Design and Preparation of Materials

A.1 Overview of design considerations (B. Wright, Westinghouse Research and Development Laboratory)

The known mechanical constraints on the design are ones of physical size and mechanical capability with the existing components of the Soviet U-02 MHD facility. The overall dimensions of a single electrode wall are length, $491 \mathrm{~mm}$; height, $100 \mathrm{~mm}$; width (at hot wall surface), 63-64 mm; width (at channel exterior), $112 \mathrm{~mm}$. The electrode wall design has no limitations as to the precise electrode configuration. The short channel length implies a constant cross-sectional flow area. Thus, a segmented electrode Faraday design is the most practical, although not the most desirable, from the viewpoint of power generation from an MHD generator. To design the electrode wall, the U-02 MHD plant operating characteristics must be known. These specifications have been transmitted via reference [1].

The concept "cold" or "hot" as it anrlies to MHD channel design is rather conventional. The term cold wall refers to one whose gas side surface is made of strongly cooled metal parts or modules, fastened in one way or another to a supporting plate or beam. The term hot wail rofers to one whose gas side surface is made of ceramic parts fastened to watercooled metal parts or modules, which in turn, are fastened to a supporting beam or plate. The objectives of the U.S.-U.S.S.R. cooperative materials program necessitate a hot wall design.

Plasma property values needed for the design of the generator come from typical working conditions of the Soviet U-02 MHD facility. The fuel is natural gas containing methane $97 \%$ by volume, ethane $2 \%$ by volume, and inerts $1 \%$ by volume. Combustion occurs with an oxidant which is moist air with $1 \%$ moisture by weight and enriched with oxygen to the extent of $40 \%$ mole concentration in dry air. Seeding is accomplished by a $\mathrm{K}_{2} \mathrm{CO}_{3}$ solution having $50 \%$ by weight $\mathrm{K}_{2} \mathrm{CO}_{3}$ and $50 \%$ by weight water. At the entrance to the channel the desired plasma conditions are:

$\begin{array}{ll}\text { Temperature } & 2600 \mathrm{~K} \\ \text { Static pressure } & 0.80 \mathrm{~atm} \\ \text { Potassium by weight } & 1 \% \\ \text { Mass flow } & 0.75 \mathrm{~kg} / \mathrm{s}\end{array}$

The internal dimensional envelope of the channel as given by the Soviets specifies a height of $0.260 \mathrm{~m}$ and a width of $0.064 \mathrm{~m}$ yielding a constant cross-sectional flow area of $0.0166 \mathrm{~m}^{2}$. For practical purposes the velocity in the channel can be considered a constant. With stoichiometric combustion, the plasma has an average density of $0.1 \mathrm{~kg} / \mathrm{m}$. Thus, from 
continuity of mass, the average channel velocity is $450 \mathrm{~m} / \mathrm{s}$. The magnetic field has a strength of $1.5 \mathrm{~T}$ which is constant the length of the channel. The average plasma conductivity and mobility are $10 \mathrm{mhos} / \mathrm{m}$ and $0.7 \mathrm{~m}^{2} / \mathrm{Wb}$, respectively. The Hall parameter has a numerical value near unity.
A.2 Preparation of materials (B. Rossing, Westinghouse Research and Development Laboratory)

The requirements of good resistance to both thermal stress damage and seed attack demand, in turn, careful control of microstructure and microchemistry for both electrodes and insulators. Thermal stress damage resistance can te increased by the presence of such crack arresting microstructural features as pores, microcracks, and second phases. In single phase materials, this can be accomplished by use of a wide variation in grain structure and a moderate level of porosity. Seed resistance is achieved by low and/or closed porosity and low levels of impurities (absence of secondary phases at grain boundaries). Both electrodes and insulators are thus fabricated by making dense high porosity grain, followed by sizing, pressing and refiring. The fabrication details for both electrodes and insulators are detailed in the following discussion.

The processing scheme for producing the ceramic electrodes is shown in Figure A.2.1. High purity, reactive powders are used as the starting materials. These materials are purchased from the following commercial sources: $\mathrm{ZrO}_{2}$ from Engine Kuhlmann, Paris France; $\mathrm{CeO}_{2}$ and $\mathrm{Y}_{2} \mathrm{O}_{3}$ from Research Chemicals, Phoenix, Arizona; and $\mathrm{Ta}_{2} \mathrm{O}_{5}$, Kaweki Beryelco, Bayertown, Pennsylvania. All powders are claimed to be greater than 99. 9\% purity with less than $100 \mathrm{ppm}$ of either $\mathrm{Fe}_{2} \mathrm{O}_{3}$ or $\mathrm{SiO}_{2}$. The purity of the three major powders has been checked by emission spectroscopic analysis; these results are shown in Table A.2.1. These results are accurate within a factor of 3 . The particle size distribution has also been determined by the centrifugal instrumentation method. The particle size distribution of the four starting powders is shown in Figure A.2.2. The average particle size (by weight) of the $\mathrm{ZrO}_{2}, \mathrm{Y}_{2} \mathrm{O}_{3}, \mathrm{CeO}_{2}$, and $\mathrm{Ta}_{2} \mathrm{O}_{5}$ powders are $1.5,4.5,6$, and 11 micrometers, respectively.

A slurry is prepared consisting of distilled water, $1200 \mathrm{gm}$ of oxide powder and organic binder (a mixture of polyvinyl alcohol and polyethylene glycol). This slurry is milled in a rubber lined ball mill filled with yttria-stabilized zirconia balls. Finally, this slurry is introduced into a spray drier to form a free flowing, homogeneous powder. These powders are, in turn, pressed at 30,000 psi into 300 to $400 \mathrm{gm}$ bars. These bars were subsequently fired for 14 hours at $1500^{\circ} \mathrm{C}$. Pycnometer densities using $-30+70$ mesh particles gave the calculated percent theoretical densities shown in Table A.2.2.

These sintered bars are crushed into fine particles using a laboratory crusher. Any iron contamination is removed by magnetic separation and 
Table A.2.1

Optical Emission Spectrographic Analysis of Starting Powders (ppmw)

\begin{tabular}{|c|c|c|c|}
\hline Element & $\begin{array}{r}\begin{array}{r}\text { Research Chemical } \\
99.9 \mathrm{CeO}_{2} \\
\end{array} \\
\end{array}$ & $\begin{array}{l}\text { Engine Kuhlmann } \\
\text { 'ver' grade } \mathrm{ZrO}_{2} \\
\end{array}$ & $\begin{array}{c}\text { Research Chemical } \\
99.9 \mathrm{Y}_{2} \mathrm{O}_{3} \\
\end{array}$ \\
\hline $\mathrm{A} 1$ & 30 & 100 & 10 \\
\hline $\mathrm{Bi}$ & $*$ & * & * \\
\hline $\mathrm{Ca}$ & 10 & $*$ & $*$ \\
\hline $\mathrm{Cd}$ & $*$ & $*$ & $\dot{x}$ \\
\hline Co & $\dot{x}$ & $\star$ & $*$ \\
\hline $\mathrm{Cr}$ & $*$ & * & $*$ \\
\hline $\mathrm{Cu}$ & $*$ & $\star$ & $\star$ \\
\hline $\mathrm{Fe}$ & $\star$ & 1 & 1 \\
\hline $\mathrm{Mg}$ & 10 & 10 & $*$ \\
\hline Mn & $*$ & * & * \\
\hline $\mathrm{Na}$ & 100 & $*$ & $\neq$ \\
\hline $\mathrm{Ni}$ & 20 & $*$ & $*$ \\
\hline $\mathrm{Pb}$ & $*$ & $\star$ & $*$ \\
\hline $\mathrm{Sb}$ & $*$ & * & $*$ \\
\hline Si & 100 & 20 & 10 \\
\hline $\mathrm{Sn}$ & $*$ & * & * \\
\hline $\mathrm{Ti}$ & $*$ & \pm & $*$ \\
\hline $\mathrm{Zn}$ & $*$ & * & * \\
\hline
\end{tabular}

Not detected, detection limits for $\mathrm{Na}, 100 \mathrm{ppm}$, for $\mathrm{Cd}, \mathrm{Sb}, \mathrm{Sn}, \mathrm{Tl}$, and $\mathrm{Zn}$, $30 \mathrm{ppm}$, for $\mathrm{Bi}, \mathrm{Ca}, \mathrm{Co}, \mathrm{Ni}, \mathrm{Pb}, 3 \mathrm{ppm}$, and for all others $1 \mathrm{ppm}$.

Table A. 2.2

\section{Composition}

$12 \mathrm{~m} / \circ \mathrm{Y}_{2} \mathrm{O}_{3}-88 \mathrm{~m} / \mathrm{o} \mathrm{ZrO}_{2}$

$18 \mathrm{~m} / \mathrm{o} \mathrm{CeO}_{2}-82 \mathrm{~m} / \mathrm{o} \mathrm{ZrO}_{2}$

$50 \mathrm{~m} / \mathrm{o} \mathrm{CeO}_{2}-50 \mathrm{~m} / \mathrm{o} \mathrm{ZrO}_{2}$

$75 \mathrm{~m} / \mathrm{o} \mathrm{CeO}_{2}-25 \mathrm{~m} / \mathrm{o} \mathrm{ZrO}_{2}$

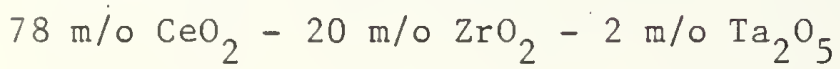

$\%$ of Theoretical Density

91.7

97.9

94.8

93.4

96.7 
leaching with acid solutions. A check of iron content by emission spectroscopy at this point indicates iron levels of $30 \mathrm{ppm}$ or less. The particles are subsequently sized by screening into three size fractions, a coarse $(-30+70$ mesh $)$ fraction, a medium $(-70+325$ mesh $)$ fraction, and a fine ( -325 mesh) fraction. Additional fine ( -325 mesh) material is produced by jet milling coarse grain material. The average particle sizes for the crushed -325 mesh and the jet milled powders are 15 and 6 micrometers, respectively. The three size fractions are mixed together in the ratio of 52 coarse to 15 medium to 33 fine. Polyethylene glycol is used as an organic binder in pressing this granular mixture. Samples $14 \mathrm{~mm} \times 35 \mathrm{~mm} \times 8 \mathrm{~mm}$ are pressed at 15,000 psi on a double action press. These samples are fired at $1600^{\circ} \mathrm{C}$ in air. Linear shrinkages during this heat treatment are less than $2.0 \%$. The porosity of the five electrode compositions varies from 14.6 to $19.9 \%$. The pore size distribution for these materials is shown in Figure A.2.3. Finally, the electrode is machined to the desired dimensions using diamond grinding tools.

The electrodes are metallized using a commercial (Engelhard \# 6082) platinum paste. Four individual thin coats are brushed on and fired. During the application and firing of the last three coats, a platinum screen is also attached to the metallized surface. Finally, a platinum $\left(0.020^{\prime \prime}\right)$ wire is welded to the platinum screen.

The magnesia insulators are purchased from the Norton Company of Worchester, Massachusetts. A high purity fused grain of magnesia is sized and hot pressed to produce a body containing approximately $15 \%$ porosity. The processing parameters in producing this material are regarded as proprietary by the manufacturer. The hot-pressed blocks which were $152 \mathrm{~mm} \times 152 \mathrm{~mm} \times 36.5 \mathrm{~mm}$ are heated in air to remove any graphite pickup and then cut into blocks 1-2 mm larger than the desired insulator dimensions. Finally, these blocks were machined into the desired insulator dimensions and shapes.

\section{A.3 Electrode wall design (B. Wright, Westinghouse Research and Development Laboratory)}

The MHD channel is the Faraday type. In each of the electrode walls, there are twenty separate electrodes with the pitch between electrodes being $24 \mathrm{~mm}$. The electrodes proper are $12 \mathrm{~mm}$ long and $62 \mathrm{~mm}$ wide. Each electrode is individually housed in an insulator made of magnesium oxide. Channel insulating walls which separate the two electrode walls are designed and constructed by the Institute of High Temperature of the U.S.S.R. Academy of Sciences. The insulating wall width determines the distance between electrode walls. Figures A.3.1 through A.3.5 illustrate the construction of the channel.

One effect of finite segmenting in the generator is to reduce the value of the scalar conductivity and Hall parameter. The conductivity and Hall parameter are reduced to apparent values of $9.6 \mathrm{mhos} / \mathrm{m}$ and 0.95 , respectively. Each pair of electrodes is connected to a separate load. 
Under open circuit conditions $(K=1) E_{y}^{\prime}=0, E_{y}=u B=675 \mathrm{~V} / \mathrm{m}$, and $j_{y}=0$, while for the axial fields $E_{x}{ }^{\prime}=E_{x}=-\beta E_{y}{ }^{\prime}=0$ and $j_{x}=0$. For short circuit conditions $(\mathrm{K}=0) \mathrm{E}_{\mathrm{y}}{ }^{\mathrm{X}}=\mathrm{uB}=675 \mathrm{~V} / \mathrm{m}, \mathrm{E}_{\mathrm{y}}=0$ and $\mathrm{j}_{\mathrm{y}}=\sigma \mathrm{E}_{\mathrm{y}}{ }^{\prime}=6413 \mathrm{~A} / \mathrm{m}^{\hat{2}}$, and the axial fields are $E_{\mathrm{X}}{ }^{\prime}=\mathrm{E}_{\mathrm{X}}=-B \mathrm{E}_{\mathrm{y}}{ }^{\prime}=-641 \mathrm{~V} / \mathrm{m}$. Thus, the current per electrode under short circuit conditions is $4.77 \mathrm{~A}$, while the open circuit voltage is $175 \mathrm{~V}$. For a Hall field of $641 \mathrm{~V} / \mathrm{m}$, the voltage between adjacent electrodes would be $15 \mathrm{~V}$.

Previous studies $[3,4]$ offer a theoretical explanation and model of interelectrode breakdown in MHD generators. It has been shown that interelectrode voltages in excess of a certain critical value cannot be sustained by the plasma over the insulator. Instead, an electrical breakdown occurs in which the local Hall voltage across the insulator segments decreases suddenly and a large axial current flows over the insulator. In combustion drive MHD generators operating at pressures near atmospheric with electrode segments of $1 \mathrm{~cm}$ length scale, the critical breakdown voltage is of the order of 40-100 V [5]. Electrode segmentation should be sufficient to prevent the critical breakdown voltage from being exceeded. Arcing processes may cause significant short-circuiting of the channel, or they can result in unacceptable damage to the channel walls. In the present design with electrode segments of $1.2 \mathrm{~cm}, 15$ volts between adjacent electrodes is more than adequate for the prevention of arcing.

To isolate the electrodes from the channel support structure, a NEMA G-10 $\frac{1}{2}$ phenolic is used for the mounting block material. In addition, the heat sink of each electrode wall is subdivided into five individual segments. Each heat sink is a water-cooled copper block which has been coated with an electrical insulating paint called LIMITRAK. All exterior surfaces of the heat sink are painted except where the magnesium oxide joins to the heat sink. Each heat sink attaches to the single piece mounting block by two bolts.

A constant nuisance to a majority of designs is coolant water leaks. Such leaks normally occur at joints or seals in the cooling system. To minimize potential water leaks, the number of joints or seals should be held to an absolute minimum. Thus, the leak-tightness of the cooling system is an important construction feature. Each heat sink has only one water inlet and outlet. Internally, the cooling water channels and manifolds are drilled, access holes plugged with copper plugs and then brazed in place in a vacuum furnace. After this operation, the integrity of the joint is checked by a helium leak test using a Mode1 925 NRC Mass Spectrometer Leak Detector. A calibration source establishes a sensitivity to helium leaks of $2 \times 10^{-11} \mathrm{cc} / \mathrm{s}$. At this sensitivity, no detectable leaks were found in any of the heat sinks.

The cooling water passages are designed for laminar flow heat transfer from the copper blocks to the cooling water. The design equation used is 


$$
Q=2 \frac{k}{D}\left(\frac{\mu}{\mu_{w}}\right)^{0.14}\left(\frac{\dot{m}_{p}}{k L}\right)^{1 / 3} \pi D L=\dot{m}_{P} \Delta T
$$

where the water passage wall temperature is assumed to be $373 \mathrm{~K}$ and the effective water passage length is $60 \mathrm{~mm}$. Figure A.3.6 for total cooling water flow into each heat sink illustrates the small water temperature rise expected.

The thickness of the electrode is a function of the thermal conductivity of the material, the heat flux and the desired face and back surface temperatures of the electrode. Each of the five electrode materials has a different thermal conductivity. All the materials have thermal conductivities which are a function of temperature. An electrode face temperature of $2073 \mathrm{~K}$ is used for design. Temperatures higher than $2073 \mathrm{~K}$ result in more rapid vaporization of the stabilizing materials in the electrodes. Temperatures lower than $2073 \mathrm{~K}$ result in a more resistive electrode. Because all 20 electrodes have the same thickness, the thickness per se is determined by the least conductive of the electrode materials. This material, $82 \mathrm{~m} / 0 \mathrm{ZrO}_{2}$ and $18 \mathrm{~m} / \mathrm{o} \mathrm{CeO}$, could not operate as an electrode when any part of it has a temperature below $1472 \mathrm{~K}$, that is, at a conductivity less than $10^{-2} \mathrm{mho} / \mathrm{cm}$. Depending on the method used for electrical contact to the ceramic electrodes, a maximum back face temperature may become a design consideration. For example, a ceramic-to-metal contact should not be operated at a temperature that enhances oxidation of the metal. The electrical contact in the present design is made with platinum which has extremely good oxidation resistance and a melting point of $2046 \mathrm{~K}$. Thus, there are two primary design constraints which are: (1) an electrode must be of low overall resistance, on the order of one ohm or less; and (2) the mechanism for current take-off from the electrode must function under a changing, severe environment and still retain a long lifetime.

Energy transfer to the electrode wall is by convection and radiation heat transfer from the plasma. Internally, there is joule heating in the electrode. Heat transfer from the plasma to the electrode is mostly by turbulent convection. The correlation for the Nusselt number of flow along a flat plate is

$$
N u_{x}=0.0296 \operatorname{Re}_{x}^{0.8} \operatorname{Pr}^{1 / 3}
$$

while the Stanton number is

$$
S t_{\mathrm{X}}=\mathrm{Nu} \mathrm{x}_{\mathrm{x}} / \mathrm{Re}_{\mathrm{x}} \operatorname{Pr}
$$


Convective heat flux through the electrode is given by

$$
(q / A)_{x}=S t_{x} \rho u\left(h_{a w}-h_{w}\right) .
$$

Boundary layer development begins $0.8 \mathrm{~m}$ upstream of the entrance to the channel. The range of numerical values for the local Stanton number from the entrance to the exit of the channel is 0.0025 to 0.0020 . Convective heat flux varies from $22 \mathrm{~W} / \mathrm{cm}^{2}$ at the channel entrance to $18 \mathrm{~W} / \mathrm{cm}^{2}$ at the channel exit. Radiation heat transfer from the plasma to the electrode is on the order of $2 \mathrm{~W} / \mathrm{cm}^{2}$. Joule heating is difficult to calculate because it requires knowing the three-dimensional temperature distribution and current paths within the electrode. An estimate of the joule heating is made by assuming current flows normal to and uniformly through the electrode. Dividing the electrode thickness into equal segments, the one-dimensional, centerline, midpoint temperature of each segment is calculated. Knowing the one dimensional temperature distribution, the resistance of each segment is determined. The electrode resistance becomes the sum of the resistances of the individual segments. For example, using an electrode thickness of $6 \mathrm{~mm}$, the most resistive material, $82 \mathrm{~m} / 0 \quad \mathrm{ZrO}_{2}$ and $18 \mathrm{~m} / \mathrm{o} \mathrm{CeO}_{2}$, has an electrode resistance on the order of 2 ohms when calculated by the above procedure. Under short circuit conditions, joule heating would contribute $6 \mathrm{w} / \mathrm{cm}^{2}$ to the heat flux. The value of $6 \mathrm{~W} / \mathrm{cm}^{2}$ for joule heating is a severe case because it is a maximum value. Thus, the largest expected value of heat flux is $30 \mathrm{~W} / \mathrm{cm}^{2}$ and occurs at the channel entrance. The smallest expected value of heat flux is $18 \mathrm{~W} / \mathrm{cm}^{2}$ and occurs at the channel exit, assuming negligible radiation heat transfer from the plasma and no joule heating.

Near the channel entrance, the electrode face temperature is $2073 \mathrm{~K}$, the electrode back surface temperature is $1500 \mathrm{~K}$ and the temperature at the interface between the $\mathrm{ZrO}_{2}$ phosphate cement and $\mathrm{MgO}$ insulator housing is $1200 \mathrm{~K}$. These temperatures are based on a one-dimensional analysis with a heat flux of $22.5 \mathrm{~W} / \mathrm{cm}^{2}$, an electrode thickness of $6 \mathrm{~mm}$, and an electrode material of pure $\mathrm{ZrO}_{2}$. Deviations from these temperatures will occur due to electrode position with respect to downstream distance, electrode material, current density in the electrode, and two-dimensional effects. To minimize deviations from these temperatures, electrode materials are positioned longitudinally in the channel beginning with the material of lowest thermal conductivity and following in order of increasing thermal conductivity. This order of materials is also one of decreasing electrical resistance and thermal shock resistance. Near the channel exit, the electrode face temperatures are $1900 \mathrm{~K}$, the back surface temperatures, $1400 \mathrm{~K}$, and the interface temperatures between the $\mathrm{MgO}$ and $\mathrm{ZrO}_{2}$ phosphate cement, $1130 \mathrm{~K}$. See Figure A.3.7. 
Each copper water-cooled heat sink has attached to it four electrode-insulator assemblies. A low thermal resistance attachment between the copper heat sinks and $\mathrm{MgO}$ insulators is made by brazing the insulator to the heat sink with a high temperature $\mathrm{Ag}-\mathrm{Cu}-$ In alloy. There inevitably appear locally very large electric fields at the electrode-insulator boundary to maintain the Hall field in the flow, which are apt to cause arc discharges due to large Hall effects causing various undesirable phenomena referred to above. Therefore, in order to realize more uniform potential distributions on the electrode walls similar to that in the main flow, the power take off is made at the extreme edge of the resistive segmented electrode opposite the edge where the current usually concentrates. This should generate counter electric fields which will, cancel induced Hall fields in the vicinity of the electrode surface. To prevent non-uniform current distribution on the hot surface of the electrode, platinum is placed on the side of the electrode which is opposite the electrode edge normally experiencing current concentrations. Electrical shorting between electrodes by the condensation of seed in the pore structure of the insulator and in the joints between insulators was avoided by two design features. First, a dense alumina plate was inserted into the insulator joints, and second, the wire leadout was enclosed in a dense alumina tube. These features are shown in Figures A.3.1 and A.3.5. Figures A.3.8 and A.3.9 give drawings of the Wêstinghouse module design.

\section{A.4 Instrumentation (B. Wright, Westinghouse Research and Development Laboratory)}

Thermocouples and voltage probes are located at various positions within the two electrode walls. Three electrodes on the anode wall each have two platinum 13\% rhodium-platinum thermocouples buried approximately $3 \mathrm{~mm}$ deep at the electrode centerline. As referenced from the channel entrance, these are the first, fourth and seventeenth electrodes. Five electrodes have chromel-alumel thermocouples positioned at the interface between the $\mathrm{ZrO}_{2}$ phosphate cement and $\mathrm{MgO}$ insulator. On the anode wall, these thermocouples are the third, tenth and eighteenth electrode positions. On the cathode wall, these thermocouples are in the fifth and fifteenth electrode positions. In addition, there are sixteen chromel-alumel thermocouples positioned in the colder regions of both the anode and cathode walls. A single voltage probe is located at the center of gravity of one-half of an electrode at the first, ninth, and seventeenth electrode positions on the anode wall, and at the eighth and sixteenth electrode positions on the cathode wall. These voltage probes will determine the resistance of the lower half of an electrode.

On the cathode wall, the fourth electrode position has an access hole for line of sight measurement of electrode surface temperature by an optical technique. This arrangement allows the surface temperature of the fourth electrode on the anode wall to be measured directly. The Institute of High Temperatures (IVTAN) is responsible for the actual 
temperature measurement. Just prior to entering the channel, the plasma temperature is measured by the sodium line reversal method, again by IVTAN. IVTAN also has voltage probes located laterally and longitudinally on the top insulating wall to measure Hall and Faraday potentials. Thermocouples are buried at various depths in the MgO of the top insulating wall near the entrance, midpoint and exit of the channel. All of the data is to be recorded in the test protocols for analysis after the test. Figure A.4.1 is an open schematic of cathode and anode showing materials, identification digits, and location of instrumentation.

The U.S. side would like to acknowledge the experience of the U.S.S.R. MHD specialists in designing hot wall electrode modules [7]. This information was helpful in designing the module described here.

\section{References}

[1] Kirillin, V. A., Sheindlin, E. A., et al., Study of the U-02 MHD facility during extented operations, Teplofizika Vysokikh Temperature (High Temperature), IX [5] (1971).

[2] Rossing, B. R., Cadoff, L. H., and Gupta, T. K., Fabrication and properties of electrodes based on zirconium oxide, in "Proc. 6th Int. Conf. in MHD Electrical Power Generation," Washington (1975).

[3] Burenkov, D. S., Dolinskii, Yu. L., Zalkind, V. I., Zelikson, Yu. M., Kirillov, V. V., Sokolov, Yu. N., and Uspenskaya, G. I., Study of interelectrode breakdown in an MHD channel on the U-02 installation, in "Second Joint US-USSR Colloquium on the Problems of MHD Conversion of Energy," Washington, DC (1975).

[4] Oliver, D. A., Time dependent phenomena in magnetohydrodynamic generators, in "Proc. First Joint Soviet-American Colloquium on the Problems of MHD Conversion of Energy," Moscow, (February 1974).

[5] Louis, J. F., Lothrop, T., and Brogan, T. R., Studies of fluid using a large combustion driven MHD generator, Phys. Fluids, 7 , 362-374 (1964).

[6] Zhimerin, D., Bashilov, V., and Motulevich, V., Results of electrophysical research on module section of magnetohydrodynamic generator ENIN-2, in "1lth Symposium on Engineering Aspects of MHD," California Institute of Technology, Pasadena, CA (1970).

[7] "Experimental Research on Model MHD Generator U-02 (Stage II)," Scientific and Technical Report, Institute of High Temperatures, U.S.S.R. Academy of Sciences (1971). 


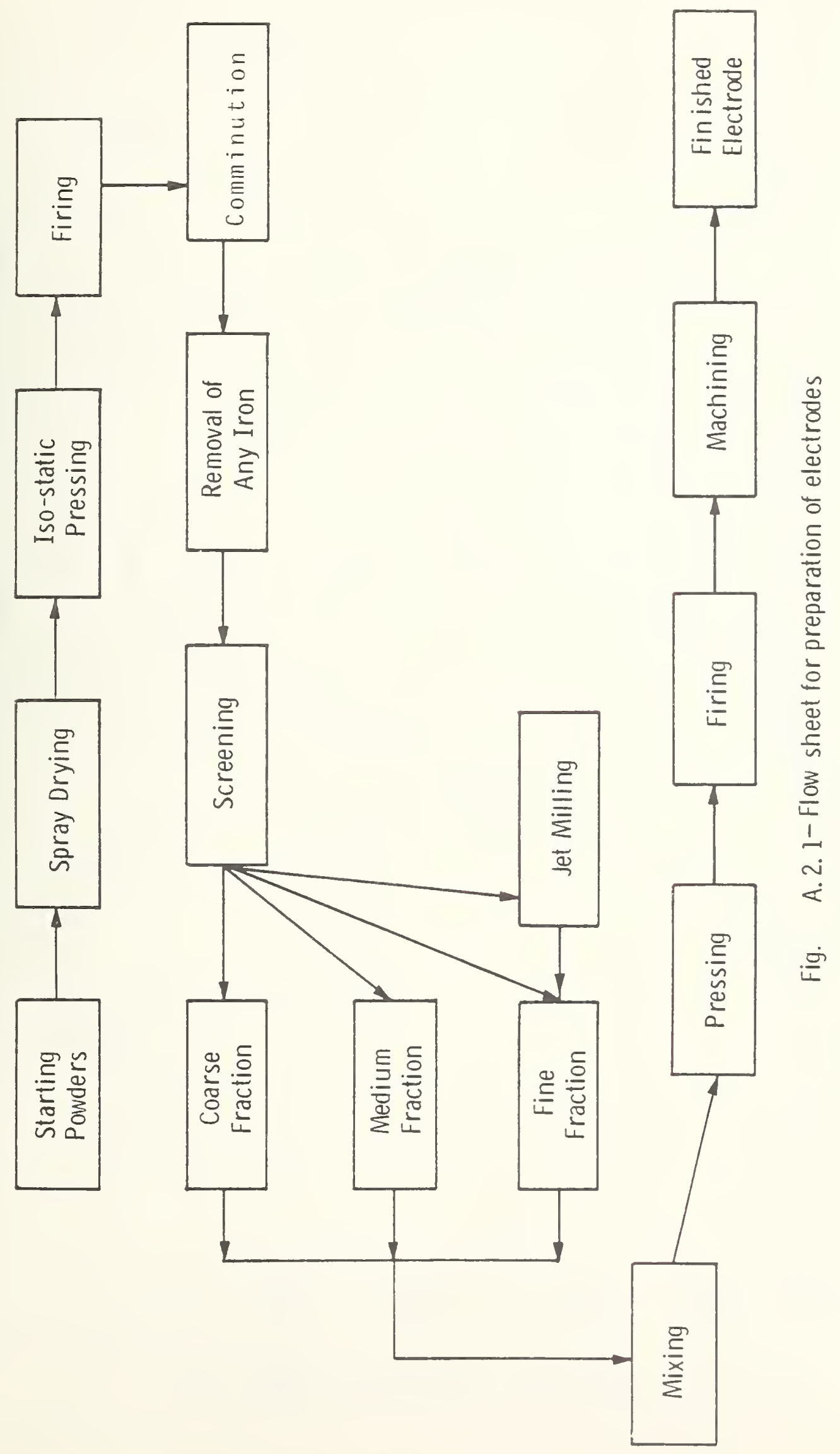




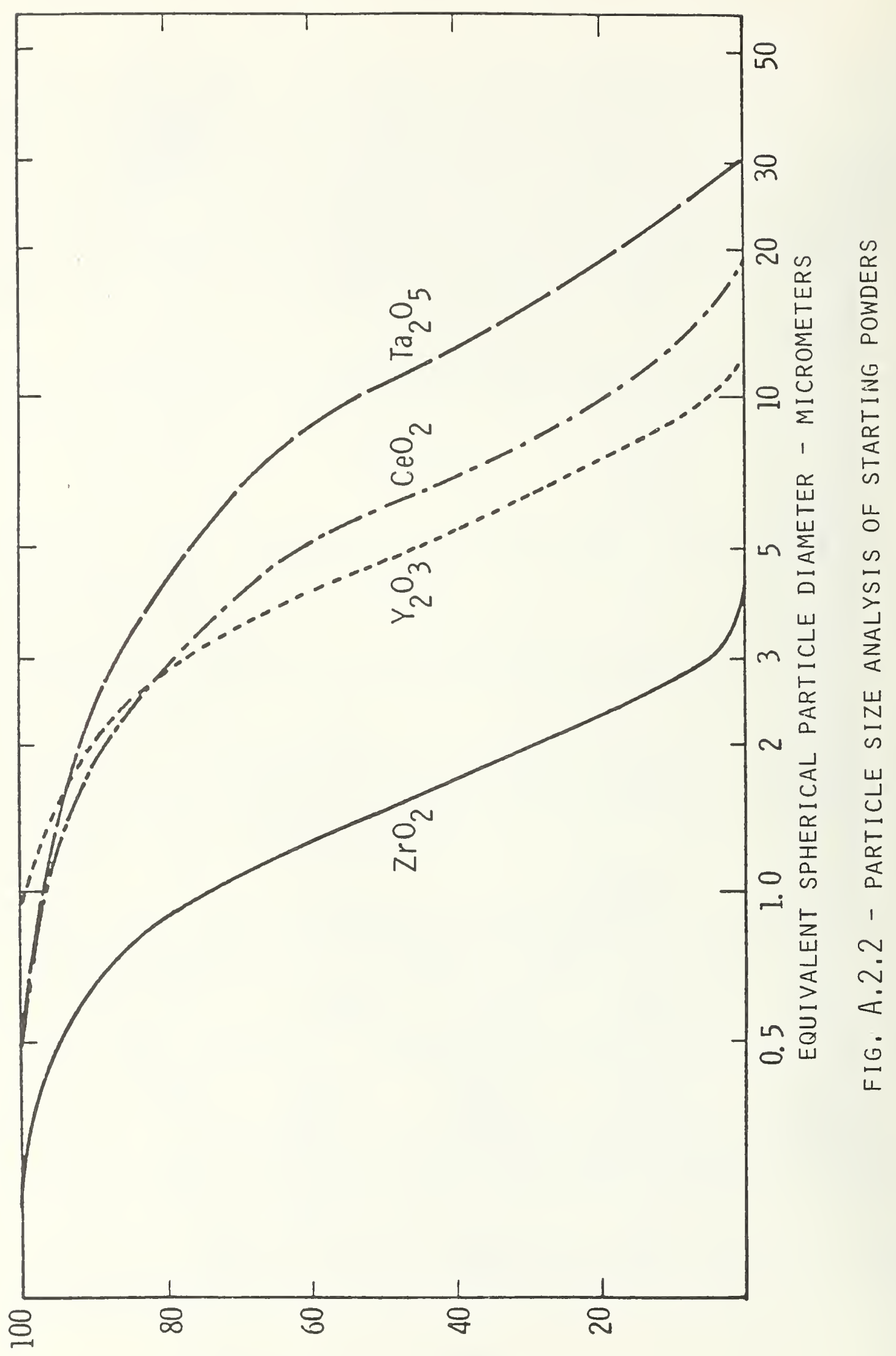

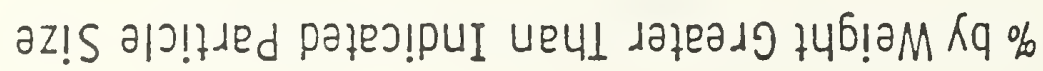




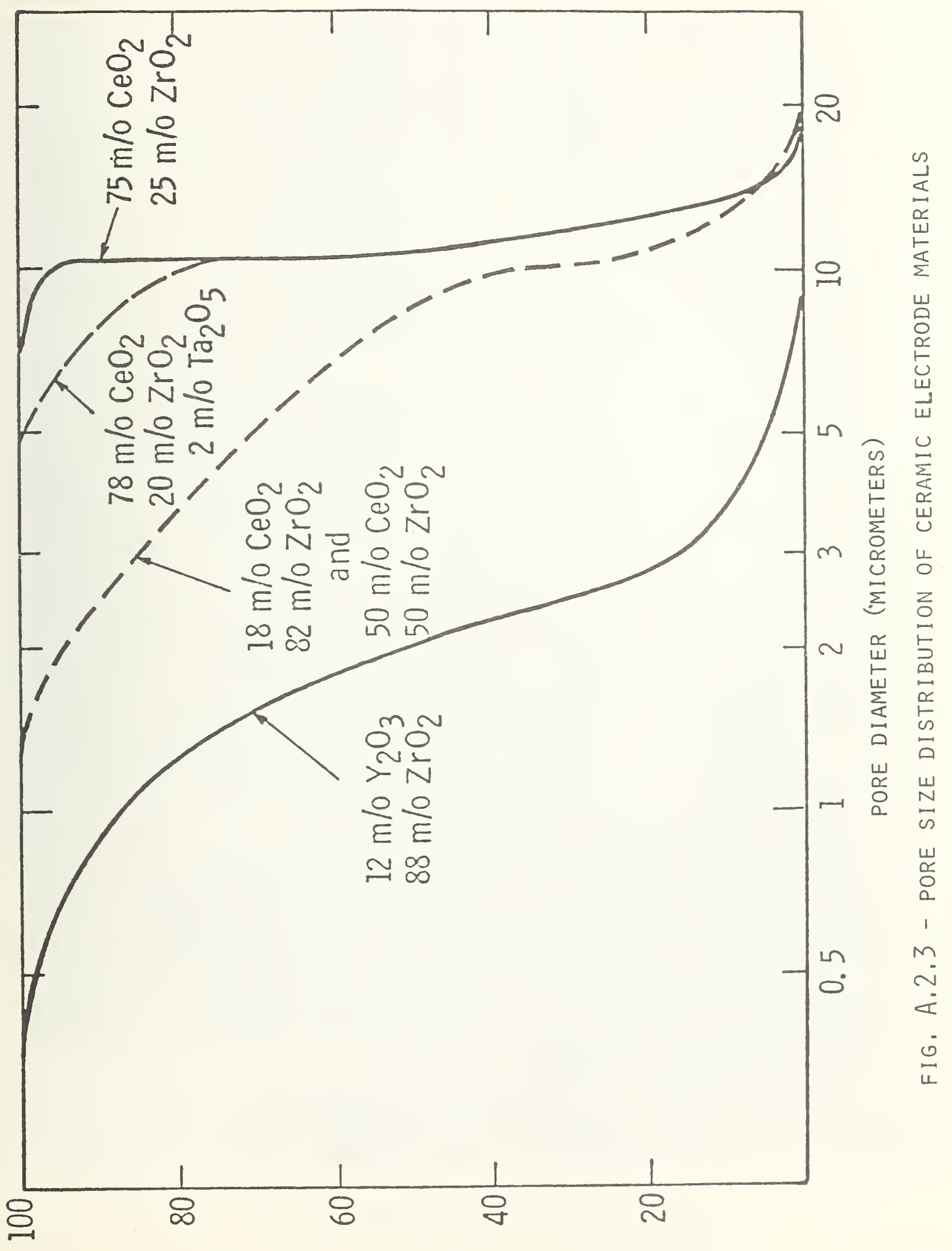

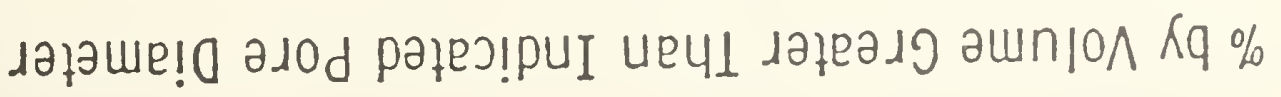




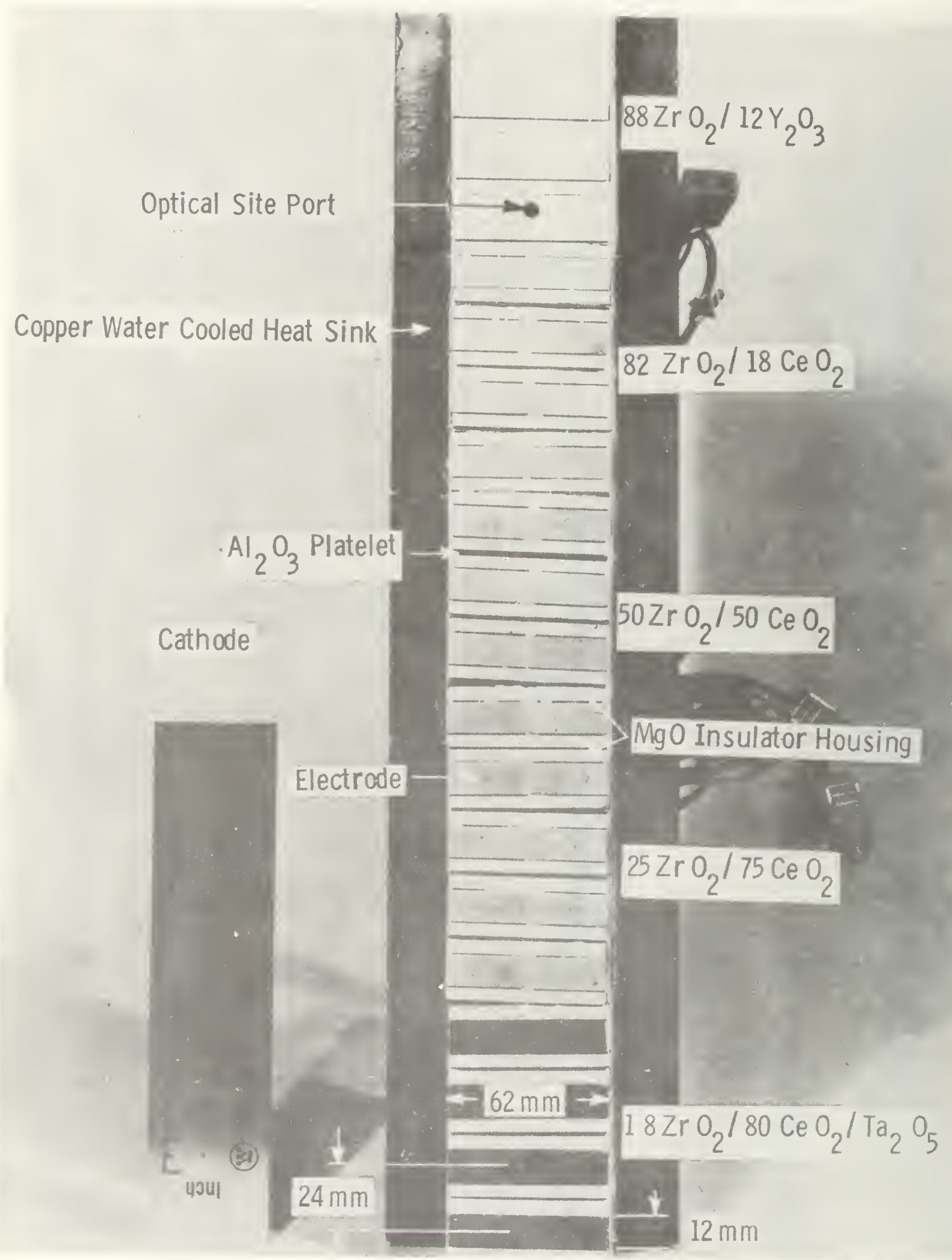

Fig. A.3.1-Plan view of cathode wall 


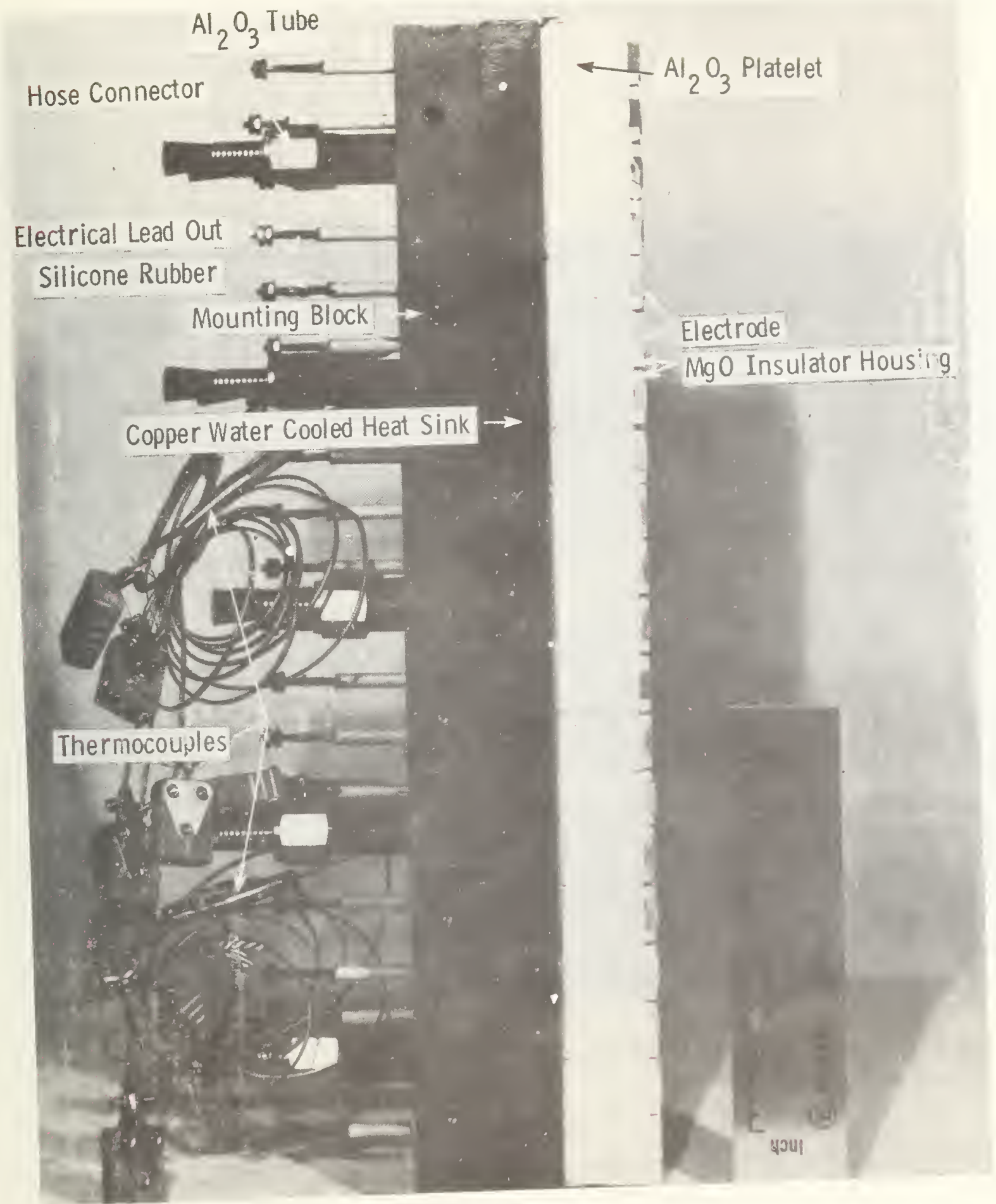

Fig. A.3.2 - Side view of anode wall 


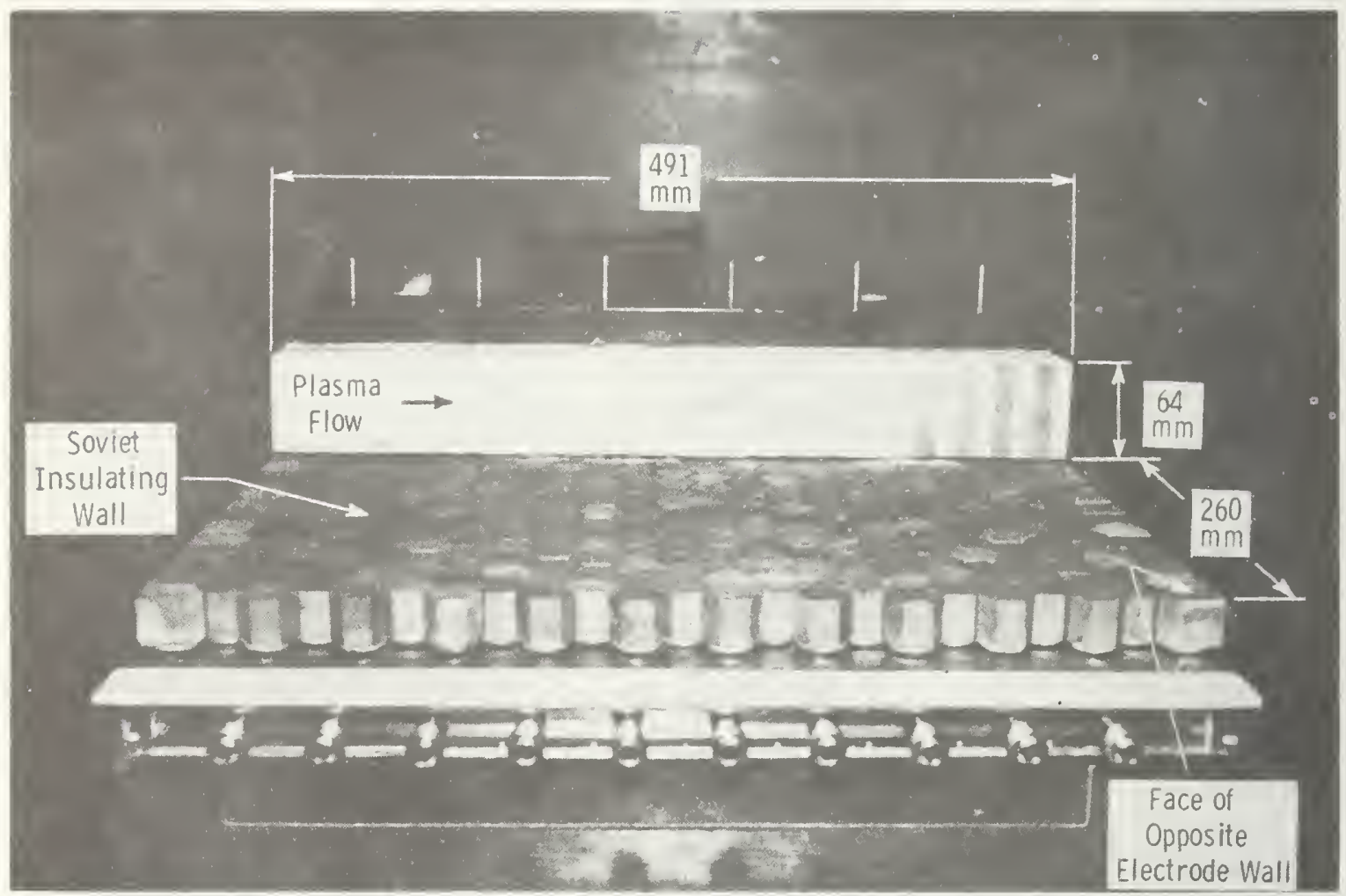

Fig. A.3.3-View showing relationship between electrode and insulating walls 


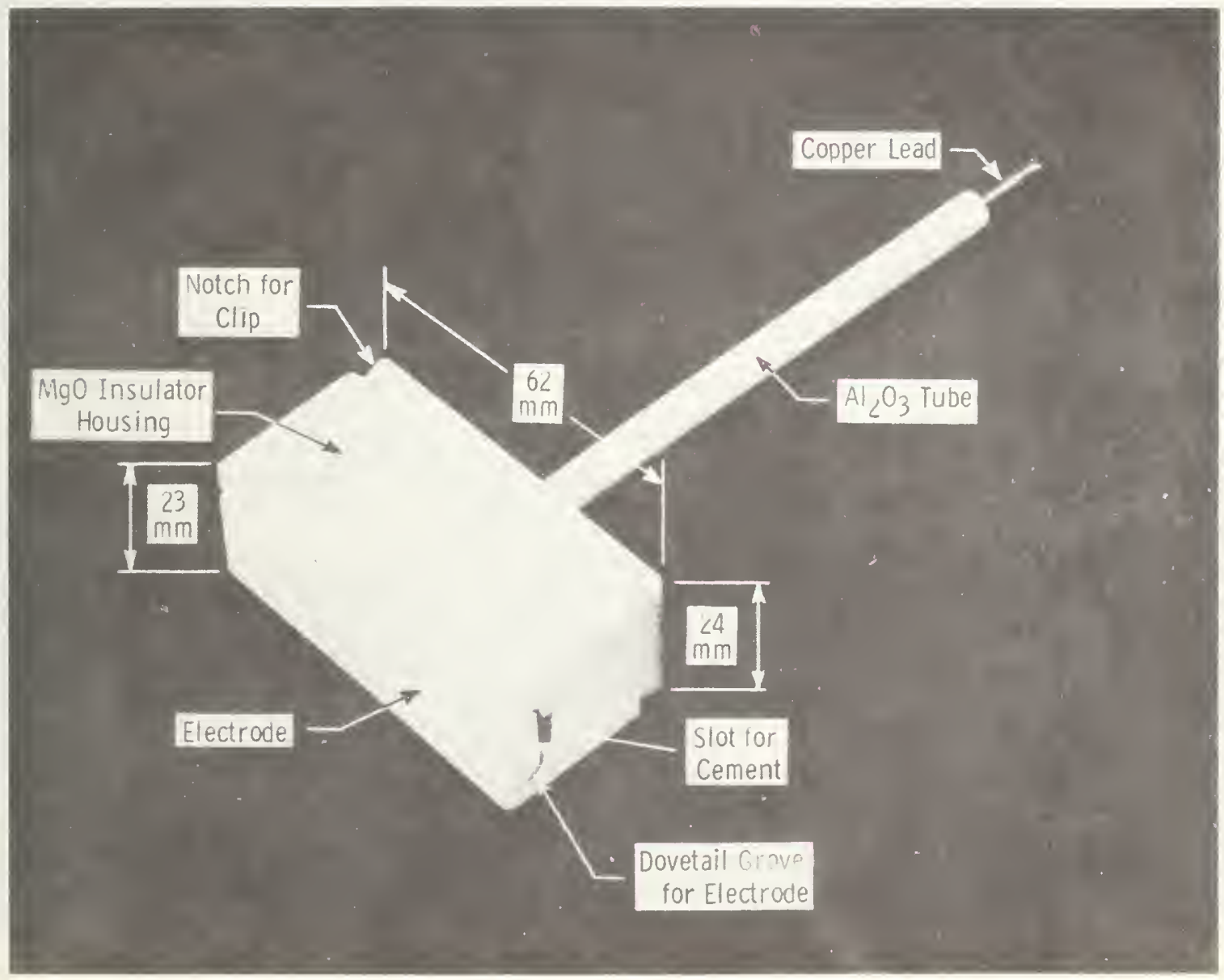

Fig. A.3.4-Electrode insulator assembly 


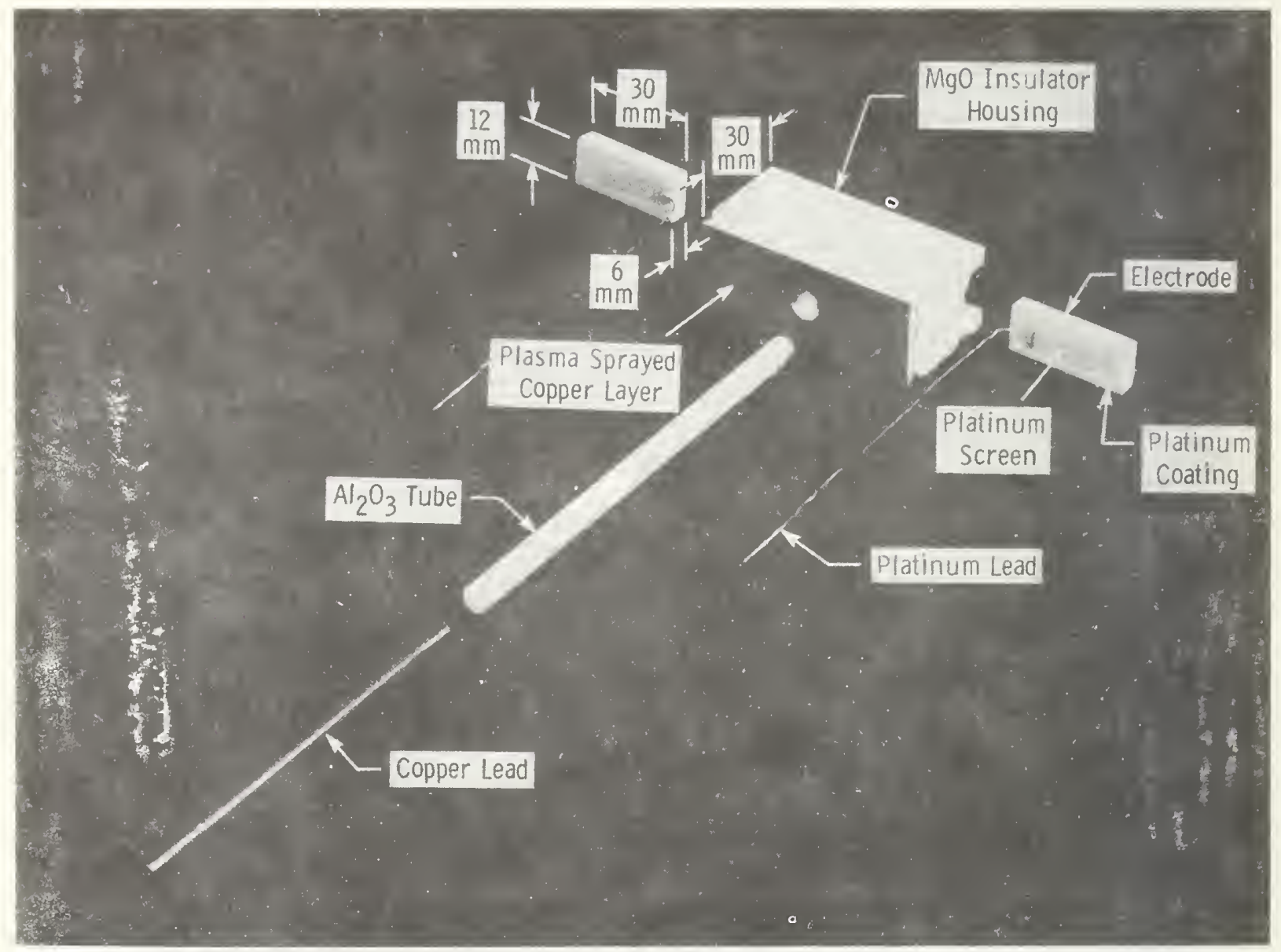

Fig. A.3.5-Exploded view of electrode insulator assembly 


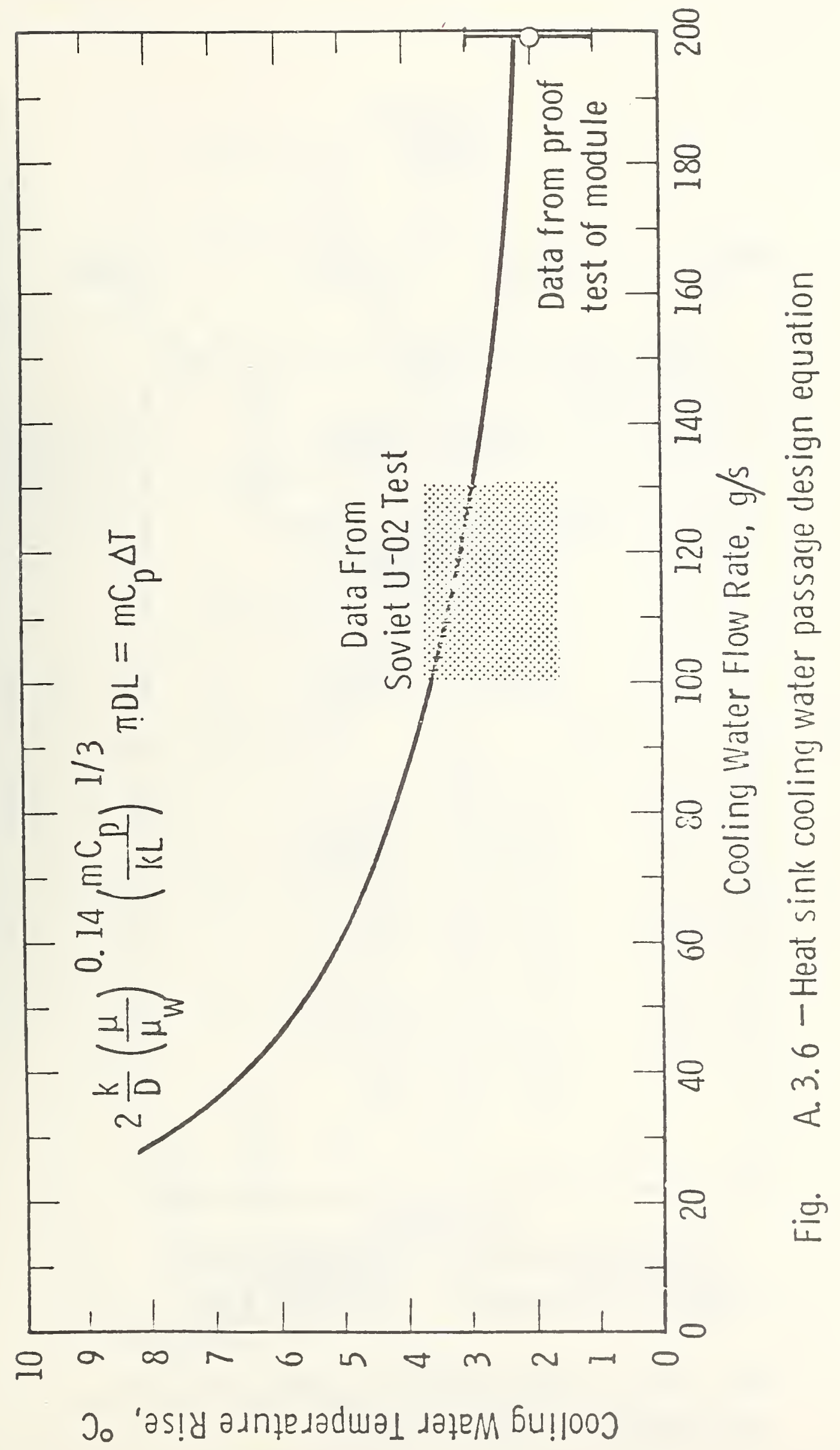


Plasma

$2600 \mathrm{~K}$

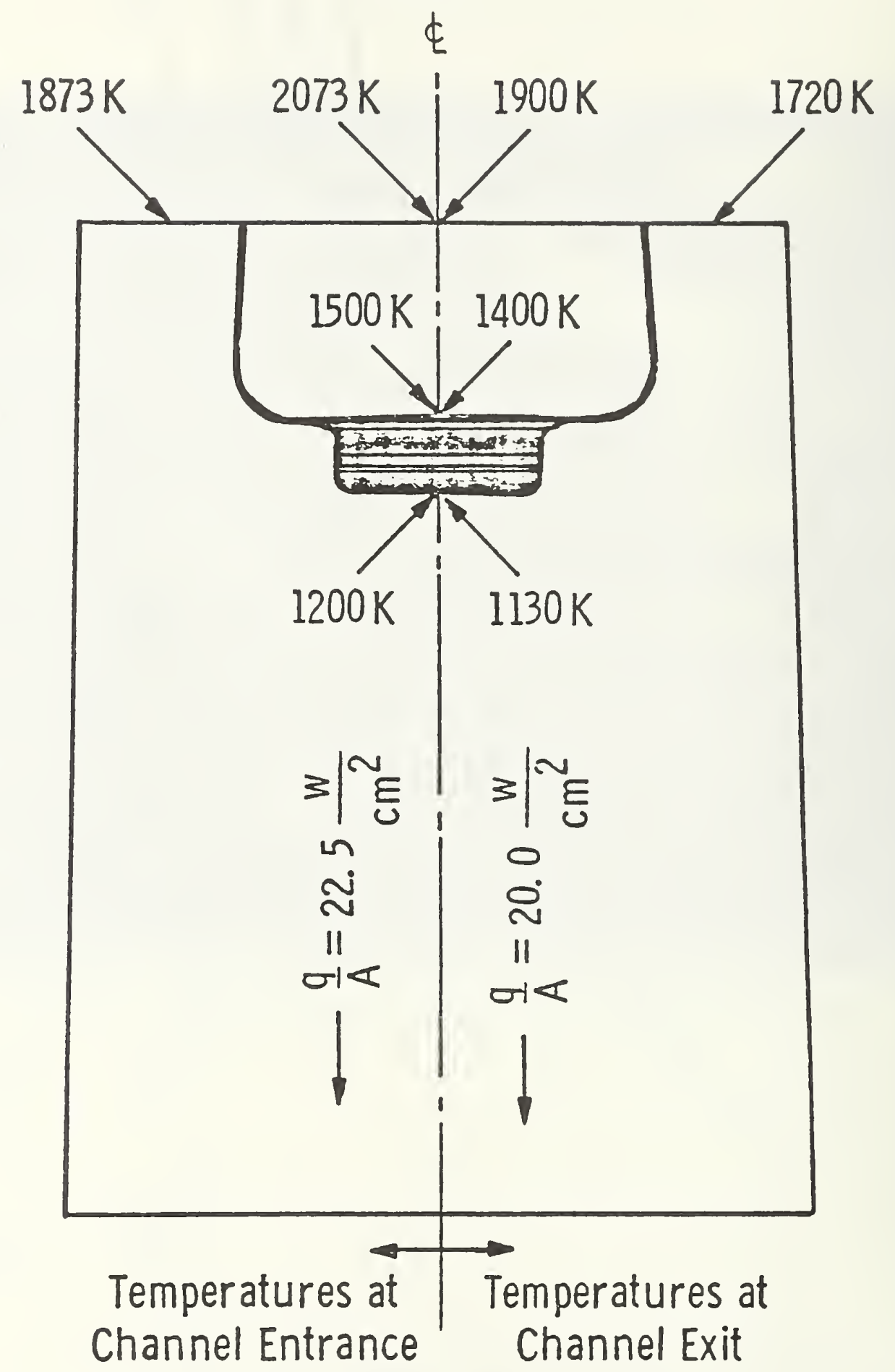

Fig A. 3.7-Calculated temperatures for the electrode insulator assembly 


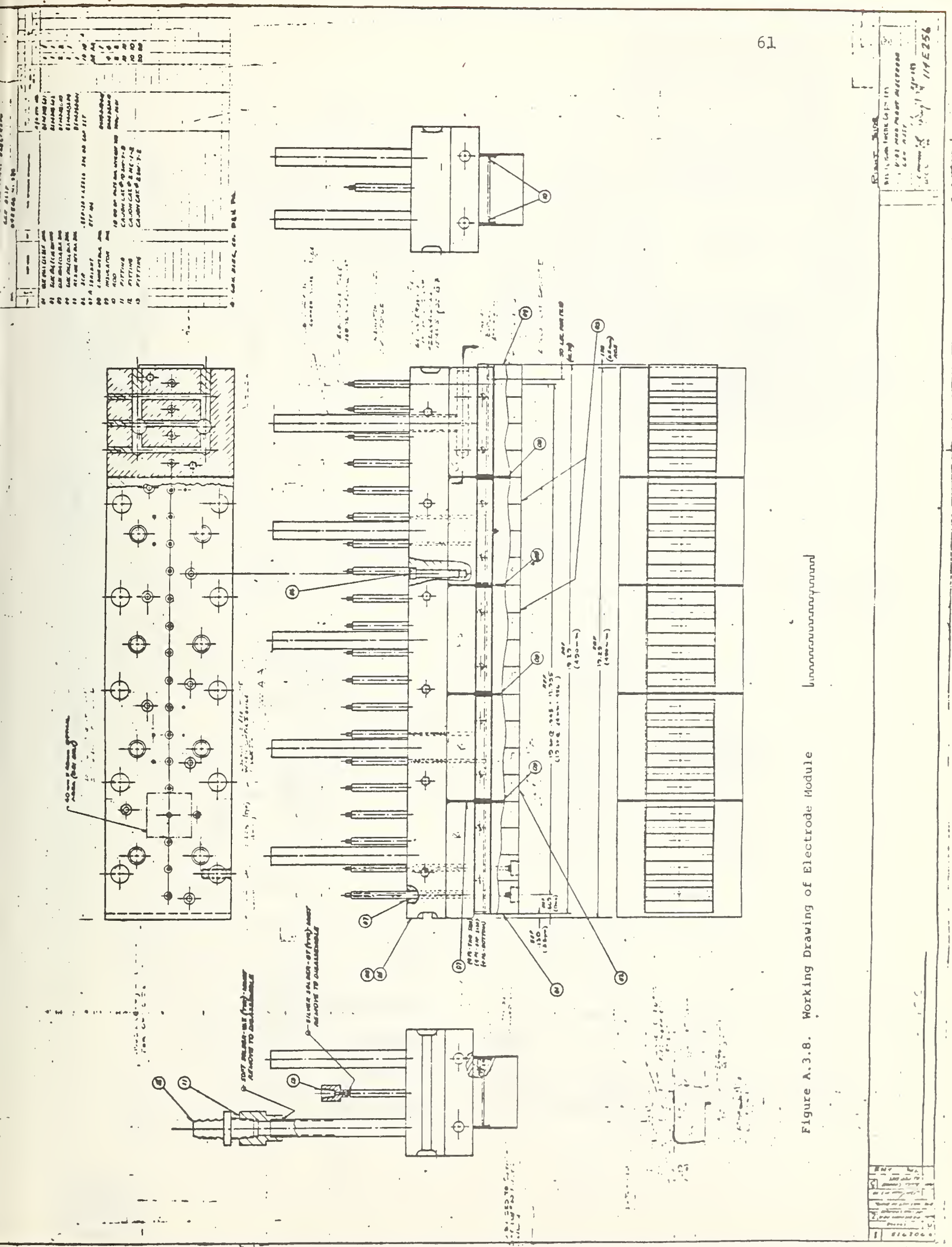




\section{List of Figures}

Figure A.2.1 Flow sheet for preparation of electrodes.

Figure A.2.2 Particle size analysis of starting powders.

Figure A.2.3 Pore size distribution of ceramic electrode materials.

Figure A.3.1 Plan view of cathode wall.

Figure A.3.2 Side view of anode wall.

Figure A.3.3 View showing relationship between electrode and insulating walls.

Figure A.3.4 Electrode insulator assembly.

Figure A.3.5 Exploded view of electrode insulator assembly.

Figure A.3.6 Heat sink cooling water passage design equation.

Figure A.3.7 Calculated temperatures for the electrode insulator assembly.

Figure A.3.8 Working drawing of electrode module.

Figure A.3.9 Working drawing of sub-module.

Figure A.4.1 Open schematic of cathode and anode showing materials, identification digits and location of instrumentation. 


\section{B. Pre-Test Materials Characterization and Analysis (U.S. Results)}

A number of samples of each electrode material was supplied by Westinghouse Electric Research Laboratory to various laboratories for pre-test analysis. In some cases, measurements were made on several samples of the same material and these different samples are designated by the appropriate suffix to the chemical composition. The samples were hot pressed, high density $\mathrm{MgO}$ insulators and $\mathrm{ZrO}_{2}$ based electrode materials. The materials were received in the insulator or electrode geometry to be used in the U-02 Phase I test and were subsequently cut into shapes required for property measurements.

For the measurements in Sections B.1, B.2, B.3, and B.4, the samples were sectionèd into smaller pieces for specific characterization and examination, Figure B.1.1. The large MgO reference insulator, 2.35 $\mathrm{x} 3.06 \mathrm{x} 6.00 \mathrm{~cm}$ was cut in the following manner, Figure B.1.1. The bars, $0.95 \times 0.95 \times 2.54 \mathrm{~cm}(\mathrm{M}-1)$ were cut from one corner for thermal expansion measurements. The ends of this bar (B-1 and $\mathrm{T}-1$ ) were used for metallography. A wafer, $0.15 \mathrm{~cm}$ thick, was cut from near the center, normal to sample length $(C-I)$. Two discs, $1.07 \mathrm{~cm}$ in diameter, were cut from this section for thermal diffusivity measurements. The remainder was used for ceramography and chemical analysis.

The two electrodes of each composition were cut differently. One was cut in two equal sections with the cut parallel to the electrode, Figure B.1.1. These sections were used for thermal expansion measurements. The other was cut normal to the electrode length with wafers for metallography and chemical analysis cut from the center and from one end. Two discs, $1.07 \mathrm{~cm}$ in diameter, were cut from one section, with the sample thickness normal to the expected heat flow in the electrode during testing.

\section{B.1 Thermal Diffusivity (J. L. Bates, Battelle NW Labs)}

The thermal diffusivities of the MgO insulator and electrode materials were measured using a laser pulse technique from.near room temperature to $1750^{\circ} \mathrm{C}$. Briefly, this method consists of heating one surface of a thin sample disc with a short heat pulse from a ruby laser. The heat pulse passes through the sample and the temperature transient on the back surface of the sample is measured as a function of time. This temperature transient is recorded and the thermal diffusivity determined from the shape of the temperature-versus-time curve and the measured sample thickness.

The sample was heated to the measurement temperature in a tungsten resistance furnace in a purified argon atmosphere at a slightly positive atmospheric pressure. Temperatures were measured with $\mathrm{W}-5 \% \operatorname{Re}$ versus $\mathrm{W}-26 \% \mathrm{Re}$ thermocouples. The samples, $1.07 \mathrm{~cm}$ in diameter and 0.07 to $0.14 \mathrm{~cm}$ thick, were mounted in the furnace in an $\alpha-\mathrm{Al}_{2} \mathrm{O}_{3}$ holder. 
The apparatus was calibrated using Armco iron and pyroceram. The absolute thermal diffusivity values of these materials are known. Thermal diffusivity $(a)$ can be calculated if the heat capacity $\left(C_{p}\right)$ and density $(p)$ values are known as a function of temperature

$$
\lambda=\alpha \cdot \mathrm{C}_{\mathrm{p}} \cdot \rho .
$$

\section{B.1.1 Mg0 Insulator}

The thermal diffusivity of $\mathrm{MgO}$ is shown in Figure B.1.2. Measurements were made on two sample thicknesses, 0.101 and $0.139 \mathrm{~cm}$. The thermal diffusivities were the same for both sample thicknesses. The reciprocal of the thermal diffusivity was plotted against temperature generating the relationship from least squares fitting, (Figure B.1.3).

$$
\alpha=\frac{1}{\mathrm{~A}+\mathrm{BT}}=\frac{1}{6.35+0.0493 \mathrm{~T}}
$$

The thermal conductivity was calculated using available heat capacity data $\left(260-2000^{\circ} \mathrm{C}\right)$;

$$
C_{p}=0.288+7.71 \times 10^{-6} \mathrm{~T}-4.03 \times 10^{-3} \mathrm{~T}^{-2} \mathrm{cal} / \mathrm{g}-^{\circ} \mathrm{C}
$$

the expression for $\alpha$, equation 2; and the recommended linear thermal expansion data:

$$
\begin{aligned}
& 11.6 \times 10^{-6} /{ }^{\circ} \mathrm{C}\left(21-540^{\circ} \mathrm{C}\right) \\
& 15.8 \times 10^{-6}\left(540-980^{\circ} \mathrm{C}\right) \\
& 17.2 \times 10^{-6}\left(980-2000^{\circ} \mathrm{C}\right)
\end{aligned}
$$

The density variation is related to the thermal expansion as

$$
\rho=\frac{\rho_{0}}{\left(1+\Delta L / L_{0}\right)^{3}}
$$

where $\rho=3.01 \mathrm{~g} / \mathrm{cm}^{3}$ (measured room temperature density).

Thus, thermal conductivity for $\mathrm{MgO}$ in the direction normal to the hot pressing direction can be expressed as: 


$$
\lambda=\frac{1}{1.49+0.0142 \mathrm{~T}} \text { watts } / \mathrm{cm}-{ }^{\circ} \mathrm{C}
$$

This equation is valid between 100 and $1500^{\circ} \mathrm{C}$.

\section{B.1.2 Electrodes}

The thermal diffusivities of the electrode materials are shown in Figures B.1.4-B.1.8. Measurements were made to as high a temperature as possible, with the limitation being the potential reaction that the electrode has with the $\alpha-\mathrm{Al}_{2} \mathrm{O}_{3}$ holder. Some samples, during measurements, eventually sintered to the holder and altered its structure. This temperature varied from $1465^{\circ} \mathrm{C}$ for the $0.02 \mathrm{Ta}_{2} \mathrm{O}_{5} \cdot 0.78 \mathrm{CeO}_{2} \cdot 0.20 \mathrm{ZrO}_{2}$ sample to near $1700^{\circ} \mathrm{C}$ for the $0.5 \mathrm{CeO}_{2}-0.5 \mathrm{ZrO}_{2}$ electrode material.

The thermal diffusivities for the electrode materials are sumarized in Figure B.1.9. There are substantial differences in the thermal diffusivity values at lower temperatures. However, the diffusivity of all the electrodes decrease with increasing temperature, which is expected for oxide materials where lattice conduction is dominant. Near $1100-1200^{\circ} \mathrm{C}$, the diffusivities tend to approach a common value, but tend to diverge at the higher temperatures as the $.18 \mathrm{CeO}_{2} \cdot 0.82 \mathrm{ZrO}_{2}$ begins to increase with increasing temperature, while the 50 and 75 mole percent $\mathrm{CeO}_{2}$ electrodes continue to decrease.

The data did not follow a usual linear $1 / \alpha$ versus temperature relationship expected for lattice conductivity. All electrode materials exhibited inflections in the curves, some at temperatures as low as $900^{\circ} \mathrm{C}$. These inflections may be related to possible changes in phase or stoichiometry. Since the thermal diffusivity measurements were made in an inert gas in the presence of hot refractory metals, such as tungsten and molybdenum, some reduction could occur. These conditions are substantially different from the air environment during fabrication. In addition, destabilization of the $\mathrm{ZrO}_{2}$ could also occur.

Calculations of thermal conductivity were not made, since heat ca. acity and density changes with temperature are not known.

\section{B.2 Thermal Expansion (J. L. Bates, Battelle NW Labs.)}

The thermal expansions of the MgO insulator and reference electrodes were measured from approximately 60 to $1500^{\circ} \mathrm{C}$ using an aluminum oxide push rod dilatometer. Measurements were made in both argon and air at atmospheric pressure. The Mg0 samples were approximately $2.5 \mathrm{~cm}$ long and electrodes were approximately $1.9 \mathrm{~cm}$ long. Heating and cooling rates were linear with temperature changes of $4^{\circ} \mathrm{C}$ per minute.

The expansion was measured with a transducer with a resolution of \pm 2.5 $\times 10^{-5} \mathrm{~cm}$. For $\mathrm{MgO}$, which expands on the order of $2 \%$ at $1400^{\circ} \mathrm{C}$, the precision of the measurement is of the order of $0.05 \%$. With a similar precision for the measurement of the calibration standard, the overall precision is $\sim 0.1 \%$. 


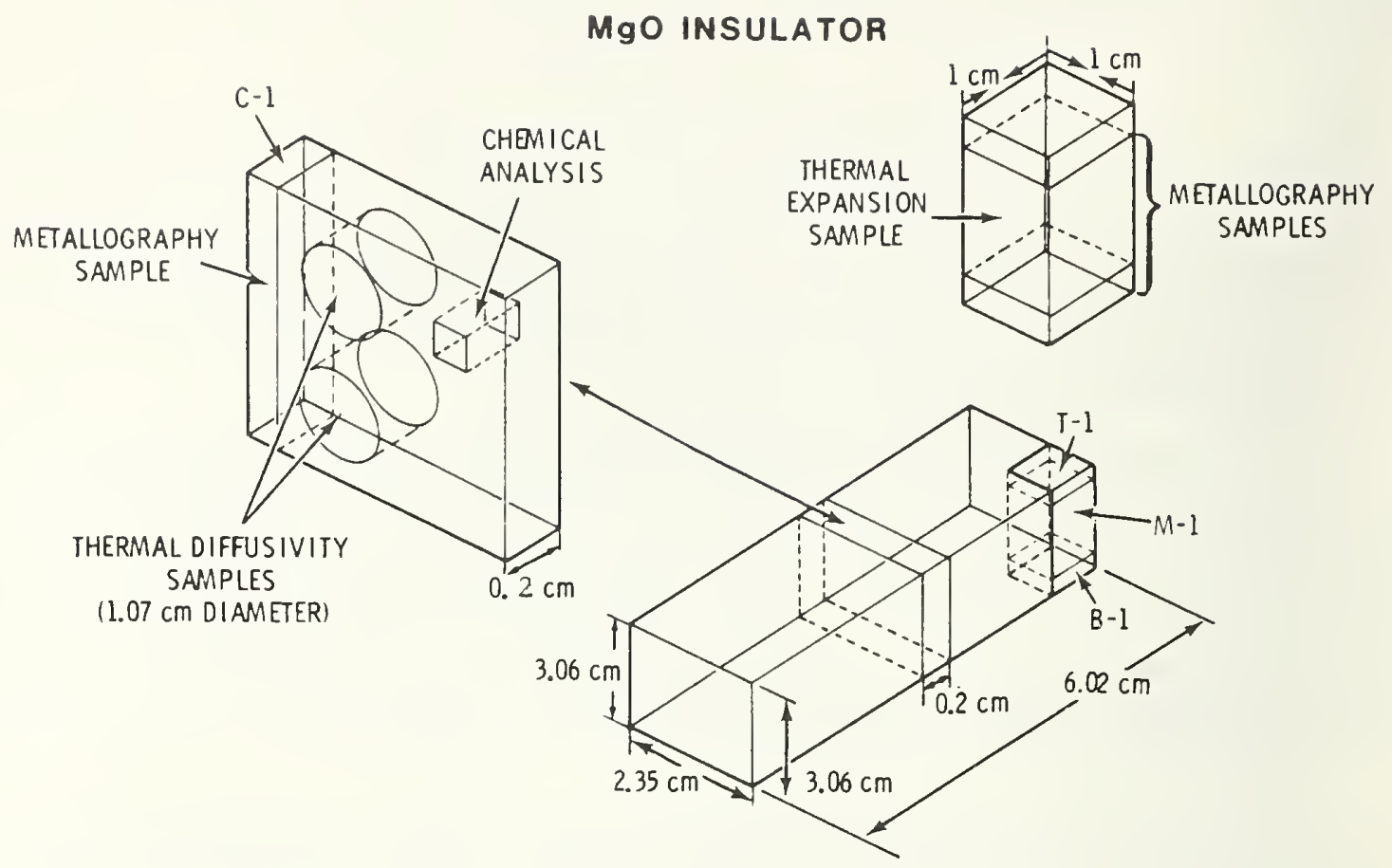

ELECTRODES

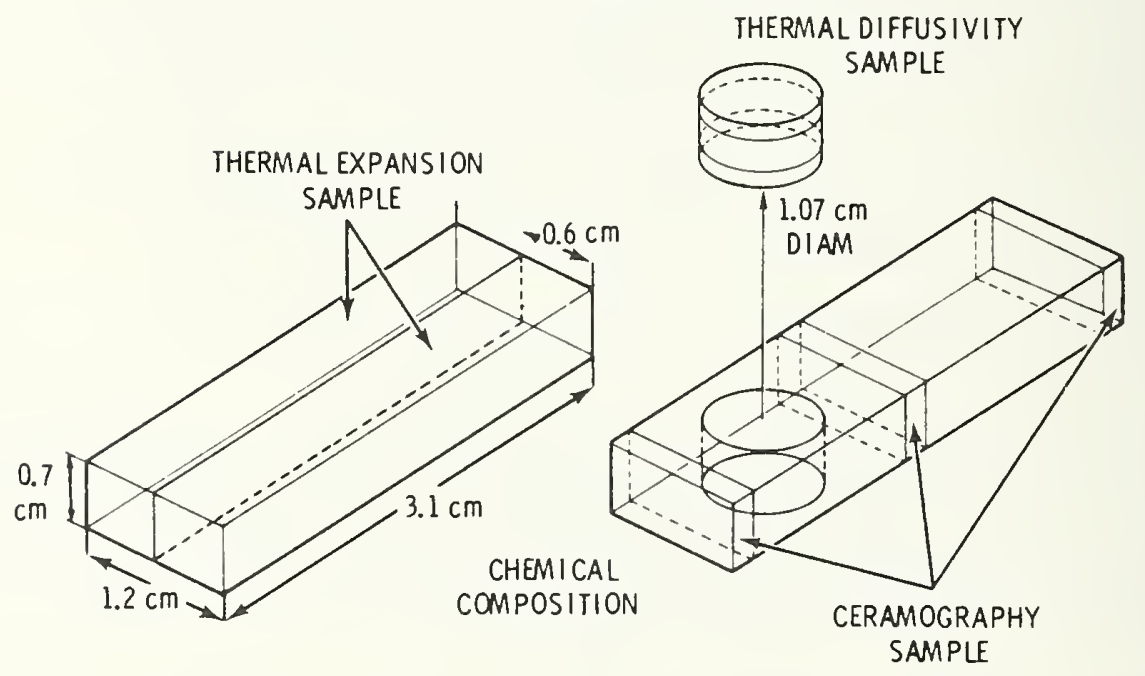

Figure B.1.1 Cutting Procedures for Precharacterization, U-02 Electrodes and Insulators. 


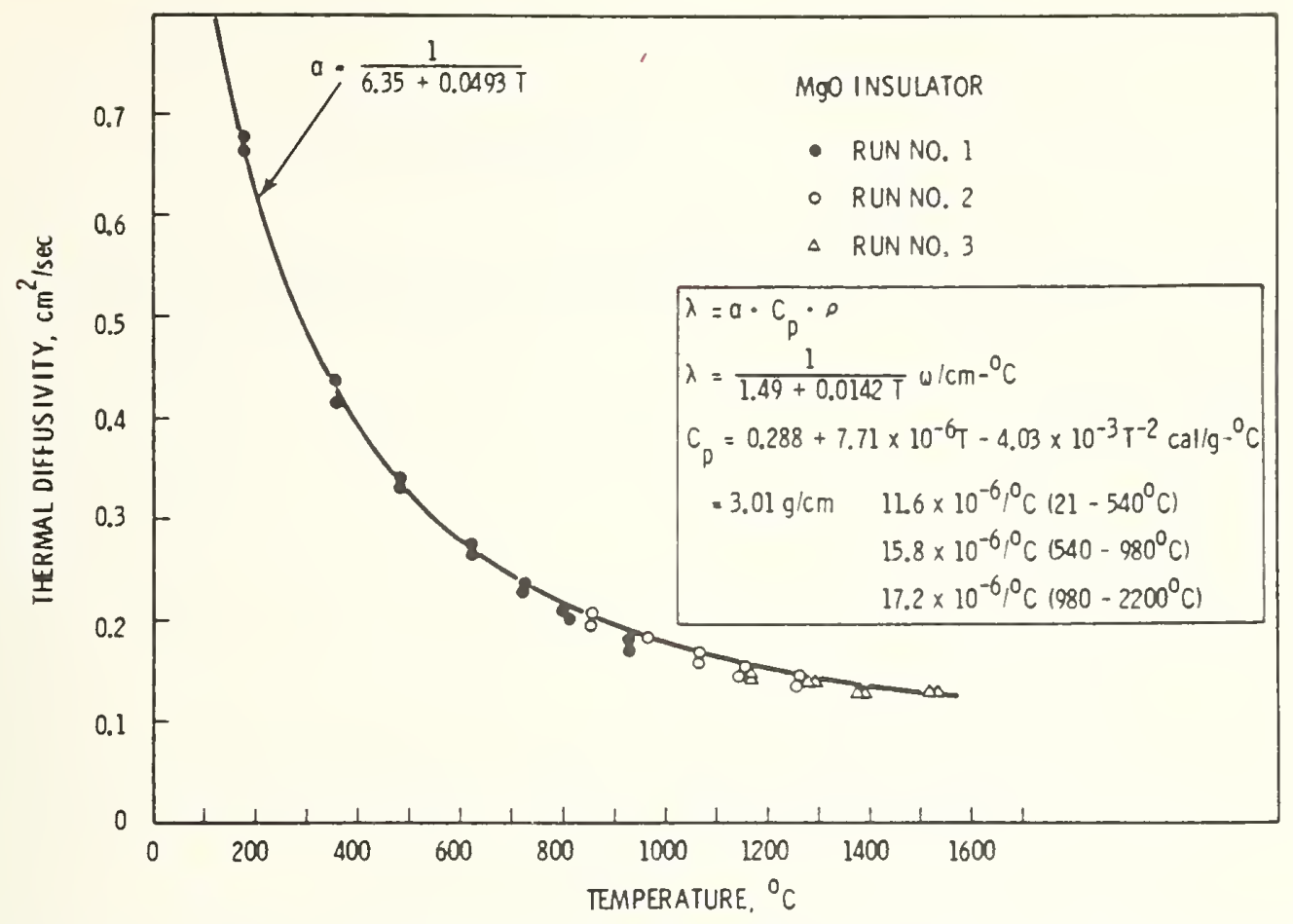

Figure B.1.2. Thermal Diffusivity $(\alpha)$ of Mg0 Insulator Showing Thermal Conductivity $(\lambda)$ Equation Calculated from Heat Capacity and Density Data.

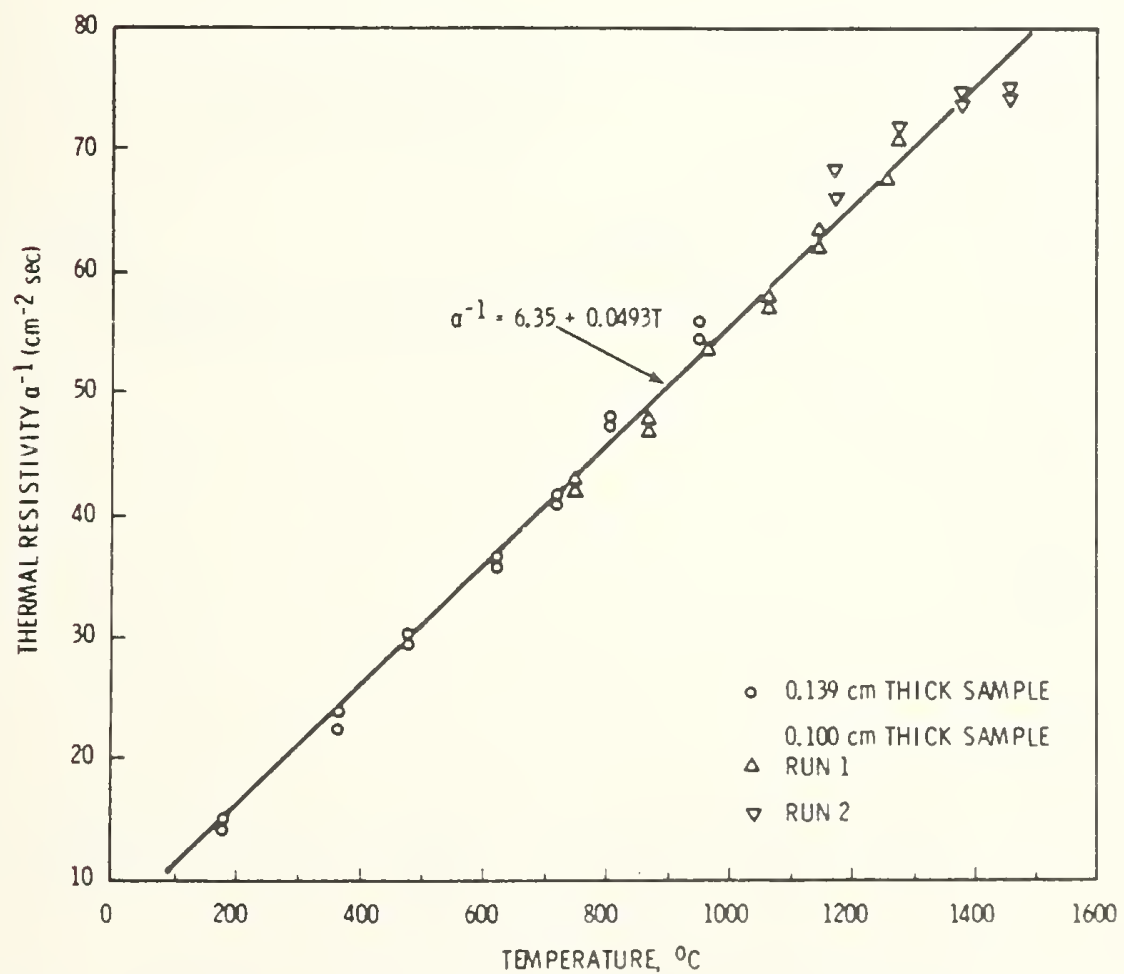

Figure B.1.3. Thermal Resistivity $(1 / \alpha)$ of MgO Insulator. 


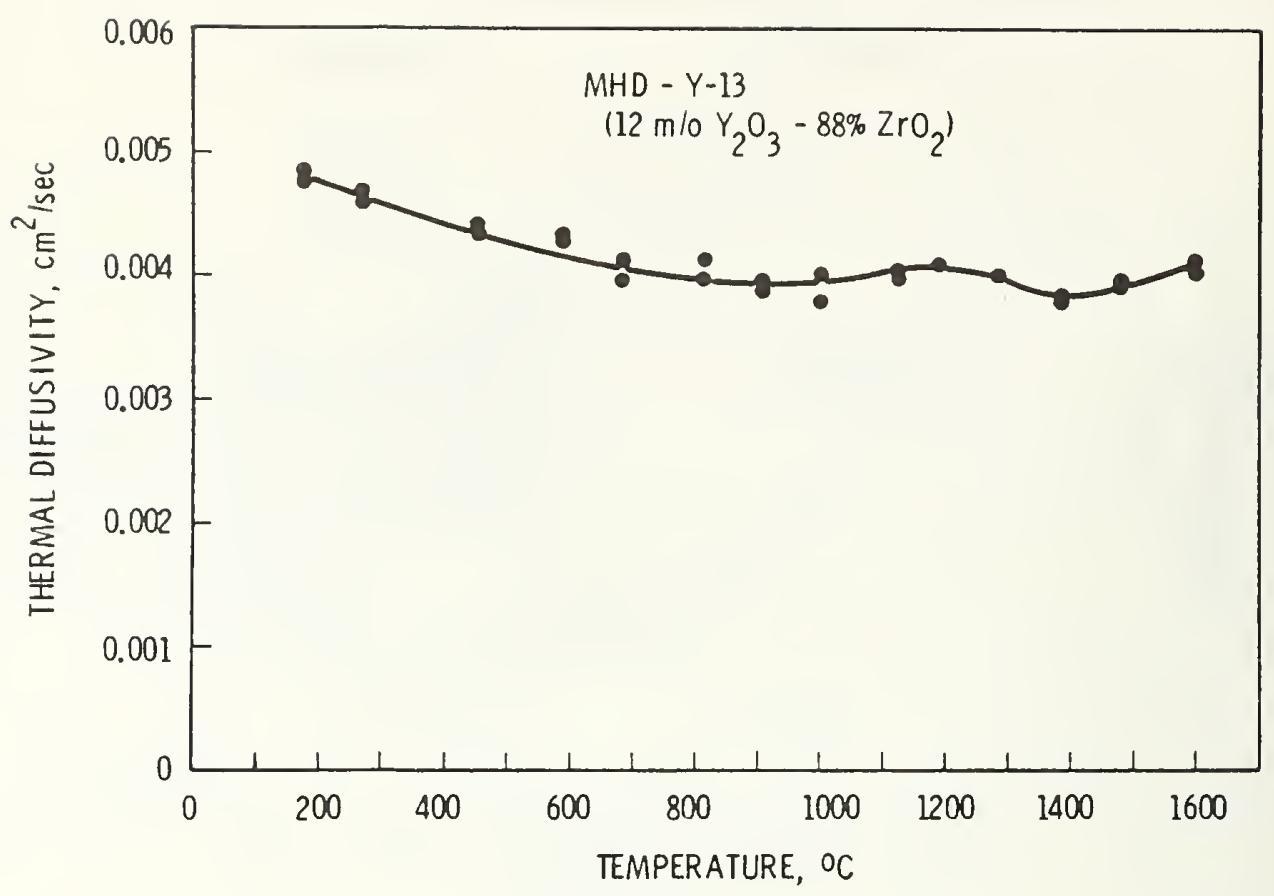

Figure B.1.4. Thermal Diffusivity of $0.12 \mathrm{Y}_{2} \mathrm{O}_{3} \cdot 0.88 \mathrm{ZrO}_{2}(\mathrm{Y}-13)$.

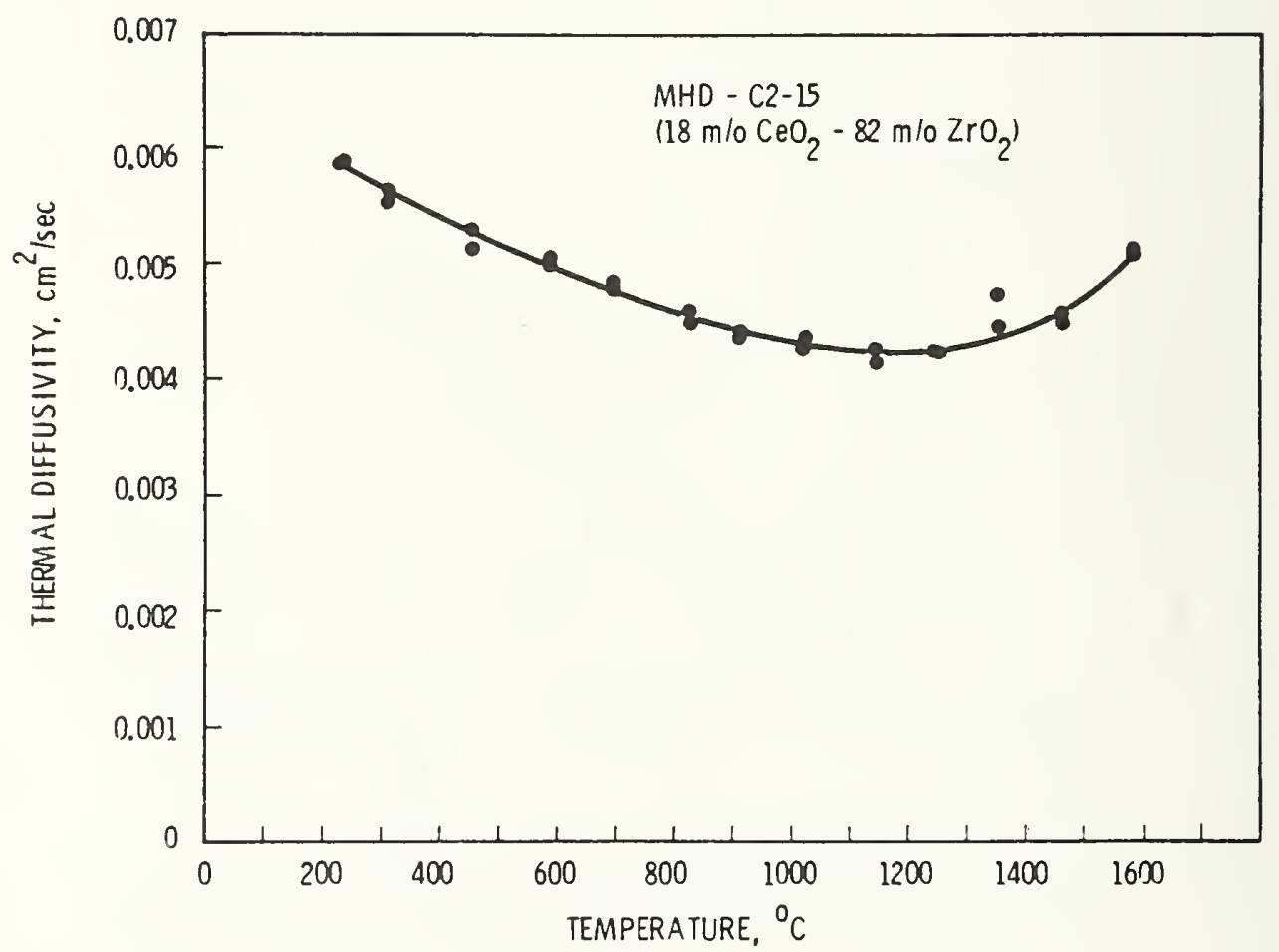

Figure B.1.5. Thermal Diffusivity of $0.18 \mathrm{CeO}_{2} \cdot 0.82 \mathrm{ZrO}_{2}(\mathrm{C} 2-15)$. 


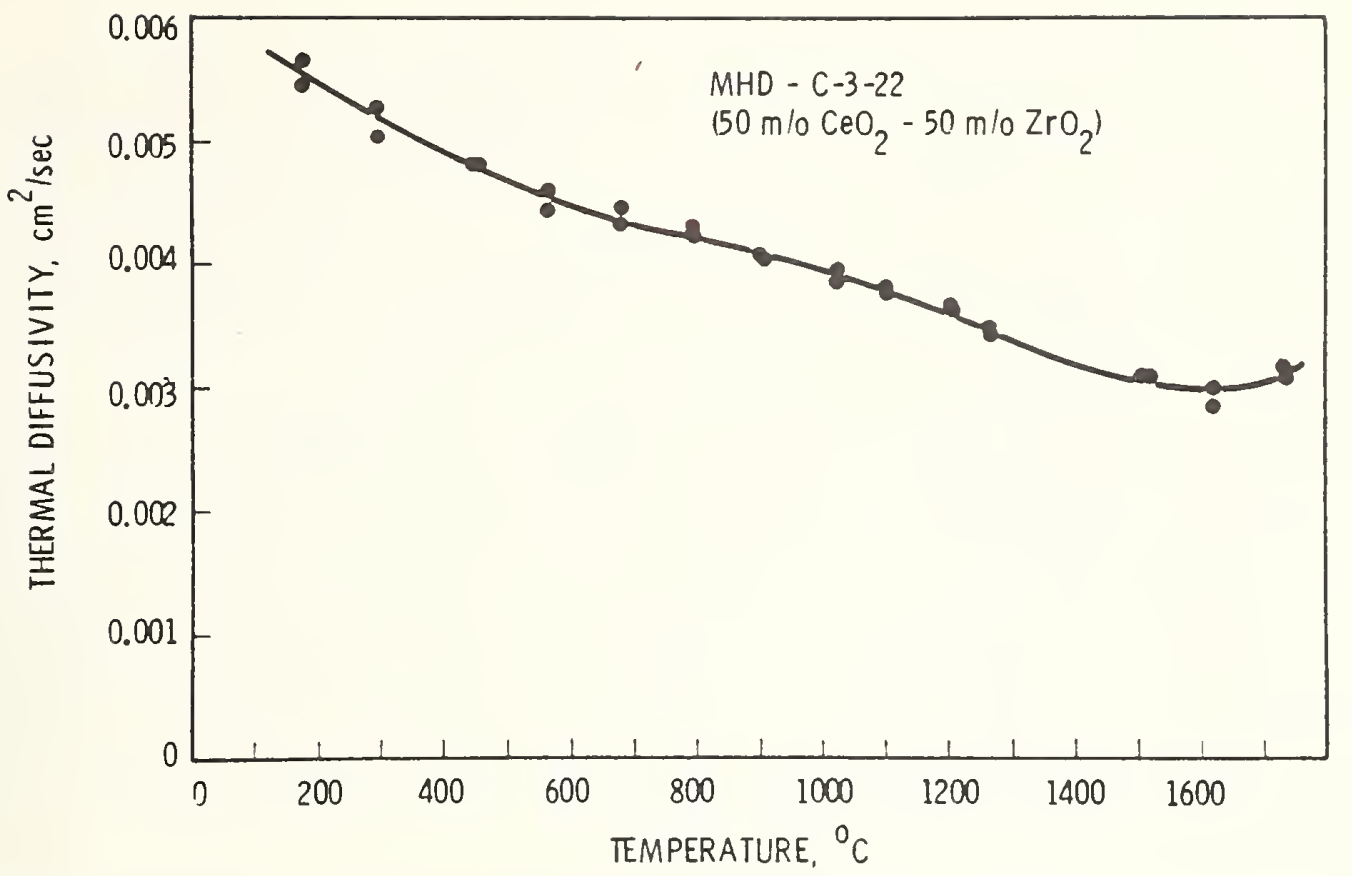

Figure B.1.6. Thermal Diffusivity of $0.5 \mathrm{CeO}_{2} \cdot 0.5 \mathrm{ZrO}_{2}(\mathrm{C} 3-22)$.

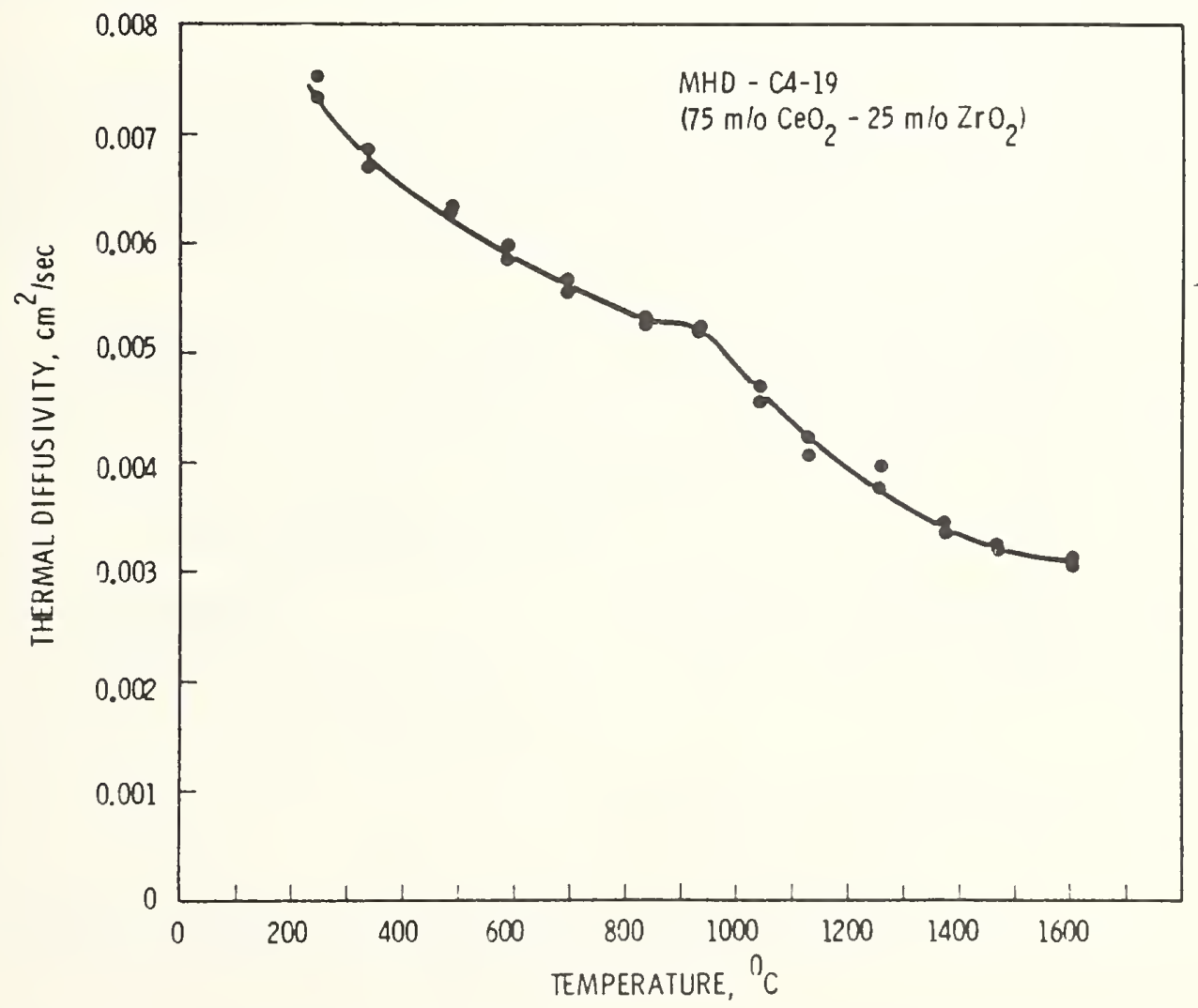

Figure B.1.7. Thermal Diffusivity of $0.75 \mathrm{CeO}_{2} \cdot 0.25 \mathrm{ZrO}_{2}(\mathrm{C} 4-19)$ 


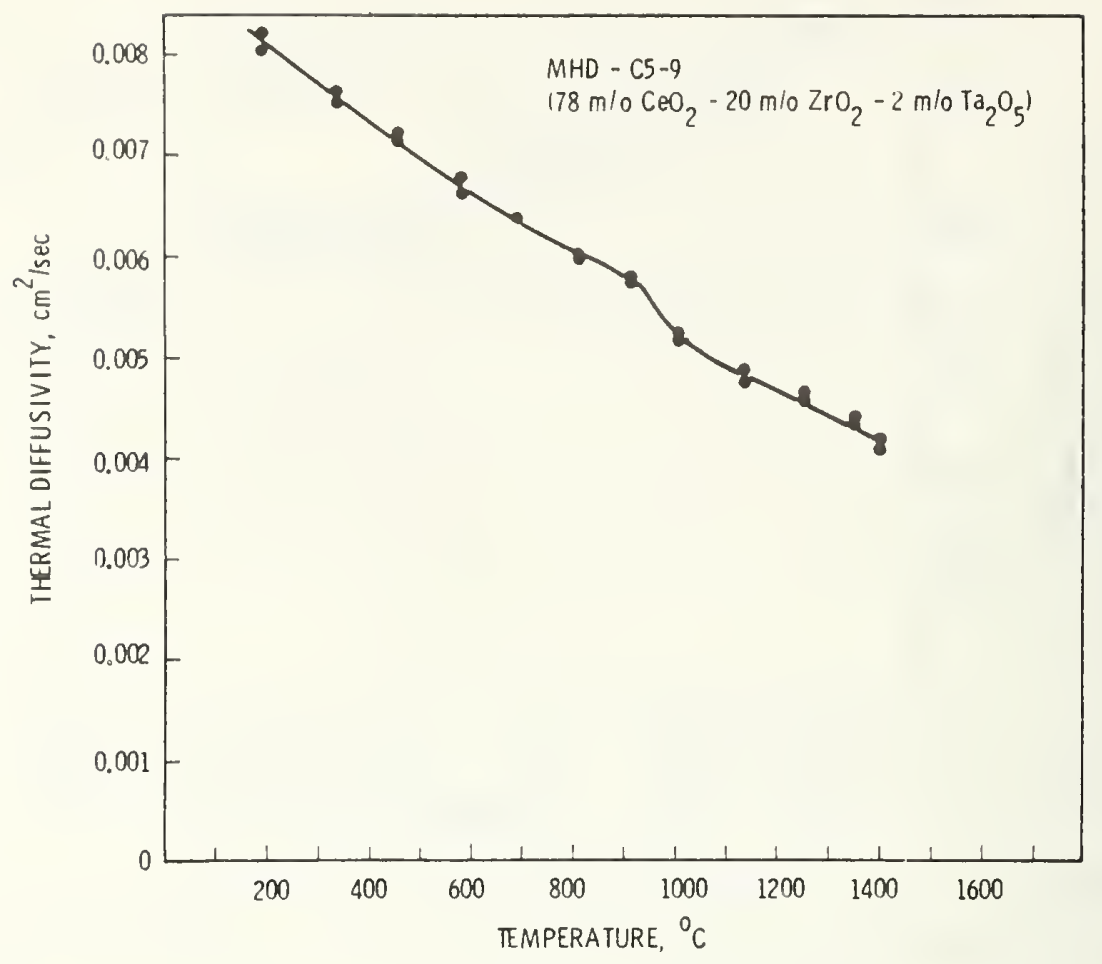

Figure B.1.8 Thermal Diffusivity of $0.78 \mathrm{CeO}_{2} \cdot 0.2 \mathrm{OZrO}_{2} \cdot 0.02 \mathrm{~T}_{2} \mathrm{O}_{5}(\mathrm{C} 5-9)$.

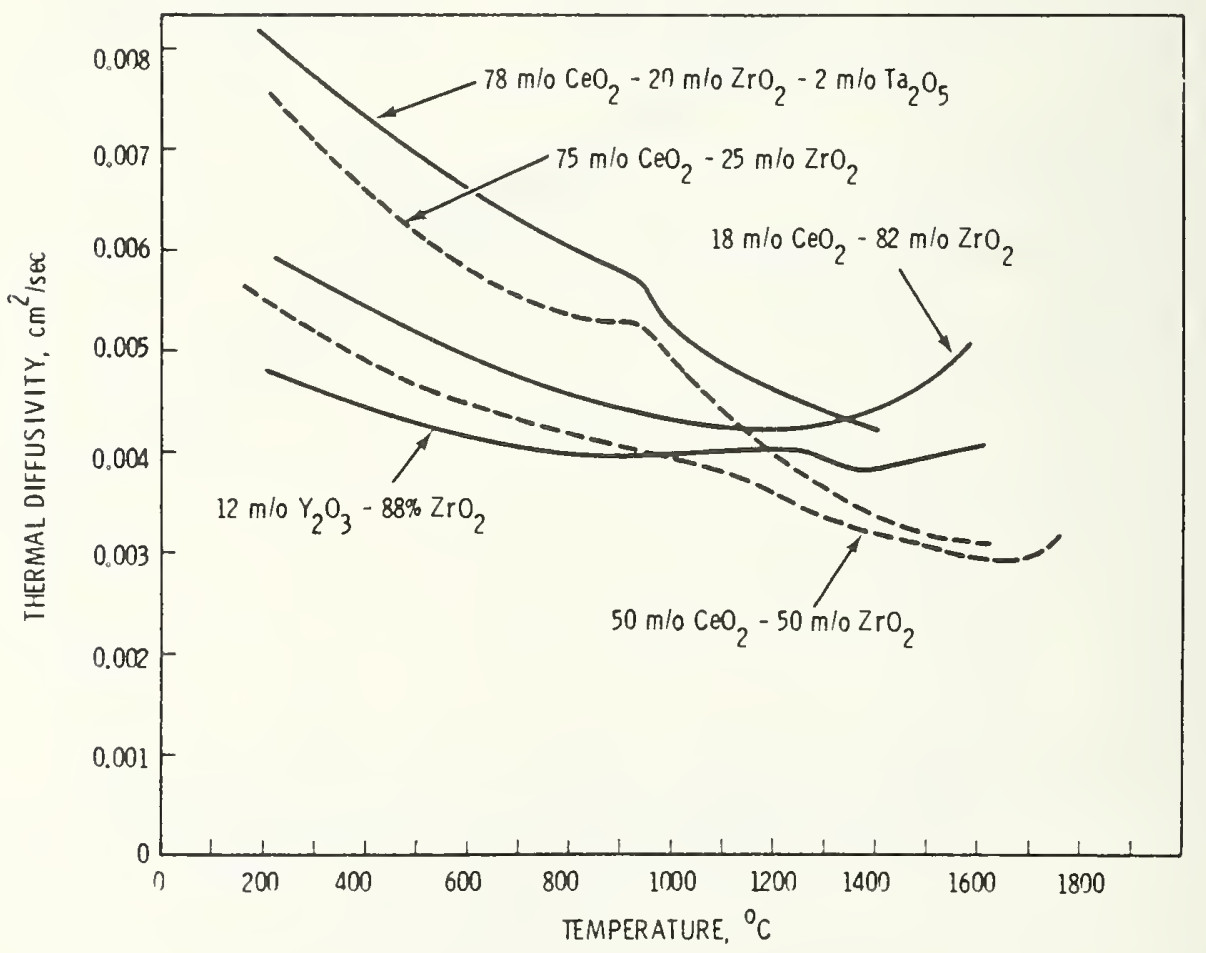

Figure B.1.9. Summary of Thermal Diffusivities for U-02 MHD Electrode Materials. 
The accuracy of the measurements was determined using a tungsten standard (SRM 737) supplied by the U.S. National Bureau of Standards, which is accurate to $\pm 5 \%$. Temperatures were measured with a platinum versus platinum-10\% rhodium thermocouple, which has been calibrated against a standard platinum resistance thermometer. The accuracy of the temperature measurement in the system is within $5^{\circ} \mathrm{C}$. The overall accuracy of the thermal expansion data is estimated to be better than $5 \%$.

The thermal expansion data are illustrated in Figures B.2.1 - B.2.6. Differences were observed in the thermal expansions $(\alpha)$ measured in argon and air, with the values of $\alpha$ larger in argon than in air. The magnitude of these differences varied between materials being smallest for the $\mathrm{Y}_{2} \mathrm{O}_{3}-\mathrm{ZrO}_{2}$ electrode and $\mathrm{MgO}$ insulator, and greatest for the $\mathrm{CeO}_{2} \cdot \mathrm{ZrO}_{2}$ electrodes. The samples which showed different expansion in air and argon also experienced changes in sample length during the measurements to $1400-1500^{\circ} \mathrm{C}$ (Table B.2.1). In general, those samples which had larger $\alpha$ values in argon also showed the largest increases in length. In addition, the $\Delta \mathrm{L} / \mathrm{L}$ values for the as-received electrodes were consistently higher during the cooling cycle.

These changes in $\alpha$ during heating in argon suggest possible stoichiometry or phase changes resulting from the lower oxygen pressures. These changes appear to be reversible as seen in the results for Mg0, Figure B.2.1, and for the $0.75 \mathrm{CeO}_{2} \cdot 0.25 \mathrm{ZrO}_{2}(\mathrm{C} 4-16)$, Figure $\mathrm{B} .2 .5$, in which the thermal expansion returned to the original air values after being first heated in argon and then in air.

The average thermal expansion coefficients from 100 to $1400^{\circ} \mathrm{C}$ calculated from $\Delta \mathrm{L} / \mathrm{L}$ (Table B.2.1) data are summarized in Table B:2.2. The $\alpha$ values for measurements made in argon are values obtained only on cooling since the values on heating can represent possible changes in sample composition or stoichiometry.

It is interesting to note that for the insulator and all electrodes, the thermal expansion values, $\alpha(100-1400)$, are larger in argon by a factor of approximately 1.1 than in air. In addition the $\alpha$ values for $\mathrm{CeO}_{2}-\mathrm{ZrO}_{2}$ electrodes increase with increasing $\mathrm{CeO}_{2}$ concentration.

\section{B.3 Chemical Composition (J. L. Bates, Battelle NW)}

The composition of the MgO was determined by emission spectrochemical analysis to a precision \pm factor of 2 . The results indicate a high purity oxide containing $20 \mathrm{ppm} \mathrm{Al,} 50 \mathrm{ppm} \mathrm{Ca}, 50 \mathrm{ppm} \mathrm{Si}$, and $50 \mathrm{ppm} \mathrm{V}$. All other elements were less than detectable concentrations.

The compositions of the electrode materials were determined by $x-r a y$ fluorescence, Table B.3.1. These results are considered accurate to $\pm 5 \%$.

B. 4 Microstructure (J. L. Bates, Battelle NW Labs.)

\section{B.4.1 MgO Insulator}

The electrode and insulator samples for metallography were vacuum impregnated with resin and polished for microstructural examination. The microstructures of the MgO insulator were substantially different depending on the orientation relative to the hot pressing directions. Figures B.4.1-B.4.3. 


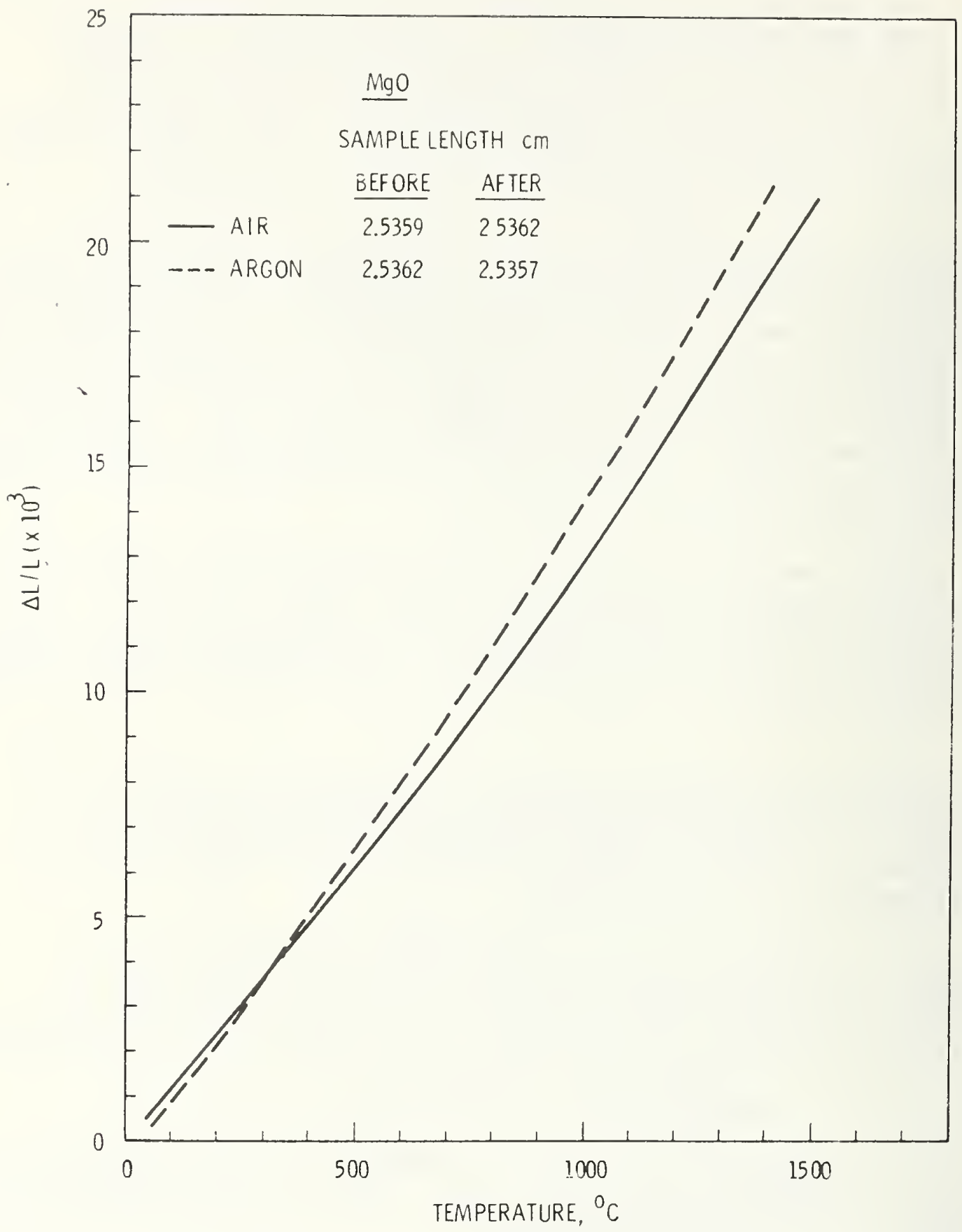

Figure B.2.1. Thermal expansion of $\operatorname{MgO}(M-1)$. 


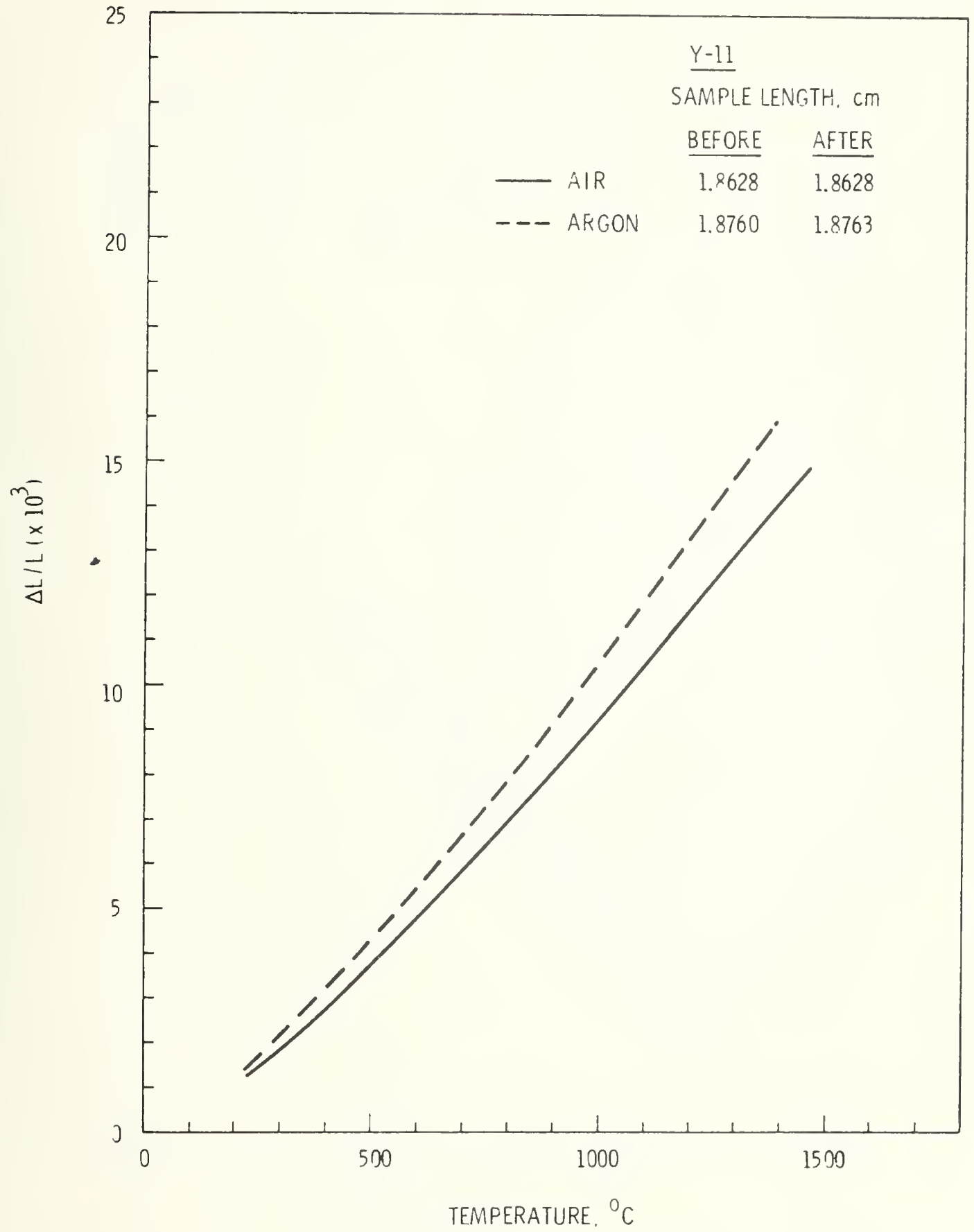

Figure B.2.2. Thermal Expansion of $0.12 \mathrm{Y}_{2} \mathrm{O}_{3} \cdot 0.88 \mathrm{ZrO}_{2}(\mathrm{Y}-11)$. 


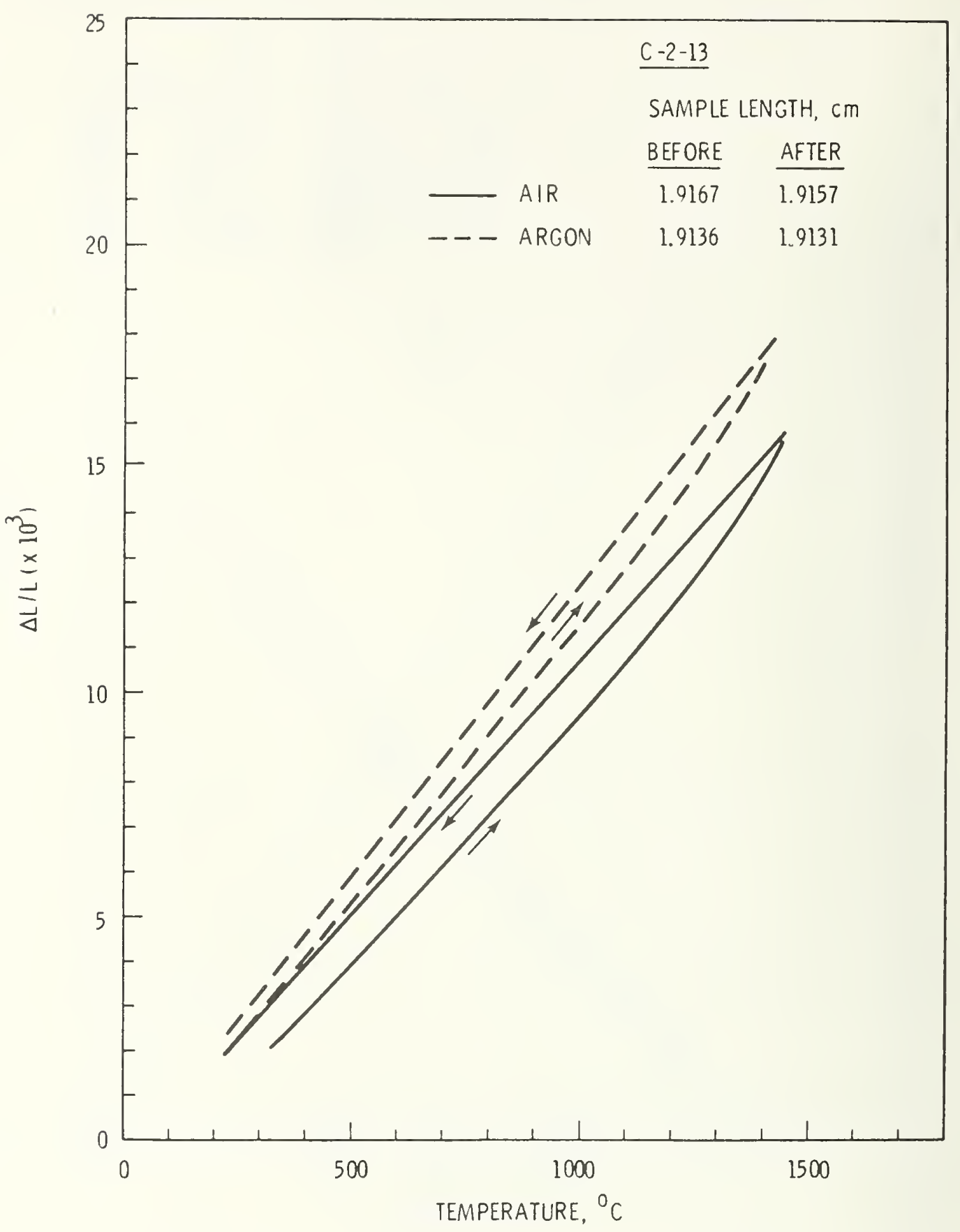

Figure B.2.3. Thermal expansion of $0.18 \mathrm{CeO}_{2} \cdot 0.82 \mathrm{ZrO}_{2}(\mathrm{C}-2-13)$. 


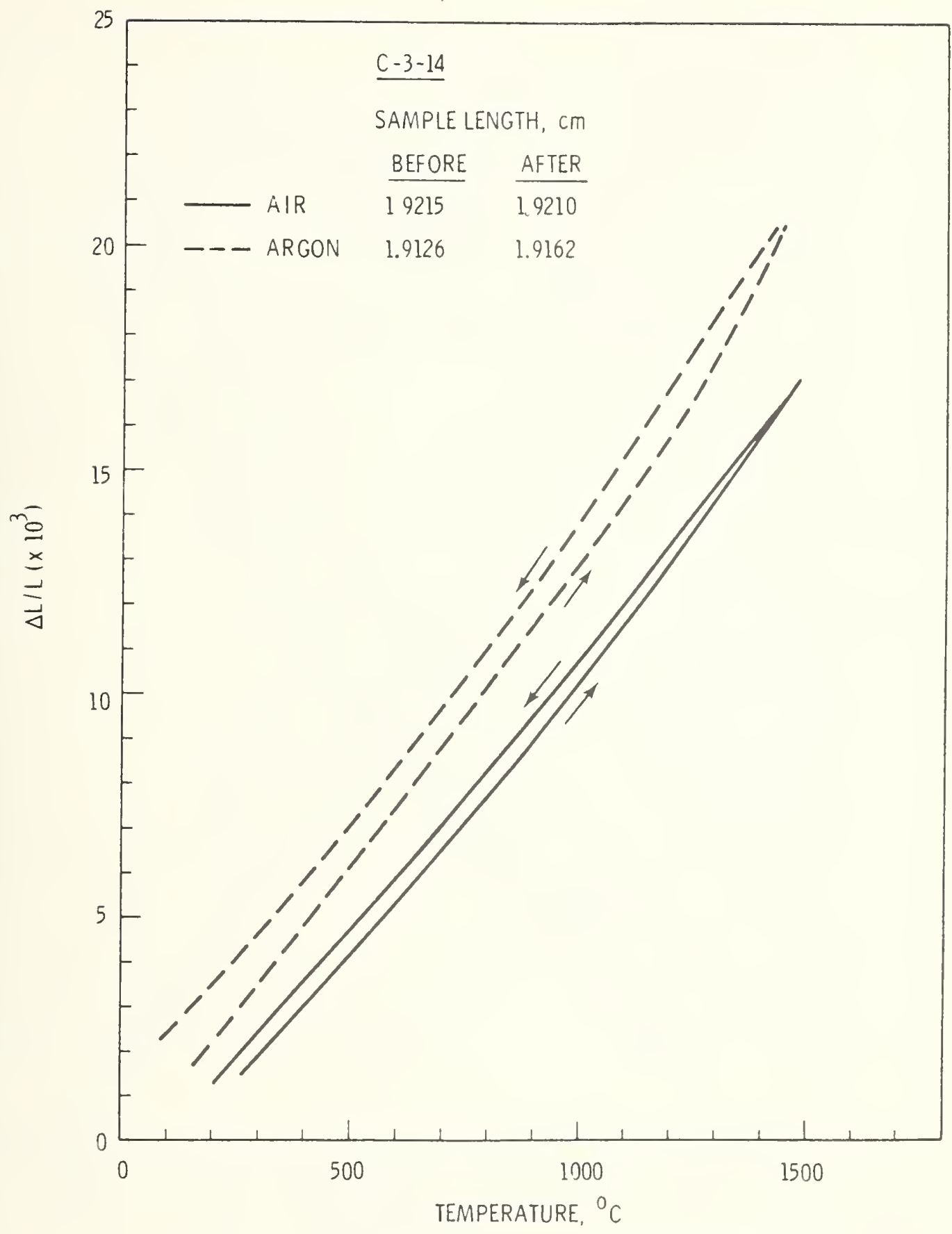

Figure B.2.4. Thermal expansion of $0.5 \mathrm{CeO}_{2} \cdot 0.5 \mathrm{ZrO}_{2}(\mathrm{C}-3-14)$. 


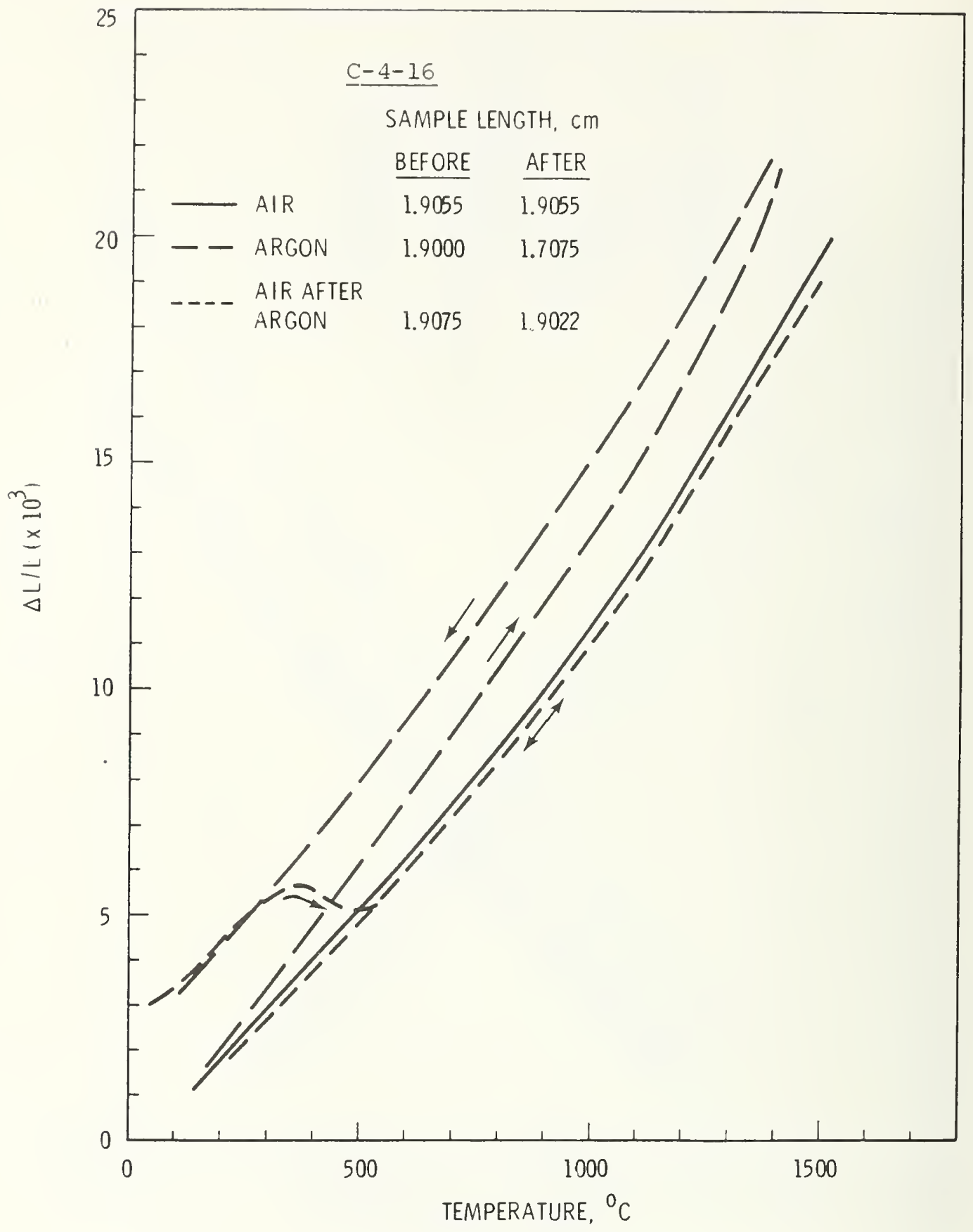

Figure B.2.5. Thermal expansion of $0.75 \mathrm{CeO}_{2} \cdot 0.25 \mathrm{ZrO}_{2}(\mathrm{C}-4-16)$. 


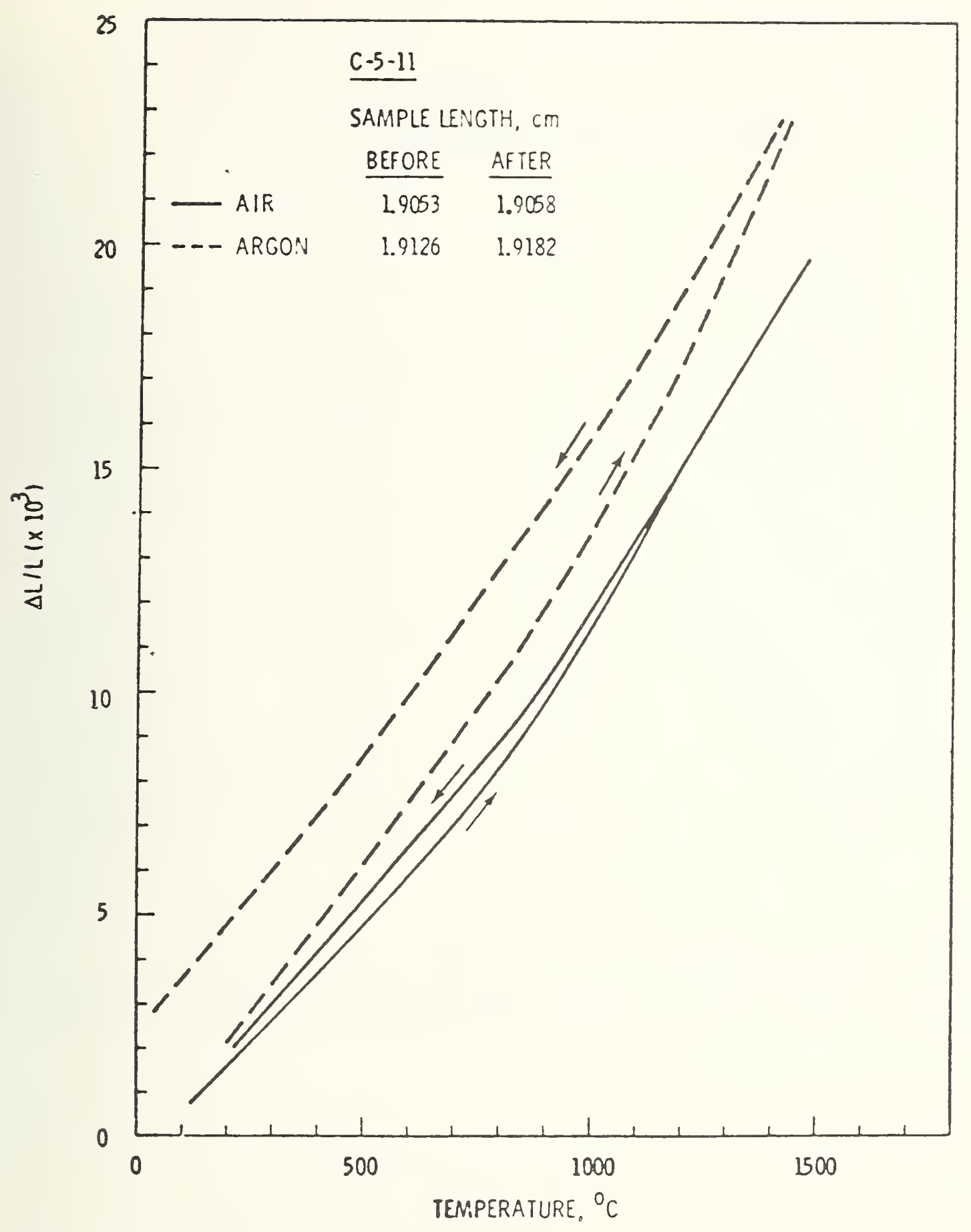

Figure B.2.6. Thermal expansicn of $0.78 \mathrm{CeO}_{2} \cdot 0.20 \mathrm{ZrO}_{2} \cdot 0.02 \mathrm{Ta}_{2} \mathrm{O}_{5} \cdot(\mathrm{C}-5-11)$. 
TABLE B.2.1

DIMENSIONAL CHANGES DUE TO THERMAL EXPANSION

OF INSULATOR AND ELECTRODES

Length $(\mathrm{cm})^{\text {l }}$

Sample

Atmosphere

Argon ${ }^{2}$

Argon ${ }^{2}$

Air $^{2}$

$Y-11$

Argon

Air

C-2-13

Argon

Air

C-3-14

Argon

Air

C-4-16

$\operatorname{Argon}^{3}$

$\mathrm{Air}^{3}$

Air

C-5-11

Argon

Air

\begin{tabular}{llr}
\multicolumn{3}{c}{ Length $(\mathrm{cm})$} \\
\hline Before & After & Change \\
2.5334 & 2.5362 & +0.0028 \\
2.5362 & 2.5357 & -0.0005 \\
2.5359 & 2.5362 & +0.0003 \\
1.8160 & 1.8763 & +0.0003 \\
1.8628 & 1.8628 & 0.0000 \\
1.9136 & 1.9131 & -0.0005 \\
1.9167 & 1.9157 & -0.0010 \\
1.9126 & & \\
1.9215 & 1.9162 & +0.0036 \\
1.9000 & 1.9210 & -0.0005 \\
1.9075 & & \\
1.9055 & 1.9075 & +0.0075 \\
1.9126 & 1.9022 & -0.0053 \\
1.9053 & 1.9055 & 0.0000 \\
& 1.9182 & +0.0056 \\
& 1.9058 & +0.0005
\end{tabular}

${ }^{1}$ Measurements accurate to $0.0005 \mathrm{~cm}$.

${ }^{2}$ All measurements made on same MgO sample in order of their listing.

${ }^{3}$ Both measurements made on same sample, first in argon followed by measurement in air. 
TABLE B. 2.2

THERMAL EXPANSION OF MgO AND ELECTRODES

$\frac{\alpha /{ }^{\circ} \mathrm{C}\left(10^{-6}\right)\left(100-1400^{\circ} \mathrm{C}\right)}{\underline{\text { Argon }}}$

MgO (M-1)

15.6

15.5

14.0

12.3

10.9

$0.12 \mathrm{Y}_{2} \mathrm{O}_{3} \cdot 0.88 \mathrm{ZrO}_{2}(\mathrm{Y}-11)$

13.1

11.5

$0.18 \mathrm{CeO}_{2} \cdot 0.82 \mathrm{ZrO}_{2}(\mathrm{C}-2-13)$

13.6

12.2

$0.75 \mathrm{CeO}_{2} \cdot 0.25 \mathrm{ZrO}_{2}(\mathrm{C}-4-16)$

14.5

13.2

$0.78 \mathrm{CeO}_{2} \cdot 0.20 \mathrm{ZrO}_{2} \cdot 0.02 \mathrm{Ta}_{2} \mathrm{O}_{5}(\mathrm{C}-5-11)$

14.9

13.6 
TABLE B. 3.1

Composition and Designation of Electrode Materials

\section{Electrode}

\begin{tabular}{l}
\hline $.12 \mathrm{Y}_{2} \mathrm{O}_{3} \cdot 0.88 \mathrm{ZrO}_{2}$ \\
$0.18 \mathrm{CeO}_{2} \cdot 0.82 \mathrm{ZrO}_{2}$ \\
$0.50 \mathrm{CeO}_{2} \cdot 0.50 \mathrm{ZrO}_{2}$ \\
$0.75 \mathrm{CeO}_{2} \cdot 0.25 \mathrm{ZrO}_{2}$ \\
$0.78 \mathrm{CeO}_{2} \cdot 0.20 \mathrm{ZrO}_{2}$ \\
$0.02 \mathrm{Ta}_{2} \mathrm{O}_{5}$ \\
Analytical samples
\end{tabular}

Reference

\begin{tabular}{|c|c|c|c|}
\hline $\mathrm{ZrO}_{2}$ & $\mathrm{Y}_{2} \mathrm{O}_{3}$ & $\mathrm{CeO}_{2}$ & $\mathrm{Ta}_{2} \mathrm{O}_{5}$ \\
\hline 88.8 & 11.2 & & \\
\hline 77.8 & & 22.2 & \\
\hline 46.2 & & 53.8 & \\
\hline 19.6 & & 80.4 & \\
\hline 16.5 & & 82.2 & 1.3 \\
\hline
\end{tabular}


Normal to the hot pressing direction ( $B-1$ and $T-1$ ) in Figures B.4.1 and B.4.2, the pores were irregular in shape and uniformly distributed around the Mg0 particles with no apparent orientation. In contrast, in the direction parallel to the hot pressing direction, the pores appear smaller and are longer in one direction than the other. The smaller width is parallel to the hot pressing direction. The grains were very dense but show evidence of deformation. The average grain size is $10 \mathrm{~km}$ with some grains as large as $0.02 \mathrm{~cm}$. The pore size varied up to $5 \mu \mathrm{m}$ across.

\section{B.4.2 Electrodes}

$\left[0.12 \mathrm{Y}_{2} \mathrm{O}_{3} \cdot 0.88 \mathrm{ZrO}_{2}(\mathrm{Y}-13-\mathrm{E}, \mathrm{M})\right]$ The microstructure of the yttria stabilized electrode is shown in Figure B.4.4. The sections from the center (Y-13-M) and edge (Y-13-E) were essentially the same; however, they differed in color. The Y-13-M was off-white, while the Y-13-E was mottled with the large grains and edges in particular being a light gray. The larger grains were round or oval in shape and contained a large number of very small pores uniformly distributed throughout. The size of the grains varied up to $65 \mu \mathrm{m}$. The edges of the large grains were irregular, indicating sintering between the oxide fines. Sirtering was also extensive in the fines between the larger grains.

$\left[0.18 \mathrm{CeO}_{2}-0.82 \mathrm{ZrO}_{2}(\mathrm{C} 2-15 \mathrm{E}, \mathrm{M})\right]$ The microstructure from the center and end of the electrode was essentially the same, Figure B.4.5. The electrode was mottled off-white and light gray. The lighter areas were near the edges. A second phase (light gray) was observed in some selected areas. The size of the large grains varied up to $0.065 \mathrm{~cm}$. These large grains contained substantial small pores uniformly distributed throughout the grains. Some evidence of sintering between the larger grains and small filler material can be seen.

$\left[0.5 \mathrm{CeO}_{2} \cdot 0.5 \mathrm{ZrO}_{2}(\mathrm{C} 3-22 \mathrm{E}, \mathrm{M})\right]$ The electrode was mottled with a light yellow background and light gray areas, Figure B.4.6. The middle (C3-22 M) was substantially darker than the end. The darker areas do not appear to be associated with any particular area. A possible second phase may also be present. The electrode contained a number of microcracks. The size of the large grains was as large as $0.065 \mathrm{~cm}$. The fines filled the spaces between the grains and some sintering is evident. The larger grains contained a uniform distribution of small pores.

$\left[0.75 \mathrm{CeO}_{2} \cdot 0.25 \mathrm{ZrO}_{2}(\mathrm{C} 4-19 \mathrm{E}, \mathrm{M})\right]$ This high ceria-containing electrode was multi-colored, with large areas of yellow, tinted with green, which were interlaced with gray, Figure B.4.7. These areas of different color were related to specific microstructures, the lighter yellow to areas free of the large grains and the darker gray to areas containing a large number of large grains. Both sections contained a substantial number of cracks which ran parallel to the length of the sample. The large grains were approximately $0.065 \mathrm{~cm}$ or less in diameter, and were uniformly dispersed with small pores, $<0.001 \mathrm{~cm}$ in diameter.

$\left[0.02 \mathrm{Ta}_{2} \mathrm{O}_{5} \cdot 0.78 \mathrm{CeO}_{2} \cdot 0.2 \mathrm{ZrO}_{2}\right.$ (C5-9 $\left.\left.\mathrm{E}, \mathrm{M}\right)\right]$ This electrode material was uniformly mottled with yellow green background and very dark green spots, Figure B.4.8. These dark green areas were directly related to the large crystallites of the material, while smaller particles are light green. These effects are easily seen in polarized light. The regular surfaces of the porosity in the areas which bind the larger particles together suggest the presence of a liquid phase during sintering. Some large and small cracks lace the electrodes, especially in the center section. The large grains were $0.065 \mathrm{~cm}$ or less in diameter. The pores in the larger grains 


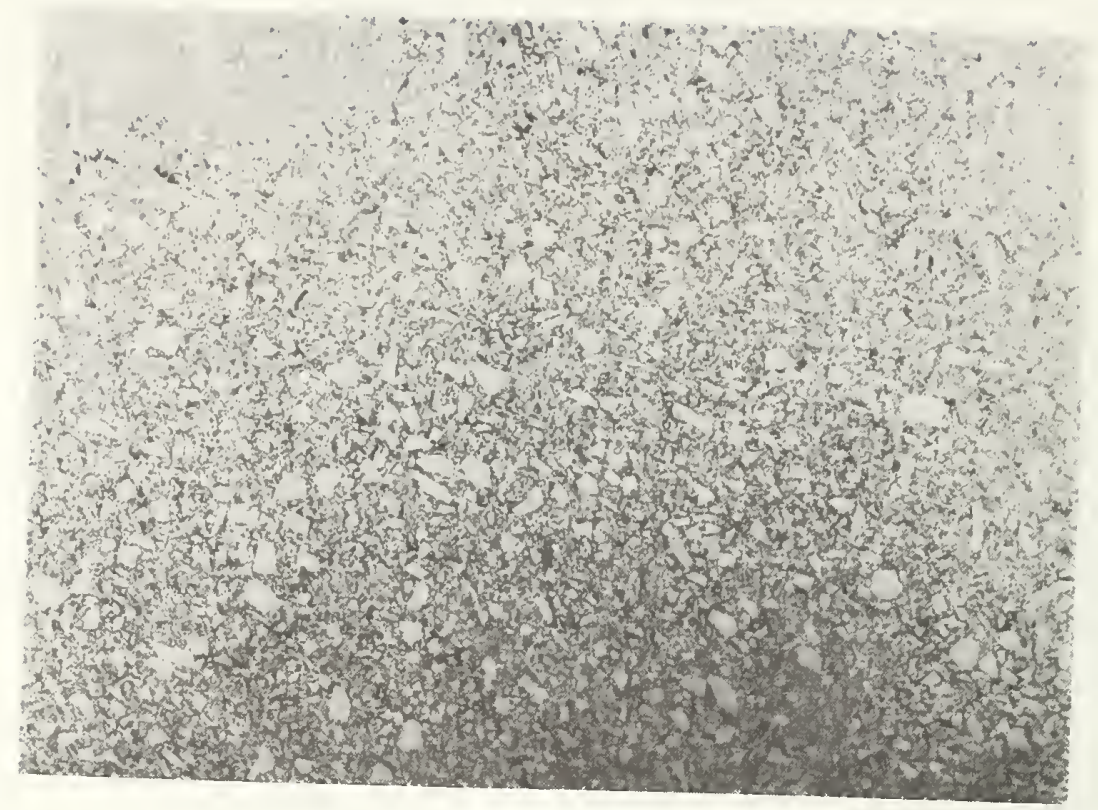

$12 x$
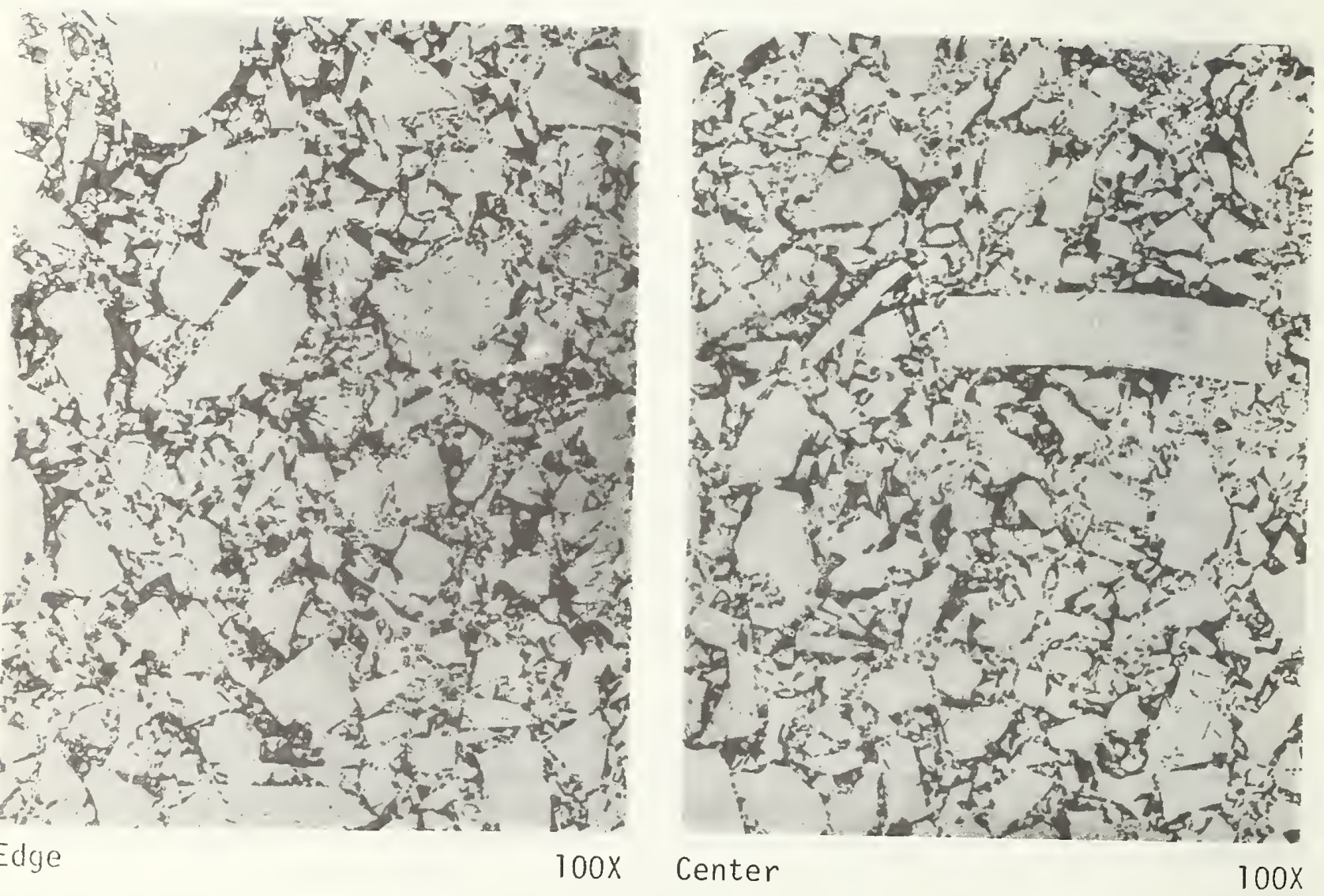

Figure B.4.1. Representative Microstructure of Mg0 Insulator, B-7 with Hot Pressing Direction Normal to the MgO Surface. 


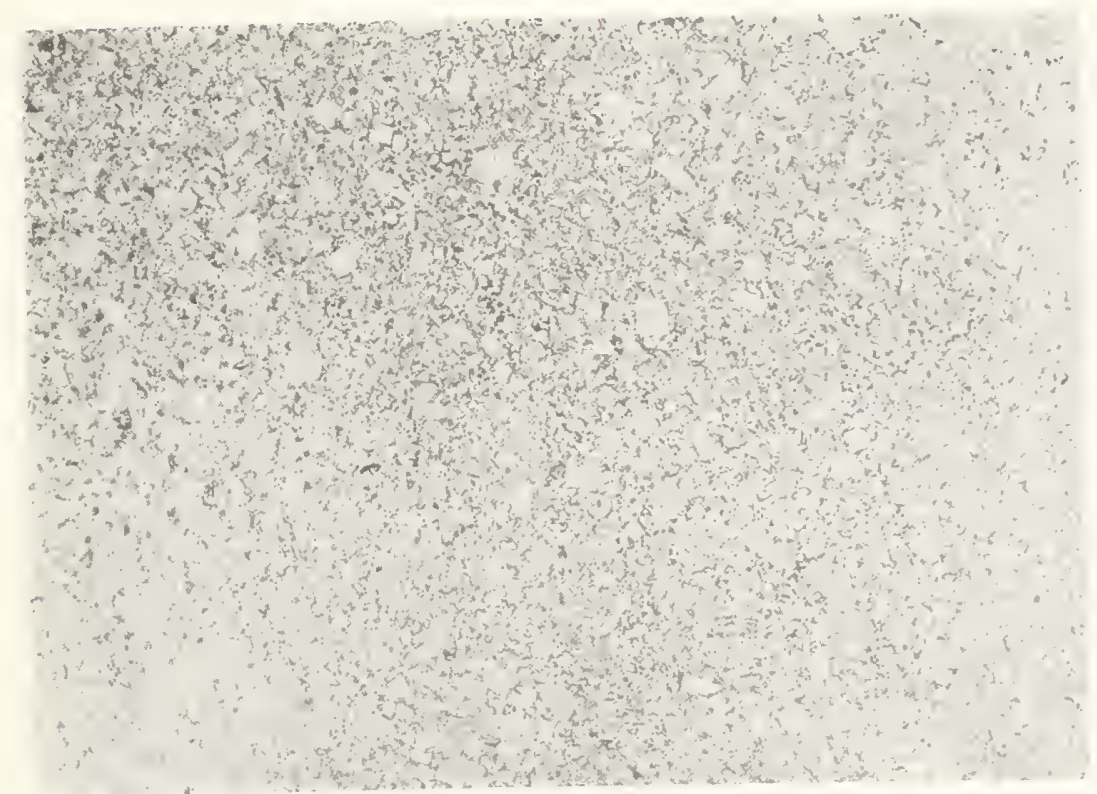

\section{Hot Pressing Direction}

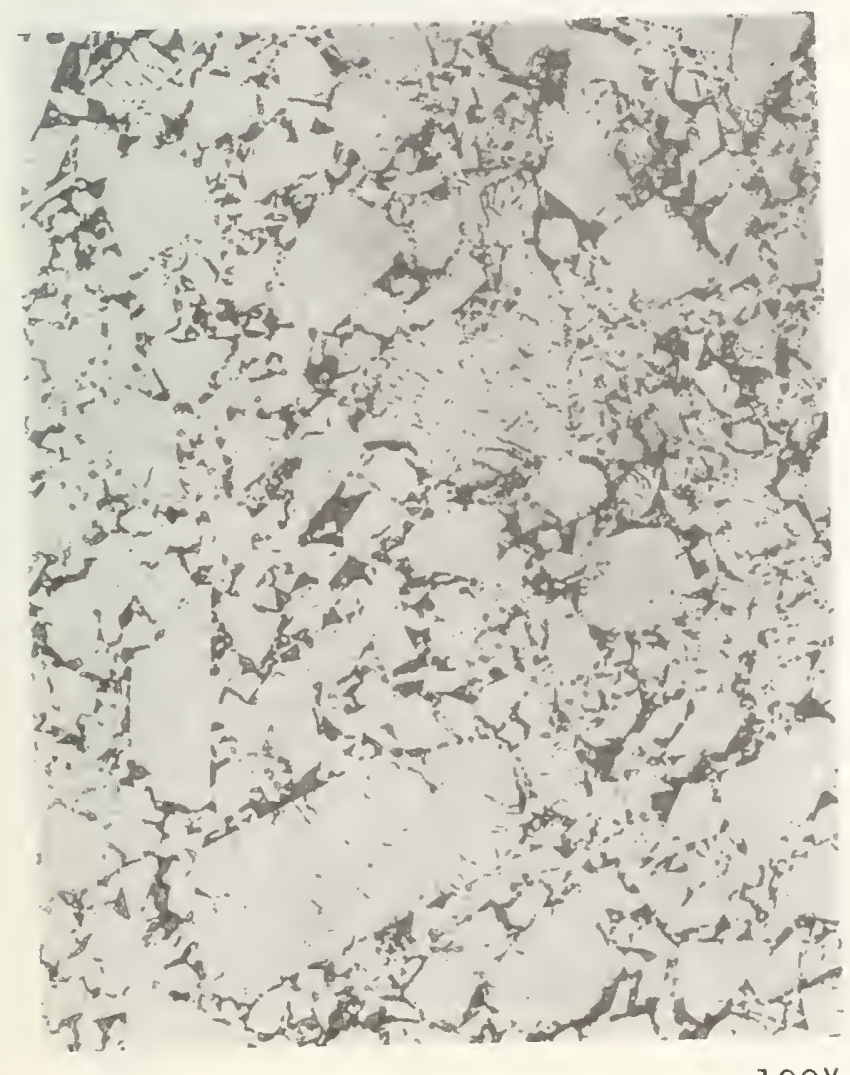

Edge

\section{X}

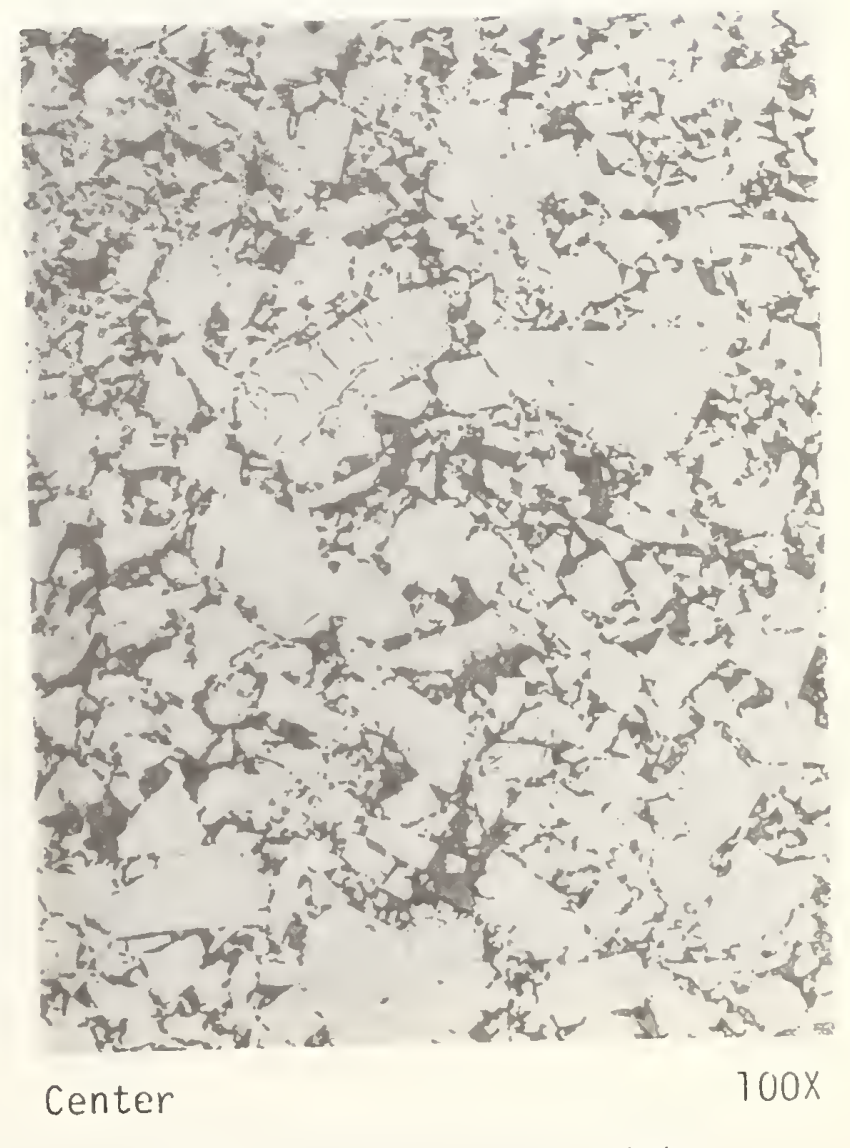

Figure B.4.2. Representative Microstructures of Mg0 Insulator T-1, with Hot Pressing Direction Normal to the MgO Surface (As-Polished). 

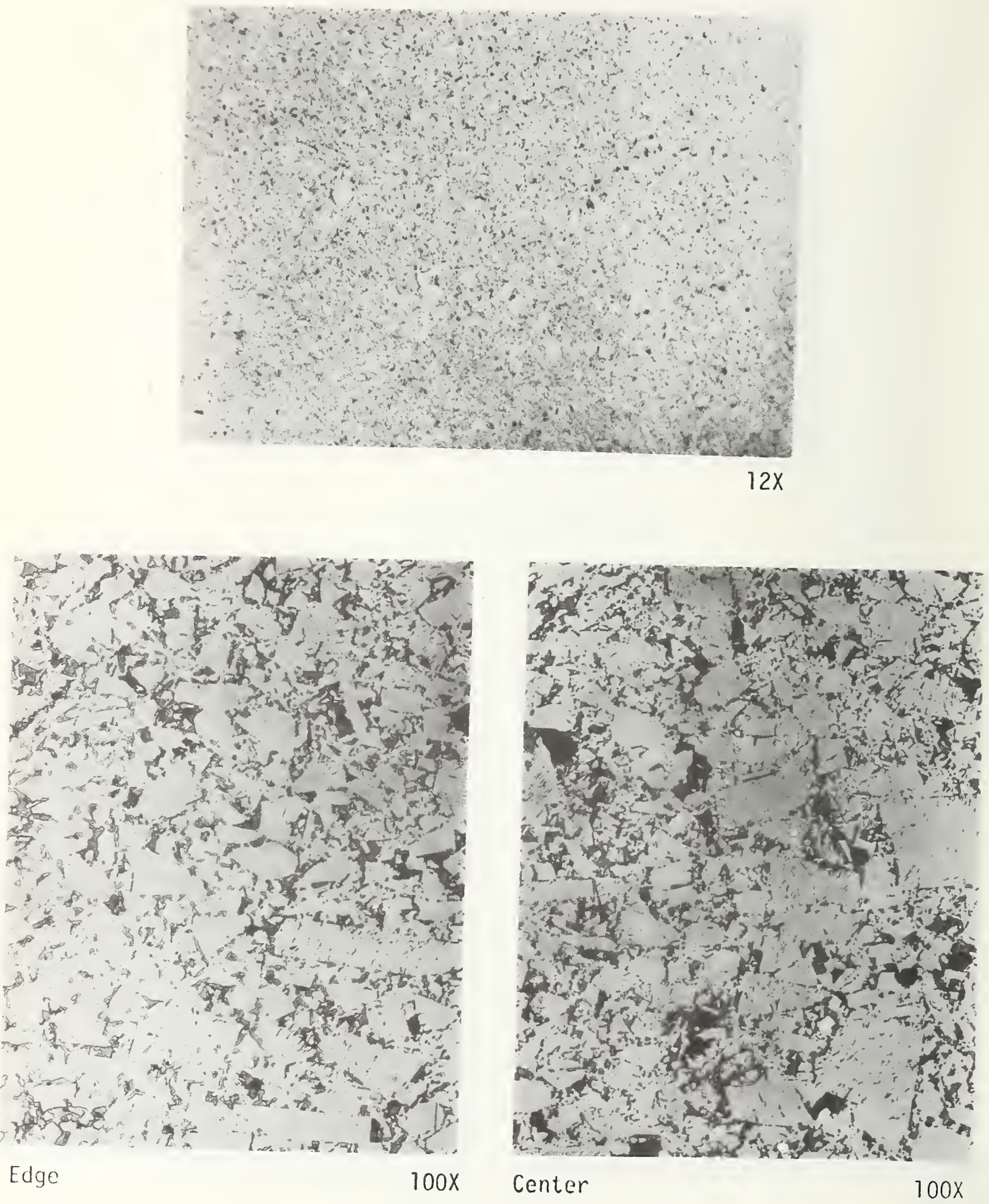

Figure B.4.3. Representative Microstructures of MgO Insulator C-1 with Hot Pressing Direction Parallel to Mgo Surface (ns-Polished). 


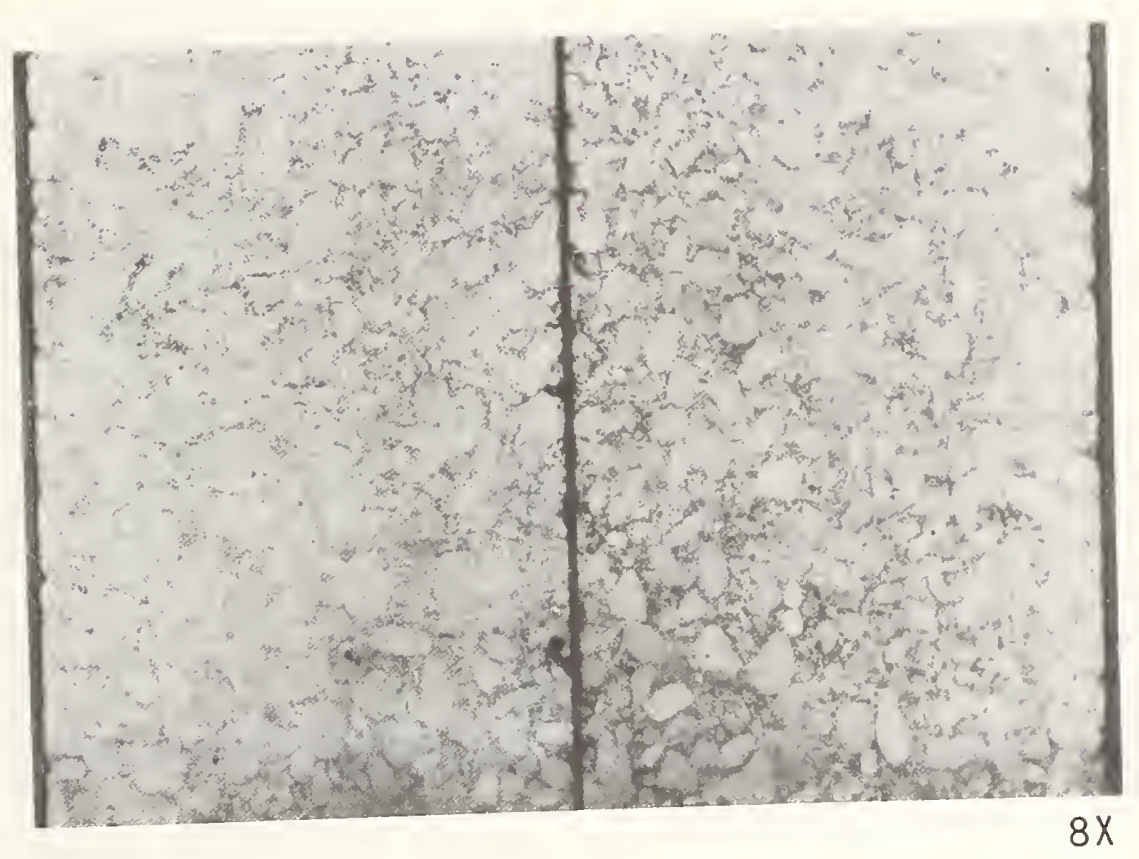

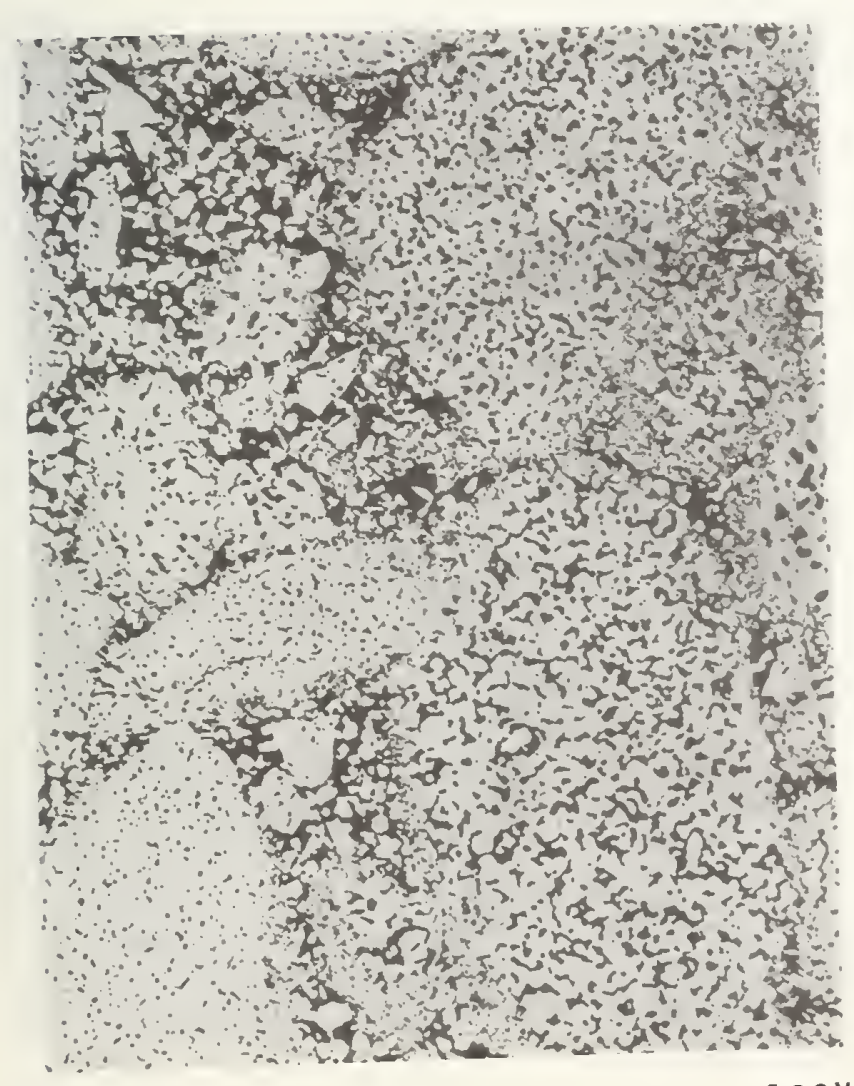

Edge

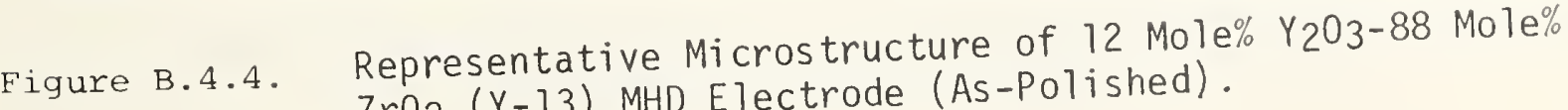

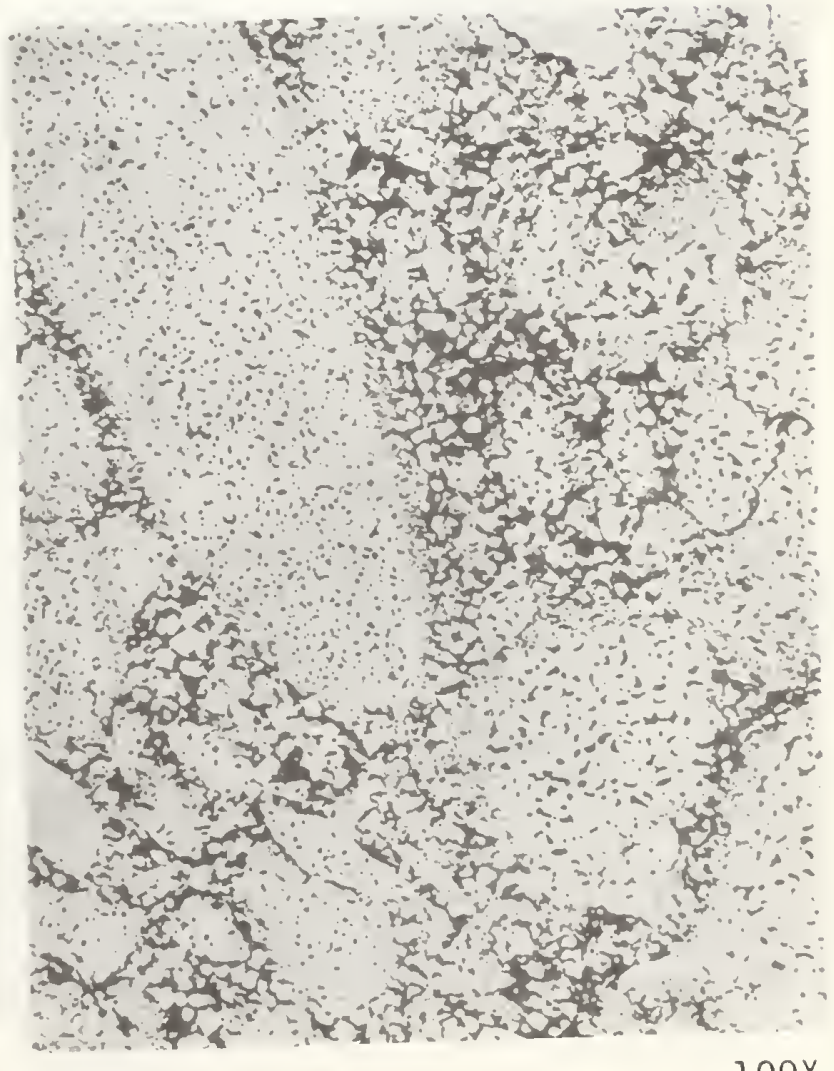

Center $\mathrm{ZrO}_{2}(\mathrm{Y}-13)$ MHD Electrode (As-Polished). 


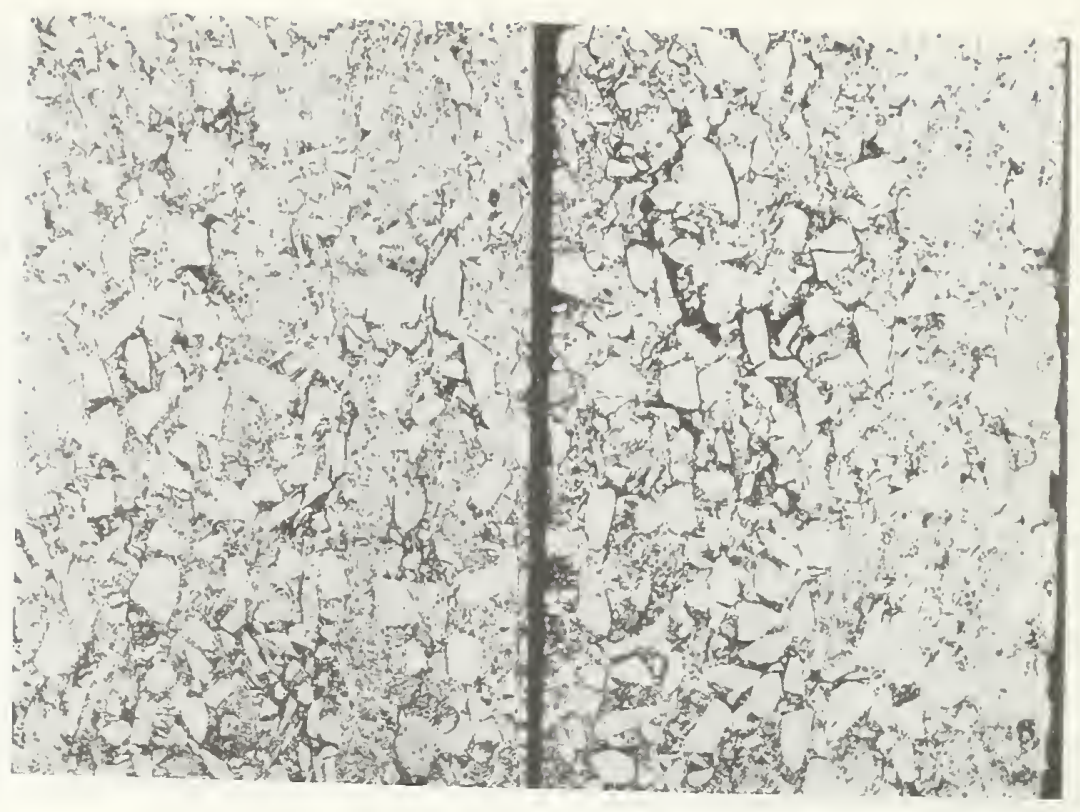

$8 x$
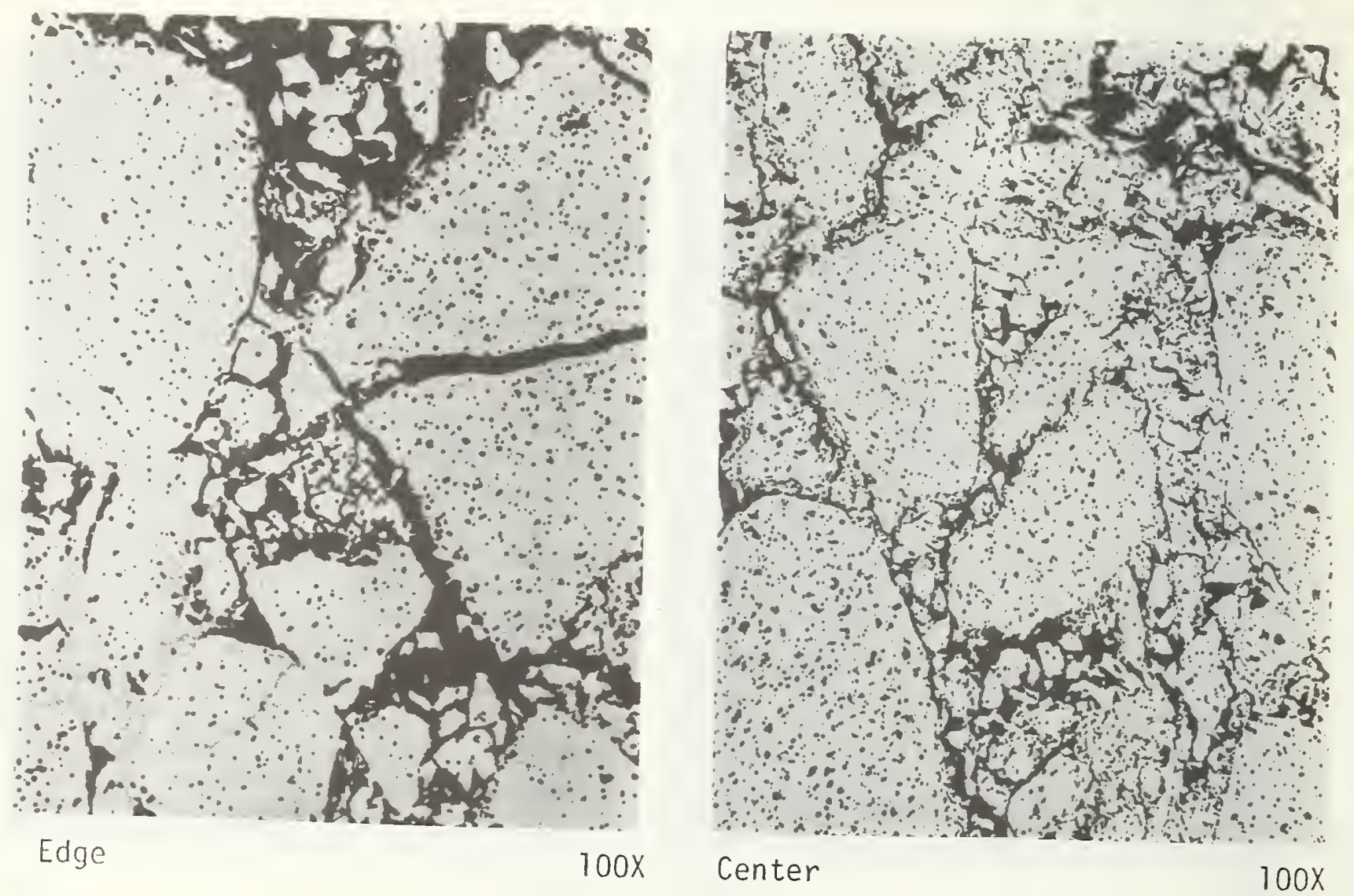

Figure B.4.5. Representative Microstructures of 18 Mole\% Ce02-82 Mole\% $\mathrm{ZrO}_{2}$ (C2-15) MHD Electrode (As-Polished). 

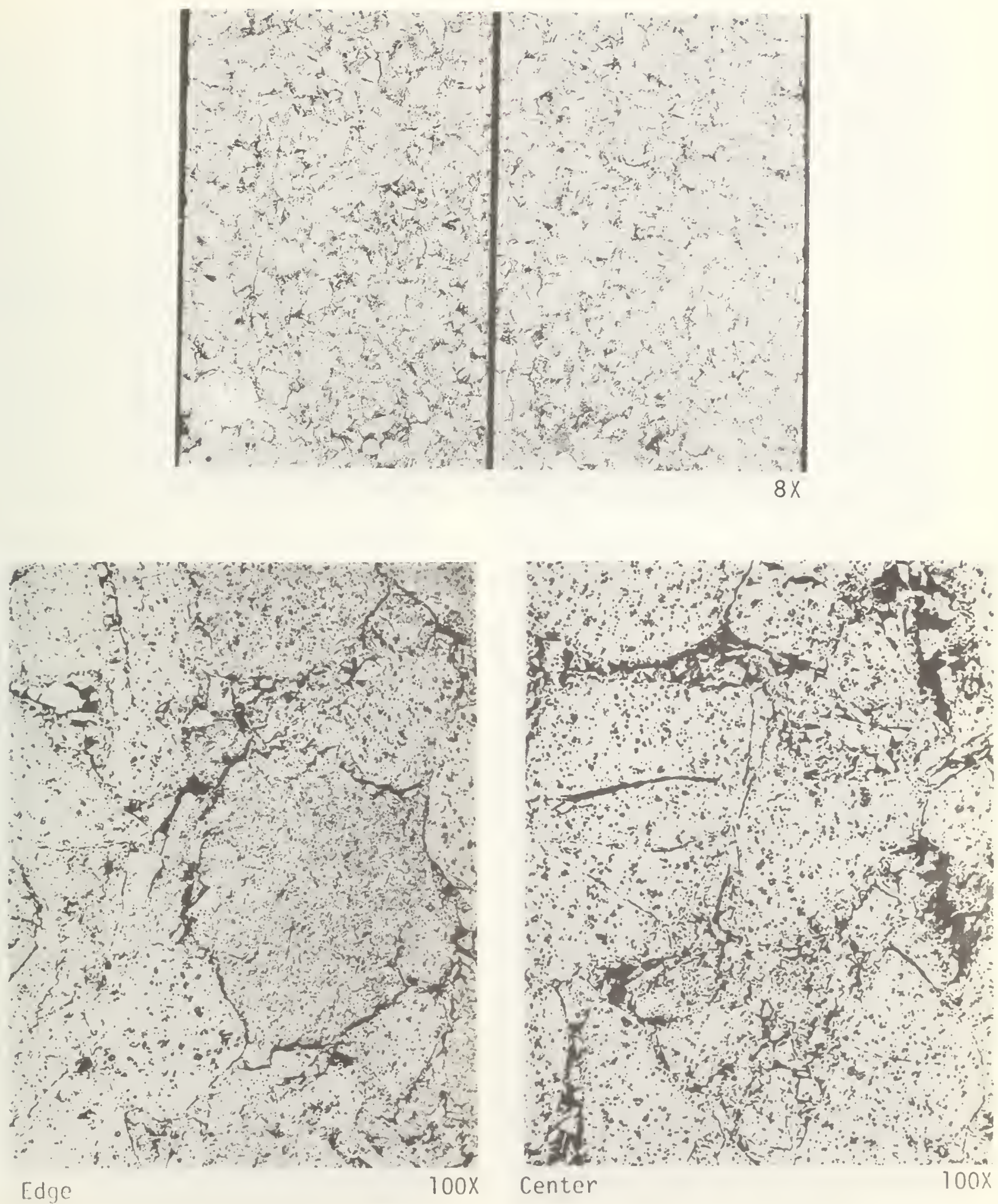

Figure B.4.6. Representative Microstructure of $50 \mathrm{~mole} \% \mathrm{CeO}_{2}-50 \mathrm{~mole} \% \mathrm{ZrO}_{2}$ (C-3-22) MHD Electrode (As-Polished). 


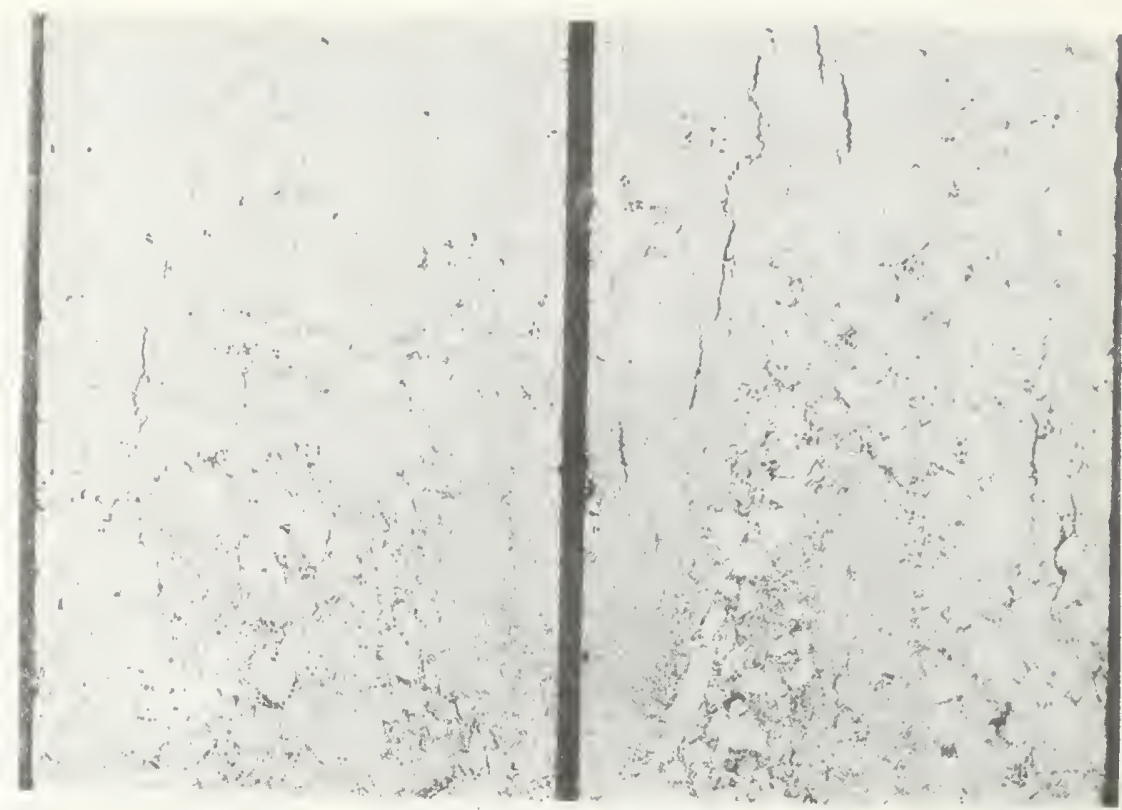

$8 X$
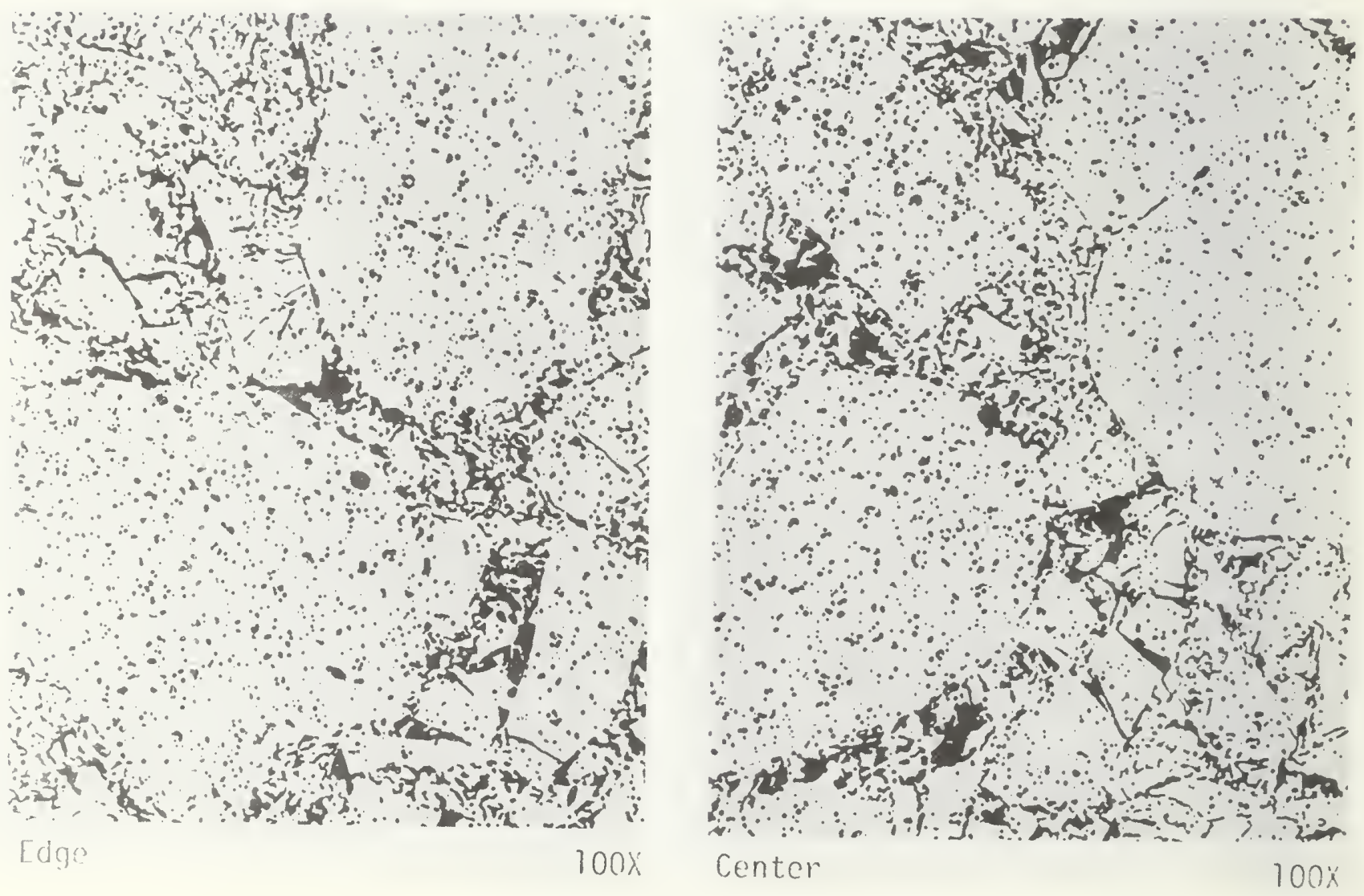

Figure B.4.7. Representative Microstructure of 75 Mole\% Ce02-25 Mole\% $\mathrm{ZrO}_{2}$ (C4-19) MHD Electrode (As-Polished). 


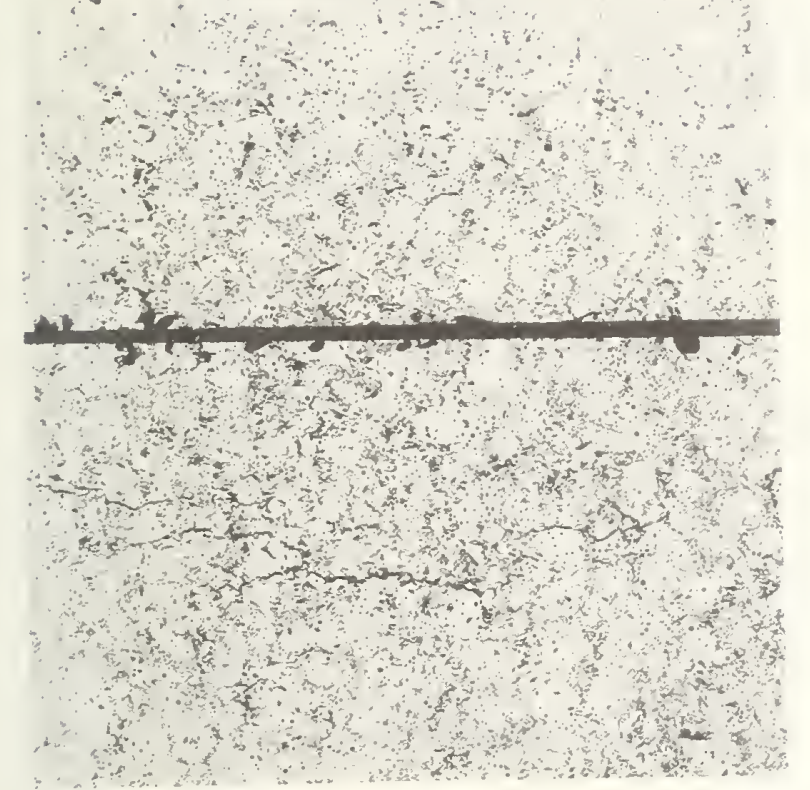

Bright Field

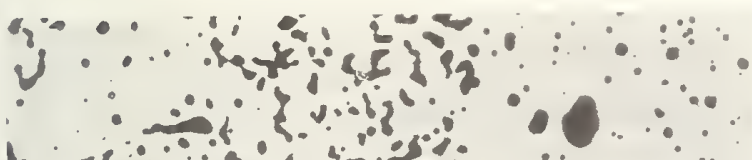

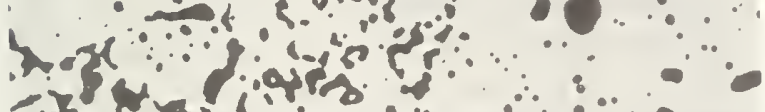

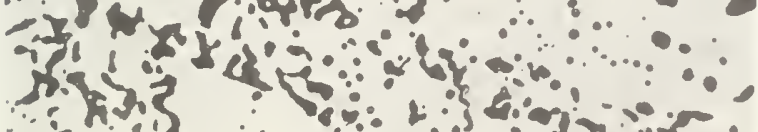

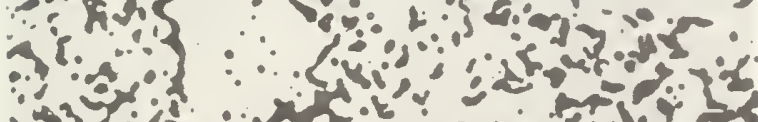
$\left\{\begin{array}{l}1 \\ 12\end{array}\right.$

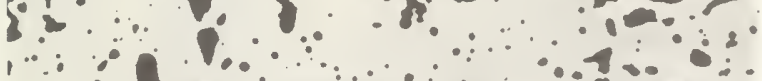

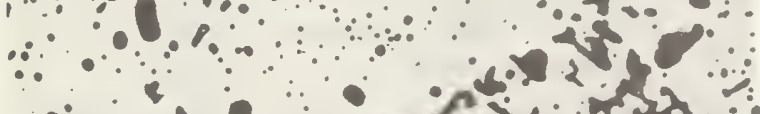

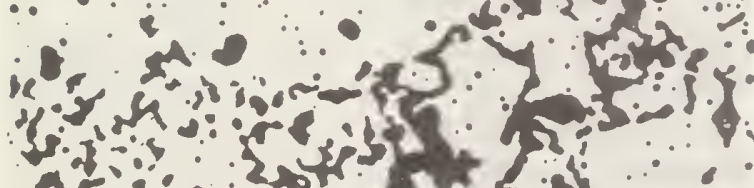

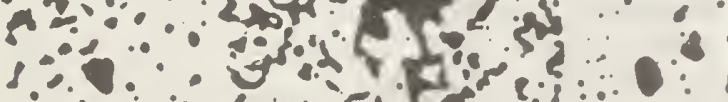

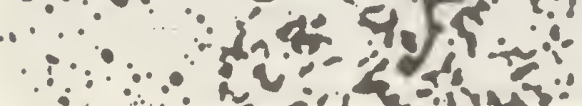

Edge
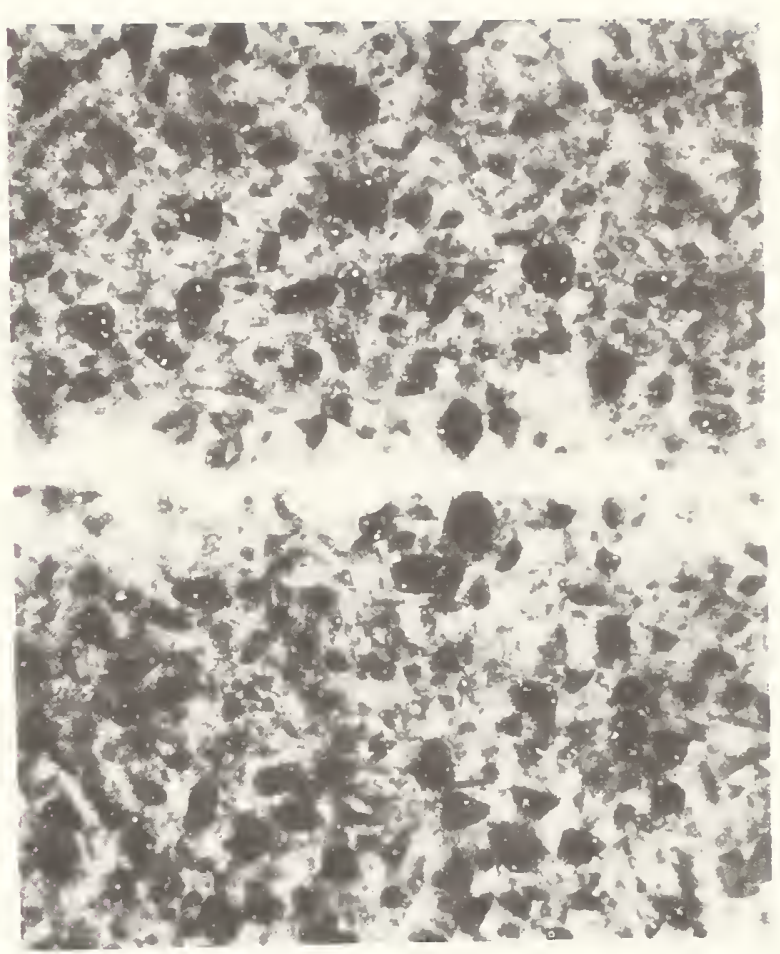

Polarized Light

$8 X$

Figure B.4.8. Representative Microstructure of $78 \mathrm{Mole} \% \mathrm{CeO} 2-20 \mathrm{Mole} \%$ $\mathrm{ZrO}_{2}-2 \mathrm{Mole} \% \mathrm{Ta}_{2} \mathrm{M}_{5}$ (C5-9) MHD Electrode (As-Polished). 
were generally spherical in shape and varied widely in size up to $0.0006 \mathrm{~cm}$ in dianeter.

\section{B.5 Electrical Conductivity (W. R. Hosler, NBS)}

The electrical resistivity of the five test electrode materials is shown in Figures B.5.1-B.5.3. The data is given as a function of temperature and at several oxygen pressures. The data points represent equilibrium values. Since, in all samples (except the $88 \mathrm{ZrO}_{2}-12 \mathrm{Y}_{2} \mathrm{O}_{3}$ ), the conductivity of the material depends on the ratio of the $\mathrm{Ce}^{3+} / \mathrm{Ce}^{4+}$, the amount of reduction is important and this is determined by the oxygen pressure. Equilibrium times of several hours were sometimes necessary to obtain equilibrium at the low temperatures.

All data were obtained using a d.c. four probe method, thus minimizing any measurement difficulties due to contact emf's or polarization effects. Resistance measurements were made as a function of current density, and current dependent effects were observed below a power density value of $\sim 1.25$ watts $/ \mathrm{cm}^{3}$. Generally, below $1200^{\circ} \mathrm{C}$, current densities of $1 \mathrm{amp} / \mathrm{cm}^{2}$ would cause joule heating. The effect, of course, is dependent on the resistivity of each sample at $1200^{\circ} \mathrm{C}$. The sample containing $78 \mathrm{CeO}_{2}-2 \mathrm{OrO}_{2}-2 \mathrm{Ta}_{2} \mathrm{O}_{5}$ has the highest conductivity and therefore showed the smallest joule heating at $1 \mathrm{amp} / \mathrm{cm}^{2}$ at $1200^{\circ} \mathrm{C}$. The effect of the 5 valent tantalum is to force some $\mathrm{Ce}^{4+}$ into $\mathrm{Ce}^{3+}$ independent of the oxygen pressure and to maintain a conducting material through electron exchange between the $\mathrm{Ce}^{4+}$ and $\mathrm{Ce}^{3+}$.

No long term current dependent effects were made on the ionically conducting $88 \mathrm{ZrO}_{2}-12 \mathrm{Y}_{2} \mathrm{O}_{3}$ where one might expect some reduction of the $\mathrm{ZrO}_{2}$ at the cathode. Current densities and measurement times were too low to expect to observe a change in these samples.

Figure B.5.4 shows the conductivity of high purity MgO ceramic material as a function of temperature at several oxygen pressures. This data is taken from C. M. Osburn and R. W. Vest, J. Am. Ceram. Soc., 54, No. 9 p. 428-435 (1971). The material was approximately $10 \%$ porous and the data has not been corrected for this effect. (Multiply given values by 1.09 to correct for porosity.)

\section{B. 6 Phase Composition (A. Perloff)}

Tables B.6.1 and B.6.2 list pertinent x-ray diffraction data for pretest, U-02 Phase I materials, listed in terms of their nominal compositions. Materials for anode and cathode use are identical. Phases present in these nominal compositions are characteristic of reaction products formed at elevated temperatures under relatively oxidizing conditions, in accordance with established thermochemical data. These untested phase and phase assemblages are discussed further with reference to post-test results (Chapter II - Section C.2).

B.7 Porosity and Pore Size Distribution (B. Rossing, Westinghouse Res. and Dev. Lab)

The porosity and pore size distribution were determined for each electrode composition and for the magnesia insulators by conventional techniques. 


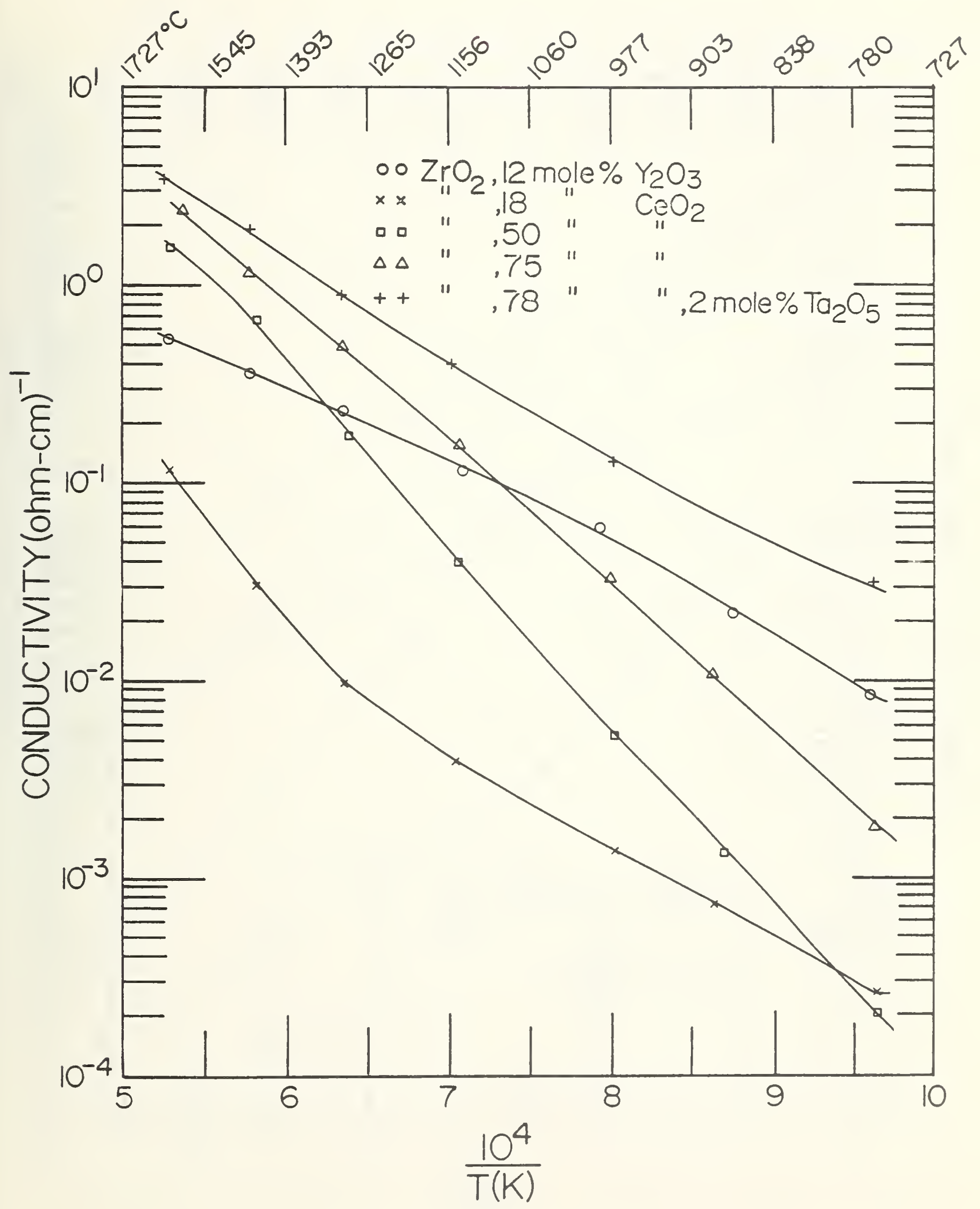

Figure B.5.1. Electrical Conductivity of Test Materials in Air. 


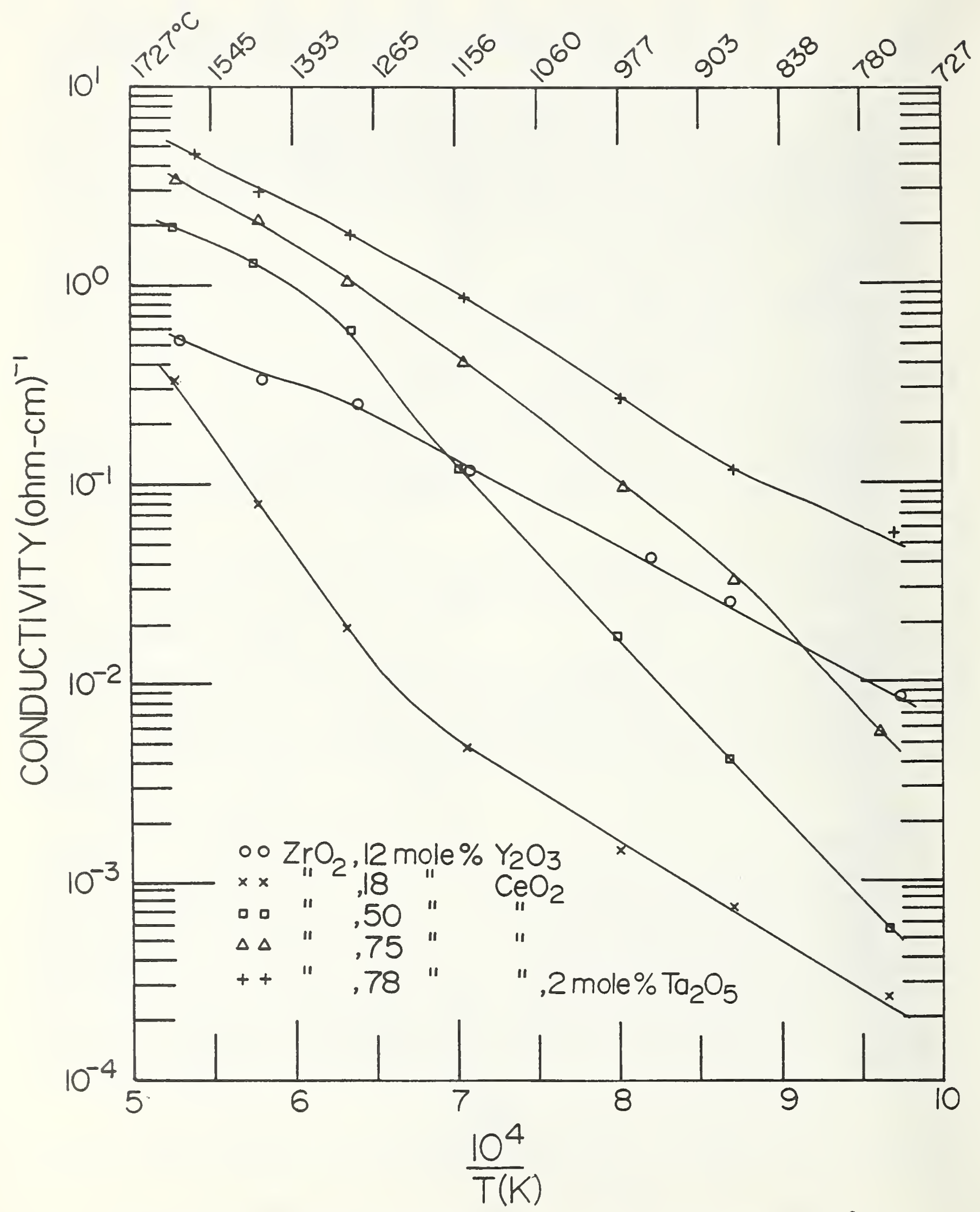

Figure B.5.2. Electrical Conductivity of Test Materials at $10^{-3}$ atm oxygen in Nitrogen. 


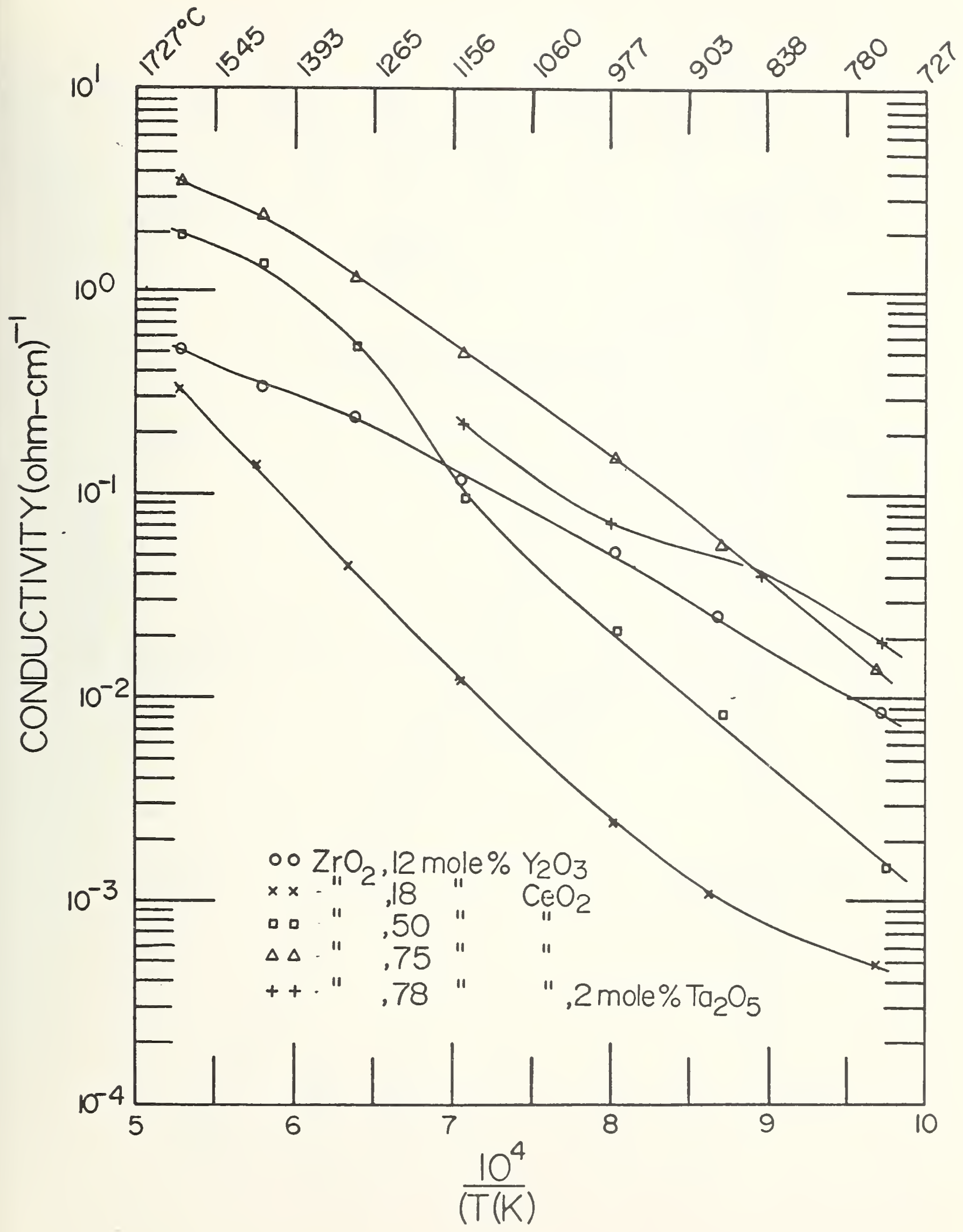

Figure B.5.3. Electrical Conductivity of rest Materials at $6 \times 10^{-6}$ atm Oxygen in Nitroqen. 


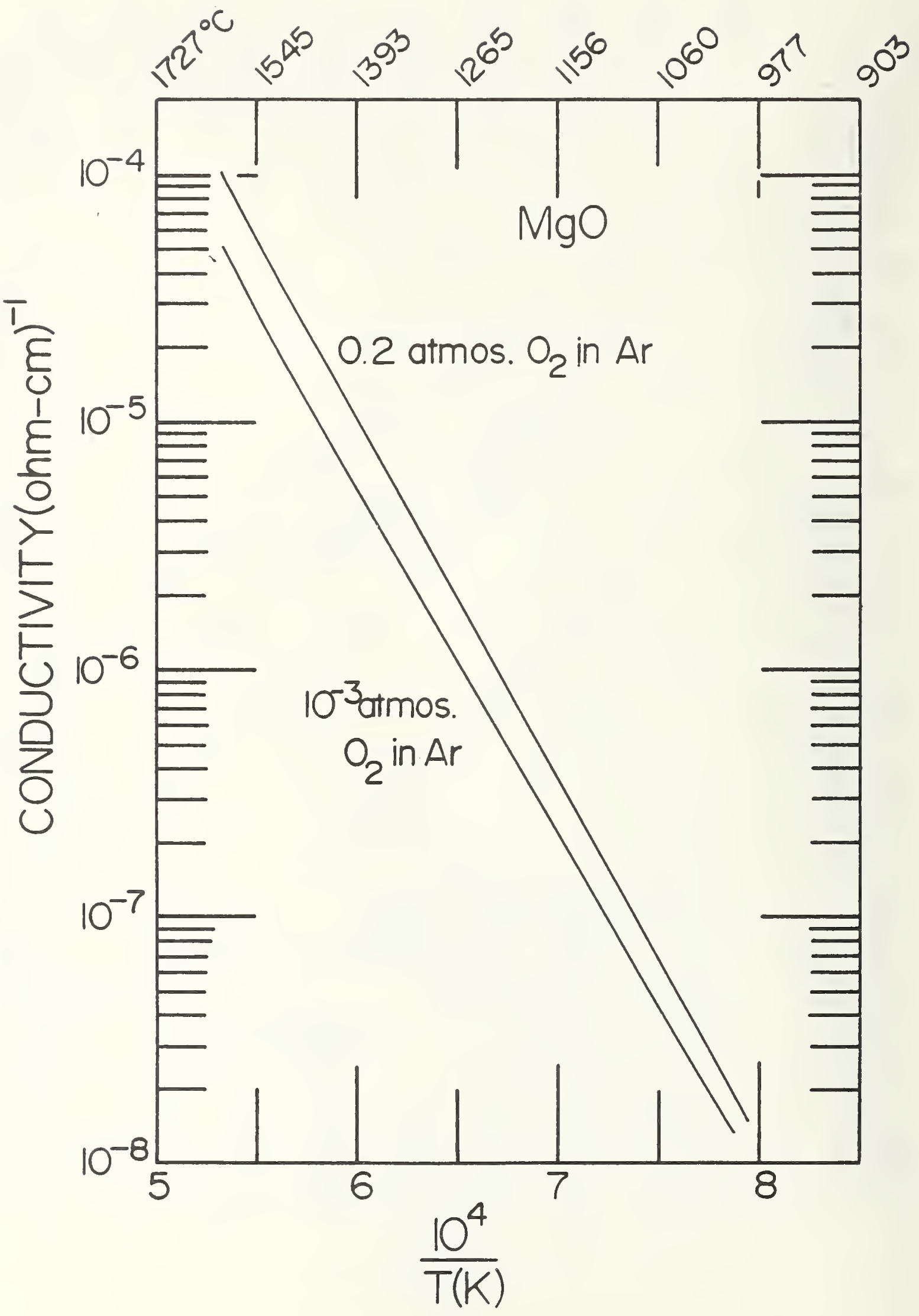

Figure B.5.4. Electrical Conductivity of Mgo Ceramic. 


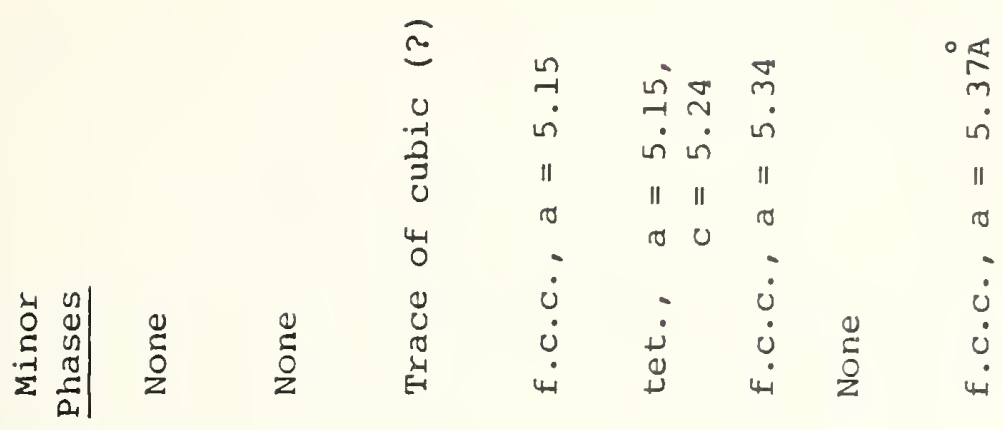

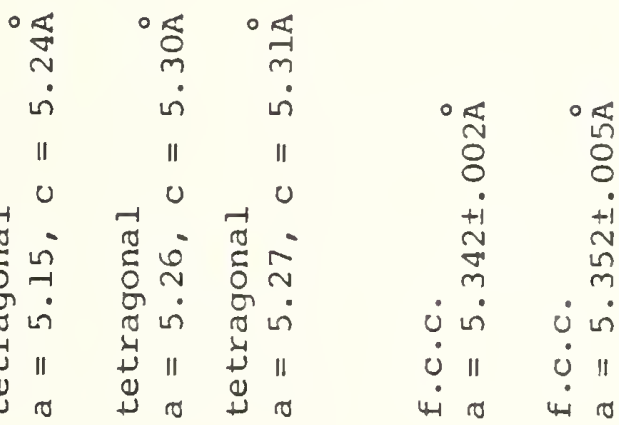
๑

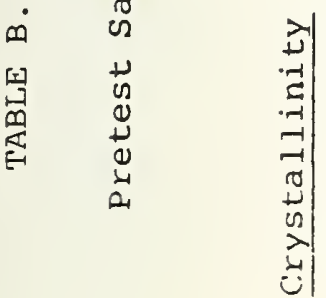

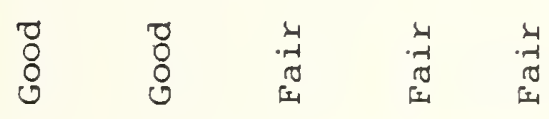
施
$\frac{\pi}{2} \frac{\pi}{2}$

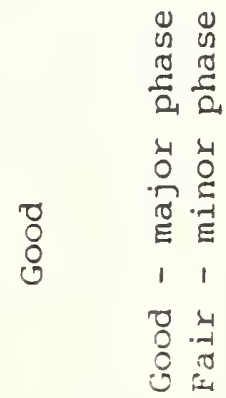

- ָู

$\begin{array}{ccccccc}0 & 0 & 11 & & 11 & & 11 \\ 0 & 0 & & 0 & 0 & 0\end{array}$

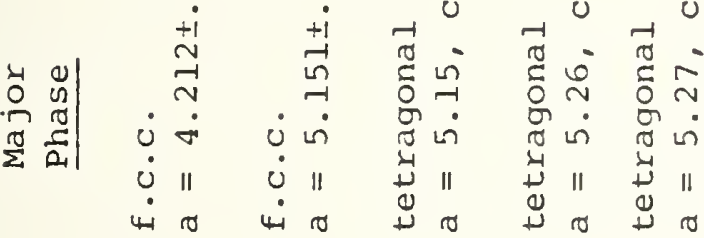

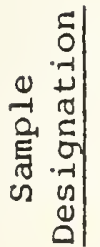

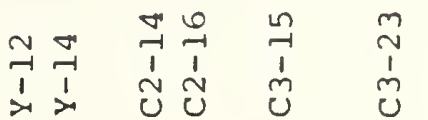

$\begin{array}{llll}\pi & 0 & 0 & N \\ 1 & 1 & 1 & 1 \\ 1 & 0 & 0 & 0\end{array}$

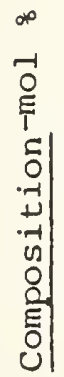

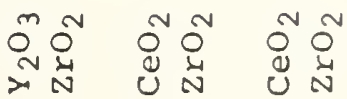

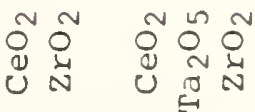

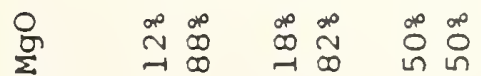

$\stackrel{\infty}{\sim} \stackrel{\infty}{\sim} \stackrel{\infty}{\sim} \stackrel{\infty}{\sim} \stackrel{\infty}{\sim}$ 
Sample

MgO

$128 \quad \mathrm{Y}_{2} \mathrm{O}_{3}$

$\mathrm{Y}-12, \mathrm{Y}-14$

$18 \% \mathrm{CeO}_{2}$

C2-14, C2-16

$50 \% \mathrm{CeO}_{2}$

C3-15

c3-23

$75 \% \mathrm{CeO}_{2}$

$\mathrm{C} 4-17, \mathrm{C} 4-2 \mathrm{O}$

$78 \% \mathrm{CeO}_{2}, \quad 2 \frac{\mathrm{Ta}_{2} \mathrm{O}_{5}}{4}$

C5-10, C5-12

\section{X-ray Results}

Pure, well-crystallized f.c.c. Mgo pattern, $\mathrm{a}=4.212 \pm .002 \AA$

Both samples well-crystallized, single phase f.c.c., a $=5.151 \pm .002 \AA$

Both samples almost all tetragonal zirconia phase with $a=5.15, c=5.24 \AA$. Trace of cubic phase (?) indicated by the presence of one very small peak. Crystallinity only fair relative to $\mathrm{C} 4$ and $\mathrm{C5}$ samples.

Crystallinity only fair for both.

Primarily tetragona ${ }_{0}$ irconia phase with $a=5.26, c=5.30 \AA$ plus a very small amount of a cubic (?) phase with $a=5.15 \AA$.

Major component - tetragonal zirconia phase $\mathrm{a}=5.27, c=5.31 \AA$. Also contains a small amount of a tetragonal phase with $a=5.15$ and $c=5.24 \AA$ plus a very smali amount of what may be a cubic phase with a $=5.34 \AA$.

Both samples well crystallized single phase f.c.c. with $a=5.342 \pm .002 \AA$.

Both samples contain two f.c.c. phases. The major component, is well-crystallized with $a=5.352 \pm .005 \mathrm{~A}$. The minor component is. not as well crystallized with $a=5.37 \pm .01 \AA$. 
The determination of the total porosity was carried out by grinding the specimen finely enough to open all pores and measuring the true density by the pycnometer method. The total porosity was calculated from:

$$
P=\frac{d_{t}-d_{b}}{d_{t}} \times 100
$$

where $d_{t}$ is the true density, $d_{b}$ the bulk density, and $P$ the percentage of total pores in relation to the bulk volume. The bulk volume was taken from measurements of a solid rectangular specimen. The open porosity was measured by three weighings substituted into the following equation:

$$
P=\frac{W-D}{W-A} \times 100
$$

where $\mathrm{P}$ is the percent of open pore volume in relation to the bulk volume, $W$ is the weight of a water saturated sample in air, D is the weight of a dry sample in air, and $\mathrm{A}$ is the weight of a water saturated sample submerged in water. Saturation with water was accomplished under vacuum. The closed porosity is then calculated as the difference between total and open porosity. The pore size distribution was accomplished by using a commercial (Micromeritics Model 非03-1) mercury penetration porosimeter. Sample volumes of approximately $20 \mathrm{~cm}^{3}$ subjected to mercury penetration at various pressures. The volume of mercury penetrating at varying pressures gave the (open) pore size distribution. The porosities and pore size distributions for all materials are shown in Table B.7.1. 
TABLE $\quad$ B. 7.1

POROSITIES AND PORE SIZE DISTRIBUTION OF INSULATORS AND ELECTRODES

Total

Porosity (\%)

16.9

17.7

15.8

19.9

17.6

14.6

\section{Closed}

Porosity (\%)

$<0.5<0.5$

2.1

5.5

3.3

1.1

Pore Size

Distribution:

\%less than: $20 \mu \mathrm{m}$

$100 \quad 100$

100

100

98

99

$15 \mu \mathrm{m}$

99100

98

98

95

98

$10 \mu \mathrm{m}$

$98 \quad 100$

56

60

24

$5 \mu \mathrm{m}$

95

95

39

41

1

$3 \mu \mathrm{m}$

89

84

io

20

$<1$

$2 \mu \mathrm{m}$

44

48

5

5

$1 \mu \mathrm{m}$

11

11

$<1$

2

$0.5 \mu \mathrm{m}$

3

2

$<1$

$0.2 \mu \mathrm{m}$

1

$<1$ 


\section{List of Figures}

Figure B.1.1. Cutting procedures for precharacterization, U-02 electrodes and insulators.

Figure B.1.2. Thermal diffusivity $(\alpha)$ of Mg0 insulator showing thermal conductivity $(\lambda)$ equation calculated from heat capacity and density data.

Figure B.1.3. Thermal resistivity $(1 / \alpha)$ of Mg0 insulator.

Figure B.1.4. Thermal diffusivity of $0.12 \mathrm{Y}_{2} \mathrm{O}_{3} \cdot 0.88 \mathrm{ZrO}_{2}(\mathrm{Y}-13)$.

Figure B.1.5. Thermal diffusivity of $0.18 \mathrm{CeO}_{2} \cdot 0.82 \mathrm{ZrO}_{2}(\mathrm{C} 2-15)$.

Figure B.1.6. Thermal diffusivity of $0.5 \mathrm{CeO}_{2} \cdot 0.5 \mathrm{ZrO}_{2}(\mathrm{C} 3-22)$.

Figure B.1.7. Thermal diffusivity of $0.75 \mathrm{CeO}_{2} \cdot 0.25 \mathrm{ZrO}_{2}$ (C4-19).

-gure B.1.8. Thermal diffusivity of $0.78 \mathrm{CeO}_{2} \cdot 0.20 \mathrm{ZrO}_{2} \cdot 0.02 \mathrm{Ta}_{2} \mathrm{O}_{5}(\mathrm{C} 5-9)$.

Eigure B.1.9. Summary of thermal diffusivities for U-02 MHD electrode materials.

Figure B.2.1. Thermal expansion of $\mathrm{MgO}(\mathrm{M}-1)$.

Eigure B.2.2. Thermal expansion of $0.12 \mathrm{Y}_{2} \mathrm{O}_{3} \cdot 0.88 \mathrm{ZrO}_{2}(\mathrm{Y}-11)$.

Figure B.2.3. Thermal expansion of $0.18 \quad \mathrm{CeO}_{2} \cdot 0.82 \quad \mathrm{ZrO}_{2}(\mathrm{C}-2-13)$.

Figure B.2.4. Thermal expansion of $0.5 \mathrm{CeO}_{2} \cdot 0.5 \mathrm{ZrO}_{2}(\mathrm{C}-3-14)$.

Figure B.2.5. Thermal expansion of $0.75 \mathrm{CeO}_{2} \cdot 0.25 \mathrm{ZrO}_{2}(\mathrm{C}-4-16)$.

$\mathrm{Fi}$, re B.2.6. Thermal expansion of $0.78 \mathrm{CeO}_{2} \cdot 0.20 \mathrm{ZrO}_{2} \cdot 0.02 \mathrm{Ta}_{2} \mathrm{O}_{5}(\mathrm{C}-5-11)$.

Figure B.4.1. Representative microstructure of Mg0 insulator, B-1 with hot pressing direction normal to the MgO surface.

Figure B.4.2. Representative microstructures of Mg0 insulator $\mathrm{T}-1$ with hot pressing direction normal to the MgO surface (As-Polished).

Figure B.4.3. Representative microstructures of $\mathrm{MgO}$ insulator $\mathrm{C}-1$ with hot pressing direction parallel to MgO surface (As-Polished).

Figure B.4.4. Representative microstructure of $12 \mathrm{~mole} \% \mathrm{Y}_{2} \mathrm{O}_{3}-88 \mathrm{~mole}^{2} \mathrm{ZrO}_{2}$ (Y-13) MHD electrode (As-Polished).

Figure B.4.5. Representative microstructures of $18 \mathrm{~mole}_{\mathrm{C}} \mathrm{CeO}_{2}-82 \mathrm{~mole}_{\mathrm{K}} \mathrm{ZrO}_{2}$ (C2-15) MHD electrode (As-Polished).

Figure B.4.6. Representative microstructure of $50 \mathrm{~mole}_{\mathrm{C}} \mathrm{CeO}_{2}-50 \mathrm{~mole}_{2} \mathrm{ZrO}_{2}$ (C-3-22) MHD electrode (As-Polished). 
Figure B.4.7. Representative microstructure of $75 \mathrm{~mole}^{2} \mathrm{CeO}_{2}-25 \mathrm{~mole}_{2} \mathrm{ZrO}_{2}$ (C4-19) MHD electrode (As-Polished).

Figure B.4.8. Representative microstructure of $78 \mathrm{~mole}^{2} \mathrm{CeO}_{2}-20 \mathrm{~mole}_{2} \mathrm{ZrO}_{2}-2$ mole\% $\mathrm{Ta}_{2} \mathrm{O}_{5}$ (C5-9) MHD electrode (As-Polished).

Figure B.5.1. Electrical conductivity of test materials in air.

Figure B.5.2. Electrical conductivity of test materials at $10^{-3}$ atm oxygen in nitrogen.

Figure B.5.3. Electrical conductivity of test materials at $6 \times 10^{-6}$ atm oxygen in nitrogen.

Figure B.5.4. Electrical conductivity of Mg0 ceramic. 


\section{Post-Test Materials Characterization And Analysis (U.S.)}

C.1 Module Disassembly and Materials Distribution (W. R. Hosler and T. Negas, NBS)

After completion of the test in Moscow on October 1, 1975, at 6:20 a.m., the electrode section was removed from the U-02 channel. Extensive photographs were taken at this time of the electrode section before disassembly and after the electrode sections were removed from the insulating walls.

A physical description of each electrode and insulator surface area was made by Dr. L. Bates, Battelle N.W. Labs., just after the test.

Anode

2101 - off-white color with localized areas of erosion, no cracking on upstream side. Mg0 shrunken away from electrode side near 2102 .

$\underline{2102}$ - similar to 2101.

2103 - similar to 2101 and 2102.

2104 - similar to 2101 except some cracking or spalling on bottom and top of electrode.

2205 - some erosion on upstream side, no cracking with electrode sections sintered together. Very light tan, color.

Mg0 appears to have eroded on upstream side between 2205 and 2206.

$\underline{2206}$ - same as 2205.

2207 - same as 2205 with Mg0 eroded between 2106 and 2107. Some possible reaction with $\mathrm{Mg} 0$.

2208 - same as 2205 with some possible reaction with Mg0. Some bloating of bottom of 2208 .

2309 - some bloating and spalling with surface appearing friable. Reaction with MgO limited. Light tan in color. Possible reaction with insulating strip $\left(\mathrm{Al}_{2} \mathrm{O}_{3}\right)$. MgO appears intact but cracked. 
2310 - same as 2309.

2311 - same as 2309.

2312 - same as 2309.

2413 - Light tan with some brown color. Top electrode in best condition of the series (2413-2416). Bottom extensively cracked and spalled. Large section missing. Some possible reaction'with areas between insulating walls and electrode Mg0 fractured and lost on downstream side.

2414 - Same color as 2413 but with light green tint. Best of this composition on anode. Cracked in a criss-cross pattern. Some evidence of spalling.

2415 - Light tan yellow cast and green tint. Eroded un upitreain side. Extensively bloated and presence of a hole under suices on upstream side.

2416 - some erosion. Light tan with some yellow and green. Evidence of reaction at interface of electrode and Mg0. Some cracking.

2517 - Light green in color, but darker than 2518 and 2510. Bloating significantly less than cathode wall. Surface more dense. Electrode section did not appear to sinter together. MgO eroded between 2517 and 2518 and is light tan in color. Slight fracture.

2518 - Green in color and darker than 2519 and 2520 - similar to 2517. Some spalling of the surface.

2519 - Light green, but lighter than 2517 and 2518. Some erosion on upstream side. Some cracking as in 2517.

2520 - Same as 2519 and cracked. Some spalling. 


\section{Cathode}

1101 - Off white color. Bloating worst in center with erosion upstream. Erosion lines parallel to plasma flow. Bloated area in bottom electrode section has upstream hole approximately $1 \mathrm{~cm}$ long and $0.3 \mathrm{~cm}$ wide. Some possible reaction with $\mathrm{Mg} 0$.

1102 - Loss near center with extensive bloating. Light tan surface, but off-white in area lost. Some erosion on upstream side. iNo sintering between electrodes.

1103 - Similak to 1102. Platinum showing on sides. Possible seed penetration in MgO between 1102 and 1103. MgO spalled between 1102 and 1103.

1104 - Light tan in color. No cracking, some evidence of bloating. Best in series. Some erosion on upstream side. Some possible reaction with $\mathrm{Al}_{2} \mathrm{O}_{3}$ spacers. This electrode has pyrometer sight port. Seed clogging is visible.

1205 - Very light tan. Extensively swelled and bloated. Very little evidence of corrosion. Electrode sections sintered together. Some possible reaction with $\mathrm{MgO}$ insulator and insulation wall. $\mathrm{Al}_{2} \mathrm{O}_{3}$ spacer between $\mathrm{Kg} 0$ insulator appears to extrude from crack. MgO light tan to brown and recessed on the edges.

1206 - similar to 1205 .

1207 - similar to 1205 .

$\underline{1208}$ - similar to 1205 .

1309 - light yellow tint in electrode center, but brown near Mg0 insulator walls. Electrode sections joined together. Extensively swelled and spalled. Some possible reaction with $\mathrm{MgO}$.

1310 - similar to 1309 .

1311 - similar to 1309 .

1312 - similar to 1309 , but cracked vertically.

1413 - Light tan in color. Electrode section bonded together. Entire surface appears to have been removed - clean in appearance, crystalline and rough. 
1414 - same as 1413 .

1415 - same as 1413 .

1416 - similar to 1413 except spalled extensively on bottom, top bloated, porous in appearance. Mg0 spalled upstream of 1416. Reaction with Mg0 possible.

1517 - yellow with green tint. Bloated and swelled. Porous. Mg0 light grey. Electrode sections joined together. Some portions of electrode removed and cracked.

1518 - same as 1517. Top and bottom spalled. Possible reaction with $\mathrm{MgC}$.

1519 - yellow to light brown. Bottom spalled Swelling extensive.

General Comments on Both Modules

The MgO insulator blocks were cracked down the center, paraliel to the module length on both electrode walls.

The $\mathrm{Al}_{2} \mathrm{O}_{3}$ spacers in most areas either swelled or reac: with seed. This effect was more pronounced on the ca-incie.

The MgO insulator walls eroded more deeply on the Ieft silif of the channel (cathode side louking downstream).

The cathode was more severely swelled and spalled than the anode.

Within four hours after the section was dismantled, the electrode walls were placed in especially designed metal containers along with an appropriate amount of dessicant. These containers were then sealed in plastic bags after alternate flushing with inert dry gas and pumping. They were placed in the original shipment boxes for return to the U.S.

The shipment container was opened at NBS on October 29, 1975.

Dr. U. Sokolov from U.S.S.R. was present and assisted in all stages of the module disassembly. After the electrode modules were removed from the metal containers, extensive photographs were made again to determine any damage that might have occurred during shipment. Figures C.1.1 and C.1.2 show the anode and cathode after shipment. No damage was detected.

In order to best analyze the results of the test, one half of each electrode was removed from each module (Figure C.1.3). These samples were used for phase and chemical composition, electron microprobe analysis and electrical conductivity measurements, where the material removed was of sufficient size to obtain usable samples. Looking downstream, the upper half of the anode electrodes (anode on right) were removed and the lower half of the cathode electrodes (cathode on right) were removed. These samples were carefully labeled and divided. One part from each sample was supplied to the U.S.S.R. (through Dr. Sokolov) for post-test analysis. The remaining part was retained at NBS for phase 


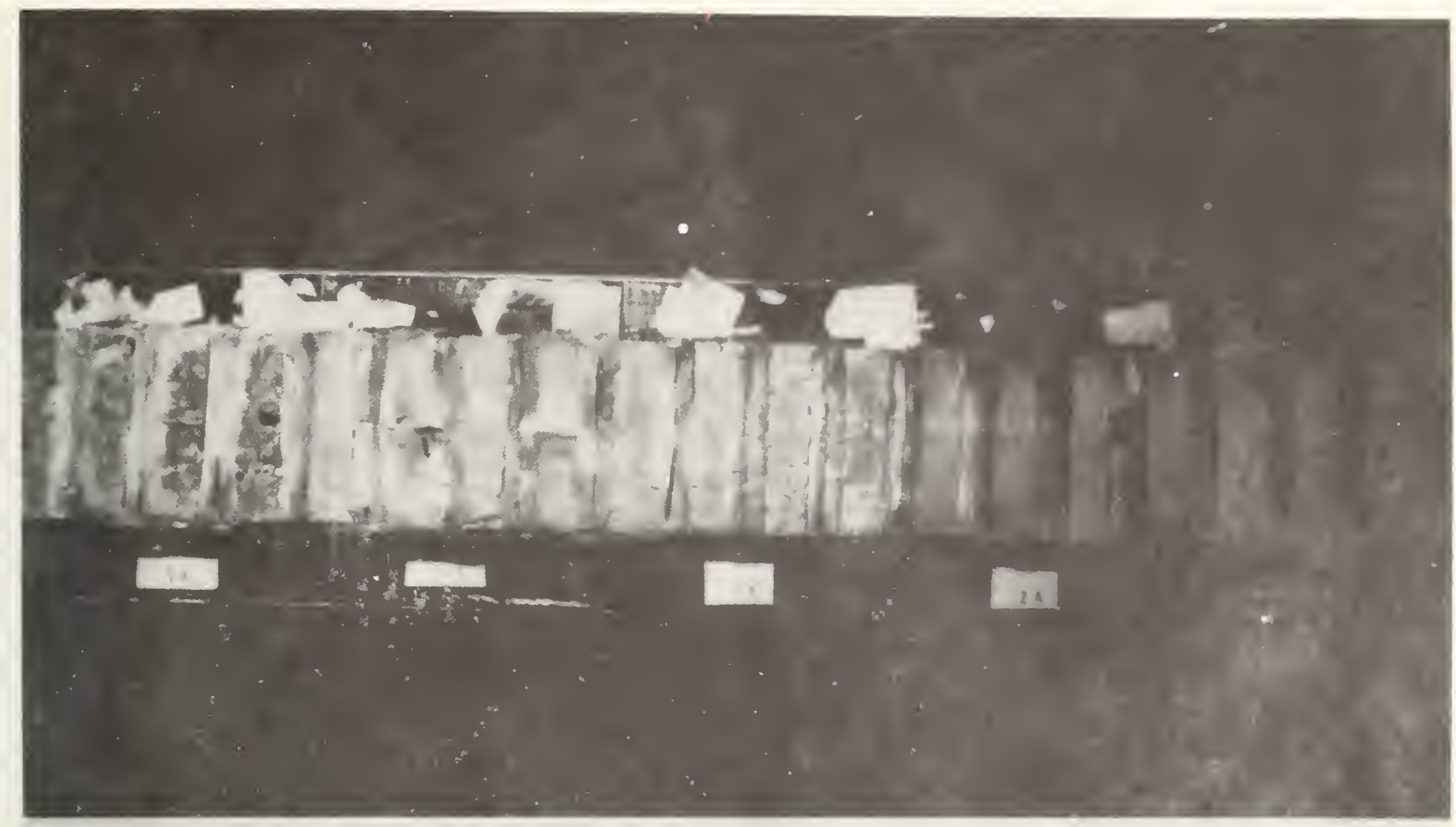

"iqur. .1.1 Anode

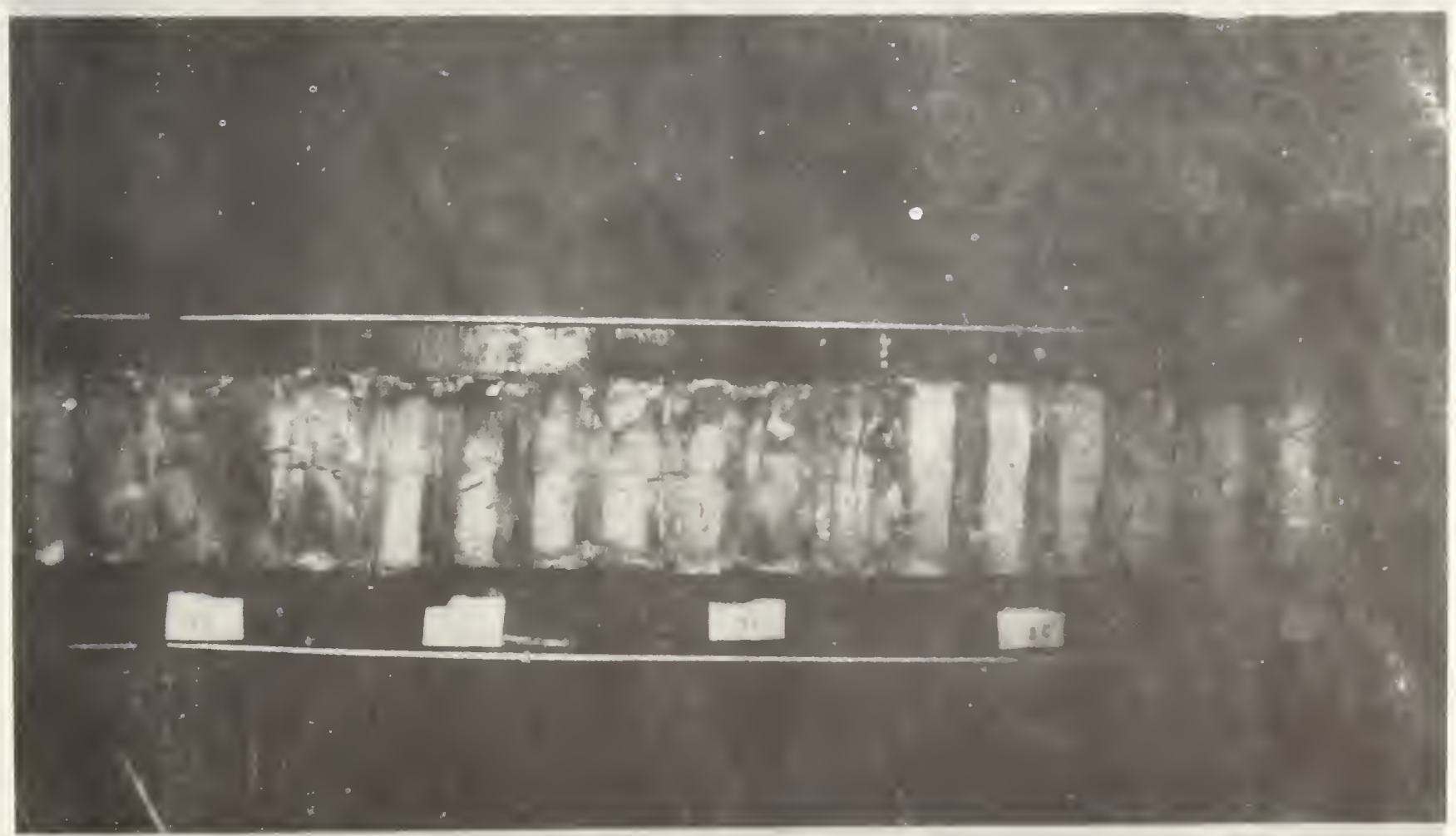




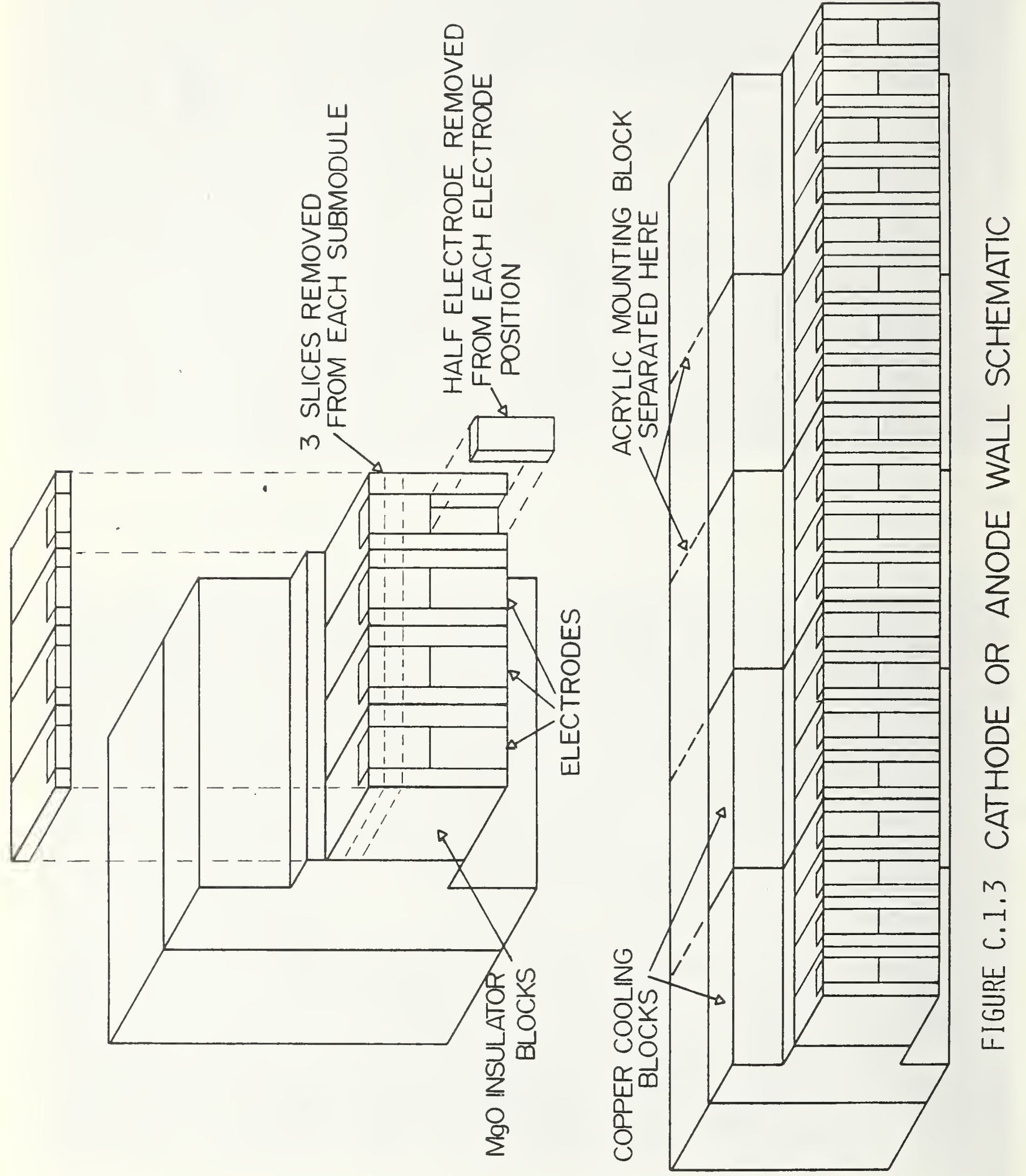


and chemical composition work. Only samples 2102, 2205, 2206, 2207, 2208 were large enough to permit electrical conductivity measurements (see Section C. 3, this chapter).

In order to assess the effects of the temperature gradient, current concentration, and seed penetration into the electrodes and into insulator blocks, it is necessary to look at a cross section of the electrode wall perpendicular to the electrode surface. In order to obtain slices of the anode and cathode modules, the entire module was potted in epoxy resin. This was done in a specially designed vacuum chamber where the resin could penetrate the electrode and insulator blocks, but the samples removed would retain their original shape and relative positions. After potting, each electrode wall was separated into sub-module sections by sawing through the acrylic holding block just below each water-cooling block sub-module division. This, then, left a total of ten sub-modules, 5 anode and 5 cathode. Each anode sub-module and each cathode sub-module held a set of 4 materials of one kind.

Each sub-module was sliced (using a diamond saw and ethylene glycol as coolant) perpendicular to the electrode surface and lengthwise, parallel to the plasma flow (Figure C.1.3). Three slices, each approximately $5 \mathrm{~mm}$ thick, were removed from each sub-module and carefully labeled. Figure C.1.4 (anode) and Figure C.1.5 (cathode) show the five outside slices from each sub-module. The inside slices from each sub-module was delivered to U.S.S.R. through Dr. Sokolov for post-test analysis in the U.S.S.R. The center slices from each sub-module were delivered to $\mathrm{Dr}$. L. Bates for electron microprobe analysis at Battelle NW. The outside slices were retained by NBS and used for correlation purposes associated with the phase and chemical composition determinations.

Extensive color and black and white photographs were taken at every stage of disassembly. These $35 \mathrm{~mm}$ slides are cataloged, but reproduction of the whole disassembly process would be impractical.

\section{Figure C.1.6 shows a schematic diagram of the cathode and anode}

materials and the identification digits. See Chapter II, Section A, Figure A.4.1, for instrumentation and load factors for the various electrode pairs. In Figure C.1.6, the cross-hatched electrode is the side of electrode pair that went open circuit during the test. Table C.1.1 gives the approximate time after the beginning of the life test ( $3 r d$ phase) when the electrode pair failed. During the 2nd phase, different currents and voltages were applied to the electrode pairs to establish the working conditions of the module for use in the life test, so that the times recorded in Table C.1.1 are not the total times of operation. Additional information on the electrode lead failure is given in Chapter II, C.5.

\section{C.2 Phase Composition and Chemical Reactions (T. Negas, C. L. McDaniel, A. Perloff)}

To obtain a fundamental understanding of the chemical behavior of $\mathrm{ZrO}_{2} / \mathrm{CeO}_{2}$ materials, subsolidus phase relations in the system $\mathrm{ZrO}_{2}-\mathrm{CeO}_{2}-\mathrm{x}$ were determined up to $1600^{\circ} \mathrm{C}$ in air. Additionally, the vaporization of cerium oxides from several compositions in the system was measured up to $1900^{\circ} \mathrm{C}$. This work, together with a preand post-test phase analysis of Battelle proof-test materials and the voluminous literature on $\mathrm{ZrO} \mathrm{O}_{2}$-cerium oxide reactions and properties constitutes a data base for the untested, "virgin" materials. These data were summarized previously by NBS in 

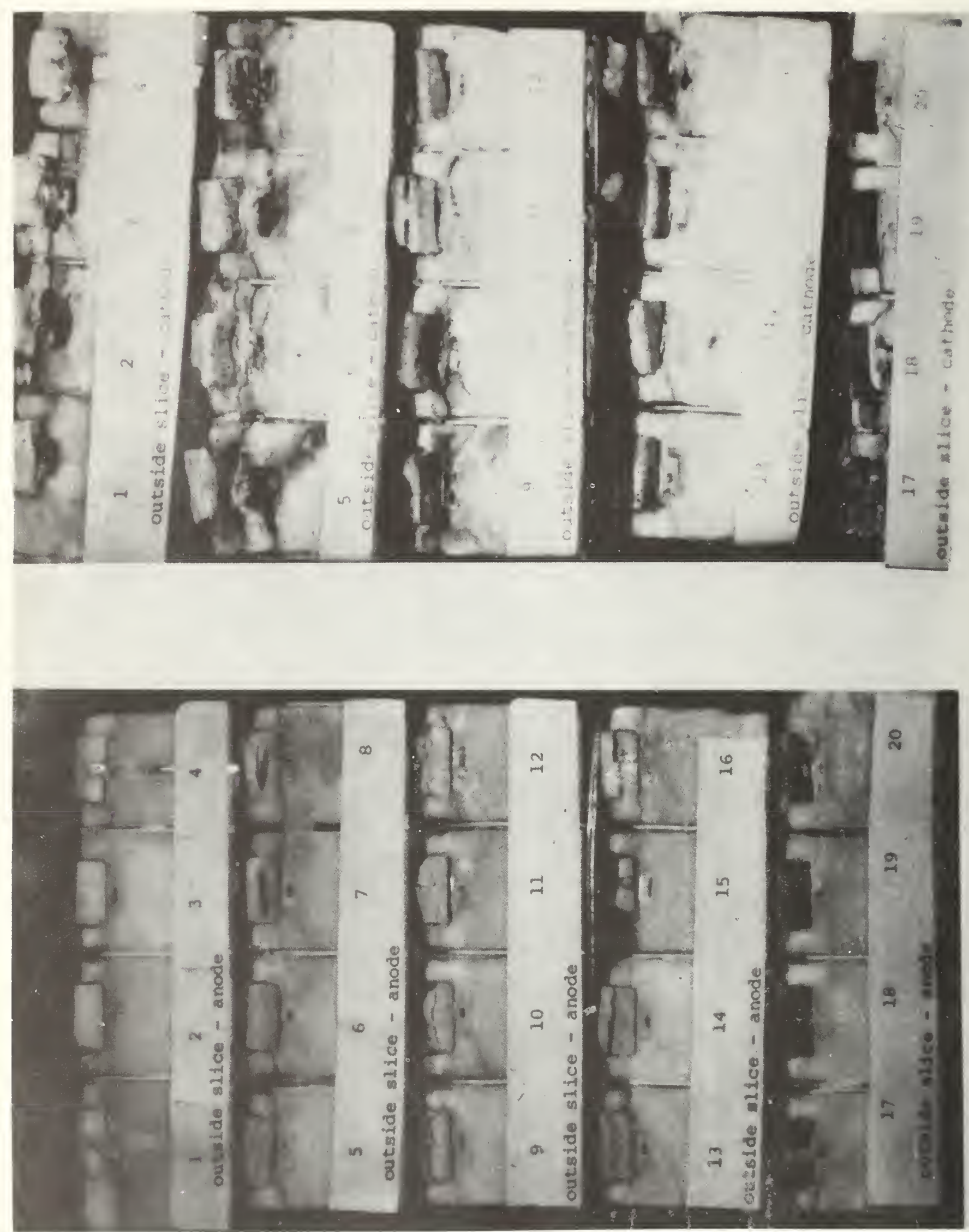


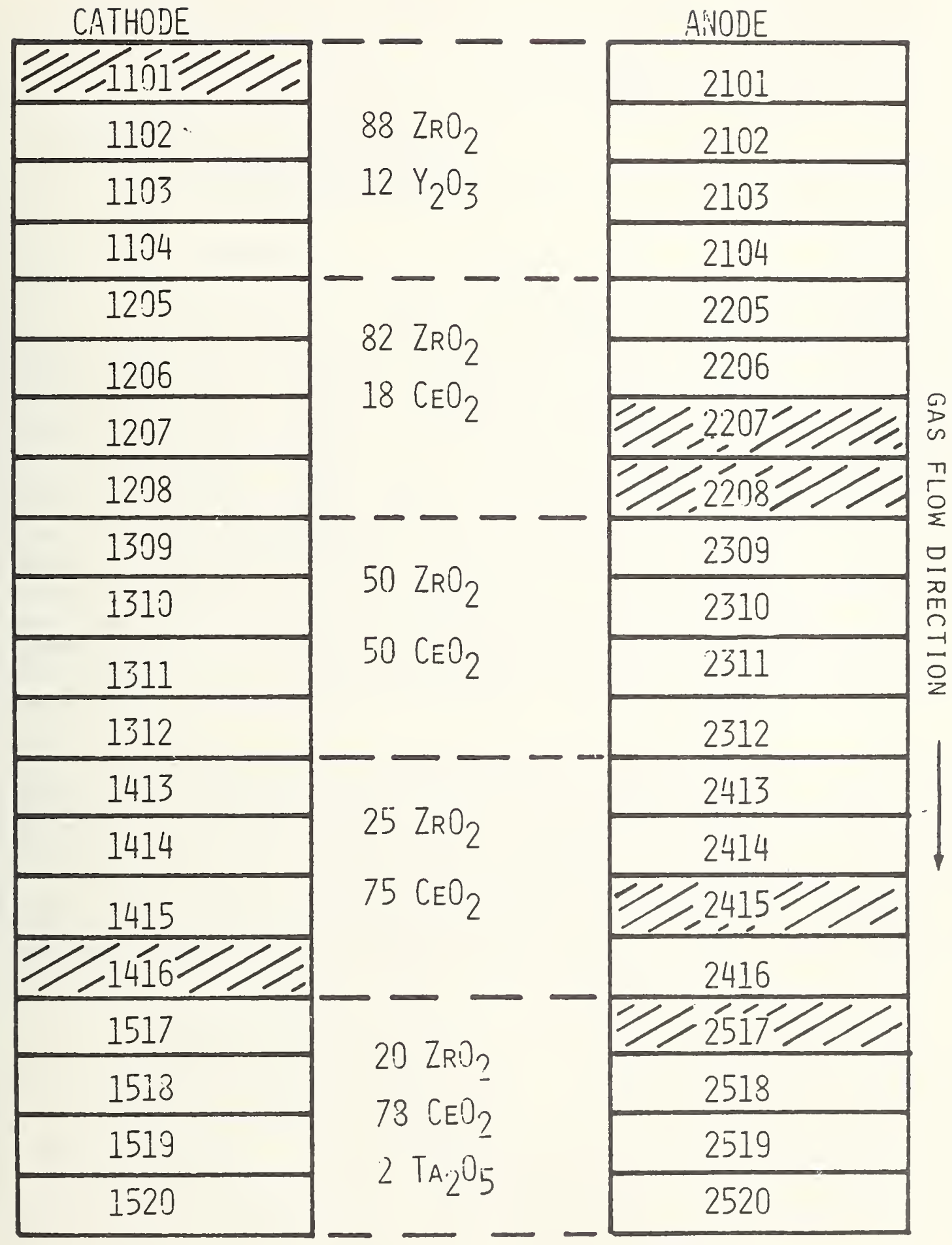

OPEN SCHEMATIC OF CATHODE AND ANODE SHOWING MATERIALS, IDENTIFICATION DIGITS AND ELECTRODE LEAD-OUT FAILURE. SHADED AREAS INDICATE WHICH LEAD FAILED (ANODE OR CATHODE). 
TABLE C.1.1

Electrode Pair

$1207-2207$

$1208-2208$

$1101-2101$

$1415-2415$

$1416-2416$

$1517-2517$
Approximate Time To Lead-Out Failure From Start of Life Test ( $3 r d$ phase)

7 min.

7 min.

1 hour $20 \mathrm{~min}$.

1 hour 45 min.

2 hours 20 min.

92 hours $40 \mathrm{~min}$. 
Quarterly Reports to ERDA. By comparing post-test characterization data with the pre-test data base, it is possible to decipher and understand the chemical and/or phase changes which occurred within the electrode during testing. For cathode materials, it was deemed necessary to reproduce certain chemical reactions in the laboratory and to correlate these data with the $x$-ray diffraction results from tested materials.

\section{C.2.1 Cathode Materials (T. Negas and C. McDaniel)}

\section{C.2.1.1 Introduction and Methods}

When the U-02, Phase I, Westinghouse module was received, dismantled, and dissected (Chapter II, C.I) at NBS, a visual observation of the electrodes immediately suggested significant alteration of the $\mathrm{Ce}_{2}$-containing $\mathrm{ZrO}_{2}$ materials at the cathode wall. These materials were severely bloated, fragmented, and banded, generally into three zones distinguished by white (top 1-3 $\mathrm{mm}$ in thickness), yellow (1-3 mm below surface), and yellow to olive-green (bottom), colorations. These zones are not of constant thickness within an individual electrode, nor similar in thickness in electrodes of identical starting composition, but with varying current density. Generally, the discolored bands increase in thickness toward the outer MgO spacers, provided by the Soviet side, to fill gaps in the module. That the zones of discoloration are indicative of phase changes of original materials and of reaction with potassium seed was considered obvious. Several x-ray diffraction powder patterns of selected specimens confirmed these initial assumptions and more extensive work followed.

The bloating or swelling of cathode materials probably occurred during and after cool-down. Almost the entire cathode wall is saturated with seed, mostly as condensed $\mathrm{K}_{2} \mathrm{CO}_{3}$. This includes the underlying MgO blocks which were cracked extensively. When exposed to moisture, $\mathrm{K}_{2} \mathrm{CO}_{3}$ (as is well known) expands (and ultimately dissolves) by hydrating. This expansion, abetted by the mismatch in the cohesion among zones (see above) of dissimilar phases and alteration products, and hence, dissimilar mechanical properties, most likely caused the swelling. Indeed, it is unlikely that the electrodes experienced bloating during operation as distended material would have been swept by the gas stream.

Numerous specimens were hand-picked carefully from within each zone of discoloration of every electrode. The $88 \mathrm{ZrO}_{2}: 12 \mathrm{Y}_{2} \mathrm{O}_{3}$ electrodes are not zoned, but samples representative of the top, middle, and bottom portions were taken. All specimens were investigated by x-ray diffraction powder analysis using filtered Cu-radiation. X-ray diffractograms were made within the $90^{\circ}-5^{\circ} 2 \theta$ range $\left(1 / 4^{\circ} 2 \theta\right.$ per minute). The magnetic susceptibility of selected specimens was measured at room temperature. In contrast to most anode materials, the fragmented cathode materials could not be removed intact so that x-ray diffraction analysis directly of every surface was rendered impossible.

\section{C.2.1.2 Results, Phase Analysis and Discussion}

\section{C.2.1.2.1 $\mathrm{CeO}_{2}$-Containing Materials}

$X$-ray diffraction analysis results from cathode materials are summarized in Table C.2.1. The outstanding characteristics of all $\mathrm{CeO}_{2}-$ containing materials are; a) alteration through phase transitions, and/or 
b) reaction with potassium seed. The identification of post-test phases in electrodes is relatively simple, provided care is taken in accounting for not only every strong diffraction line, but' every weak maximum in diffractograms. This point is crucial, particularly for materials taken from the yellowish interior zones of most $\mathrm{ZrO}_{2} / \mathrm{CeO}_{2}$ electrodes. For example, the phase termed $\left(C_{1}\right)$ in Table C.2.1 is not a true cubic solid-solution based on the fluorite structure, but rather a cubic material based on a similar structure-type. This identification can be made only on the presence of certain weak diffraction maxima.

It is a particularly difficult task to reconstruct a selfconsistent scenario which encompasses electrochemical/environmental factors during testing, and, therefore, which accounts for the observed post-test facts in the form of a series of established phases and phase assemblages. Additionally, the effects of the cool-down process during which reoxidation of materials and, possibly, back-diffusion of seed can occur must be factored into the scenario. Clearly then, attempts to reconstruct such a scenario is similar to piecing together a complex jigsaw puzzle which lacks important parts. A detailed account of phase transitions and chemical reactions in $2 \mathrm{rO}_{2} / \mathrm{CeO}_{2}$ materials is beyond the scope of this report. These data will be detailed by T. Negas (NBS) elsewhere. Several typical examples, displaying the alteration of $\mathrm{CeO}_{2} / \mathrm{ZrO}_{2}$ cathode materials, however, are illustrated below.

Figure C.2.1a is a portion of the $\mathrm{x}$-ray diffraction powder pattern of the untested 82 ( $\mathrm{mol} \% \mathrm{ZrO}_{2}-18 \mathrm{CeO}_{2}$ composition. It consists of single-phase, tetragonal zirconia solid solution ( $T$ ). Figures C.2.1b, c, d, are equivalent $x$-ray tracings for this material (electrode 1205, open circuit) after the U-02 test. Figure C.2.1b is the pattern for the upper (white), "hot" zone of the electrode. Notice the crystallographic changes within this zone (compare with Figure C.2.1a). These changes are unrelated to reactions with potassium, but are typical for materials subjected to elevated temperatures followed by reoxidation on cooling. Single-phase, stabilized tetragonal zirconia at the 82-18 composition when heated above $1700-1750^{\circ}$ under relatively oxidizing conditions $\left(\mathrm{P}_{2}>10^{-3} \mathrm{~atm}\right)$, decomposes to a $\mathrm{ZrO}_{2}-\mathrm{rich}$ tetragonal solid-solution, plus a cubic fluorite solid solution richer in cerium oxide. If the temperature is high enough, a single-phase cubic fluorite solid solution develops. If reducing conditions, whether provided by a gaseous environment or made effective by electrochemical means, are prevalent, this stabilized tetragonal zirconia solid-solution decomposes, even at relatively low temperatures, to a zirconia-rich solid solution plus a cubic phase richer in reduced cerium oxide but not a true fluorite. Concurrent with these phase transitions is the vaporization of cerium oxide. Loss of cerium oxide, particularly at the "hot" surfaces, drives the bulk composition (82-18) toward compositions richer in $\mathrm{ZrO}_{2}$. When cooled to room temperature, and if not enough time is permitted to completely re-equilibrate the bulk composition to the thermodynamically stable phase(s), a multi-phased, reoxidized assemblage results. $\mathrm{ZrO}_{2}-\mathrm{rich}$ solid solutions formed at the elevated temperatures via decomposition reactions, or through vaporization localized at the surface, no longer are stabilized but transform to monoclinic zirconia when cooled through the tetragonal-monoclinic transition. These phenomena are not peculiar to the 82-18 composition, but are reflected by most $\mathrm{CeO}_{2}$-containing electrodes at the cathode and anode (hot surfaces).

Figure C.2.1c and C.2.1d are pertinent $x$-ray tracings of the yellow, and yellow to olive-green zones, respectively, of the electrode (see 
Figures C.2.1a and C.2.1b). These phases appear to be related to reductiondecomposition reactions and/or reactions with seed in situ, followed by reoxidation on cooling. The symbol $\mathrm{M}$ represents nearly pure, destabilized monoclinic $\mathrm{ZrO}_{2} ;\left(\mathrm{C}_{1}\right)$, a cubic phase similar to, but not a true cubic fluorite; and P, a new ( $K, \mathrm{Ce}, \mathrm{Zr}$ )-oxide. Figure C.2.2 is a portion of the X-ray pattern of this new mixed oxide, prepared in this laboratory, coexisting with $\mathrm{CeO}_{2}$.

Figures C.2.3a, b, c are the pertinent $x$-ray tracings for similar zones (white, yellow, and yellow to olive-green, respectively, for electrode $1208,1.25 \mathrm{~A} / \mathrm{cm}^{2}$. These also should be compared with the untested 82-18 material, Figure C.2.1a. These patterns indicate little difference between electrodes 1205 (open circuit) and $1208\left(1.25 \mathrm{~A} / \mathrm{cm}^{2}\right)$.

Figure C.2.4a represents the $50 \mathrm{ZrO}_{2}-50 \mathrm{CeO}_{2}$ composition prepared under oxidizing conditions below $1500^{\circ} \mathrm{C}$. It is obvious that this composition consists of two phases, a $\mathrm{ZrO}_{2}$-rich, tetragonal solid-solution plus a $\mathrm{CeO}_{2}-$ rich, cubic fluorite solid-solution, as predicted by phase diagrams. When heated above $1550^{\circ} \mathrm{C}$, this two-phase mixture transforms to a single phase, cubic fluorite solid-solution, Figure C.2.4b. U-02 test specimens for this composition (anode and cathode) are in very poor condition, and an x-ray pattern directly of the electrode surface could be obtained only from 2312 (anode). Nevertheless, it is evident from the anode data (see this report) and from the Batteile post-proof test data (anode and cathode, short-term test), that the "hot" portion of the 50-50 electrodes shows direct evidence (materials of smaller cell dimensions) for vaporization of cerium oxide.

Figures C.2.5a and C.2.5b represent the yellow, and yeliow to olive-green (bottom) zones, respectively of electrode $1310\left(50 \mathrm{ZrO}_{2}-50 \mathrm{CeO}_{2}\right)$, $0.8 \mathrm{~A} / \mathrm{cm}$. Notice the significant structural-chemical change when compared with Figures C.2.4a and C.2.4b. Indeed, it is possible to identify the (K, Ce, Zr) oxide (P) phase as well as nearly pure $\mathrm{CeO}_{2}\left(\mathrm{C}_{2}\right)$. The $\left(\mathrm{C}_{1}\right)$-phase, mentioned above, is also obvious. Electrode $1312,50 \mathrm{ZrO}_{2}-50 \mathrm{CeO}_{2}$, open circuit, retains these features but phase $(P)$ is far less evident. In general, open circuit materials, especially within the 14 and 15 series (high $\mathrm{CeO}_{2}$-content) appear to be far less altered by seed.

The purpose of comparing the x-ray diffractograms of several pre- and post-test materials, is to demonstrate unequivocally that chemical/structural alterations have resulted for $\mathrm{CeO}_{2}$-containing electrodes. These alterations can be attributed to the combined effects of electrochemical/ environmentally imposed reduction, reactions with seed, and partial reoxidation during cool-down. Let us now consider the $x$-ray evidence with respect to a pictorial review of the information.

Figures C.2.7 and C.2.8; Figures C.2.9 and C.2.10; Figures C.2.11 and C.2.12; and Figures C.2.13 and C.2.14, compare the gross features of anode and cathode cross-sections, respectively, of the $82 \mathrm{ZrO}_{2}-18 \mathrm{CeO}_{2}, 50 \mathrm{ZrO}_{2}-50 \mathrm{CeO}_{2}$, $25 \mathrm{ZrO}_{2}-75 \mathrm{CeO}_{2}$, and $78 \mathrm{CeO}_{2}-2 \mathrm{OZrO}_{2}-2 \mathrm{Ta}_{2} \mathrm{O}_{5}$ materials, respectively. Reduction/ reaction of cathode materials, manifested by the discoloration and banding or zoning, alluded to above, is clearly evident. Compare, for example, the colorless anodes in Figure C.2.9 with the cathode counterparts, Figure C.2.10. 
(The $\mathrm{Ta}_{2} \mathrm{O}_{5}$-containing material is greenish in color to begin with and, hence, distinctions are more subtle, see below.) Let us now continue and "zero in" on individual electrodes to indicate certain features which cannot be ignored by those seriously attempting to characterize these materials.

Figure C.2.15 shows electrode 1205 (cathode, $82 \mathrm{ZrO}_{2}-18 \mathrm{CeO}_{2}$ ). Here we observe clearly the various zones characterized by $x$-ray diffraction in Table C.2.1. The lowermost, olive-green, band is a reaction zone which consists predominately of monoclinic zirconia plus the $\mathrm{K}, \mathrm{Ce}, \mathrm{Zr}-o x i d e$ (Phase P) compound. The yellowish interior zone consists predominately of monoclinic zirconia plus the cubic pseudo-fluorite $\left(\mathrm{C}_{1}\right)$ phase. This zone, in turn, grades into an upper white zone characterized by monoclinic $\mathrm{ZrO}_{2}$ plus poorly crystalline cubic fluorite and tetragonal solid solution variants. The $(P)$-phase and $\left(C_{1}\right)$-phase are discussed below. Figures C.2.16 and C.2.17, cathode electrodes $\left(82 \mathrm{ZrO}_{2}-18 \mathrm{CeO}_{2}\right) 1206$ and 1207 , respectively, reveal nearly identical zones differing only in thickness, not phase assemblage. Figure C.2.18 is the anode electrode 2207 corresponding with cathode 1207, Figure C.2.17. The bottom of 2207 consists of unaltered, fully oxidized, tetragonal zirconia solid-solution. However, above this zone, notice the greenish "bleb" (also evident in electrode 2208, see Figure C.2.7). This is a reaction zone, characterized by the (P-phase) $\mathrm{K}$, Ce, Zr-oxide plus monoclinic $\mathrm{ZrO}_{2}$, but which now is located, not at the electrode base, but within the interior.

Figures C.2.19, C.2.20, C.2.21, and C.2.22 show cathode electrodes, $1309,1310,1311$, and 1312 , respectively, $50 \mathrm{ZrO}_{2}-50 \mathrm{CeO}_{2}$. This is a particularly interesting series as these electrodes functioned throughout the test period and, therefore, would be expected to best characterize reduction/ reaction phenomena. Again, notice the distinct coloration banding which, in contrast, is absent for anode materials (see, for example, Figure C.2.23, anode $\left.2312,50 \mathrm{ZrO}_{2}-50 \mathrm{CeO}_{2}\right)$. Because the initial bulk composition is richer in $\mathrm{CeO}_{2}$, phase assemblages, of course, are different from the previous $\left(82 \mathrm{ZrO}_{2}-18 \mathrm{CeO}_{2}\right)$ series. In Figures C.2.19 and C.2.20, there are three zones of discoloration clearly evident. The greenish bottom zone is one involving reaction with seed and consists of the $(P)$-phase plus the $\left(C_{1}\right)$-phase together with phase $\left(\mathrm{C}_{2}\right)$, (see Table C.2.1), a cubic fluorite having a cell parameter approaching that of nearly pure $\mathrm{CeO}_{2}$. The yellow zones are nearly pure $\left(\mathrm{C}_{1}\right)$-phase. These grade into the white zones, characterized by cubic fluorite solidsolution variants. The $0.5 \mathrm{~A} / \mathrm{cm}^{2}$ and open circuit materials (Figures C.2.21 and C.2.22) show the yellow $\left(C_{1}\right)$-phase band extending to the electrode base. Extensive reaction with seed is not apparent although $\mathrm{x}$-ray data reveal small amounts of the (P)-phase in both materials (see Table C.2.1).

The $25 \mathrm{ZrO}_{2}-75 \mathrm{CeO}_{2}$ composition cathode series is illustrated in Figures C.2.24 (1413, open circuit), C.2.25 (1414, $\left.0.5 \mathrm{~A} / \mathrm{cm}^{2}\right)$, C.2.26 $\left(1415,0.8 \mathrm{~A} / \mathrm{cm}^{2}\right)$, C. $2.27\left(1416,1.25 \mathrm{~A} / \mathrm{cm}^{2}\right.$, interior cross-section) and C.2.28 (1416, $125 \mathrm{~A} / \mathrm{cm}^{2}$, outside cross-section). Again, because of differences in initial bulk composition and electrochemical characteristics, phase assemblages for this series differ somewhat from those of the previous two 
series. Electrodes 1413 (Figure C.2.24, open circuit) and 1415 (Figure C.2.26, $0.8 \mathrm{~A} / \mathrm{cm}^{2}$, but failed during the test) have similar features. Both appear unaltered (i.e., no reaction with seed or phase transitions), although reduction is evident by the yellowish (fine-grained)-blue (coarse-grained) bottom zones. The extent of reduction during operation is unclear because, on cooling, reduced $\mathrm{Ce} / \mathrm{Zr}$-oxide readily reoxidizes. It appears that the finer-grained yellowish groundmass has reoxidized to a greater extent than the blue coarse grains. Electrode $1414\left(0.5 \mathrm{~A} / \mathrm{cm}^{2}\right)$ which operated throughout the test and electrode $1416\left(1.25 \mathrm{~A} / \mathrm{cm}^{2}\right)$ which $\mathrm{failed}$ during the test reveal additional features. Notice the yellow-green zone in Figure C.2.25 (1414) and the yellow-green outer edges of electrode 1416 in Figure C.2.28. These are reaction zones characterized by the (P)-phase plus a cubic fluorite solid-solution with a cell parameter approaching pure $\mathrm{CeO}_{2}\left(\mathrm{C}_{2}\right.$-phase, Table C.2.1). Yellow to white zones consist of cubic fluorite solid solutions similar to the starting material. Figure C.2.27, an interior cross-section of 1416, shows only diffuse reaction areas, generally limited to the lower-outer edges of the electrode. The biue-zone is reduced cubic fluorite solid solution.

Figures C.2.29, C.2.30, C.2.31, C.2.32, C.2.33, and C.2.34 are cathode and anode materials for the $78 \mathrm{CeO}_{2}-2 \mathrm{OZrO}_{2}-2 \mathrm{Ta}_{2} \mathrm{O}_{5}$ composition. Electrodes $1517,1.25 \mathrm{~A} / \mathrm{cm}^{2}$, (Figure C.2.29) and $1518,0.8 \mathrm{~A} / \mathrm{cm}^{2}$ (Eigure C.2.30) show nearly identical features. The olive-green bottom zones are reaction areas and consist of the (P)-phase plus cubic fluorite solid solutions with variable cell parameters (but predominately a fluorite phase having a cell parameter approaching that of nearly pure $\mathrm{CeO}_{2}$ ). Upper yellow-blue portions consist of a mixture of several cubic fluorite solid solutions similar to the original starting material. In contrast, electrodes $1519,0.5 \mathrm{~A} / \mathrm{cm}^{2}$, (Figure C.2.31) and 1520, open circuit, (Figure C.2.32) are not altered by seed, but were subjected to some reduction. Compare, for example, electrode 1519 (Figure C.2.31) with its anode counterpart, 2519 , Figure C.2.33. The green coloration at the anode is more typical of the original starting material. Anode electrode 2520, open circuit, Figure C.2.34, also provides an interesting contrast with its cathode equivalent, 1520, Figure C.2.32. Notice the finer-grained, olive-green zone (lower right, Figure C.2.34). Again, this is a reaction zone characterized by the (P)-phase plus nearly pure $\mathrm{CeO}_{2}$. Notice also the thin, white, uppermost zone in Figures C.2.31, C.2.32, C.2.33, and C.2.34. This zone reflects loss of coloration due to loss of $\mathrm{Ta}_{2} \mathrm{O}_{5}$, presumably via vaporization.

\section{Figures C.2.35, C.2.36, and C.2.37 provide additional} views of electrodes 1205 and 1208. Figure C.2.35 is a longitudinal fracture surface of 1205, while C.2.36 is the cross-section of an interior fracture surface. Both clearly show the distinct banding previously discussed.

Figure C.2.35 also clearly shows a white, vitreous-like (recrystallized?) uppermost zone which is typical of most materials, including the $\mathrm{ZrO}_{2} / \mathrm{Y}_{2} \mathrm{O}_{3}$ materials. Figure C.2.37 is a cross-section, fracture surface, of electrode 1208. Again, the zoning is obvious, but the lowermost (reaction) zone is somewhat thicker than in electrode 1205. 
Several lines of evidence have: a) aided in the identification of phase and phase assemblages in tested electrodes, and b) permitted the observation that considerable reduction of materials, particularly, $82 \mathrm{ZrO}_{2}-18 \mathrm{CeO}_{2}$ and $50 \mathrm{ZrO}_{2}-50 \mathrm{CeO}_{2}$, must have taken place during operation followed by reoxidation on cooling. The P-phase, associated with reactions with seed, is a cubic perovskite. Single crystals of the material identical to that found in electrodes were grown in the laboratory. EDX analysis revealed a composition near $\mathrm{KCeZr}_{2} \mathrm{O}_{6}$. The phase termed $\left(C_{1}\right)$, a cubic pseudo-fluorite with pseudo a $=5.26 \AA$ is clearly a pyrochlore-type compound with true $a=10.52 \AA$. Within the yellow zones of the $50 \mathrm{ZrO}_{2} / 50 \mathrm{CeO}_{2}$ electrodes, it is found in nearly single phase form. This is not unusual as the pure pyrochlore $\mathrm{Ce}_{2}{ }^{3+} \mathrm{Zr}_{2} \mathrm{O}_{7}$ has the correct $\mathrm{Ce} / \mathrm{Zr}$ ratio existing in the electrode material. However, pure $\mathrm{Ce}_{2}{ }^{3+} \mathrm{Zr}_{2} \mathrm{O}_{7}$ has a cell parameter, $\underline{a}=10.74 \AA$, which is considerably larger than the material found in the electrodes. With increased amounts of the smaller Ce ${ }^{4+}$ cation in a pyrochlore formulation such as $\mathrm{Ce}_{2}^{3}+\mathrm{Ce}_{\mathrm{x}}^{4}+\mathrm{Zr}_{2} \mathrm{O}_{7+1 / 2 \mathrm{x}}$, the cel1 parameter should decrease (provided that transformation to a cubic fluorite does not occur). Thus, to arrive at a small cell parameter of $a$ reduced pyrochlore must be at least partially oxidized. The experimental proof is straightforward. First, pure $\mathrm{Ce}_{2} \mathrm{Zr}_{2} \mathrm{O}_{7}$ was prepared at $1475^{\circ} \mathrm{C}$, under vacuum, in a thermogravimetric apparatus. The grey-green material has $\mathrm{a}=10.74 \mathrm{~A}$. This material was next reoxidized in air, but not permitted to transform to the equilibrium phase assemblage in air. The result is a yellow product, nearly fully oxidized, but yet a pyrochlore with a $=10.52 \mathrm{~A}$, identical with electrode alteration products. Additional experiments have revealed how $\mathrm{ZrO}_{2} / \mathrm{CeO}_{2}$ materials react with alkali seed to yield the phase assemblages (including monoclinic $\mathrm{ZrO}_{2}$ ) observed in tested electrodes.

It is difficult to attribute reduction of materials at the cathode totally to the MHD $\mathrm{P}_{\mathrm{O}}$ environment, particularly within the lower temperature regimes at the base of lower portions of the electrodes. Electrochemically aided reduction at the cathode base must remain a strong possibility. Such a process would yield relatively unaltered, oxidized, phase and phase assemblages at the base of anodes. Indeed, this is exactly what is observed. Seed penetration may also contribute to electrochemical processes.

\section{C.2.1.2.2 $\mathrm{Y}_{2} \mathrm{O}_{3}$-Stabilized $\mathrm{ZrO}_{2}$ (cathode) and $\mathrm{MgO}$ Insulators}

The $88 \mathrm{ZrO}_{2}-12 \mathrm{Y}_{2} \mathrm{O}_{3}$ cathode materials exhibited less obvious alteration. The upper ( $<1 \mathrm{~mm}$ surface) of these electrodes (cathode) apparently recrystallized, forming a surface with a glassy-like appearance. This zone separated and buckled from the underlying electrode groundmass. Within portions of the bottom of these electrodes, monoclinic (destabilized) zirconia, as well as a cubic zirconia solid-solution, with a cubic cell parameter smaller than the pure (82-18) material was identified. These phases may result from reaction with seed or from electrochemical action but time has not permitted definitive answers based on laboratory experiments.

Mg0 insulators (cathode and anode) were investigated by $\mathrm{x}$-ray diffraction for potential chemical/phase changes. Apart from the extensive amount of seed (as $\mathrm{K}_{2} \mathrm{CO}_{3}$ and/or $\mathrm{K}_{2} \mathrm{CO}_{3}$ hydrate) found beneath the cathode electrodes within the $\mathrm{MgO}$, insulators exposed to the plasma were altered chemically 
at their surface. Surprisingly, $x$-ray lines (only a portion shown in Figure C.2.6) corresponding to a cubic, spinel-like material are present in the typical Mg0 pattern. Virgin material does not contain this phase. If this material is a spinel, the small, cubic cell parameter suggests that it is $\mathrm{MgAl}_{2} \mathrm{O}_{4}$. This phase is also present in trace quantities at the surfaces of many of the anode materials and probably of cathode materials. The latter could not be confirmed, as cathode surfaces were too fragmented and irregular for direct x-ray analysis. If $\mathrm{MgAl}_{2} \mathrm{O}_{4}$ is the phase present, then $\mathrm{Al}_{2} \mathrm{O}_{3}$ somehow must have been transported via the vapor phase to react with available Mg0. This may appear to be a trival point, but it should be recognized that a chemical reaction leading to the formation of a new chemical species could have a degrading effect on the original mechanical/ electrical properties of a virgin material.

\section{C.2.1.2.3 Special Considerations}

Although this portion of this report is concerned only with the documentation of phase/chemical characterization of electrode materials, several related questions remain open to interpretation and further study. Given that alteration of materials proceeded at the cathode at an accelerated rate with respect to the anode, how does seed reach, penetrate and react with materials? Is the difference in reactivity of cathode and anode with seed due to better sealing or higher working temperatures at the anode? If not, are alterations at the cathode aecelerated by electrochemical means? It appears unlikely that seed as $\mathrm{K}_{(\mathrm{g})}$ is the dominating factor, otherwise anode and cathode materials should reflect nearly identical chemical reaction phenomena. Possibly, $\mathrm{K}^{+}(\mathrm{g})$ attracted from the plasma to and/or formed at the cathode surface (and attracted) according to $\mathrm{K}(\mathrm{g}) \rightarrow \mathrm{K}(\mathrm{g})+\mathrm{e}$ is the controlling factor. $\mathrm{K}^{+}(\mathrm{g})$ at the anode necessarily would be repelled except, perhaps, for open circuit materials. Given the reality of seed penetration and reaction, which should accelerate with time, can cathode materials based on $\mathrm{CeO}_{2} / \mathrm{ZrO}_{2}$ components, even with their additional, inherent problems such as vaporization of cerium oxide and phase transitions particularly at low effective $\mathrm{P}_{2}$ environments, be "sealed" to prevent attack in future, longer duration tests? Finally, to what extent are the phase transitions and attack by alkali seed detrimental to electrode performance?

\section{C.2.2 Anode Materials (A. Perloff)}

Anode materials show little evidence associated with alteration by potassium seed. The distinct color zoning, typical of cathode, $\mathrm{CeO}_{2} / \mathrm{ZrO}_{2}$ electrodes is not obvious although a faint yellowish discoloration is apparent at the bottom of some electrodes. Direct evidence for reaction with seed was found by $T$. Negas at the bottom of electrode 2520 significantly, an open circuit material as well as 2207 and 2208 (see above).

Generally, the hot surface material of anode electrodes tends to be monoclinic, cubic and/or tetragonal phases with smaller unit cells than the original bulk material. This suggests that the surface phases are richer in $\mathrm{ZrO}_{2}$ and were formed via vaporization of cerium oxides. For example, the $\mathrm{ZrO}_{2}-\mathrm{CeO}_{2}$ compositions initially rich in $\mathrm{ZrO}_{2}\left(82 \% \mathrm{ZrO}_{2}, 18 \% \mathrm{CeO}_{2}, 50 \% \mathrm{ZrO}_{2}, 50 \% \mathrm{CeO}_{2}\right)$ also show the formation of some monoclinic $\mathrm{ZrO}_{2}$ on the surface. The crystallinity of surface materials is generally poorer (i.e., finer particles or more disorder) than the original materials, which is an additional indication of decomposition. Many of the samples have small amounts of a spinel phase (most probably $\mathrm{MgAl}_{2} \mathrm{O}_{4}$ ) on the surface. Table C.2.2 summarizes pertinent data. 


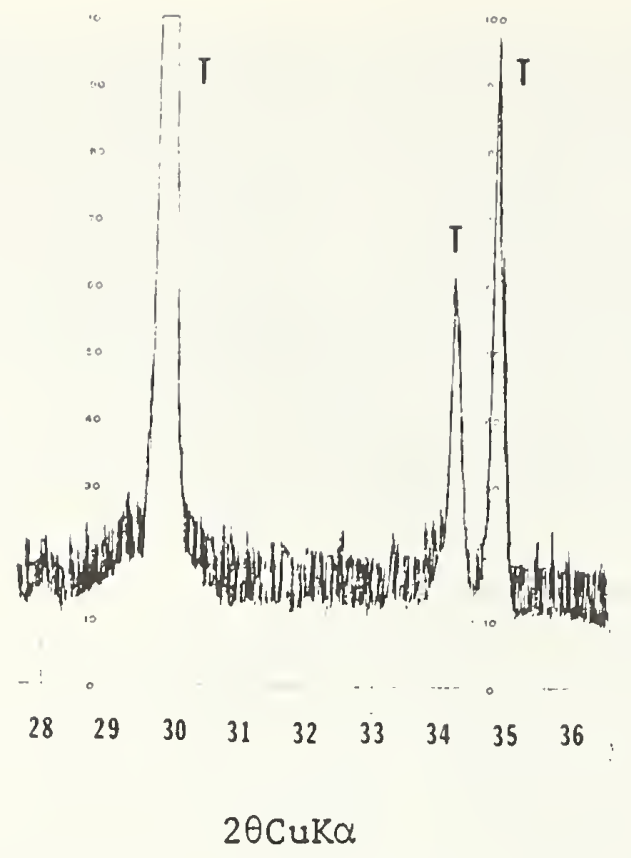

Figure C.2.Ia. Portion of X-ray diffraction powder pattern of the $82 \mathrm{ZrO}_{2}-18 \mathrm{CeO}_{2}$, $1500^{\circ} \mathrm{C}$ material prepared under oxidizing conditions (untested). $\mathrm{T}=$ tetragonal ${ }^{2}$ zirconia solid-solution. Compare with Figures C.2.1b, C.2.1c, C.2.1d and C.2.3a, C. $2.3 b, C .2 .3 c$.
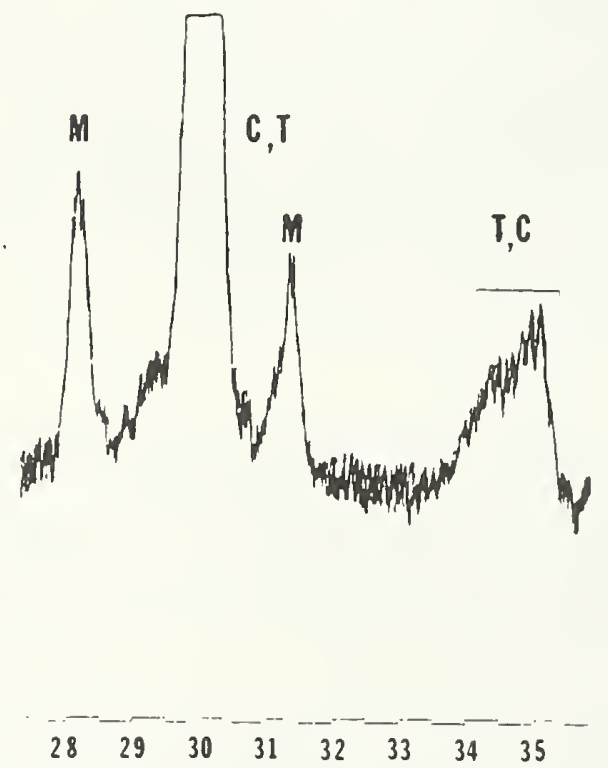

\section{$2 \theta \mathrm{CuK} \alpha$}

Figure C.2.1b. Portion of X-ray diffraction powder pattern of cathode electrode 1205 , open circuit, $82 \mathrm{ZrO}_{2}-18 \mathrm{CeO}_{2}$ (tested). White upper surface, see Table C.2.I. $M=$ monoclinic zirconia; ${ }^{2} \mathrm{C}, \mathrm{T}=$ poorly crystalline cubic fluorite and/or tetragonal solid-solutions. 

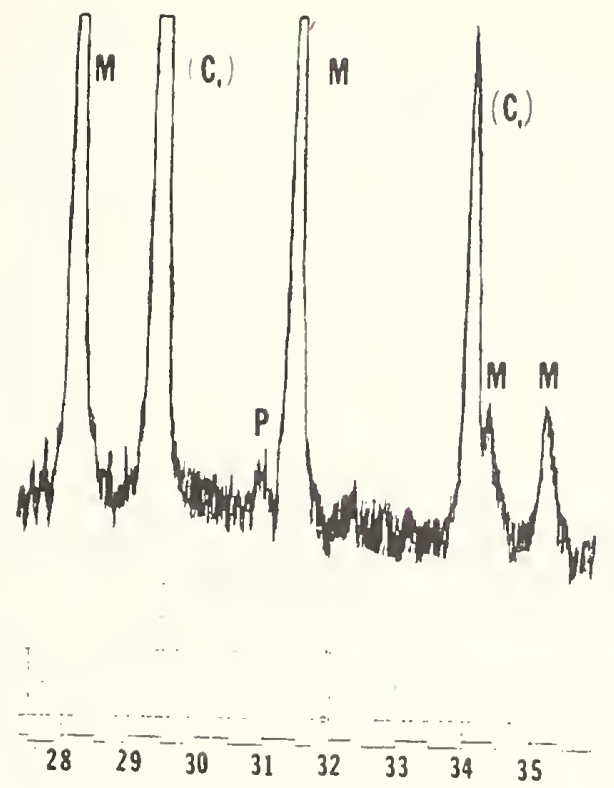

\section{$2 \theta \operatorname{CuK} \alpha$}

Figure C.2.1c. Portion of X-ray diffraction powder pattern of cathode electrode 1205 , open circuit, $82 \mathrm{ZrO}_{2}-18 \mathrm{CeO}_{2}$ (tested). Yellow interior zone, see Table C.2.1. $M=$ monoclinic zirconia; ${ }^{2}\left(C_{1}\right)$ = cubic pseudo-fluorite (cubic subcell $\underline{a}=5.26 \AA) ; P=(K, C e, Z r-o x i d e)$.

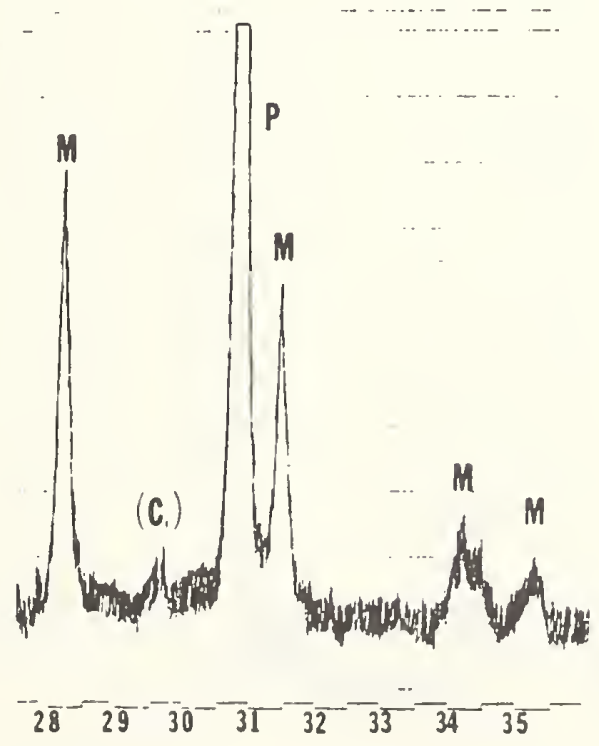

$2 \theta \mathrm{CuK} \alpha$

Figure C.2.1d. Portion of X-ray diffraction powder pattern of cathode electrode 1205 , open circuit, $82 \mathrm{ZrO} 2-18 \mathrm{CeO}_{2}$ (tested). Yellow, olive-green bottom zone, see Table C.2.1. $M=$ monoclinic zirconia; $\left(C_{1}\right)$ = cubic, pseudo-fluorite (cubic subcell $\underline{a}=5.26 \AA) ; P=(K, C e, Z r$-oxide $)$. 


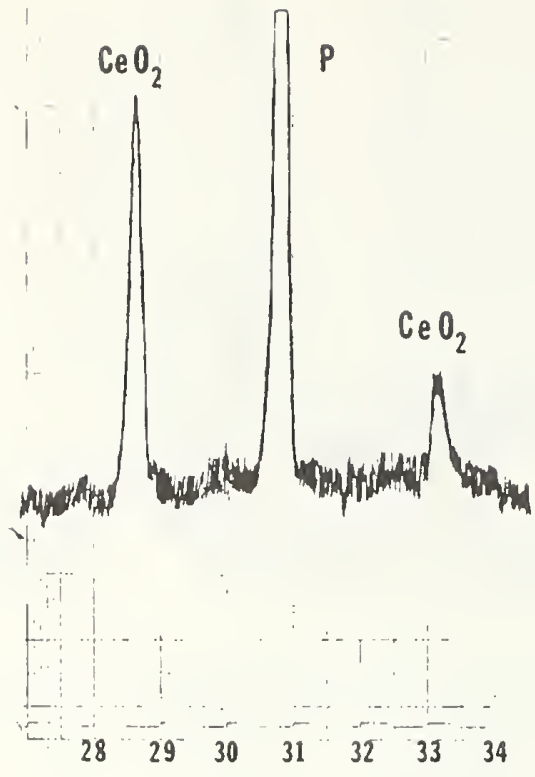

$2 \theta \mathrm{CuK} \alpha$

Figure C.2.2. Portion of X-ray diffraction powder pattern of synthetic products resulting from reactions of $\mathrm{CeO}_{2}, \mathrm{ZrO}_{2}$, and $\mathrm{K}_{2} \mathrm{O} . \mathrm{P}=(\mathrm{K}, \mathrm{Ce}, \mathrm{Zr}$-oxide). Compare synthetic phase $P$ with $P$ phase in Figures C.2.1c, C.2.1d and C.2.5b.

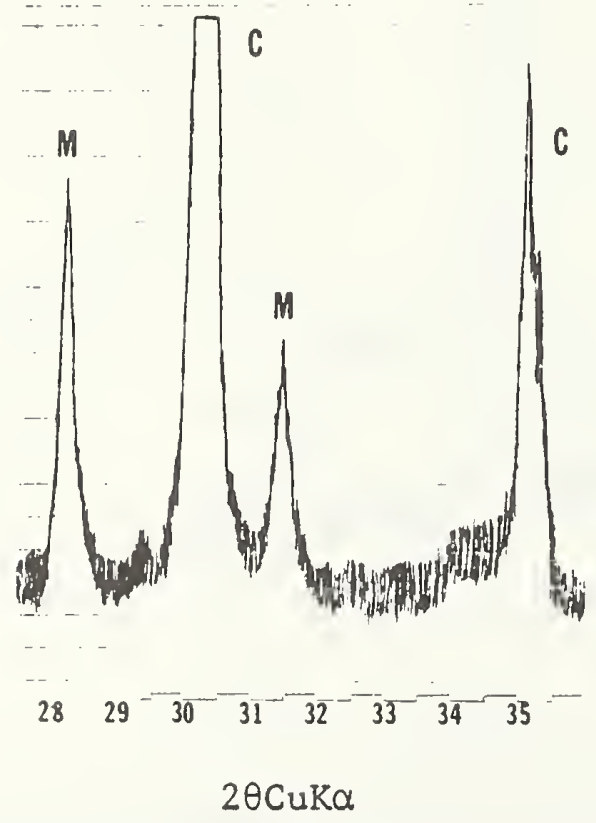

Figure C.2.3a. ,Portion of X-ray diffraction powder pattern of cathode electrode $1208,1.25 \mathrm{~A} / \mathrm{cm}^{2}, 82 \mathrm{ZrO}_{2}-18 \mathrm{CeO}_{2}$ (tested). White zone, top, see Table C.2.1. $\mathrm{M}=$ monoclinic zirconia; $\mathrm{C}=$ two or more cubic fluorite solid-solutions. 


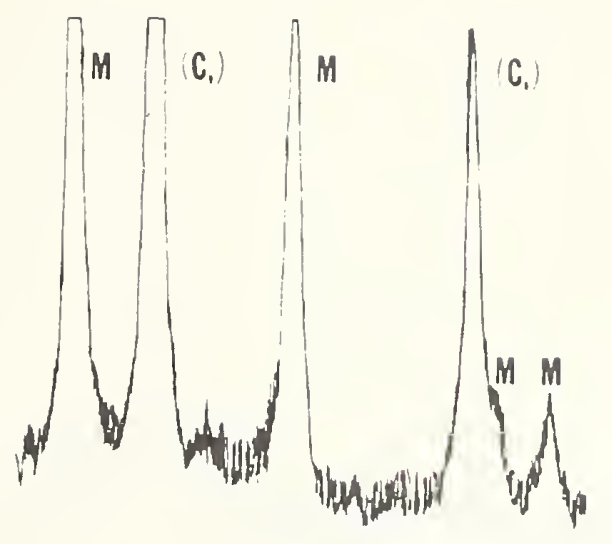

$\begin{array}{llllllll}28 & 29 & 30 & 31 & 32 & 33 & 34 & 35\end{array}$

$2 \theta \operatorname{cuk} \alpha$

Figure C.2.3b. ${ }_{2}$ Portion of X-ray diffraction powder pattern of cathode electrode $1208,1.25 \mathrm{~A} / \mathrm{cm}^{2}, 82 \mathrm{ZrO}_{2}-18 \mathrm{CeO}_{2}$ (tested). Yellowish Interior zone, see Table C.2.1. $M=$ monoclinic zirconia; $\left(C_{1}\right)$ = cubic, pseudo-fluorite (cubic subcell $\underline{a}=5.26 \AA$.

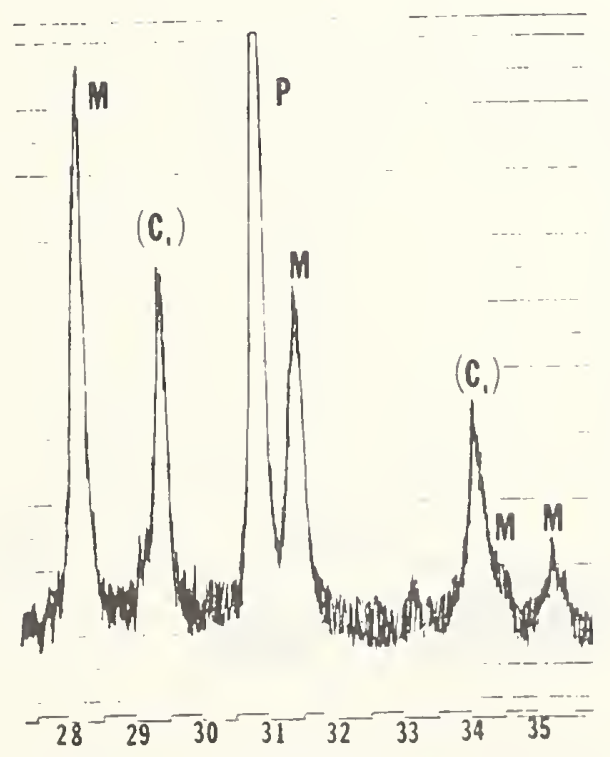

\section{$2 \theta \operatorname{CuK} \alpha$}

Figure C.2.3C. Portion of X-ray diffraction powder pattern of cathode electrode $1208,1.25 \mathrm{~A} / \mathrm{cm}^{2}, 82 \mathrm{ZrO}_{2}-18 \mathrm{CeO}_{2}$ (tested). Yellowish-green bottom zone, see Table C.2.I. $M=$ monoclinic zirconia; $\left(C_{1}\right)=$ cubic, pseudo-fluorite (cubic subcel1 $\underline{a}=5.26 \AA ; P=(K, C e, Z r$-oxide). 


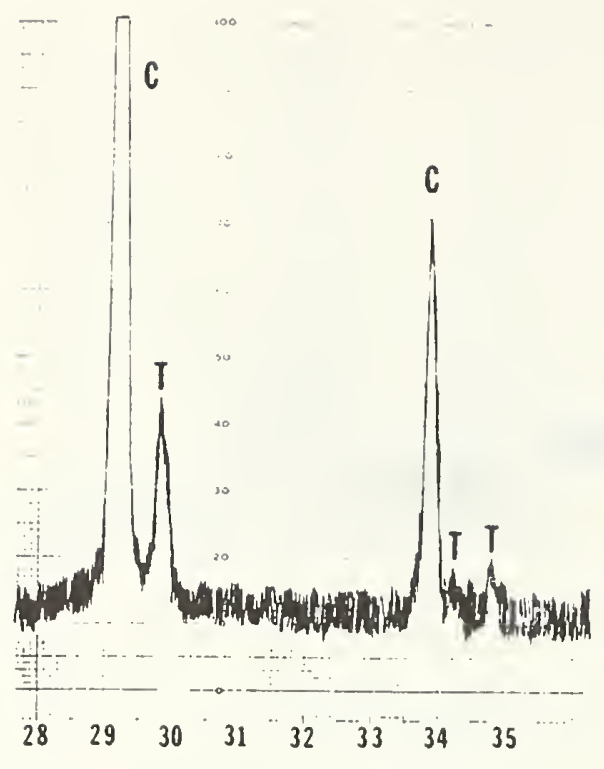

$2 \theta \mathrm{CuK} \alpha$

Figure C.2.4a. Portion of x-ray diffraction powder pattern of the $50 \mathrm{ZrO}_{2}-50 \mathrm{CeO}$, $1500^{\circ} \mathrm{C}$ oxidizing conditions (untested). $\mathrm{T}$ = tetragonal zirconia solid-solution; $\mathrm{C}=$ cubic fluorite solid-solution. Compare with Figures C.2.4b, C.2.5a and C. $2.5 b$.

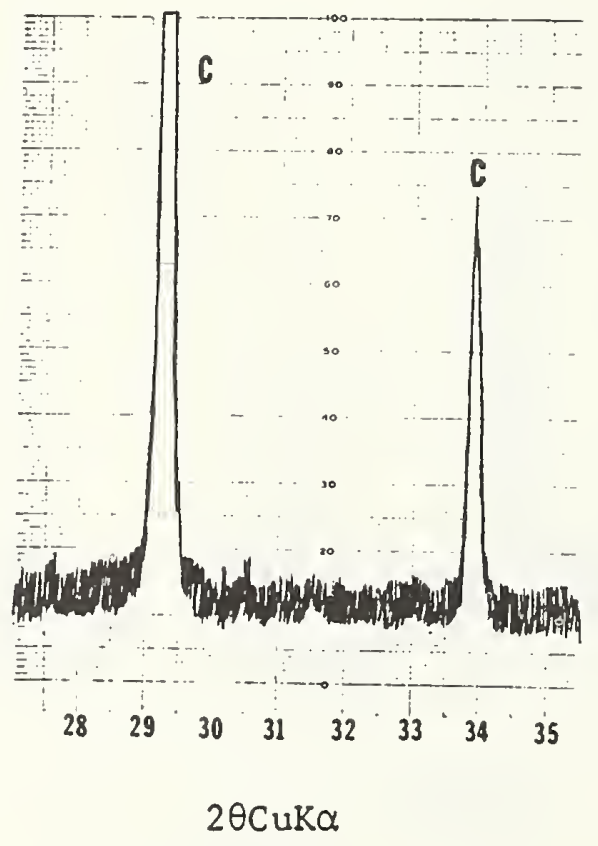

Figure C.2.4b. Portion of X-ray diffraction powder pattern of the $5 \mathrm{OZrO}_{2}-50 \mathrm{CeO}_{2}$, $1600^{\circ} \mathrm{C}$ oxidizing conditions (untested). $\mathrm{C}=$ cubic fluorite solid-solution. Compare with Figures C.2.4a, C.2.5a and C.2.5b. 


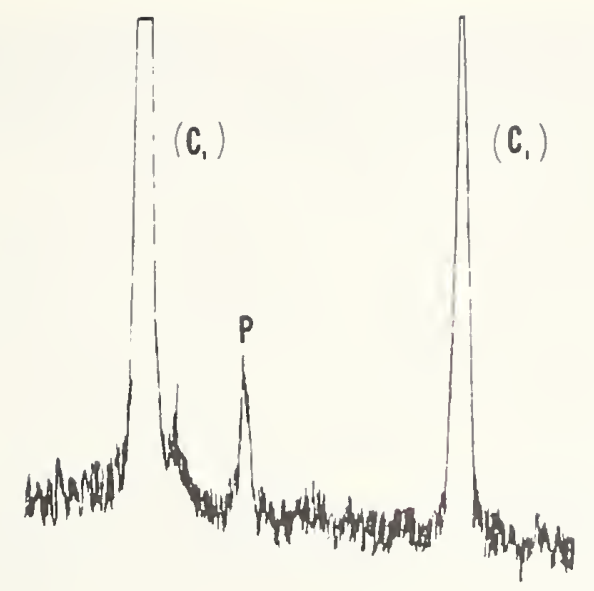

$\begin{array}{llllllll}28 & 29 & 30 & 31 & 32 & 33 & 34 & 35\end{array}$

$2 \theta \operatorname{CuK} \alpha$

Figure C.2.5a.2 Portion of X-ray diffraction powder pattern of cathode electrode $1310,0.8 \mathrm{~A} / \mathrm{cm}^{2}, 50 \mathrm{ZrO}_{2}-50 \mathrm{CeO}_{2}$ (tested). Yellow interior, see Table C.2.1. $\left(C_{1}\right)=$ cubic, pseudo-filuorite (cubic subcell $\left.a=5.26 \AA\right) ; P=(K, C e, Z r-o x i d e)$. Compare with Figures C.2.4a and C.2.4b.

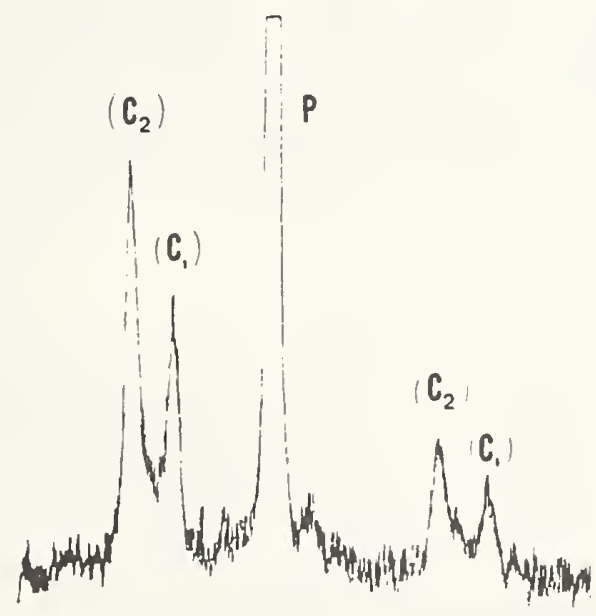

$\begin{array}{llllllll}28 & 29 & 30 & 31 & 32 & 33 & 34 & 35\end{array}$

$2 \theta \mathrm{CuK} \alpha$

Figure C.2.5b. 2 Portion of X-ray diffraction powder pattern of cathode electrode $1310,0.8 \mathrm{~A} / \mathrm{cm}^{2}, 50 \mathrm{ZrO}_{2}-50 \mathrm{CeO}_{2}$ (tested). Yellowish-green bottom zone, see Table C.2.1. $\left(C_{1}\right)=$ cubic, pseudo-fluorite (cubic subcell $\left.a=5.26 \AA\right) ; P=(K, C e$, Zr-oxide); $\left(C_{2}\right) \stackrel{1}{=}$ cubic fluorite solid-solution $a=5.38 \AA$. 


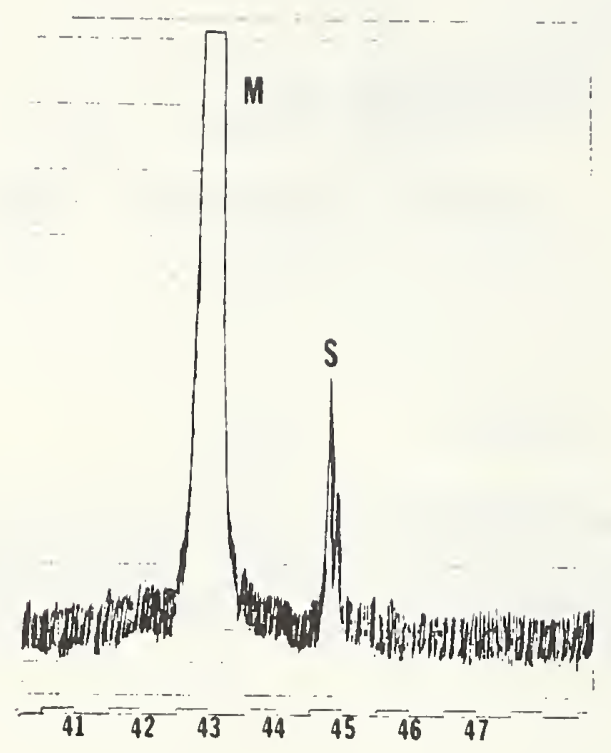

$2 \theta \mathrm{CuK} \alpha$

Figure C.2.6. Portion of X-ray diffraction powder pattern of a typical MgOinsulator, "hot", surface. $M=\mathrm{MgO}, \mathrm{S}=$ spinel, probably $\mathrm{MgAl}_{2} \mathrm{O}_{4}$. $\mathrm{S}$ not detected in untested $\mathrm{MgO}$. 

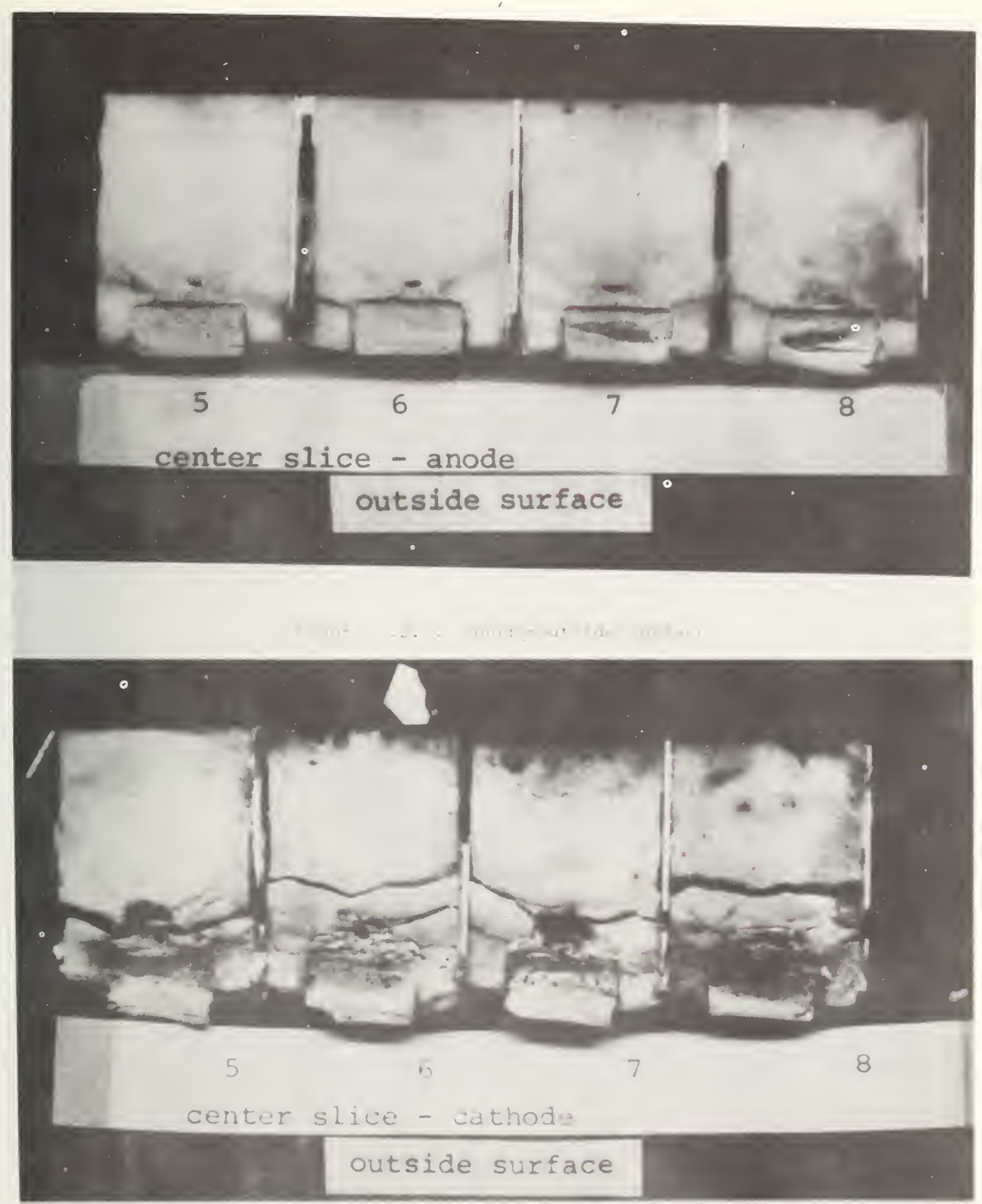


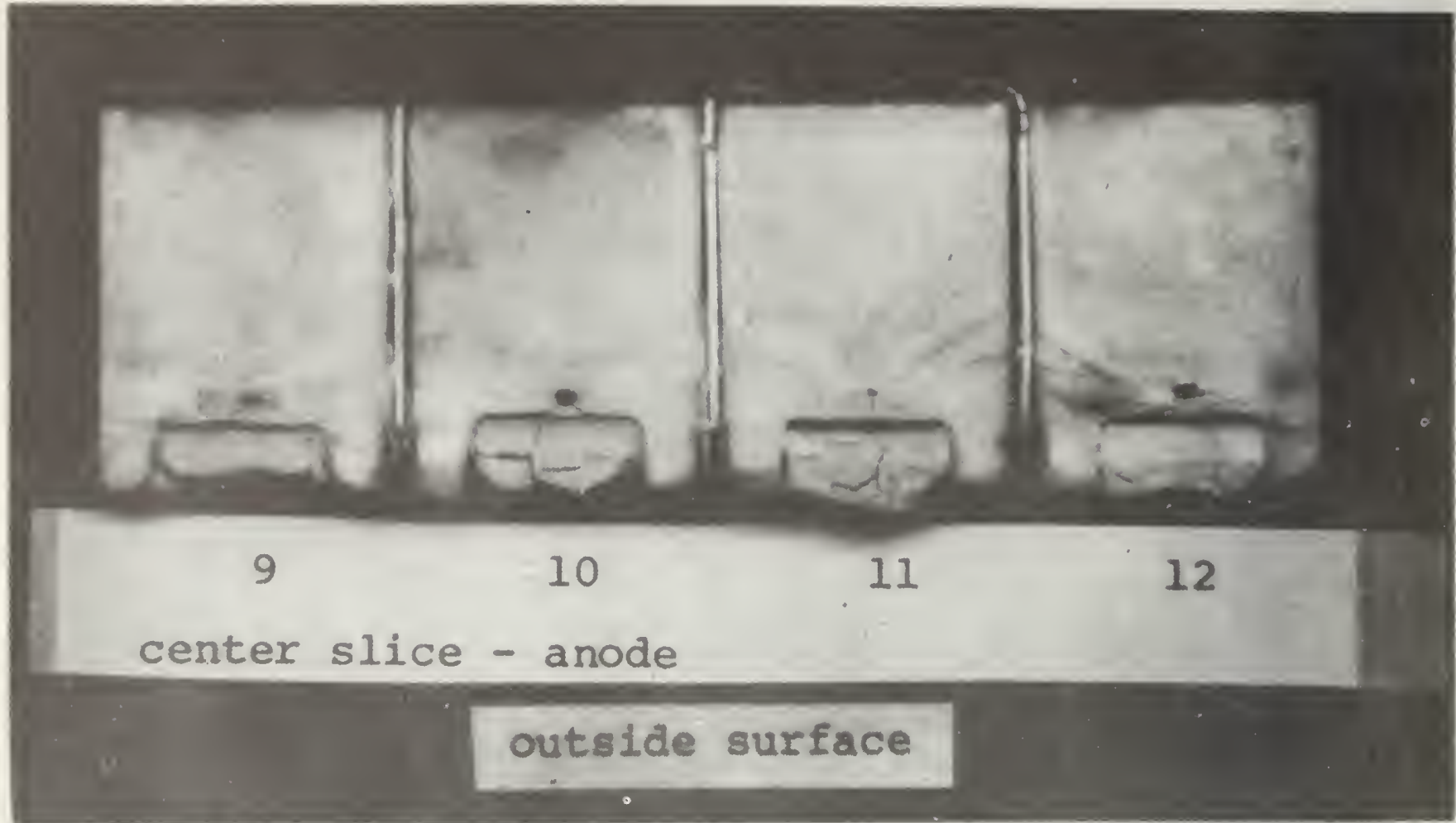

Figure C.2.9 Anode

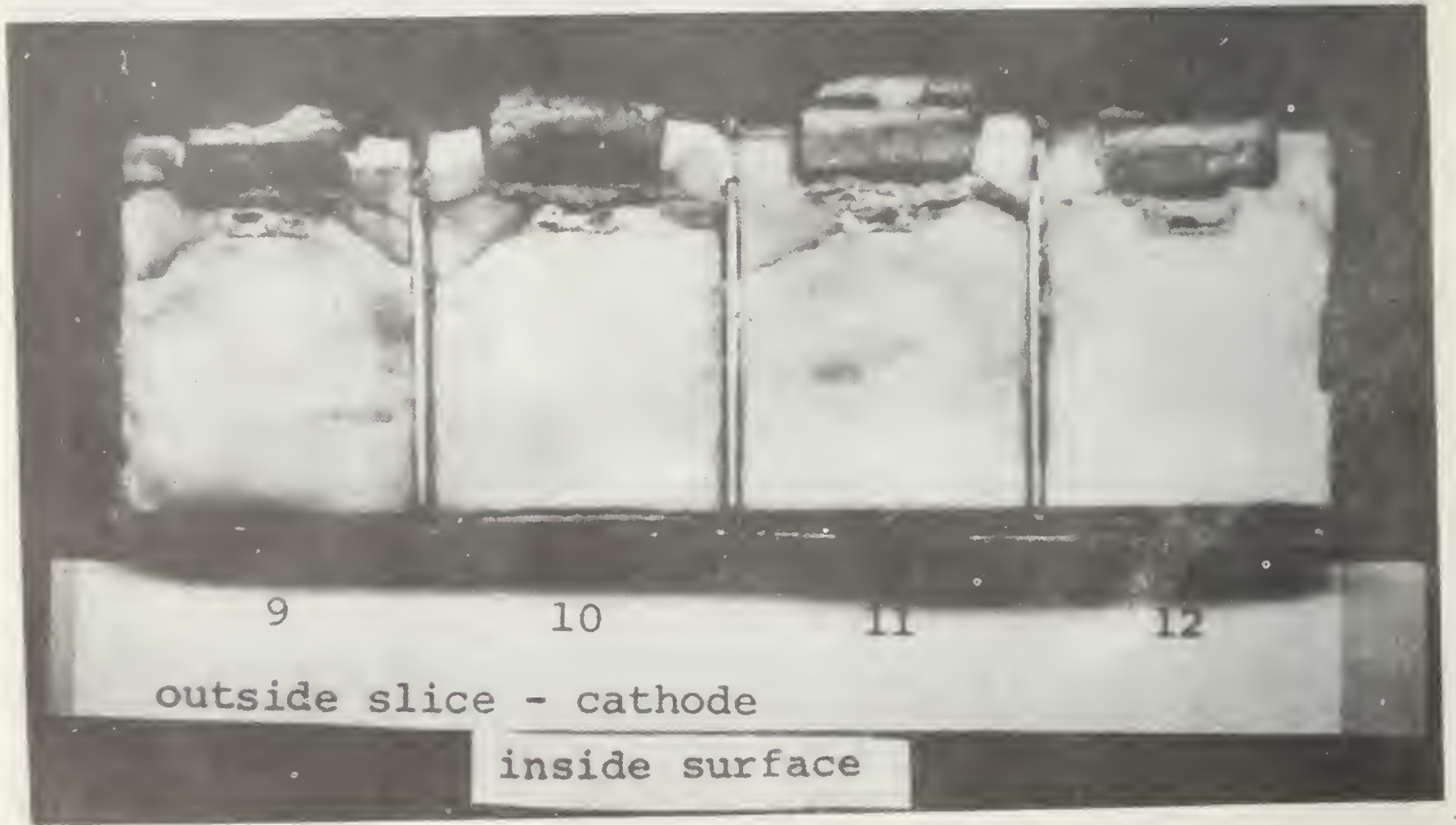



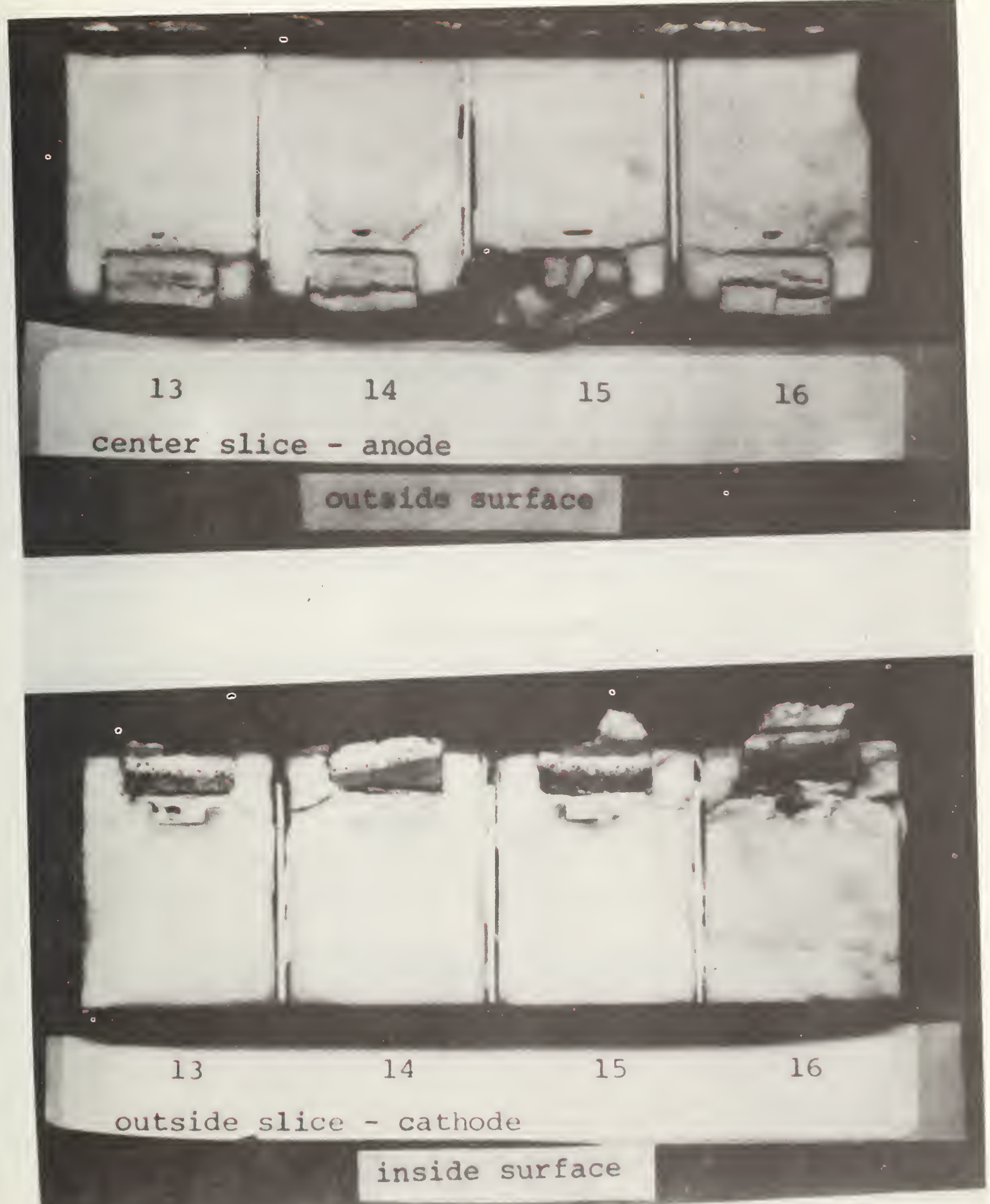

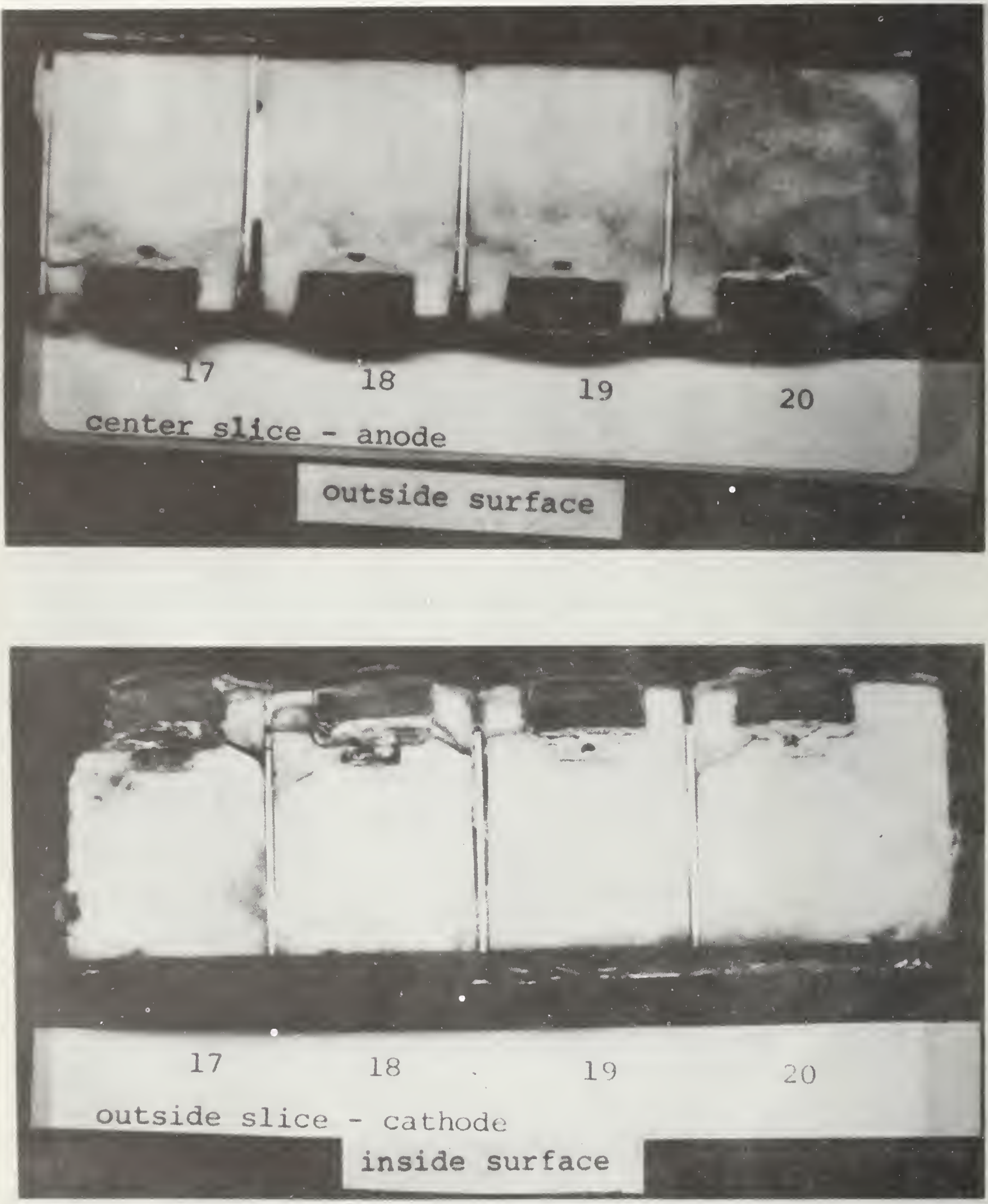

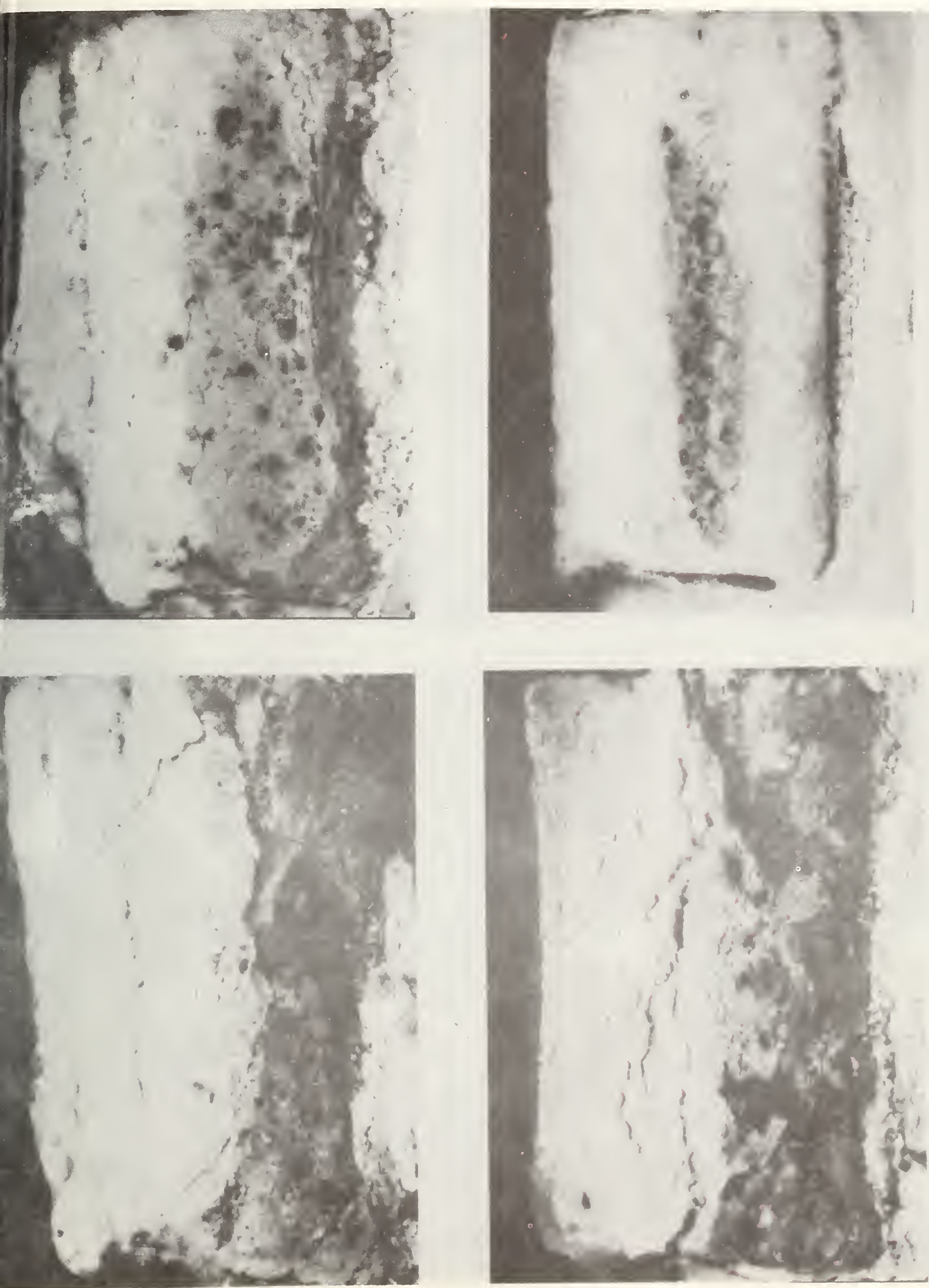

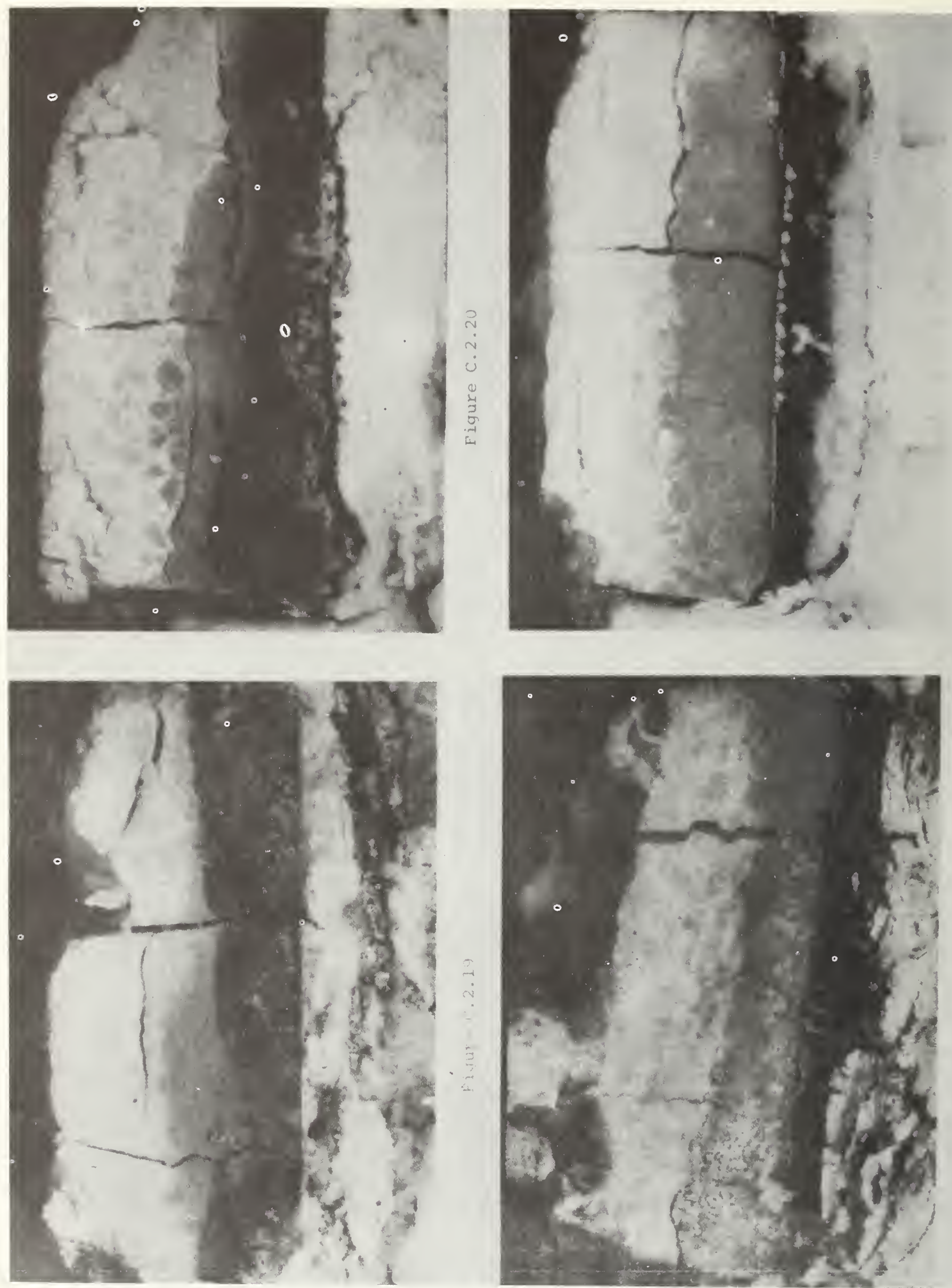

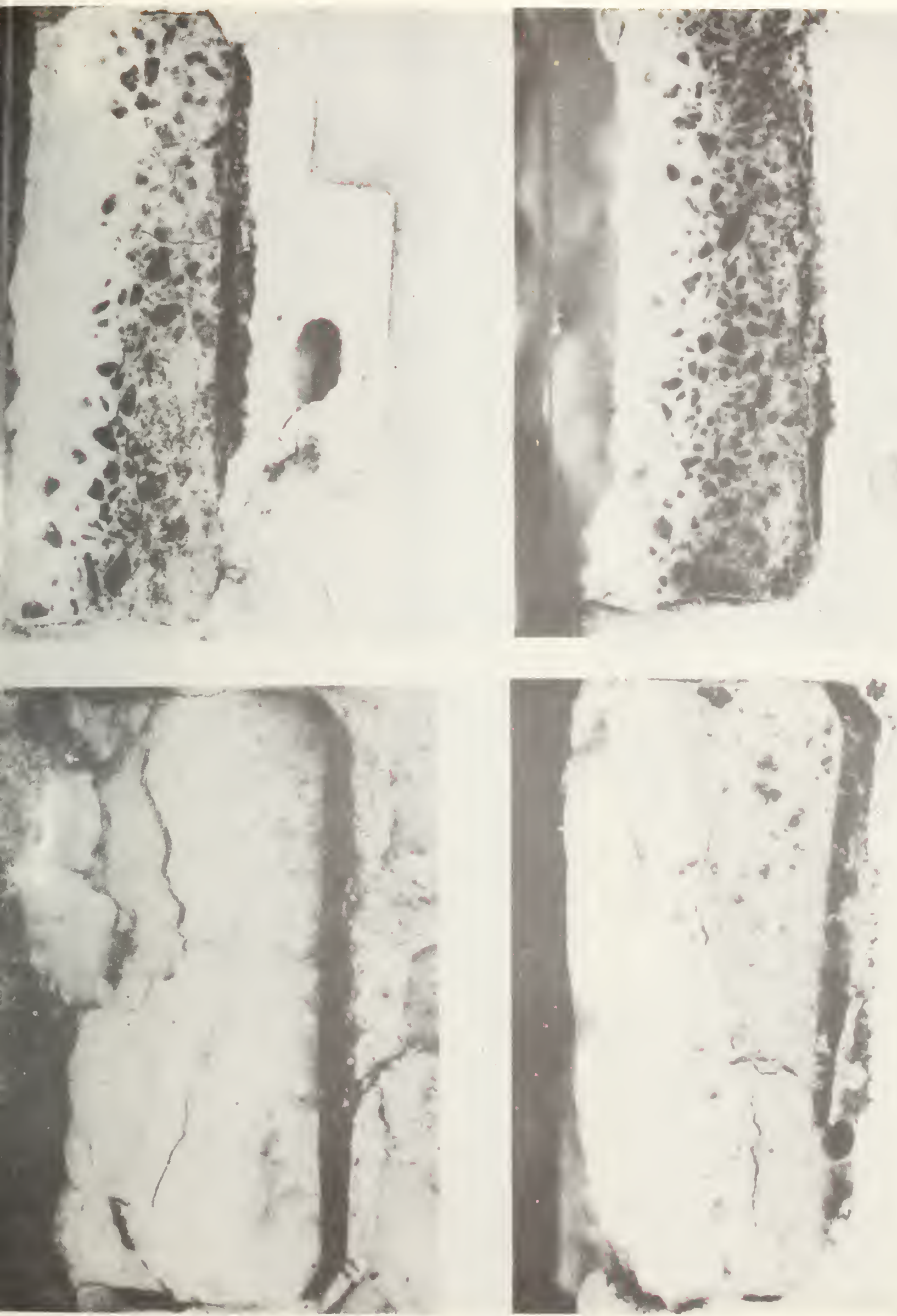

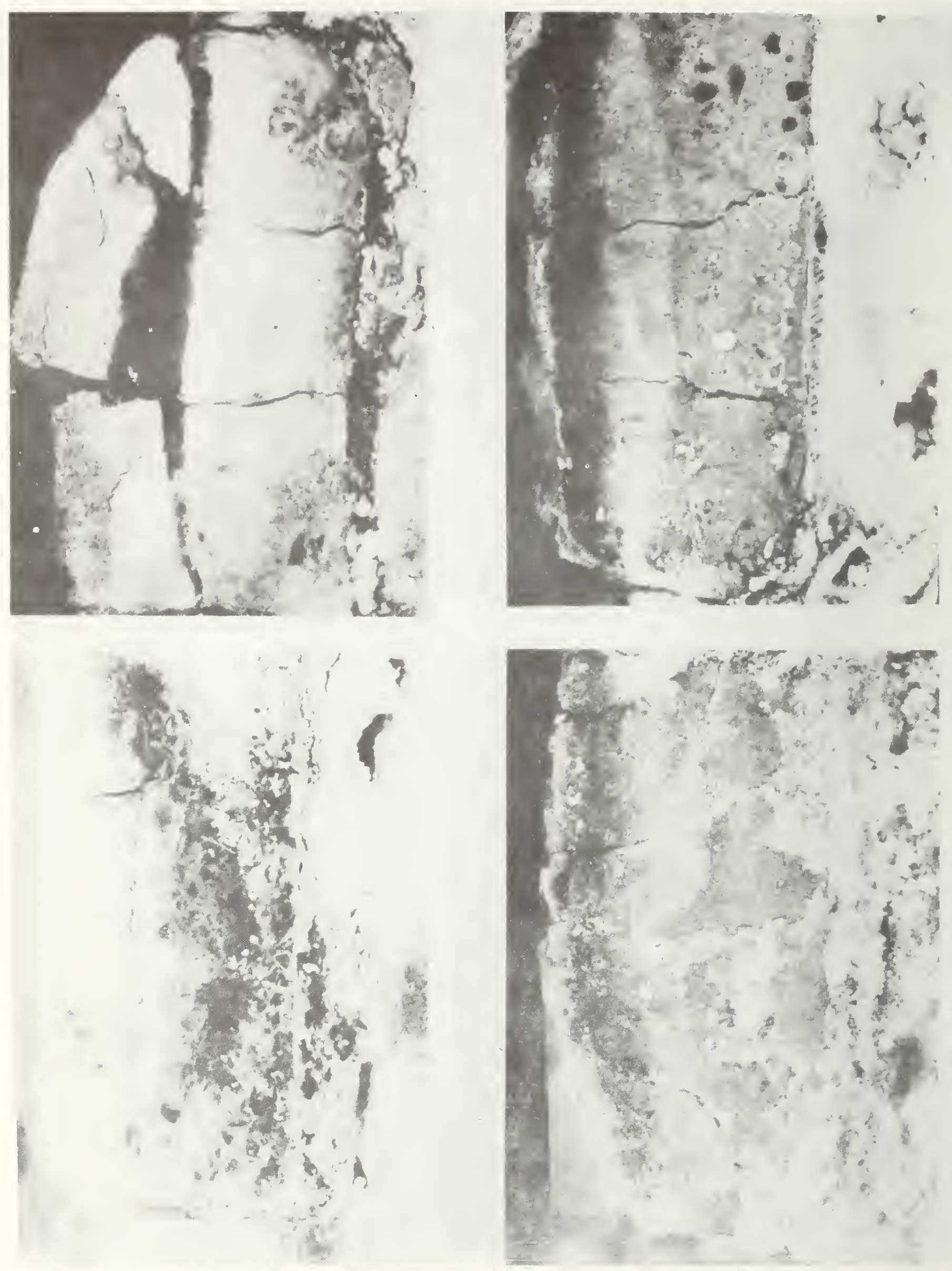

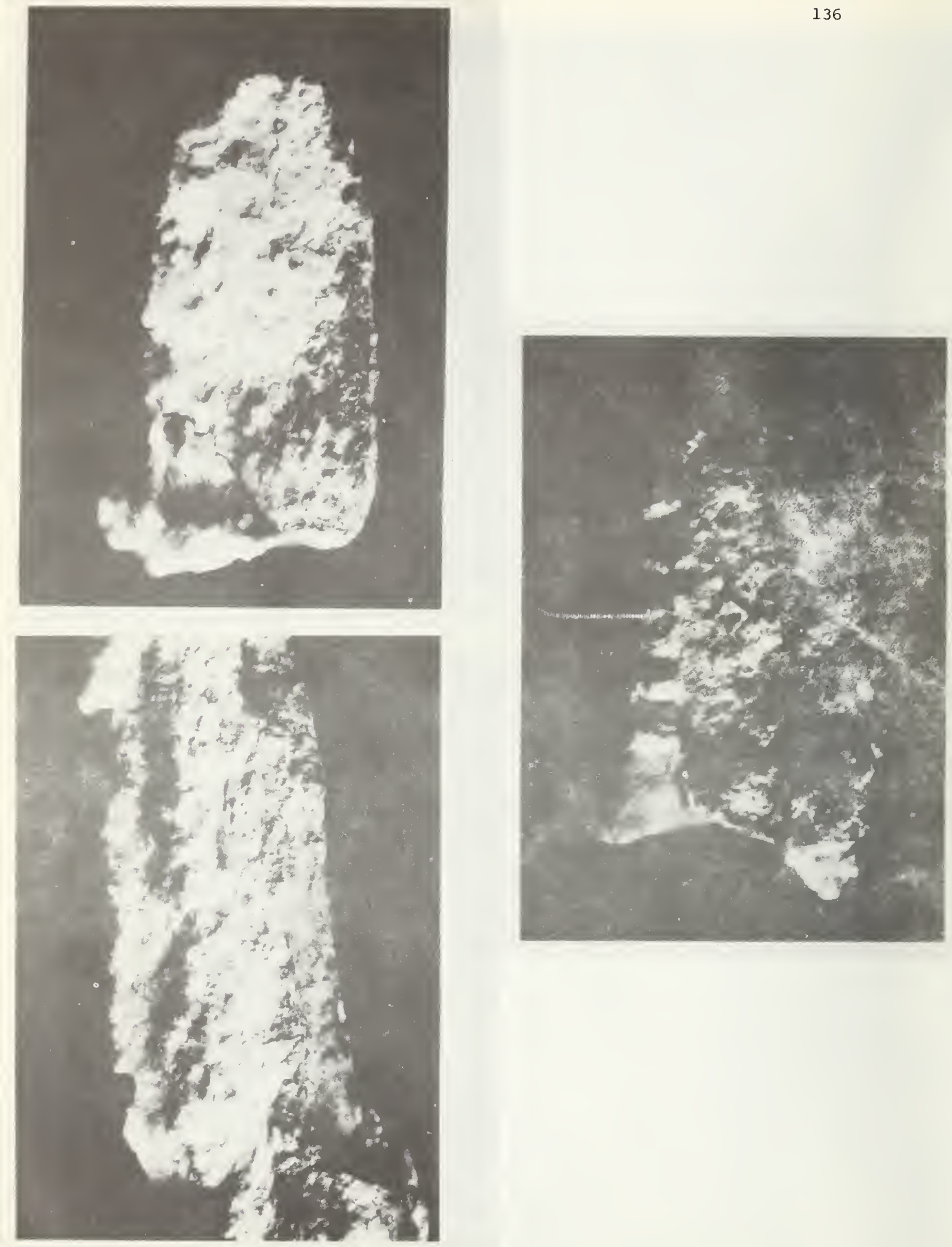

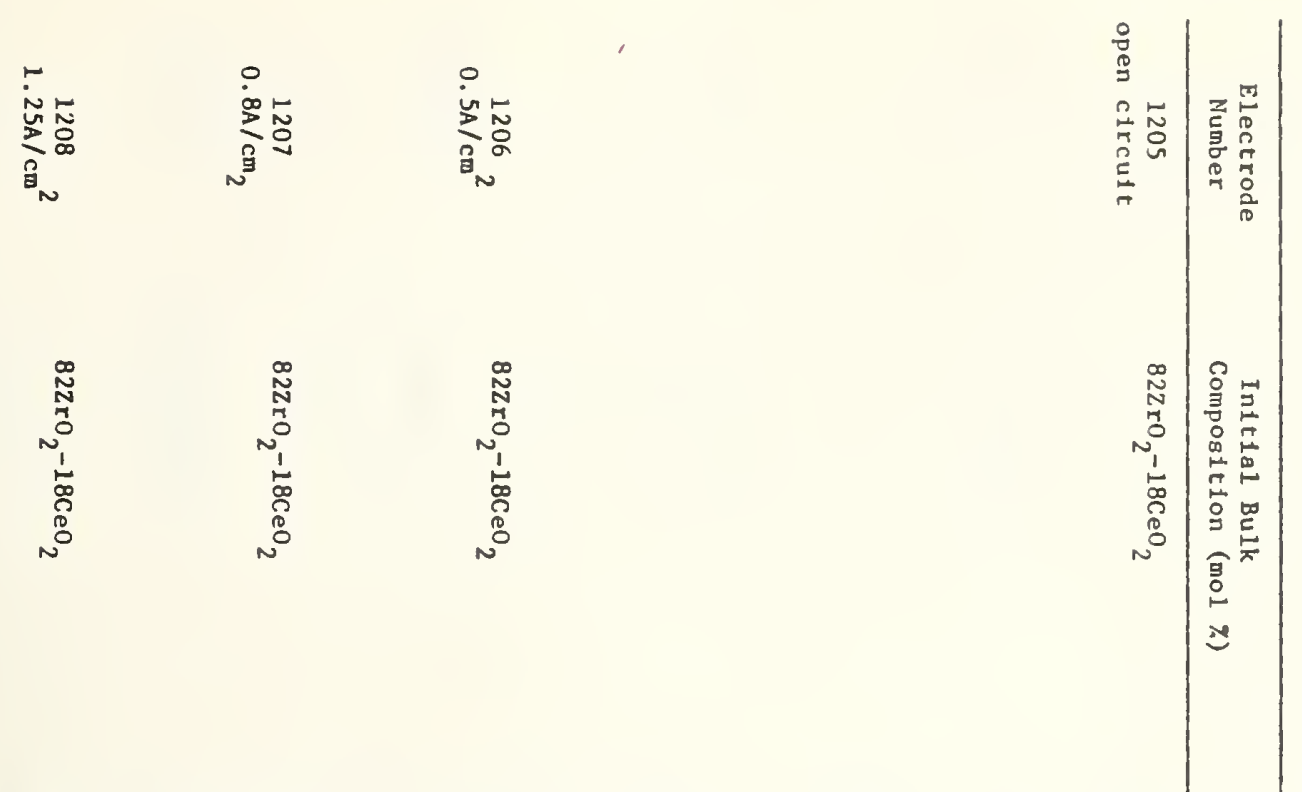

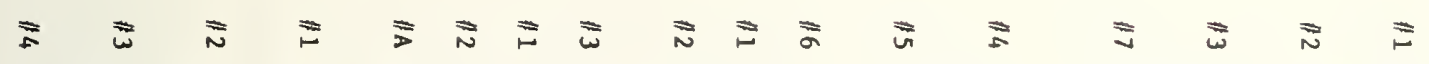

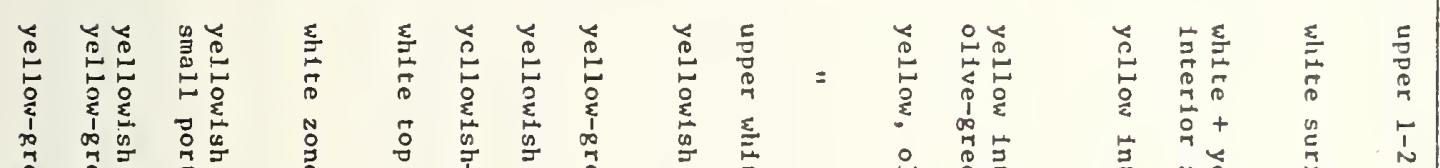

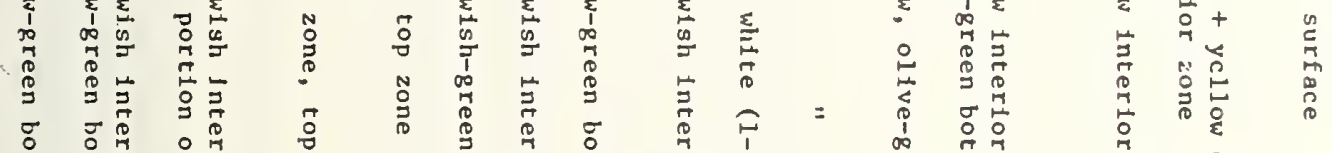

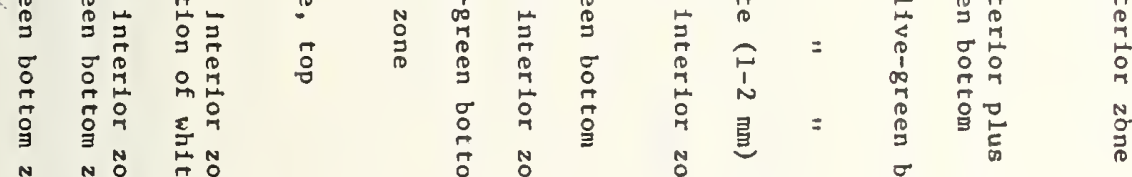

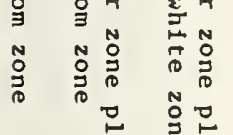

总

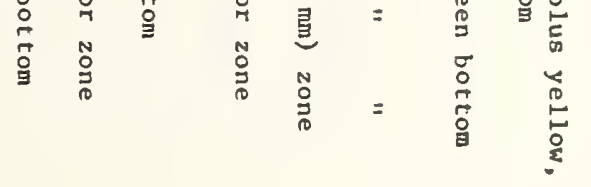

2
2
0
0
0
0
5
0
0
0
2

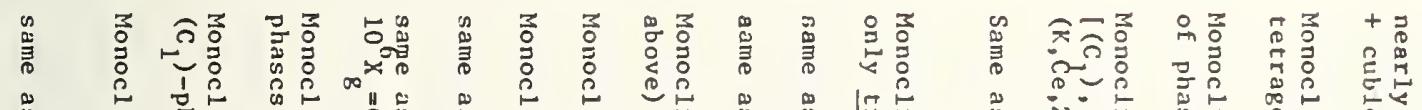

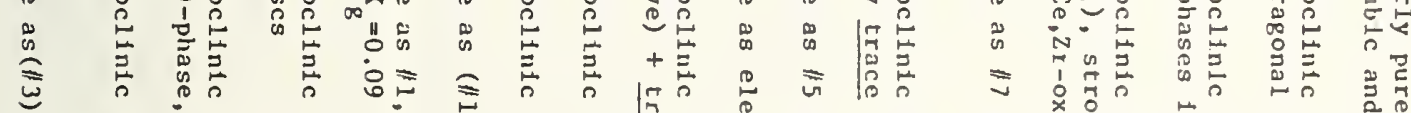

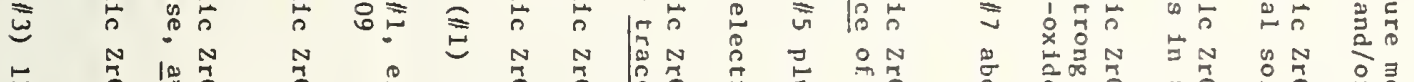

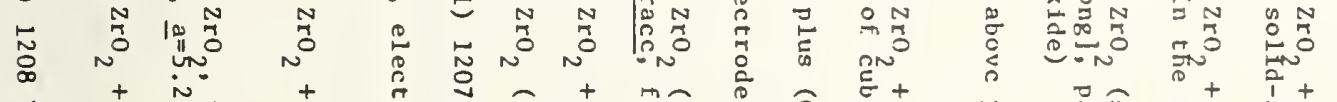

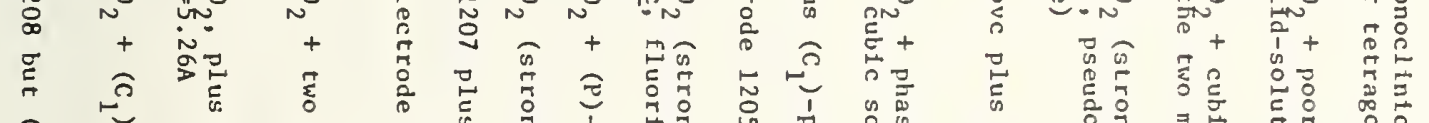

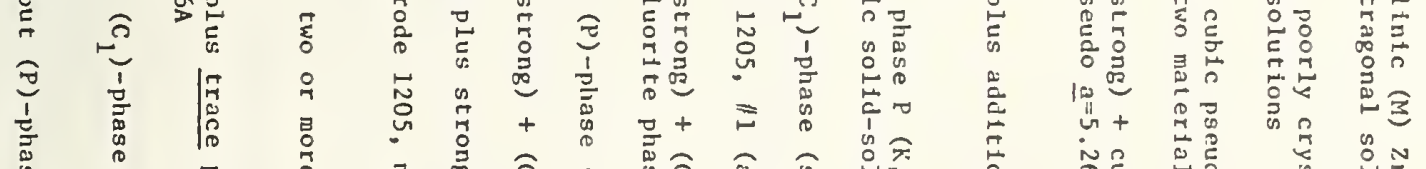

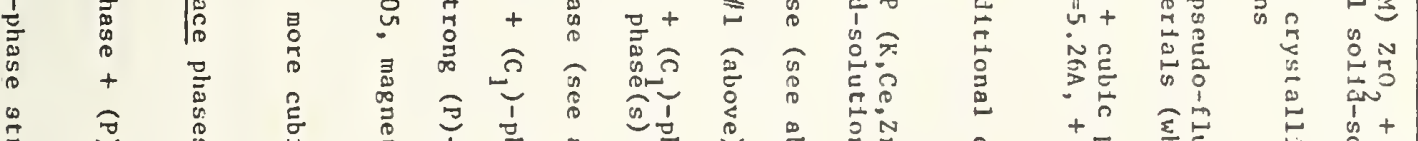

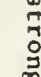



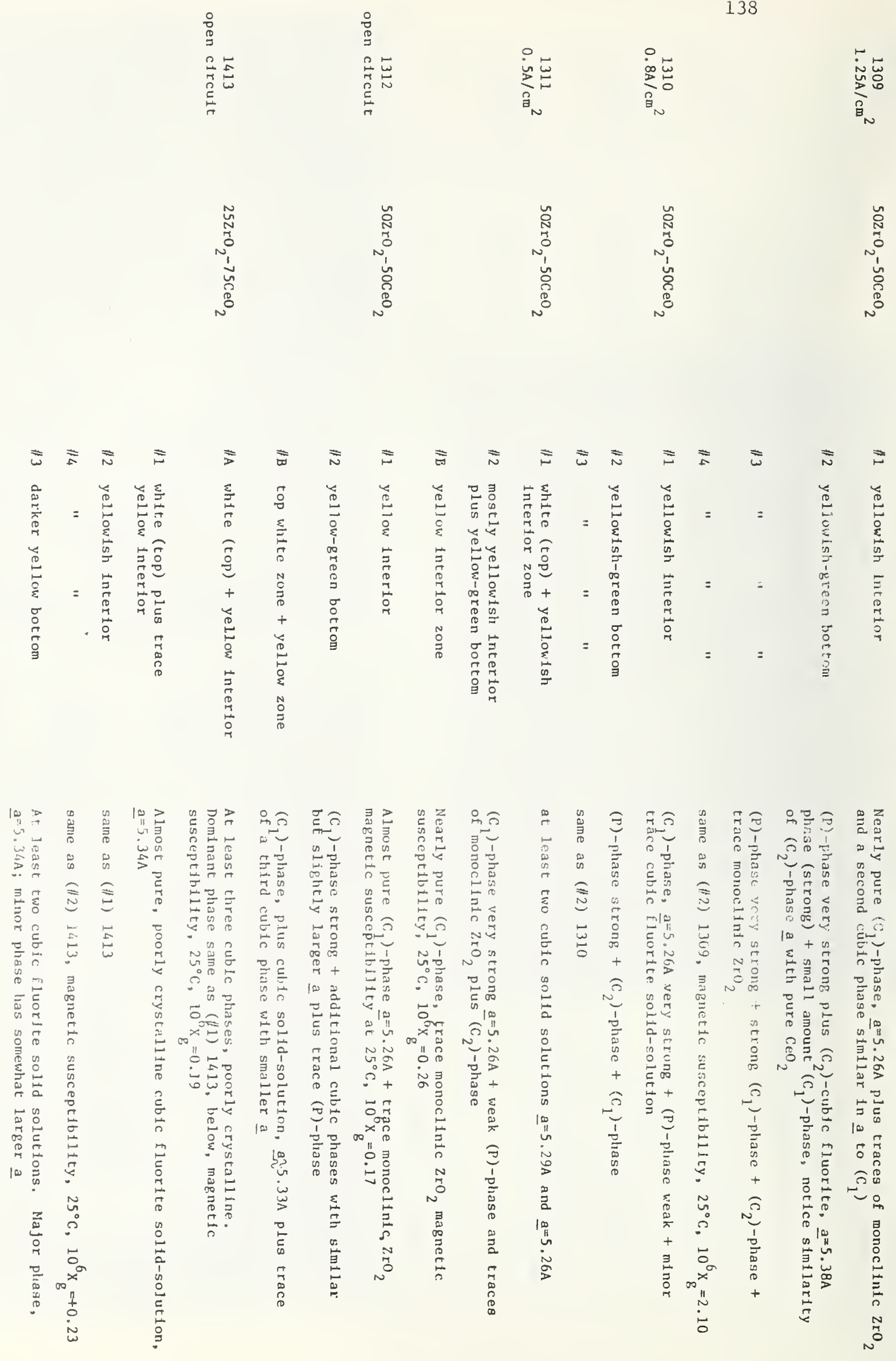


\section{욜}

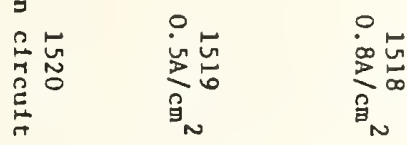

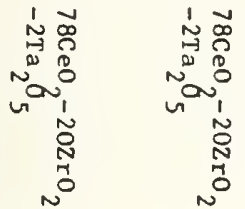

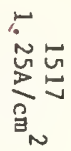

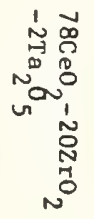

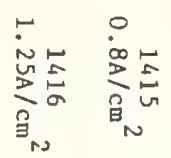

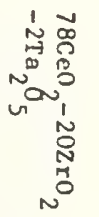

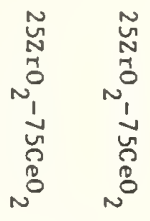

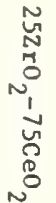

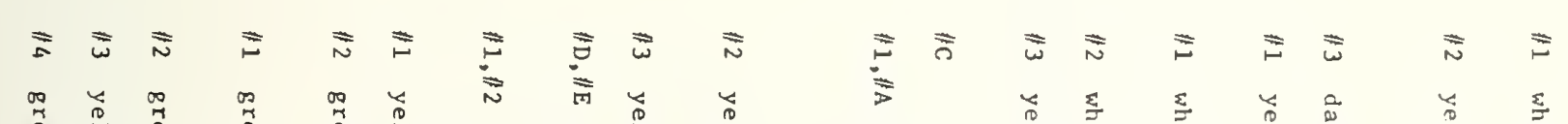

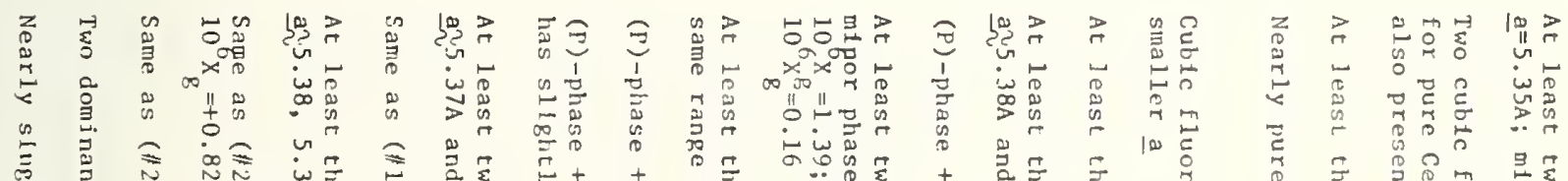

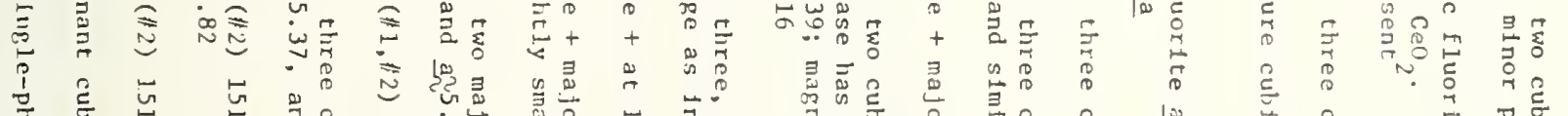

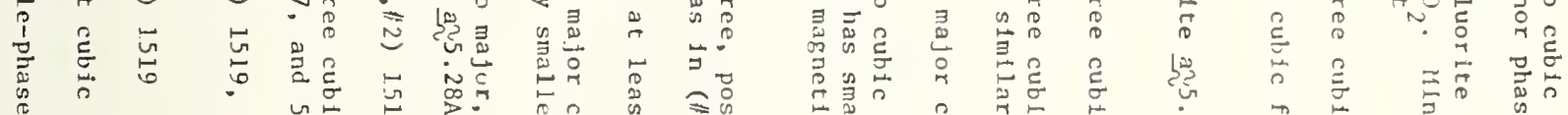

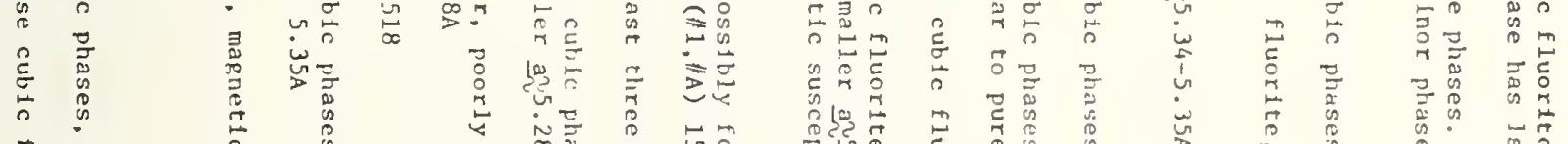

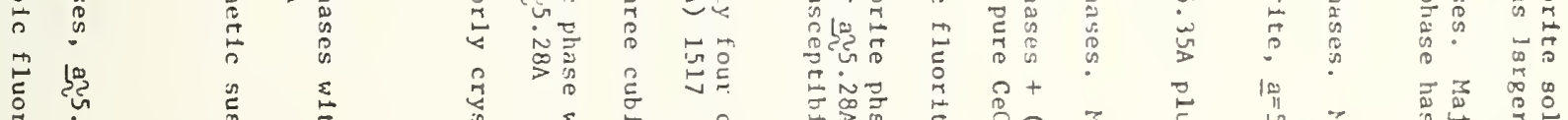

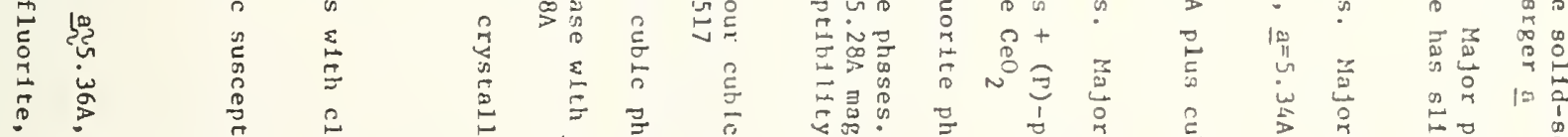

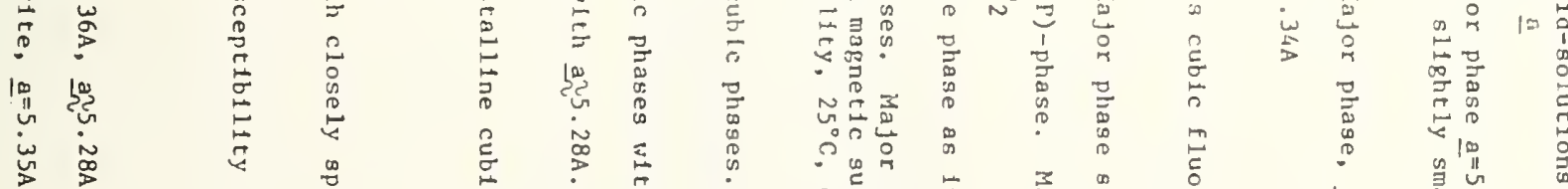

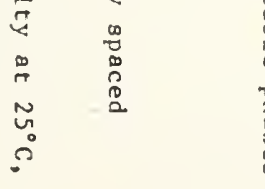

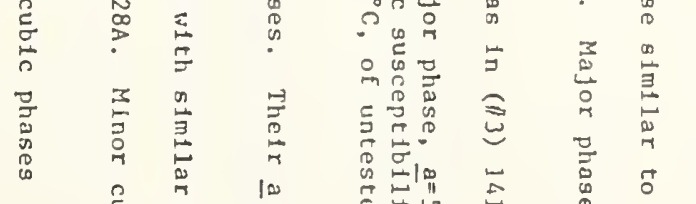

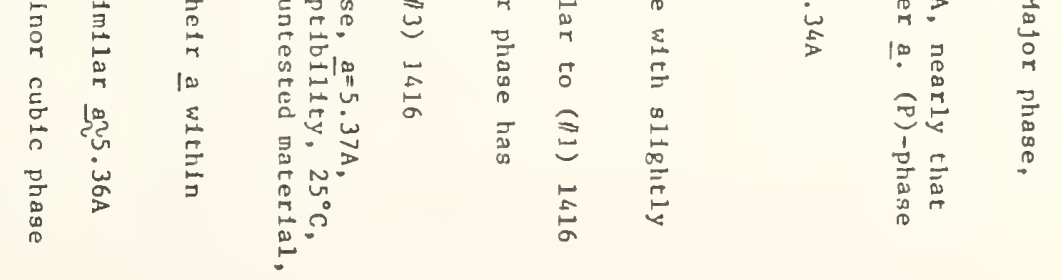



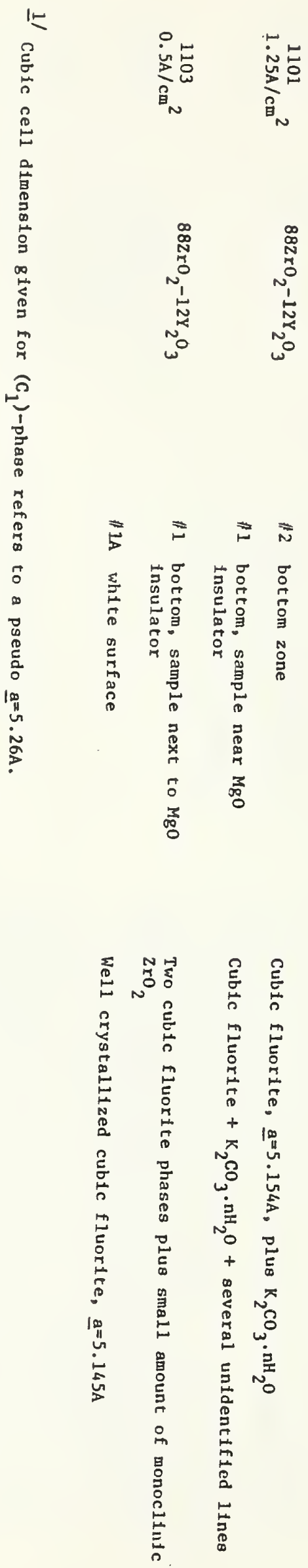
Anode Electrode X-ray Results

1. Composition -- $88 \% \mathrm{ZrO}_{2}, 12 \% \mathrm{Y}_{2} \mathrm{O}_{3}$

Original - Very well-crystallized f.c.c., $a=5.151 \AA$

Post Proof Test - Well-crystallized f.c.c., $a=5.136 \AA$.

Very slight suggestion of line splitting which could indicate lower symmetry or multiple phases.

Post Phase I Test Samples - bulk material f.c.c., a $=5.15^{\circ}$

2101 Surface crystallinity good, f.c.c., an 5.14A.

Intensity varies from original. Line

sharpness varies to suggest splitting in

some directions.

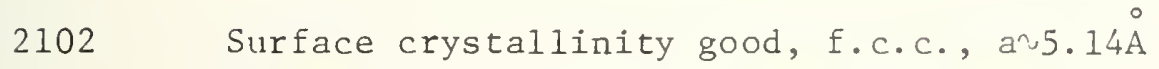

oriented intensitites. Some peaks show

distinct line splitting.

2103 Similar to 2101. Oriented intensities and probable line splitting. Approximately

f.c.c., $a=5 \cdot 14 \AA$.

2104 Approximately f.c.c., a $5.14 \AA$. Oriented

intensities and some distinct line splitting

Small amount of spinel visible.

2. Composition -- $82 \% \mathrm{ZrO}_{2}, 18 \% \mathrm{CeO}_{2}$

Original - Almost all tetragonal, $a=5.15, c=5.24 \AA$

Post Proof Test - Almost all f.C.C., $a=5.11 \AA$. (Surface)

Post Phase I Test Samples - Crystallinity generally poor although some of the poor resolution may be due to uneven surfaces.

2205-2208 A.11 surface patterns show primarily a cubic (or very nearly cubic) phase with a $5.1 \AA$. They also show monoclinic $\mathrm{ZrO}_{2}$ and spinel (probably $\mathrm{MgAI}_{2} \mathrm{O}_{4}$ ) 
3. Composition -- $50 \% \mathrm{ZrO}_{2}, 50 \% \mathrm{CeO}_{2}$

Original - Primarily tetragonal ( $a=5.26, c=5.30 \AA$ ) plus a small amount of a cubic phase $(a=5.15 \mathrm{~A})$ or tetragonal $(a=5.15, c=5.24 \AA)$ and a trace of a probably cubic phase $(a=5 \cdot 34 \AA)$.

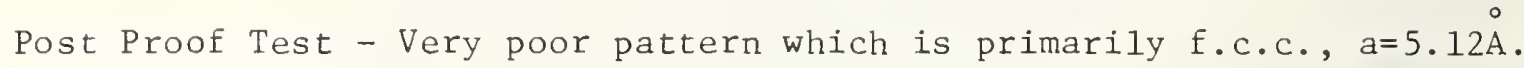

Post Phase I Test Samples - very poor condition. Only the 2312 sample could be used to obtain a surface pattern. All other patterns were obtained by grinding samples from the top and bottom portions of the electrodes.

2309 Top portion is mostly cubic (or nearly cubic) $a=5.26 \mathrm{~A}$. It also contains small amounts of approximately cubic cells with cell edges of $5.21 \AA$ and $5.16 \AA$ plus a small amount of monoclinic $\mathrm{ZrO}_{2}$.

Bottom portion has three phases present which are similar to the original material: cubic, $a=5.33 \AA$; tetragonal $a=5.27, c=5.31 \AA$; tetragonal $a=5.15, c=5.24 \AA$.

2310 Top portion is mostly nearly cubic (probably tetragonal $a=5.26, c=5.29 \AA$ ) plus small amounts of material with smaller cells ( $2.21 \AA$, $\sim 5.13 \AA$ ).

Bottom portion is mostly cubic $(a=5.34 \AA)$ plus some tetragonal $(a=5.15, c=5.24 \AA)$.

2311 Top portion is almost all tetragonal ( $a=5.26, c=5.30 \AA$ ) plus a trace of a smaller tetragonal phase $(a=5.15$, $c=5.24 \AA$ ).

Bottom portion is mostly cubic $(a=5.34 \AA$ ) plus some tetragonal $(a=5.15, c=5.24 \AA)$. 
2312

The surface is mostly two phases: - cubic $(a=5.14 \AA)$ and tetragonal $(a=5.18, c=5.26 \AA)$. Small amounts of monoclinic $\mathrm{ZrO}_{2}$ and spinel are aiso visible.

The bulk surface material is primarily cubic (or nearly so) with a $\sim 5.27 \AA$. It also contains smaller amounts of phases with smaller cells with cell edges $\sim 5.21$, $5.16,5.14 \AA$.

4. Composition -- $25 \% \mathrm{ZrO}_{2}, 75 \% \mathrm{CeO}_{2}$

Original - Well crystallized f.c.c., $a=5.342 \mathrm{~A}^{\circ}$

Post Proof Test - Very poorly crystallized mixture of at least three phases of cubic or nearly cubic materials with cells $25.33,5.26$, $5.19 \AA^{\circ}$ (surface).

Post Phase I Test Samples were considerably fragmented. Surface patterns could be obtained only on the 2413 and 2416 electrodes.

2413 The surface is mostly a cubic phase $(a=5.14 \AA)$. There is also some spinel visible plus traces of monoclinic $\mathrm{ZrO}_{2}$ and a possible cubic $(\mathrm{a}=5.26 \AA)$ phase.

2414 Could not get a useable surface pattern. The ground. upper portion is mostly the same as the original material (cubic, $a=5.34 \AA$ ). It also contains small amounts of two other phases: tetragonal, $a=5.23$, $c=5.29 \AA$; probably cubic a $5.16 \AA$.

2415 No surface pattern. A loose piece which was mostly surface material was ground for $x$-ray examination. It was mostly cubic with a $5.13 \AA$ plus a smal1 amount of two probably cubic phases, $a=5.22 \AA, a^{\prime}=5.19 \AA$.

2416 Surface pattern is predominantly cubic (or nearly so) with a 5.2A. Small amounts of a minor cubic component (a $5.3 \AA$ ) and spinel are visible. 
5. Composition -- $20 \% \mathrm{ZrO}_{2}, 78 \% \mathrm{CeO}_{2}, 2 \% \mathrm{Ta}_{2} \mathrm{O}_{5}$

Original - Consists of a major component (well crystallized f.c.c., $a=5.35 \AA$ ) and a minor component (not as well crystallized f.c.c., $a=5 \cdot 37 \AA$ ).

Post Proaf Test - Pattern is nearly cubic, but the crystallinity is only fair. Slight splitting of high angle lines suggest that it may be tetragonal with $\mathrm{a} \simeq \mathrm{c} \simeq 5.34 \AA$ or two cubics with $a=5.34 \AA$ and $a^{\prime}=5.35 \AA$.

Post Phase I Test Samples - All samples have a thin white coating (presumably due to loss of $\mathrm{Ta}$ ) and are green like the original beneath this surface coating. The bulk green material is the well crystallized f.c.c. phase $(a=5.35 \AA)$.

The white coating, when chipped off and ground, is primarily the f.c.c. phase $(a=5.35 \AA)$ but, also, contains at least two other phases with smaller cubic or nearly cubic cells (a' $5.2 \AA, a " \sim 5.3 \AA$ ) which are presumably richer in $\mathrm{ZrO}_{2}$.

The surface patterns of all these samples show primarily a poorly crystallized pattern of the $5.2 \AA$ material plus smaller amounts of the $5.3 \AA$ material. Additionally, the surfaces showed:

2517 Traces of spinel and an unidentified material.

2518 Traces of monoclinic $\mathrm{ZrO}_{2}$ and an unidentified material.

2519 No additional phases.

2520 Trace of spinel. 


\section{C.3 Electrical Conductivity (W. R. Hosler, and A. J. Armstrong, NBS)}

Since most electrode sections were cracked and eroded to some extent, it was impossible to remove each half electrode referred to in Section C-1 of this chapter in original condition. Measurement of electrical conductivity requires a sample of sufficient size to permit attachment of electrodes. Only those anode electrodes, 2102, 2205, 2206, 2207, 2208 could be used for posttest electrical data.

In addition, the significance of post-test electrical data is in question. It is difficult to reproduce in the laboratory measurement apparatus, the exact conditions that were present in the test facility plasma. These conductivity measurements are bulk measurements taken with the entire sample at the same temperature and in a particular atmosphere of oxygen partial pressure. No alkali seed was present in the measuring apparatus. It would seem likely that during the measurement, the condition of the sample could be altered considerably from that actually existing while it was exposed to the test plasma.

However, the measurements do indicate that no permanent damage had been done to the anode electrodes measured since the pre- and post-data are very similar. See Figures C.3.1 and C.3.2. This data should be compared with that given in Figures B.5.1, B.5.2, and B.5.3 of section B.5, this chapter. While the series of samples containing $82 \mathrm{ZrO}_{2}-18 \mathrm{CeO}_{2}$ have the lowest electrical conductivity of any material tested, its mechanical resistance to fracture on the anode is the greatest since all anode electrodes of this series were removed intact.

C.4 Metallography and Electron Microprobe Analysis (J. L. Bates, J. L. Daniel, Battelle Pacific NW Laboratories)

The cross sections of U-02 channel provided by the National Bureau of Standards were vacuum impregnated in mounting resin and polished in a non-aqueous media. Special precautions were required to prevent the smearing of potassium. The following electrode pairs were examined initially:

$$
\begin{aligned}
& \text { Electrode Pair } \\
& 1103-2103 \\
& 1206-2206 \\
& 1309-2309 \\
& 1414-2414 \\
& 1517-2517
\end{aligned}
$$

(The electrodes in parentheses received only cursory metallographic examination at lower magnifications.)

Photographs of polished cross sections were taken at lower magnification and a montage was prepared for this report. 


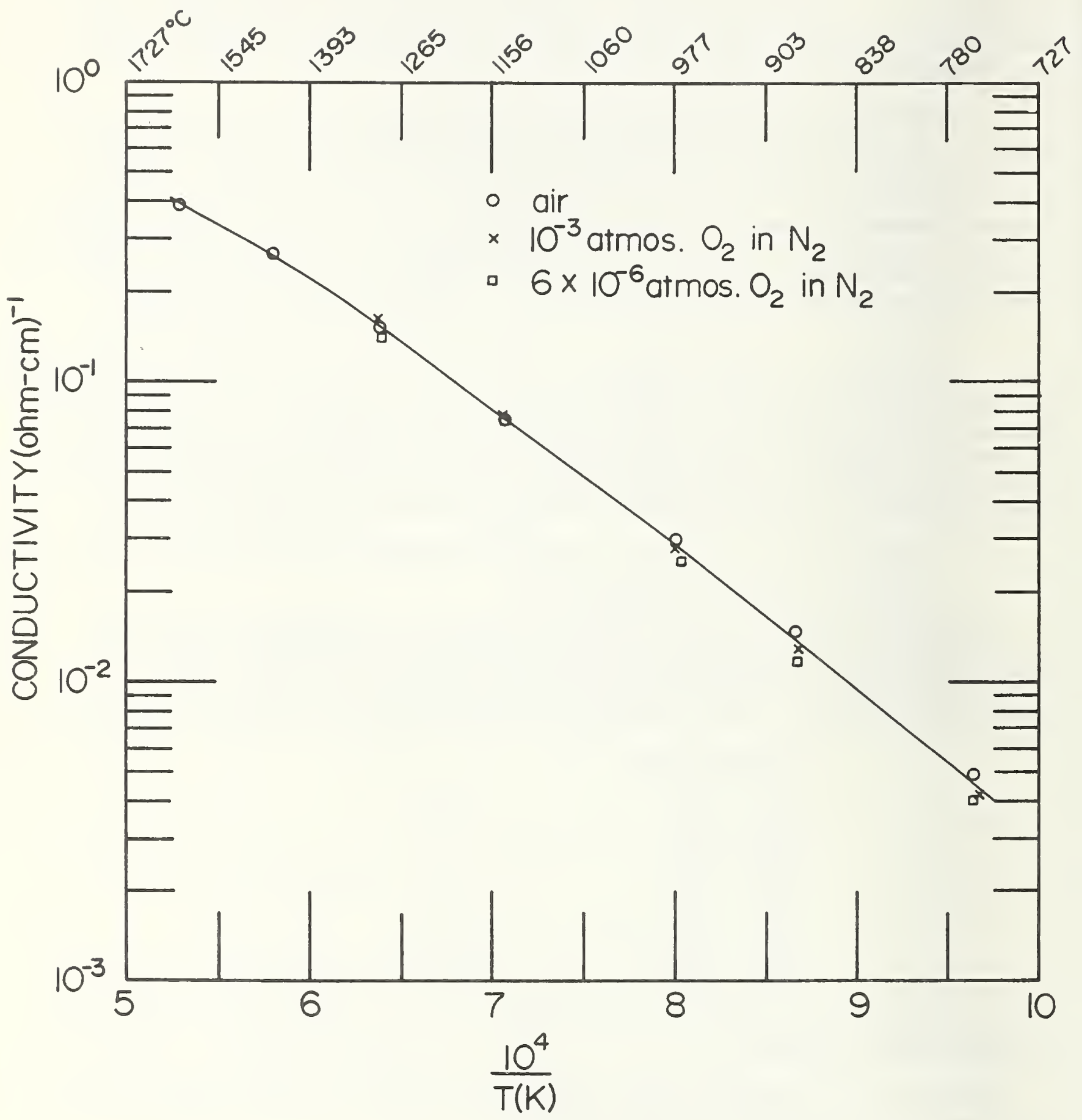

Figure C.3.1. Post-test Electrical Conductivity of Electrode 2102 $\left(88 \mathrm{ZrO}_{2}-12 \mathrm{Y}_{2} \mathrm{O}_{3}\right.$ ). 


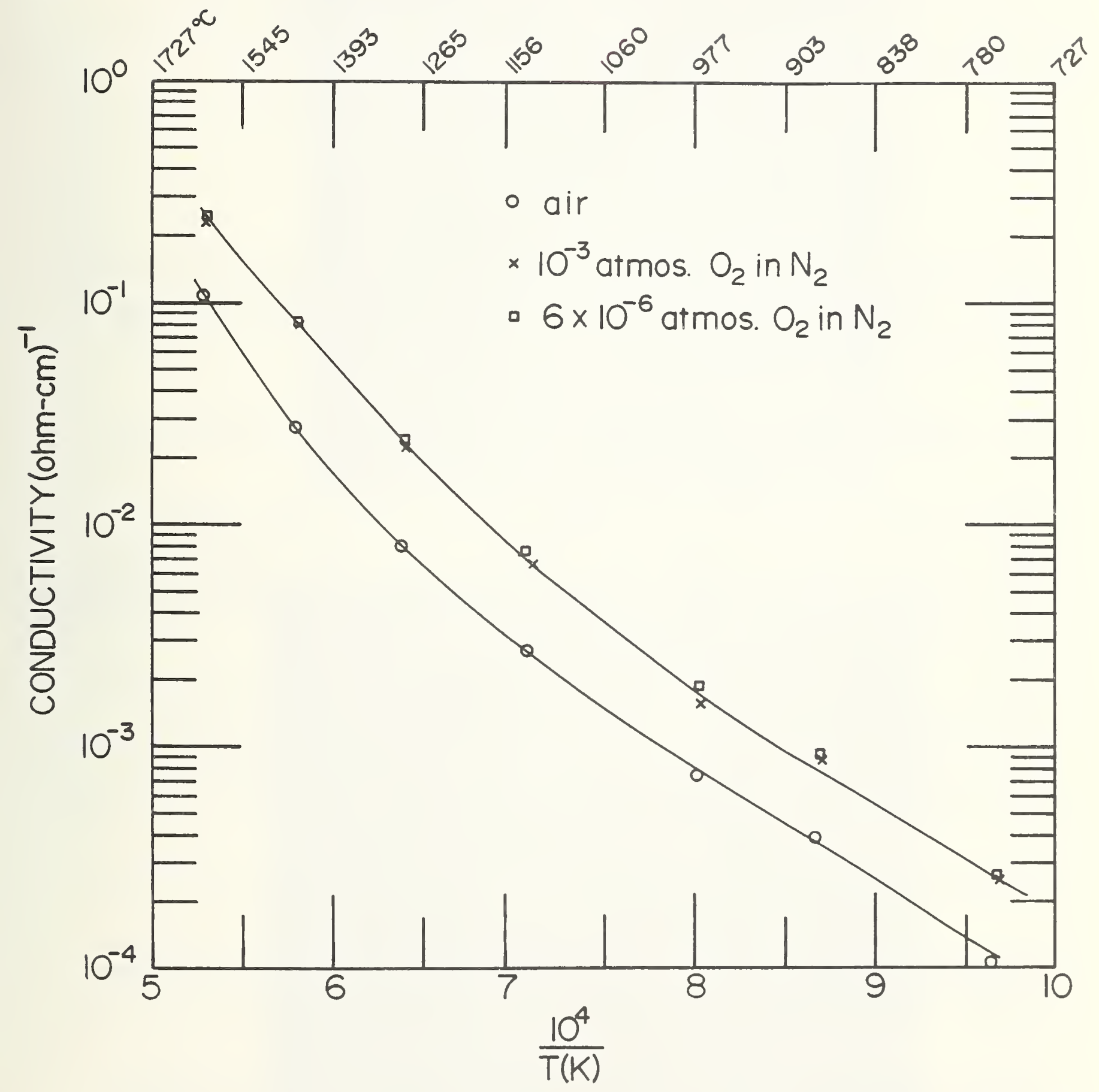

Figure C.3.2. Post-test Electrical Conductivity of Electrode 2206 $\left(82 \mathrm{ZrO}_{2}-18 \mathrm{CeO}_{2}\right)$. 
The cross section was examined with a scanning electron microscope and electron microprobe. These techniques, coupled with the optical microscopy, were used to identify the location and composition of the phases present in the $\mathrm{MgO}$ and electrodes. These compositions are expressed as approximate mass ratios of the elements.

The following is a detailed description of structural characterizations of each electrode pair:

$0.12 \mathrm{Y}_{2} \mathrm{O}_{3} \cdot 0.88 \mathrm{ZrO}_{2}(1100-2100$ Electrode Pairs $)$

1103 Cathode (Figure C.4.1): The electrode and MgO were extensively fractured. The electrode has expanded to a thickness of $0.71 \mathrm{~cm}$ and raised $0.35 \mathrm{~cm}$ above the MgO surface. Break-up occurred mainly between the larger, dense particles. There is also extensive reaction between the cement, potassium, and the MgO, especially at interior corners.

The Pt separated from the electrode, with little evidence of the wire mesh remaining. Some $P t$ has diffused into adjacent areas of the electrode and cement.

The electrode is single phase and contains no potassium except a trace adjacent to the Pt. The black area below the Pt, originally the $\mathrm{ZrO}_{2}$ cement, is very high in potassium and in many areas is almost pure potassium. The potassium extends down into the $\mathrm{MgO}$ and is located in the lower density areas which surround the dense MgO particles. The $\mathrm{K}$ concentration in the MgO decreases as the distance from the electrode increases.

The MgO adjacent to the electrode and at the gas surface has recrystallized and is single phase with large grains and few pores. About $0.1-0.2 \mathrm{~cm}$ below this layer is another recrystallized structure with columnar-1ike grains. This section also contains a second phase of $\mathrm{Zr}-\mathrm{Ca}$ located in cracks and pores $(\mathrm{Zr} / \mathrm{Ca} \cong 17 / 1)$. There is also a dark band of pure zirconia containing no calcium.

Below this, the $\mathrm{MgO}$ is free of $\mathrm{Zr}$ and $\mathrm{Ca}$ with some $\mathrm{K}$, which increases toward the cooler parts of the insulator.

2103 Anode (Figure C.4.1): There is little change in the overall structure of the electrode and insulator. Some separation has occurred in the cement causing the electrode to raise. The MgO has fractured with cracks initiating from the internal, machined corners.

The electrode has recrystallized to a depth of $\sim 0.05 \mathrm{~cm}$ below the surface and contains two second phases. The phase at the grain boundaries is composed of $\mathrm{Al}, \mathrm{K}$, and $\mathrm{Ca}$ with ratios of $\mathrm{Al} / \mathrm{K} \approx 6$ and $\mathrm{A} 1 / \mathrm{Ca} \approx 10$. This phase extends only to a depth of $0.02 \mathrm{~cm}$ from the surface. The lighter colored continuous phase is composed of $\mathrm{Zr}$ and $\mathrm{Y}$, and is free of potassium. The center of the 

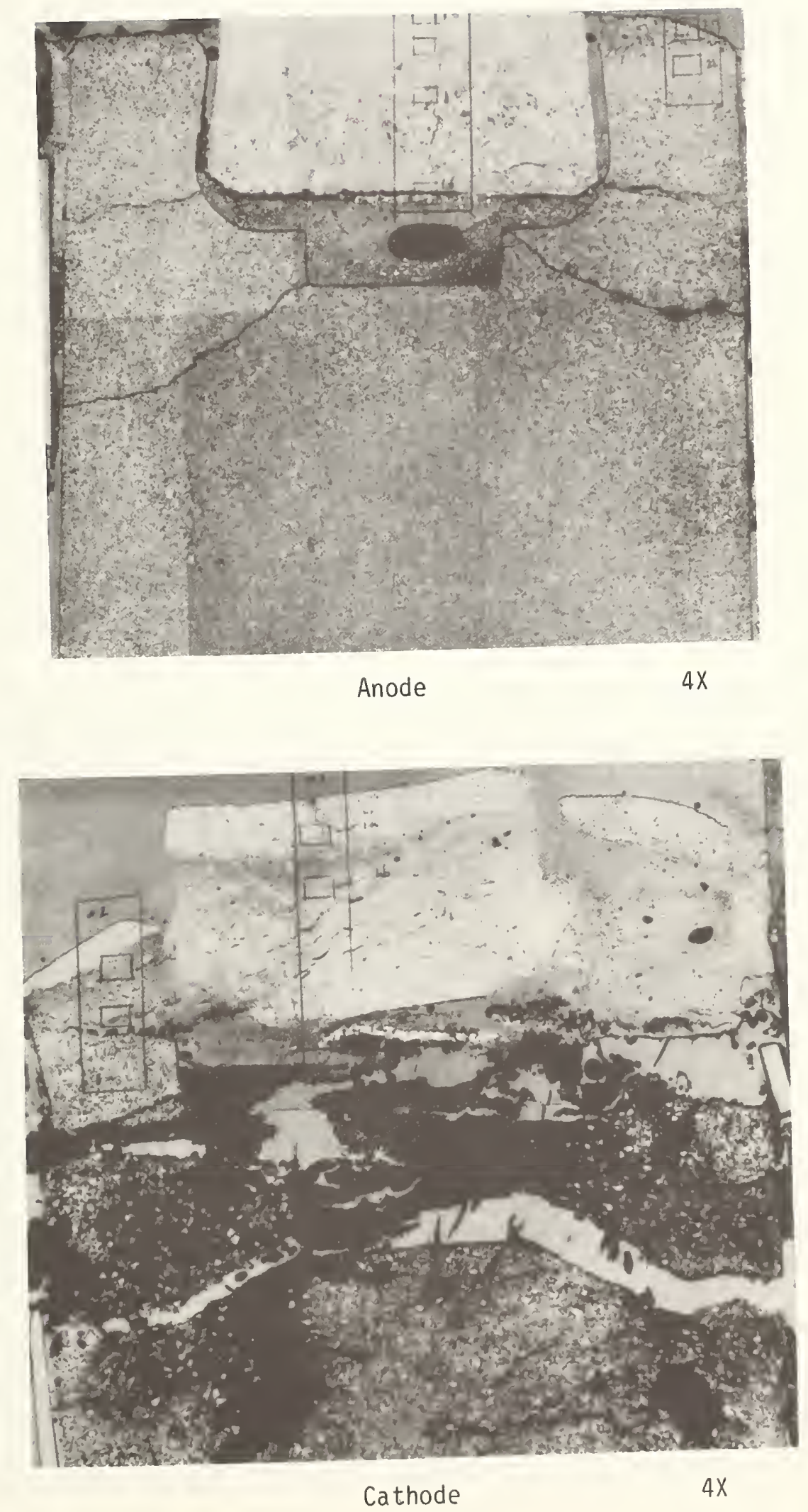

Figure C.4.1. Cross sections of anode and cathode for electrode pair 2103 and $1103\left(0.12 \mathrm{Y}_{2} \mathrm{O}_{3} \cdot 0.88 \mathrm{ZrO}_{2}\right)$. 
electrode has a single phase $\mathrm{Zr} / \mathrm{Y}$ structure, similar to the reference material, but is somewhat fractured. However, in some isolated areas, the lower density porous oxide areas contain varying amounts of $\mathrm{K}$ and $\mathrm{Ca}$. One area, for example, has $\mathrm{Zr} / \mathrm{K} \approx 2.5$ and $\mathrm{Zr} / \mathrm{Ca} \approx 7$.

The electrode immediately adjacent to the Pt and cement contain some $\mathrm{K}$ and some second phase with a $\mathrm{Zr} / \mathrm{Ca}$ of 1.3 .

The large $\mathrm{ZrO}_{2}$ particles in the cement have a $\mathrm{Zr} / \mathrm{Ca}$ ratio of 10 . The smaller particulates surrounding these larger particles contain $\mathrm{K}$ with a different $\mathrm{Zr} / \mathrm{Ca}$ ratio of 3.4 . The $\mathrm{Zr} / \mathrm{K}$ ratio is $\approx 7.3$. The potassium is present in the low density portions of the cement.

The $\mathrm{MgO}$ below the cement contains both $\mathrm{K}$ and $\mathrm{Zr}$ with ratios $\mathrm{Mg} / \mathrm{K} \approx 7.1$ and $\mathrm{Mg} / \mathrm{Zr} \approx 15$. This phase is concentrated in the pores and cracks. The larger MgO is free of K. The potassium diminishes rapidly away from the cement and at $0.1 \mathrm{~cm}$ from the cement only a trace of $K$ is found. At $0.2 \mathrm{~cm}$, no $K$ can be detected.

The MgO at the plasma surface has recrystallized to a depth of $0.31 \mathrm{~cm}$, from a dense surface into columnar type grains and pores and eventually into equiaxial grain growth.

Large second phase particles, up to $45 \mu \mathrm{m}$, are found near the surface and are composed of $\mathrm{Zr}$ and $\mathrm{Ca}$ with $\mathrm{Zr} / \mathrm{Ca} \approx 5$. Some of this phase persists below the surface into the columnar grains, but decreases as the distance from the surface increases. The $\mathrm{MgO}$ has a trace of $\mathrm{Fe}$, but is free of $\mathrm{K}$. However, the potassium begins to increase outside the columnar grain area and at $\downarrow 0.3 \mathrm{~cm}$, near the cement area, $80 \mu \mathrm{m}$ particles of $\mathrm{Zr}$, Ca, and $\mathrm{K}$ phase are found with ratios of $\mathrm{K} / \mathrm{Zr} \approx 2.5$ and $\mathrm{K} / \mathrm{Ca} \approx 1.3$. It is very prevalent in the cracks.

\section{$0.18 \mathrm{CeO}_{2} \cdot 0.82 \mathrm{ZrO}_{2}(1200-2200$ Electrode Pairs $)$}

1206 Cathode (Figure 4.2): The electrode has broken, segmented, swollen extensively and has interacted with the cement and $\mathrm{MgO}$. The top of the $0.67 \mathrm{~cm}$ thick electrode has recrystallized to a depth of $0.2 \mathrm{~cm}$ into a single phase, dense body $(\mathrm{Zr} / \mathrm{Ce} \approx 3$ ) with large rounded pores near the surface. There is, however, a trace of a second phase with $\mathrm{Zr} / \mathrm{Ca}$ ratio of 15 . The electrode is free of this phase below $0.24 \mathrm{~cm}$ and is also free of $\mathrm{K}$ except in the area immediately adjacent to the $\mathrm{Pt}$. This area also contains a second phase with a general composition of $\mathrm{Zr} / \mathrm{Si} \approx 3.5, \mathrm{Zr} / \mathrm{K} \approx 2.4$, and $\mathrm{K} / \mathrm{Ce} \approx 3.2$.

The reacted area surrounding the electrode adjacent to the MgO, which may have contained the $\mathrm{ZrO}_{2}$ cement, is three phase and is composed of fine grains and small pores. These phases are yet to be determined, but does have a high concentration of $\mathrm{K}$. 
The Mgo surface exposed to the plasma has recrystallized to a depth of $\approx 0.33$ $\mathrm{cm}$ and contains two phases containing $\mathrm{Zr}-\mathrm{Ca}$ and $\mathrm{Si}-\mathrm{Ca}(\mathrm{Si} / \mathrm{Ca} \approx 5)$. These precipitates, 1 to $5 \mu \mathrm{m}$ in diameter, are found only near the surface. A $0.13 \mathrm{~cm}$ thick columnar grain formation is located immediately below the above area. It also contains some second phase material at the pores of a composition similar to that at the surface. The cracks are parallel to the surface. The cement and $\mathrm{MgO}$ below the electrode have reacted extensively with the potassium. The resultant phase has penetrated between the platinum and the electrode. Some areas are pure potassium.

2206 Anode (Figure C.4.2): The electrode has recrystallized only on the surface near the plasma. The remainder of the electrode has changed relatively little, although there is some evidence of break-up in the lower density areas surrounding the larger particles. The electrode surface, which was exposed to the plasma, contains three phases, one of which can only be resolved above 1000X. A major phase (gray) contains $\mathrm{Mg}, \mathrm{Al}$, and $\mathrm{Ca}$ with $\mathrm{Al} / \mathrm{Mg} \sim 3$ and $\mathrm{Al} / \mathrm{Ca} \sim 1$. Inside this gray area, the very fine phase (light) contains $\mathrm{Al}, \mathrm{Zr}$, and $\mathrm{Ca}$ with $\mathrm{Al} / \mathrm{Zr} \sim 16$ and $\mathrm{Al} / \mathrm{Ca} \sim 3.5$. The lighter phase which surrounds these two phases is $\mathrm{Zr} / \mathrm{Ca} \sim 10.4$. This surface layer contains little, if any $\mathrm{Ce}$, but is high in $\mathrm{Ca}$ which decreases rapidly away from the surface. At $\sim 0.3 \mu \mathrm{m}$ from surface, the Ca is gone, and $\mathrm{Ce}$, has returned to the original composition. This area is free of potassium. The remainder of the anode is single phase. However, the microprobe results indicate the presence of potassium $>0.24 \mathrm{~cm}$ below the surface. The $\mathrm{K}$ occurs in several forms, one of which is a finger-like structure, that often crosses some cracks, indicating it may have resulted during polishing. Another form of the potassium appears as a particle, 3-10 $\mathrm{mm}$ in size, sitting on the surface. In the areas between this debris, no potassium is detected. Thus, the presence of $\mathrm{K}$ in the lower portion of the electrode will require some more resolution. However, since all other areas show the presence of relatively little $\mathrm{K}$, the source, other than the anode itself, cannot be defined.

The cement contains significant amounts of potassium, although the concentrations are orders of magnitude less than at the corresponding cathode. The $\mathrm{K}$ is located in the lower density areas ( $\mathrm{Kr} / \mathrm{K} \sim 11$ ) surrounding the larger calcia stabilized, zirconia particles, $\mathrm{Zr} / \mathrm{Ca} \sim 6$.

The Mgo, immediately below the cement, contains $\mathrm{Zr}$ and $\mathrm{K}, \mathrm{Mg} / \mathrm{Zr} \sim 27$ and $\mathrm{Mg} / \mathrm{K} \sim 11$. These elements are found only within a $0.05 \mathrm{~cm}$ band in the $\mathrm{MgO}$ adjacent to the cement.

The MgO exposed to the plasma has recrystallized to a depth of $\sim 0.2 \mathrm{~cm}$. A second phase composed of $\mathrm{Zr}$ and $\mathrm{Ca}$ is found in this area, $\mathrm{Zr} / \mathrm{Ca} \sim 9$. The MgO surrounding this phase, contains only a trace of iron, $\mathrm{Mg} / \mathrm{Fe} \sim 30$. This area also contains no potassium.

Below $0.2-0.25 \mathrm{~cm}$, the potassium concentration gradually increases, expecially in the cracks. Below the large crack, near the bottom of the electrode, there are areas of high potassium in the low density MgO. Concentrations of $\mathrm{K}$ in the anode are small compared to corresponding areas in the cathode. 

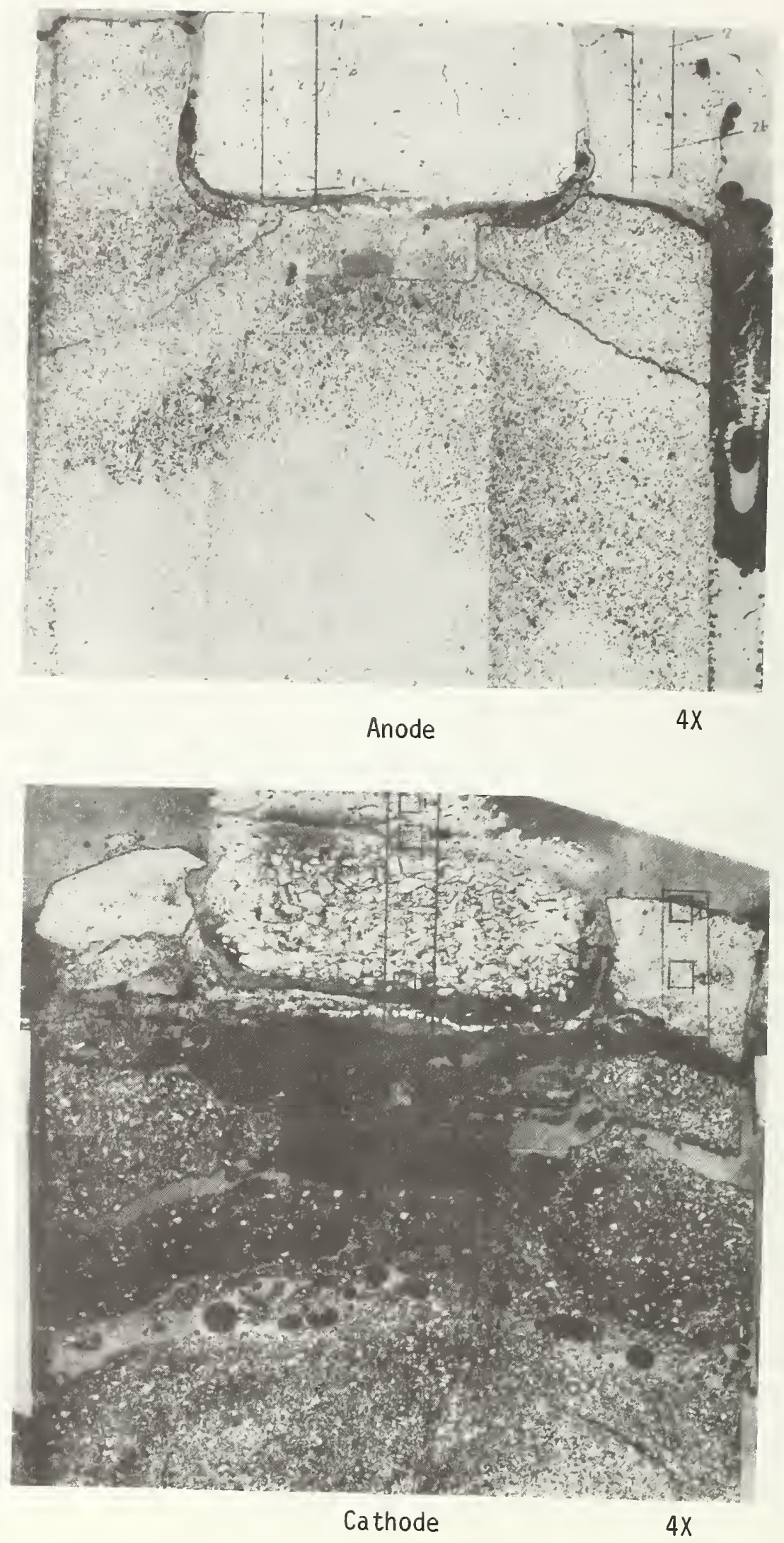

Figure C.4.2. Cross Sections of Anode and Cathode for Electrode Pair 2206 and $1206\left(0.18 \mathrm{CeO}_{2} \cdot 0.82 \mathrm{ZrO}_{2}\right)$ 
$0.5 \mathrm{CeO}_{2} \cdot 0.5 \mathrm{ZrO}_{2}(1300-2300$ Electrode Pairs $)$

1309 Cathode (Figure C.4.3): This cathode was fractured more than any other of the electrodes examined to date with total separation of electrode from the insulator. Pieces had to be replaced in some locations and may be mis-oriented.

The microstructure of the electrode was completely changed. There is a parallel crack $0.2 \mathrm{~cm}$ from the surface and the material has recrystallized extensively on both sides of this crack. Below this area, the electrode is cracked and has a multiphase structure.

The structure of the $\mathrm{MgO}$ has changed to a depth of $\sim 0.38 \mathrm{~cm}$. The surface is dense to a depth of $0.08 \mathrm{~cm}$ with a restructured columnar grain effect. Pores run parallel to these grains and to the thermal gradient. To more clearly describe these results, areas have been numbered (Figure C.4.3) and each of these areas are described in detail.

- 1-2:

This detached recrystallized area of the electrode is single phase and only a trace, if any, $K$ is present. The surface appears depleted in $\mathrm{Ce}(\mathrm{Zr} / \mathrm{Ce} \sim 2)$ and the area of recrystallized columnar grains has a $\mathrm{Zr} / \mathrm{Ce}$ ratio 3 indicating some loss or migration of $\mathrm{Ce}$. The recrystallized top surface does not contain any potassium.

- 3: In the center of the above area of the electrode, there is a Mg-Al containing second phase of unknown origin.

- 4: About $0.1 \mathrm{~cm}$ from the surface, the potassium begins to appear and continues to increase toward the bottom of the electrode.

$\circ 5:$

About $0.1 \mathrm{~cm}$ below the surface, and extending from the bottom of the $\mathrm{K}$ free area, the electrode is composed of two phases, totally different from the original oxide. The matrix phase is composed of about equal amounts of $\mathrm{Zr}$ and Ce plus $K$. The second phase, $\sim 20 \%$ of total area, is almost all $\mathrm{Ce}$ and contains no $\mathrm{K}$ with trace amounts of $\mathrm{Zr}$.

- 8-9: Near the bottom of the electrode, just above the Pt, there is an area which contains significant amounts of $\mathrm{Ca}$ in addition to $\mathrm{Zr}$ and $\mathrm{Ce}$. The $\mathrm{Ce}$ content is low. Some $\mathrm{Hf}$ is also present.

10: Just below the Pt, a black area is very high in $\mathrm{K}$ with some very small amounts of $\mathrm{Zr}, \mathrm{Ce}$, and $\mathrm{Zn}$. 
11: In the MgO near the bottom of the electrode and adjacent to the cement, the black area is nearly pure $\mathrm{K}$ with only trace amounts of $\mathrm{Ce}, \mathrm{Hf}$, and $\mathrm{Mg}$. In the $\mathrm{MgO}$, the $\mathrm{K}$ is concentrated in the low density areas surrounding the large MgO particles.

In a crack in the upper left corner of the electrode, there is a wide band of solidified $k$.

At the interface between the original $\mathrm{MgO}$ and electrode, a new phase has developed either from the cement or the electrode. It is a porous structure composed mainly of $\mathrm{Zr}$ with substantial $\mathrm{Hf}, \mathrm{K}$, and some $\mathrm{Ca}$. In the $\mathrm{MgO}$ adjacent to this area, the MgO contains a second phase of $\mathrm{Zr}$ and $\mathrm{Hf}$, but is free of $\mathrm{Ca}$ or $\mathrm{K}$.

14-15: The $\mathrm{Al}_{2} \mathrm{O}_{3}$ spacer between insulators has become potassium B-alumina. The top section (14) contains $\mathrm{K}(\mathrm{Al} / \mathrm{K} \approx 30)$. The $\mathrm{K}$ appears to be diffusing into the $\mathrm{Al}_{2} \mathrm{O}_{3}$ from the outside edges forming a distinct cone shaped area at the reaction boundary. The $\mathrm{K}$ is concentrated at the pores and the reaction area is also more porous. The $\mathrm{Al}_{2} \mathrm{O}_{3}$ below (15) contains no $\mathrm{K}$.

16-17: In the high density, recrystallized Mgo surface, there is a bright second phase composed of $\mathrm{Zr}$ with smaller amounts of $\mathrm{Ca}$ $(\mathrm{Zr} / \mathrm{Ca} \approx 24)$ and $\mathrm{Ce}(\mathrm{Zr} / \mathrm{Ce} \approx 6)$ and some $\mathrm{Mg}$ and $\mathrm{Hf}$.

18-19: In the columnar grain region of the MgO, a second phase is found at the pores. These pores are $\mathrm{Ca}$ stabilized $\mathrm{ZrO}_{2}$ containing Hf and $\mathrm{Ce}$.

In the $\mathrm{MgO}$, which has only partially recrystallized, the $\mathrm{Zr}$ containing second phase is not present and $\mathrm{K}$ is present in the irregularly shaped pores. The $\mathrm{K}$ concentration increases as the distance from the surface increases.

2309 Anode (Figure C.4.3): The electrode has fractured and top surface $(\sim 0.2 \mathrm{~cm})$ is missing. The exposed surface which remains has recrystallized into a dense body with spherical pores. The electrode is also cracked and has separated from the cement and platinum. The cement remains relatively intact with some separation from the $\mathrm{MgO}$.

At the surface, the MgO is recrystallized to the same depth as the electrode. A second phase is found near the surface to a depth of $\sim 0.05 \mathrm{~cm}$. The MgO again is cracked, initiated at the machined internal corners which seat the electrode. 

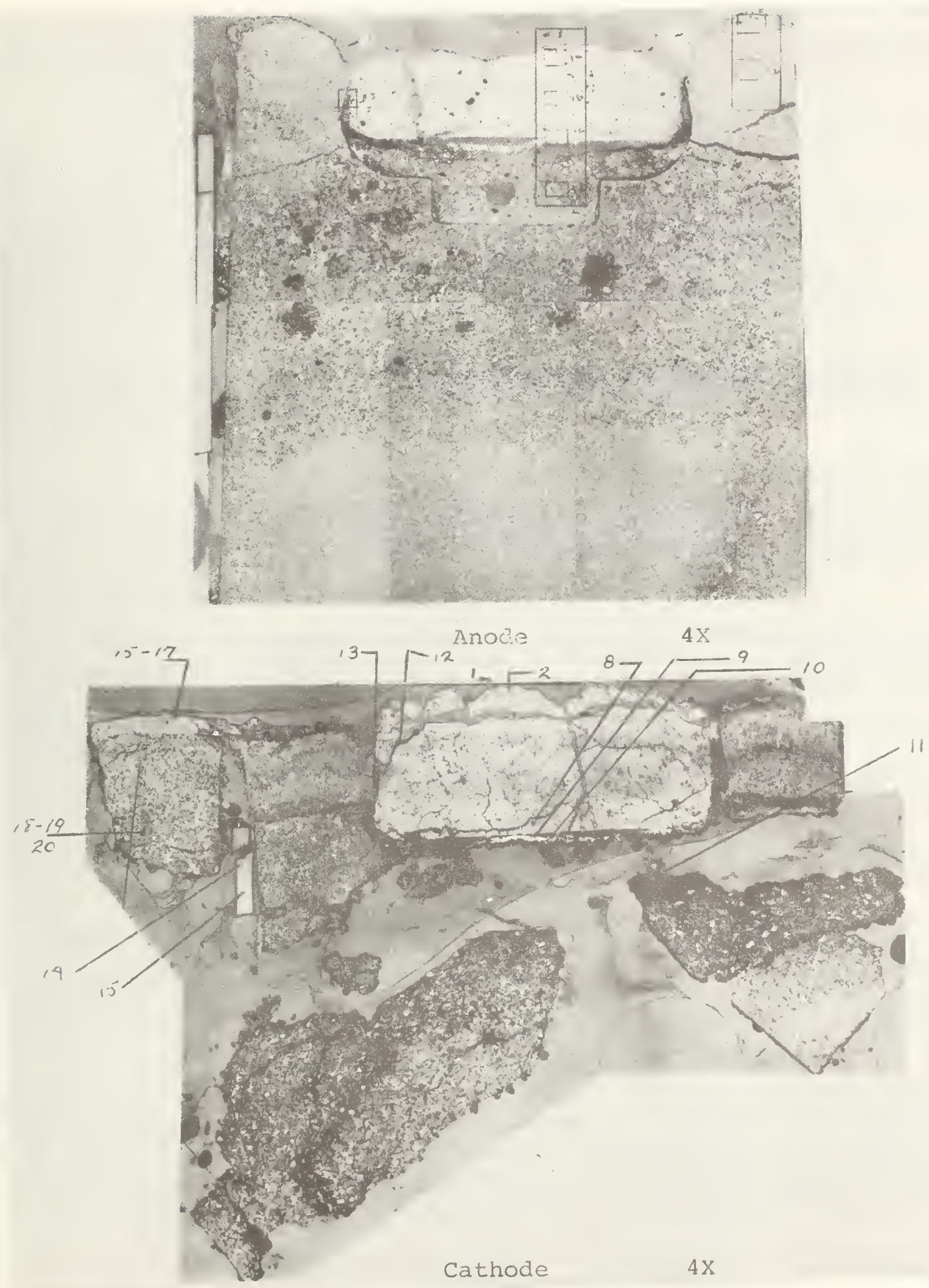

Figure C.4.3 Cross Sections of Anode and Cathode for Electrode Pair
2309 and $1309\left(0.5 \mathrm{CeO}_{2} \cdot 0.5 \mathrm{ZrO}_{2}\right)$ 
The remaining exposed surface of the electrode, which has recrystallized, also has a gray second phase located principally at the grain boundaries. This phase contains $\mathrm{Ce}, \mathrm{K}, \mathrm{Zr}$, and $\mathrm{Al}(\mathrm{Ce} / \mathrm{K} \approx 0.7, \mathrm{Ce} / \mathrm{Zr} \approx 4, \mathrm{Al} / \mathrm{Ce} \approx 6)$. These ratios vary, but the $A l$ and $K$ are always high. This second phase is limited to a narrow band, $0.1 \mathrm{~cm}$ thick along the surface.

Near the center of the electrode, there appears to be a light gray phase in the optical micrograph. However, this has the same composition as the matrix and is thought to be shallow pores or cracks. Some of the large cracks in the electrode interior contain $\mathrm{K}$, $\mathrm{Al}$, and $\mathrm{Si}$ with ratios $\mathrm{k} / \mathrm{Al} \approx 1$ and $\mathrm{K} / \mathrm{Si} \approx 2$.

A dark gray zone between the platinum and the electrode contains $\mathrm{Zr}$ with some Ca, apparently originating from the cement. It does not, however, contain any $\mathrm{K}$.

The larger particles in the cement immediately below the $\mathrm{Pt}$ are $\mathrm{Zr}$ and $\mathrm{Ca}(\mathrm{Zr} / \mathrm{Ca} \approx 7)$. The low density areas surrounding these particles contain about equal amounts of $\mathrm{Zr}$ and $\mathrm{K}$ plus the $\mathrm{Ca}$. At $0.1 \mathrm{~cm}$ from the top edge of the cement, the $\mathrm{Zr} / \mathrm{K}$ ratio is $\approx 15$ and at $0.15 \mathrm{~cm}$, the ratio is $\approx 17$.

In the MgO below the cement, the large particles are pure Mgo. The low density $\mathrm{MgO}$ is high in $\mathrm{K}$ with some $\mathrm{Zr}$. The $\mathrm{K}$ concentration decreases as the distance from the electrode increases.

In the recrystallized MgO near the electrode surface, there are two phases. The light gray phase occurs only near the surface and contains $\mathrm{Zr}, \mathrm{Ca}$, $\mathrm{Ce}$, and $\mathrm{Si}$. The ratios are $\mathrm{Zr} / \mathrm{Ce} \approx 4, \mathrm{Zr} / \mathrm{Ca} \approx 3.4$, and $\mathrm{Zr} / \mathrm{Si} \approx 4.4$. The bright phase contains $\mathrm{Mg}$ and $\mathrm{Si}$ with $\mathrm{Mg} / \mathrm{Si}$ ratio $\approx 1.2 / 1$.

A crack in the MgO contains a 100-150 $\mu \mathrm{m}$ band of almost pure Ca.

Near the Pt on the side of the electrode between the MgO, there is a phase composed of nearly $100 \% \mathrm{Zr}$ with a trace of $\mathrm{K}$. There is no Ca present. The material adjacent to the $\mathrm{MgO}$ in this same area contains $\mathrm{Zr}$ with high $\mathrm{K}$.

$0.75 \mathrm{CeO}_{2} \cdot 0.25 \mathrm{ZrO}_{2}(1400-2400$ Electrode Pairs $)$

1414 Cathode (Figure C.4.4): The changes in the upper portion of the electrode were extensive with the electrode separating from the Pt and cement. The MgO was cracked, but not extensively degraded. The top half of the electrode had fragmented into smaller pieces, with only remnants of larger particles remaining. The surface had recrystallized to a depth of only $0.03 \mathrm{~cm}$.

The Pt paste and mesh had separated from the electrode in the center and from the cement. The mesh was eroded slightly. 
The recrystallized band in the electrode contained very small, $10-25 / \mu \mathrm{m}$ diameter, second phase particles composed of $\mathrm{Al}$, Ca and Ce, with ratios of $\mathrm{Ce} / \mathrm{Al} \approx 7.5$ and $\mathrm{Ce} / \mathrm{Ca} \approx 12$. This phase did not contain $\mathrm{Zr}$ and was found in a band to a depth of $300 \mu \mathrm{m}$ from the surface.

Next to the surface is a narrow band of almost pure $K$. Potassium is also found in some cracks in this recrystallized area. Some pores in this area also contain a phase composed of $\mathrm{Zr}, \mathrm{K}$, and $\mathrm{Ce}$ with ratios $\mathrm{Ce} / \mathrm{Zr} \approx 5$ and $\mathrm{Ce} / \mathrm{K} \approx 5$. The continuous matrix contains no potassium. In the broken central portion of the electrode, the oxide contains no $\mathrm{K}$ with $\mathrm{Ce} / \mathrm{Zr} \approx 5$.

The bottom of the electrode is high in $\mathrm{K}$, especially in the low density areas surrounding the large particles and in the cracks found in the larger particles. Some $1-5 \mu \mathrm{m}$ particles of pure $\mathrm{K}$ are scattered in the low density area. There is a narrow band of pure $K$ adjacent to the bottom of the electrode. The platinum is partly eroded, presumably by the $\mathrm{K}$, since the pores in the Pt are also hj.gh in $\mathrm{K}$.

The cement contains significant quantities of $K$ located in the void spaces around the large solid particles. These particles contain $\mathrm{Zr}$ but no Ca. The $\mathrm{Ca}$ is located in the smaller granular phase which surrounds these particles. The MgO immediately below the cement is high in $\mathrm{K}$. However, the $\mathrm{K}$ diminishes rapidly and $0.2 \mathrm{~cm}$ from the cement, the $\mathrm{MgO}$ is free of $\mathrm{K}$.

In the recrystallized $\mathrm{MgO}$ near the electrode surface, there is a high concentration of $\mathrm{K}$ in the pores and cracks. In addition, there is a light second phase containing $\mathrm{Zr}, \mathrm{Ce}, \mathrm{Ca}$, and $\mathrm{Mg}$ with ratios $\mathrm{Zr} / \mathrm{Ce} \approx 10, \mathrm{Zr} / \mathrm{Ca} \approx 16$, and $\mathrm{Zr} / \mathrm{Mg} \approx 20$. This phase seems to be located only in the more dense band $\sim 0.1$ to $0.6 \mathrm{~cm}$ next to the surface. Below this band, this phase is less dense and is smaller in size and composition changes to Ce/Zr ratio of 5.0 with no $\mathrm{Ca}$ or $\mathrm{Mg}$.

The potassium in the MgO increases as the distance from the surface increases, $\sim 0.6-0.8 \mathrm{~cm}$, then decreases as the distance exceeds $\sim 0,8 \mathrm{~cm}$.

2414 Anode (Figure C.4.4): The electrode and insulator are relatively intact although the electrode is badly cracked and separated from the Pt and cement. The electrode separated horizontally and parallel to the surface about midway between the top and the bottom. Recrystallization occurred to a depth between 0.06 and $0.1 \mathrm{~cm}$ from the surface. The lighter phase in the recrystallized area does, however, contain extensive second phase containing $\mathrm{Zr}, \mathrm{Ca}$, and $\mathrm{Ce}$ with ratios $\mathrm{Ce} / \mathrm{Zr} \approx 4, \mathrm{Ce} / \mathrm{Ca} \approx 10$. There is no $\mathrm{K}$ in this phase. A light gray phase contains $\mathrm{Al}, \mathrm{Cr}, \mathrm{K}, \mathrm{Ca}$, and $\mathrm{Ce}$ with ratios $\mathrm{Al} / \mathrm{Ce} \approx 3$, $\mathrm{Al} / \mathrm{Zr} \approx 31, \mathrm{Al} / \mathrm{K} \approx 15$, and $\mathrm{Al} / \mathrm{Ca} \approx 5$. These phases appear isolated near the surface. The pores in the electrode near the Pt contains $\mathrm{Zr}, \mathrm{Ca}$, and $\mathrm{Ce}$ inclusions with $\mathrm{Zr} / \mathrm{Ca} \approx 7$ and $\mathrm{Zr} / \mathrm{Ce} \approx 5$. This portion of the electrode is free of $\mathrm{K}$. The low density portion of the cement contains $\mathrm{K}$ with $\mathrm{Zr} / \mathrm{K}$ ratio near 3 . This ratio varies widely within the cement. 

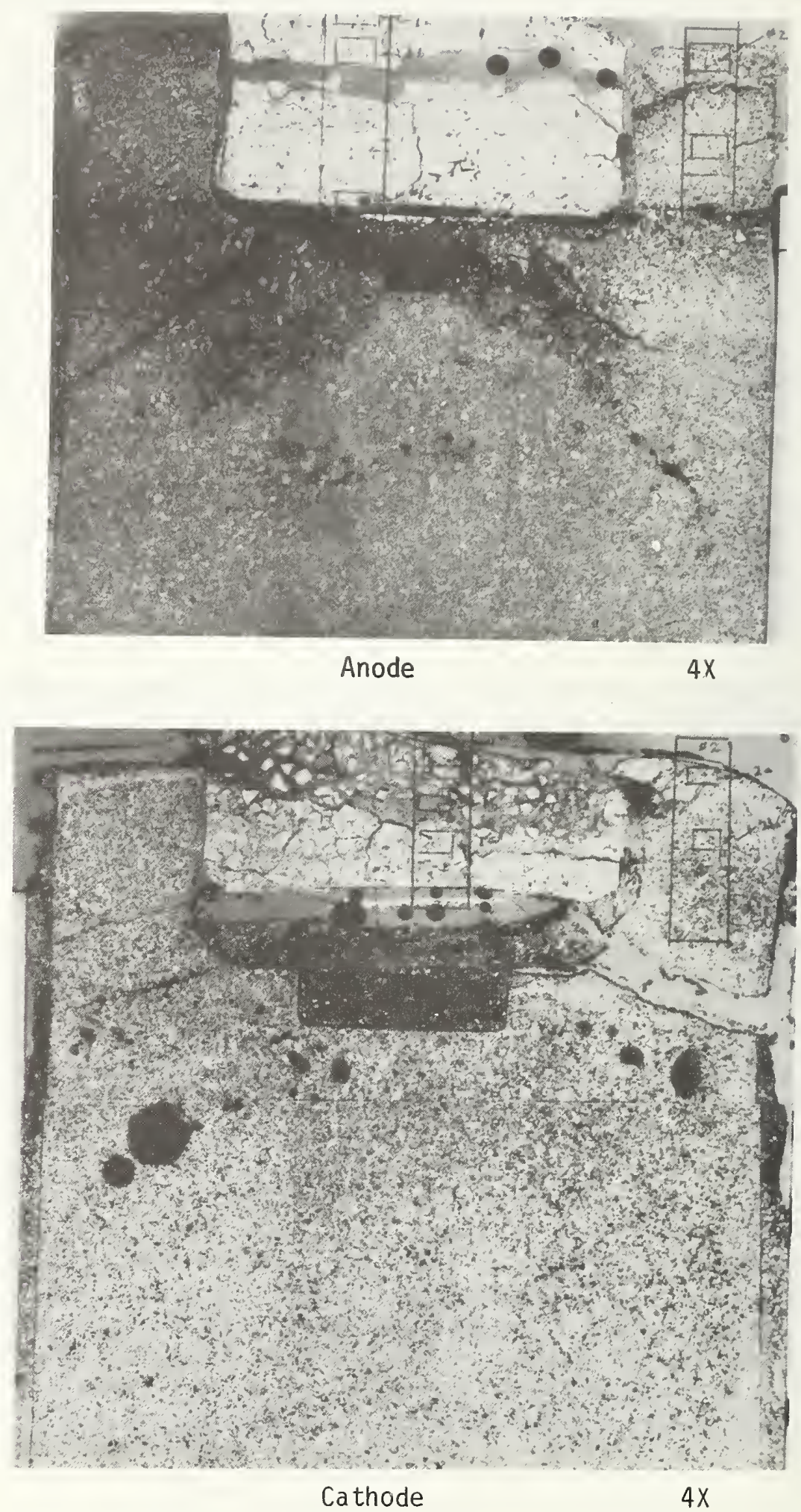

Figure C.4.4. Cross Sections of Anode and Cathode for Electrode Pair 2414 and $1414\left(0.75 \mathrm{CeO}_{2} \cdot 0.25 \mathrm{ZrO}_{2}\right)$ 
The MgO, adjacent to the cement, contains a small amount of $K$. At $0.05 \mathrm{~cm}$, a trace of $\mathrm{K}$ is found, and at $0.1 \mathrm{~cm}$ from the cement, the $\mathrm{MgO}$ is free of potassium.

The MgO at the surface adjacent to the electrode is crystallized containing large spherical pores and a bright second phase at the surface. This phase is composed of $\mathrm{Ce}, \mathrm{Zr}, \mathrm{Ca}$, and a trace of $\mathrm{Si}$. Ratios are $\mathrm{Ce} / \mathrm{Zr} \approx 2$, $\mathrm{Ce} / \mathrm{Ca} \approx 5$, and $\mathrm{Ce} / \mathrm{Si} \approx 8$. The continuous phase in this area contains $\mathrm{Mg}, \mathrm{Zr}, \mathrm{K}, \mathrm{Ca}, \mathrm{Fe}$, Ni with ratios $\mathrm{Mg} / \mathrm{Zr} \approx 33, \mathrm{Mg} / \mathrm{K} \approx 11$, $\mathrm{Mg} / \mathrm{Ca} \approx 13, \mathrm{Mg} / \mathrm{Fe} \approx 22$, and $\mathrm{Mg} / \mathrm{Ni} \approx 33$. This latter phase is concentrated at the surface and at $0.1 \mathrm{~cm}$ from the surface, only $\mathrm{Si}$ and $\mathrm{K}$ remain. There is a large increase of $\mathrm{K}$ in the cracks of the $\mathrm{MgO}$.

The copper bonding has separated from the back of the MgO. The Cu interface is two phase, being composed of silver and copper.

$0.78 \mathrm{CeO}_{2} \cdot 0.20 \mathrm{ZrO}_{2} \cdot 0.02 \mathrm{Ta}_{2} \mathrm{O}_{5}(1500-2500$ Electrode Pairs $)$

1517 Cathode (Figure C.4.5): The electrode has experienced substantial fracture with nearly complete restructuring. The MgO insulator and cement supporting the electrode is extensively degraded with the Pt separated from the electrode.

The surface of the electrode exposed to the plasma has recrystallized to a depth of $20.04 \mathrm{~cm}$ and is a two phase region also containing large pores. Along the very outer edge ( 0.01 . cm width) there is a phase containing $\mathrm{Zr}$, $\mathrm{Ce}$, and $\mathrm{Ca}$ with a $\mathrm{Zr} / \mathrm{Ce}$ ratio of $\approx 4$ and a $\mathrm{Zr} / \mathrm{Ca}$ ratio near 7 . There is little or no $\mathrm{Ta}$ in this layer. This area of high $\mathrm{Zr}$ decreases very rapidly and at about $100 \mu \mathrm{m}$ below the surface the $\mathrm{Ce} / \mathrm{Zr} \approx 2$ and the $\mathrm{Ta}$ begins to increase. This area is free of $K$.

Beyond $0.01 \mathrm{~cm}$, there are three phases, a light gray phase containing Ce, $\mathrm{Ta}, \mathrm{Ca}$, and $\mathrm{Zr}$ with $\mathrm{Ce} / \mathrm{Ta} \approx 4 ; \mathrm{Ce} / \mathrm{Ca} \approx 4 ;$ and $\mathrm{Ce} / \mathrm{Zr} \approx 3$. The darker phase contains $\mathrm{Ce}, \mathrm{Ca}$, and $\mathrm{Zr}$ with ratios $\mathrm{Ce} / \mathrm{Ca} \approx 3.5$ and $\mathrm{Ce} / \mathrm{Zr} \approx 6$. The area is also free of $K$. The original continuous phase has a Ce/Zr $\approx 12$ with a trace of Ta. At approximately $0.1 \mathrm{~cm}$ beneath the surface, the Ce/Zr/Ta ratios approach that of the reference electrode.

At $0.25 \mathrm{~cm}$ beneath the surface, $\mathrm{K}$ begins to appear with a Ce/K ratio 12 . At $0.35,0.45$ and $0.55 \mathrm{~cm}$, the surface of the Ce/K ratios are approximately 8,6 , and 6 respectively.

In the center of the electrode a second phase comprising $1-2 \%$ of total area appears. The continuous phase is $\mathrm{Ce}$ and $\mathrm{Zr}$ only with $\mathrm{Ce} / \mathrm{Zr} \approx 12$. The second phase contains $\mathrm{Ce}, \mathrm{K}, \mathrm{Zr}$, and a trace of $\mathrm{Ta}$ with $\mathrm{Ce} / \mathrm{K} \approx 12, \mathrm{Ce} / \mathrm{Zr}-3$. This structure extends down to the bottom of the electrode.

Between the separated Pt and the electrode is a large porous structure area containing long needle-like grains. This area is almost pure $\mathrm{Zr}$ and is free of $\mathrm{Ce}$, Ca, but does contain some $\mathrm{K}$. The black area below the Pt is very high in $\mathrm{K}$. The remnants of the cement contain large $\mathrm{ZrO}_{2}$ particles with $\mathrm{Zr} / \mathrm{Ca} \approx 8$. The area surrounding these particles, which orginally were low density cement, is nearly pure $k$. 
The MgO below the cement contains large quantities of $\mathrm{K}$. The $\mathrm{Mg} / \mathrm{K}$ ratios at the cement-MgO interface and $0.1 \mathrm{~cm}$ below are 4 and 3 respectively.

The $\mathrm{MgO}$ at the plasma surface has also restructured. Immediately adjacent to the surface is a single phase recrystallized area, some of which appears to have spalled away. This area contains $\mathrm{Ce}, \mathrm{Ca}, \mathrm{K}, \mathrm{Zr}$, and $\mathrm{Ta}$ with ratios $\mathrm{Ce} / \mathrm{T} \approx \approx 12, \mathrm{Ce} / \mathrm{Ca} \approx 5, \mathrm{Ce} / \mathrm{K} \approx 6$, and $\mathrm{Ce} / \mathrm{Zr} \approx 2$.

Immediately below this begins a two phase region which at a depth of $0.2 \mathrm{~cm}$ contains pure $\mathrm{Mg}$ and a grain boundary, minor phase containing $\mathrm{Ce}$, $\mathrm{K}$, and $\mathrm{Zr}$, with ratios $\mathrm{Ce} / \mathrm{K} 1.6$ and $\mathrm{Ce} / \mathrm{Zr}$ 1. This second phase decreases toward the bottom of the electrode whereas the potassium begins to increase especially at the grain boundaries.

2517 Anode (Figure C.4.5): The electrode has fractured considerably. However this was an instrumented section and the central hole may have contributed to the fragmentation. The surrounding $\mathrm{MgO}$ is also cracked with most structural changes occurring near the plasma surface. The Pt has separated from the electrode while the cement remains partially intact.

The surface of the electrode has recrystallized to a depth of $0.25-0.3 \mathrm{~cm}$. Along the entire surface is a two phase area, a gray phase containing $\mathrm{Al}$ and $\mathrm{K}$ with $\mathrm{Al} / \mathrm{K} \approx 3.4$ and a light phase containing $\mathrm{Zr}, \mathrm{Ca}$, and $\mathrm{Ce}$, with $\mathrm{Ce} / \mathrm{Ca} \approx 4$ and $\mathrm{Ce} / \mathrm{Zr} \approx 1$. This is much lower than normal. The concentration of this phase deareases rapidly toward the interior of the electrode and at $0.05 \mathrm{~cm}$ below the surface the $\mathrm{Zr} / \mathrm{Ce}$ ratio has returned to the expected value.

The remainder of the electrode has a normal composition, but small amounts of $\mathrm{K}$ are found in the cracks.

The cement contains high concentrations of $\mathrm{K}$ located in the low density porous areas of the cement.

The MgO immediately adjacent to the cement contains considerable $\mathrm{K}$ and also some $\mathrm{Zr}$, with the $\mathrm{Mg} / \mathrm{K} \approx 7$ and the $\mathrm{Mg} / \mathrm{Zr} \approx 14$. Both the $\mathrm{Zr}$ and $\mathrm{K}$ are located in the lower density $\mathrm{MgO}$ and decrease rapidly in concentration toward the bulk MgO. At $0.1 \mathrm{~cm}$ below the cement, the $\mathrm{Mg} / \mathrm{K} \approx 13$ and at $0.4 \mathrm{~cm}$ the $\mathrm{MgO}$ is free of $\mathrm{K}$.

The MgO surface has recrystallized to varying dgrees to depths up to $0.4 \mathrm{~cm}$. This area is generally single phase MgO except at the surface where some two phase particles are attached. The lighter phase contains $\mathrm{Zr}$ and $\mathrm{Ca}$ only with a $\mathrm{Zr} / \mathrm{Ca}$ ratio of $\approx 8$. The darker continous gray phase contains $\mathrm{Al}$, $\mathrm{Mg}$, and traces of $\mathrm{Fe}$. The $\mathrm{Al} / \mathrm{Mg}$ ratio is $\approx 2.8$ and the $\mathrm{Al} / \mathrm{Fe}$ ratio is $\approx 19$. This area is free of $\mathrm{K}$. Some of these phases, in particular the $\mathrm{Zr}-\mathrm{Ca}$ phase, extend into the $\mathrm{MgO}$ to a depth of $\approx 0.05 \mathrm{~cm}$. 
The MgO contains only small amounts of $\mathrm{K}$ which increases as the distance from the surface increases. Only trace amounts of $\mathrm{K}$ are found near the surface and at 0.18 and $0.35 \mathrm{~cm}$ below the surface, the $\mathrm{Mg} / \mathrm{K}$ ratios are $\approx 20$ and $\approx 4$, respectively. Below the large crack which is found $1 \mathrm{~cm}$ below the surface the $K$ again begins to decrease. 


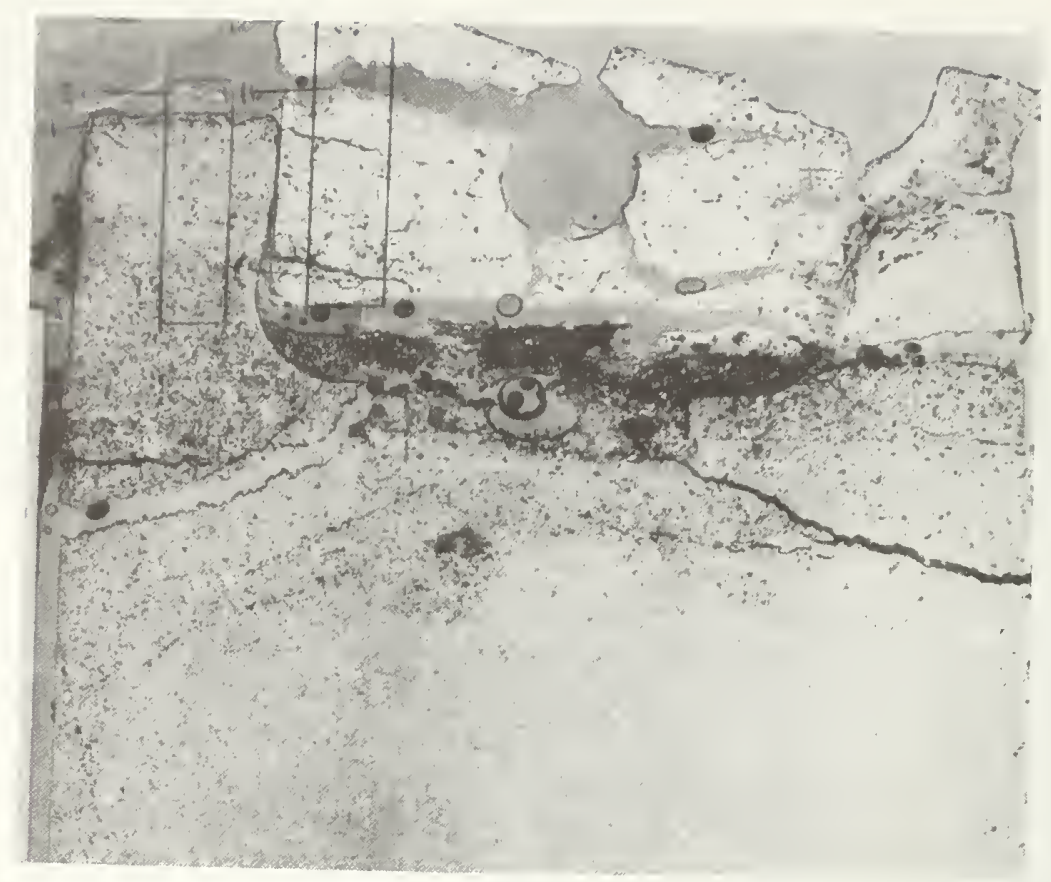

Anode

$4 x$

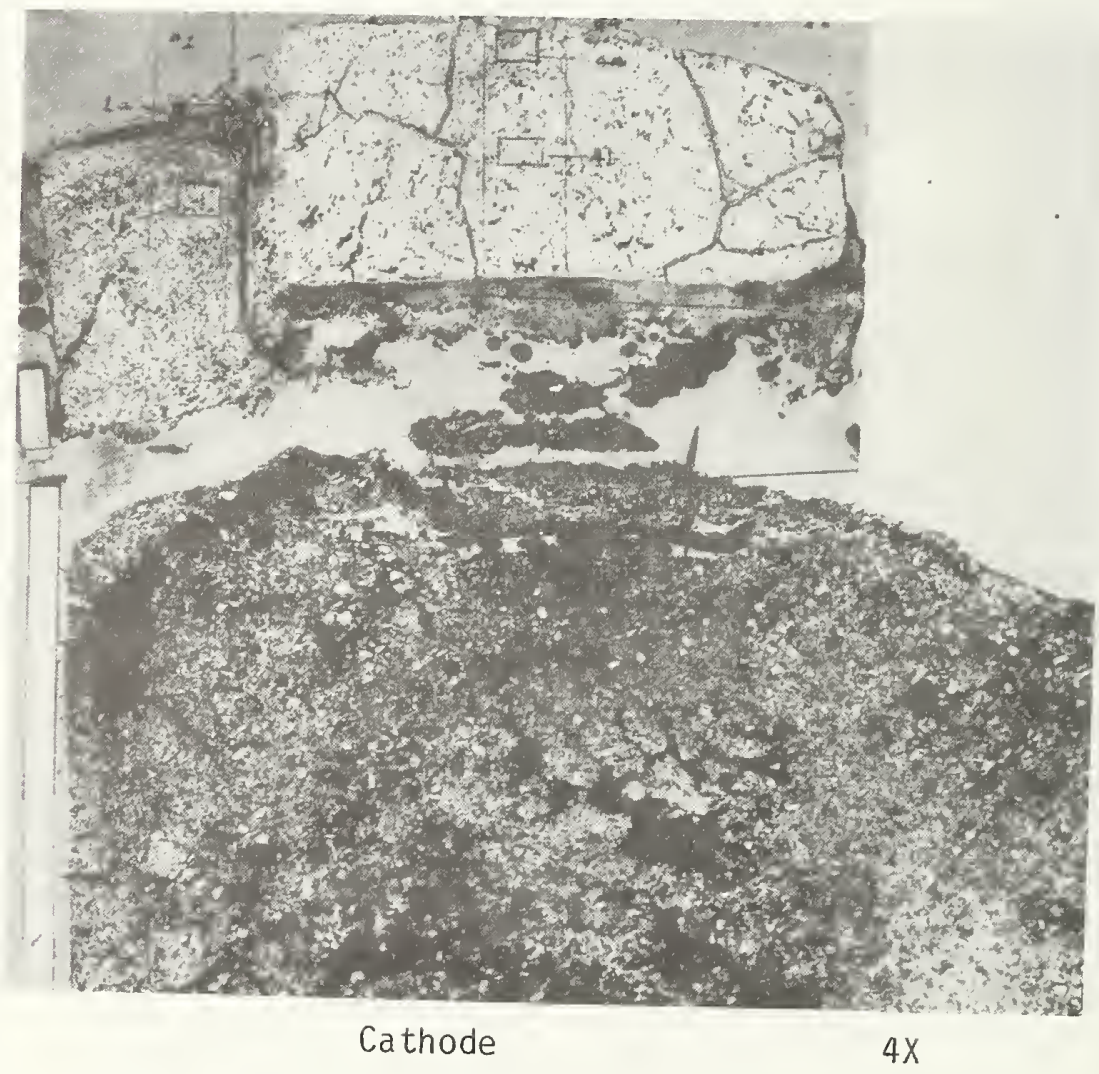

Figure C.4.5. Cross Sections of Anode and Cathode for Electrode Pair 2517 and $1517\left(0.78 \mathrm{CeO}_{2} \cdot 0.20 \mathrm{ZrO}_{2} \cdot 0.02 \mathrm{Ta}_{2} \mathrm{O}_{5}\right)$. 


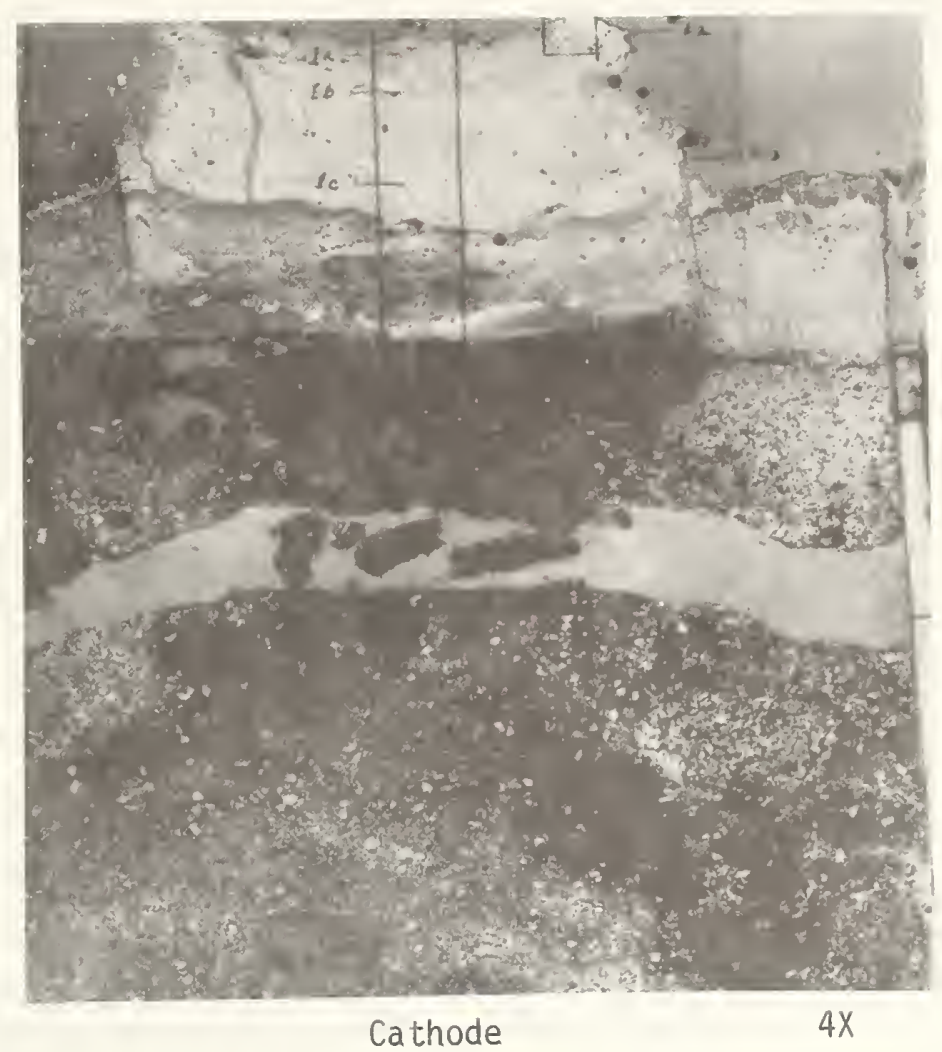

Figure C.4.6. Cross Section of Cathode $1102\left(0.12 Y_{2} \mathrm{O}_{3} \cdot 0.88 \mathrm{ZrO}_{2}\right)$

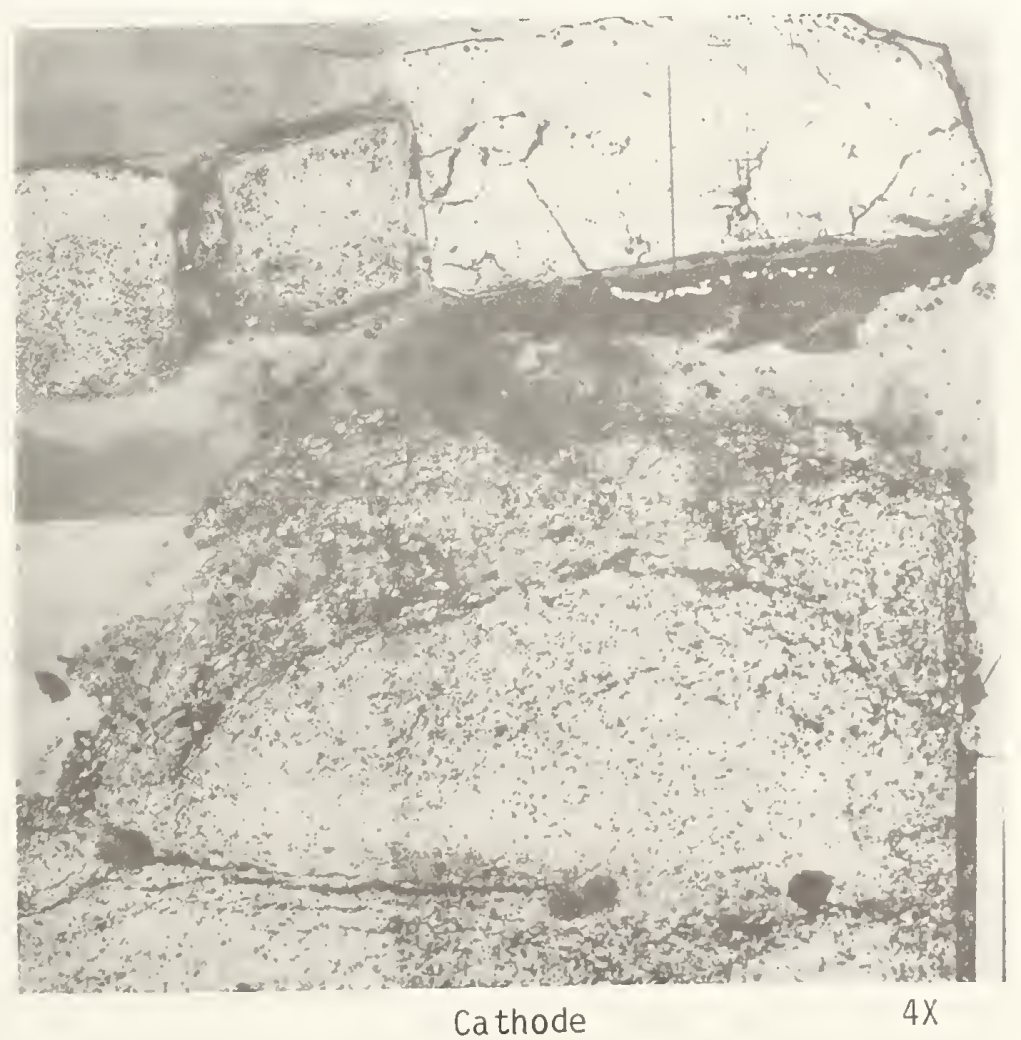

Figure C.4.7. Cross Section of Cathode $1310\left(0.5 \mathrm{CeO}_{2} \cdot 0.5 \quad \mathrm{ZrO}_{2}\right)$ 
C.4.1 Specific Observations Concerning Various Materials of the Tested Channel.

\section{Potassium}

The highest concentrations of potassium were associated with the cathode side of the channel, concentrating in that portion of the materials which were at operating temperature of approximately 600 to $1300{ }^{\circ} \mathrm{C}$. In the $\mathrm{MgO}$, cement, and in some electrodes, the potassium is associated with the lower density, porous areas which surround the large oxide particles. Potassium is also found in cracks. It appears that the transport of potassium in the oxide is directly related to the open porosity associated with the low density structure of the maserials.

Little potassium is found on or near the plasma surface of the Mgo or cathode. Some potassium was found on the anode surfaces.

Mg0 Insulator

The MgO exposed to the plasma had recrystallized to depths as much as $0.4 \mathrm{~cm}$. Although not observed in all electrode pairs, the recrystallization of the MgO generally consisted of three different structures.

(1) Dense band near the surface which varied in width from 0.02 to $0.10 \mathrm{~cm}$. This layer was 3 to 5 times wider on the cathode side than on the anode. This layer also contained a second phase composed principally of zirconia and calcia. However, on the downstream electrodes, this phase also contained increasing amounts of cerium. The calcium concentration was highest on the anode. The anode also often contained silicon. No potassium was observed at the surface. Other impurities, eg. $\mathrm{Fe}, \mathrm{Ni}, \mathrm{Al}$ were also observed on specific electrodes, but in small amounts.

(2) Columnar type grains extended to depths between $0.7-0.18 \mathrm{~cm}$. (The depths were approximately the same for the cathode and anode). These long grains were associated with a high porosity at the grain boundaries. On the cathode side, a second phase was found at the grain boundaries. This phase is thought to be a $\mathrm{CeO}_{2}$ stabilized $\mathrm{ZrO}_{2}$ since more and more $\mathrm{CeO}_{2}$ was found in the downstream $\mathrm{MgO}$. Little, if any, second phase was present in the columnar type grains of the Mgo near the anode. This area, except in selected cracks, was also free of potassium.

(3) Equiaxed grain growth occurred to a depth from the surface of approximately 0.3 to $0.4 \mathrm{~cm}$. This recrystallization appeared as a densification of the low density fines which surrounded the larger particles, in a decrease in the number of pores, and in an increase in pore size. This recrystallized area of the cathode only sometimes contained a second phase and was also the area where potassium was first observed in the $\mathrm{MgO}$.

- The erosion, degradation and recrystallization of the Mgo appeared to be more severe on the MgO which was on the upstream side of the electrode. Perhaps associated with this effect, is the apparent increased reaction between the MgO, the cement and the upstream side of the electrode. This effect appeared to be more pronounced on the anode than on the cathode. 
-The cracking of the MgO appeared similar for all electrodes. Cracks appeared to initiate from the corners of the machined recesses in the insulator. In most insulators, these cracks were found $00.60 .7 \mathrm{~cm}$ from the surface. Most of these cracks contained potassium.

-The potassium penetrated deep into the MgO below the cement and cathode. Penetration in the $\mathrm{MgO}$ below the cement of the anodes was minor, with only trace amounts $0.05 \mathrm{~cm}$ below the cement-MgO interface. The potassium penetration was greatest in the high current density cathodes.

\section{Electrodes}

The microstructure of each electrode pair was unique but some general conclusions may be made.

- The surface of most electrodes had recrystallized into a dense layer often with large spherical pores. This layer varied in thickness $(0.02-0.1 \mathrm{~cm})$ from electrode to electrode. With the exception of the 1103 cathode, the surface contained from one to three phases, with the concentration of the second phases highest at the plasma surface. These second phases on the cathode were principally zirconia containing varying amounts of calcium and cerium. On the anode surface, more than one phase was found and in addition to the zirconiacalciaceria phase, phases high in aluminum were present. Potassium was also found in some phases. These results are summarized in Table C.4.1. 
Table C.4.1 PHASES AND APPROXIMATE CONPOSITIONS IN ELECTRODES: NEAR PLASMA SURFACE

MAJOR PHASE*

MINOR PHASE*

Cathode

1103

1206

1309

1414

1517

Anode

2103

2206

2309

2414

2515
(1) $\mathrm{Ce} / \operatorname{Zr} \sim 12$ (Cont.)

$$
\begin{aligned}
& \mathrm{Zr} / \mathrm{Y} \sim 2.6 \\
& \mathrm{Zr} / \mathrm{Ce} \sim 3 \\
& \mathrm{Zr} / \mathrm{Ca}
\end{aligned}
$$

$$
\text { (1) Ce/Zr u12 (Cont.) }
$$

(1) $\mathrm{Zr} / \mathrm{Ca} \sim 15$

(I) $\mathrm{Ce} / \mathrm{AI} \sim 7.5$, $\mathrm{Ce} / \mathrm{Ca} \sim 12$

(1) $\mathrm{Ce} / \mathrm{K} \sim 12$, $\mathrm{Ce} / \mathrm{Zr} \sim 3$
$\mathrm{Al} / \mathrm{Ca}$ 20, $\mathrm{A} 1 / \mathrm{K} \sim 6$

(1) $\mathrm{Al} / \mathrm{Mg} \sim 3$, $\mathrm{Al} / \mathrm{Ca} \sim 11$

(2) $\mathrm{Al} / \mathrm{Zr} \sim 16$, $\mathrm{Al} / \mathrm{Ca} \sim 3.5$

(1) $\mathrm{Ce} / \mathrm{K}$ w 0.7 , $\mathrm{Ce} / \mathrm{Zr} \sim 4$, $\mathrm{Al} / \mathrm{Ce} \sim 5.5$

(1) $\mathrm{Ce} / \mathrm{Zr} \cdot 4$, $\mathrm{Ce} / \mathrm{Ca}$ v10

(2) $\mathrm{Al} / \mathrm{Ce}$ ?3, $\mathrm{Al} / \mathrm{Zr}$ 231, $\mathrm{A} 1 / \mathrm{K} \sim 15$, $\mathrm{A} 1 / \mathrm{Ca} \sim 5$

(1) $\mathrm{Al} / \mathrm{K} \quad 33.4$

*The compositions are expressed in mass ratios of the metals. 
- The phase compositions at the center of the electrodes also varied, and often contained more than one phase. These results are summarized in Table C.4.2.

Table C.4.2 PHASES AND APPROXIMATE CONPOSITIONS IN ELECTRODES: NEAR CENTER

MAJOR PHASE*

MINOR PHASE*

\section{Cathode}

1103

1206

1309

1414

1517

Anode

2103

2106

2309

2414

2517
$\mathrm{Zr} / \mathrm{Y} \sim 2.6$

$\mathrm{Zr} / \mathrm{Ce} \sim 2.6$

$\mathrm{Zr} / \mathrm{Ce} \sim 1, \mathrm{Zr} / \mathrm{K} \sim 0.5$

$\mathrm{Ce}, \mathrm{Zr}, \mathrm{K}$

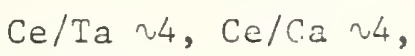
$\mathrm{Ce} / \mathrm{Zr} \sim 3$

$$
\mathrm{Zr} / \mathrm{Y} \sim 2.6
$$

$\mathrm{Zr} / \mathrm{Ce} \sim 2.6$

$\mathrm{Zr} / \mathrm{Ce} \sim 0.2$

$\mathrm{Ce} / \mathrm{Zr} \sim 4.5$

$\mathrm{Ce} / \mathrm{Zr} \sim 7$
(1) $\mathrm{Zr} / \mathrm{Ca} \sim 11$ to no $\mathrm{Ca}$

(1) $\mathrm{Ce}(20 \%)$

(1) K (in cracks and pores)

(1) $\mathrm{Ce} / \mathrm{Ca}$ ح3.5, $\mathrm{Ce} / \mathrm{Zr} \sim 6$

(2) $\mathrm{Zr} / \mathrm{Ce} \sim 4$, $\mathrm{Zr} / \mathrm{Ca} \sim 7$
(1) $\mathrm{Zr} / \mathrm{K} \sim 2.5$, $\mathrm{Zr} / \mathrm{Ca} \sim 7$ (in pores and cracks)

(1) $\mathrm{K}$ (high in low density oxide)

(1) K/AI $\sim 1$, $\mathrm{K} / \mathrm{Si} \sim 2$ (in cracks)

(1) K (trace in cracks)

*The compositions are expressed in mass ratios of the metals. 
- Similarly, the electrode near the platinum current lead-out also was

contaminated. The possible phases and compositions are summarized in Table C.4.3.

Table C.4.3 PHASES AND APPROPRIATE COMPOSITIONS IN ELECTRODE: ADJACENT PT LEADS

$\underline{\text { MAJOR PHASES* }}$

MINOR PHASES*

\section{Cathode}

1103

1206

1309

1914

1517

Anode

1103

1206

2309

2414

2517

$$
\begin{aligned}
& \mathrm{Zr} / \mathrm{Y} \sim 2.6 \\
& \mathrm{Zr} / \mathrm{Ce} \sim 3.2 \\
& (\mathrm{Zr}+\mathrm{Ce}) / \mathrm{K} \sim 1 \\
& \mathrm{Ce}, \mathrm{Zr}, \mathrm{K} \\
& --\mathrm{N} . \mathrm{D} .
\end{aligned}
$$

(1) $\mathrm{K}$

(1) $\mathrm{Zr} / \mathrm{K} \sim 2.4$

(2) $\mathrm{Zr} / \mathrm{Si} \sim 3.5$

(1) $\mathrm{K}$ (in pores)

(1) $\mathrm{K}$ $+N \cdot D$.
(1) $2 \div 15 \% 0$, $\mathrm{Zr}$ ! Ca 21.3

(1) $\mathrm{K}$

(1) $\mathrm{Pt}$

(2) $\mathrm{Zr} / \mathrm{Ca}$

(1) $\mathrm{Zr} / \mathrm{Ce} \sim 5$, $\mathrm{Zr} / \mathrm{Ca} \sim 7$

(I) $\mathrm{K}$

"The compositions are expressed in mass ratios of the metals.

\section{Cement}

The cement acts as a major source of potassium concentration and possible path of seed transport into the $\mathrm{MgO}$ and electrode. The highest concentration of potassium in the cement was found in the cathodes and increased with current density. Total degradation of the cement can occur. Conversely, the cement associated with the anode remained intact, but contained $\sim 10 \%$ potassium associated totally with the low density portion of the cement.

\section{Aluminum Oxide}

The $\mathrm{Al}_{2} \mathrm{O}_{3}$ spacers reacted with the potassium, but did not appear to react in any other way with the cther materials. The higher temperature top edge of the sintered $\mathrm{Al}_{2} \mathrm{O}_{3}$ plate appeared to form $\mathrm{B}-\mathrm{Al}_{2} \mathrm{O}_{3}$ with $\mathrm{Al} / \mathrm{K} \sim 30$. The potassium diffuses into the $\mathrm{Al}_{2}^{2} \mathrm{O}_{3}^{3}$ from the outside edges forming a distinct cone-shaped reaction bounciary. The potassium is concentrated at pores within the $\mathrm{AI}_{2} \mathrm{O}_{3}$. The $\mathrm{B}_{-} \mathrm{AI}_{2} \mathrm{O}_{3}$ has a higher porosity than the original $\mathrm{Al}_{2} \mathrm{O}_{3} \cdot$ 


\section{C.5 Radiograph and Current Lead-oút Analysis (E. Farabaugh, NBS)}

In contact radiography, the image contrast is due entirely to the variation in x-ray absorption from point-to-point in the specimen. Distinguishing specific features in the radiograph depends on the relative contrast, and thus, on the differential absorption of $x$-rays in materials of differing density and atomic constitution. This method of characterization requires only an $x-r a y$ source and an emulsion to record the image.

The accompanying radiographs (Figures C.5.1-C.5.5) were taken using an uncollimated beam of $x$-rays from a tungsten rotating anode operating at $200 \mathrm{kv}$. This high voltage source allowed the viewing of the thick anode and cathode electrodes in transmission. The images were recorded directly on type 57 Polaroid film. The specimen to source and specimen to film distances were $20 \mathrm{~cm}$ and $2 \mathrm{~cm}$, respectively. In the radiographs, the exact shape of the electrode is not always recorded. This is due to the geometry of the experimental arrangement and the size of the $x$-ray source. However, the important features, the breaks in the platinum leads, are always easily detected.

In the series of radiographs of the anode side, breaks are seen in A2-7, A2-8, A4-15 and A5-17. These electrodes were noted as opening up during the test run. On the cathode side, $\mathrm{C} 1-1, \mathrm{Cl}-4, \mathrm{C} 3-9, \mathrm{C} 4-15$ and $\mathrm{C} 4-16$ are seen to be discontinuous. Of the cathode elements, Cl-1 was noted to have opened up during the test. C3-9 was part of electrode 非 which behaved erratically during the latter part of the test but never did open up completely. The radiograph of C3-9 shows that the leads are not in good condition, explaining this behavior. C4-15 and C4-16 were patt of electrodes 非 15 and 非 16 which also were recorded as opening up during the test. C1-4, which served as a position of an optical sight port, shows no leads in the radiograph. Thus, electrode $\|_{1}$ failed on the cathode side while $\|^{7} 7$ and 非 8 failed on the anode side. The poor performance of 非 9 was due to cathode lead problems, the radiograph showing the leads are very nearly broken. Electrode 非15 appears to have opened up obviously on the anode side and not quite so dramatically on the cathode side. Electrodes 非16 and 非17 failed on the cathode and anode sides, respectively. Four breaks, therefore, occurred in the anodes and 3 in the cathodes, so the discontinuities in the platinum leads showed no preference for anode or cathode assembly.

It should be noted that there is one case where one of the double leads failed, while the other remained intact allowing the electrode unit to function for the complete test. The radiograph of Cl-2 shows only one of the two leads to be broken, allowing the electrode to operate properly.

In all of the cases where leads opened up, it appears that the platinum melted at a point near its connection to the electrode and then, forming a ball, melted back along the lead. In fact, a ball of what is believed to be platinum, is seen near the base on $\mathrm{A} 2-7, \mathrm{~A} 5-15, \mathrm{~A} 5-17$ and $\mathrm{Cl}-1$.

To address ourselves to the problem of lead melting, it was decided to remove several of the leads that failed and examine them optically and with the SEM. Anode electrodes A2-7, A2-8 and A5-15 were selected for this examination. 
The leads of A2-7 were easily removed and an optical micrograph of the leads is shown in Figure C.5.6. The ball of platinum is seen on the end of one of the leads. The other lead does not have such a strong indication of melting, but it is believed that the round shaped dark image in the radiograph of A2-7 is melted platinum which dropped off the lead. (Note is taken here of the material adhering to the melted end of the platinum lead. More will be said about this later) A4-15 also was easily removed. An optical micrograph of platinum leads of $\mathrm{A} 4-15$ is shown in Figure C.5.7. In this case, the leads have melted together with material between them. Note the nearly identical images in the radiograph of A4-15 and the optical micrograph. The 1eads of A2-8 were not removed as easily. In fact, in attempting to pull the leads out of the ceramic tube, the leads parted, leaving some of the lead (including the melted end) in the $\mathrm{Al}_{2} \mathrm{O}_{3}$ ceramic tube. ( $\mathrm{t}$ should be pointed out here that none of the platinum lead assemblies were securely held to the ceramic tube by paint on the end of the tubes. In fact, it seems possible that some of the twists in the leads, as indicated by the radiographs, could be attributed to movement of the lead assembly when nuts were placed on or removed from the threaded ends of the lead assembly). In order to optically examine 非2-8 electrode assembly (electrode and the ceramic tube cemented to the electrode), it was removed from the $\mathrm{MgO}$ insulator. Once removed, the $\mathrm{Al}_{2} \mathrm{O}_{3}$ tube containing the leads was cut so as to reveal the lead inside the tube. Figure C.5.8 shows the assembly as removed from the insulator with the ceramic tube cut to show the lead. Figure C.5.9 is a higher magnification optical micrograph of the same electrode. In this micrograph, the melted end is clearly seen as is the necked down end where the lead pulled apart in the removal attempt. It is observed that the melted bead has formed on the lead in a region of tube where there was a void in the cement. This explains why the lead could not be easily pulled out. The cement in the tube is a zirconia cement which was forced down the tube when the platinum leads were put in place. In looking back over the radiographs, it is seen that all the breaks in the leads could be seen, that is, they did not occur in the opaque areas as indicated in the radiographs. The opaque areas correspond to the presence of $\mathrm{Zr}$ or $\mathrm{Zr}$ compounds which have a high absorption for $\mathrm{x}$-rays. Thus, the opaque areas in the radiographs show the parts of the ceramic tube in which the platinum leads are well surrounded by zirconia cement. One is brought to the conclusion that. breaks occurred in the leads at places where the leads were not embedded in the cement. It is thought that the cement may have enhanced the performance of the leads by conducting away heat from the lead and protecting them from damage due to joule heating. The cement also provides support to the leads when connections are made to the lead assembly. Consideration, however, must be given to the possibility of chemical attack and degradation of the lead, especially in light of Figure C.5.10, which showed the melted end of the lead and the powdery material adhering to it.

Figure C.5.10 is a secondary electron SEM micrograph showing the melted end of the lead of A2-8, and the powdery material which was white in color. Some of the powder was scraped off and an $x-r a y$ powder pattern was taken. The analysis of the data from this film showed the material to be $\mathrm{KCl}$. Comparison made on the two strongest lines and three other weaker lines showed good agreement. The lead as shown in Figure C.5.10 was also analyzed with EDX on the SEM. Figure C.5.11 shows the spectrum obtained by looking at the white material at $950 \mathrm{X}$ with an accelerative voltage of $20 \mathrm{kV}$ on the SEM. The two strongest peaks shown in the spectrum are due to $\mathrm{Cl}\left(\mathrm{K}_{2}\right.$ at $\left.2.62 \mathrm{kev}\right)$ and $\mathrm{K}\left(\mathrm{K}_{2}\right.$ at $\left.3.31 \mathrm{kev}\right)$. Thus, these two techniques confirm that the material seen on the end of the lead is $\mathrm{KCl}$. It is felt that the KCl had nothing to do with the lead failure. It probably came down on the lead after it melted in the form of a polycrystalline powder and a few small crystals (some well developed crystallites can be seen at high magnification under the SEM). The $\mathrm{K}$ for thi KCl has obviously come from the seeded 
plasma in the channel. Other SEM work has indicated the $\mathrm{K}$ is present almost everywhere in the insulator and electrode assemblies. The Cl has probably come from a small weight percent of oxy-chloride frequently used as a binder in the zirconia cement.

The conclusions of this examination are:

1. The leads melted and were not chemically attacked. It is suggested that in assembly, a scratch or bend was put into the lead in a region which was not surrounded by the cement. Joule heating developed and without the cement to conduct away the heat, the lead melted.

2. Thus leads should:

a. be double and each of sufficient size to carry the current without excessive joule heating.

b. be embedded as well as possible in the cement.

c. the lead assembly should be more securely attached to the ceramic tube at the rear of the electrode insulator assembly in order to prevent possible damage to leads by twisting when making electrical connections. 


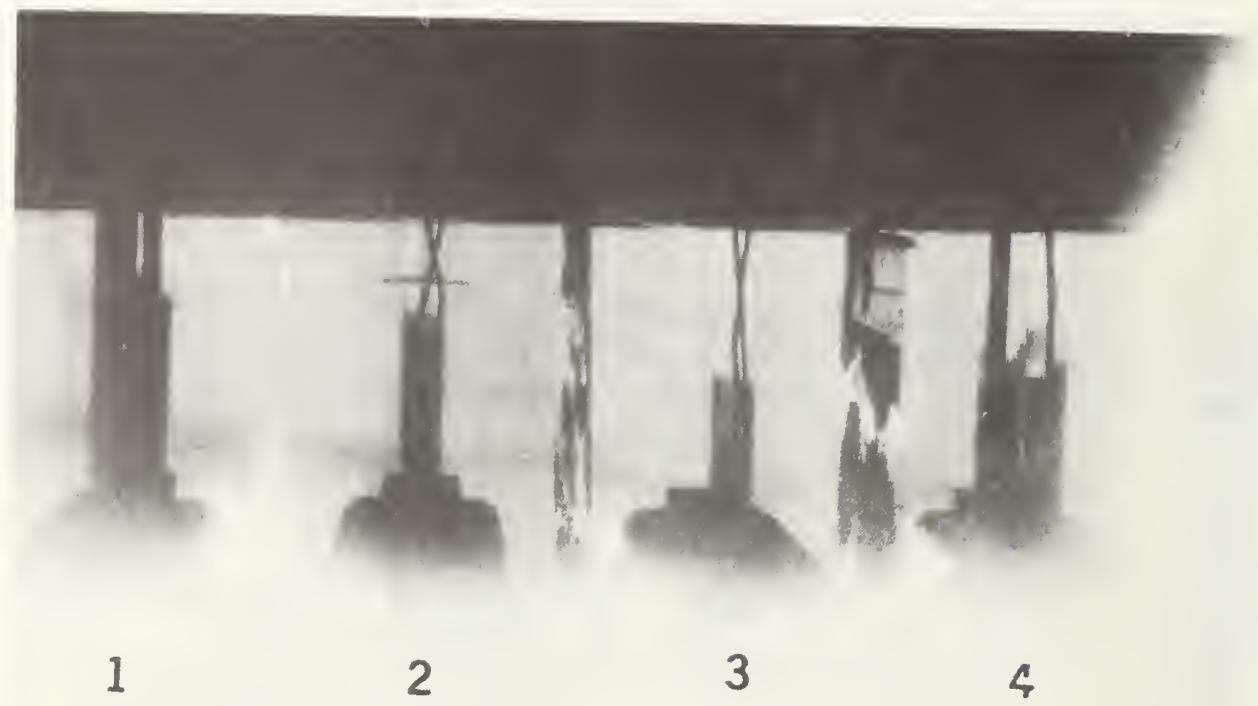

A 1

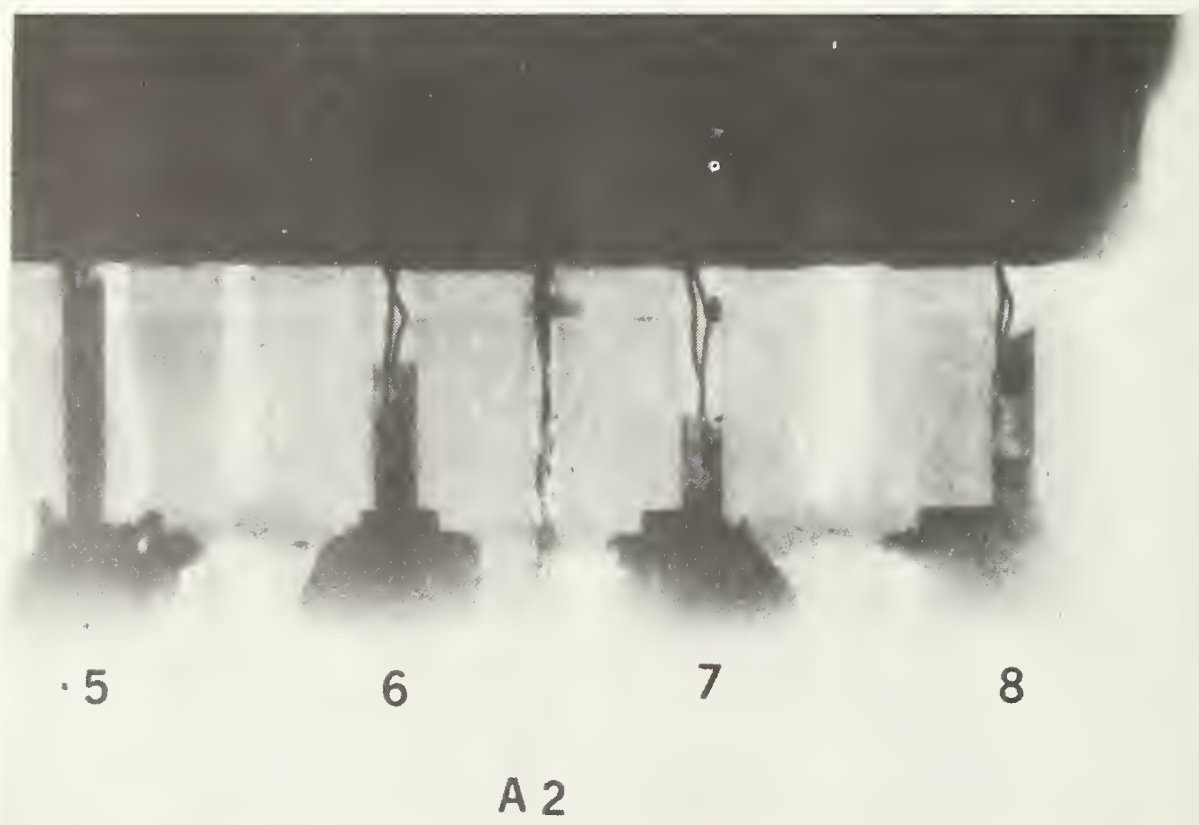

Figure C.5.1. Radiographs of anode and cathode submodule 1. 

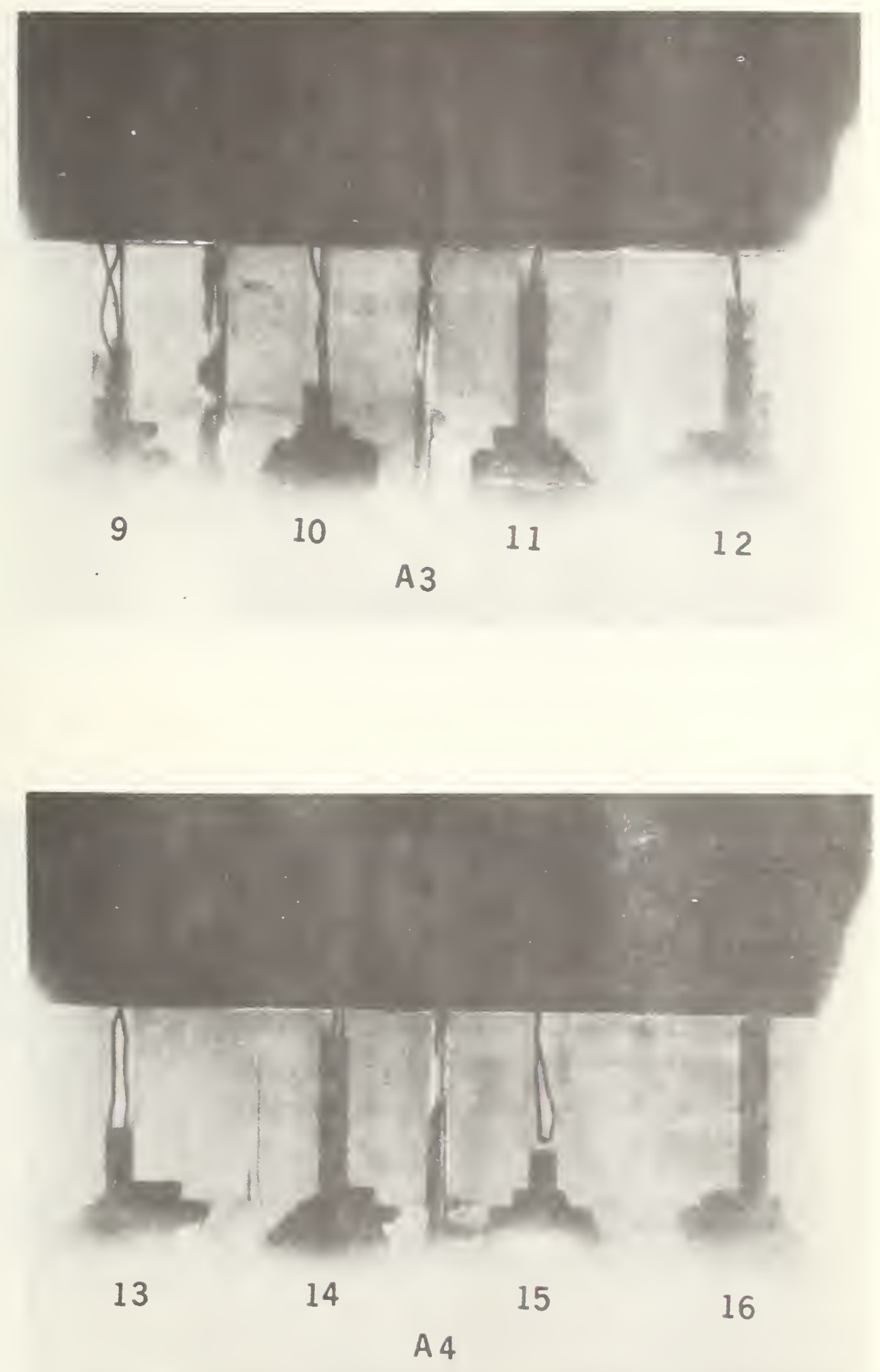

Fiaure C.5.2. Radiographs of anode and cathode submodule 2 . 

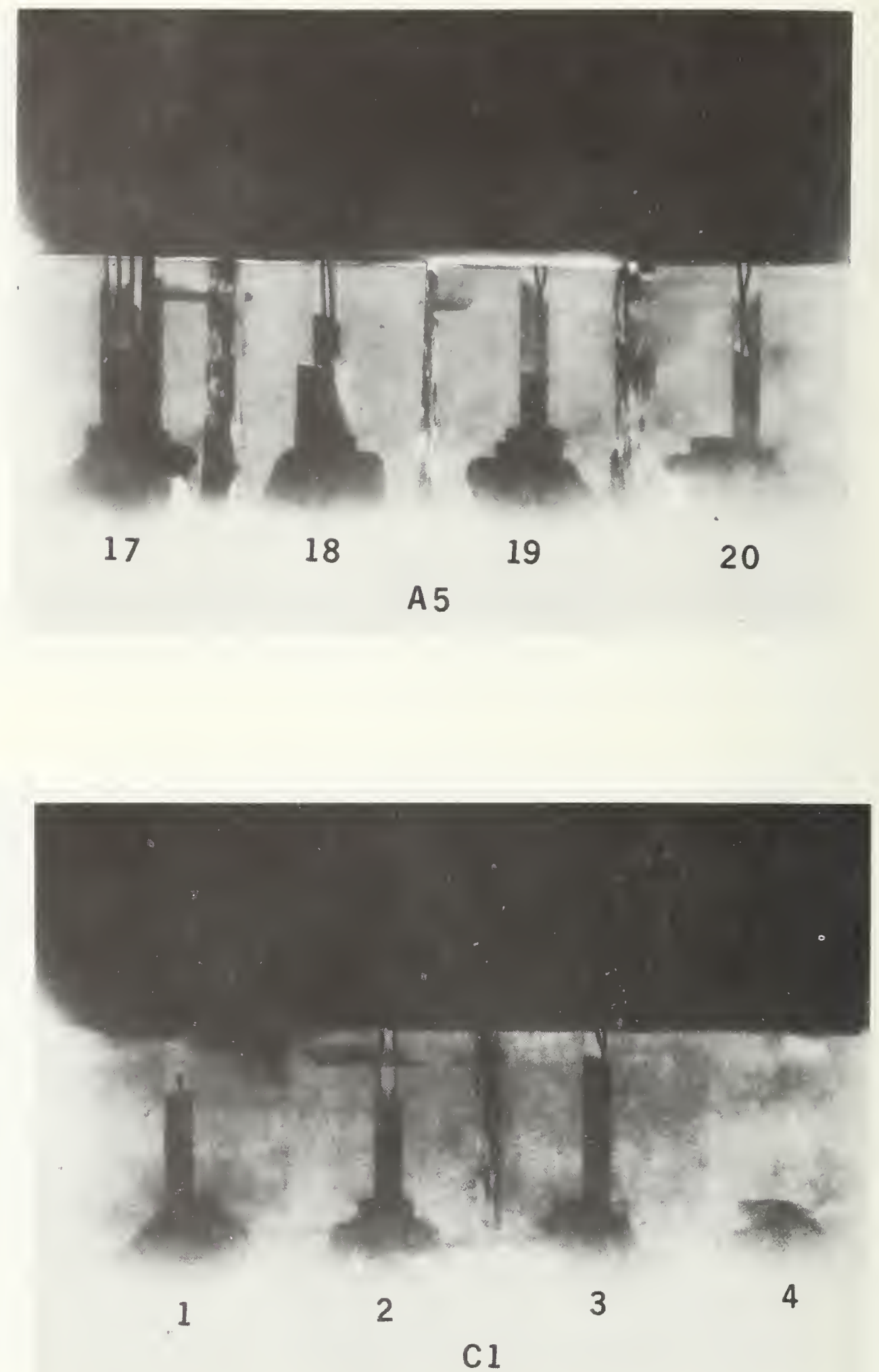

Figure C.5.3. Radiographs of anode and cathode submodule 3 . 

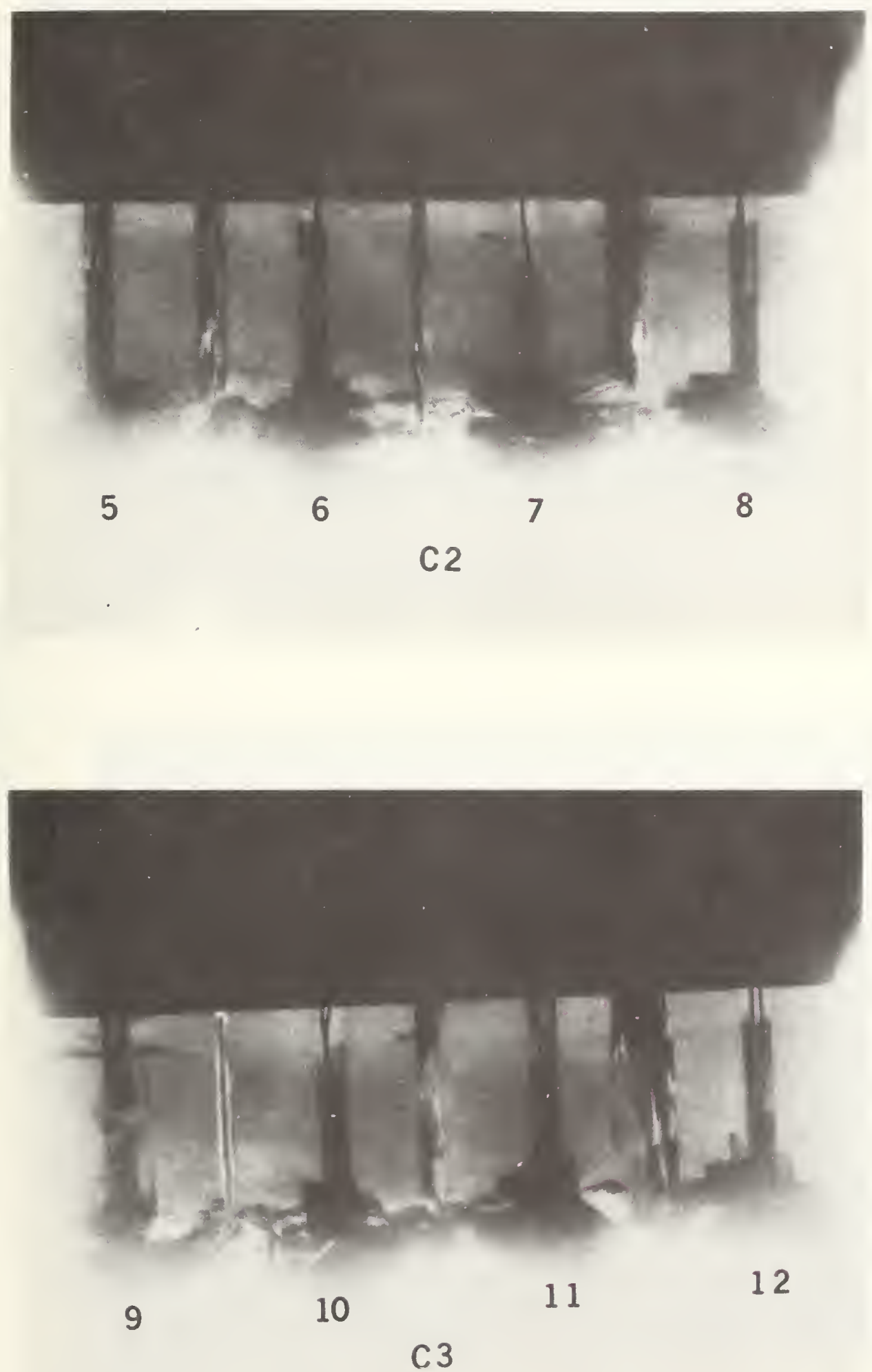

Figure C.5.4. Radiographs of anode and cathode submodule 4. 

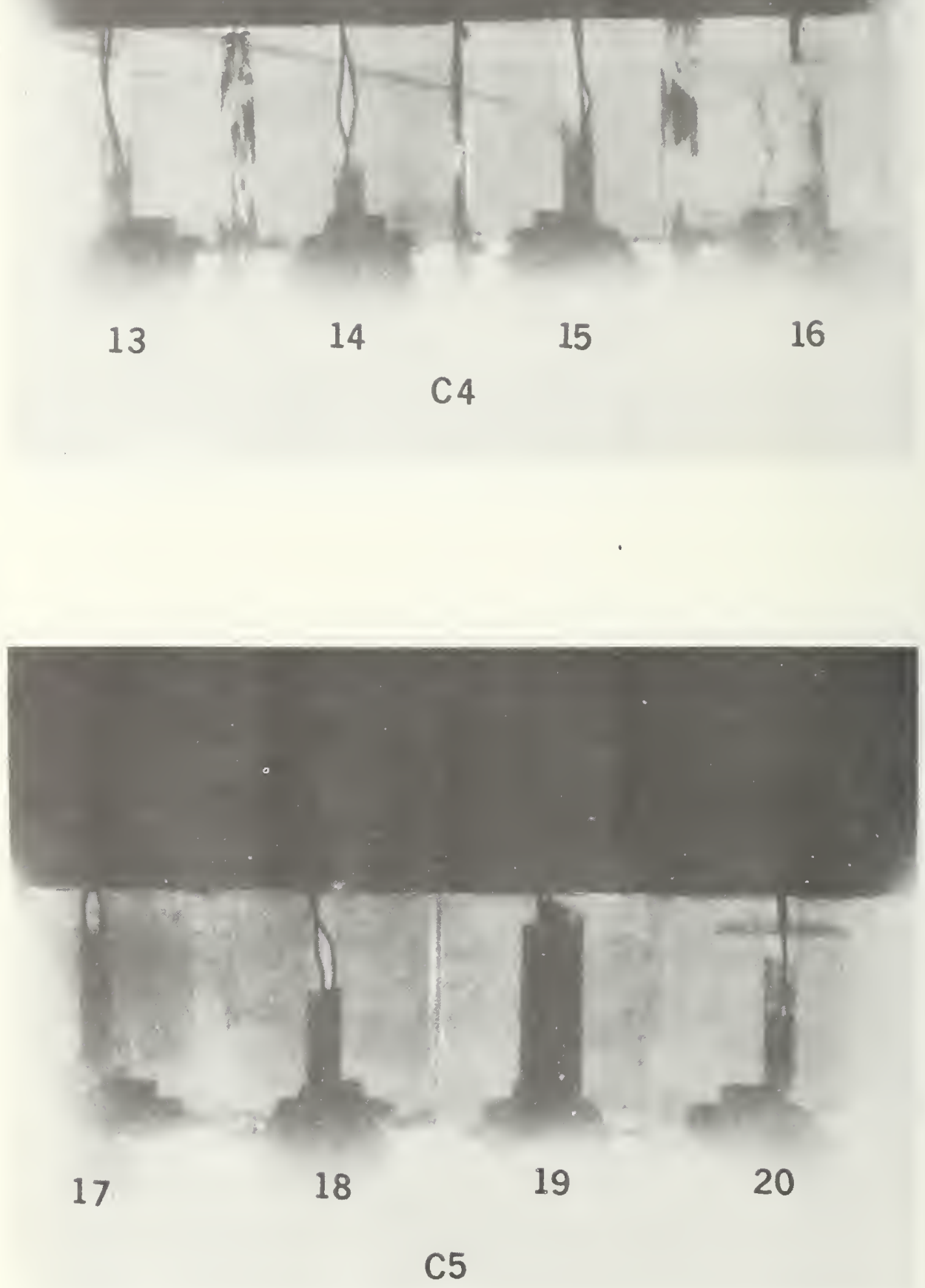

Figure C.5.5. Radiographs of anode and cathode submodule 5. 


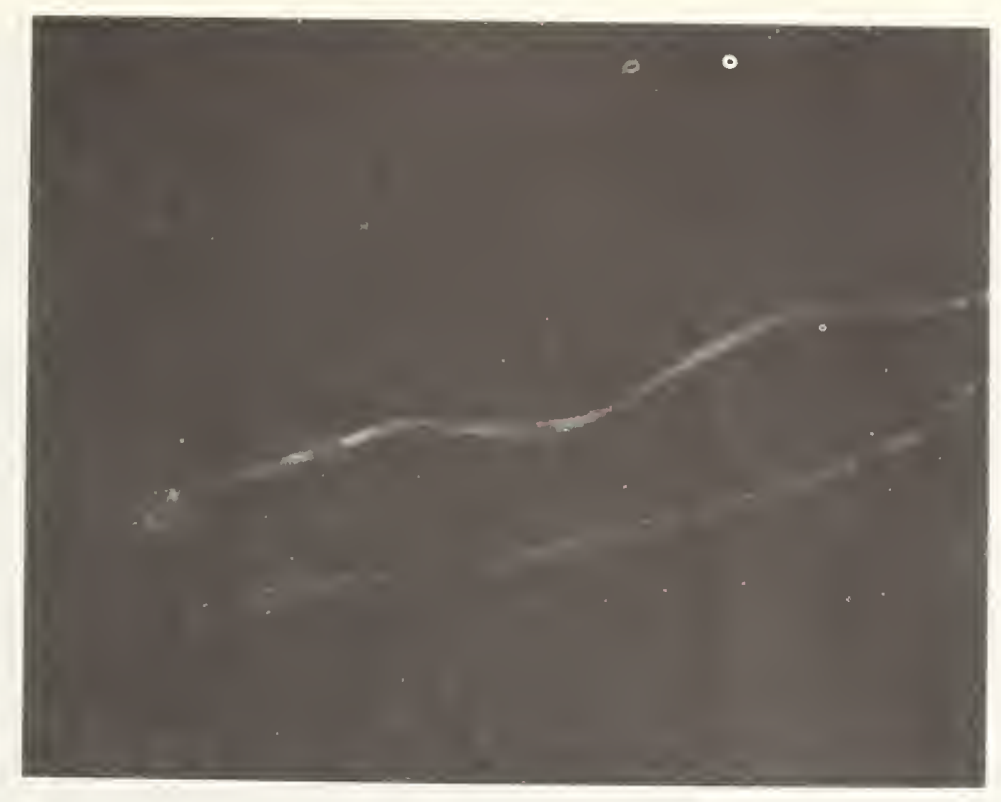

Figure C.5.6. Optical micrograph of melted lead of A2-7.

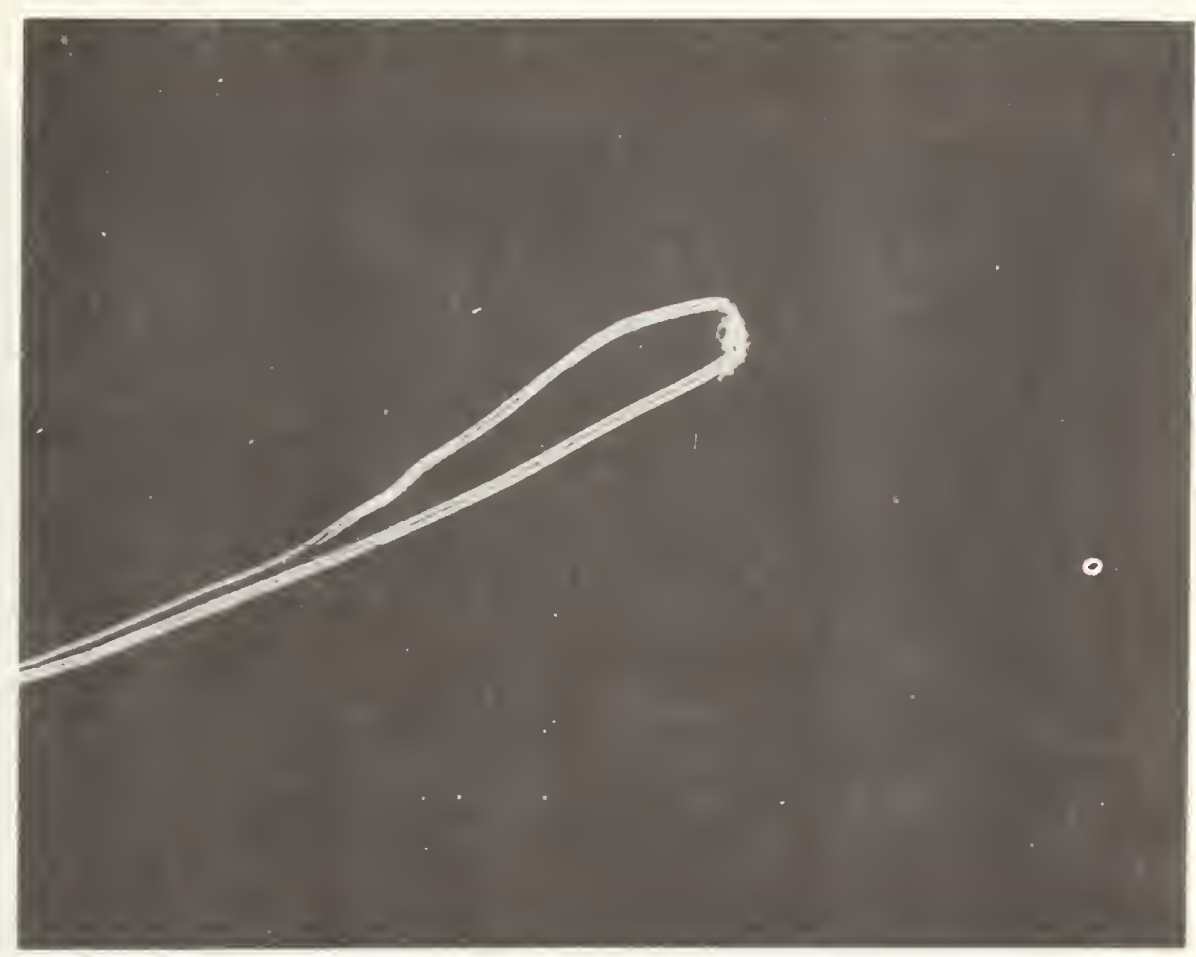

Figure C.5.7. Optical micrograph of leads melted together of A4-15. 


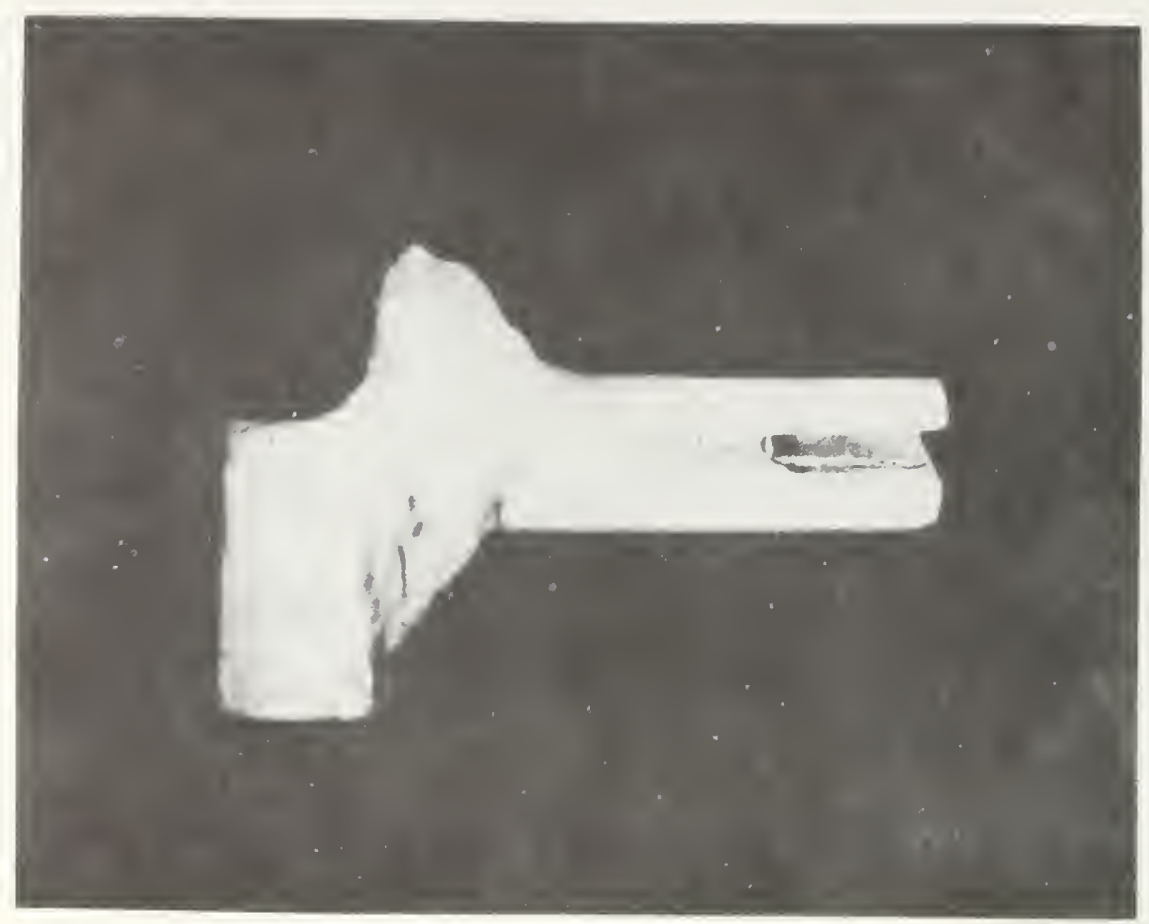

Figure C.5.8. Cptical micrograph of electrode and ceramic tube of A2-8 cut to show the melted platinum lead.

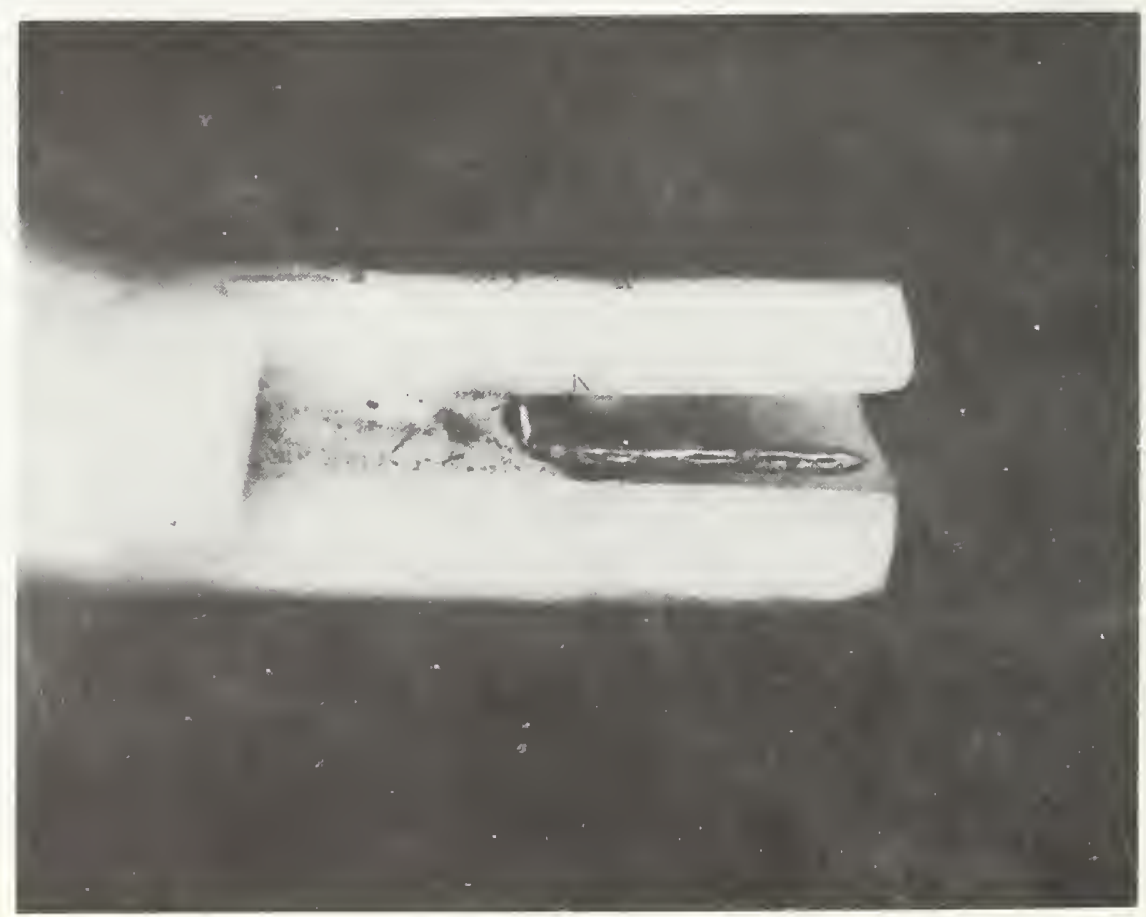

Figure C.5.9. Higher magnification optical micrograph of A2-8. 


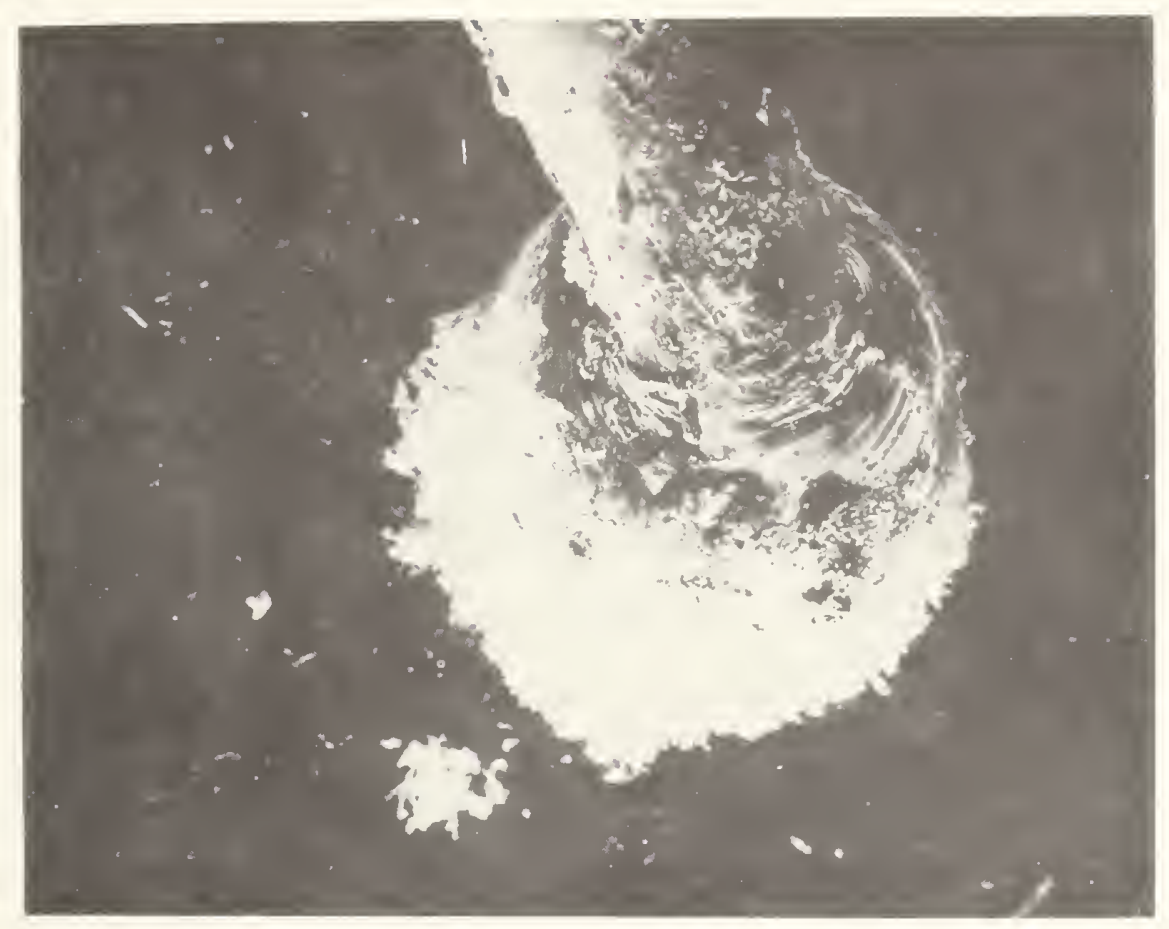

Figure C.5.10. Secondary electron SEM micrograph of melted end of the platinum lead of A2-7.

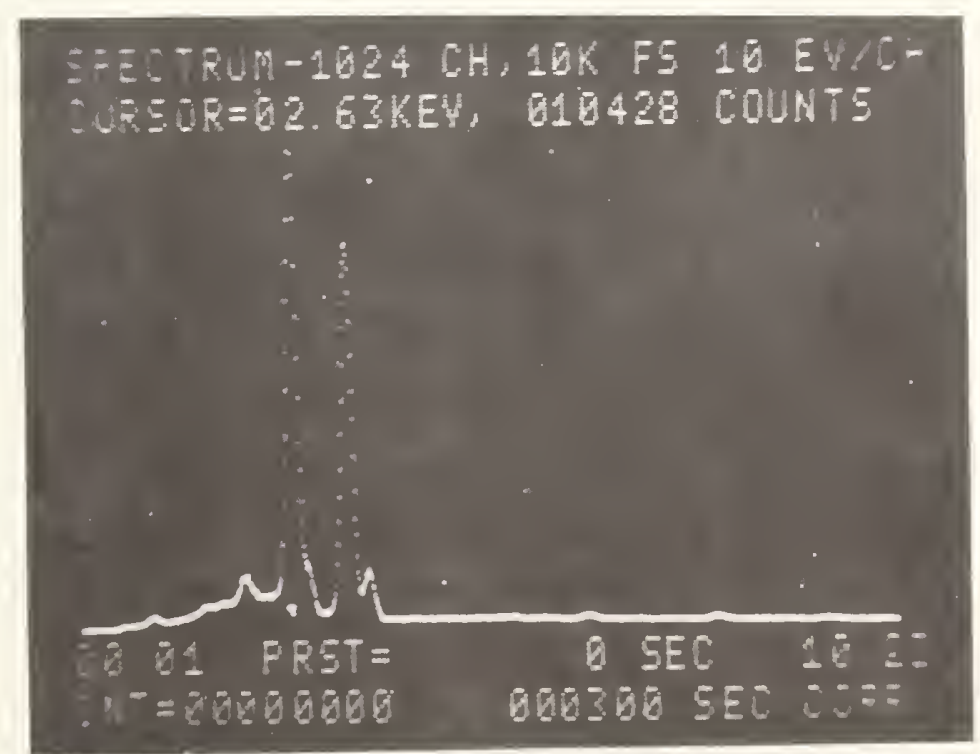

Figure C.5.11. EDX spectra taken from powdery material formed on the melted lead. The strong peaks are due to $\mathrm{Cl}$ and $K$. 


\section{List of Figures}

Figure C.1.1. Anode wall after shipment to NBS.

Figure C.1.2. Cathode wall after shipment to NBS.

Figure C.1.3. Cathode or anode wall schematic.

Figure C.1.4. Inside surface of the outside slice from each anode submodule (see Figure C.1.3.).

Figure C.1.5. Inside surface of the outside slice from each cathode submodule (see Figure C.1.3.).

Figure C.1.6. Open schematic of cathode and anode showing materials, identification digits and electrode lead-out failure. Shaded areas indicate which lead failed (anode or cathode).

Figure C.2.1a. Portion of x-ray diffraction powder pattern of the $82 \mathrm{ZrO}_{2}-18 \mathrm{Ce}_{2}$, $1500{ }^{\circ} \mathrm{C}$ material prepared under oxidizing conditions (untêsted). $\mathrm{T}=$ tetragonal zirconia solid-solution. Compare with Figures C.2.1b, C.2.1c, C.2.1d and C.2.3a, C.2.3b, C.2.3c.

Figure C.2.1b. Portion of x-ray diffraction powder pattern of cathode electrode 1205 , open circuit, $82 \mathrm{ZrO}_{2}-18 \mathrm{CeO}_{2}$ (tested). White upper surface see Table C.2.1. $M=$ monoclinic zirconia; $C, T=$ poorly crystalline cubic fluorite and/or tetragonal solid-solutions. 
Figure C.2.Ic. Portion of x-ray diffraction powder pattern of cathode electrode 1205 , open circuit, $82 \mathrm{ZrO}_{2}-18 \mathrm{CeO}_{2}$ (tested). Yellow interior zone, see Table C.2.1. M = monoclinic zirconia; $\left(C_{l}\right)=$ cubic pseudofluorite (cubic subcell $\underline{a}=5.26 \AA$ ); $\mathrm{P}=\mathrm{K}, \mathrm{Ce}, \mathrm{Zr}$-oxide).

Figure C.2.1d. Portion of x-ray diffraction powder pattern of cathode electrode 1205 , open circuit, $82 \mathrm{ZrO}_{2}-18 \mathrm{CeO}_{2}$ (tested). Yellow, olive-green botton zone, see Table C.2.1. $\mathbb{1}^{2}=$ monoclinic zirconia; $\left(C_{1}\right)=$ cubic pseudo-fluorite (cubic subcell $a=5.26 \AA$ ) ; P $=(\mathrm{K}, \mathrm{Ce}, \mathrm{Zr}-$ oxide).

Figure C.2.2. Portion of x-ray diffraction powder pattern of synthetic products resulting from reactions of $\mathrm{CeO}_{2}, \mathrm{ZrO}_{2}$, and $\mathrm{K}_{2} \mathrm{O} . \mathrm{P}=(\mathrm{K}, \mathrm{Ce}, \mathrm{Zr}-$ oxide). Compare synthetic phase $P$ with $P$ phase in Figures C.2.1c, C.2.1d and C.2.5b.

Figure C.2.3a. Portion of x-ray diffraction powaer pattern of cathode electrode $1208,1.25 \mathrm{~A} / \mathrm{cm}^{2}, 82 \mathrm{ZrO}_{2}-18 \mathrm{CeO}_{2}$ (tested). White zone, top, see Table C.2.1. $M=$ monoclinic zirconia; $C=$ two or more cubic fluorite solid-solutions.

Figure C.2.3b. Portion of x-ray diffraction powder pattern of cathode electrode $1208,1.25 \mathrm{~A} / \mathrm{cm}^{2}, 82 \mathrm{ZrO}_{2}-18 \mathrm{CeO}_{2}$ (tested). Yellowish interior zone, see Table C.2.1. $M=$ monoclinic zirconia; $\left(C_{1}\right)=$ cubic pseudo-fluorite (cubic subcel1 $\mathrm{a}=5.26 \AA$.

Figure C.2.3c. Portion of x-ray diffraction powder pattern of cathode electrode 1208 , $1.25 \mathrm{~A} / \mathrm{cm}^{2}, 82 \mathrm{ZrO}_{2}-18 \mathrm{CeO}_{2}$ (tested). Yellowish-green bottom zone, see Table C.2.1. ${ }^{M}=$ monoclinic zirconia; $\left(C_{1}\right)=$ cubic, pseudofluorite cubic subcell $\underline{a}=5.26 \AA ; P=(K, C e, Z r$-oxide).

Figure C.2.4a. Portion of x-ray diffraction powder pattern of the $50 \mathrm{ZrO} \mathrm{O}_{2}-50 \mathrm{CeO}_{2}$, $1500{ }^{\circ} \mathrm{C}$ oxidizing conditions (untested). $\mathrm{T}=$ tetragonal $^{2}$ zirconia solid-solution; $C=$ cubic fluorite solid-solution. Compare with Figures C.2.4b, C.2.5a and C.2.5b.

Figure C.2.4b. Portion of x-ray diffraction powder pattern of the $50 \mathrm{ZrO}_{2}-50 \mathrm{CeO}_{2}$, $1600{ }^{\circ} \mathrm{C}$ oxidizing conditions (untested). $\mathrm{C}=$ cubic fluorite solidsolution. Compare with Figures C.2.4a, C.2.5a and C.2.5b. 
Figure C.2.5a. Portion of x-ray diffraction powder pattern of cathode electrode $1310,0.8 \mathrm{~A} / \mathrm{cm}^{2}, 50 \mathrm{zr} 0-50 \mathrm{Ce} 0$ (tested). Yellow interior, see Table C.2.1. $\left(\mathrm{C}_{1}\right)=$ cubic, pseudo-fluorite (cubic subcell a = $5.26 \mathrm{~A}) ; \mathrm{P}=(\mathrm{K}, \mathrm{Ce}, \mathrm{Zr-oxide})$. Compare with Figures C.2.4a and C. 2.4b.

Figure C.2.5b. Portion of x-ray diffraction powder pattern of cathode electrode $1310,0.8 \mathrm{~A} / \mathrm{cm}^{2}, 50 \mathrm{ZrO}_{2}-50 \mathrm{CeO}_{2}$ (tested). Yellowish-green bottom zone, see Table C.2.1. ${ }^{2}\left(\mathrm{C}_{1}\right)={ }^{2}$ cubic, pseudo-fluorite (cubic subcell $\underline{\mathrm{a}}=5.26 \mathrm{~A}) ; \mathrm{P}=(\mathrm{K}, \mathrm{Ce}, \mathrm{Zr}$-oxide $) ;\left(\mathrm{C}_{2}\right)=$ cubic fluorite solidsolution $\underline{a}=5.38 \AA$ ).

Figure C.2.6. Portion of x-ray diffraction powder pattern of a typical Mg0-insulator, "hot", surface. $\mathrm{M}=\mathrm{MgO}, \mathrm{S}=$ spinel, probably $\mathrm{MgAl}_{2} \mathrm{O}_{4}$. S not detected in untested $\mathrm{MgO}$.

Figure C.2.7. Anode series 2205 through 2208, $82 \mathrm{ZrO}_{2}-18 \mathrm{CeO}_{2}$.

Figure C.2.8. Cathode series 1205 through 1208, $82 \mathrm{ZrO}_{2}-18 \mathrm{CeO}_{2}$.

Figure C.2.9. Anode series 2309 through 2312, $50 \mathrm{ZrO}_{2}-50 \mathrm{CeO}_{2}$.

Figure C.2.10. Cathode series 1309 through $1312,502 \mathrm{rO}_{2}-\mathrm{50CeO}_{2}$.

Figure C.2.11. Anode series 2413 through $2416,25 \mathrm{ZrO}_{2}-75 \mathrm{CeO}_{2}$.

Figure C.2.12. Cathode series 1413 through $1416,25 \mathrm{ZrO}_{2}-75 \mathrm{CeO}_{2}$.

Figure C.2.13. Anode series 2517 through $2520,78 \mathrm{CeO}_{2}-2 \mathrm{ZrO}_{2}-2 \mathrm{Ta}_{2} \mathrm{O}_{5}$.

Figure C.2.14. Cathode series 1517 through $1520,78 \mathrm{CeO}_{2}-2 \mathrm{OZrO}_{2}-2 \mathrm{Ta}_{2} \mathrm{O}_{5}$.

Figure C.2.15. Cathode electrode 1205, open circuit, $82 \mathrm{ZrO}_{2}-18 \mathrm{CeO}_{2}$.

Figure C.2.16. Cathode electrode $1206,0.5 \mathrm{~A} / \mathrm{cm}^{2}, 82 \mathrm{ZrO}_{2}-18 \mathrm{CeO}_{2}$.

Figure C.2.17. Cathode electrode $1207,0.8 \mathrm{~A} / \mathrm{cm}^{2}, 82 \mathrm{ZrO}_{2}-18 \mathrm{CeO}_{2}$.

Figure C.2.18. Anode electrode $2207,0.8 \mathrm{~A} / \mathrm{cm}^{2}, 82 \mathrm{ZrO}_{2}-18 \mathrm{CeO}_{2}$, compare with Figure C.2.17. 
Figure C.2.19. Cathode electrode $1309,1.25 \mathrm{~A} / \mathrm{cm}^{2}, 50 \mathrm{ZrO}_{2}-50 \mathrm{CeO}_{2}$.

Figure C.2.20. Cathode electrode $1310,0.8 \mathrm{~A} / \mathrm{cm}^{2}, 50 \mathrm{ZrO}_{2}-50 \mathrm{CeO}_{2}$.

Figure C.2.21. Cathode electrode $1311,0.5 \mathrm{~A} / \mathrm{cm}^{2}, 502 \mathrm{rO}_{2}-50 \mathrm{CeO}_{2}$.

Figure C.2.22. Cathode electrode 1312, open circuit, $50 \mathrm{ZrO}_{2}-50 \mathrm{CeO}_{2}$.

Figure C.2.23. Anode electrode, 2312, open circuit, $50 \mathrm{ZrO}_{2}-50 \mathrm{CeO}_{2}$.

Figure C.2.24. Cathode electrode 1413, open circuit, $25 \mathrm{ZrO}_{2}-75 \mathrm{CeO}_{2}$.

Figure C.2.25. Cathode electrode $1414,0.5 \mathrm{~A} / \mathrm{cm}^{2}, 25 \mathrm{ZrO}_{2}-75 \mathrm{CeO}_{2}$.

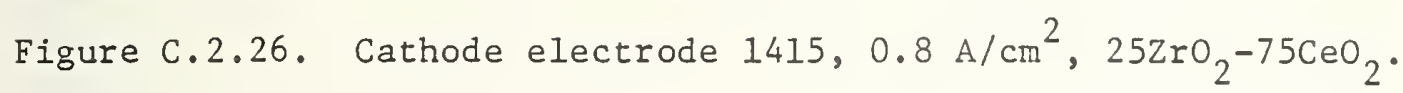
Figure C.2.27. Cathode electrode $1416,1.25 \mathrm{~A} / \mathrm{cm}^{2}, 25 \mathrm{ZrO}_{2}-75 \mathrm{CeO}_{2}$, interior
cross section. Figure C.2.28. Cathode electrode $1416,1.25 \mathrm{~A} / \mathrm{cm}^{2}, 25 \mathrm{ZrO}_{2}-75 \mathrm{CeO}_{2}$,
outside cross section.

Figure C.2.29. Cathode electrode $1517,1.25 \mathrm{~A} / \mathrm{cm}^{2}, 78 \mathrm{CeO}_{2}-2 \mathrm{OrrO}_{2}-2 \mathrm{Ta}_{2} \mathrm{O}_{5}$.

Figure C.2.30. Cathode electrode 1518, $0.8 \mathrm{~A} / \mathrm{cm}^{2}, 78 \mathrm{CeO}_{2}-2 \mathrm{ZrO}_{2}-2 \mathrm{Ta}_{2} \mathrm{O}_{5}$.

Figure C.2.31. Cathode electrode $1519,0.5 \mathrm{~A} / \mathrm{cm}^{2}, 78 \mathrm{CeO}_{2}-2 \mathrm{ZrO}_{2}-2 \mathrm{Ta}_{2} \mathrm{O}_{5}$.

Figure C.2.32. Cathode electrode 1520, open circuit, $78 \mathrm{CeO}_{2}-2 \mathrm{OZrO}_{2}-2 \mathrm{Ta}_{2} \mathrm{O}_{5}$.

Figure C.2.33. Anode electrode $2519,0.5 \mathrm{~A} / \mathrm{cm}^{2}, 78 \mathrm{CeO}_{2}-2 \mathrm{OZrO}_{2}-2 \mathrm{Ta}_{2} \mathrm{O}_{5}$, compare with Figure C.2.31.

Figure C.2.34. Anode electrode 2520, open circuit, $78 \mathrm{CeO}_{2}-20 \mathrm{ZrO}_{2}-2 \mathrm{Ta}_{2} \mathrm{O}_{5}$, compare with Figure C.2.32.

Figure C.2.35. Cathode electrode 1205, open circuit, $82 \mathrm{ZrO}_{2}-18 \mathrm{CeO}_{2}$, longitudinal section, fracture surface.

Figure C.2.36. Cathode electrode 1205, open circuit, $82 \mathrm{ZrO}_{2}-18 \mathrm{CeO}_{2}$, cross section, fracture surface.

Figure C.2.37. Cathode electrode $1208,1.25 \mathrm{~A} / \mathrm{cm}^{2}, 82 \mathrm{ZrO}_{2}-18 \mathrm{CeO}_{2}$, cross section, fracture surface.

Figure C.3.1. Post-test electrical conductivity of electrode 2102 $\left(88 \mathrm{ZrO}_{2}-12 \mathrm{Y}_{2} \mathrm{O}_{3}\right.$ ).

Figure C.3.2. Post-test electrical conductivity of electrode 2206 $\left(82 \mathrm{ZrO}_{2}-18 \mathrm{CeO}_{2}\right)$. 
Figure C.4.1. Cross sections of anode and cathode for electrode pair 2103 and $1103\left(0.12 \mathrm{Y}_{2} \mathrm{O}_{3} \cdot 0.88 \mathrm{ZrO}_{2}\right)$.

Figure C.4.2. Cross sections of anode and cathode for electrode pair 2206 and $1206\left(0.18 \mathrm{CeO}_{2} \cdot 0.82 \mathrm{ZrO}_{2}\right)$.

Figure C.4.3. Cross sections of anode and cathode for electrode pair 2309 and $1309\left(0.5 \mathrm{CeO}_{2} \cdot 0.5 \mathrm{ZrO}_{2}\right)$.

Figure C.4.4. Cross sections of anode and cathode for electrode pair 2414 and $1414\left(0.75 \mathrm{CeO}_{2} \cdot 0.25 \mathrm{ZrO}_{2}\right)$.

Figure C.4.5. Cross sections of anode and cathode for electrode pair 2517 and $1517\left(0.75 \mathrm{CeO}_{2} \cdot 0.20 \mathrm{ZrO}_{2} \cdot 0.02 \mathrm{Ta}_{2} \mathrm{O}_{5}\right)$.

Figure C.4.6. Cross section of cathode $1102\left(0.12 \mathrm{Y}_{2} \mathrm{O}_{3} \cdot 0.88 \quad \mathrm{ZrO}_{2}\right)$.

Figure C.4.7. Cross section of cathode $1310\left(0.5 \mathrm{CeO}_{2} \cdot 0.5 \mathrm{ZrO}_{2}\right)$.

Figure C.5.1. Radiographs of anode and cathode submodule 1.

Figure C.5.2. Radiographs of anode and cathode submodule 2 .

Figure C.5.3. Radiographs of anode and cathode submodule 3 .

Figure C.5.4. Radiographs of anode and cathode submodule 4 .

Figure C.5.5. Radiographs of anode and cathode submodule 5 .

Figure C.5.6. Optical Micrograph of melted lead of A2-7.

Figure C.5.7. Optical micrograph of leads melted together of A4-15.

Figure C.5.8. Optical micrograph of electrode and ceramic tube of A2-8 cut to show the melted platinum lead.

Figure C.5.9. Higher magnification optical micrograph of A2-8.

Figure C.5.10. Secondary electron SEM micrographs of melted end of the platinum lead of $\mathrm{A} 2-7$.

Figure C.5.11. EDX spectra taken from powdery material formed on the melted lead. The strong peaks are due to $\mathrm{Cl}$ and $\mathrm{K}$. 
D. USSR Results on Pre- and Post-Test Materials Characterization and Analysis (G. P. Telegin, A. I. Romanov, Y. P. Gokhshtein, Yu. L. Krasulin, T. I. Borodina, A. S. Golubkova, V. L. Vinogradov, and D. A. Vysotskii, L. G. Smirnova, A. B. Ivanov)

\section{D.1. Magnesia Ceramics in Channel Insulating Walls}

Magnesia ceramics have been used as ceramic material for the insulating walls of magnetohydrodynamic generator channel walls. Electrosmelted magnesia served as a raw material in producing the magnesia ceramics. The granular magnesia powder (grain size < $1 \mathrm{~mm}$ ) was mixed with the finely dispersed component and charged with a magnesium chloride solution. Magnesium chloride acts as a plasticizing agent during extrusion and facilitates the formation of magnesium oxychloride and magnesium hydroxide in the reaction with finely dispersed magnesium oxide. With the decomposition of the oxychloride and hydroxide, highly active magnesium oxide forms in the firing process, which facilitates caking of the electrosmelted magnesium oxide. The material was produced by pressing with a specific pressure of $3000 \mathrm{~kg} / \mathrm{cm}^{2}$. Firing was carried out at $1600^{\circ} \mathrm{C}$. The concentration of magnesium oxide in the magnesia ceramic was about $97 \%$. The apparent porosity of the product was $13-14 \%$.

Figure D.1.1 shows a microphotograph of a transparent section of the magnesia ceramic. The filler (the light portion) consists of magnesia granules with diameters of up to 800 microns; they form idomorphic crystals with clearly differentiated three-dimensional cleavage fissuring. The connecting mass consists of small Mgo crystals.

In the granular filler, magnesia crystals deformed along the cleavage plane are observed. Thin streaks of silicate are seen around the magnesia grains. These streaks are composed of calcium silicate ("rankinite", $\alpha-\mathrm{Ca}_{2} \mathrm{SiO}_{4}$ ), and magnesioferrite.

The distribution of pores of the ceramic specimens (in regard to size) was determined by the mercury porosity determination method. $98.6 \%$ of all the pores had radii between 100,000 and $31,620 \AA$.

The magnesia ceramic offers adequately high electrical resistance under high-temperature conditions ( 1 to $1.5 \cdot 10^{3} \mathrm{ohm} \mathrm{cm}$. at $1500^{\circ} \mathrm{C}$ ). The change in conductivity of the magnesia ceramic with an increase in temperature is shown in Figure D.1.2.

The heat conductivity of the magnesia ceramic in the temperature range from $200-1600^{\circ} \mathrm{C}$ (Figure D.1.3) was determined by the "pipe" method; this method utilizes radial thermal flow from an internal heat source located along the axis of the cylindrical samples.

The coefficient of thermal expansion, determined in a vacuum for the temperature range of $20-1800^{\circ} \mathrm{C}$, equals $16.0 \times 10^{-6} /$ degree. Maximum expansion at $1800^{\circ} \mathrm{C}$ is $2.93 \%$. 
A study of the thermomechanical properties of the magnesia ceramic was carried out under isothermic conditions in a temperature range of $20-1600^{\circ} \mathrm{C}$, with single-axis compression or expansion in an oxidizing environment. The testing was carried out using automatic testing equipment at the Moscow State University Institute of Mechanics. Testing and calibration of this equipment provides a constant temperature with an accuracy of $\pm 0.5 \%$, measurement of the load with an accuracy of $\pm 1 \%$, and of the characteristics of deformation with an accuracy of $\pm 2 \%$.

In Figures D.1.4 and D.1.5, the deformation curves B versus $\varepsilon$ of the magnesia ceramic samples at compression and under tension are shown for various temperatures. At a temperature of $1200^{\circ} \mathrm{C}$, the magnesia ceramic becomes plastic and the character of the curve becomes nonlinear.

The "creep" testing was conducted under conditions of static load and exposure to constant compression load, smaller in magnitude than the limit of proportionality. "Creep" curves $\varepsilon$ versus time ( $\tau$ ) (Figure D.1.6) show the continuous growth in deformation of the test samples with time. The rate at which "creeping" stabilizes increases with an increase in temperature or with an increase in load.

The rate of vaporization was determined in "bi-parabolic" optical ovens using test pieces $8 \mathrm{~mm}$ in diameter and $30 \mathrm{~mm}$ long. The rate of vaporization in relation to temperature increases according to a nearly exponential law. Up to $2200 \mathrm{~K}$ the amount of evaporation is not significant; primarily the impurities contained in the Mgo evaporate. In the temperature range from $2300-2500^{\circ} \mathrm{C}$, the rate of vaporization increases sharply. The data is shown in Figure D.1.7.

During the tests, the insulating walls were in the form of panels of small modules, in which the ceramic material and the reinforcing foundation were divided into sections, in order to insulate the modules from one another. This construction of the insulating panels is shown in Figure A.2, Chapter I. The basic ceramic element is a hexagonal module of magnesia ceramic (1), attached to a copper base (2) by brazing through the copper under-layer. The copper base serves to conduct heat away from the ceramic to the cooling water, and also for attachment to the carrier plate (3). The carrier plate of the channel is made of stainless steel.

The working portion of the channel has a cross section $64 \times 220 \mathrm{~mm}^{2}$ and a length of $490 \mathrm{~mm}$.

After testing for 125 hours, the surface of the ceramic modules had not experienced any change. Neither cracking nor chips were observed (D.1.8). Because of the high surface temperatures of the plate at the time of the test, there were no seed deposits on the modules. Analysis of the seed amount absorbed by the ceramic in the course of testing indicated that the ceramic had accumilated an insignificant quantity of seed at the zone of its maximum concentration ( $3-4 \mathrm{~mm}$ from the surface); this was not more than $1 \%$.

During testing, basic attention was directed to the determination of the changes in insulating characteristics of the wall during extended operation. Results of measurement of the resistance of the channel elements showed a high level of insulation of the channel wall sections. 


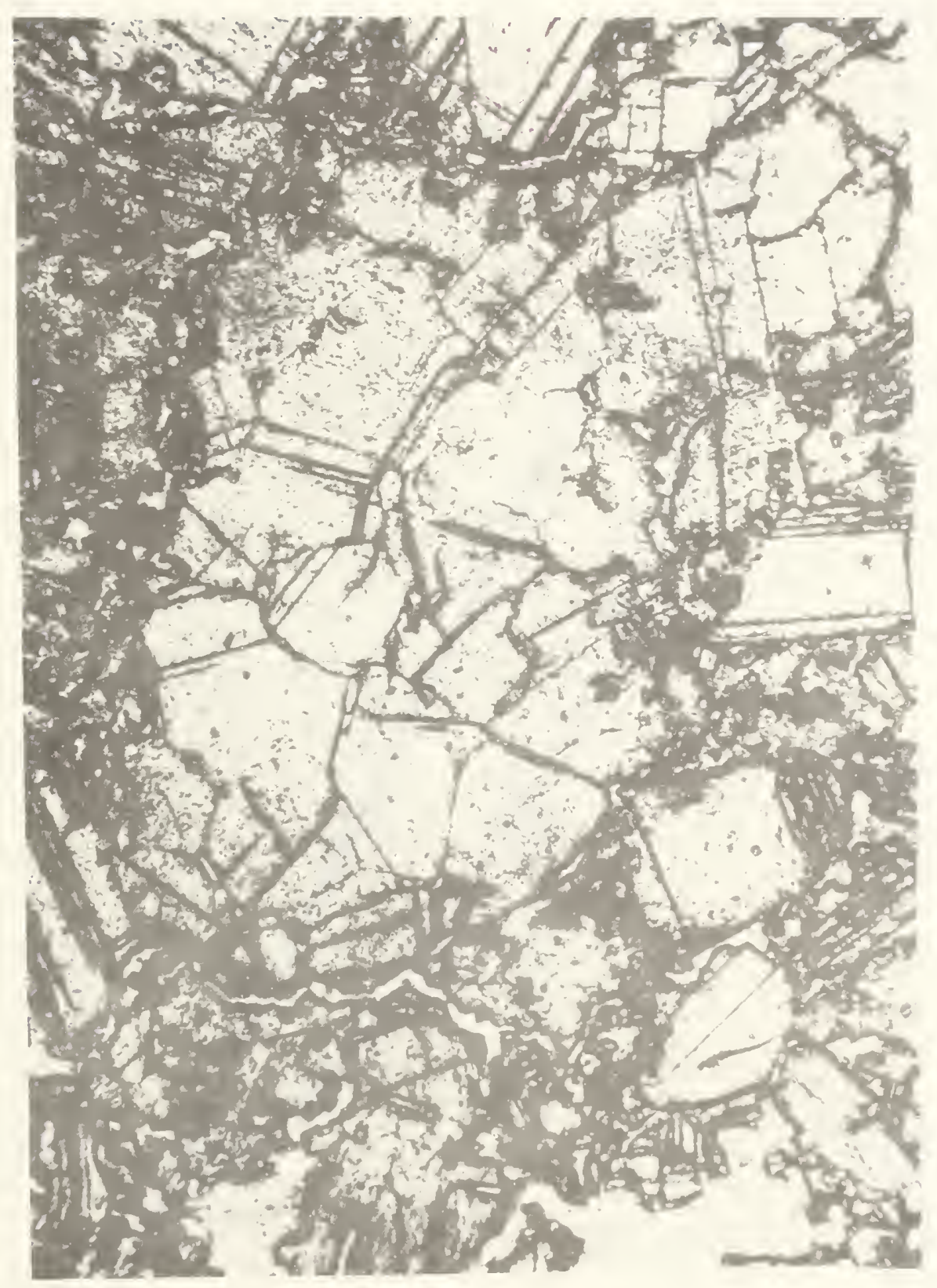

Figure D.1.1. Microstructure of test piece of magnesium ceramic. Transparent section, 46x. 


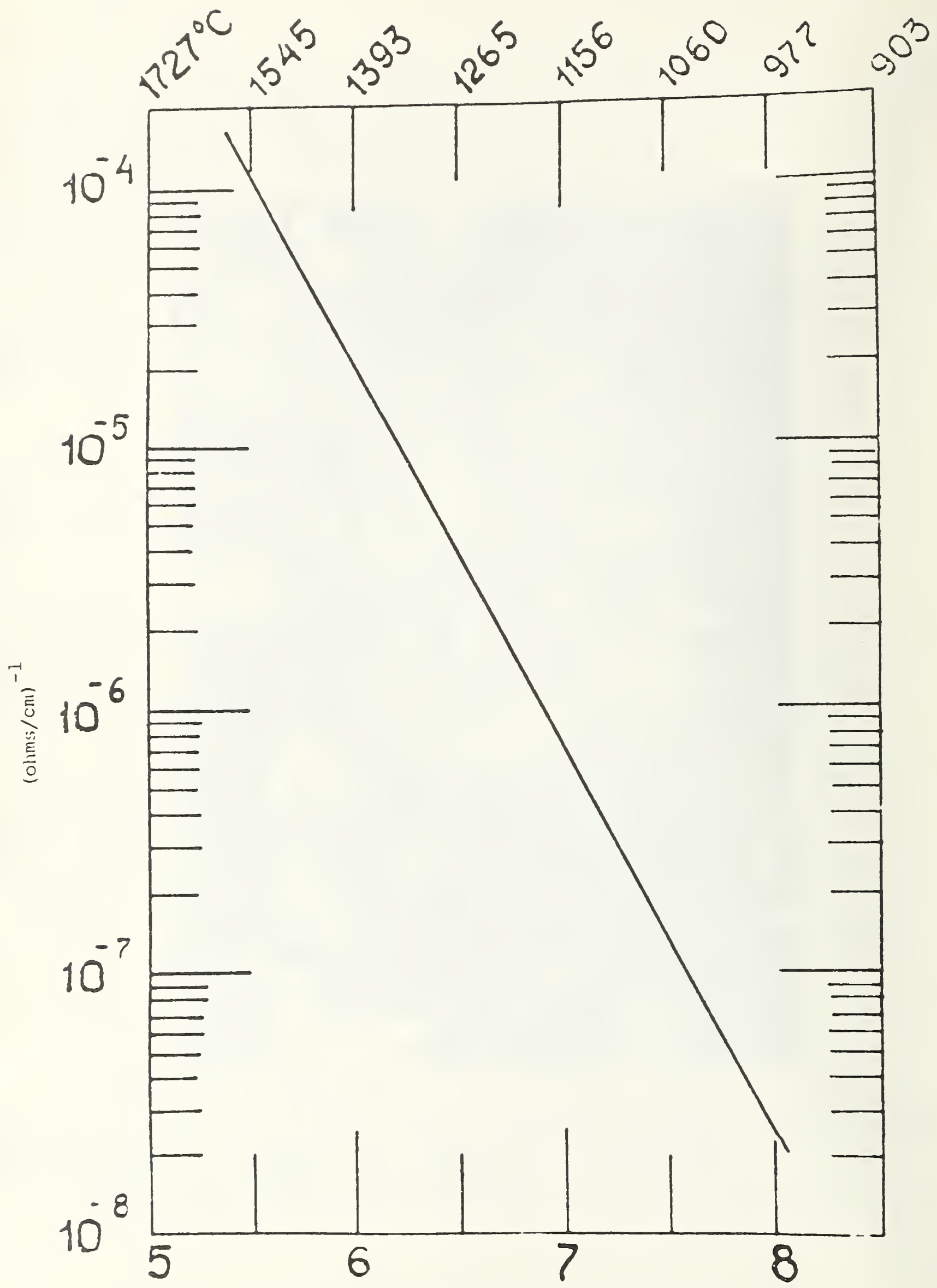

Eigure D.1.2. Dependence of the conductivity of magnesium ceramic on temperature. 


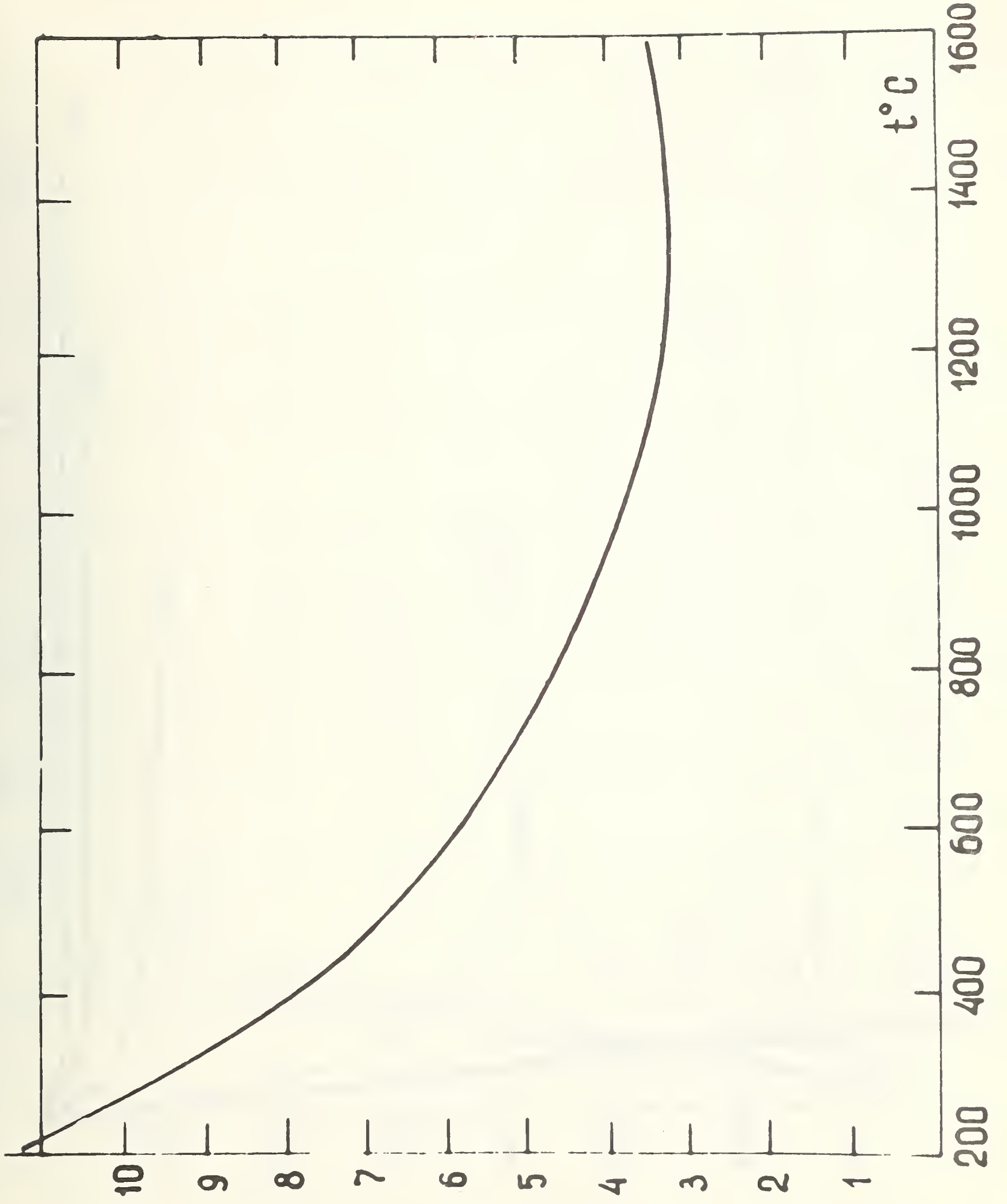

6әp. u/s77em ' $r$

Figure D.1.3. Dependence of the thermal conductivity of magnesium ceramic on temperature. 


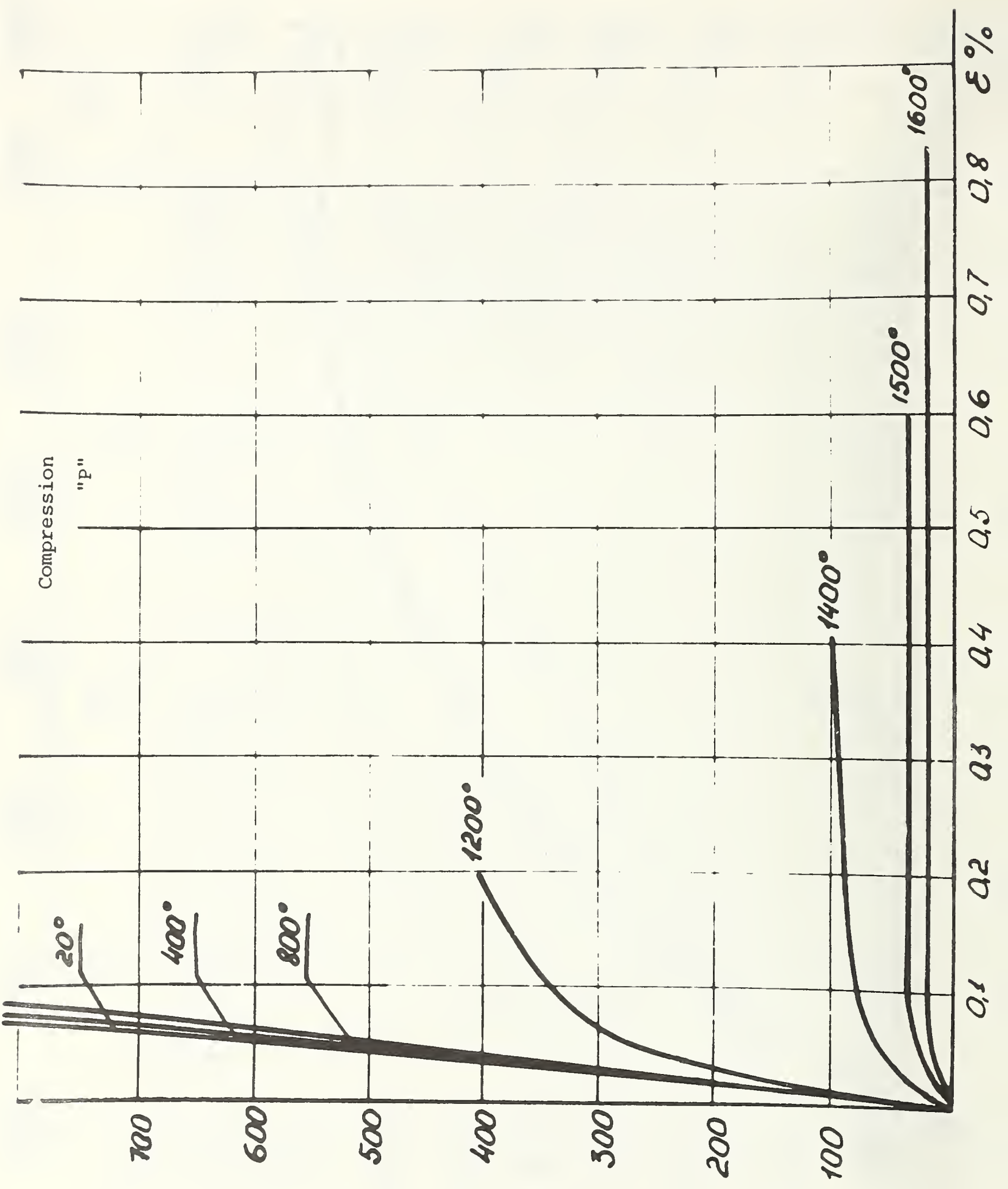

Figure D.1.4. Deformation curve "B-E" of test pieces of
magnesium ceramic under compression. 


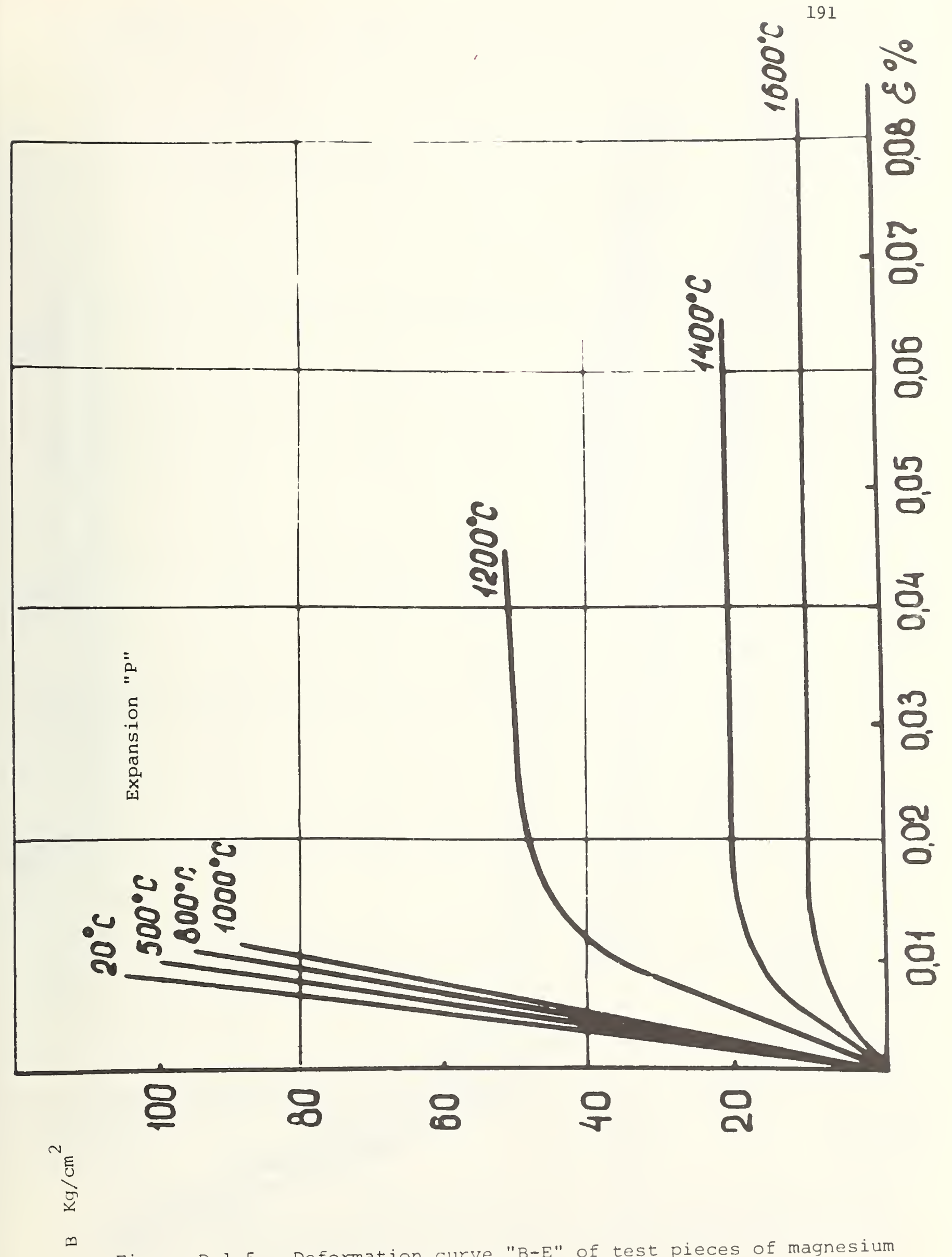

Figure D.1.5. Deformation curve "B-E" of test pieces of magnesium ceramic under tension. 


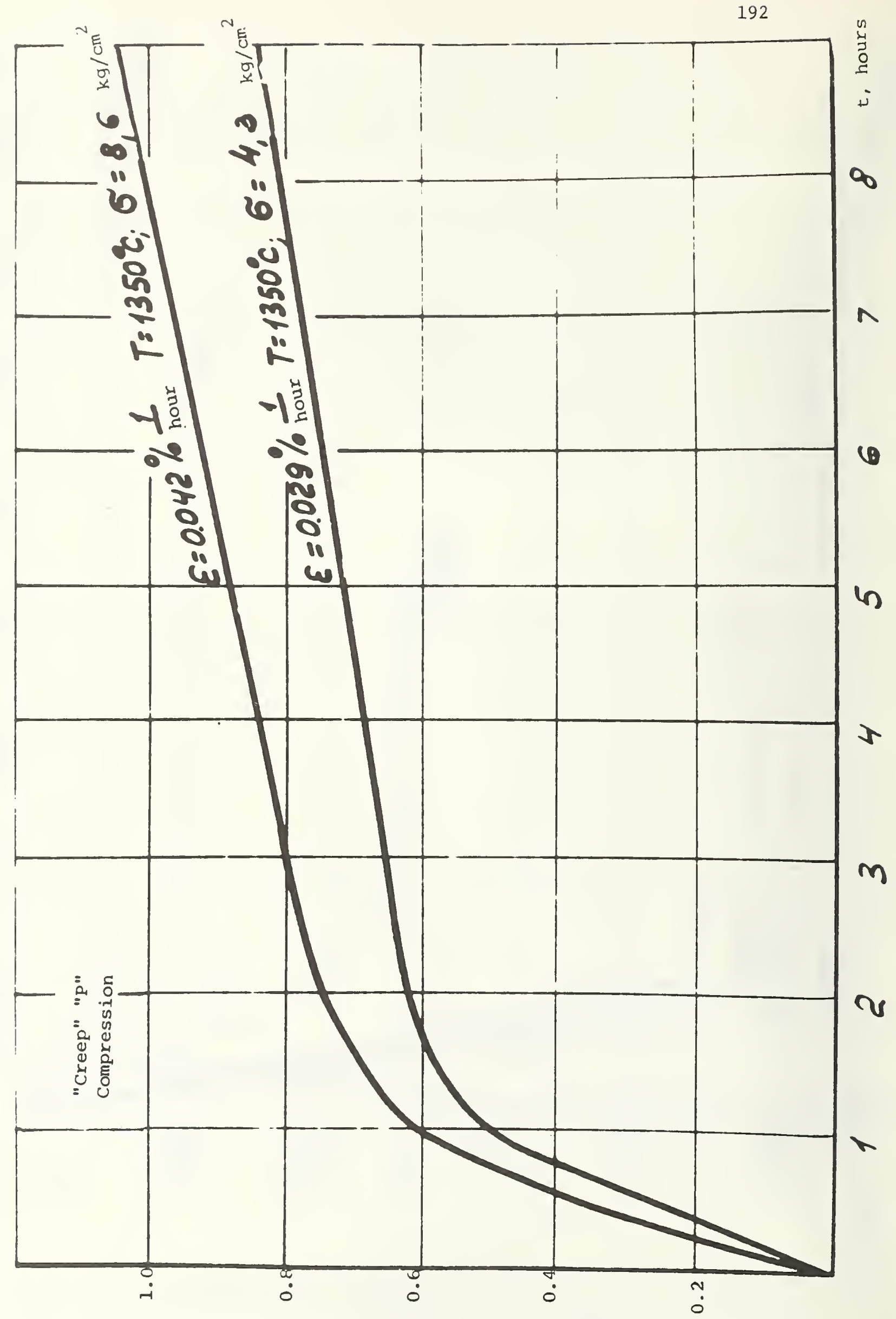

Figure D.1.6. "Creeping" curve $\varepsilon$ vs $t$ of magnesium ceramic. 


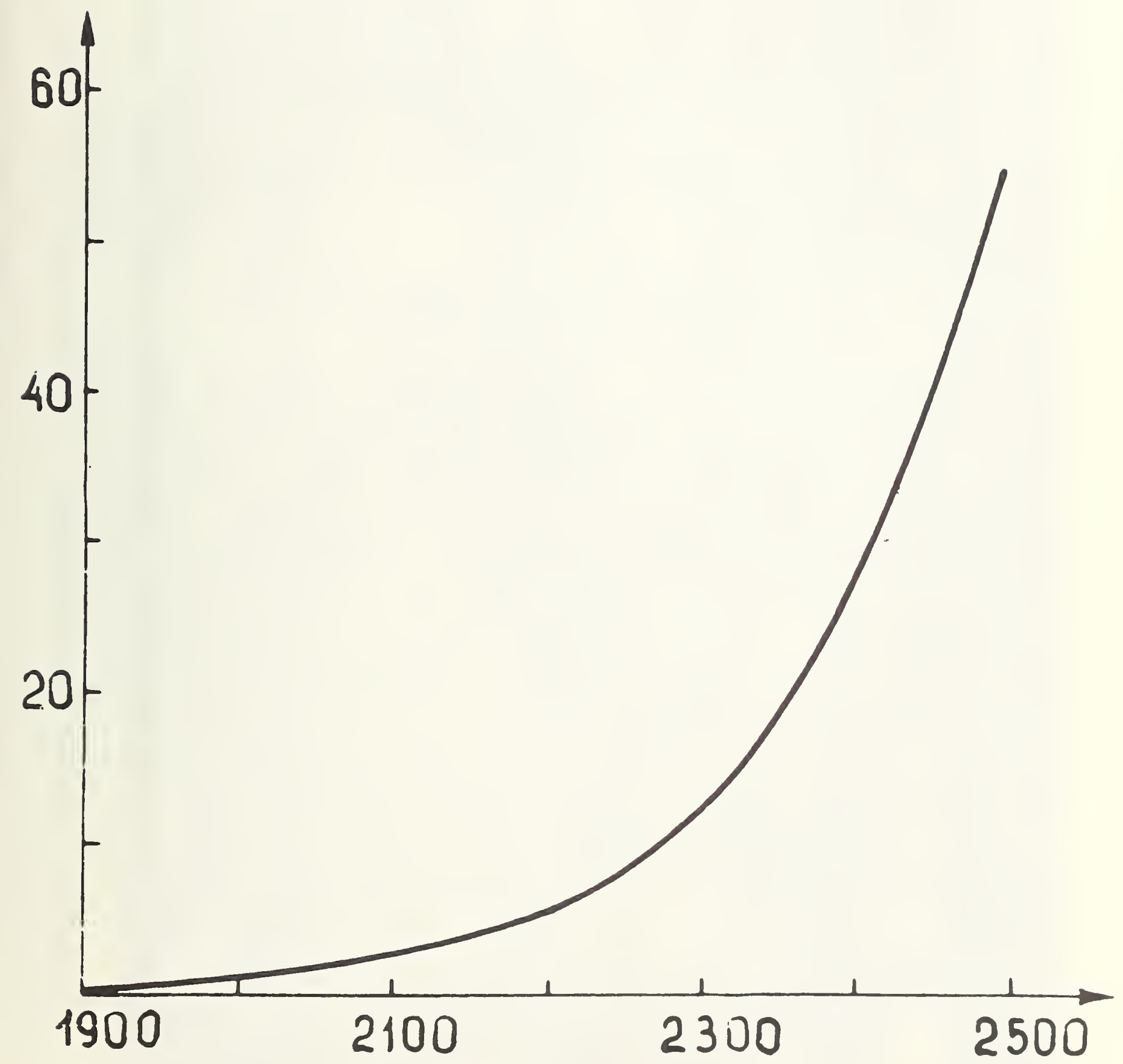

Temperature, ${ }^{\circ} \mathrm{K}$

Figure D.1.7. Dependence of the speed of vaporization of magnesium ceramic on temperature. 
Analysis of the test modules of magnesia ceramic showed that the upper part of the module, in contact with the gas flow, acquired a lighter coloration and showed a more prominent grainy texture as a result of the migration of iron oxide from the insulator to the working space. While the structure of the ceramic in the low temperature zones did not differ from the initial structure, recrystallization of the magnesia was observed in the working part of the insulator.

\section{D.2 Phase Composition and Structure of Materials Tested in the U-02}

\section{D.2.1 Objects and Methods of the Studies}

A study of the changes occurring in the composition of electrode materials as a result of electrode tests in the channel of the U-02 facility was made by $x$-ray phase and $x$-ray spectrum analysis. We studied the compòsition of samples consisting of sections from the side parts of electrodes. In tests in the channel these electrodes were subjected to lower temperatures than the central sections that were studied by the U.S. side.

Since the U.S. side made a detailed analysis of the phase composition of all the electrodes tested, the U.S.S.R. side made similar studies only for certain electrodes. One of the aims of the phase study was to determine possible differences in the composition of the materials of the central and the side segments of the electrodes.

For the studies, two pairs of electrodes for each of the compositions tested were selected, one of each of the two pairs of electrodes was run at open circuit during the test. We studied the composition of materials for the following electrode pairs: 2 and 4 (without current) (initial composition $88 \mathrm{ZrO}_{2}-12 \mathrm{Y}_{2} \mathrm{O}_{3}$ ); 5 (without current) and $7\left(j=0.8 \mathrm{~A} / \mathrm{cm}^{2}\right)$ (initial composition $82 \mathrm{ZrO}_{2}-18 \mathrm{CeO}_{2}$ ); $10\left(j=0.8 \mathrm{~A} / \mathrm{cm}^{2}\right.$ ) and 12 (without current) (initial composition 50 $\left.\mathrm{ZrO}_{2}-50 \mathrm{CeO}\right)^{3}$; 13 (without current) and $15\left(j=0.8 \mathrm{~A} / \mathrm{cm}^{2}\right.$ ) (initial composition $25 \mathrm{ZrO}_{2}-75 \mathrm{CeO}_{2}, 17\left(j=1.25 \mathrm{~A} / \mathrm{cm}^{2}\right)$ initial composition $\left.20 \mathrm{ZrO}_{2}-78 \mathrm{CeO}_{2}-2 \mathrm{Ta}_{2} \mathrm{O}_{5}\right)$.

For each of these samples laminar diffractograms were made of the successive surfaces of the sections in the area between the working surface and the platinum. The width of the zone studied in each shot was $1 \mathrm{~mm}$. For samples with the initial composition $88 \mathrm{ZrO}_{2}-12 \mathrm{Y}_{2} \mathrm{O}_{3}$ a phase analysis of the cement material and the cold parts of the insulator: was also made. The diffractograms were made on filtered Cu-radiation in the range of angles of $2 \theta$ of $3-100^{\circ}$ with a sample rotation rate of 2 degrees/min.

Moreover, in order to make the phase composition more accurate, additional diffractograms have been made in a number of cases in the range $2 \theta: 27-35^{\circ} ; 46-50^{\circ}$ and $55-60^{\circ}$ with a sample rotation speed of 0.5 degrees/min.

For all the samples listed above, curves of the intensity of distribution of the $\mathrm{K}_{\alpha}$-radiation of potassium and zirconium were obtained by means of $\mathrm{x}$-ray spectral analysis. In the samples containing $\mathrm{CeO}_{2}$ the distribution curves for the intensity of $\mathrm{L}_{\alpha_{1}}$-radiation and 
in the samples containing $\mathrm{Y}_{2} \mathrm{O}_{3}-\mathrm{L}_{\alpha} \mathrm{Pt}$ were recorded. Recordings of the intensity of radiation from $K, \mathrm{Zr}$ and $\mathrm{Ce}$ in the microvolumes of each electrode were performed along lines perpendicular to the working surface of the electrode. For comparison of the distribution of the intensity $I_{\alpha}$ radiation $\mathrm{K}$ in various parts of the electrode, curves along lines parallel to each other were recorded at points equidistant from the "hot" layer of the electrode, the topography of the surface was the same or differed little.

\section{D.2.2 Results of X-Ray Phase Analysis}

The results of $x$-ray phase analysis of the electrode materials are shown in Table D.2.2.1 and D.2.2.2. In the description of the recorded phases, in order to simplify comparison of the data for the central and side segments of the electrodes, the designations introduced by the U.S. investigators were used: $C_{1}$ phase with a pyrochlor structure and the period $a=10.52 \AA$ (or with the "pseudofluorite" lattice, $a=$ $5.26 \AA) ; C_{2}$ phase with fluorite structure and period close to the period of the lattice of pure $\mathrm{CeO}_{2}: a=5.38$ to $5.39 \mathrm{~A} ; \mathrm{P}$ phase with a cubic perovskite structure and lattice period a $=4.09 \AA$. Additional studies of the composition of the $\mathrm{C}_{l}$ and $\mathrm{P}$ phases were not performed by the U.S. side to establish the composition of these phases. Thus, under $\mathrm{C}_{1}$ phase we include the phase $\mathrm{Ce}_{2} \mathrm{O}_{3} \cdot 2 \mathrm{ZrO}_{2}$, in which part of the $\mathrm{Ce}^{3+}$ cations are replaced by $\mathrm{Ce}^{4+}$. The $\mathrm{P}$ phase is apparently a product of the reaction of the seed with $\mathrm{ZrO}_{2}$ and $\mathrm{CeO}_{2}$.

The data of phase analysis of the samples before their tests differ slightly from the corresponding U.S. data. On the diffractograms of the samples of all the initial electrode materials and Mg0 there are weak maximums not pertaining to the basic phases and indicating the presence of admixture phases in the initial materials. Identification of these phases was not successful, and in Table D.2.2.1 they are given under the arbitrary designations $A, B, D, E$. In the sample with composition of $50 \mathrm{ZrO}_{2}-50 \mathrm{CeO}_{2}$, in addition to the other secondary phases, there are probably $C_{1}$ and $C_{2}$ phases.

The phase compositions of samples taken from central and side segments of the tested electrodes have noticeable differences in a number of cases.

Materials with the initial composition $88 \mathrm{ZrO}_{2}-12 \mathrm{Y}_{2} \mathrm{O}_{3}$ electrode pairs 2 and 4 (without current)

Change of the electrode materials containing $\mathrm{Y}_{2} \mathrm{O}_{3}$ appears mainly in the appearance of monoclinic $\mathrm{ZrO}_{2}$, which is a product of partial destabilization of the fluorite solid solution with a $\mathrm{ZrO}_{2}$ base. Monoclinic $\mathrm{ZrO}_{2}$ appeared in all the electrodes studied with the exception of anode 2104. The content of monoclinic $\mathrm{ZrO}_{2}$ increases in areas adjacent to the platinum. The greatest anount of monoclinic $\mathrm{ZrO}_{2}$ was recorded in cathode 1102. For this cathode in the regions around the platinum we observed a decrease in the period of the fluorite solid solution lattice in 
comparison with the period of the initial material lattice. On all the electrode sections studied we recorded traces of the presence of $\mathrm{KHCO}_{3}$.

The composition of the materials of the central and side sections of the electrodes is the same.

Materials with the initial composition $82 \mathrm{ZrO}_{2}-18 \mathrm{CeO}_{2}$ electrode pairs: 5 (without current and $7\left(j=0.8 \mathrm{~A} / \mathrm{cm}^{2}\right)$

For the electrodes of the 5 th and 7 th pairs the presence of a significant amount of monoclinic $\mathrm{ZrO}_{2}$ is common for the entire cross section of the electrode from the working surface to the platinum and a significant amount of $\mathrm{KHCO}_{3}$, the content of which increases as the platinum is approached.

The main difference between cathodes 1205 and 1207 is the fact that in 1205 the reaction of the seed with $\mathrm{ZrO}_{2} / \mathrm{CeO}_{2}$ occurred across the entire section of the sample, and the P-phase is dominant, while in 1207 there is only a small amount of $\mathrm{P}$-phase, the zone of its presence not being adjacent to platinum. On the other hand, the $\mathrm{C}_{1}$-phase, indicating reduction of $\mathrm{Ce}^{4+}$, is dominant across almost the entire section of 1207 , while in 1205, it is present only in the $\simeq 2 \mathrm{~mm}$ zone, beginning from the "hot" surface of the electrode. In 1205 the dominating phase (P) is accompanied by the cubic fluorite solid solution enriched with $\mathrm{CeO}_{2}$, while in 1207 , in addition to the dominating $C_{1}$-phase there is a tetragonal solid solution similar to the initial solid solution.

In the central segments of these cathodes there is a different distribution of $C_{1}$ and $P$ phases across the cross section of the electrodes. The zone of reaction of the seed with the electrode material is adjacent to platinum, and the $C_{1}$ phase is present in the middle regions of the sections. In addition, unlike the lateral segments, in the central areas of 1207 across the entire section there is no tetragonal s lid solution similar to the initial solution.

The material of anode 2205 contains a significant amount of tetragonal solid solution unchanged in comparison with the original. In the material of anode 2207 there was breakup of the initial solid solution into two cubic fluorite solid solutions enriched with $\mathrm{ZrO}_{2}$. As noted above, the materials of both these anodes, as well as the cathodes, contain significant amounts of monoclinic $\mathrm{ZrO}_{2}$, which indicates the intense destabilization processes occurring in these electrodes. But the degree of destabilization in the material of the side segments of the electrodes is less than in the central segments, thus in the side segments there is an unchanged (in comparison with the initial) tetragonal solid structure, usually absent in the central segments. In addition, the sections of anodes studied by us do not contain the P-phase in distinction from the central part of anode 2207 .

Materials with the initial composition $50 \mathrm{ZrO}_{2}-50 \mathrm{CeO}_{2}$ electrode pairs $10\left(j=0.8 \mathrm{~A} / \mathrm{cm}^{2}\right.$ ) and 12 (without current)

In these cathode sections the dominant phase is the $\mathrm{C}_{1}$-phase, indicating reduction of $\mathrm{Ce}^{4+}$. The difference between cathodes 1310 and 
1312 is mainly the fact that in 1310 there occurred the reaction $\mathrm{ZrO}_{2} / \mathrm{CeO}_{2}$ with the seed (the reaction zone coincides with the zone of yellow color), while in cathode 1312 no traces of this reaction were detected. In addition, in 1312 next to the working surface a certain amount of tetragonal solid solution was retained, similar to the initial. In 1310 there is no tetragonal solid solution.

In the upper parts of anodes 2310 and 2312 there was formation of $\mathrm{C}_{1}$-phase, while 2310 also retained tetragonal solid solution, the main phase for the initial composition $50 \mathrm{ZrO}_{2}-50 \mathrm{CeO}_{2}$.

In the lower parts of the anodes the fluoride solid solution is dominant with the lattice period $a=5.29 \AA$ and tetragonal solid solution $(\mathrm{a}=5.15, c=5.24 \AA$ ) characteristic of compositions with a low constant of $\mathrm{CeO}_{2}$, for example, for the composition $82 \mathrm{ZrO}_{2}-18 \mathrm{CeO}_{2}$. In addition, in areas adjacent to platinum cubic fluorite phases are present, enriched with $\mathrm{CeO}_{2}$. These regions are the zones of the reaction of $\mathrm{ZrO}_{2} / \mathrm{CeO}_{2}$ with the seed.

The composition of the materials of the central and side areas of the electrodes studied (with the exception of 2312) is generally similar, although the sections from the side areas of the cathodes did not have a green color zone, in distinction from the central areas. It should be noted, however, that in the central area of anode 2310 the P-phase noted in the side areas of this anode are absent.

Materials with the initial composition $25 \mathrm{ZrO}_{2}-75 \mathrm{CeO}_{2}$ electrode pairs: 13 (without current) and $15\left(j=0.8 \mathrm{~A} / \mathrm{cm}^{2}\right)$

The main phase for the materials of electrode pairs 13 and 15 is fluorite solid solutions similar to the initial solution $(a=5.34 \AA$ ). At the same time, all the samples studied have cubic solid solutions at fluorite with smaller lattice periods. On the sections of cathodes 1413 and 1415 we recorded a significant amount of $\mathrm{KHCO}_{2}$, but no $\mathrm{P}$-phase was revealed. In distinction from the cathodes, the reaction of the seed with $\mathrm{ZrO}_{2} / \mathrm{CeO}_{2}$ occurred in both anodes; in 2415 we observed only traces of $\mathrm{P}-$ phase, while in 2413 there is a strong P-phase in the zone not adjacent to platinum and coinciding with the region of gray-brown color.

In cathode 1413 and in both anodes, there is monoclinic $\mathrm{ZrO}_{2}$ near the platinum. Anode 2413 is distinguished by the presence of almost pure $\mathrm{CeO}_{2}\left(\mathrm{C}_{2}\right.$-phase) in it.

The composition of the cathodes in the central and side sections is rather similar. The composition of the anodes differs significantly, at least in the surface layers.

In the central segments at these anodes, the cubic phase with an $\mathrm{a}=5.14$ period predominates. This indicates a significant enrichment at the solid solution with zirconia; this is substantially less pronounced in the lateral segments at the electrodes. 
Materials with the initial composition $20 \mathrm{ZrO}_{2}-78 \mathrm{CeO}_{2}-2 \mathrm{Ta}_{2} \mathrm{O}_{5}$ electrode pairs $17\left(j=1.25 \mathrm{~A} / \mathrm{cm}^{2}\right.$ ) and 20 (without current)

The main phase of the upper parts of cathodes 1517 and 1520 , as well as anode 2520, is fluorite solid solution ( $A=5.35$ ), similar to the initial. In anode 2517 a phase richer in $\mathrm{CeO}_{2}$ dominates. Reaction with the seed occurred in all electrodes. The reaction zones fit the olive-green-yellow and olive-green areas and consist of areas 2-3 mm wide, adjacent to platinum. In all the electrodes studied we observed an assembly of cubic phases with varying lattice periods. The difference in cathode 1517 is the presence of the $C_{1}$-phase in the upper part of the electrode.

On the whole, for electrodes 17 and 20 we observed agreement of the composition in the central and side segments.

\section{Cement}

In the cement material (both on the cathode and on the anode walls) there was partial destabilization of the cubic solid solution on a $\mathrm{ZrO}_{2}$ base. The amount of monoclinic $\mathrm{ZrO}_{2}$ forming as a result of the breakup of the cubic solid solution increases from platinum to the cold part of the cement. The cement is a concentrator of potassium carbonate hydration products. In general, $\mathrm{KHCO}_{3}$ is present in the cement. X-ray spectrum analysis shows that the amount of potassium increases with approach to the cold end of the cement, the $\mathrm{K}$ content being higher in the cement on the cathode wall than in the cement of the anode wall.

In the gray areas of the cement, in addition to $\mathrm{KHCO}_{3}$, we also recorded both $\mathrm{K}_{2} \mathrm{CO}_{3}-1-1 / 2 \mathrm{H}_{2} \mathrm{O}$ and $\mathrm{K}_{2} \mathrm{CO}_{3} \cdot\left(2 \mathrm{KHCO}_{2}\right) \cdot\left(1.5 \mathrm{H}_{2} \mathrm{O}\right)$. In these same sections we noted the presence of magnesium oxide.

In the cement layers adjacent to the platinum lattice we observed a certain amount of $\mathrm{Pt}$. The width of the platinum diffusion zone varies from about 0.2 to $0.3 \mathrm{~mm}$ for the different electrodes, and in some cases (for example, anode 2104) it spreads over all the section of the cement.

The $\mathrm{MgO}_{2}$ insulator

In the cold parts of the cathode wall insulators we recorded a significant amount of potassium hydration products: $\mathrm{KHCO}_{3} \quad \mathrm{~K}_{2} \mathrm{CO}_{3}-$ 1-1/2 $\mathrm{H}_{2} \mathrm{O}, \mathrm{K}_{2} \mathrm{CO}_{3} \cdot\left(2 \mathrm{KHCO}_{3}\right) \cdot 1.5\left(\mathrm{H}_{2} \mathrm{O}\right)$. On similar parts of the cathode wall insulators, $\mathrm{K}$ is absent.

\section{D.2.3 Discussion of the Results}

As follows from the results of $x$-ray phase analysis, significant changes occurred in the electrode materials due to the breakup on the initial solid solutions and reactions with the seed. Here the materials with the initial composition $82 \mathrm{ZrO}_{2}-18 \mathrm{CeO}_{2}$ and $50 \mathrm{ZrO}_{2}-50 \mathrm{CeO}_{2}$ underwent the greatest changes. It is for these electrodes that the breakup of the solid solutions is most clearly expressed, as well as the reaction of the electrode material with the seed.

For the materials of all the compositions tested breakup of the initial solid solutions is observed both on the cathodes and on 
the anodes, it is also clearly expressed on electrodes without current. The breakup products are monoclinic $\mathrm{ZrO}_{2}$ and an assembly of cubic phases with varying content of $\mathrm{CeO}_{2}$; it is possible to separate solid solutions enriched or depleted of $\mathrm{CeO}_{2}$ compared with the initial composition.

The materials of these electrodes are to a greater or lesser degree premeated with potassium, hydration of which forms the compound $\mathrm{KHCO}_{3}$. As is shown by $x$-ray spectrum studies, $\mathrm{K}$ is present in all the samples studied both directly on the working surface and in deeper layers. As a rule, the intensity of $\mathrm{K}_{\alpha_{l}}$ radiation $\mathrm{K}$ increases at a depth of 2 to $3 \mathrm{~mm}$ from the working surface, and has a significantly higher value in this zone than in the hot layers of the electrode.

In the majority of electrode materials containing $\mathrm{CeO}_{2}$, there was a reaction of $\mathrm{ZrO}_{2} / \mathrm{CeO}_{2}$ with the seed. The reaction occurred (both in the cathodes and in the anodes) mainly in zones 1 to $3 \mathrm{~mm}$ wide, either adjacent to platinum or approximately $1 \mathrm{~mm}$ from it.

Analysis of the results obtained for cathode and anode materials containing $\mathrm{CeO}_{2}$ shows that at this stage of the studies there is not a sufficient basis to unequivocally equate the coloring of each of the color zones observed on the electrodes with the presence of any single phase. It is possible that the yellow color of the mateiial is to a certain degree connected with reduction of $\mathrm{Ce}^{4+}$.

The composition of the electrode materials of the central and side areas generally agree in some cases, and differ significantly in other cases. The differences are apparently connected with che temperature differences on these electrode segments. It should be noted that, as study has shown, the phases present in the materials are irreguiarly distributed through the volume of the electrodes. For example, the phase composition of the materials of two neighboring sections of the same sample, at a distance of approximately $1 \mathrm{~mm}$ from each other, in the majority of cases differ at least in the ratio of the amount of main phases and also in the amount of $\mathrm{KHCO}_{3}$. Thus, in addition to the change in the phase composition from the hot to the cold layers of the electrode, there are also variations of the composition in layers parallel to the working surface. Probably, the nonuniformity of the phase composition at various parts of the electrode is connected with the irregularity of distribution of the seed penetrating into the electrode. These electrodes are characterized by an extremely irregular distribution of $\mathrm{K}$. In the electrode layers parallel to the working surface, the intensity of the $\mathrm{K}_{\alpha_{1}}$, for $\mathrm{K}$ undergoes severe changes. For example, the zone of high $\mathrm{K}_{\alpha_{1}}$ intensity on the working surface changes in width from 0 to $0.7 \mathrm{~mm}$. Similar zones in the cold parts of the electrode also change their size and intensity. Figures D.2.3.1a,b and D.2.3.2a,b show the distribution curves of the $\mathrm{K}_{\alpha}$ intensity of $\mathrm{K}$ along lines perpendicular to the working surface for the 1310 cathode and 2520 anode, illustrating this change in the width and intensity of the $\mathrm{K}_{\alpha_{l}}$ zones of $\mathrm{K}$ in the hot and cold parts of the electrode. Similar situations are also observed on electrodes of other compositions.

In addition, experiments have shown that the amount of $\mathrm{K}$ recorded on sections exposed to air over a long period proves to be greater than on corresponding fresh sections. The $\mathrm{K}$ distribution patterns for these sections are similar.

This result is apparently connected with the hydration of the seed penetrating into the depth of the electrodes. 
All the electrode material composition changes recorded and discussed above occur as a result of the simultaneous effect of three main factors: high temperatures (and subsequent cooling), seed and electrochemical processes. It is their simultaneous action that leads to the complex phase composition situation in these electrodes. It is apparent that in order to explain the phase conversion mechanism occurring in the electrodes it is necessary to have a clear idea of the role of each of these factors. But at the present stage of study we can apparently speak only of their cumulative effect, since to determine the degree of influence of each of the factors requires additional experiments and studies.

Table D.2.2.1. Sample Composition before Tests.

Sample (mol.\%) Main phase $(a, c-\AA) \quad$ Additional phases (a, $\mathrm{A}$ )

$88 \mathrm{ZrO}_{2}$

$12 \mathrm{Y}_{2} \mathrm{O}_{3}$

$82 \mathrm{ZrO}_{2}-$

$18 \mathrm{CeO}_{2}$

$50 \mathrm{ZrO}_{2}-$

$50 \mathrm{CeO}_{2}$ f.c.c.

$\mathrm{a}=5.152$

Tetragonal solid sol.

$\mathrm{a}=5.15 ; \mathrm{c}=5.24$

Tetragonal solid sol.

$\mathrm{a}=5.26 ; \mathrm{c}=5.33$
Admixture phase A

Admixture phase $A+B$

$\mathrm{C}_{1}$-phase, $\mathrm{a}=5.26+$ tetragon, $\mathrm{a}^{\mathrm{a}}=5.15$

$c=5.24^{-}+$f.c.c.,

$a=5.34+C_{2}$-phase,

$\mathrm{a}=5.38+$ admixture

phase $B$

$\mathrm{a}=5.35$

$78 \mathrm{CeO}_{2}-$

$2 \mathrm{Ta}_{2} \mathrm{O}_{5}$

Mg0 f.c.c.

$\mathrm{a}=5.34$

f.c. c.

f.c.c.

admixture phase E

f.c.c., $a=5.23+$

admixture phase D

f.c.c., $a=5.15+$

admixture phases $D+B$

$\mathrm{a}=4.210$ 


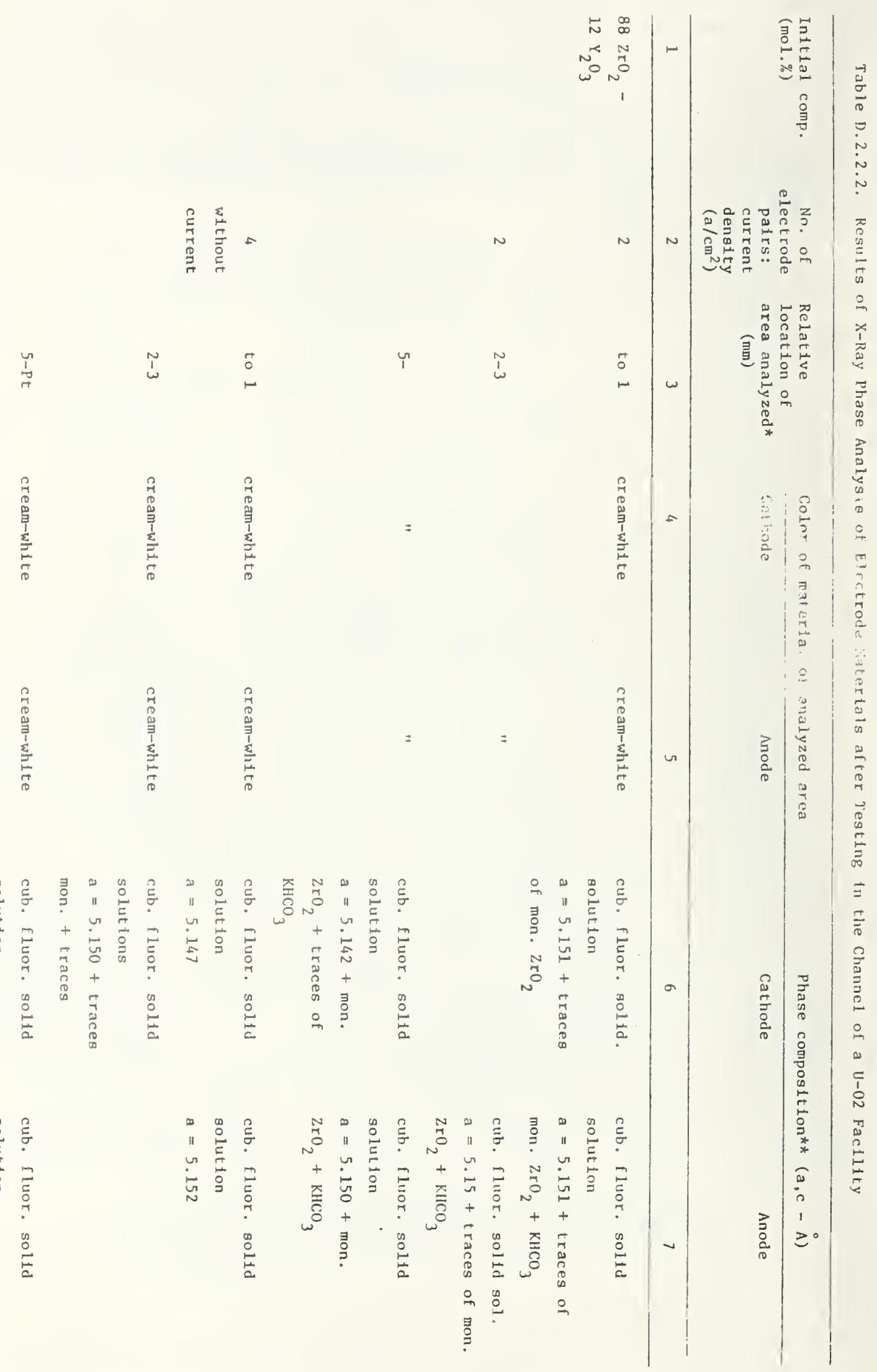


i

$\vdots$

$\tilde{\omega}$

$\stackrel{5}{2}$

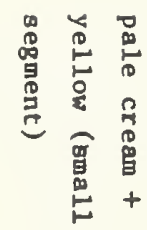

0.0
0
0

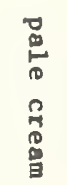

若

葛

員

虽

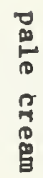

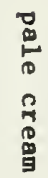

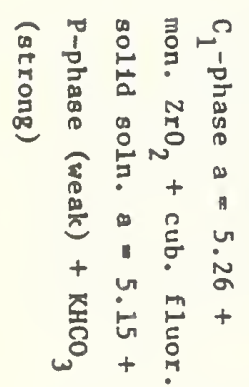

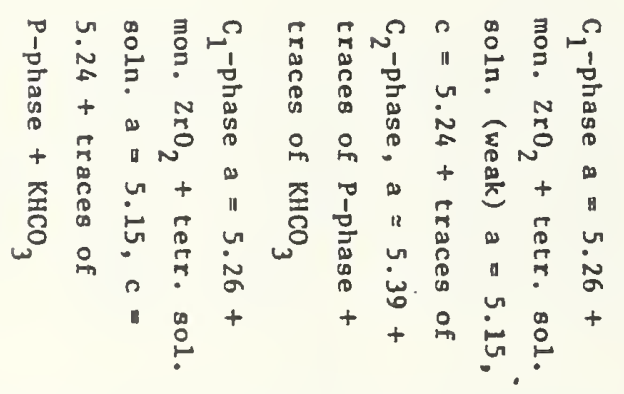

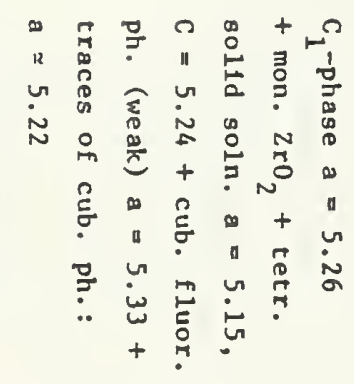

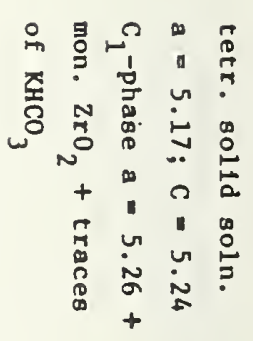

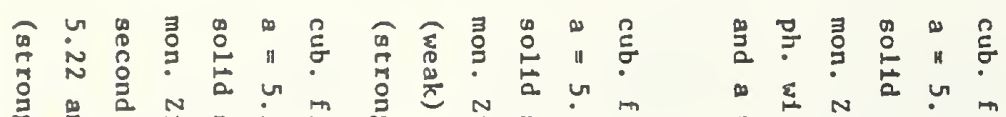

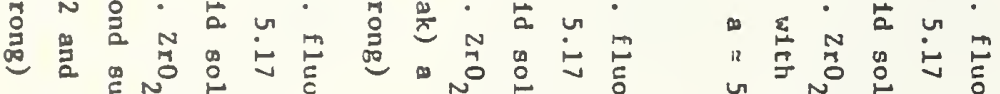

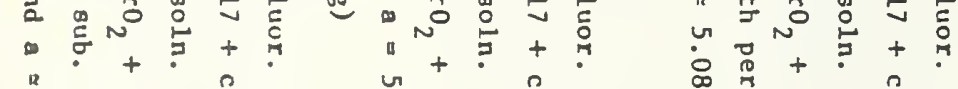

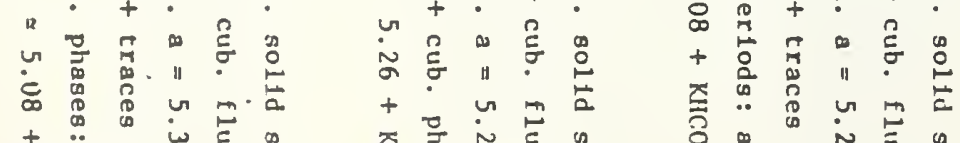

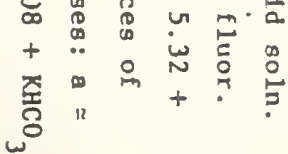

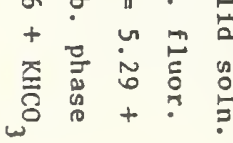

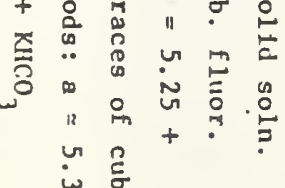

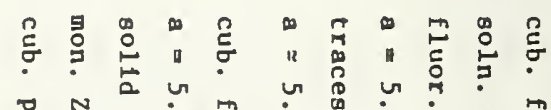

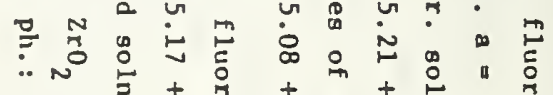

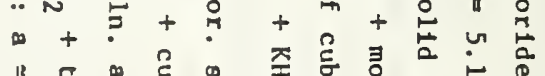

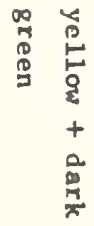



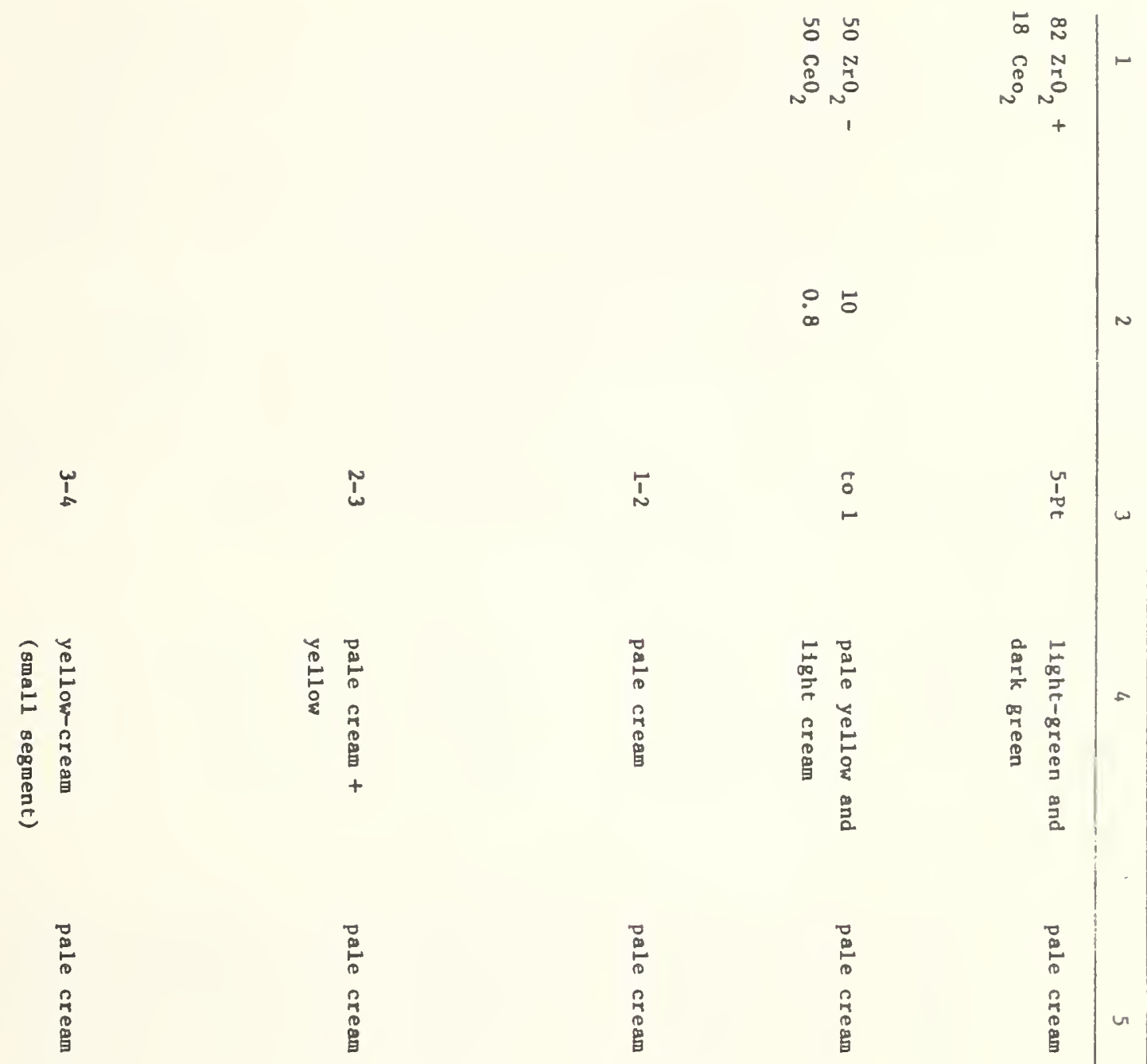

$i_{\infty} 5$

$\stackrel{\mathfrak{1}}{\sim}$

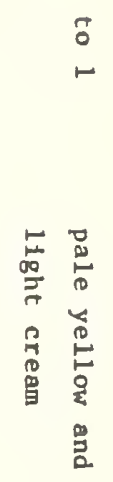

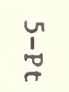
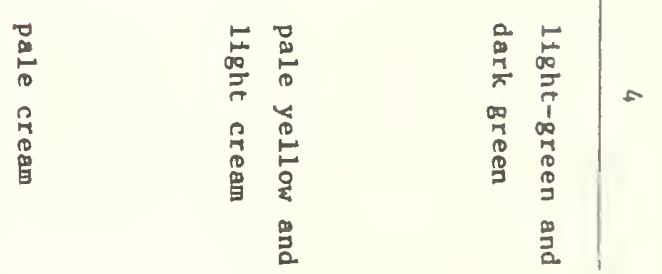

0
$\stackrel{0}{0}$
0
0
0
0
0
0

0
0
0
0
0
0
0
0

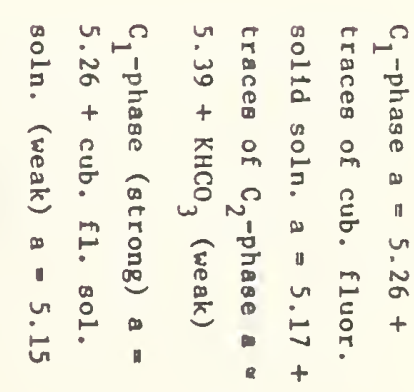

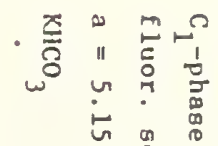

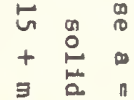

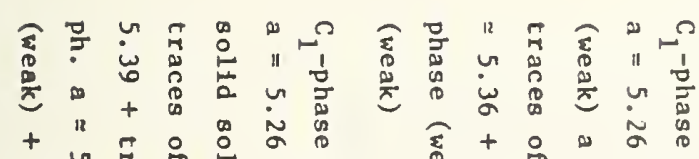

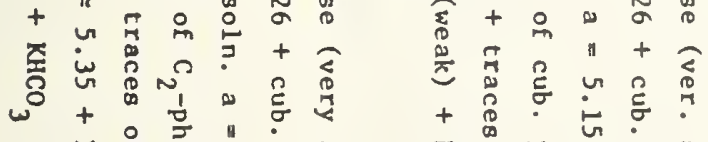

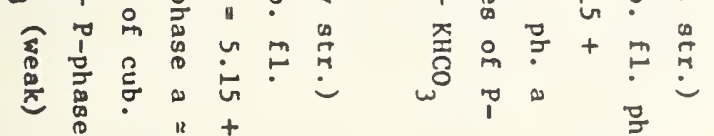

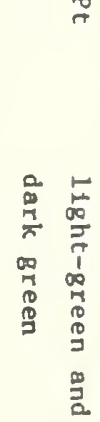

종ำ

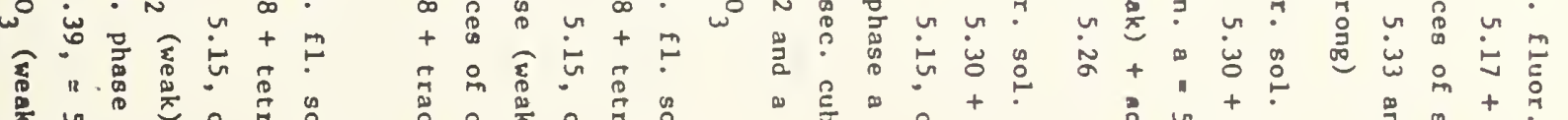

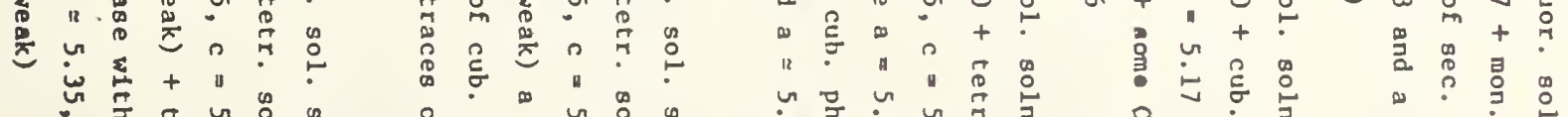

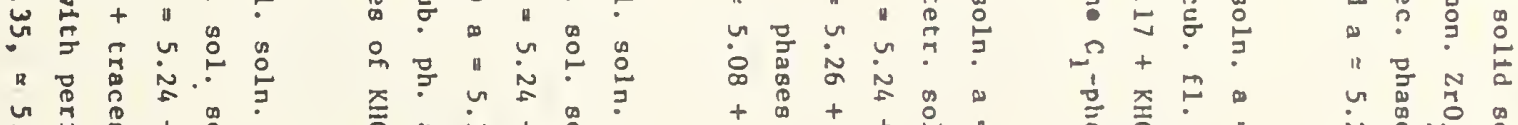

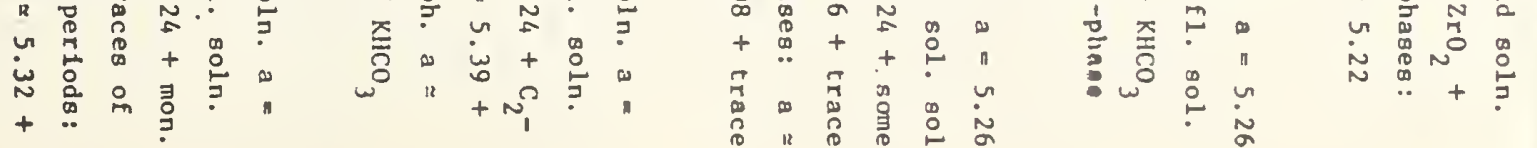




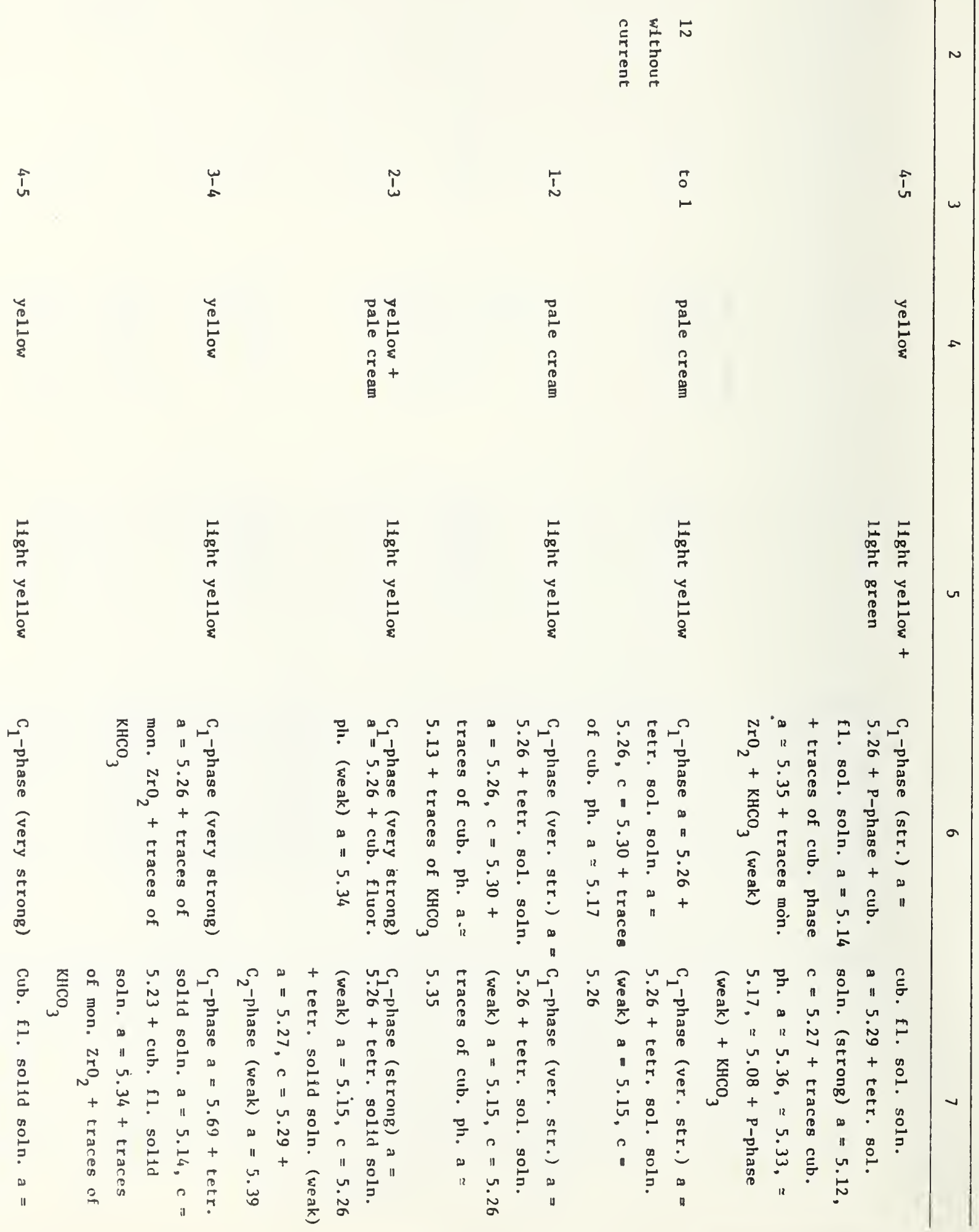




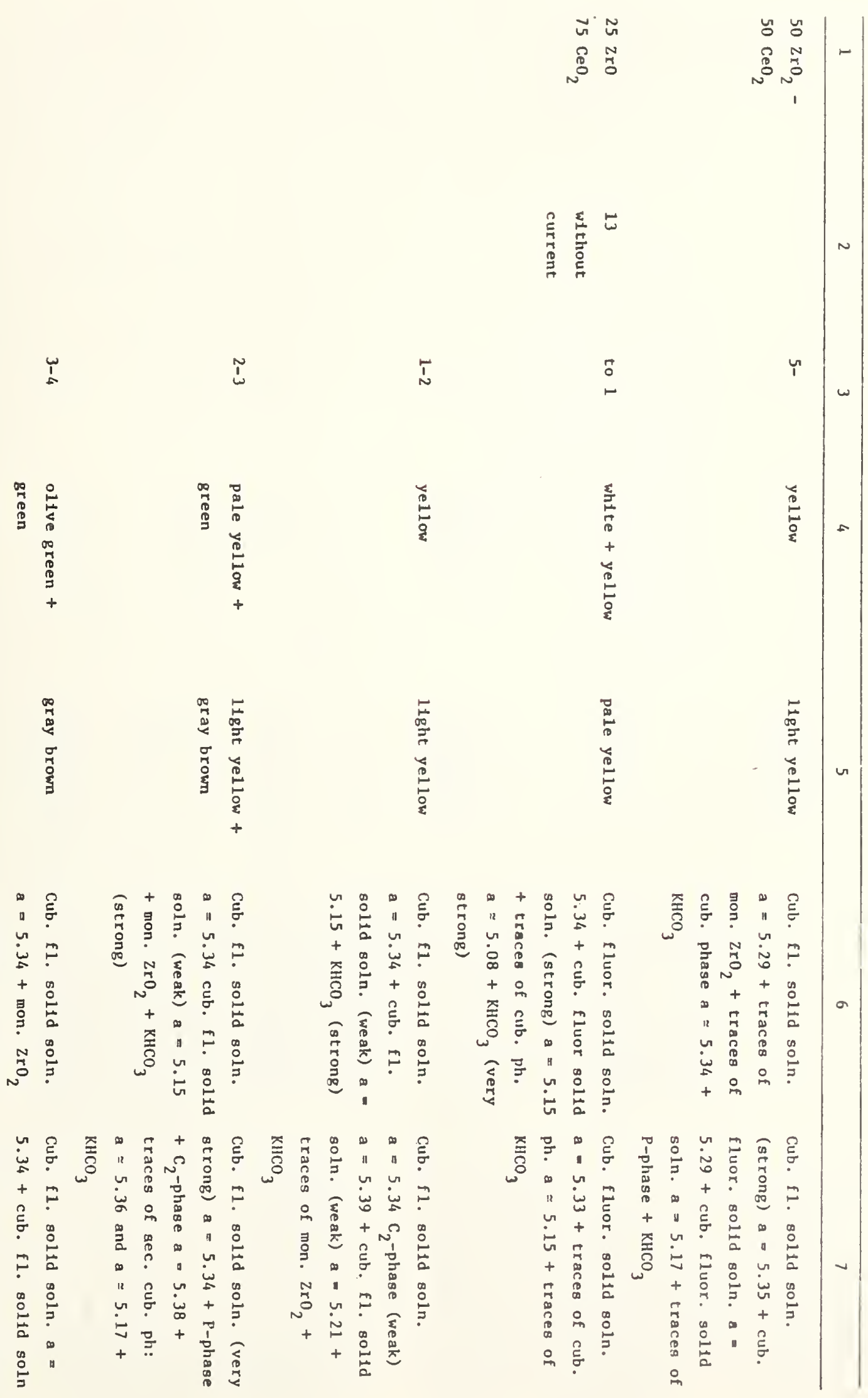


$\stackrel{i}{i}$

$\stackrel{i}{\omega}$

$\stackrel{i}{\sim}$

जิ

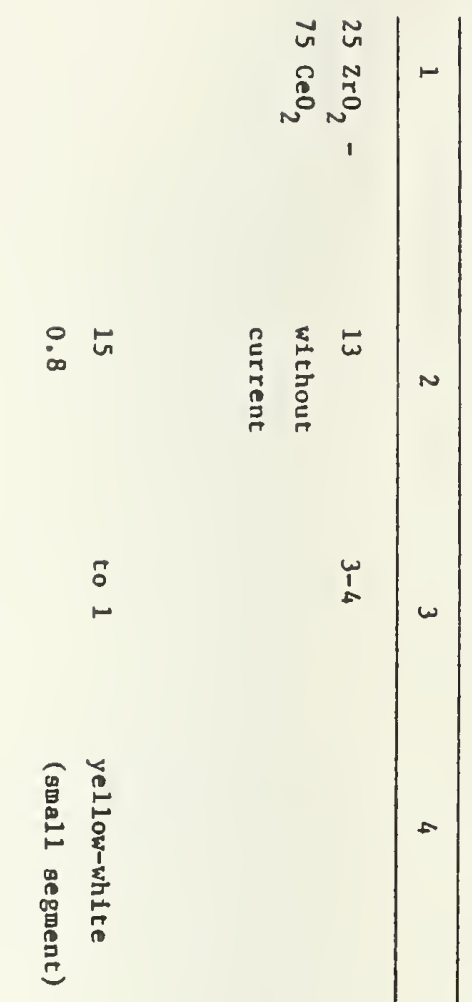

0
0
0
0
0
0
0
0
0

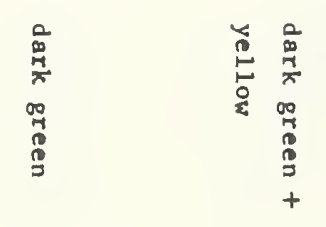

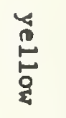

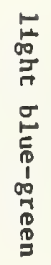

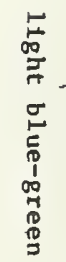

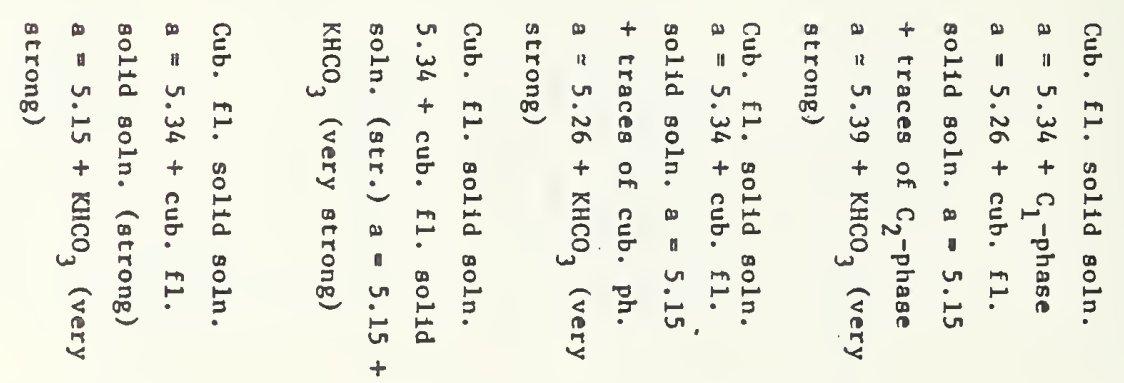

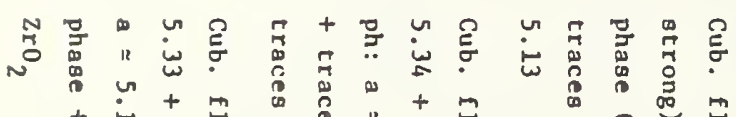
$+5+? \begin{array}{lll}0 \\ + \\ +\end{array}$

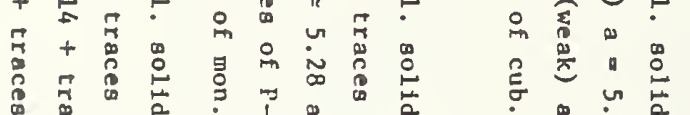

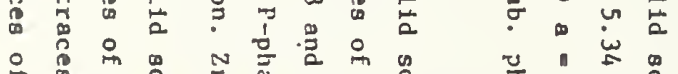

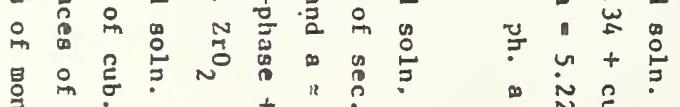

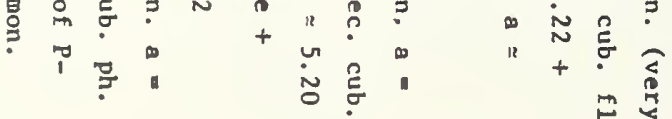

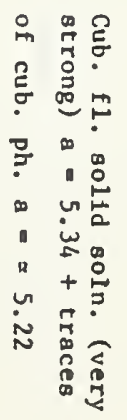

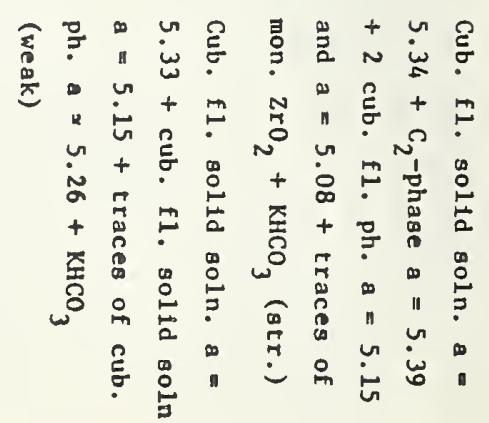




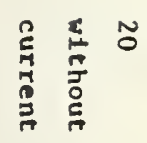

\begin{tabular}{|c|c|c|c|c|c|}
\hline$\stackrel{\text { ๘ }}{\text { r }}$ & $\hat{i}$ & $\stackrel{w}{t}$ & $\tilde{\omega}$ & $\stackrel{i}{\sim}$ & \\
\hline 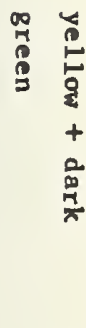 & $\begin{array}{l}0 \\
\stackrel{2}{4} \\
0 \\
\infty \\
0 \\
0 \\
0 \\
3 \\
3\end{array}$ & 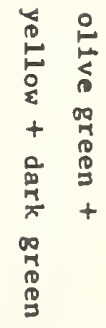 & 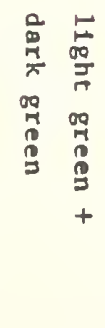 & 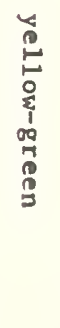 & 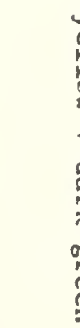 \\
\hline 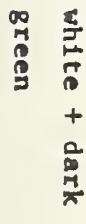 & 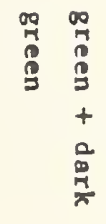 & 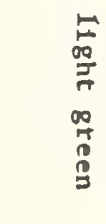 & 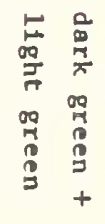 & 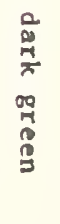 & 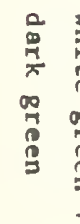 \\
\hline
\end{tabular}

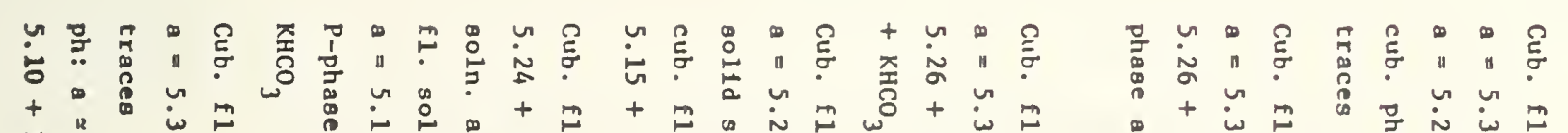

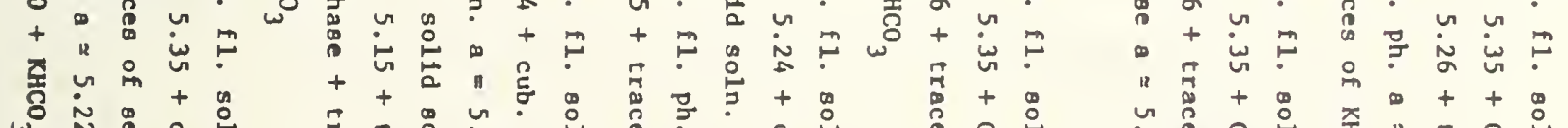

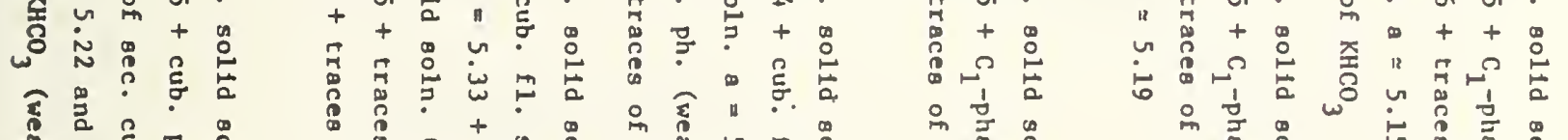

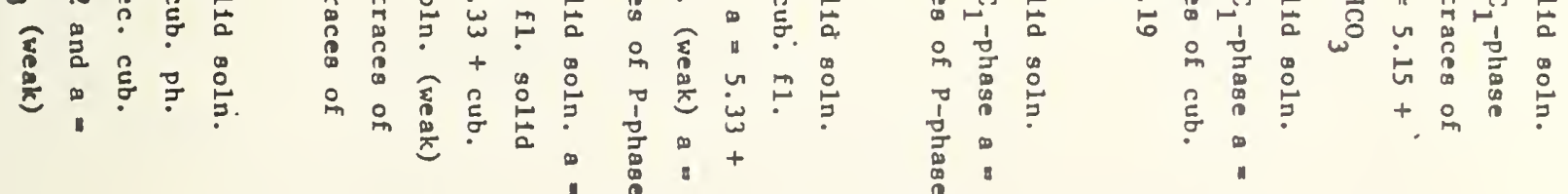

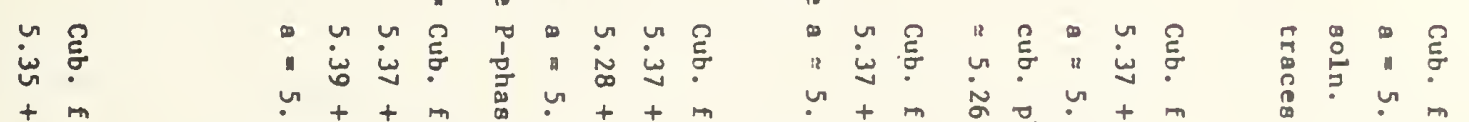

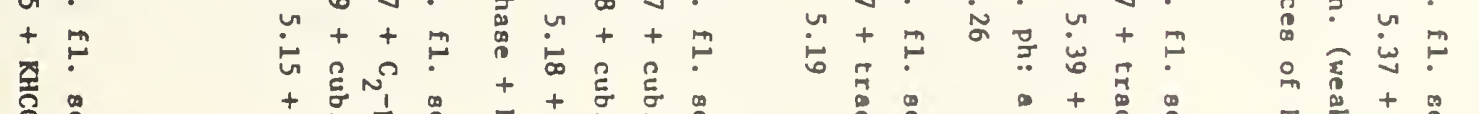

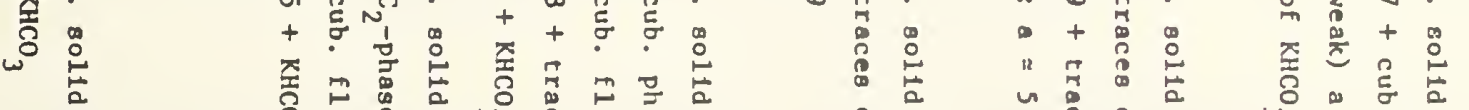

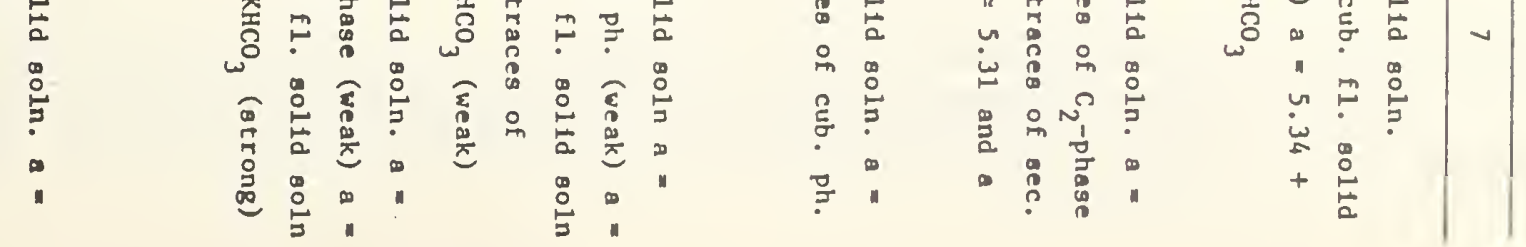



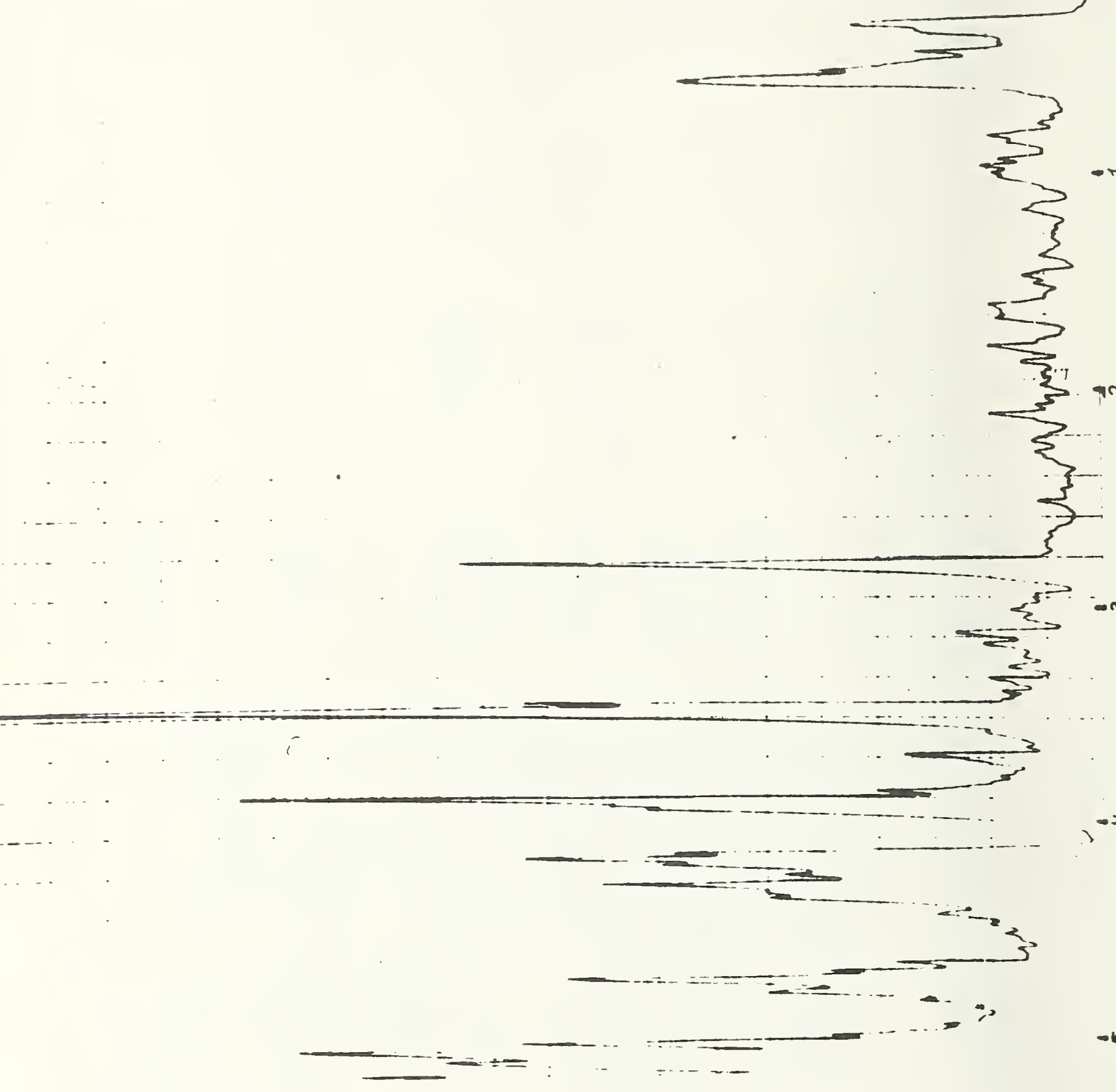

Figure D.2.3.1a. Distribution of the intensity of $K_{\alpha} l$ radiation $K$ for the 1310 cathode: Along an arbitrary line perpendicula: to the working layer of the electrode (central part of the section). 


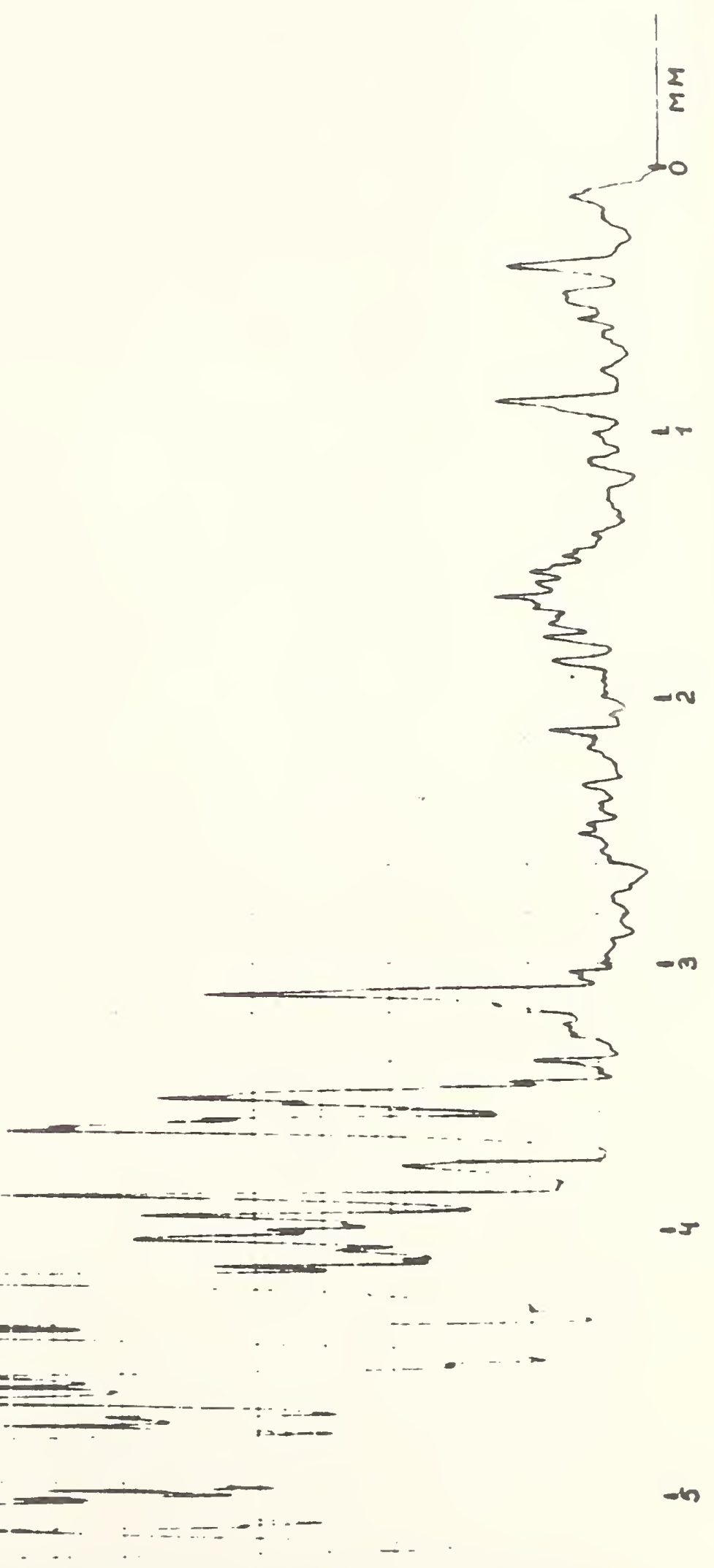

Figure D.2.3.1b. Distribution of the intensity of $K_{\alpha l}$ radiation $K$ for the 1310 cathode: Along a line parallel to line a) and $500 \mathrm{mcm}$ from it. 


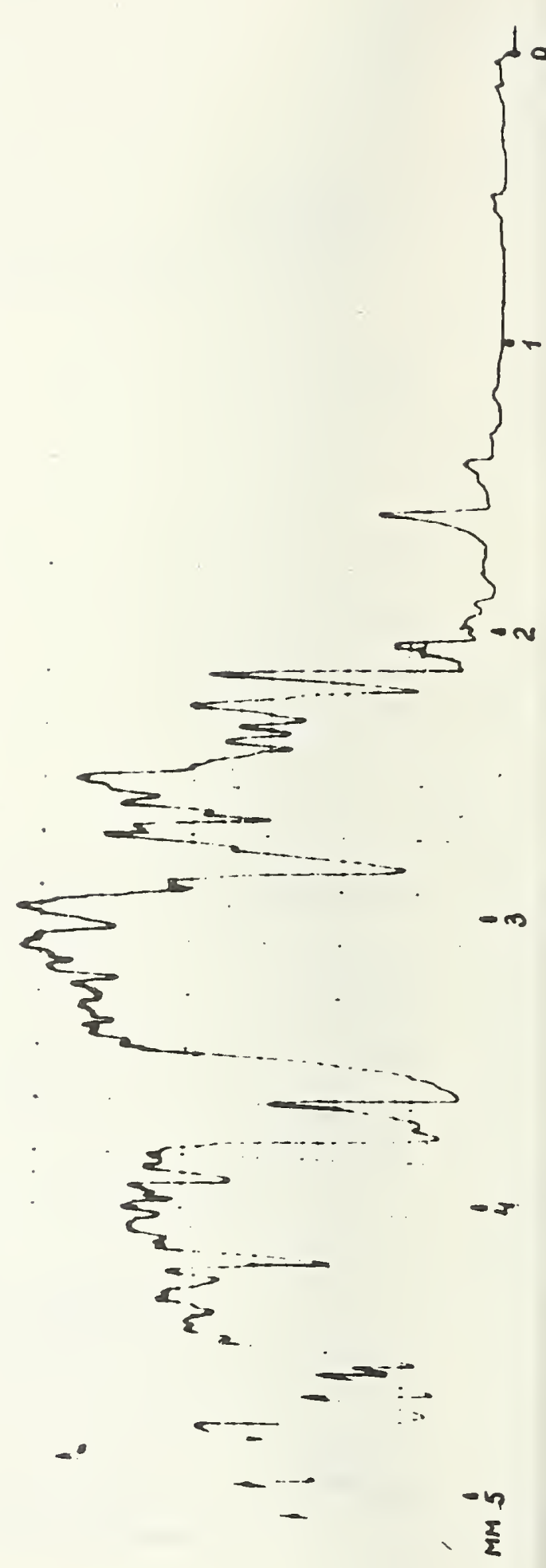

Figure D.2.3.2a. Distribution of the $\mathrm{K}_{\alpha} \mathrm{l}$ radiation intensity $\mathrm{K}$ for the 2520 anode: Along an arbitrary line perpendicular to the working layer of the electrode (central part of the section). 


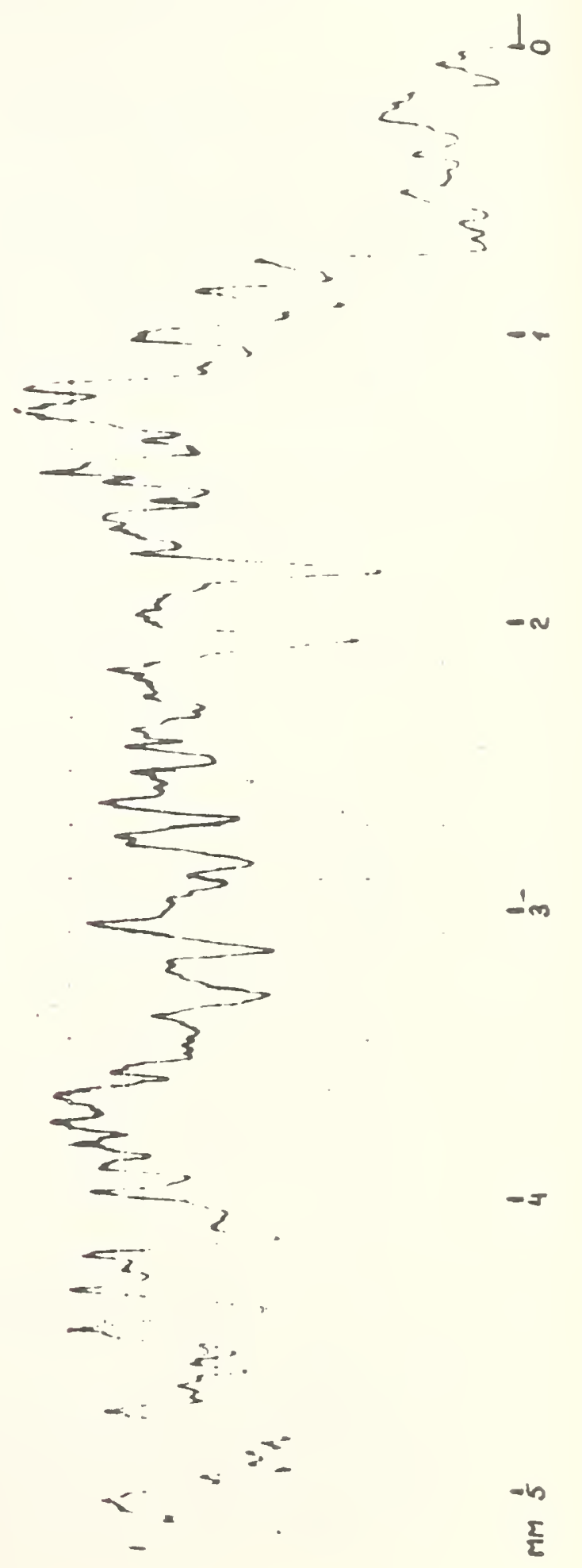

Figure D.2.3.2b. Distribution of the $K_{a}$ radiation intensity $K$ for the 2520 anode: Along a line parallel to line a) and $800 \mathrm{mcm}$ from it. 
D.3 Electrochemical Investigations of Electrodes with Compositions I $\left(88 \mathrm{ZrO}_{2}, 12 \mathrm{Y}_{2} \mathrm{O}_{3}\right)$ and II (82 $\mathrm{ZrO}_{2}$, $18 \mathrm{CeO}_{2}$ ).

D.3.1 Hot ceramic electrodes with composiitons consisting of $88 \mathrm{~mol} \% \quad \mathrm{ZrO}_{2} \quad 12 \mathrm{~mol} \% \mathrm{Y}_{2} \mathrm{O}_{3}$

The fluorite structure has a lattice constant a $=5.151 \pm$ $0.002 \mathrm{~A}$. The open porosity is $17.7 \%$; the closed porosity amounts to less than $0.5 \%$. The ceramics specimen is a solid electrolyte with anionic conductivity. In accordance with the data from the "VDN Limited" and Magnesium Electron Limited, the following admixtures predominate in specimens having the above-mentioned composition: $0.2 \% \mathrm{TiO}_{2} ; 0.2 \% \mathrm{SiO}_{2}$; $0.02 \% \mathrm{Fe}_{2} \mathrm{O}_{3}$ and so forth. The admixture composition in Soviet specimens differ somewhat from the admixture composition contained in American specimens. Table D.3.1.1 presents data concerning the electrical conductivity of ceramics as a function of the temperature.

Table D.3.1.1. The specific electroconductivity of the binary system 88 mol\% $\mathrm{ZrO}_{2}-12$ mol\% $\mathrm{Y}_{2} \mathrm{O}_{3}$ as a function of the temperature.

$$
\sigma \mathrm{ohm}^{-1} \mathrm{~cm}^{-1}
$$

Temperature

${ }^{\circ} \mathrm{C} \quad$ American data

Data from laboratories

using electrochemical

Reference

methods in their investi-

data

gation

$\begin{array}{rrrr}900 & 2.5 \cdot 10^{-2} & 3.0 \cdot 10^{-2} & 1.8 \cdot 10^{-2} \\ 1000 & 6.5 \cdot 10^{-2} & 6.0 \cdot 10^{-2} & 2.4 \cdot 10^{-2} \\ 1100 & 9.6 \cdot 10^{-2} & 1.0 \cdot 10^{-1} & 7.7 \cdot 10^{-2} \\ 1200 & 1.3 \cdot 10^{-1} & 2.0 \cdot 10^{-1} & 1.1 \cdot 10^{-1} \\ 1300 & 2.4 \cdot 10^{-1} & 3.0 \cdot 10^{-1} & 2.0 \cdot 10^{-1} \\ 1400 & 3.8 \cdot 10^{-1} & 4.2 \cdot 10^{-1} & 3.5 \cdot 10^{-1}\end{array}$

The conductivity values given show that the experimental IVTAN data practically coincide with the data of American investigators. The $\sigma$ values (IVTAN) refer to the $\mathrm{ZrO}_{2}-\mathrm{Y}_{2} \mathrm{O}_{3}$ specimens, which were produced in laboratories that use electrochemical methods for the investigation of materials. A good correlation between the data attests to the fact that the admixture conductivity does not contribute anything at all to the general conductivity at this temperature interval.

The microstructure of the cathode interphase layer exerts a significant influence on the critical current (the limiting current of oxygen diffusion). Its thickness depends on the method by which the platinum current outlet is attached to the ceramics. If the platinum is pressed 
into the ceramic, then the thickness of 'the unbroken layer of the solid electrolyte, which is adjacent to the current outlet, attains approximately $10^{-6}$ or $10^{-7} \mathrm{~cm}$. However, in the case where the surface of the ceramic is coated with platinum, which then is brazed, the continuous surface becomes thicker and more vacuum tight. For this reason, it is desirable to choose the method in which the platinum is coated on the surface of the ceramics. We assume that U.S. investigators used the method described below.

It is well known that the critical current, the area current, is connected with a certain diffusion mechanism. Two mechanisms are possible for the delivery of the $\mathrm{O}_{2}$ to the platinum cathode:

1) $\mathrm{O}_{2}$ diffusion in the pores down to the triphase boundary: cathode-solid electrolyte-gas;

2) $\mathrm{O}_{2}$ diffusion in the pores with subsequent diffusion in the thin layer of the solid electrolyte to the boundary: electrolytecathode. The $\mathrm{O}_{2}$ is dissolved in the ceramic with the formation of the $0^{2-}$ anion-vacancy pairs, which diffuse with the diffusion coefficient $\mathrm{D}=1$ to $2 \cdot 10^{-6} \mathrm{~cm}^{2} / \mathrm{sec}$ at $1300-1400^{\circ} \mathrm{C}$.

Independent of the concrete geometry of the cathodic space, the conclusion can be drawn from the experimental data that the oxygen passes the unbroken thin layer in the solid electrolyte after diffusion in the pores of the remainder of the path to the cathode. The second stage is significant in that it:

1) makes possible the participation of oxygen in the cathode process, which is guided by the electric field at the cathode-electrolyte boundary; and

2) Iimits the value of the critical current.

The current goes through the current leadout-anode because of the discharge of the oxygen anions. The anions are supplied to the anode through migration in the electric field, but the discharge of $\mathrm{O}_{2}$ from the anode does not regulate the current but it is regulated by the supply of $\mathrm{O}_{2}$ to the cathode. For this reason, with the increase of the voltage in the specimen the dependency of the current on the anode potential does not disclose the limiting current plateau. It is precisely the cathode which is responsible for the critical current density. [See Ya. P. Gokhstein, R. A. Khaikin, Teplofixika vysokikh temperatur 7, No. 5, 1031 (1969); Ya. P. Gokhstein, DAN, 190, No. 1, 140 (1970); Ya. P. Gokhstein, A. A. Safonov, Teplofixika vysokikh temperatur 8, No. 2, 398 (1970); Ya. P. Gokhstein, A. A. Safonov, DAN, 195, No. 1, 109 (1970)].

A U.S. specimen with a composition of $88 \mathrm{~mol} \% \mathrm{ZrO}_{2}-$ $12 \mathrm{mo} \% \mathrm{Y}_{2} \mathrm{O}_{3}$ was tested under laboratory conditions, in air, at a temperature of $1400^{\circ} \mathrm{C}$ and in the absence of thermal-shock (detailed account will be presented later).

The faces of two specimens were coated with platinum and using arc welding, a platinum grid was attached to this platinum. A platinum wire with a $0.5 \mathrm{~mm}$ diameter was soldered on the grid. The specimens were provided with platinum probes at distances of $\sim 0.1$ and $0.16 \mathrm{~cm}$ from the cathode and anode, respectively.

The tests were conducted in a Silit furnace and the temperature of the furnace was determined with the aid of two platinum- 
rhodium thermocouples. At a temperature of $1400^{\circ} \mathrm{C} \pm 10^{\circ} \mathrm{C}$ the furnace worked in a stable fashion. Together with the main specimen, a completely analogous control specimen was introduced into the furnace; a current did not pass through this specimen.

During the experiments of this study, the potential of the electrode-platinum current leadout was measured at a preset current in comparison to the probe. The volt-ampere curves "current density-potential" were recorded by means of PDS-021m (double coordinate recording potentiometer) both in the negative and the positive areas of the potential. On the "current density-potential" curve in the negative area of the potential, where the current leadout providing the measurements serves as a cathode, the extreme oxygen diffusion current (critical current density) is found at $\sim 0.1 \mathrm{a} / \mathrm{cm}^{2}$ across the sample. For $\mathrm{ZrO}_{2}-\mathrm{Y}_{2} \mathrm{O}_{3}$ ceramics with approximately the same composition, an open porosity of $25 \%$ (IVTAN specimens), and platinum disks pressed into the specimen, the limiting current of the oxygen diffusion appeared at $0.62 \mathrm{a} / \mathrm{cm}^{2}$ in the beginning and $0.8 \mathrm{a} / \mathrm{cm}^{2}$ at the end (in the cross section of the specimen). (Figure D.3.1.1).

It is well known that the limiting current of the oxygen diffusion $j \mathrm{~m}$ in the case of unidimensional diffusion is determined by the following equation

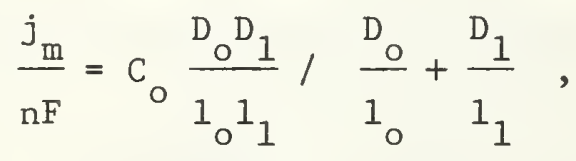

where $\mathrm{n}$ - the flow rate of the electrons in the reaction $(\mathrm{n}=2)$;

$\mathrm{F}$ - the Faraday number;

$\mathrm{C}_{\mathrm{O}}$ - the $\mathrm{O}_{2}$ concentration outside the specimen; the diffusion layers is composed of two layers a porous layer (0) and an unbroken one (1) with thickness $1_{0}$ and $1_{1}$ and diffusion coefficients $D_{0}$ and $D_{1}$.

The diffusion of oxygen through the unbroken layer (the second stage of the diffusion mechanism) is the basic, essential stage, limiting the value of the critical current. When the platinum is coated on the ceramic specimen, an unbroken, vacuum-tight layer, $1_{1}$, is formed thicker than the unbroken layer $l_{1}$ of the sample with a platinum current leadout pressed into the ceramic. The oxygen must be diffused through a thicker and denser ceramic layer. For this reason the diffusion coefficient $D_{1}$ is less than the value $D_{1}$ in the case where the platinum is pressed into the ceramic and, as a consequence of this, the critical current becomes significantly smaller than $j_{\mathrm{m}}$ which was obtained from a specimen with a pressed platinum leadout.

The gaseous oxygen (diffusion coefficient at the given temperature, $14 \mathrm{~cm}^{2} / \mathrm{sec}$ ), which comes from the air to the surface of the platinum (not continguous with the ceramics), does not have an effect on the value of the limiting current of the oxygen diffusion. The investigation established the oxygen diffusion mechanism at the phase boundary: ceramic-platinum (coated on the surface of the ceramics) at a temperature close to the temperature of the current 


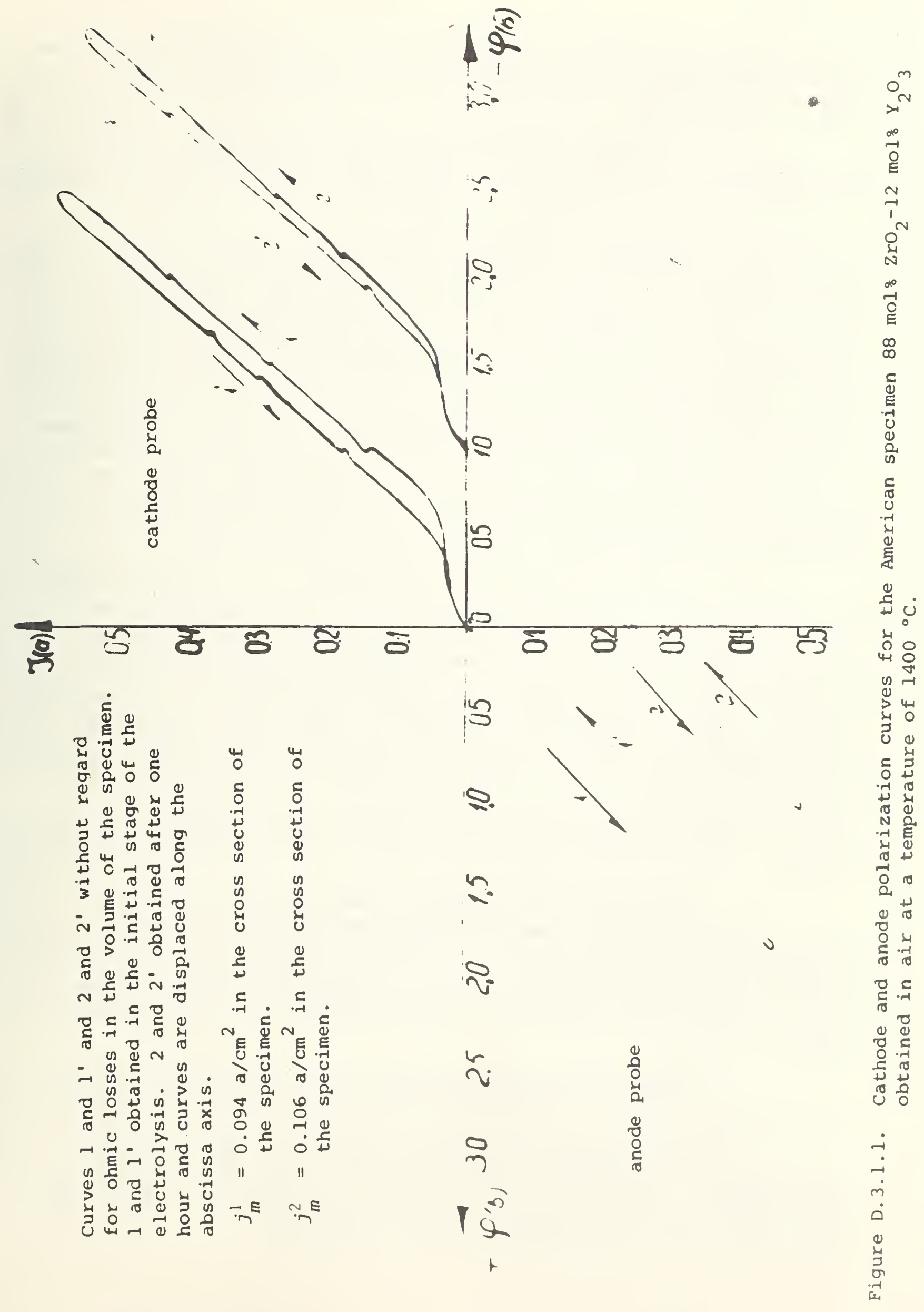


leadout under the operating conditions of the electrode in the U-02 channel. The control specimen did not change; the coated platinum on the two faces was not damaged.

Following is a description of electrodes with a composition of $88 \mathrm{~mol} \% \mathrm{ZrO}_{2}-12 \mathrm{~mol} \% \mathrm{Y}_{2} \mathrm{O}_{3}$ on the cathode and anode walls of the $\mathrm{U}-02$ channel (a cross section of the cathode and anode walls is investigated).

A sketch of the construction of the U.S. electrode shows that besides the presence of the platinum coating on the surface of the ceramics, the platinum coated face with the platinum grid is fixed in the insulator with cement basically containing $\mathrm{ZrO}_{2}$, stabilized by calcium oxide. The passage of direct current through the specimen must induce electrochemical reactions both in the interphase layer, the "platinum-ceramics" layer, and on the boundary of the platinum with the cement. This somewhat complicates the method for determining the critical current density since one has to investigate separately the processes on both sides of the coated platinum. Computations on the basis of readings from thermocouples which were located in the $\mathrm{MgO}$ at a distance of $8.3 \mathrm{~mm}$ from the hot surface of the ceramics gave the following figures: on the boundary of the platinum-ceramics division the temperature fluctuated within the range of $1300-1350^{\circ} \mathrm{C}$, but on the surface of the platinum which was immersed in cement, the temperature attained $1250^{\circ} \mathrm{C}$.

Let us first of all look at electrode pair 1104 and 2104; the current did not pass through this electrode. On the cathode the electrode remained practically intact. The height of the ceramics was approximately $6.2 \mathrm{~mm}$ and its breadth, approximately $13.2 \mathrm{~mm}$. Between the cement and the ceramics one can see the platinum layer. However, on the right side of the ceramics one can observe some corrosion in the platinum, which reacted with the ceramics at $1300^{\circ} \mathrm{C}$, as a consequence of the penetration of the $\mathrm{KOH}$ fusion into the ceramic pores. As a result of the reaction two layers of gray color are formed on the boundary with the platinum and a bit lower in the cement area. The cement remained unaffected and exhibited a rose tint. There was no microfissures on the cathode. On the cathodic wall of the insulator there were two small fissures.

On the anode the electrode also remained practically intact. The height of the ceramics was approximately $6.1 \mathrm{~mm}$ and the breadth, approximately $12.8 \mathrm{~mm}$. The platinum between the ceramics and the cement was not affected since the seed practically did not penetrate the anode. Neither in structure nor in color did the cement change in comparison with the cement on the cathode. The Mg0 did not bear any fissures.

Thus, one may ascertain that in the absence of a current the cathode and anode of this electrode pair were not corroded.

A current of 8.5 A passed through electrode 1101-2101; this amounted to $1.09 \mathrm{~A} / \mathrm{cm}^{2}$. After supplying current to the specimen for a period of 15-60 minutes, the electric circuit was disrupted because the platinum wire on the cathode melted. The melting of the platinum on the cathode was corroborated by an x-ray photograph. 
It is interesting to noté that under laboratory conditions it was established that for the U.S. specimen with the same composition, flaking of the brazed platinum in the ceramics had occurred from the composition face on the cathode after a current with a density of 1 $\mathrm{A} / \mathrm{cm}^{2}$ had been transmitted during a period of 17 hours. The ceramic specimen with its two faces brazed with platinum was hung in the Silit furnace with the aid of a platinum wire. The electrical circuit was not disrupted at $1400^{\circ} \mathrm{C}$. Electrical measurements attested to this fact.

Because of the low value of the limiting current of the oxygen diffusion, the potential of the platinum cathode, beyond very short time intervals, attains values at which the reduction of $\mathrm{Zr}^{4+}$ from the solid electrolyte with a composition of $88 \mathrm{~mol} \% \mathrm{ZrO}_{2}-12 \mathrm{~mol} \%$ $\mathrm{Y}_{2} \mathrm{O}_{3}$ begins in the cathodic area. The reduced zirconium dioxide $\left(\mathrm{Zr}_{2} \mathrm{O}_{3}\right.$ or $\left.\mathrm{ZrO}\right)$ is oxidized by the oxygen of the air into $\mathrm{ZrO}_{2}$. The reverse conversion of the electrochemical reaction products into zirconium dioxide does not at all denote the reduction of its initial structure. In the general case, the atoms are already rearranged during the formation of the blackened zone and in the reverse process, the zirconium dioxide is obtained in the form of a tetragonal modification, i.e. the original ceramics specimen is destabilized. During the cooling of the specimen within the range of $1000-1100^{\circ} \mathrm{C}$ in the thin layer of the face adjacent to the platinum current outlet, the transition from a tetragonal modification into a monoclinic system takes place. Since the transition from one modification to another is accompanied by a change in the volume of the zirconium dioxide, the deformation of the surface of the face on which the platinum was brazed led to a flaking of the platinum from the surface of the ceramics. Consequently, under laboratory conditions in atmosphere air at $1400^{\circ} \mathrm{C}$, electrochemical processes took place in the cathodic region and led to the destabilization of the ceramics with a composition of $88 \mathrm{~mol}_{\mathrm{ZrO}}-12 \mathrm{Y}_{2} \mathrm{O}_{3}$. With a gradual cooling of the specimen within the range of $1000-1100^{\circ} \mathrm{C}$, the brazed platinum separated from the face on the cathodic side of the ceramics because of the transition of the tetragonal modification of the zirconium dioxide to the monoclinic.

However, the U.S. specimens, which were placed in the U-02 channel, contained cement in which the back side of the brazed platinum with the platinum grid soldered to it was located. In the process of starting, this mass was thermoprocessed and sintered at $1300^{\circ}$. The sintered mass retained the platinum in a stable manner, not allowing it to be separated from the surface of the ceramics during the lengthy transmission of the current through the electrode. In such a manner, the conditions were created in the U-02 channel for the electrochemical processes both in the interpahse layer, the "ceramics-platinum" layer, and in the back side of the platinum immersed in cement.

A current which significantly exceeded the limiting current of the oxygen diffusion was supplied in electrode pair 11012101. This excess led to electrochemical processes (according to the scheme stated above) occurring at a significant rate in the interphase layer, the "platinum-ceramics" layer. During the imposition of the electric field, the penetration of the $\mathrm{KOH}$ fusion (admixture) into the 
cathode of electrode 1101 contributed to the corrosion of the platinum and the interreaction of the layer with the reduction of the zirconium dioxide. As a result of such an interreaction, the blackened zone is formed. Electrochemical processes also take place from the back part of the platinum, which is immersed in cement, to the boundary of the phases, leading to the penetration of the blackened zone and the barrier layer. (We assume that the cement basically contains $\mathrm{ZrO}_{2}-\mathrm{CaO}$ ). During the passage of the current through the current outlet the platinum wire heated up intensely and melted at some distance from the soldered joint as a result of the formation of the blackened zone. (See Chapter II, Section C.5.)

The height of the electrode is $7 \mathrm{~mm}$; its breadth is 13.8 $\mathrm{mm}$. The area of the cathode of electrode 1101 increased in comparison to the area of the cathode of electrode 1104 through which the current did not pass. The area of the blackened zone in the ceramics in the immediate vicinity of the platinum current outlet is $5 \times 1.5 \mathrm{~mm}$ but the area of the blackened zone in the cement region is $9 \times 3 \mathrm{~mm}$. From the right side on the cathode of electrode 1101 there are fissures. From the right and left sides on the $\mathrm{MgO}$ insulator one can see fissures. The height of the anode of electrode 2101 is approximately $6.1 \mathrm{~mm}$; its breadth is $12.6 \mathrm{~mm}$, i.e., its area practically did not change in comparison with the area of the anode of electrode 2104 through which the current did not pass. In this way the anode of electrode 2101 was not damaged in spite of the fact that a significant amount of current passed through it.

Electrode pair 1102-2102 was subjected to an electric current of $6.0 \mathrm{~A}$, which amounts to approximately $0.77 \mathrm{~A} / \mathrm{cm}^{2}$. For 18 hours after applying an electric field to it, the current dropped to 4.0 $A$ and the power of the current was maintained practically constant for a period of 110 hours. The mean current density in the specimen cross section amounted to $0.53 \mathrm{~A} / \mathrm{cm}^{2}$. The formation of blackened zones on both sides of the platinum current outlet attests to the fact that the basic electrochemical reaction took place-the formation of the reduced zirconium dioxide in the cathodic regions and the destabilization of the ceramics. This fact indicates that in the given case the current was supplied continuously to the electrode, exceeding the critical current density.

The area of the cathode of electrode 1102 increased in comparison with the area of the cathode of electrode 1104 through which the current did not pass. The height of the cathode of electrode 1102 is $8.2 \mathrm{~mm}$; its breadth is $13.1 \mathrm{~mm}$. The zone of the destabilized ceramics formed close to the platinum current outlet in the cathodic area. In the given case, the melted $\mathrm{KOH}$ penetrated the ceramics of the cathode and corroded the platinum. It interreacted with the product of the electrochemical reaction. Such an interreaction caused the formation of the blackened zone in the cathodic layer of the ceramics with a $3 \mathrm{~mm}$ thickness. Beyond this zone the fissure. follows. In the cement region bordering on the platinum there are also electrochemical reactions, which lead to the formation of a blackened zone with a $5 \mathrm{~mm}$ thickness. The expansion of the zone in the cement region caused the formation of deep fissures in the insulator. 
The anode of electrode 2102 was not damaged. Its area, in comparison with the area of the anode of electrode 2104, did not change. The height of the anode of electrode 2102 is $6.1 \mathrm{~mm}$; its breadth is $12.8 \mathrm{~mm}$.

A current of 2.5 A passed through electrode pair 11032103. It passed continuously for a period of 110 hours. However, after 18 hours the current dropped to $1.8 \mathrm{~A}$; after 53.4 hours, to $1.2 \mathrm{~A}$; after 77 hours, to $1.4 \mathrm{~A}$; and then the power of the current again fell to 1.2 A. After some time the current rose to $1.58 \mathrm{~A}$. On the average one can assume the current density on a cross section of the specimen was approximately $0.2 \mathrm{~A} / \mathrm{cm}^{2}$. The formation of the blackened zone on both sides of the platinum current outlet is also proof of the reduction of $\mathrm{Zr}^{4+}$ on the platinum cathode and of the destabilization of $\mathrm{ZrO}_{2}-\mathrm{Y}_{2} \mathrm{O}_{3}$ in the cathodic region of the ceramics. The platinum also interreacted with the electrochemicai reaction products because of the penetration of the admixture into the cathode. This fact suggests that the value $0.2 \mathrm{~A} / \mathrm{cm}^{2}$ in the cross section of the specimen also exceeds the critical current density. The area of the cathode of electrode 1103 increased in comparison with the area of the cathode of electrode 1104, through which the current did not pass. The height of the cathode of electrode 1102 is $8.8 \mathrm{~mm}$; its breadth is $13 \mathrm{~mm}$. Close to the platinum the blackened zone developed with a thickness of $2 \mathrm{~mm}$. A fissure resulted between this zone and the remaining portion of the ceramics. The thickness of the blackened zone in tne immediate vicinity of the platinum in the cerpnt region is $2.5 \mathrm{~mm}$. A fissure resulted between this zone and the remaining portion of the ceramics. The thickness of the blackened zone in the immediate vicinity of the platinum in the cement region is $2.5 \mathrm{~mm}$. A zone which is not as dark followed it and had a thickness of $3 \mathrm{~mm}$. Fissures were iormed ir. the MgO insulator. The anode of electrode 2103 did not change in comparison with the anode of electrode 2104.

\section{D.3.2 American specimens with a composition of $18 \mathrm{~mol} \%$ $\mathrm{CeO}_{2}-82 \mathrm{~mol} \% \mathrm{ZrO}_{2}$}

A ceramic sample with a low content of ceric oxide can be represented by a tetragonal system with the lattice parameters $a=5.15$ and $c=5.24 \AA$; the cubic phase is practically absent. The structure of the ceramic with the composition given attests to the incomplete stabilization of the zirconium dioxide since in the process of sintering, the composition does not crystallize according to the fluorite type. Owing to the presence of $\mathrm{CeO}_{2}$ in the system the transition of the monoclinic phase of the $\mathrm{ZrO}_{2}$ to the tetragonal one is facilitated. According to the data of U.S. investigators the open porosity amounts to $17.7 \%$ and the closed, to less than $0.5 \%$.

In the process of sintering in atmosphere air (at $1550^{\circ} \mathrm{C}$ ), the following electrochemical reaction takes place

$$
2 \mathrm{Ce}_{\mathrm{Zr}}^{\mathrm{x}}+\mathrm{O}_{0}^{\mathrm{x}} \rightarrow 1 / 2 \mathrm{O}_{2}+2 \mathrm{Ce}_{\mathrm{Zr}}^{-}+\mathrm{V}_{\mathrm{o}}^{2+}
$$

In this equation the symbols denote respectively: Ce $\mathrm{Zr}_{\mathrm{r}}^{\mathrm{X}}-$ $\mathrm{Ce}^{4+}$ in the cationic sublattice: $0_{0}^{\mathrm{x}}-$ oxygen anion $\left(0^{2-}\right)$ in the anionic sublattice; $\mathrm{Ce}_{\mathrm{Zr}}^{-}$- center in the binary system which is the characteristic 
transition of $\mathrm{Ce}^{4+}$ or $\mathrm{Ce}^{3+}$ according to the equation $\mathrm{Ce}_{\mathrm{Zr}}^{\mathrm{X}}+\mathrm{e} \rightarrow \mathrm{Ce}_{\mathrm{Zr}}^{-}+$ $\mathrm{V}^{2+}$ - the twice ionized vacancy of the oxygen, which is formed as a result of the $\mathrm{V}_{0}^{\mathrm{X}}$ giving off two electrons.

The binary system, $18 \mathrm{~mol} \% \mathrm{CeO}_{2}-82 \mathrm{~mol} \% \mathrm{ZrO}_{2}$, possesses the lowest electrical conductivity in comparison with other types of ceramic compositions which contain a significantly larger amount of $\mathrm{CeO}_{2}$. Table D.3.2.1 gives data on the conductivity of American and Soviet specimens with a composition of $18 \mathrm{~mol} \% \mathrm{CeO}_{2}-82 \mathrm{~mol} \% \mathrm{ZrO}_{2}$. The Soviet specimens (IVTAN) were investigated in 1970 in laboratories using electrochemical methods for the investigation of fireproof materials.

Table D.3.2.1. The specific electroconductivity of the system 18 mol\% $\mathrm{CeO}_{2}-82 \mathrm{~mol} \% \mathrm{ZrO}_{2}$ as a function of the temperature.

\begin{tabular}{lll}
\hline & \multicolumn{3}{c}{$\sigma \mathrm{ohm}^{-1} \mathrm{~cm}^{-1}$} \\
\cline { 2 - 3 } Temperature, ${ }^{\circ} \mathrm{C}$ & American specimens & IVTAN specimens \\
\hline 780 & $2.9 \cdot 10^{-4}$ & $3.6 \cdot 10^{-4}$ \\
838 & $5.0 \cdot 10^{-4}$ & $5.6 \cdot 10^{-4}$ \\
903 & $8.2 \cdot 10^{-4}$ & $8.0 \cdot 10^{-4}$ \\
977 & $0.95 \cdot 10^{-3}$ & $1.04 \cdot 10^{-3}$ \\
1060 & $3.07 \cdot 10^{-3}$ & $3.15 \cdot 10^{-3}$ \\
1156 & $5.36 \cdot 10^{-3}$ & $6.00 \cdot 10^{-3}$ \\
1265 & $8.00 \cdot 10^{-3}$ & $8.88 \cdot 10^{-2}$ \\
1393 & $2.21 \cdot 10^{-2}$ & $2.88 \cdot 10^{-3}$ \\
\hline
\end{tabular}

Experimental data on conductivity, which were obtained by U.S. and U.S.S.R. investigators, correlate well with each other. A juxtaposition of the conductivity results proves that admixtures at the given temperature interval make a negligibly small contribution to the values of the specific electroconductivity.

American specimens with a composition of 18 mol\% $\mathrm{CeO}_{2}+82$ mol\% $\mathrm{ZrO}_{2}$ were investigated under laboratory conditions in air, at $1400^{\circ} \mathrm{C}$ and in the absence of thermal shock.

The specimens had the form of a rectangular parallelepiped; the platinum was brazed on two of its faces. A platinum mesh was arcwelded to the platinum coated surface. The presence of two probes at different points along the specimen permitted a determination of the change in the resistance of the solid solution during the passage of direct current through it. In the initial state there were no cracks in the two specimens. The geometrical dimensions of the specimens are shown in Figure D.3.2.1.

Tests were carried out in the Silit furnace; the temperature of the furnace was determined with the aid of two platinum-platinum rhodium thermocouples. At the temperature of $1400 \pm 10^{\circ} \mathrm{C}$ the furnace worked in a stable manner. Together with the basic specimen, an identical specimen through which the current did not pass was introduced into the furnace. 
㫜 总

ᄂก $\sim n m$

० $\ddot{\sim} \dot{0} \dot{0}$

II II II II

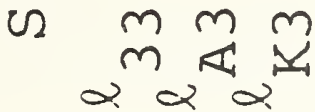

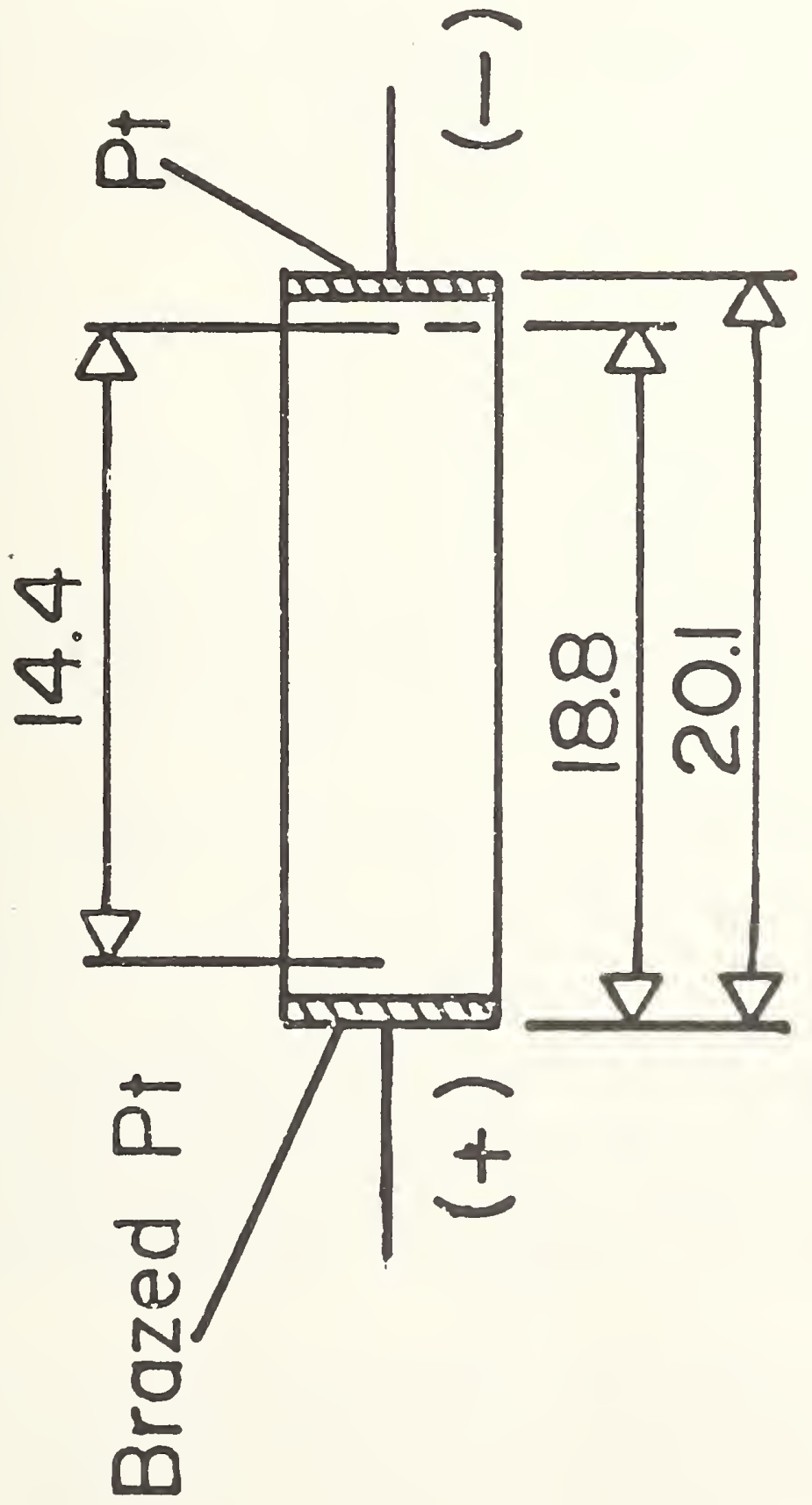

岂

4

0

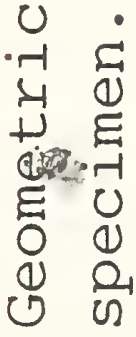

$\dot{r}$
$\dot{m}$
$\dot{0}$

0
3
0
0
01 
The conductivity of the U.S. specimen was measured under laboratory conditions duirng the passage of direct current by using polarity to exclude the influence of the thermoelectromotive force. The data obtained correlated with the conductivity values determined by the IVTAN in 1970. The values of the specific conductance are shown in Table D.3.2.2.

Table D.3.2.2. The specific electrical conductivity as a function of the temperature for two compositions of the binary system $\mathrm{ZrO}_{2}-\mathrm{CeO}_{2}$.

Composition

of the

American

specimens $\begin{array}{lll}\text { Tempera- } & \sigma \mathrm{ohm}^{-1} \mathrm{~cm}^{-1} & \begin{array}{l}\text { Composition } \\ \text { of the } \\ \text { American }\end{array}\end{array}$

specimens
Tempera- $\sigma \mathrm{ohm}^{-1} \mathrm{~cm}^{-1}$ ture ${ }^{\circ} \mathrm{C}$

\begin{tabular}{|c|c|c|c|c|c|c|c|}
\hline $18 \mathrm{~mol} \% \mathrm{CeO}_{2}^{-}$ & 1020 & 1.17 & $\cdot 10^{-3}$ & $15-16$ mo $1 \%$ & - & & - \\
\hline \multirow[t]{9}{*}{82 mol\% } & 1070 & 1.54 & $\cdot 10^{-3}$ & $\mathrm{CeO}_{2}-85-84$ & 1060 & 1.52 & $10^{-3}$ \\
\hline & 1120 & 1.93 & - $10^{-3}$ & $\operatorname{mol} \% \mathrm{ZrO}_{2}$ & - & & - \\
\hline & 1150 & 2.42 & - $10^{-3}$ & & 1156 & 3.60 & - $10^{-3}$ \\
\hline & 1200 & 3.47 & - $10^{-3}$ & & - & & - \\
\hline & 1240 & 4.33 & $\cdot 10^{-3}$ & & 1265 & 5.4 & . $10^{-3}$ \\
\hline & 1290 & 6.9 & $10^{-3}$ & & - & & - \\
\hline & 1340 & 9.75 & . $10^{-3}$ & & - & & - \\
\hline & 1390 & 1.53 & $\therefore 10^{-2}$ & · & 1393 & 1.45 & - $10^{-2}$ \\
\hline & 1400 & 1.66 & - $10^{-2}$ & & - & & - \\
\hline
\end{tabular}

The $\sigma$ values, which are given in Table D.3.2.2, show that the samples with a composition $18 \mathrm{~mol}_{\mathrm{CeO}}-92 \mathrm{~mol} \% \mathrm{ZrO}_{2}$, sent later to the IVTAN from the USA, differ somewhat in the ceric oxide content from the American specimens tested in the U-02 channe1. Evidently, instead of $18 \mathrm{~mol}^{\%} \mathrm{CeO}_{2}$, they contain $15-16 \mathrm{mo} 1 \% \mathrm{CeO}_{2}$. However, a small difference in the ceric oxide content in the binary system does not influence the mechanism of the electrochemical reactions which take place in the interphase layers.

The ion transfer number was measured using a concentration galvanic cell without the transfer of the tested mass as a function of the temperature for the two compositions of the binary system $\mathrm{ZrO}_{2}$ $\mathrm{CeO}_{2}$. Table D.3.2.3 gives the data on the number of ion transfers. 
As can be seen from the data in Table D.3.2.3, the electronic part of the conductivity in the ceramics increases with an increase in temperature which confirms that a reaction has taken place in the oxidizing medium:

$$
2 \mathrm{CeO}_{2} \rightarrow \mathrm{Ce}_{2} \mathrm{O}_{3}+1 / 2 \mathrm{O}_{2} \cdots
$$

the oxygen is released into the medium.

Table D.3.2.3. The number of ion transfers for the binary system $\mathrm{ZrO}_{2}-\mathrm{CeO}_{2}$ as a function of the temperature $\left(\mathrm{Po}_{2}\right)$ cathode $=1$ atm; $\left(\mathrm{Po}_{2}\right)$ anode $=10^{-1} \mathrm{~atm}$.

\begin{tabular}{|c|c|c|c|c|c|c|}
\hline \multirow{2}{*}{$\begin{array}{r}\text { Composition } \\
\qquad t^{\circ}\end{array}$} & \multicolumn{3}{|c|}{$\begin{array}{r}\text { Ion transfer number } \\
\left(t_{i}\right), \%\end{array}$} & \multicolumn{3}{|c|}{$\begin{array}{l}\text { Electron transfer } \\
\text { number }\left(t_{e l}\right), \%\end{array}$} \\
\hline & $1127^{\circ} \mathrm{C}$ & $1327^{\circ} \mathrm{C}$ & $1527^{\circ} \mathrm{C}$ & $1127^{\circ} \mathrm{C}$ & $1327^{\circ} \mathrm{C}$ & $1527^{\circ} \mathrm{C}$ \\
\hline $\begin{array}{l}15 \mathrm{~mol} \% \mathrm{CeO}_{2}- \\
-85 \mathrm{~mol} \%\end{array}$ & 66.5 & 50.0 & 44.0 & 33.5 & 50.0 & 56.0 \\
\hline $\begin{array}{l}18 \mathrm{~mol} \% \mathrm{CeO}_{2}- \\
-82 \mathrm{mo} 1 \%\end{array}$ & 65.5 & 45.4 & 39.4 & 34.5 & 54.6 & 60.6 \\
\hline
\end{tabular}

The sesquioxide $\left(\mathrm{Ce}_{2} \mathrm{O}_{3}\right)$ content increases in the binary system $\mathrm{ZrO}_{2}-\mathrm{CeO}_{2}$ with an increase in temperature. Ceramics with the compositions indicated above are mixed semiconductors. It would be desirable to determine the ceric sesquioxide content in the ceramics with the aid of $x$-ray diffraction analysis.

At a set current level, the potential of the electrodeplatinum current leadout was measured with respect to the probe. Figure D.3.2.2a and D.3.2.2b give the "current density-potential" curves in the positive and negative regions of the potentials, where the platinum current outlet (on which the measurements are carried out) serve as a cathode or anode. These data are obtained when the direct current initially passed through the specimen. Curves 1 and 2 in Figure D.3.2.2a were plotted on the double coordinate, self-recording potentiometer PDS$021 \mathrm{M}$ without regard for the ohmic losses in the volume of the specimen as the potential changes toward negative values (1) and back (2). Curves 3 and 4 in Figure D.3.2.2b are also obtained on the PDS without regard for the ohmic losses in the volume of the specimen as the potential losses toward positive values (3) and back (4). The time for plotting the curve in one direction was 30 minutes.

In the cathode and anode volt-ampere characteristics between the direct and reverse course of the curves there arose a hysterisis (lagging), which was proof of the occurrence of electrochemical reactions in the interphase layers. The limiting current of oxygen diffusion practically did not appear. On the cathode branch of the curve, a bend is barely visible at $-1.8 \mathrm{v}$ with reference to the platinum probe. 
For clarity, Table D.3.2.4 gives values for the voltage (v) between the anode and cathode, the anode and the probe, the probes, the probe and the cathode in the initial stages of current transmission through the specimen; these values were obtained while measuring the volt-ampere characteristics.

Using the data in Table D.3.2.4, we computed the values of specific resistance o between the anode and the probe, the cathode and the probe as a function of the current density. The results of the computation are tabulated in Table D.3.2.5.

Table D.3.2.4. Volt-ampere characteristics obtained for the specimen with a composition of $18 \mathrm{~mol} \% \mathrm{CeO}_{2}-92 \mathrm{~mol} \% \mathrm{ZrO}_{2}$ in the initial stage of current transmission in air at $1400^{\circ} \mathrm{C}$ in the furnace (direct course of the curve). (Measurement time, 30 minutes.) Polarity + - .

\begin{tabular}{|c|c|c|c|c|c|}
\hline $\begin{array}{l}\text { V } \\
\text { Anode- } \\
\text { cathode } \\
\text { Voltage }\end{array}$ & $\begin{array}{l}\text { V } \\
\text { anode } \\
\text { probe } \\
\text { Voltage }\end{array}$ & $\begin{array}{c}\text { V } \\
\text { probe probe } \\
\text { Voltage }\end{array}$ & $\begin{array}{l}\text { V } \\
\text { probe } \\
\text { cathode } \\
\text { Voltage }\end{array}$ & $\begin{array}{c}\text { current } \\
\mathrm{A}\end{array}$ & $\begin{array}{l}\text { Current } \\
\text { density in } \\
\text { the cross } \\
\text { section of } \\
\text { the specimen }\end{array}$ \\
\hline 11.62 & 0.55 & 10.30 & 0.78 & 0.05 & 0.1094 \\
\hline 16.15 & 0.80 & 14.30 & 1.05 & 0.07 & 0.1532 \\
\hline 22.95 & 1.20 & 20.30 & 1.45 & 0.10 & 0.2188 \\
\hline 32.05 & 1.75 & 28.20 & 2.10 & 0.125 & 0.2735 \\
\hline 44.55 & 2.60 & 39.10 & 2.85 & 0.225 & 0.4923 \\
\hline 48.60 & 2.95 & 42.50 & 3.15 & 0.30 & 0.6564 \\
\hline 49.46 & 3.05 & 43.10 & 3.30 & 0.33 & 0.7220 \\
\hline
\end{tabular}

The $\rho$ values in the electrode layer during the initial stage of current transmission (Table D.3.2.5) show to what extent the basic lattice defects of the tested ceramic in the specimen volume were changed in the cathode and anode regions; this had a direct influence on the conductivity of the system. As can be seen from the data in Table D.3.2.5, the $\rho$ values between the anode and the probe, and the cathode and the probe differ significantly; the deviation between the o values increases with an increase in the current density in the cross section of the specimen. Undoubtedly the Joule effect exerts an influence on the change of the specific resistance in all portions of the specimen. However, from the data of Table D.3.2.5 one can see that this effect is not decisive since the $\rho$ changes in the electrode regions and between the probes differ substantially according to the value. The Joule effect would have to lead to a monotonous drop in specific resistance in all portions of the ceramics when the current density is increased. However, this is not observed in the anode region of the specimen (see the data in Table D.3.2.5). With all the values of $j$, the specific resistance of the ceramic between the anode and the probe is much higher than $p$ between the cathode and the probe. Furthermore, the values of the specific resistance of the ceramics between the anode and probe increase considerably within the range of $0.11-0.27 \mathrm{~A} / \mathrm{cm}^{2}$; then with an increase in $j, 0$ (anode-probe) gradually declines and according to the value it is $58-61 \%$ higher than the values of $\rho$ between the cathode and the probe. 
Table D.3.2.5. p values between the anode and the probe and the cathode and the probe as a function of the current density at $1400^{\circ} \mathrm{C}$.

\begin{tabular}{|c|c|c|c|c|c|c|c|}
\hline $\begin{array}{c}\text { anode } \\
\text { cathode } \\
V\end{array}$ & $\begin{array}{l}\text { anode } \\
\text { probe, } \\
\text { ohm } \\
\text { R }\end{array}$ & $\begin{array}{l}\text { anode } \\
\text { probe, } \\
\text { ohm } \cdot \mathrm{cm} \\
\rho\end{array}$ & $\begin{array}{c}\text { cathode } \\
\text { probe, } \\
\text { ohm } \\
\text { R }\end{array}$ & $\begin{array}{c}\text { cathode } \\
\text { probe } \\
\text { ohm } \cdot \text { cm } \\
.\end{array}$ & $\mathrm{A} / \mathrm{cm}^{2}$ & $\begin{array}{l}\text { \% devia- } \\
\text { tion be- } \\
\text { tween } \\
\text { values }\end{array}$ & Note: \\
\hline 11.62 & 11.00 & 67.02 & 15.60 & 54.84 & 0.1094 & +22.5 & values in \\
\hline 16.15 & 11.43 & 69.64 & 15.00 & 52.73 & 0.1532 & +31.8 & the cathodic \\
\hline 22.95 & 12.00 & 73.12 & 14.50 & 50.97 & 0.2188 & +43.4 & region taken \\
\hline 32.05 & 14.00 & 85.30 & 16.80 & 59.05 & 0.2735 & +44.4 & to be beyond \\
\hline 44.55 & 11.55 & 70.37 & 12.66 & 44.60 & 0.4923 & +57.7 & $100 \%$ \\
\hline 48.60 & 9.83 & 59.89 & 10.50 & 36.91 & 0.6564 & +62.2 & \\
\hline 49.46 & 9.30 & 56.67 & 10.00 & 35.15 & 0.7220 & +61.2 & \\
\hline
\end{tabular}

It is necessary to clarify the reason for the lack of agreement between the $p$ values in the near electrode layers and the specific resistance of the specimen ( $\rho$ between the probes). For this purpose, the values of the voltage $(v)$ between the probes (as given in Table D.3.2.4) were used. Let us compute the specific resistance of the ceramic in the volume of the specimen and compare it with the $p$ values, obtained in Table D.3.2.5. The results of the computation are given in Table D.3.2.6.

From the data in Table D.3.2.5 and D.3.2.6 one can see that the specific resistance of the ceramics in the volume of the specimen is lower than the $p$ values between the anode and probe but it is greater than the $p$ values in the volume of the specimen in the cathode region. This fact indicates the change in the composition of the ceramics near the platinum cathode. Evidently, as a result of the electrochemical reaction in the cathode a new phase is formed; the conductivity of this phase grows with an increase in current density. In the anode region one observes another picture, the formation of a double layer, of an electrochemical barrier layer, the resistance of this increases with an increase in current density.

The conductivity of the ceramics between the probes within the range of $0.1-0.22 \mathrm{~A} / \mathrm{cm}^{2}$ practically coincides with the $\sigma$ values, which are given in Table D.3.2.2 for $1390-1400^{\circ} \mathrm{C}$. A drop in the conductivity of the ceramics is observed only at $0.27 \mathrm{~A} / \mathrm{cm}^{2}$; then, with an increase in the current density, the $\sigma$ values gradually increase, evidently because of the Joule effect. Let us clarify the effect of the heating-up of the specimen on its conductivity, due to the passage of current through the specimen.

The surface, with an emissivity $\varepsilon$, radiates energy $\mathrm{E}=\varepsilon \sigma \mathrm{T}^{4}$ where $\sigma=5.67 \cdot \mathrm{degree}^{4}$. For a system of $82 \mathrm{~mol} \% \mathrm{ZrO}{ }_{2}$ $+18 \mathrm{~mol}^{\circ} \mathrm{CeO}_{2}, \varepsilon=0.42$ at $1700 \mathrm{~K}\left(1427^{\circ} \mathrm{C}\right)$ [See Handbook of thermophysical properties of solid materials, Pergamon Press, 1961].

In the differential form:

$$
\Delta \mathrm{E}=4 \varepsilon \sigma \mathrm{T}^{3} \Delta \mathrm{T} \ldots
$$


where $\Delta E$ is the increment of radiative energy due to the generation of heat within the specimen and $\Delta \mathrm{T}$ the corresponding temperature increment of the surface.

If heat with an intensity $A$ is generated within an infinite cylinder with radius $\theta$, with respect to the unit volume, then the difference between the temperatures on the axis of the cylinder and on its surface amounts to

$$
\delta \mathrm{T}=\mathrm{A} \theta^{2} / 4 \mathrm{~K} \ldots
$$

where $\mathrm{K}$ is the coefficient of the heat conductivity [G. Karslou, D. Eger, The heat conductivity of solid bodies, "Nauka," Moscow, 1964].

Let us evaluate the maximum temperature drop between the center and the surface of the rectangular specimen. Such an estimate is known for the cylindrical specimen (see the above-mentioned reference). Since the temperature drop increases with an increase in the diameter of the cylinder, this analysis can be applied to a parallelepiped under the condition that the maximum transverse dimension (the cross section of the specimen) be used as a diameter.

Let us assume that the American specimen in the form of a rectangular parallelepiped is inscribed into a circle and that the length of the edge of the base is a. Then the length of the diagonal of the transverse section of the specimen $d=\alpha \sqrt{2}$ and $\theta=\alpha / \sqrt{2}$. If instead of $\theta$ we substituted $\alpha / \sqrt{2}$ into (4), then we obtain,

$$
\delta \mathrm{T}=\mathrm{A} \frac{a^{2}}{2} / 4 \mathrm{~K} \ldots
$$

Thus, if the temperature at all points of the parallelepiped was equal to $\mathrm{T}$ before heating, then with a stationary heat generation it rises in the center of the specimen to $T_{0}=T+\Delta T+\delta T$. The $T_{0}$ found in this way can be used as the maximum value of the temperature for a parallelepiped of finite length.

Table D.3.2.6. Values of the specific resistance of the specimen between the probes; comparison of $\rho$ (probe-probe) and $\rho$ (anode-probe) as a function of the current density. Medium air, $1400^{\circ} \mathrm{C}$ in the furnace

\begin{tabular}{|c|c|c|c|c|c|}
\hline $\begin{array}{c}\text { probe- } \\
\text { probe } \\
\text { V }\end{array}$ & $\begin{array}{l}\text { probe- } \\
\text { probe } \\
\text { ohm R }\end{array}$ & $\begin{array}{l}\text { probe- } \\
\text { probe } \\
\text { ohm·cm } \\
\rho\end{array}$ & $\begin{array}{c}\text { specimen }_{(\mathrm{ohm} \cdot \mathrm{cm})^{-1}} \\
\sigma\end{array}$ & $\begin{array}{l}\text { Difference } \\
\text { between } \\
\text { values } \\
\text { (anode-probe) } \\
\text { and } \rho \text { (probe- } \\
\text { probe) ohm } \cdot \mathrm{cm}\end{array}$ & $j a / c m^{2}$ \\
\hline 10.30 & 206.0 & 65.4 & $1.5310^{-2}$ & 1.62 & 0.1094 \\
\hline 14.30 & 204.3 & 64.8 & $1.5410^{-2}$ & 4.84 & 0.1532 \\
\hline 20.30 & 203.0 & 63.3 & $1.5810^{-2}$ & 9.82 & 0.2188 \\
\hline 28.20 & 225.0 & 71.4 & $1.4010^{-2}$ & 13.90 & 0.2735 \\
\hline 39.10 & 170.4 & 54.1 & $1.8510^{-2}$ & 16.27 & 0.4923 \\
\hline 42.50 & 141.6 & 44.9 & $2.2210^{-2}$ & 14.99 & 0.6564 \\
\hline 43.10 & 130.6 & 41.4 & $2.4210^{-2}$ & 15.27 & 0.7220 \\
\hline
\end{tabular}
(initial stage of current transmission through the specimen). 
The temperature equalization rate in different places of the body is determined by the heat conductivity coefficient $K$, which is divided into the heat capacity of the unit volume of the body, i.e., the value

$$
\begin{gathered}
\alpha=\frac{\mathrm{K}}{\rho \cdot \mathrm{C}_{\mathrm{p}} \frac{\mathrm{cm}^{2}}{\mathrm{sec}}} \\
{\left[\frac{\mathrm{cal}}{\frac{\mathrm{cm} \mathrm{sec} \mathrm{degree}}{\mathrm{g} \cdot \frac{\mathrm{cal}}{\mathrm{cm} \cdot \text { degree }}}}=\frac{\mathrm{cal} \cdot \mathrm{cm}^{3} \cdot \mathrm{g} \cdot \mathrm{degree}}{\mathrm{cal} \cdot \mathrm{g} \cdot \mathrm{cm} \cdot \mathrm{s} \varrho \mathrm{c} \cdot \text { degree }}=\frac{\mathrm{cm}^{2}}{\mathrm{sec}}\right]}
\end{gathered}
$$

Here $\rho$ - density; pressure;

C - the heat capacity of the unit mass of the body under constant $\alpha$ - temperature conductivity.

In agreement with the data of American investigators for the composition of $18 \mathrm{~mol}_{\mathrm{Ce}} \mathrm{Ce}_{2}-92 \mathrm{~mol} \% \mathrm{ZrO} 2$, at $1673 \mathrm{~K}\left(1400^{\circ} \mathrm{C}\right) \alpha=$ $0.0045 \mathrm{~cm}^{2} / \mathrm{sec} ; \rho=5.3 \mathrm{~g} / \mathrm{cm}^{3}$.

$$
\begin{gathered}
C_{p}=0.288+7.71 \cdot 10^{-6} \cdot 1673-\frac{4.03 \cdot 10^{-3}}{1673^{2}}=0.288+0.013= \\
\simeq 0.301 \frac{\mathrm{cal}}{\mathrm{g} \cdot \mathrm{degree}} \\
\mathrm{K}=0.0045 \cdot 5.3 \cdot 0.301=7.18 \cdot 10^{-3} \frac{\mathrm{cal}}{\mathrm{cm} \cdot \mathrm{sec} \cdot \text { degree }}
\end{gathered}
$$

The process of heat transfer takes place in a quiescent medium. This means that in the medium there are no drops in pressure which would lead to the creation of motion in it.

Let us carry out the computation using the data of one of the tests given in Table D.3.2.4. The length of the specimen is $2.01 \mathrm{~cm}$; the length of the edge of the base $a=0.676 \mathrm{~cm}$; the current $=0133 \mathrm{a}$ (which corresponds to $0.72 \mathrm{~A} / \mathrm{cm}^{2}$ ); and the ohmic drop in the specimen is $49.46 \mathrm{v}$. The lateral surface of the specimen $\mathrm{S}=5.435 \mathrm{~cm}^{2}$; the volume $\mathrm{V}=0.9185 \mathrm{~cm}^{3}$.

The power of the heat generation $W=0.33 \mathrm{a} \cdot 49.46$ $\mathrm{v}=16.32$ watts (W). Moreover,

$$
\begin{aligned}
\Delta E & =\frac{W}{S}=\frac{16.32}{5.435}=3.003 \frac{\mathrm{W}}{\mathrm{cm}^{2}} ; \\
A & =\frac{\mathrm{W}}{\mathrm{V}}=\frac{16.32}{0.9185}=17.76 \frac{\mathrm{W}}{\mathrm{cm}^{3}}
\end{aligned}
$$




$$
\begin{aligned}
& \Delta \mathrm{T}=\frac{3.003}{4 \times 0.42 \times 5.67 \times 10^{-12} \times 1673^{3}}=67.32 \text { degree } \\
& \delta \mathrm{T}=\frac{17.76 \times 0.2285}{4 \times 7.18 \times 10^{-3}}=141.3 \text { degree } \\
& \mathrm{T}_{\mathrm{O}}=1673+67+141=1881 \mathrm{~K}=1608^{\circ} \mathrm{C} .
\end{aligned}
$$

The maximum drop in temperature between the center and surface of the specimen amounts to $208^{\circ}$.

The results of the computation for other values of the current are tabulated in Table D.3.2.7.

From the data in Tables D.3.2.6 and D.3.2.7 it follows that within the range $0.1-0.22 \mathrm{~A} / \mathrm{cm}^{2}$ the heating of the specimen due to the passage of current through it is negligibly small since the values of the specific electrical conductivity of the ceramics ( $\rho$ between probes) practically coincided with the conductivity of the ceramics, measured with the four-probe method during the transmission of a direct current of 5 ma through it (see the data in Table D.3.2.2). Within this current density range the $\rho$ values between the probes are lower than the $\rho$ values between the anode and the probe, but much higher than the specific resistance in the volume of the ceramics in the near-cathode region. This experimental fact indicates that already in the initial stage of current transmission through the specimen (even with small current densities in the platinum cathode), an electrochemical reduction of $\mathrm{Zr}^{4+}$ occurs; there may also be a reduction of the $\mathrm{Ce}^{4+}$, leading to a change in the composition of the ceramics in the cathodic region. Simultaneously in the anode region, a double electric layer,

\begin{tabular}{|c|c|c|c|c|c|c|c|c|c|}
\hline $\begin{array}{c}\text { Current } \\
I_{a}\end{array}$ & $j\left(A / \mathrm{cm}^{2}\right)$ & $\begin{array}{c}\mathrm{w} \\
\text { watts }\end{array}$ & $\begin{array}{l}\Delta E=\frac{W}{S} \\
W / \mathrm{cm}^{2}\end{array}$ & $\begin{array}{c}\Delta \mathrm{T} \\
\text { degree }\end{array}$ & $\begin{array}{l}A=\frac{w}{v} \\
w / \mathrm{cm}^{3}\end{array}$ & $\begin{array}{c}\delta \mathrm{T}, \\
\text { degree }\end{array}$ & $\begin{array}{c}\mathrm{T}_{\mathrm{o}} \mathrm{K} \\
\text { degree }\end{array}$ & $\mathrm{T}^{\circ} \mathrm{C}$ & $\begin{array}{l}\text { Maximum } \\
\text { tempera- } \\
\text { ture drop, } \\
\text { degrees }\end{array}$ \\
\hline
\end{tabular}
electrochemical barrier layer, begins to be formed.

Table D.3.2.7. Temperature drop between the center and the surface of the parallelepiped-shaped sample. Temperature $\mathrm{T}=1673^{\circ} \mathrm{C}\left(1400^{\circ} \mathrm{C}\right)$

$\begin{array}{lrrrrrrrrr}0.05 & 0.1094 & 0.58 & 0.1067 & 2.39 & 0.6314 & 5.02 & 1680 & 1407 & 7 \\ 0.07 & 0.1532 & 1.13 & 0.2079 & 4.66 & 1.23 & 9.78 & 1687 & 1414 & 14 \\ 0.10 & 0.2188 & 2.29 & 0.4213 & 9.45 & 2.493 & 19.84 & 1702 & 1429 & 29 \\ 0.125 & 0.2735 & 4.00 & 0.7359 & 16.50 & 4.355 & 34.65 & 1724 & 1451 & 51 \\ 0.225 & 0.4923 & 10.01 & 1.842 & 41.30 & 10.90 & 86.70 & 1781 & 1508 & 108 \\ 0.30 & 0.6564 & 14.58 & 2.682 & 60.13 & 15.87 & 126.2 & 1859 & 1586 & 186 \\ 0.33 & 0.7220 & 16.32 & 3.003 & 67.32 & 17.76 & 141.3 & 1881 & 1608 & 208\end{array}$

With $0.27 \mathrm{~A} / \mathrm{cm}^{2}$ one observes a drop in the temperature between the center and the surface of the specimen, amounting to 51 degrees. However, such a maximum possible temperature drop in practice has little effect on the 
heating up of the specimen since in all portions of the specimen there is an increase in the specific resistance of the ceramics in comparison to the $\rho$ value for $0.22 \mathrm{~A} / \mathrm{cm}^{2}$ (see the data in Tables D.3.2.5 and D.3.2.6). Evidently, with such a current density there is a strong interaction between the characteristic defects of the lattice, leading to a drop in the conductivity of the ceramics. However, in this case the $\rho$ value between the probes is lower than the $\rho$ value between the cathode and the probe. Beginning with $0.49 \mathrm{~A} / \mathrm{cm}^{2}$ and higher current densities, one observes a heating up of the specimen due to the transmission of current through it. A comparison of the conductivity values and the data $\sigma$, which we and U.S. investigators found for ceramics having two compositions: $15-16 \mathrm{~mol}^{\%} \mathrm{CeO}_{2}-85-84 \mathrm{~mol}_{\%} \mathrm{ZrO}_{2}$ and $18 \mathrm{~mol} \%$ $\mathrm{CeO}_{2}-82 \mathrm{~mol}_{\%} \mathrm{ZrO}_{2}$, shows that the values $1.85 \cdot 10^{-2}, 2.22 \cdot 10^{-2}$ and $2.42 \cdot 10^{-2} 1 / \mathrm{ohm} \cdot \mathrm{cm}$ correspond approximately to the following temperature levels: $1450^{\circ}, 1490^{\circ}$, and $1500^{\circ} \mathrm{C}$.

As a "result of the heat flow from hotter to cooler places, which continues until the temperature is equalized in the whole body, an equilibrium temperature is established after a certain period of time. In this manner, the heating of the specimen by means of current passage, causes a rise in the temperature of the specimen body as a function of the current density within the range of $0.49-0.72 \mathrm{~A} / \mathrm{cm}^{2}$; this temperature rise does not exceed $50-100^{\circ}$. However, even the heating of the specimen by the passage of current did not change the picture. In all cases $p$ between the probes was lower than $\rho$ between the anode and the probe and significantly higher than the values of $\rho$ between the cathode and the probe. The heating up of the specimen due to the transmission of the current did not stop the electrochemical processes in the near-electrode regions; on the contrary, it increased the rate of the electrochemical reactions and enhanced the interreaction of the characteristic lattice defects.

Table D.3.2.8 presents a comparison of the conductivity of the ceramics and the conductivity of the near-cathode layer zone.

Table D.3.2.8. Comparison of the specific electrical conductivity of the ceramics and the conductivity of the cathode layer zone as a function of the current density. $1500^{\circ} \mathrm{C}$ in the furnace.

$\begin{array}{rll}\mathrm{j} \mathrm{a} / \mathrm{cm}^{2} & \begin{array}{l}\sigma \text { ceramics } \\ (\mathrm{ohm} \cdot \mathrm{cm})^{-1}\end{array} & \sigma \text { cathode } \\ & \begin{array}{l}\text { layer zone } \\ (\mathrm{ohm} \cdot \mathrm{cm})^{-1}\end{array}\end{array}$

Percentage deviation be- Note: tween the values

$\begin{array}{ll}0.1094 & 1.53 \cdot 10^{-2} \\ 0.1532 & 1.54 \cdot 10^{-2} \\ 0.2188 & 1.58 \cdot 10^{-2} \\ 0.2735 & 1.40 \cdot 10^{-2} \\ 0.4923 & 1.85 \cdot 10^{-2} \\ 0.6564 & 2.22 \cdot 10^{-2} \\ 0.7220 & 2.42 \cdot 10^{-2}\end{array}$

$1.83 \cdot 10^{-2}$

$1.90 \cdot 10^{-2}$

$1.96 \cdot 10^{-2}$

$1.69 \cdot 10^{-2}$

$2.24 \cdot 10^{-2}$

$2.85 \cdot 10^{-2}$
$+19.6$

$+23.0$

$+24.0$

$+20.7$

$+21.0$

$+22.0$

$+17.70$
Values of the ceramics (between the probes) assumed to be $100 \%$ 
On the average the $\sigma$ values of the zone in the cathode region exceed by $21 \%$ the value of the specific conductivity of the ceramics, which attests to the fact of a change in composition of the ceramics close to the platinum cathode as a result of the electrochemical reduction of the $\mathrm{Zr}^{4+}$ in the cathode. Let us determine the potential difference $\phi$ at the boundary of the platinum anode with the ceramics. To do this we use the formula

$$
\phi=V \text { anode-probe }-\frac{V_{z-z} \cdot{ }^{\imath} z-z}{\ell_{z-z}} \ldots \quad \text { (7), }
$$

where $\mathrm{V}_{\text {anode-probe }}$ and $\mathrm{V}_{z-z}$ are the voltages between the anode and the probe, and between the other probes, respectively.

The results of the computation are given in Table D.3.2.9.

The data in Table D.3.2.9 illustrate the formation of a double electric layer at the boundary of the platinum anode with the ceramics. The potential difference increases with an increase in the current density in the specimen cross section.

Table D.3.2.9. Potential difference $\phi$ in the interphase layer anode probe as a function of the current density in the initial stage of the current transmission through the specimen.

\begin{tabular}{lcccc}
\hline $\mathrm{jA} / \mathrm{cm}^{2}$ & $\begin{array}{c}\mathrm{V} \text { anode-cathode } \\
\mathrm{mV}\end{array}$ & $\begin{array}{c}\mathrm{V} \text { anode-probe } \\
\mathrm{mV}\end{array}$ & $\frac{V_{z-z^{\ell} z}}{\ell_{z-z}}$ \\
& & & & $\begin{array}{c}\phi \\
\mathrm{mV}\end{array}$ \\
\hline 0.1094 & 550 & 10300 & 536.4 & 13.6 \\
0.1532 & 800 & 14300 & 744.8 & 55.2 \\
0.2188 & 1200 & 20300 & 1057 & 143.0 \\
0.2735 & 1750 & 28200 & 1468 & 282.0 \\
0.4923 & 2600 & 39100 & 2036 & 564.0 \\
0.6564 & 2950 & 42500 & 2214 & 736.0 \\
0.7220 & 3050 & 43100 & 2244 & 806.0 \\
\hline
\end{tabular}

Let us examine the influence of the direct current on the ceramics duirng its continuous passage through the specimen. To do this a current of 0.1 a $\left(j=0.2188 \mathrm{~A} / \mathrm{cm}^{2}\right)$ was passed through the U.S. specimen for a period of 16 hours. After a certain period of time (as indicated), the volt-ampere characteristics were measured. The results of the measurements are tabulated in Table D.3.2.10.

After the current had been transmitted through the specimen for a period of 16 hours, it did not change the appearance of the sample; there were no cracks; the brazed platinum on both faces of the parallelepiped and the platinum wire welded to it were in good condition. 
Table D.3.2.10. Volt-ampere characteristics obtained for a specimen with the composition of $18 \mathrm{~mol} \% \mathrm{CeO}_{2}-82 \mathrm{~mol} \% \mathrm{ZrO}_{2}$ after 16 hours of transmitting a current of 0.1 a in air at $1400^{\circ} \mathrm{C}$. Direct course of the curve measured after 30 minutes. Polarity +- .

\begin{tabular}{|c|c|c|c|c|c|c|c|c|c|}
\hline V & $\begin{array}{l}\text { anode- } \\
\text { cathode } \\
\text { V }\end{array}$ & V & $\begin{array}{c}\text { anode- } \\
\text { probe } \\
\text { V }\end{array}$ & V & $\begin{array}{l}\text { probe- } \\
\text { probe }\end{array}$ & V & $\begin{array}{l}\text { probe- } \\
\text { cathode }\end{array}$ & $\begin{array}{c}\text { current } \\
a\end{array}$ & j $\mathrm{A} / \mathrm{cm}^{2}$ \\
\hline
\end{tabular}

$\begin{array}{rrrlll}4.78 & 0.53 & 3.65 & 0.60 & 0.02 & 0.044 \\ 9.58 & 1.08 & 7.30 & 1.20 & 0.04 & 0.087 \\ 14.40 & 1.60 & 11.00 & 1.8 & 0.06 & 0.1313 \\ 19.90 & 2.10 & 14.50 & 2.40 & 0.08 & 0.1750 \\ 23.40 & 2.60 & 17.90 & 2.90 & 0.10 & 0.2188 \\ 27.10 & 3.00 & 20.70 & 3.40 & 0.12 & 0.2625 \\ 30.80 & 3.50 & 23.50 & 3.80 & 0.14 & 0.3063 \\ 33.30 & 3.70 & 25.5 & 4.10 & 0.16 & 0.3501 \\ 36.30 & 4.10 & 27.70 & 4.50 & 0.18 & 0.3936 \\ 39.70 & 4.50 & 30.20 & 5.00 & 0.20 & 0.4376 \\ 42.50 & 5.00 & 32.00 & 5.50 & 0.23 & 0.5032 \\ 44.40 & 5.20 & 33.40 & 5.80 & 0.25 & 0.5470\end{array}$

Let us determine the potential difference on the boundary of the platinum anode with the ceramics after subjecting it to a current of $0.1 \mathrm{a}\left(0.2188 \mathrm{~A} / \mathrm{cm}^{2}\right)$ during a period of 16 hours. Formula (7) was used for the calculation. The results of the computation are tabulated in Table D.3.2.11.

The potential drop $\phi$ in the anode region includes the potential difference in the double layer and the ohmic decrease in the surface of the ceramics region which is located beyond the limits of the double layer. The values $\phi$ show a significant change in the electrochemical parameters of the tested specimen as a result of the continuous transmission of the current through it. This change in $\phi$ was caused by the interaction of the basic lattice defects in the electrode region. The $\phi^{l}$ values point to the formation of an electrochemical barrier layer in the anode region; this layer impedes the transmission of the current. The potential drop in the anode region significantly exceeds the $\phi$ values obtained for the same specimen investigated in the initial stage of the current transmission (see Table D.3.2.9). Thus, for example, for $0.2188 \mathrm{~A} / \mathrm{cm}^{2}$ the $\phi^{1}$ value exceeds by 11 times the value of $\phi$, and for $0.5 \mathrm{~A} / \mathrm{cm}^{2}$ the $\phi^{l}$ value is almost 6 times larger than the value of the potential difference in the double layer. 
Table D.3.2.11. Potential drop $\phi^{l}$ in the anode region as a function of the current density after 16 hours of processing the specimen with a current of $0.1 \mathrm{a}\left(0.2188 \mathrm{~A} / \mathrm{cm}^{2}\right)$.

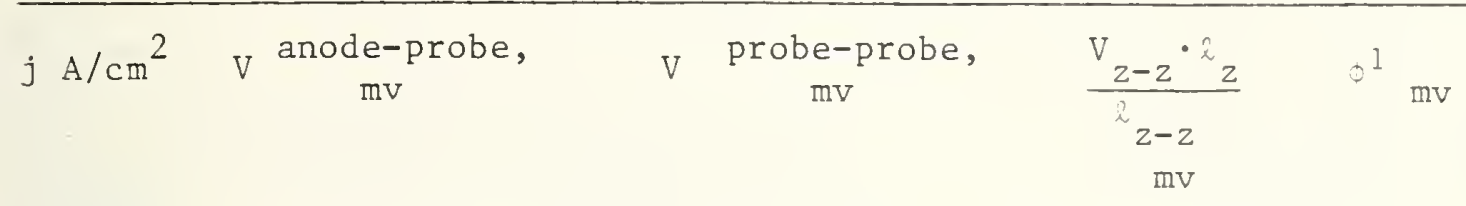

\begin{tabular}{lrrrr}
\hline 0.0440 & 530 & 3650 & 190.1 & 340 \\
0.0870 & 1080 & 7300 & 380 & 700 \\
0.1313 & 1600 & 11000 & 572 & 1028 \\
0.1750 & 2100 & 14500 & 755 & 1345 \\
0.2188 & 2600 & 17900 & 932 & 1668 \\
0.2625 & 3000 & 20700 & 1078 & 1922 \\
0.3063 & 3500 & 23500 & 1224 & 2276 \\
0.3501 & 3700 & 25500 & 1328 & 2372 \\
0.3938 & 4100 & 27700 & 1442 & 2658 \\
0.4376 & 4500 & 30200 & 1573 & 2927 \\
0.5032 & 5000 & 32000 & 1666 & 3334 \\
0.5470 & 5200 & 33400 & 1739 & 3461
\end{tabular}

It is also necessary to clarify to what extent the electrochemical properties of the ceramics are changed as a result of the continuous transmission of current through the specimen. To do this the data in Table D.3.2.10 are used.

First, let us examine the change in the conductivity of the ceramics as a result of the continuous transmission of a current of 0.1 a through the specimen $\left(j=0.2188 \mathrm{~A} / \mathrm{cm}^{2}\right)$. Table D.3.2.12 presents a comparison of the $\sigma$ values and the specific conductivity of the specimen in the initial stage of the electrolysis. The specific electrical conductivity of the ceramics was determined between two probes located in different cross sections of the specimen. The value of the current density, which was selected in the laboratory, is close to the value $0.25 \mathrm{~A} / \mathrm{cm}^{2}$, which is the value used in conducting the continuous experiment in the U-02 channel.

From the data in Table D.3.2.12 it follows that after subjecting the specimen to a current of $0.1 \mathrm{~A}$, the conductivity of the ceramics increased in comparison with its conductivity in the initial stage of the current transmission. Within the range of $0.04-0.22$ $\mathrm{A} / \mathrm{cm}^{2}, \sigma\left(=1.74 \cdot 10^{-2} \mathrm{ohm}^{-1} \cdot \mathrm{cm}^{-1}\right)$ was $12 \%$ larger than the previous value of $\sigma\left(=1.55 \cdot 10^{-2} \mathrm{ohm}^{-1} \cdot \mathrm{cm}^{-1}\right)$. With the indicated current densities the heating up of the specimen due to the transmission of the current was negligibly sma1l. At the end of the continuous current transmission through the specimen, the conductivity of the ceramics was measured by the four-probe method and good agreement was found between the value of the specific electrical conductivity of the ceramics and the $\sigma$ values, which were obtained for the specimen after long time current passage. With $\mathrm{j} \approx 0.5 \mathrm{~A} / \mathrm{cm}^{2}$ the deviation between the $J$ values amounted to $20 \%$, which attests to the fact of the increase in the conductivity of the ceramics after subjecting it to the current. 
Table D.3.2.12. Comparison of the values of the specific electrical conductivity of the specimen, obtained in the initial stage of the current transmission, and the $\sigma$ values, measured after a lengthy current transmission $\left(0.2188 \mathrm{~A} / \mathrm{cm}^{2}\right)$ for 16 hours. $1400^{\circ} \mathrm{C}$. Medium Air.

In the initial stage of current transmission

$\begin{array}{ccc}R z-z, & \text { l z-z, } & \sigma \\ \mathrm{ohm} & \mathrm{ohm} \cdot \mathrm{cm} & (\mathrm{ohm} \mathrm{cm})^{-1}\end{array}$
After a lengthy transmission of of a current of 0.1 A through the specimen \begin{tabular}{ll}
$j$ & $\begin{array}{l}(0.1 \mathrm{~A}) \text { through the } \\
\mathrm{A} / \mathrm{cm}^{2}\end{array} \mathrm{~A} / \mathrm{cm}^{2}$ \\
\hline
\end{tabular} $\begin{array}{cl}j & \begin{array}{l}(0.1 \mathrm{~A}) \text { through the } \\ \mathrm{A} / \mathrm{cm}^{2}\end{array} \\ \mathrm{~A} / \mathrm{cm}^{2}\end{array}$

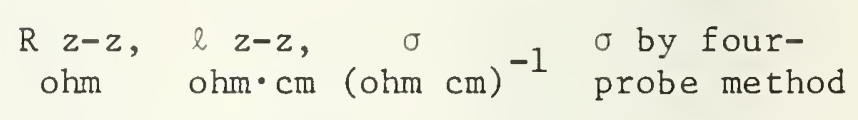

$\begin{array}{lll}0.1094 & 206 & 65.4 \\ 0.1532 & 204.3 & 64.8 \\ 0.2188 & 203.0 & 63.3 \\ 0.2735 & 225.0 & 71.4 \\ 0.4923 & 170.4 & 54.1 \\ 0.6564 & 141.6 & 44.9 \\ 0.7220 & 130.6 & 41.4\end{array}$

$1.53 \cdot 10^{-2}$
$1.54 \cdot 10^{-2}$
$1.58 \cdot 10^{-2}$
$1.40 \cdot 10^{-2}$
$1.85 \cdot 10^{-2}$
$2.22 \cdot 10^{-2}$
$2.42 \cdot 10^{-2}$

0.044

0.087

0.1313

0.1750

0.2188

0.2625

0.3069

0.3501

0.3938

0.4376

0.5032

0.5470

Evidently, a continuous current transmission through the specimen contributes to an increase in the electronic part of the conductivity in comparison with the electron transfer number obtained for the same ceramics in the absence of an electric field. The effect of increasing the conductivity of the ceramics was caused by the reaction (1) tending to form the centers $\mathrm{Ce}_{\mathrm{Zr}}^{-}$

However, a different pattern is observed in the near-electrode layers as a result of the current. Table D.3.2.13 gives the $\rho$ values for the cathodic region of the ceramics, which were obtained in the initial stage of the current transmission through the specimen and after it had been subjected to the continuous transmission of the current $(0.1$ A).

As can be seen from the data in Table D.3.2.13, the specific resistance of the ceramics in the cathode region increased significantly in comparison with the $p$ values between the cathode and the probe, which were measured in the initial stage of processing the specimen with the current. Such an increase in the resistance of the ceramics in the cathode region can clarify the reduction of $\mathrm{Zr}^{4+}$ in the platinum cathode and the subsequent oxidation of the reaction products to a tetragonal and monoclinic modification of $\mathrm{ZrO}_{2}$, i.e., the initial system of $18 \mathrm{~mol} \% \mathrm{CeO}_{2}-82 \mathrm{~mol} \% \mathrm{ZrO}_{2}$ in the cathode region is destabilized. The transition from one phase to another is accompanied by a change in the specific volume of the binary system. The deformation can cause a flaking of the brazed platinum on the cathode side of the specimen with a current density exceeding $0.4 \mathrm{~A} / \mathrm{cm}^{2}$. 
Table D.3.2.13. Comparison of $p$ values between the cathode and probe, obtained in the initial stage of current transmission, and the $p$ values probe cathode, computed after a long time current transmission $\left(0.2188 \mathrm{~A} / \mathrm{cm}^{2}\right)$ during a period of 16 hours. $\mathrm{T}=1400^{\circ} \mathrm{C}$.

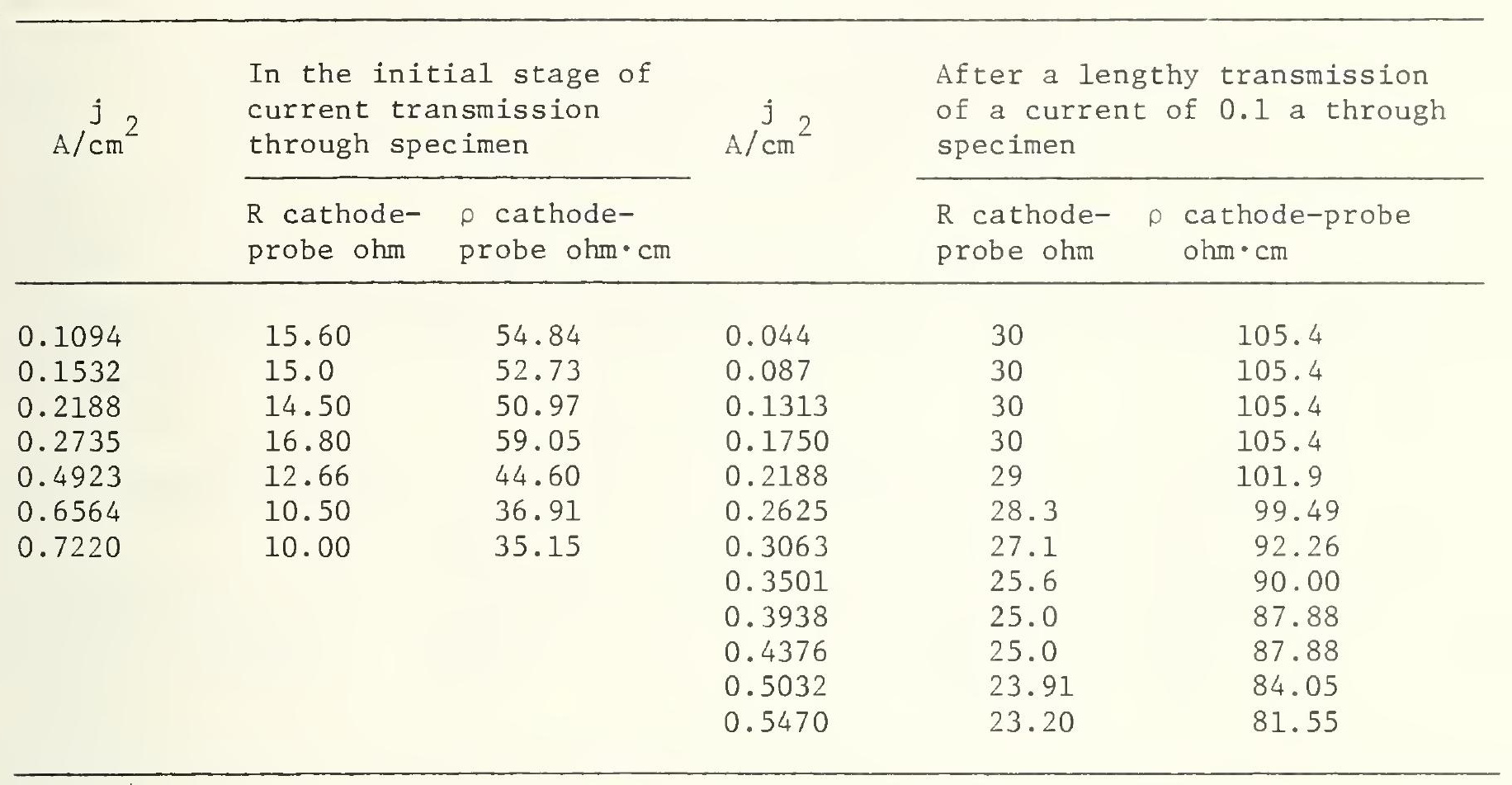

Table D.3.2.14 gives $\rho$ values for the anode region of the ceramics, obtained in the initial stage of subjecting the specimen to the current, and after a lengthy current transmission.

In the anode region of the ceramics--already indicated above--an electrochemical barrier layer is formed as a result of the interaction of the defects of $\mathrm{Ce}_{\bar{z}} \mathbf{r}$ with a twice ionized vacancy of oxygen. Moreover, an associate is formed; the composition of this associate has been studied in supplementary investigations (the influence of the double layer on the barrier layer has been explored with highfrequency methods). Work, in the study of these ceramics is being continued.

Following is a description of U.S. specimens with a composition consisting of $18 \mathrm{~mol} \% \mathrm{CeO}_{2}-82 \mathrm{~mol} \% \mathrm{ZrO}_{2}$ after having undergone lengthy tests in the $\mathrm{U}-02$ channel.

1. First let us look at electrode pair 1205-2205, through which no current was passed. The cathode of electrode 1205 has a height of $6.8 \mathrm{~mm}$ and a length $13.6 \mathrm{~mm}$. The platinum is visible. Beyond the platinum, cement follows. On the cathode close to the platinum, a green zone $2.8 \mathrm{~mm}$ high is visible; beyond it, there is a zone with a light yellow color. One can see a black zone in the cement region. The area is $5 \times 3 \mathrm{~mm}$. This zone wedges into the MgO insulator, forming a fissure in it. The cathode of electrode 1205 is practically intact. 
The anode of electrode 2205 looks good. Its height is $6.8 \mathrm{~mm}$; its length is $13.8 \mathrm{~mm}$. The platinum is visible. Beyond it, cement of a light yellowish color follows. The ceramics are light yellow.

2. A current of 2.8 A passed through electrode pair 1206-2206 but after an hour a current of 1.6 A was transmitted through it. Eighteen hours after beginning the test the current rose to $1.8 \mathrm{~A}$. Such a current strength was maintained for 60 hours; then the current rose to $2.2 \mathrm{~A}$. Electrode pair 1206-2206 worked for more than 110 hours. One can state that on the average a current of 2 A passed through the electrode; this amounts to $0.25 \mathrm{~A} / \mathrm{cm}^{2}$.

Table D.3.2.14. Comparison of $\rho$ values between the anode and the probe, obtained in the initial stage of current transmission through the specimen and after a lengthy current transmission for a period of 16 hours. $1400^{\circ} \mathrm{C}$. Medium air.

\begin{tabular}{|c|c|c|c|c|}
\hline \multirow[t]{2}{*}{${\stackrel{\mathrm{A}}{\mathrm{j}} \mathrm{cm}^{2}}^{2}$} & $\begin{array}{l}\text { In the initial stage of } \\
\text { current transmission } \\
\text { through the specimen }\end{array}$ & \multirow[t]{2}{*}{$\mathrm{A} / \mathrm{cm}^{\mathrm{j}} 2$} & \multicolumn{2}{|c|}{$\begin{array}{l}\text { After a lengthy current } \\
\text { transmission through the } \\
\text { specimen }\end{array}$} \\
\hline & $\begin{array}{cc}R \text { anode- } & \rho \text { anode- } \\
\text { probe } & \text { probe } \\
\text { ohm } & o h m \cdot c m\end{array}$ & & $\begin{array}{l}R \text { anode- } \\
\text { probe } \\
\text { ohm }\end{array}$ & $\begin{array}{l}\text { anode-probe } \\
\mathrm{ohm} \cdot \mathrm{cm}\end{array}$ \\
\hline
\end{tabular}

$\begin{array}{llllll}0.1094 & 11.0 & 67.02 & 0.044 & 26.5 & 161.4 \\ 0.1532 & 11.43 & 69.64 & 0.087 & 27.0 & 164.5 \\ 0.2188 & 12.00 & 73.12 & 0.1313 & 26.7 & 162.7 \\ 0.2735 & 14.00 & 85.30 & 0.1750 & 26.25 & 159.9 \\ 0.4923 & 11.55 & 70.37 & 0.2188 & 26.0 & 158.4 \\ 0.6564 & 9.83 & 59.89 & 0.2625 & 25.0 & 152.3 \\ 0.7220 & 9.30 & 56.67 & 0.3063 & 25.0 & 152.3 \\ & & & 0.3501 & 23.0 & 140.7 \\ & & & 0.3938 & 22.8 & 138.9 \\ & & & 0.4376 & 22.5 & 137.1 \\ & & & 0.5032 & 21.7 & 132.4 \\ & & & 0.5470 & 20.8 & 126.7\end{array}$

The cathode of electrode 1206 became deformed: its height is $12.6 \mathrm{~mm}$; its length, $13.8 \mathrm{~mm}$. The platinum is visible. The cement follows the platinum. Its area increased. The cement wedged into the Mg0, causing deep cracks in the insulator. On the boundary of the cement with the $\mathrm{MgO}$ there were small black spots. Close to the platinum the ceramics has a yellow-green zone, $2.5 \mathrm{~mm}$ high. A yellow-green zone follows this zone in the ceramics. The ceramics specimen is intact.

The anode of electrode 2206 is in good condition. The color of the ceramics is light yellow; the cement practically did not change in shade. The insulator is intact. The height of the ceramics is $6.8 \mathrm{~mm}$; the length is $13 \mathrm{~mm}$. The platinum is visible. The anode of electrode 2206 is in good condition. 
3. A current of 8.5 A was 'passed through electrode 7, which amounts to $1 \mathrm{~A} / \mathrm{cm}^{2}$. However, after 15-60 minutes the platinum wire which was welded to the platinum grid melted. The melting of the platinum in the anode caused the formation of a barrier layer in the anode region (see the results of the investigation of a specimen with a composition consisting of $18 \mathrm{~mol}_{\mathrm{CeO}}-82 \mathrm{~mol} \% \mathrm{ZrO}_{2}$ in the electrochemical laboratory IVTAN) The platinum wire was heated to the melting temperature by the current because of the presence of a barrier layer in the anode layer.

The cathode of electrode 1207 was not destroyed. The platinum was greatly deformed but it was visible. Close to the platinum the ceramic has a zone of a green color with small dark spots; a light green zone follows this zone. The dimensions of the ceramics are the following: height 7.1 $\mathrm{mm}$; length, $13.9 \mathrm{~mm}$. The cement follows the platinum; its area increased. The cement wedged into the $\mathrm{MgO}$, forming a fissure in the insulator. On the boundary with the Mg0 there is a black zone close to the cement.

The anode of electrode 2207 is in good condition. Substantial changes are not visible in the ceramics of the electrode.

4. A current of 8.5 A was passed through electrode pair 1208-2208, which amounts to $1 \mathrm{~A} / \mathrm{cm}^{2}$. After 15-60 minutes the platinum wire also melted in the anode. The reason for the melting of the platinum wire is the same as that for electrode pair 1207-2207.

The cathode of electrode 1208 has approximately the same zones as in the ceramics of cathode 1207. The insulator was destroyed to a great extent.

The anode of electrode 2208 is practically intact. The cement is also intact. 
D.4. Qualitative Analysis of the Stability of Electrode Materials, using the High-Temperature Treatment Method

Recrystallization, evaporation and erosion are among the processes which cause the destruction of materials in the MHD-generator channel.

Al1 these phenomena were detected after tests on American electrode walls in the U-02 unit.

In order to have a supplementary qualitative comparison of the stability of the candidate electrode materials in a high temperature range, a thermal processing of these materials was undertaken in a high temperature gas furnace. Samples of compositions 1-5 (Table D.4.1), distributed in crucibles made of zirconium dioxide, were subjected to heating using the products of methane combustion of oxygen up to $2200^{\circ} \mathrm{C}$ at a rate of $300^{\circ} \mathrm{C}$ per hour. This thermal processing at $2200^{\circ} \mathrm{C}$ lasted for 5 hours.

Table D.4.1 gives data on the weight changes in the samples tested.

As can be deduced from the table, zirconium dioxide stabilized by yttrium oxide has the maximum stability.

The structure of the materials before and after the tests was examined using the scanning electron microscope. The corresponding photographs are presented in Figures D.4.1. to D.4.6.

Table D.4.1. Weight change in electrode material samples after thermal processing at $220^{\circ} \mathrm{C}$.

\begin{tabular}{|c|}
\hline Composition \\
\hline
\end{tabular}

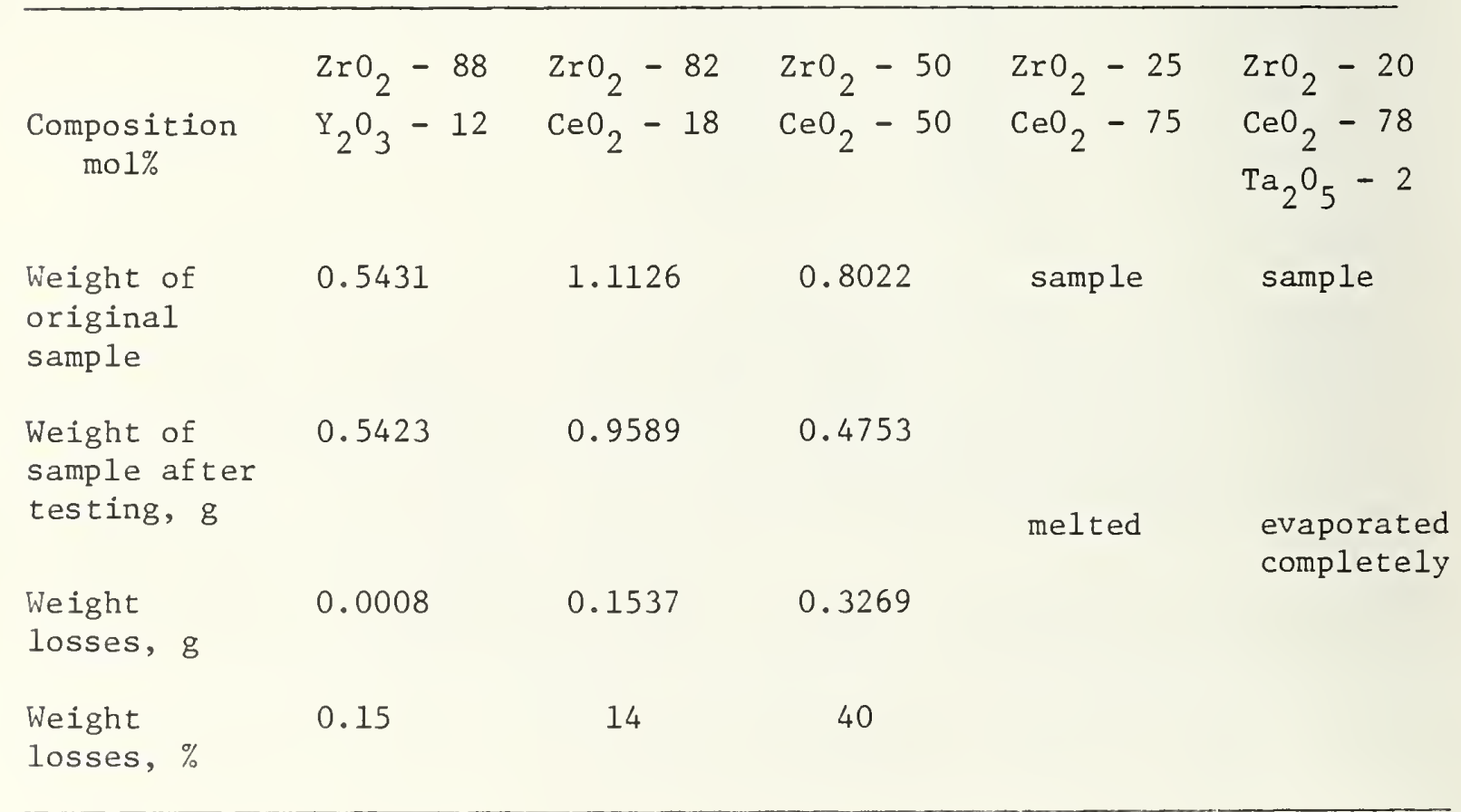




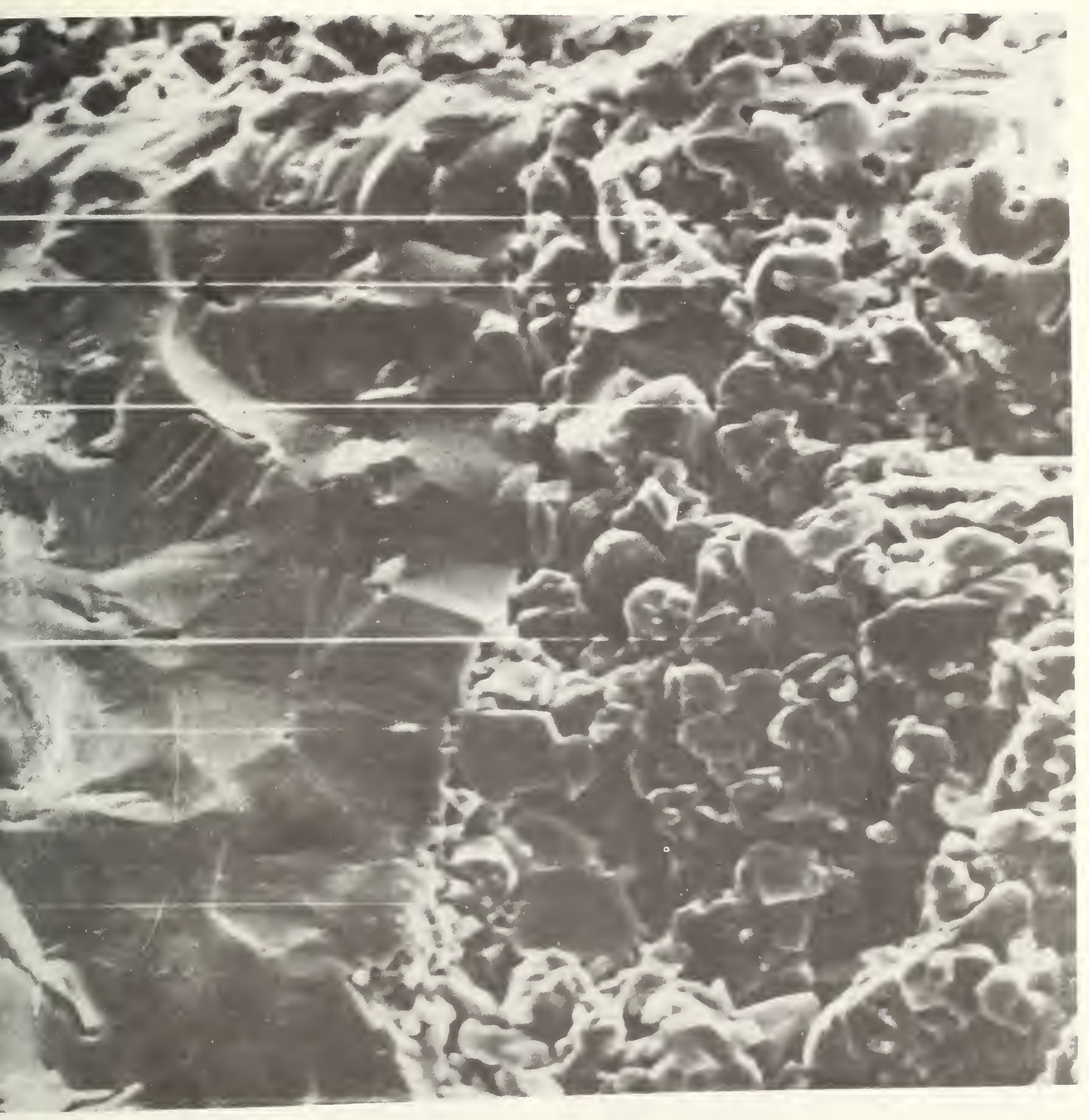

Figure D.4.1. Sample structure I before testing (x 1200). 


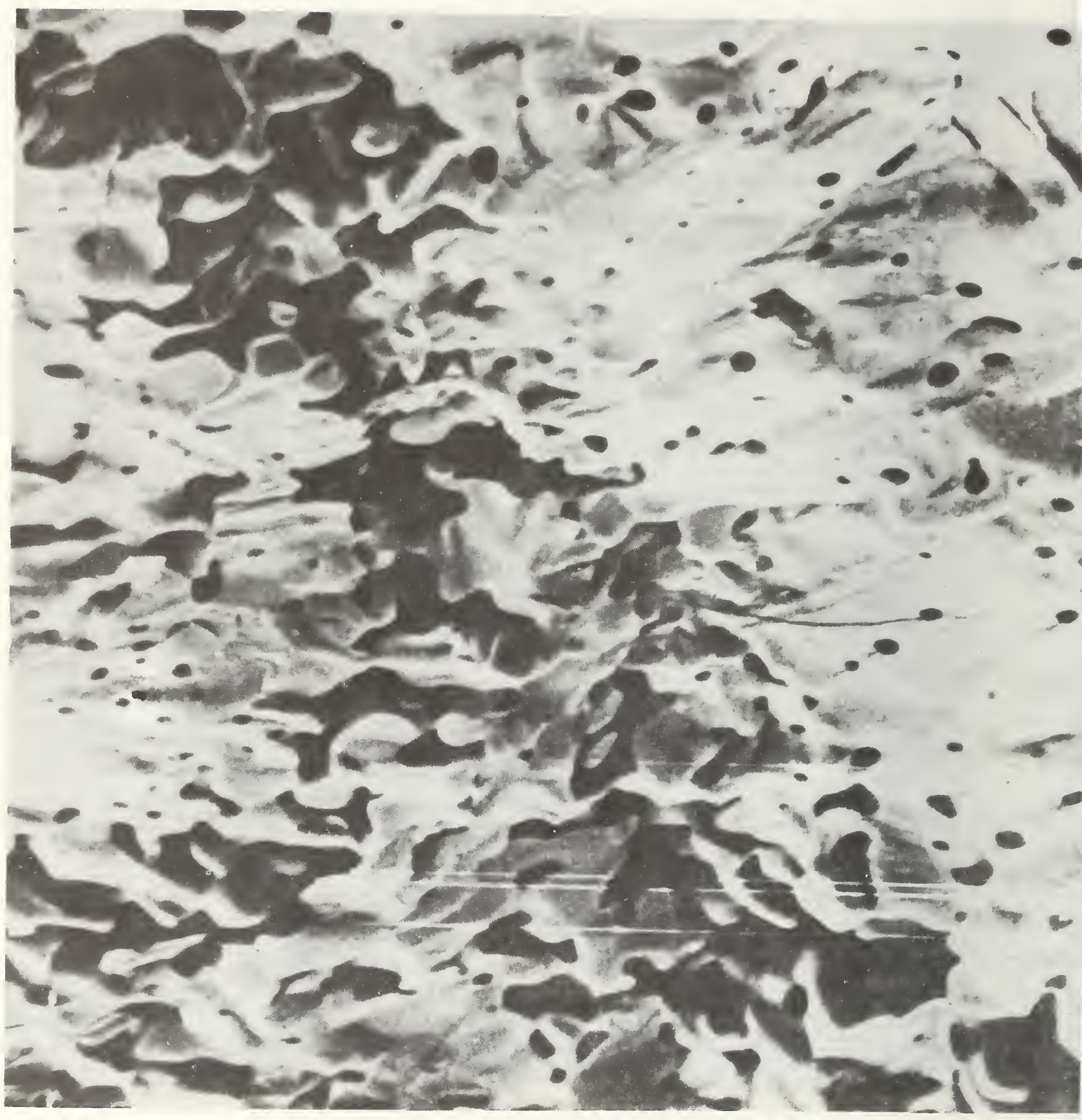

Figure D.4.2. Sample structure I after testing (x 1200). 


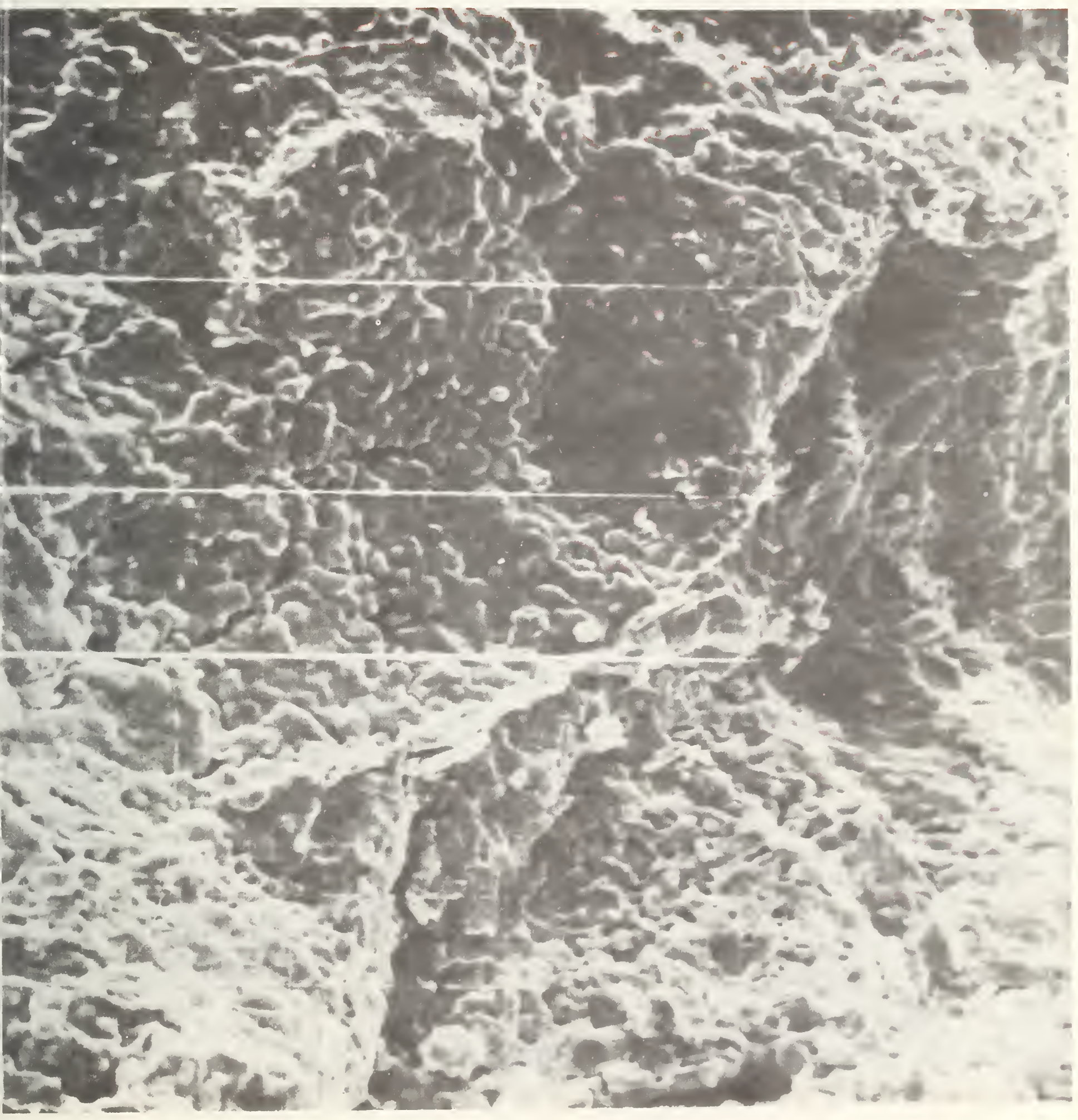

Pigure D.4.3 Sample structure II before testing $(x 600)$. 


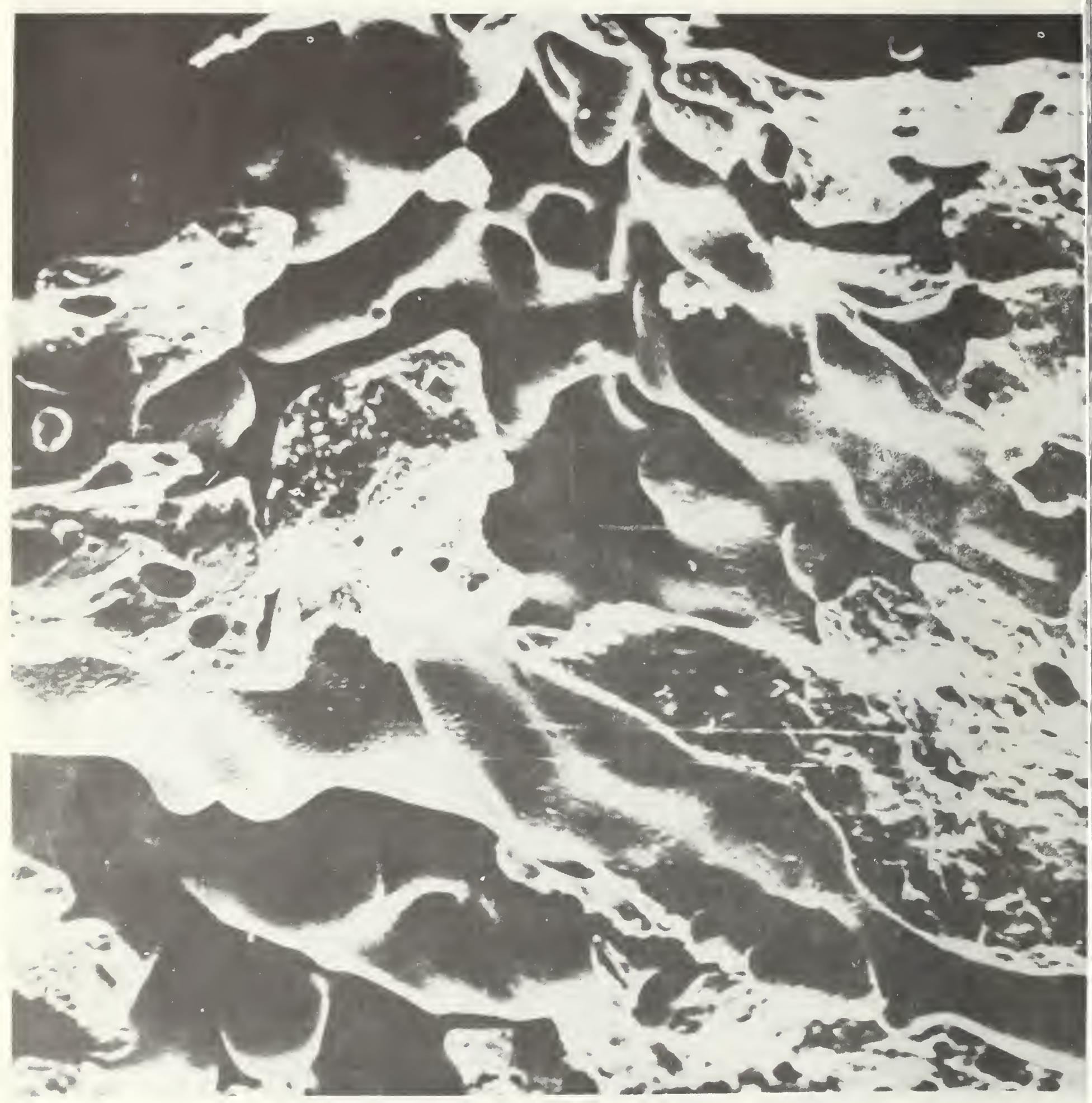

Figure D.4:4. Sample structure II after testing ( $\mathrm{x}$ 600). 


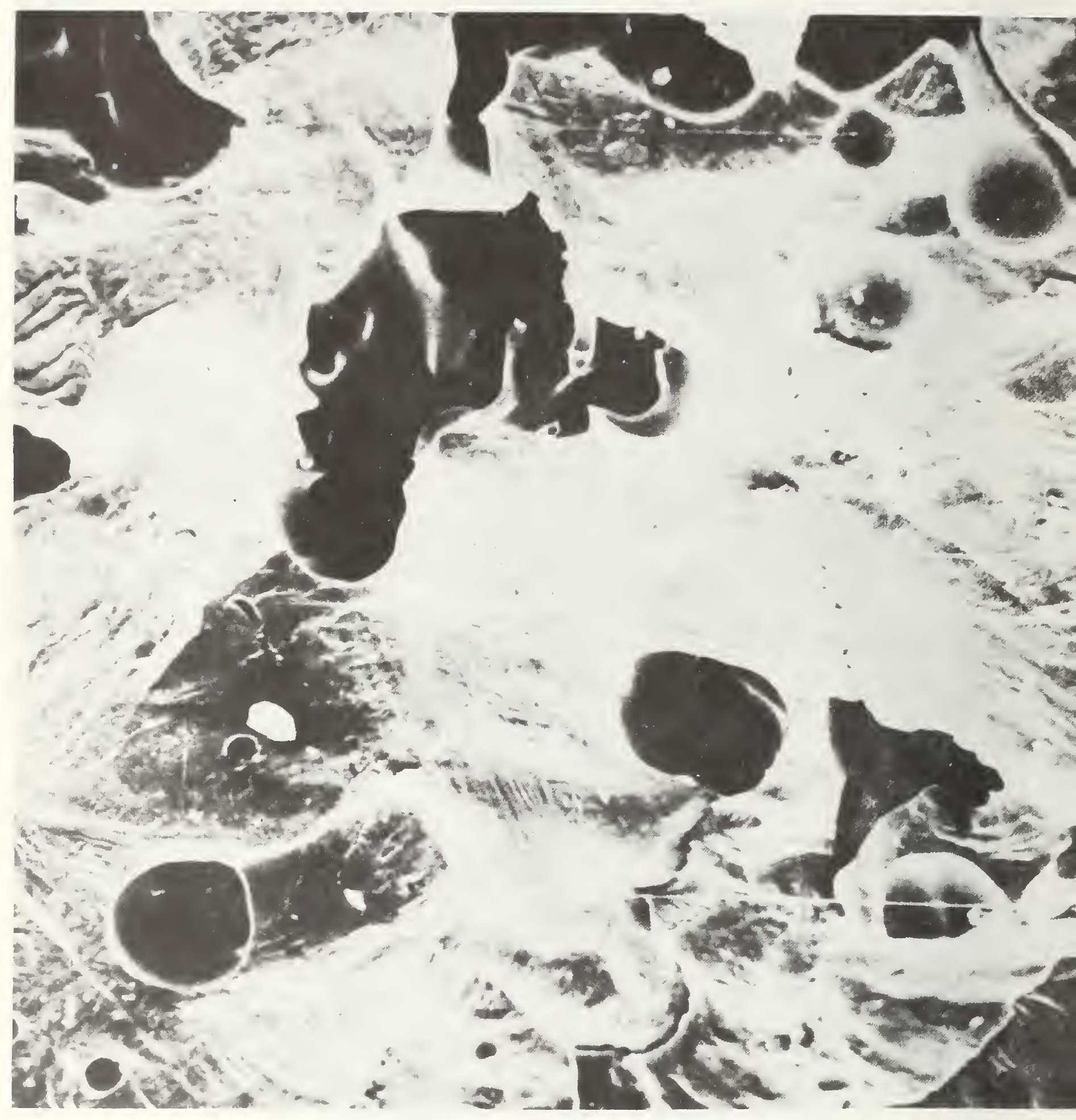

Figure D.4.6. Sample structure III after testing (x 1500). 
The observed structure changes in the samples after thermal processing indicate the compression of the materials and the growth of the grains and pores. These phenomena develop at a higher rate in materials containing cerium oxide.

$$
\begin{aligned}
& \text { D.4.1. Investigations of the } \mathrm{ZrO}_{2}+\mathrm{Y}_{2} \mathrm{O}_{3}(8.7 \mathrm{~mol} \%) \text { carried } \\
& \text { out in the U.S.S.R. }
\end{aligned}
$$

Electrode walls must operate in a hot MHD-generator channel for a period of several hundred hours at a surface temperature $\geq 1800^{\circ} \mathrm{C}$.

Stabilized zirconium dioxide and, in particular, zirconium dioxide stabilized by yttrium oxide are among the more promising electrode materials.

The temperature at which the material must operate as an electrode is found in the range of intensive recrystallization.

Besides recrystallization the material experiences the influence of alkaline seed. These two factors lead to a substantial change in the initial mechanical properties and, as a result, to the destruction of the electrode modules.

From 1966 to 1970 comprehensive investigations of the properties of materials made of zirconium dioxide stabilized by yttrium oxide, which were cbtained through traditional technological methods, were carried out at the Institute of High Temperature. In addition, electrodes were tested in the $\mathrm{U} 02$ unit [1].

Table D.4.1.1 gives data concerning the evaporation rate of zirconium dioxide stabilized by 15 weight \% yttrium oxide as a function of the temperature and the composition of the medium in which the tests were carried out. The samples had an open porosity of approximately $25 \%$.

From the data presented one can see that the evaporation rate is determined both by the temperature of the hot surface as well as by the environment. The observed drop of the evaporation rate in argon is evidently caused by a lower rate of diffusion of the evaporation products into the gas, which is under excess pressure [2].

During the operation of the electrodes in contact with a high temperature flow of ionized plasma, the mass may be carried away not only as a result of the evaporation, but also as a result of the dynamic effect of the current and chemical interaction of the low temperatuie plasma with the material of the electrode. The tests showed that a surface temperature of $2300 \mathrm{~K}$ and a plasma flow velocity of $500 \mathrm{~m} / \mathrm{sec}$, the rate at which the mass is carried off amounted to $0.02 \mathrm{~g} / \mathrm{m}^{2} \mathrm{sec}$. With the introduction of potassium seed into the plasma, the carrying off rate is increased by no more than $15 \%$. It is characteristic that as time passes a relatively constant erosion rate is established: this explains the carrying away of weakly bound material grains, the selective evaporation of admixtures, and the additional sintering in the surface layer of the material. Comparative investigations of erosion resistance 
of zirconium dioxide stabilized by potassium and yttrium oxides as well as studies of the evaporation process permit us to come to a conclusion as to the increased stability of zirconium dioxide stabilized by yttrium oxide.

Table D.4.1.1. Temperature dependency of evaporation rate in various environments

$\mathrm{T}^{\circ} \mathrm{K}$

Evaporation rate $\mathrm{g} / \mathrm{m}^{2} \mathrm{sec} \cdot 10^{2}$

\begin{tabular}{|c|c|c|c|c|c|c|c|c|c|}
\hline K & 3000 & 2800 & 2600 & 2500 & 2450 & 2400 & 2300 & 2200 & 2100 \\
\hline Vacuum & & & & & & & & & \\
\hline $\begin{array}{l}1,10^{-3} \\
\mathrm{mmHg}\end{array}$ & - & - & - & - & 2.72 & - & 2.26 & - & 1.33 \\
\hline Air & 4.42 & 1.76 & 1.47 & - & - & 1.40 & 1.00 & 0.88 & - \\
\hline $\begin{array}{l}\text { Argon } \\
0,2 \text { atn }\end{array}$ & - & - & - & 1.35 & 1.29 & 1.06 & 0.76 & 0.59 & - \\
\hline
\end{tabular}

A comparison of the data on the evaporation rate (Table D.4.1.1) and the erosion removal rate with the results from lengthy (up to 80 hours) erosion resistance tests [3] shows that this material is practically not affected by evaporation and erosion at a temperature up to $2100 \mathrm{~K}$.

Thermal conductivity. The dependence of the coefficient of thermal conductivity on temperature has been investigated in the range 500-2100 K. At a temperature of $2100 \mathrm{~K}$ the value of thermal conductivity amounts to 1.35 watts/m degree. The deviation from this value in the total investigated temperature range does not exceed $\pm 15 \%$.

Spectral emittance. In the thermal computations of the MHDgenerator channel it is necessary to take into account the radiant heat exchange. Table D.4.1.2 gives the temperature dependence of the spectral degree of blackness for zirconium dioxide stabilized by yttrium oxide.

Table D.4.1.2. Temperature dependency of spectral emittance of $\mathrm{ZrO}_{2}(\mathrm{Y})$ [1].

\begin{tabular}{lllllll}
\hline $\mathrm{T}^{\circ} \mathrm{K}$ & 2000 & 2150 & 2250 & 2300 & 2350 & 2400 \\
\hline$\varepsilon \lambda$ & 0.47 & 0.64 & 0.71 & 0.78 & 0.81 & 0.81 \\
\hline
\end{tabular}

The value of the spectral emittance increases almost linearly in the 200-2300 $\mathrm{K}$ range and changes slightly in the 2300-2400 $\mathrm{K}$ interval.

Thermal expansion. The value of the coefficient of thermal expansion in the $900-2000^{\circ} \mathrm{C}$ interval remains practically constant $(1.3-$ $1.35 \cdot 10^{-}-$degree $^{-1}$ ) for samples fired both at $1750^{\circ} \mathrm{C}$ and at $2000^{\circ} \mathrm{C}$. 
Compression strength. Table D.4.1.3 presents the values of the elastic modulus, E, the yield strength, $Y$, and the deformation, $\Delta l$, before destruction.

Table D.4.1.3. Stability properties $\mathrm{ZrO}_{2}+\mathrm{Y}_{2} \mathrm{O}_{3}$

\begin{tabular}{|c|c|c|c|c|c|c|c|}
\hline \multicolumn{2}{|r|}{ Properties } & \multicolumn{2}{|l|}{$\mathrm{T}^{\circ} \mathrm{C}$} & \multicolumn{2}{|l|}{$20^{\circ} \mathrm{C}$} & \multicolumn{2}{|l|}{$2000^{\circ} \mathrm{C}$} \\
\hline & E. $10^{5}$ & $\mathrm{~kg} / \mathrm{cm}^{2}$ & & \multicolumn{2}{|l|}{2.0} & \multicolumn{2}{|l|}{0.026} \\
\hline & Y. & $\mathrm{kg} / \mathrm{cm}^{2}$ & & \multicolumn{2}{|l|}{180} & \multicolumn{2}{|l|}{5} \\
\hline & $\Delta \ell$. & $\%$ & & \multicolumn{2}{|l|}{0.1} & \multicolumn{2}{|l|}{0.22} \\
\hline Time & of experimen & $s$, hours & 1 & 2 & 3 & 4 & 5 \\
\hline Creep & $p$ rate, $\%$ & & 0.7 & 0.36 & 0.33 & 0.30 & 0.27 \\
\hline
\end{tabular}

The creep rate ( $\sigma_{\text {rate }}=0.5 \mathrm{~kg} / \mathrm{cm}, T=2000^{\circ} \mathrm{C}$ ) decreases during the experiment and this decline is particularly sharp in the first hour of the experiment.

Electrical conductivity. Table D.4.1.4 presents data on the electrical conductivity of the material consisting of zirconium dioxide stabilized by $8.7 \mathrm{~mol} \%$ (15 weight \%) and having a porosity of $25 \%$. The temperature dependence of the electrical conductivity is investigated by the four-probe method in air.

Interaction with potassium and its compounds. Complex chemical, $\mathrm{x}$-ray, and microscopic investigations show [4] that upon the migration of potassium compounds into the body of the electrode, a chemical interaction of the stabilized zirconium dioxide and the potassium salts takes place in the region of the ceramic electrodes located between two isotherms having temperatures corresponding to 1250 and $950^{\circ} \mathrm{C}$.

Table D.4.1.4. Electroconductivity dependency of temperature.

\begin{tabular}{llllll}
\hline$T^{\circ} \mathrm{K}$ & 1430 & 1570 & 1650 & 1770 & 1820 \\
\hline$(\mathrm{ohm} \cdot \mathrm{cm})^{-1}$ & $1.10^{-1}$ & $2.10^{-1}$ & $2.5 .10^{-1}$ & $3.4 .10^{-1}$ & $5.10^{-1}$ \\
\hline
\end{tabular}

J. Dubois [5] determined absolute values for the chemical corrosion rate of zirconium dioxide stabilized by potassium oxide and oxides of certain rare earth elements after exposure to potassium sulfate and potassium carbonate salts at $1200^{\circ} \mathrm{C}$.

It was established that potassium sulfate interreacts with the stabilized zirconium dioxide in a more active manner than potassium carbonate. With a chemical corrosion rate of $0.1 \mathrm{mg} / \mathrm{cm} \cdot$ hour the change 
in the linear dimensions of the specimens of stabilized zirconium under conditions of surface interaction with these salts amounts to less than $0.2 \mathrm{~mm}$ after 1000 hours of operation. In the presence of admixtures $\left(\mathrm{SiO}_{2}, \mathrm{Al}_{2} \mathrm{O}_{3}, \mathrm{Fe}_{2} \mathrm{O}_{3}\right)$ in the stabilized zirconium dioxide, which form low temperature phases along the grain boundaries, the chemical interreaction of $\mathrm{K}_{2} \mathrm{SO}_{4}$ and $\mathrm{K}_{2} \mathrm{CO}_{3}$ with $\mathrm{ZrO}_{2}$ basically occurs along the boundaries of the grains where the glass phase is distributed and is accompanied by crazing of the samples and partial destabilization. Under the effect of a direct 'current the corrosion process is intensified due to electrochemical processes on the boundaries of the solid electrolyte-molten salt division.

Investigations of the corrosion resistance of stabilized zirconium dioxide to potassium compounds at high temperatures (1800$2000^{\circ} \mathrm{C}$ ) indicate that under these conditions there is no detectable interreaction of the seed with the electrode material. After testing electrodes made of stabilized zirconium dioxide in the experimental MHD-generator channel with a wall temperature of $1900^{\circ} \mathrm{C}$, no reaction products of $\mathrm{ZrO}_{2}$ with potassium were detected [6]. Such reactions are improbable on the basis of the following thermodynamic data:

$\begin{array}{rlr}-\Delta Z_{298}^{0} \quad \mathrm{Kcal} / \mathrm{g}-\text { atmosphere oxygen: } & \mathrm{K}_{2} \mathrm{O} & 81.2 \\ & \mathrm{ZrO}_{2} & 123.8 \\ & \mathrm{Y}_{2} \mathrm{O}_{2} & 140.5\end{array}$

Potassium zirconates are subjected to dissociation when heated [7] (see Table D.4.1.5).

Table D.4.1.5. Thermal decomposition of potassium zirconates.

Temperature of the initial decomposition
Temperature range of thermal decomposition
Phases

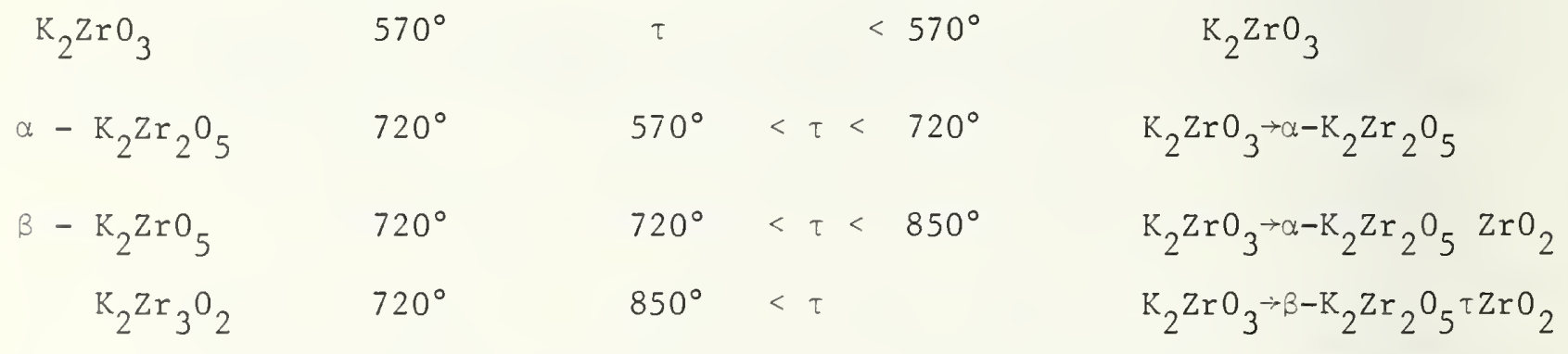

In conformity with the data [8] more than $80 \%$ of the potassium in the flow of combustion products is found in the form of a hydroxide at $1950^{\circ} \mathrm{C} ; 15-20 \%$ is in atomic form. At a temperature of $1950^{\circ} \mathrm{C}$ almost all the potassium is converted into $\mathrm{KOH}$; as the temperature drops, the potassium condenses and due to the absorption of $\mathrm{CO}_{2}$ from the combustion products is converted into $\mathrm{K}_{2} \mathrm{CO}_{3}$ and $\mathrm{KHCO}_{2}-$-compounds which are distinguished by being highly hygroscopic. Therefore, the destruction of the stabilized $\mathrm{ZrO}_{2}$ in the temperature range between the isotherms $1250-950^{\circ} \mathrm{C}$ can be 
explained by the interreaction between the condensed potassium salts and the admixtures in the refractory material (mainly with $\mathrm{SiO}_{2}$ ) and by the secondary hydration of potassium carbonate and bicarbonate which is accompanied by significant volume changes.

Experiments carried out in the $\mathrm{U}-02$ confirmed the data of French investigators [5,6]. The maximum content of potassium compounds (up to 7 weight \%) was detected in zones of the electrodes which are located between the isotherms 1250 and $850^{\circ} \mathrm{C}$. Hence, the low temperature limit for the use of porous ceramic electrodes should be set at 1300$1400^{\circ} \mathrm{C}$. At the same time, it should be noted that in order to avoid the condensation of potassium compounds on the ceramic walls while the channel is operating in the transitional mode, the start of the seed injection into the plasma and the termination of the seed supply should be carried out only when the channel is thoroughly heated.

Recrystallization. After testing electrode materials in the $\mathrm{U}-02$ unit for a period of 1 hour at a surface temperature of $2000^{\circ} \mathrm{C}$, it was established that over their total cross section the electrodes are composed of a monophase material of different densities; the difference in the structure is determined by the operating temperature of the electrode wa11.

Structural changes appear more clearly in a narrow band at a distance of $1 \mathrm{~mm}$ from the operating surface. In this region there is an abrupt growth of grains and pores, and shrinkage is being observed.

When the experiment was prolonged to 100 hours under similar conditions [3] the directional character of the recrystallization was noticed. This was accompanied by a tenfold increase of the grain size (from $10 \mu$ in the original material to 100-120 $\mu$ after the test). Grains and large pores acquire an elongated form and are oriented in a direction perpendicular to the hot surface. Channel-shaped pores break up the material into discrete microblocks, which leads to a sharp decline in the strength of the material [9].

\section{References}

[1] A. B. Ivanov, et. al., Oxide materials for the hot channel of the open cycle MHD-generator, in Material for the MHD-generator channel, pp. 52-62, Nauka, 1969.

[2] V. V. Yanulis and I. S. Mayauskas, The use of solar and arc furnaces for the determination of the evaporation rate of refractory materials, Geliotekhnika, No. 6, 1967.

[3] I. S. Mayauskas, R. I. Abraitis and G. A. Grinyute, The erosion effect of the flow of combustion products containing potassium on zirconium dioxide, Report SM-107/83 at a symposium for obtaining electroenergy with the aid of MHD-generators, MAGATE, Warsaw, 1968. 
[4] J. Millet, Les mechanismes de corrosion des electrodes ceramiques MHD, SM-107/67, Electricity from MHD, 1968, JAEA, Vienna, 1968.

[5] J. Dubois, Corrosion chimique de materiaux les composes alcalines de la simence, EDF, 1966.

[6] A. B. Ivanov, Zirconia and zirconia compounds, Electricity from MHD, 1968, Vol. XI, Pp. 3835-3845, IAEA, Vienna, 1968.

[7] M. Tournoux, Rev. Haut. Temper. et Refract., 1, N4, 343, 1964.

[8] M. A. Styrikovich, A. E. Sheindlin and I. L. Mostinskii, Ionizing seed in an open-cycle MHD-generator operating on gaseous fuel, in The MHD-method for obtaining electrical power, Energiya, p. 40, 1968 .

[9] A. T. Andrianov, A study of the thermal aging of ceramics made of pure oxides $\mathrm{Al}_{2} \mathrm{O}_{3}, \mathrm{MgO}, \mathrm{ZrO}_{2}, \mathrm{MgO} \cdot \mathrm{Al}_{2} \mathrm{O}_{3}$, Avtoref. kand. dis. Mosk, khimikotekhnolog. in-ta, 1971. 


\section{List of Figures}

Figure D.1.1. Microstructure of test piece of magnesium ceramic. Transparent section, $46 \mathrm{X}$.

Figure D.1.2. Dependence of the conductivity of magnesium ceramic on temperature.

Figure D.1.3. Dependence of the thermal conductivity of magnesium ceramic on temperature.

Figure D.1.4. Deformation curve "B-E" of test pieces of magnesium ceramic under compression.

Figure D.1.5. Deformation curve "B-E" of test pieces of magnesium ceramic under tension.

Figure D.1.6. "Creeping" curve $\varepsilon$ vs $t$ of magnesium ceramic.

Figure D.1.7. Dependence of the speed of vaporization of magnesium ceramic on temperature.

Figure D.1.8. External view of the insulating wall after testing in U-02 channel.

Figure D.2.3.1a. Distribution of the intensity of $\mathrm{K}_{\alpha} \mathrm{l}$ radiation $\mathrm{K}$ for the 1310 cathode: along an arbitrary line perpendicular to the working layer of the electrode (central part of the section).

Figure D.2.3.1b. Distribution of the intensity of $K_{\alpha}$ radiation $K$ for the 1310 cathode: along a line parallel to line a) and $500 \mathrm{mcm}$ from it.

Figure D.2.3.2a. Distribution of the $\mathrm{K}_{\alpha} \mathrm{l}$ radiation intensity $\mathrm{K}$ for the 2520 anode: along an arbitrary line perpendicular to the working layer of the electrode (central part of the section).

Figure D.2.3.2b. Distribution of the $K_{\text {l }}$ radiation intensity $K$ for the 2520 anode: along a line parallel to line a) and 800 mcm from it.

Figure D.3.1.1. Cathode and anode polarization curves for the American specimen $88 \mathrm{~mol} \% \mathrm{ZrO}_{2}-12 \mathrm{~mol} \% \mathrm{Y}_{2} \mathrm{O}_{3}$ obtained in air at a temperature of $1400^{\circ} \mathrm{C}$.

Figure D.3.2.1. Geometric dimensions of the tested specimen.

Figure D.3.2.2a,b. Cathode and anode curves for the specimen - 18 mol\% $\mathrm{CeO}_{2}-92 \mathrm{~mol} \% \mathrm{ZrO}_{2}$ - obtained in air at a temperature of $1400^{\circ} \mathrm{C}$.

Figure D.4.1. Sample structure I before testing ( $x$ 1200). 
Figure D.4.2. Sample structure I after testing ( $x$ 1200).

Figure D.4.3. Sample structure II before testing ( $x$ 600).

Figure D.4.4. Sample structure II after testing ( $\mathrm{x}$ 600).

Figure D.4.5. Sample structure III before testing ( $x$ 1500).

Figure D.4.6. Sample structure III after testing ( $x$ 1500). 
CHAPTER IV

Conclusions - U.S. and U.S.S.R.

A. Conclusions from Phase Composition, Chemical Reactions, Metallography, and Microprobe Analysis (U.S.)

A.1 Conclusions from phase composition and chemical reactions

1. The effects caused by seed penetration are more pronounced at the cathode wall.

a. All $\mathrm{CeO}_{2} / \mathrm{ZrO}_{2}$-based cathode materials within lower, cooler, zones show alteration products typical of reactions with seed. Reaction intensity is more evident for current-carrying materials.

b. Within the $\mathrm{ZrO}_{2}$-cements and $\mathrm{MgO}$ insulators below cathode materials, seed, condensed as $\mathrm{K}_{2} \mathrm{CO}_{3}$ and 7 or hydrate, is ubiquitous.

c. Reaction with seed at the anode electrodes is less pronounced and, generally occurs within localized interior zones.

2. Except for $\mathrm{Y}_{2} \mathrm{O}_{3}$-stabilized $\mathrm{ZrO}_{2}$ materials, and contrary to anode materials, $\mathrm{CeO}_{2} / \mathrm{ZrO}_{2}$ cathode materials appear to have been subjected to reduction in situ followed by complete to nearly complete reoxidation during shut-down.

a. Phase transitions due to reduction are manifested particularly by the presence of monoclinic $\mathrm{ZrO}_{2}$, together with certain additional phases.

3. Surface $\mathrm{x}$-ray analysis, particularly of $\mathrm{CeO}_{2} / \mathrm{ZrO}_{2}$-anode materials, show depletion of $\mathrm{CeO}_{2}$. The Ta-containing electrodes also show Ta-depletion.

4. Phase transitions leading to alteration of the microstructure of virgin cathode materials may have enhanced seed penetration. Cements also provide good avenues for seed penetration.

5. Mgo insulators (anode and cathode), especially where exposed to the plasma, show compounds with $\mathrm{Al}_{2} \mathrm{O}_{3}$ and cubic zirconia from x-ray diffraction data. These may contribute to the alteration and the degradation of the erosion resistance of virgin materials.

6. Bloating of cathode materials apparently was caused by hydration and expansion of condensed seed during and after the cool-down period.

7. Lead-out failure in electrode pairs was not caused by chemical attack, but rather by joule heating and eventual melting. Evidence for presence of KC1 within lead-out tubes indicated $\mathrm{K}$-penetration within this area.

8. There appears to be no evidence for damage of electrode materials solely by current transport.

9. $\mathrm{ZrO}_{2} / \mathrm{Y}_{2} \mathrm{O}_{3}$ materials at the cathode show evidence for partial destabilization of cubic zirconia. Presently, it is unclear whether this process is related to seed reactions or electrochemical phenomena.

10. The information from Phase I U-02 test is extensive, but complete analysis of all elements would require years of study. 


\section{A.2 Conclusions from Metallography and Microprobe Analysis}

Based on SEM and microprobe analysis carried out at Battelle Pacific Northwest Laboratories, a number of conclusions can be drawn. These conclusions were made from the metallographic and electron microscope evaluations of eight to twelve of the electrodes. Since the examination and evaluations are not complete, these conclusions are considered preliminary and may be modified after the structural characterization is completed.

1. The cathode degradation was substantially greater than the anode, presumably due to electrochemical effects.

2. Cement, which acts as a source of potassium concentration, is a major design problem.

3. Potassium transport and concentration occurs principally through and in the open porosity of the low density phases of the Migo, cement and electrode.

4. The mechanical swelling of the cement and IgO appears to result from hydration of the $\mathrm{K}_{2} \mathrm{CO}_{3}$ which is accompanied by a $40 \%$ increase in volume.

5. Microstructural and electron microscopy results agree in general with the x-ray diffraction phases studies.

6. Contamination of the insulator and electrode surfaces are apparently due to oxide contaminants carried by the plasma.

7. There is a preferential loss of Ce and/or Ta from the surfaces of the high Ce containing electrodes.

8. Potassium not only influences the mechanical breakup of the MgO, cement and electrodes, but also appears to influence or enhance recrystallization, transport of other elements and formation of new phases in the electrodes and insulators. 

